\title{
Repurt of the Proceediags of the
}

$\frac{\text { Third Entomological Meeting }}{\text { V00 Sin }}$ 



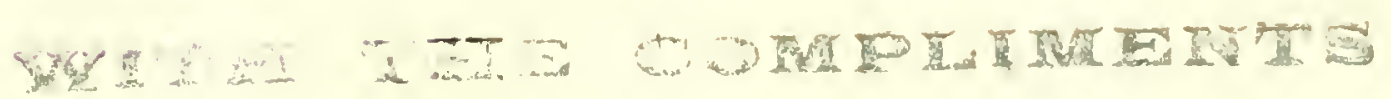

$$
\text { cos the }
$$

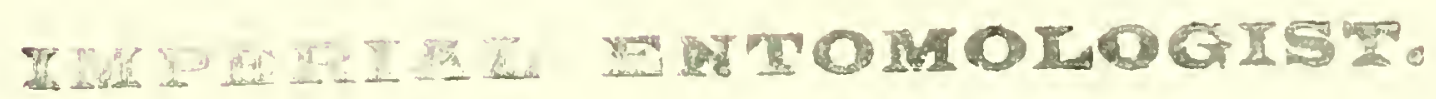





\section{REPORT}

OF THE

\section{Proceedings of the Third Entomological SCeeting}

Held at Pusa on the 3rd to 15th February 1919

In Three Volumes

Edited by

T. BAINBRIGGE FLETCHER, R.N., F.L.S., F.E.S., F.Z.S., Imperial Entomologist

VOLUME I
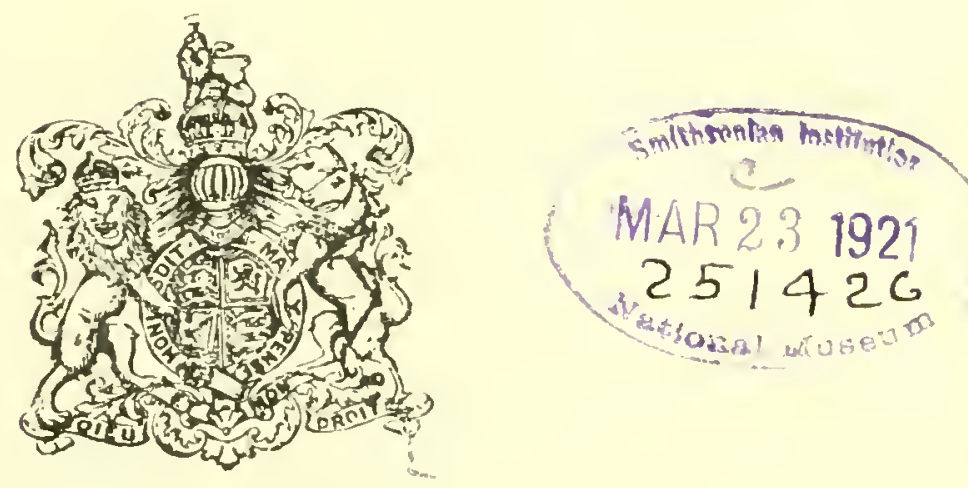

CALCOTTA

SUPERINTENDENT GOVERINAENT PIINTING, INDIA 1920 


\section{Agents for the Sale of Books Published by the}

\section{Superintendent of Government Printing, India, Calcutta.}

\section{IN EUROPE.}

Constable of Co., 10, Orange Street, Leicester square, Loudon, W.C.

Kegin Paul, Trench, Trubner \& Co., 68-74, Carter lane, E.C., and 25, Museum Strcet, Londou, W.C.

Bernard Quariteh, 11, Grafton Street, Sew Bond street, London, $W$

P. S. King of Sons, $2 \& 4$, Great Snith Street, Testniinster, London, S.W.

H. S. ling of Co., 65, Cornbill, E.C., and 9, Pall Mall, Loudon, W.

Grundlay \& Co., jt, Parliament Street, Loudon, S.W.
Luzac of Co., 46 , Great Russell Street, Loudon, IV.C.

W. Tlacker \& Co., 2, Creed Lane, London, E.C.

T. Fisher Unwin, t.td., 1, Adelphi Terrace, Loudon, W.C.

Wm. Weiloy \& sion, as, lissex strect, strand, London.

B. H. Blackwell, 50\& 51, Broad Street, Oxford. Deight on bell \& Co., Ltd., Canubridge.

Oliver and Boyd, Twecldale Court, Ediuburgh. J. Ponsonby, Itd., 116, Graft on Strect, Dublin. Ernest L.croux, 28, Rue Bonaparte, Paris. Martinus Nijhoff, 'The Hague, Holland.

\section{IN INDIA AND CEYLON.}

Thacker, Spink \& Co., Caleutta and simla.

Sewman \& Co., Calcutta.

R. Cambray of Co., Calcutta.

S. F. Lahiri \& Co., Calcutta.

B. Banerjee d: Co., Calcutta.

The Indian School Supply Depôt, 309, Bow Bazar Street, Caleutta, and 226 , Nawabpur. Daeca.

Butterworth \& Co. (India), Ltd., Caleutta.

Eai M. C. Sarcar liuladur \& Sons, 9 1-2.1, Harrison Road, Caleutta.

The Weldon Library, 57, Park street, West, Calcutta.

Standard Literature Company, Limited, Calcutta.

Lal chand s sons, Caleutia.

Higginbothams, l.tu., Madras.

V. Kalyanarama Iyer \& Co., Madras.

G. A. Satesan \& Co., Madras.

$\therefore$ Murthy \& Co., Madras.

Thompson \& Co., Madras.

Temple \& Co., Madrás.

P. R. Rama Iyer \& Co., Madras.

Vas \& Co., II adras.

E. M. Gopalakrislma Kone, Madura.

Thacker \& Co., Ltd., liombay.

A. J. Combridge \& Co., Bombay.

D. B. Taraporevala, Sons \& Co., Bombay.

Mrs. Radhabai Atmaram Sagoon, Bombay.

sunder Pandurang, Bombay.

Gopal Narayan de Co., Bombay.
Ram Clandra Govind \& Son, Falbaderi, Bombay:

'Th" standard linok stall, Karachi.

Mangal.las Harkishendas, -urat.

liarsanlas Naranulas \& Sons, Surat.

A. H. Wheeler \& Co., Allahabad, Caleutta and bombay.

N. 1. Mathur, supdt., Tazir Kanun-i-Hind Press, Allahabad.

Rai Sahib M. Gulah Singh \& Sons, Mufd-1-Am Press, Lahore and Allahabad.

liana Krishna \& cons, Lahore.

supdt., American Baptist Mission Press, kangoon.

Manager, the "Hitavada" Nagpur.

s. C. Talukdar, Proprietor, students and Com. pany, Cooch Behar.

A. M. \& J. Ferguson, Ceylon.

Manager, Educationa! Book Depôts, Nagpur and Jubbulpore."

Manager of the Imperial Book Depot, 63, Chandney Chank street, Delhi.

Manager, "The Agra Medieal Hall and Cooperative Assoeiation, Itd." (Suecessors to A. John \& Co., Agra).

Supdt., Basel Mission Book and. Tract Depository, Mangalore."

P. Varadaehary \& Co., Madras.*

H. Liddell, Printer, ete., 7, Sonth Road, Allahabad."

Ram Dayal Agarwala, 184, Katra, Allahabad.

D. C. Anand \& Sons, Peshawar.*

Manager, Newal Kishore Press, Lucknow.*

- Ageuts for the sale of Legislative Department publications only. 


\section{PREFACE.}

THE following Report contains an account of the Proceedings of the 1 Third Entomological Meeting, held at Pusa on 3rd to 15th February 1919. As in the case of the Report of the Proceedings of the Second Entomological Meeting, every endeavour has been made to provide as full and complete a record as possible. A mere abstract is of very little use to those workers who require to refer to the record for references on particular points. The cordial reception accorded to the preceding Reporthas indicated clearly the general appreciation of a detailed record of the Proceedings of a Meeting of this kind.

Notes on the discussions which took place were taken at the time by Messrs. M. Afzal Husain and (1. R. Dutt, who acted as Joint-Secretaries, and to whom I am indebted for their assistance. These notes were again gone over and rewritten by myself.

This Report contains a record of ninety-two original papers read at the Meeting, exhibitions and discussions, covering various aspects of Indian Entomology. It will, I hope, be found useful by all interested in Entomology, both in and outside of India. That such Meetings are of interest and use to all entomological workers in India will, I think, be self-evident from this Report.

It will perhaps save correspondence if I state here that no Report was published of the First Entomological Meeting held in 1915. The Report of the Second Meeting, held in 1917, is still available.

PUSA,

T. BAINBRIGGE FLETCHER, Imperial Entomologist.

281 th June 1919. 



\title{
List of those who attended the Third Entomological Meeting held at Pusa on 3rd to 15th February 1919.
}

\author{
Members.
}

1. E. A. ANDrews, 33.A., Entomologist to the Indian Tra Ascreiation.

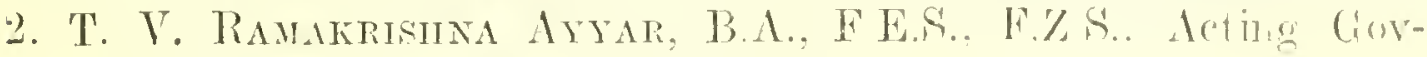
emment Futcmologist, Combatone.

3. C. F. C. Beeson, M.A., I.F.S., Forest Zoologist to the Gorernment of India.

4. Dr. C. A. Bentley, Sanitary Commissioner to the Govermment of Bengal.

5. A. N. Bose, Assistant to the Imperial Agricultural Bacteriologist, Pusa.

6. B. C. Burt, B.Sc., F.C.S., M.B.E., Deputy Director of Agriculture, United Provinces.

7. P. C. Chaudhuri, Superintendent of Sericulture, Berhampore.

8. E. A. d'A Breu, F.Z.S., Curator of the Central Musmm, Nagpur.

9. E. S. David, Entomological Assistant, United Provinces.

10. M. N. De, Sericultural Assistant, Pusa.

11. Captain Froilano De Melio, Director of the Bacteriological Laboratory, Goa.

12. V. G. Deshpaxde, B.A., Entomological Assistant, Bombay.

13. H. L. Dutr, M.S.A., Officiating Economic Botanist, Jihar amd Orisea.

14. G. R. Dutr, B.A., Entomological Assistant, Pusa (Joint Sccrelury).

15. T. Batnbrigge Fletcher, R.N., F.L.S., F.E.S., F.Z.S., Impurial Entomologist to the Government of India (Chamman).

16. C. C. Girosir, B.A., Entomological Assistant, Pnsa.

17. L. H. Gough, Ph.D., F.E.S., Director of the Entomological Service, Egypt.

18. H. S. Govind 'RAo, Student, Agricultural Bacteriological Section, Pusa.

19. S. Gupta, L. Ag., Entomological Assistant, Assam.

20. Abdul Haq, Fieldman, Entomological Section, Puea.

21. TIarmar Prasad, Assistant, Agricultural Bacteriological Section, Pusa.

22. S. Hrgandotton, Director of Agriculture, (iwalior.

23. M. Afzal Husain, M.Sc., Supcrnumerary Entomolngist, J'uea (Joint Secretary).

VOL. I 


\section{( vi )}

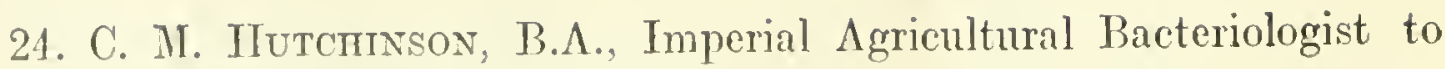
the Govermment of India.

25. C. M. Ixclis, MI.B.O.U., Laheria Serai.

26. P. ISAAC, B.A., Entomological Assistant, Madras.

27. T. N. Jinvert, L. Ag., Entomological Assistant, Bombày.

28. Ramrao S. Kasergode, L. Ag., Assistant Professor of Entomology, Poona.

29. J. L. Kinare, I. Ag., Lecturer in Entomology, Nagpur.

30. K. Kunm Kanana, M.A., F.E.S., Senior Entomological Assistant, Mrsole.

31. J. MACKenna, C.I.E., M.A., I.C.S., Agricultural Adviser to the, Gorernment of India.

32. C. S. Misra, B.A., First Assistant, Entomological Section, Pusa.

33. Amman Mujtaba, Head Ficldman, Entomological Section, Pusa.

34. 1. NowroJ, B.A., Entomological Assistant, Pusa.

35. G. D. Ojna, Fieldman, Entomological Section, Pusa.

36. C. U. PATẼ, Entomological Assistant, Baroda.

37. R. Madmatax Pillat, D. AG., Entomological Assistant, Travancore.

38. Y. Ranachandra Rao, M.A., F.E.S., Entomological Assistant, Pusa.

39. Ran Saran, Fieldman, Entomological Section, Pusa.

40. W. Romertson Brown, Agricultural Officer, North-West Frontier Province.

41. P. C. Sex, Entomological Collector, Bengal.

42. R. Senior-Winite, F.E.S., Matale, Ceylon.

43. Divarka Prasad Sixgit, Ficldman, Entomological Section, Pusa.

14. Marcinnd Sixgm, L. Ag., Agricultural Officer, Patiala.

4:) A. T. C. Wakefreun, O.B.E., Director-General of Industries, Agriculture and.Commerce, Hyderabad (Decean).

46. M. Zimarudin, Forest Officer, Phopal.

The following, who did not attend the Mecting, took part by the contribution of papers.

17. R. D. Axsтeıd, M.A., Deputy Director of Agriculture, Planting Districts, Sonth India.

48. Professor C. T. Bnutes, IIarvard University, United States of America.

19. Míjor I'. C. Fraser, I.MI.S., Bombay.

50. D. 'T. Fullaway, Entomologist to Board of Commissioners of Agriculture and Forestry, ILawaii.

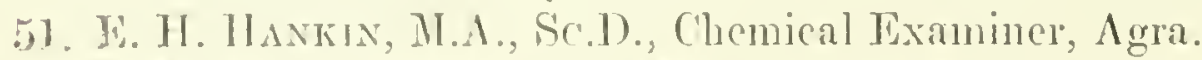

52. H. Mexтick, B.A.. F.R.S., Marlborough, England. 


\section{( vil )}

53. W. Ormiston, F.E.S., Haldummulla, Ceylon.

54. Professor E. B. Poulron, D.Sc., F.R.S., Oxford University.

55. Baini Prasad, D.Sc., Officiating Director of Fisheries, Bengal, Bihar and Orissa.

56. David Share, F.R.S., Brockenhurst, England.

57. T. Shirani, D.Sc., F.E.S., Govermment Entomologist, Formosa.

58. T. V. Subramaxian, Entomological Assistant, Madras.

59. K. D. Shroff,-B.A., Entomological Assistant, Buma.

60. A. W. Slater, Caleutta.

61. J. Henry Watson, F.E.S., Manchester, England.

62. F. C. Wrlccocks, F.E.S., Entomologrist to the Sultanie Agrlicultural Society, Cairo, Egypt. 



\section{CONTENTS.}

Preface
List of those who attended the llecting
Opening Address by the Agrieultural Adviser
Chairman's Opening Address
Committecs.

\section{Papers read at the Hecting.}

1. Insect control, by E. A. Andrews . . . . . . 23

2. Annotated list of Indian Crop-pests, by T'. Bainbrigge Fleteher • • 33

3. Some Insects recently noted as injurious in South India, by 'T.V. Rumakrishna Ayyar . . . . . . . . . . 314

4. Note on the more important Insect Pestis of Planting Districts of South India and the methods of control used. by R. D. Anstcad . . . . . . :328

5. A list of Lepidopter"a noted to attack cultivated plants in Ceylon, by li. SeniorWhite • • • • • • • • • 332

6. A list of plants with their Lepidopterous Pests in Ceylon by R. Senior-White . 3337

7. A list of the Pests of Cereals in Burma, by K. D. Slirofl . . • . 311

8. A list of the P'ests of P'ulses in Burma, by K. D. Shroff . . . . . 343

9. A list of the Pests of Oil-seed plants in Burma, by K. D. Shroff . . $\quad 347$

10. A list of the Pests of Tobaceo in Jurma, by K. D. Shroff . . . . 340

11. A list of the Pests of Vegetables in Burma, by K. J). Shroff . . . . . 343

12. Notes on miscellaneous Pests in Burma, by K. D. shroft . . . . 352

13. A list of the Pests of Sugarcane in Burma, by K. D. Shroff . . . . 354

14. Borers in Sugarcane, Rice, etc., by T. Bainbrigge Fletcher and C. C. Ghosh . $35 t$ 



\section{LIST OF PLATES.}

PAOE.

Plate 1. Group of Thirl Entomological Meeting •

I

2. Larva of Oxyombulyx sericeipennis on walnut at Shillong; Sphingid (Langin zenzeroides) larva on apple at Shillong . . . \$8

3. Larva of Actius selene; larva of Antheren roylei . . . . 99

, 4. Notodontid larva on apple at Shillong; Boarmiane (No. 2) larva on apple at Shillong . . . . . . . . . . 101

5. Belippe larva on apple at Shillong; Limacodid larve on apple at Shillong . . . . . . . . 105

6. Stages of Dyscerus fetcheri on apple fruits at Shillong • . 210

7. Dyscerus maligmus in fruits of Prumus nepalensis at Shillong. Apple fruits attacked by grulos of Dy,seress molignus at Shillong . 211

8. Lindu nigro-scututa, girdling apple twigs at shillong . . . 216

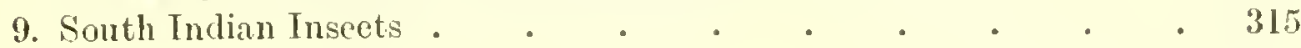

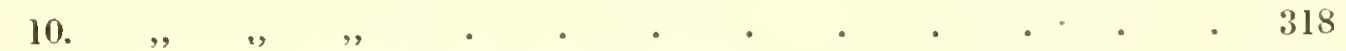

11. Philanthus rameslerishne, Alcides pictus. • . • • • 319

" 12. Jak Weevil; Rubber Seolytid; Rubber Platypodid . • . 320

" 13. Alcides bubo (Coloured) . . . . . . . . 321

" 14. Shot-hole Borer (Xyleborus fornicatus) of Castor stem at Bangalore . 32:2

" 15. Cirphis albistigma (Coloured) . . . . . . . . 323

" 16. Orgyia postica (Coloured) . . . . . . . . 324

" 18. Bitter-gourd-vine Gall-fly $• . \quad \cdot \quad \cdot \quad \cdot \quad \cdot \quad \cdot \quad \cdot 324$

" 19. Purohiti sp.; Woolly Aphid on bamboo $\quad \cdot \quad \cdot \quad \cdot \quad \cdot \quad \cdot \quad \cdot 325$

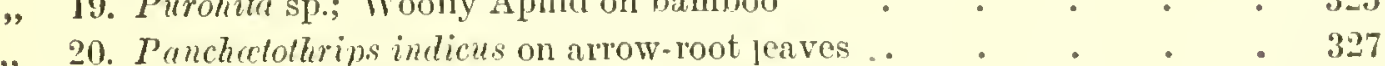

"20. Panchelotirips indicus on arrow-root jeaves .. • • • •

" 21. A Burmese fishing basket (Dalu) • • • • • • • . 359

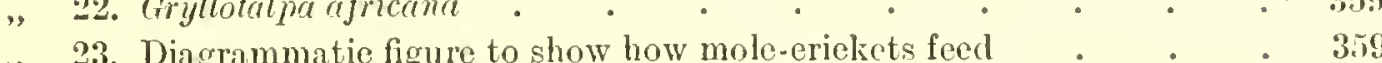

2.4. Anomala biharensis (C. S. 1744) . . . . . . . 361

" 25. Adoretus caliginosus (C. S. 1793) . . . . . . . . . 361

" 26. Autoserice sp. (C. S. 1654); Dresterius sp. . . . . . . 361

"27. Diagrammatic figure to show how Melolonthid grubs feed . . 361

"28. Weekly rainfall, mean temperature and mean humidity at Pusa during 1918 . . . . . . . • . 370

29. Anthomyiad Fly (C. S. 1867) in Juar shoot . . . . . 370

" 30. Pachylliplosis oryzce (Coloured) . . . . . . . 371

" 31. Stictespis ceratitina; C. S. 1814 larva; Annual life-eyele of Lamiad Borer (C.S. 1814) . . . . . . . . . . 371

32. (C. S. 1814) Lamiad Borer Beetle . . . . . . . . 372

"33. Weevil Borer in rarli shoot (C.S. 1778) \} . 372 Purple Zeuzerid larva boring in Kanra; Annual life-eycle of purple

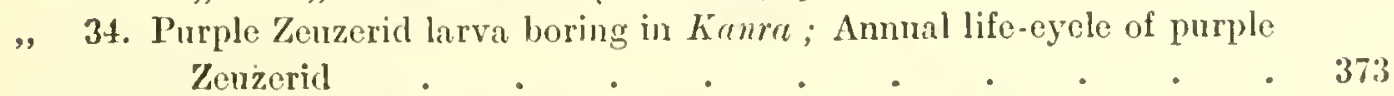

„35. Borer in Saccharum sponteneum stem (C. S. 1696); Annunl lifeeycle of Borer in Saccharum spontaneum (C. S. 1696) . . . 37 . 
Prate 36. Sesamia inferens (Coloured) .

"37. Sesamin inforens and Sesamin uniformis; posterior cxtremity of

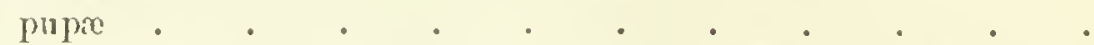

, 38. Borer in Saccharum spontancum (C. S. 1666); Borer in lanra root (C. S. 1771$)$

" 39. Borer in Eleusine coracana (C. S. 1S37) ; annual life-cycle of Eimmalocera depresselle . . . . . . . . . . 378

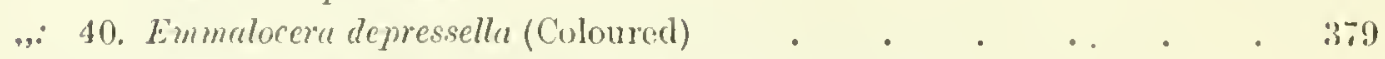

, 41. Scirpophaga xanthogastrella (anerifuna) (Coloured) . . . . 381

, 42. Annual life-cycle of Scirpophaga xemthogrestrelle; S. monostigmre; annual life-cycle of Schonobius bipunctifer . . . . . . . 38:

, 43. Schonobius bipunctifer (Colonred) . . . . . . . . 383

". 44. Raphimetopus ablutella in sugarcane (C. S. 1S01); Anmmal life-cycle of Chilo simplex.

, 45. Egg-cluster of Chilo simplex (C. S. 1819); and Chilo simplex larva .

.46. Chilo simplex larva (C. S. 1580); C. simplex pupa (C. S. 1561) . .

.47. Chilo simplex moths (C. S. 15.51) . • . • . .

, 4S. Diatrea auricitiu larva (C. S. 1574) ; D. auricilia pupa (C. S. 1560) .

, 49. Egg-cluster of Diatrena auricilia (C. S. 1787); egg-cluster of $D$. renosetu; aninual life-eycle of $D$. renosata; annual life-cycle of D. auriciliu . . . . . . . . . . . . 3st

, 50. Diatraca venosata larva (C. S. 1635); D. venosatn pupa (C. S. 1607) . 38S

, 51. Diatraa venosala moths . . . . . . . . . . . 388

"52. Argyria tumidicostalis, larva and pupa

. 53. Argyrin tumidicostalis larva; annual life-cyele of Diatran sp. (C. S. 1674) . . . . . . . . . . . . . . 389 54. Argyriatumidicostalis, moths . . . . . . . moth (C. S. 1835) . . . . . . . . . . 392

, 63. Borer in ikri (C. S. 1835); lavva and pupa . . . . .

, 64. Pyralidl larra boring in Saccharum spontancum; (F. 18), Borcr in iliri stem, larva 
Proceedings of the Third Entomological Meeting VOLUME 1 




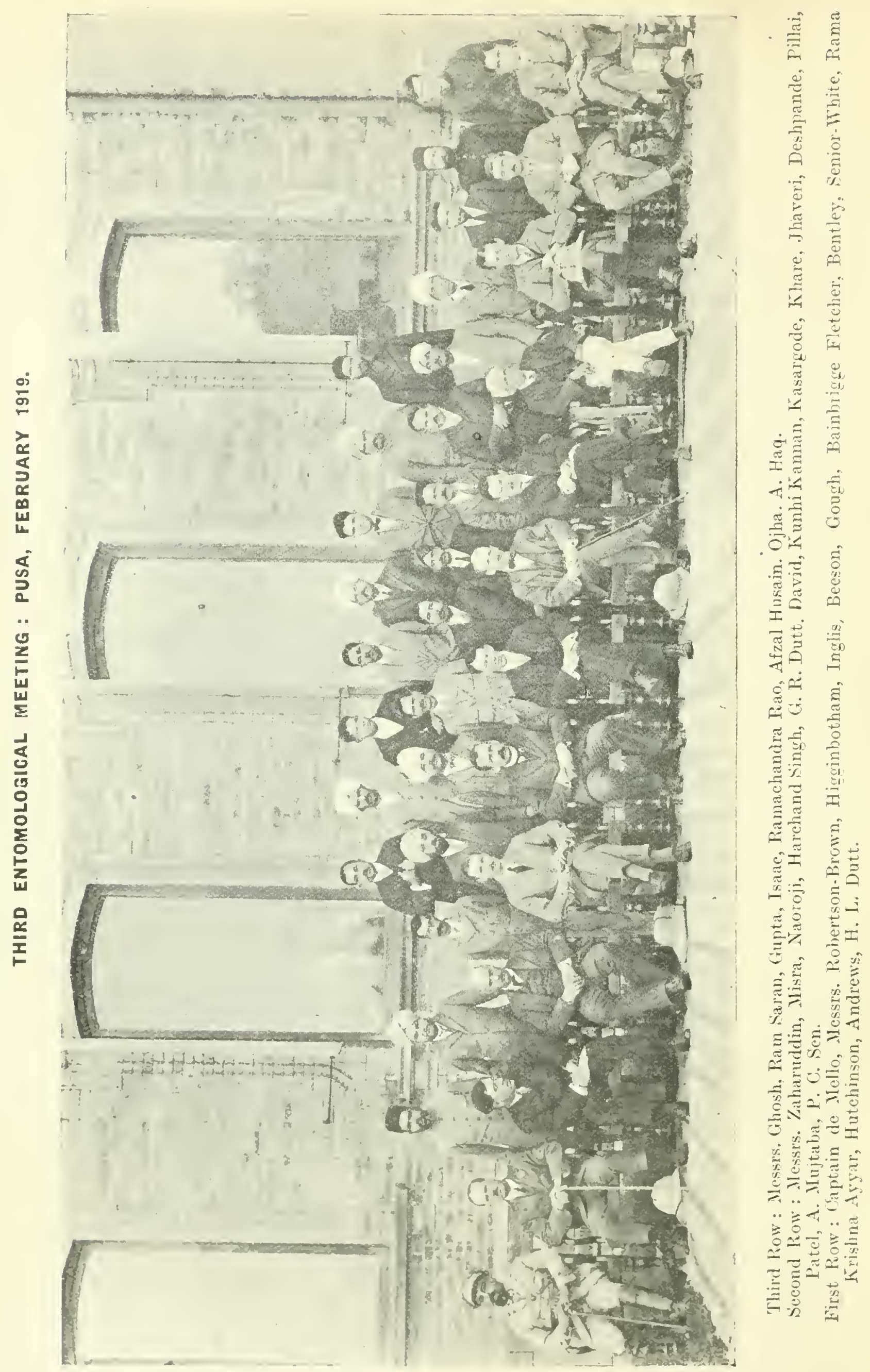




\section{PROCEEDINGS}

\section{OF THE \\ Third Entomological Meeting}

The Third Entomological Neeting was held at Pusa from 3rd to 15th February 1919, both days inclusive. The Proceedings rere opened in a short speech of welcome to the delegates by Mr. J. Mackenna, C.I. L., I.C.S., Agricultural Adviser to the Government of India, who was followed by the Chairman. Mr. T. Bainbrigge Fletcher, R.N., F.I.S., F.E.S., F.Z.S., in an Address to the Meeting, after which the business before the Meeting was proceeded with, as is detailed in the following accomnt of the Proceedings.

Openixg Speech by the Agriculturat Adriser to the Governatext OF INDIA.

Mr. Fletcher and Gentlemen. I desire to extend to you a very cordial Mr. Mackennam relcome to Pnsa. And in particular I wish, on bchalf of myself and of the Govermment of India, heartily to greet representatives from the Portuguese Government in the person of Captain de Mello and from Egy as represented by Dr. Gough. Froni all parts of the Indian Iimpire ám! from graat distances you have come to attend these meetings and I trust that, on their conclusion, you will agree that the time and the effort involved, has been well worth it. I have much pleasure, Gentlemen in welcoming you all.

Sectional Meetings of the Board of Agriculture are now a recognized part of our departmental activities. But. before the adoption of this formal scheme by the Government of India, Mr. Bainbrigge Fletcher was in the habit of holding, at regular intervals, informal meetings of workers on Entomology at which many important and valuable discussions took place. These meetings are now official and will be convened by the Government of India, but I hope that their value will not be diminished but rather enhanced by their change from informality to formality. It has been most gratifying to me, as I am sure it must be to you. to have heard from many sources appreciations of the ralue of your last published Proceedings. They were so recorded as to aroid entirely the oflicial 
style and were invested with a personal tone which gave them a very live interest.

The experiences of the last few years have turned men's thoughts more to the practical aspects of life and this is bound to be reflected in our views on education. I think one result of the war will be that education will take on a much more live aspect, and that the study of living phenomena will be greatly increased. And I venture to predict that a new era is arising as regards the study of biological questions. Entomology is bound to come into greater prominence in the future. Already on the medical side men are talking of the next great war as the war of man against insects.

On the side of Agricultural Entomology with which we are more porticularly concerned the war being waged by you against the depredators of our agricultural crops is no less important. It is of little avail that improved agricultural methods should give us higher yielding crops, if annually the ravages of insects can be calculated in millions of pounds sterling. In time of war the mobilisation of our food supplies is almost as important as the mobilisation of our fighting men and any efiorts of science which will assist in ensuring to us the full furits of the earth or their preservation, when garnered, are of incalculable value to the nation. To the creation of such a position of security the labours of our Entomological workers contribute. It is quiet, inconspicuous work, in which, I fear, the public as a whole take little interest. But it is none the less. valuable that it is unobtrusive and umpretentious, and all honour is due to the small body of zealous and eamest workers, who are content to make its pursuit their life work. "Science is * * * like virtue its own exceeding sreat roward."

I cannot, however, but feel that the time is coming when there will be an awakening to the vast importance of the subject in India. The popularity of these small conferences indicates that there is an increasing interest. Much has been done by Mr. Bainbrigge Fletcher to impress on Govermment the importance of the subject and his views on the expansion and centralization of Entomological work in India haxe been cordially endorsed by the Indian Industrial Commission. The future therefore sccms full of promise.

I trust that the results of your labours will be to rour own profit and advantage and to the benefit of the agriculture of this rast Empire.

\section{Address by the Chatrian.}

Fletcher.

I am sure that we are all much indebted to Mr. Mackenna for coming here today and opening our Procecdings, and that we all appreciate the 
kindly words he has used regarding our past Meetings and this present one.

It is once again my privilege, on behalf of the Staft of the Entomological Section of this Institute, to welcome to Pusa the many delegates who have come here from all parts of India, and even on this occasion from Ceylon and Egrpt. We have at this Weeting a larger and more represcntative gathering than at either of our previous Meetings. Assam, Bengal, Bihar and Orissa, the United Prorinces, the North-ITest Frontier Province. Bombay, the Central Provinces and Madras have all sent one or more delegates of the Agricultural Service and only the Punjab and Burma are unrepresented, although Mr. K. D). Shroft has contributed a long list of papers on Burmese insect and other pests. Hyderabad, which has not been represented before at our Heetings, has sent Mr. Makefield, the Director-General of Industries, A griculture and Commerce. Baroda is also represented by Mr. Patel; Central India by Mr. S. Higginbottom, Director of Agriculture, Gwalior, and Mr. M. Zaharuddin, Forest Officer; Patiala by Mr. Harchand Singh, Superiutendent of Dairy Farms, and Hysore and Travancore hare each sent an entomological delegate. From the Forest Department ne hare Mr. C. Beeson, the Forest Zoologist, who has promised us several papers, amoingst which we shall all look fortward to hearing that on some problems in forest insect control. Mi. Osmaston, Director of the Forest Research Institute at Dehra Dun, had also intended to have been present here to-day, but was unfortunately prevented at the last moment. The Indian Tea Association has very kindly permitted the attendance of their Entomologist, Mr. E. A. Andrens, who has promised us two papers on Tea Pests and another on the control of insect pest.. The Bengal Goveriment have also permitted the attendance of Dr. C. A. Bentley, their Sanitary Commissioner, and of Dr. Baini Prasad, who will not be able to attend this meeting but has promised to seid us a paper about aquatic insects as destroyers of fish in India. Portuguese India has sent a delegate in the person of Captain Froilano de Mello who has contributed a paper descriptive of those curious protozoal parasites, the Trichonymphids, found in extraordinary numbers in some species of Termites. Portugal, I may remind you, is a very old ally of ours and we therefore welcome Captain Froilano de Mello to our Meeting because he is present not only in his scientific capacity, since his presence is a mark of the amity existing between the British and Portuguese nations. Dr. Leris H. Gough, Director of the Entomological Section, has been sent all the way from Egypt especially to represent his Government at this Meeting. 'The problems of entomological research in Egypt are in many ways similar to those which we 
have in India and we therefore appreciate all the more the delcgation of a special representative of the Gorernment of Egypt. Dr. Gough has brought with him a most interesting paper on Pink Bollworm in Egypt, into which country it was introduced from India, and I am sure that we shall all look forward to hearing it next week. The Government of Ceylon were asked to send their Government Entomologist but unfor.. tunately were unable to send a delegate to this Meeting although they intimated that they hoped to be able to do so in future. Ceylon, howerer, is not left umrepresented, as Mr. R. Senior-White has been sufficiently interested to come all the way from Ceylon to Pusa in order to give us all the information he can about the insect pests of Ceylon, most of which, I need scarcely add, are identical with ours in India, of which Ceylon is, entomogeographically speaking, only a part. Mr. C. M. Inglis, from Laheria Serai, is also taking part in this Mceting and has sent his collection of wild Indian silkmoths for exhibition.

On behalf of the Entomological Section of this Institute, I welcome all these delegates to our Meeting and hope that their visit to Pusa may be a pleasant one in every way so that they may carry away pleasant recollections as well as any items of information they may pick up. At the same time, I trust that they will leave us the richer for all the new information concerning insects which they have doubtless brought with them.

We are to-day commencing the third of our Entomological Meetings, of which the first was held here in 1915 and the sccond in 1917, but the present Meeting differs from the former ones in three respects :-

(1) It is intended to last for a fortnight instead of only a week and, unless we become seriously pressed for time, we shall hold neetings in the moming only, learing the aftemoons free for the risitors to consult collections and records and to gather any information and to see the place generally. In order that you may do this last I have arranged with the other Heads of Sections at Pusa for convenient dates and times for you to risit their Sections if you care to do so. At the end of this ILeeting we shall be able to see whether the one-week or two-week arrangement is preferable and arrange accordingly for future Meetings. .

(2) This Heeting differs from the former two in being of a more official character. 'The First Meeting in 1915 was arranged on my own initiative in order primarily to get the provincial workers in eloser touch with one mother and with our work at P'usa and also to link up the work done in the Agrieultural Department with that being done by other entomological workers in Inclia, whether their results were applied to agriculture or not. Nuch the same remarks apply to our Second Hceting. Since then, lowever, the Tenth Mceting of the Board of Agriculture was held 
at Poona in December 1917 and, among other subjects discussed, was this question of Sectional Meetings, regarding which the Board passed the following Resolution :-

"That meetings of the.....entomological......sections be held in years in which there is no meeting of the Board of Agrieulture, and that these should not be confined to members of the agricultural department but others irterested in these subjects be invited to attend."

This Resolution of the Board has been approved by the Coremment of India and the present Meeting is the result of definite orders that such conferences are to be held henceforth at fairly definite interrals. The Resolution which I have just read, as you see, states definitely that they are to be "held in years in which there is no meeting of the Board of Agriculture." Now, the Board of Agriculture meets every second year, sometime in the cold weather between November and February inelusive, so this Resolution, if strictly interpreted, indicates that Entomological Heetings also are to be biennial events in future. Their order of frequeney, however, is perhaps a matter which we can settle for ourelyes if we desire to do so and go about it in a formal manner. I nse the word "formal" deliberately, because, as I said just now, this Heeting is on a more oflicial basis than previous ones and because I think there will be certain advantages if we adopt slightly more formality in this and subsequent Neetings. I do not wish for a moment to imply that there is any idea of stifling discussion at these Heatings. We are all met here with the very object of mutual discussion. But there are a few things which we might perhaps do more formally, partly with the idea of saving time at the general meetings and partly with the idea of giving more force to our collectire opinion on any subject. I propose therefore to appoint Committees to report on any subjects which mar be usefully considered in this way in order that they may draw up and present to the Heeting reports which may form uscful bases for discussion. I also propose, in cases where a subject is of sufficient importance and there is a clear preponderance of considered opinion after. disenssion regarding it, that such subject may form matter for a Resolntion of the Heeting regarding it. If for example there is a consensus of opinion regarding the order of frequency of our Meetings, the best way to give it expresion would be by a formal Resolution, which would doubtless be duly considered by Govermment. You might consider this during the Neeting and at its close give your views regarding the next meeting, its duration, the date and place at which it should be held. As you know, the Board of Agriculture is a peripatetic body, meeting biemially, alternately at Pusa and in one of the Provinces. Hitherto, we have met at Pusa 
because the collections and records are centralized at Pusa so far as the Agricultural Department is concerned. But these Meetings are not confined to the Agricultural Department, and it may be that it might be adrantagcous for our Mectings to be held elsewhere, at least occasionally. I mercly throw ont the suggestion, which is for you to consider in order that you in your turn may be able to make any suggestions you think proper, at the close of this Mecting, regarding any subsequent ones.

(3) Iou have been asked to bring with you to this Meeting written papers or notes on any subjects regarding which you have information to lay before the Meeting. The object of this is to facilitate securing a proper record of the Proceedings. At the 1915 Meeting the record kept proved so incomplete that it was not worth publication. At the 1917 Mceting notes were taken as far as possible and these were worked up afterwards to form the Proceedings which were published and circulated to all of you. I may tell you that it took a great deal of hard roork to go orer the mass of notes taken and to rewrite, as far as possible in their omn rords, what everyone had to say about every subject. I leare it to you to say how far we sncceeded. We at least rest content in the linowledge that we did our best.

At the present Meeting the papers submitted will be read either in whole or in part or in abstract or merely by title-according to their gencral interest. After each paper is read, it will be open for general discussion.

Since our last Meeting the War has caused us to mourn the loss of a ralued colleague who attended our First Meeting here four years ago. Edward John Woodhouse died of wounds received in action in France on 18th December 1917 at the age of 33 . At the outbreak of war he was a Captain in the Bihar Light Horse and in 1915 he jomed the Indian Army Reserve of Officers, being subsequently attached to a Caralry regiment.

I first met Mr. Woodhouse in December 1910 when he came to Pusa to consult regarding the Agrotis ypsiton campaign at Mokameh. The use of poisoned bran baits, which had been recommended by Mr. Lefroy. had proved a failure, as the baits had dried up without being tonched by the caterpillars, and it was not evident what was the next step to take. Just previous to this we had received some circulars about their traps from the Andres-Maire Company at Alexandria and, knoming from previous experience of sugaring in England that Agrotis moths were attracted to sweet baits, I suggested a trial of these traps, and it was arranged that one should be got out for Pusa and another one for Sabour. The result of the trial was completely successful and 
these traps have been used for control of Agrotis y gitur to a considerable extent since then, as Mr. Woodhouse told us himself in this rery room just four years ago. Subsequently I met Mr. Woodhouse nany times and had considerable correspondence with him regarding entomological matters, in which he took a keen interest. althongh he was of course a Botanist. His untimely death has deprived us of a valued colleague, whose place will be hard to fill.

Another whose death has occurred since our last Weeting is Mr. Charles William Mason, who was the first Supernumerary Entomologist at Pusa and who will be remembered by many of you, although he left India just before my arrival so that I never met him personally. He came out to Pusa in December 1000 and during the next three rears was stationed here, being chicfy occupied in an investigation of the food of birds, especially in relation to the ralue of birds to agriculture by their destruction of insect pests, and the third rolume of Entomological Memoirs of this Department is wholly deroted to a record of this work.

After his return to England in 1910 he studied for some time at the South-Eastern Agricultural College at Wye, and afterwards ment to America as a Camegie student to undergo further training in Entomology. Snbsequently he was appointed to succeed Nr. E. Ballard as Gorermment Entomologist in Nyasaland, where he died of black-mater ferer on 28th November 1917 at the Gorermment Farm at Namiwawa. In his Annual Report for the year ended 3ist March 1918, the Director of Agriculture in Nyasaland says :- "Mr. Mason was an exceptionally able and popular officer. his enthusiasm and care produced work of a very high standard. his researches in comnection with tobacco and cotton pests conferred a lasting benefit on the planting community, and his demise in the prime of young manhood is not only a loss to the Department and his fellow workers but to Tropical Agriculture in Africa."

That is, I am sure, a statement which you will desire to endorse and I therefore propose to place the following Resolution before you :-

The Dntomological Workers assembled at this ITeeting desire to Resolution I express their sense of the loss to Entomological Science sustained by the untimely deaths of their formcr co-workers in India, the late Edward John Woodhouse and Charles William Mason.

\section{[This Resolution was passed in silence, all standing.]}

Before coming to a consideration of the subjects on our programme. there are one or two other points which I should like to put before rout although they are not perhaps suitable for discussion at the full Mecting.

It has been suggested, from more than one direction. that we might form an Entomological Society in India and thus link together all the various workers on entomology in India, Burma and Ceylon. In this 
connection I may draw your attention to Appendix $H$ to the Report of the Indian Industrial Commission in which they say:-

"We desire to attract attention to the almost complete absence of scientific and techmical societies in India. So long as the majority of the men in this country from whom such societies would naturally draw their members belonged to Government executive services, the subordination essential to discipline was unfavourable to their inception and growth; but this phase is gradually passing away, owing to the much wider diffusion of scientific knowledge, to the rapid expansion of organized industries, and to the greatly increased number of scientific and technical experts in private employment."

$\begin{array}{llllll}* & * & * & * & * & * \\ * & * & * & * & * & *\end{array}$

"It is mmecessary for us to dwell at any length upon the advantages which arise from a free interchange of ideas between men working in the same field of scientific investigation, and the stimulating eflect of instructed criticism on men engaged in technical pursuits.

"We are of opinion that the interests of India demand the establishment of Tndian institutes, societies and associations analogous to the Tnstitution of Civil Engineers, the C'hemical Society. and the British Association for the Advancenent of Science. Action in this direction is urgently reyuired to provide for the growing needs of Indians. It is true that ther have free access to the English societies on the same terms as any other subjects of the Empire, and they are also freely admitted to American societies: but berond the prestige attaching to membership and the periodic receipt of copies of publications, they derive little or no benefit from such distant associations, and ther are altogether deprived of the advantages which arise from personal intercourse between the members. In matters comected with administration, the ralue of personat discussion has been recognized ly fiovermment, and every year an increasing number of conferences and committees meet to discuss specific problems. Nen are convoked from all parts of India to exchange views, and experience shows that such meetings are well worth the time devoted to them and the expense incured in bringing the officers together. But something more than this is necessary, and the morement in favour of it has found expression in the establishment of the Indian Science Congress. which was started four years ago and holds annual meetings in the month of January in one or other of the capital cities of Intlia."

$\begin{array}{llllll}* & * & * & * & * & * \\ * & * & * & * & * & *\end{array}$


"There would be advantages arising from a strong central society covering the whole of India, as membership thereof would confer a much greater prestige. Apart from the reading and discussion of professional papers. such a society would ineritably interest itself in many problems with which the State has to deal, and in which it would be advantageous to obtain the considered opinion of such a representative body."

\% $\quad * \quad \%$

"Such an institution should be an entirely independent body. to which Govermment can very well give an annual grant or subsidy in return for the indirect advantages which the country would enjoy in consequence of its establishment. We have in view an institution whose activities would be mainly deroted to professional and technical questions; its existence therefore would be of great value in establishing a standard of professional conduct and elliciency."

The above extracts refer more particularly to a soeietr of Engincers but as regards general scientific work in India they will show rou what the Commission lad in mind and I have no doubt that Government would view with sympathy any real desire on the part of scientific workers of any lind in India to form such societies and would perhaps assist to some extent. I do not linow, howerer, to what extent the formation of an Entomological Society would meet the wishes and requirements of entomologists in India, nor, I must confess, do I quite sce what would be the functions of such a Society. If my scheme for centralization of entomological work in India eventuates, such a Central Institute and Service rould fulfil all the ends of a Society as regards such it ens as publications, collections, references and assistance generally to other workers. Even as it is, our periodical Meetings provide ample opportunity for discussion of any problems and it is difficult to see how more frequent or better attended meetings could be arranged in such a rast country as India, nor is there any lack at present of facilities for publication in this country. If, howerer, any of you have any definite ideas on this subject. we might discuss it informally one afternoon or erening whilst we are all here and then, if any general agreement is reached, it might be brought forward more formally during the Jleeting.

Another subject which might perhaps be discussed informally at first is my scheme for the expansion of entomological work in India, which you will find published in Appendix $\mathbf{K}$ of the Industrial Commission's Report. Copies of this Report are laid on the tahle for your perusal and when you have had tme to go over it me might discuss that also one afternoon or evening.

Our former Meetings were both held under the shadow of the Creat War which has now happily come to a close and which has affected our 
work in so many ways. One of the obvious results of the war has been the great difficulty in obtaining apparatus. Another has been the setback to our work owing to the difficulty in obtaining identifications of specimens, practically all of our younger specialists having gone to the front. Another and more serious result has been the loss of parcels of specimens owing to the piratical action of the Germans in sinking merchant ressels indiscriminately. Tre at Pusa lost a large collection of Braconid parasites of Earias fabia and E. insulana, which means a loss of sereral years' work, and I understand that the Forest Research Institute and the Zoological Surrey have also sustained similar losses. Onr losses in India. have of course been infinitesimal in comparison to the damage and wanton destruction in Enrope of collections in varions branches of natural history. Some of the finest entomological collections in the world were in Russia, in Belgium and in Rumania. The deliberate destruction of irreplaceable objects of science and art, such as has taken place during this war, stamps the German people as an uncivilized race of a rery low type. It is sincerely to be hoped that in the future all entomological workers in India will mark their disapprobation of such misdeeds by declining to have any dealings with all Germans, that they will refuse to work with apparatus of any kind " made in Germany," that they will refuse to send any more collections for identification tö Germany and thereby aroid having any more Indian insects described in a most barbarous language, and that they will as far as possible ignore all German literature published since August 1914.

This last point, even if we are all agreed on it, will be difficult to enforce unless we can obtain universal agreement, but this might possibly be obtained, as many others must be of the same way of thinking at the present time. In his recent revision of the Hypsotropinæ, for example, Sir George Hampson says, "No quotations from German authors published since 1st August 1914 are inserted. "Hostes humani generis'."

The International Entomological Congress, which met at Brussels in 1910 and at Oxford in 1912, was to have held its Third Session at Tienna in 1915. I have not heard any particulars regarding the third session, which was postponed indefinitely, but it is possible that it may be held at some date before onr next Meeting and, if so, it would lend reight to our views if we could lay before the Congress our collectire opinion on the subject of the treatment to be accorded to German workers and German entomological literature in the future.

My own view, which I have held for a long time, is that the whole question of scientific publications requires overhauling and that published scientific work (in entomology at all erents), to ensure proper recognition, should be restricted as regards both the media and the languages 
in which it appears. Separate publications (for example, books; although nothing should be considered as a book unless it contains a minimum number of pares) cannot easily be legislated for but there seems to be no end to the various serial publications in which entomological work appears now-a-days. Some time ago the Imperial Bureau of Entomology gave an incomplete census of present-day periodicals in which entomological articles are published, and this list, so far as I remember, came to over. seventeen hundred. It is absolutely impossible to see all these, eren in the best libraries anywhere, and eren a useful abstract hke the "Zoolozical Record" is not really complete. Nany important papers are published in Transactions of Societies, etc., which to the entomological world contain little else of importance and no private worker and few public libraries can take in complete sets of such Transactions merely for the sake of an occasional paper which otherwise is orerlooked or not accessible when required for reference. To talie the case of India only, we have entomological papers appearing in the Memoirs, Bulletins and Annual Reports of the Agricultural and Forest Departments, the Memoirs and Records of the Indian Musem, the Asiatic Society's Journal, the Bombay Natural History Society's Journal, the Indian Journal of Medical Rescarch, the Journal of the Indian Tea Association, the Planters' Chronicle, Spolia Zeylanica, and half a hundred other Bulletins, Reports, Annuals and what-not issued by various Covemment Departments, Native States and other's, although liardly one of these publications is devoted entirely to Entomology. I have dealt with this in my proposals for expansion and centralization of entomological work in India and only wish to draw your attention now to the large mass of current literature already in cristence in India. But India is a comparativaly small contributor to entomological literature and we require a wordwide scheme to centralize work as much as possible.

My idea, roughly, is this, that the leading entomological (or zoological) societies or workers in every civilized country should consider the literary output of their own country and compile a limited list of publications which would be considered official from the point of riew of scientific worth. For example, in England a dozen to twenty (at the ontside) publications-sich as the Transactions and Proceedings of the Royal, Linnean, Zoological, and Entomological Societies, the Entomologist, the Entomologists' Monthly Magazine, the Entomologists' Record and a few other leading publicatrous in pure and applied entomology, including a lew provincial publications-should suffice for all scientific work. If anyone wished to publish in non-official publications they could do so, and their papers wonld of course be on record but would possess no scientific value. The effect of this would be that the amateur and casual 
workers would still be able to publish in their local Societies' Transactions and so on, but the serious worker would only have to consider a comparatively limited output of literature-limited, that is to say, for any one country but of pretty wide extent (probably 150 to 200 publications) for the whole world. It would be better to have separate lists for entomological and zoological (non-entomologieal) papers, although the lists might overlap in many cases. A permanent Committee in each country could consider applications for admission to the list of recognized publications but no new publications should be admitted unless a clear want for additional publication-space was proved and in any case such admission should not be retrospective in effect. The lists approved by each local committee to. be serutinized and fually passed by an international committee (for example, at the International Zoological and Entomological Congresses).

I quite see that there would be diffculties in starting such a scheme but, once started, I think it would work. And, unless something of this sort be done, it is not easy to imagine how entomological workers will get on, say a hundred years hence, if publications multiply at the present rate. It would, of course, only be possible to make such a scheme prospective from a definite date, of which due notice would be given.

Another thing is the question of languages. It is not only the German language which is concerned but the whole matter is becoming one of general convenience. It is impossible for any ordinary man to be conversant, even as far as mere reading goes, with English, French, Latin, German, Dutch, Russian, Italian, Portuguese, Spanish and Japanese, in all of which languages important papers are appearing now-a-daysto say nothing of more or less occasional important papers in such languages as Magyar. So far no original entomological papers of any permanent value have appeared in any Indian vernacular, but I linow of nothing under the present rules governing publication of scientific work to prevent anyone publishing a paper in (say) Bengali or Malayalam and, although quite unintelligible to more than ninety-nine per cent. of the entomological world, such a publication would be recognized and secure priority under the present rules. Indeed, I know of no rule which would prevent my publishing a deseription of a new insect in an Indian vernacular in some obscure local daily paper.

The present state of affairs is ridiculous and requires amending, not only by limiting the number of publications, but also by some limitation of the languages in which original scientific work should be allowed to appear and be recognized. I should restrict these languages to English. French, and perhaps Latin. In any case German should be absolutely barred in future. The local publication-committee in each country 
should recommend in what language each proposed "recognized" publication would be issued and the international committee should then go over these loeal lists and decide finally. There rould probably be a considerable amount of disagreement orer this language question, but. as feelings are after this War, the Allies would probably secure a preponderance at any international meeting in the near future, and it would be as well to take adrantage of this before public opinion on the subject becomes blunted.

The war has at least brought home the importance of a knowledge of entomology to many people whose previous idea of entomologists pictured them as useless, albeit harmless, cranks whose main object in life was the pursuit of butterflies by means of large green nets. The health of our troops in all the areas of the war has, howerer, required a rast deal of entomological work in controlling the rarious flies. mosquitos. lice and other insects which are carriers of discase, especially when large bodies of men are kept together in small areas under erowded and often necessarily insanitary conditions. Never before in such a short time has such a large number of entomological workers been employed on practical work of this nature and never before has entomology so proved its ralue in this particular section of its sphere of usefuhess. In the South African War the British Amy lost nearly twice as many men from preventible diseases, chiefly typhoid ferer, as it did from casualties in action. In the Spanish-American war one-sixth of the American troops was attaclied by typhoid. Truly was it said that "Disease, not battle, digs the soldier"s grave." But we have changed all that now-a-days to a very large extent and the preventible losses by disease during the recent war have been reduced to a comparatively trifling proportion, thanlis to the adoption of scientific method, amongst which entomological investigations must be included. The transport and storage of the immense quantities of food-stuffs required for our forces during the war has also called foreible attention to the damage dore to such food-stufis by the numerons insect pests which attack stored produce. And the present world shortage of food and raw vegetable material is considerably aggrarated by the losses caused by insect pests. It is not easily realized what these losses anount to in the aggregate. Taking only the case of agricultural crops grown in India, we may say that on an average ten per cent. of the total produce is destroyed by insect pests. In some cases it is more and in others less. The Director of Agriculture in Assam told me recently that, as the result of crop-cutting experiments in some districts in $A$ s.am, it was found that ninety per cent. of the paddy crop was destroyed ninsect pesis and this is apparently a nomal figure. Of course, we often find cases even of total destruction, but they are sporadic as a rule. 
'Taking, however, ten per' cent. as an average and ealculating the total amount of loss annually in India we shall arrive at a figure which at the lowest camot be placed at less than about R.s. 5,00,000,000. We have a long way to go yet in India before we can make people understand the magnitude of this loss due to insect pests and to take Entomology really seriously, but the war will have had at least one good result if it helps to open people's eyes to these facts.

The war has been responsible for the introduction of the word "camouflage," and you have probably all seen pictures of disguised gun-positions, and of tanks and ships painted in weird combinations of colours. But concealing colouration was not an invention of the war. It was adopted by the animal world long ago and the insect world particularly can show innumerable examples of things being not what they seem to be. Later on, I shall show you an excellent example of this. I might also call your attention to an article by Mr. J. C. Nottram in the Proceedings of the Zoological Society for 1916 (pp. 383-419) which deals with Indian butterflies and analyses their colour-patterns, showing exactly how the various effects are produced. This is essentially the "camouflage" principle, as evolved during the war.

Insects have in fact anticipated many of man's present-day inventions. Our newspapers, which have brought us day by day the latest news of the happenings during the great struggle, are printed on paper which is almost wholly made from rood-pulp and for years past the pine forests of the north temperate zone in Europe and North America have been ruthlessly destroyed at the rate of something like thirty million tons of timber per anum to satisfy the world's insatiable desire for paper. But few of those who read their daily paper know that the first suggestion that wood-fibre might be used for paper-making was made by an entomologist, Reaumur, who some two hundred years ago observed the structure of wasps' nests and how they are made of a paperlike material produced by these insects by the mastication of wood fibres. His observation seems trivial but its after-effects afiord only one of the many instances of the foundation of a great industry upon results obtained in seientific investigation. As Professor Silvanus P. Thompson has well put it :- " The seemingly useless or trivial observation made by one worker leads on to a useful observation by another; and so science adrances, "creeping on from point to point." It is impossible to foresee what will be the ultimate practical outcome of even the smallest observation in matters scientific, provided that the observation is accurate, but we may be sure that sooner or later it will fit in with other equally small and seemingly useless facts to form a coherent whole. When we see the extensive uses of magneto-electricity now-a-days we are apt to 
forget the seemingly trivial observation which led to this. In one of his experiments at the Royal Institution in London Faraday showed that when a magnet is brought suddenly near a coil of wire a slight electric current is induced in the coil. The experiment does not appear very impressive and a lady in the audience probably expressed the general sentiment when she asked afterwards, "But, Professor Faraday, even if the effect you explained is produced, what is the use of it?" To which Faraday replied, "Madam, will you tell me the use of a new-born child ?"

Nearly all the great inventions of our modern world. wireless telegraphy, the telephone, the aeroplane, radium, anæsthetics and ant:toxins, spectrum analysis and X-rays, all had their foundations in purely scientific work and were not the result of deliberate intention to make something of service to humanity. Scientific subjects do not progress necessarily on the lines of direct usefulness. Their applied side may come many years after the actual discoveries themselves. Applying this to economic work in Entomology, as I said just now, provided that our work is accurate and honest, every smallest observation will ultimately prove to be of use whether in the immediate future it seems likely to be practically useful or not. As Aristotle said, "Let us first understand the facts, and then we may seek the cause."

I am inclined to think that the control of insect pests in the future will be based on the dictum that "prevention is better than cure," and that such prevention will be attained by an exact knowledge of each insect concerned, knowledge so exact that it will be known exactly under what conditions trouble is likely to occur, so that preventive measures can be taken before any actual damage has been done. This is not the case at present, as most of our so-called control measures are mere palliatives, aiming only at minimizing damage which is already being done. I think that the control methods of the future will be based on forecasts of the increase to destructive numbers of the particular insect concerned and that such forecasts will be based on an intensive study. of a large number of exact records of occurrence of such insect. Why, for instance, does Xylotrechus quadripes, the Coffee Borer, appear in some years in swarms, whilst in other years this beetle is by no means plentiful? Why do locust swarms invade India in some years and not regularly every year? I think that, when we have accumulated exact records of such visitations and compare them with weather statistics and other records, we may find some correlation between them and, if so, we shall then be able to make insect-pest forecasts which can be used to nip the impending increase in the bud. But we shall only be able to do this when we have accumulated sufficient exact records of the

VOL. 1 
occurrence of insect pests and for this reason all exact records at the present day are of importance.

Entomology especially is such a vast science, with so many interrelated and interdependent branches, that progress in any one branch is necessarily dependent on progress in other branches as well. Economic rork depends on progress in systematics, in the natural history (in its largest sense) of the insects concerned, and in control methods as applied to insects generally, as well as on some knowledge of the particular subject (agriculture, forestry, etc.) with which any particular insect is concerned, and all of these branches must be taken together if the best results are to be secured. The economic entomologist who thinks, for example, that he can get on quite well without bothering about the systematic side is on a par with the systematist who only pays attention to adult characters of insects and despises all information regarding their early stages and habits; nor is the work of either likely to stand the te'st of time.

But, although we cannot afford to neglect any aspect of Entomology as a whole, it has become quite impossible for any one man to be proficient in, or even conversant with, the whole of such a vast subject as is Entomology now-a-days. We have, each of us, to do what we can in our little corner and to look to others for information on other subjects. Entomological research has become extremely specialized and tends to become more so in the future. There are no general entomologists now-a-days. The man who really knows his subject is a specialist in a comparatively small group of insects or in some other branch of entomology. And so it is more and more coming to pass that we must rely on other's work for our own information, and this means that progress is only possible, in more than a very limited area at least, by mutual help. The specialist in one subject must be ready to help others in his speciality and must himself apply to others for help outside of his own special group. As Laplace put it, "Nature is so varied in her manifestations and phenomena and the difficulty of elucidating their causes is so great, that many must unite their knowledge and efforts in order to comprehend her and force her to reveal her laws." A Meeting of this sort provides an excellent opportmity for the exercise of that mutual confidence and mutual aid, of which I spoke at our last Mecting, and I hope that we shall all acquire at least a mutual knowledge of one another's informatiou on the various subjects for discussion at this Heeting.

Turning to the programme before us, you will see that a very large number of papers has been promised. The programme has been divided into twelve sections, purely for convenience in arranging the papers on various subjects. A paper may fall under more than one section. A 
paper on a crop-pest, for example, might be placed under Agricultural Entomology or may deal with its life-history or systematics in which cases it could equally well be placed under these other sections.

The first Section includes especially papers on Agricultural Entomology and we commence with an annotated list of general crop-pests followed by a paper on fruit-pests, both of which might be taken together to save time. There are two ways of discussing crop-pests, one by taking each crop separatey and going over its pests, the other by taking the insects themselves one by one in systematic order and going over their distribution, occurrence on various foodplants and control. At our last Meeting we went over our pest-list by crops. At this Meeting we will do it the other way and consider each insect separately. We have prepared lists of these insects in systematic order and have summarized our information up to date. We shall thus indicate briefly what is known about each insect and you will be able to tell us any further facts. To facilitate matters I have had a series of the insects concerned put together so that if there is any doubt regarding the insect referred to you can refer to the specimens exhibited to make sure what is meant. I must say, however, that I am quite unable to define what is a crop or what is a pest. Many plants, regarded as uscless in some districts, are in others prized or even cultivated for their products. Ber (Zizyphus juiuba) is one. In most parts of the Plains it grows wild, but in some districts it is used extensively for growing lac or is cultivated for its fruits, and in such cases any insect attacking it and reducing its vigour must be looked on as a pest. Again, some insects are pests in some districts and not in others. Margaronia coesalis is a case in point. In Southern India and Assam it is a pest of jak (Artocarpus integrifolia), but here at Pusa, where there are many jak trees and it occurs, it has never been noted to attack jak at all. Then there are the potential pests, to which I called your attention at the last Neeting, quoting Prays citri as an example. Another example is Dacus olece, the destructive Olive Fruit-fly of the Mediterranean Region; we know that it occurs in North-Western India and that it is likely to prove a serious menace to the budding olive-growing industry in Kashmir and the NorthWest Frontier Province, although we do not as yet know of its having attacked cultivated olives. Yet another class of insects which would ba refused admission to the pest-list by some people are those which have never actually been reported as doing damage. But it must be remembered that, in a country like India, it is comparatively rarely that any damage by insect pests is reported. Scrious damage may be done for years without ever coming to the notice of the entomological staffs. Gracillaria sachrysa, for example, oceurs throughout the North- 
West Frontier Province from Parachinar to Abbottabad and also in Assam at Shillong and probably all along the Himalayas and does serious. damage to young apple leaves; yet it has never been reported. Similarly, apple fruits in Shillong are badly bored by two species of weevils, yet this has never been reported and we might have waited a long time for any knowledge of these pests if I had not happened to inquire into the subject of fruit-pests at Shillong last year. I think, therefore, that so far as pests are concermed it is better to be inclusive than exclusive when we come to list them. It does no harm to include a doubtful case in the list even if it ultimately turns out not to be a pest, but if we exclude it and it subsequently does do damage there is a danger that earlier information about it may be overlooked and not be available when required. If it is on the list as a possible pest it is, so to speak, in our mind's eye and we are more likely to collect further information about it. At the same time it must be clearly understocd that no list of pests cain be looked on as anything like complete. We camnot foretell what insects, or eren what groups, may turn out to be inimical. No one, for example, in any part of the world has ever looked on the Perlidæ as of any economic importance except that they serve as bait for anglers. Nevertheless, a species has lately been found to damage orchard foliage in the United States, and quite possibly some of our Indian species may do the same. Every year, every month, new pests come to light and our knowledge of the old ones is increased, and it will not be in our time that anything in the way of finality is achieved. However, we shall help on this end by accumulating as many facts as we can, taking care only to prepare a firm foundation of accurate facts on which our successors may build securely.

Most of the other papers in this Section are sufficiently explained by their titles and call for few remarks at this stage.

Mr. Andrews, Entomologist to the Indian Tea Association, is giving us a paper on the control of insect pests. This subject has of course been discussed generally at previous Meetings as regards particular points, but not as a separate entity by itself. It will therefore be useful to have a paper on this subject. You will find a general resume, so far as crop-pests are concerned, in my book on South Indian Insects (Chapter $\mathrm{XI}$ ) and I do not think that there is very much to add to that so far as the ordinary Plains crops are concerned. In the case of tea, the conditions are considerably different. In any case, we shall all be glad to hear what Mr. Andrews has to say.

I have already referred to Dr. Gough's paper on the Pink Bollworm in Egypt; this will be given as an evening lecture illustrated by lantern slïdes. Mr. F. (T. Willcoclis, Entomologist to the Sultanic Agriculturali 
Society in Egypt, has also sent a most interesting paper on his experiments on the survival of resting stage larve of the Pink Bollworm in cotton-bolls buried at different depths and under different conditions in the ground. In my Address to the Second Meeting, two years ago, I referred to Mr. Willcocks illuminating experiments on the length of time during which Pink Bollworm larræ were found to be able to rest in cottonseed in Egypt, and the present experiments show how these larve are able to survive in cotton-bolls buried in the soil even when an irrigated crop has been grown in the ground beneath which these bolls were buried.

At our last Meeting also I referred to the visit paid to India by Mr. D. T. Fullaway especially to collect parasites of Chatodacus cucurbita, our common Cucurbit Fruit-fly, for importation into Hawaii, and Mr. Fullaway has very kindly sent us a paper describing his visit to India and the success achieved in Hawaii by the parasite. Opius fletcheri, which he was successful in transporting from India to Honolulu.

Section II, Forest Entomology, only contains one paper, on some problems in forest insect control, by Mr. Beeson, the Forest Zoologist. In many cases the insects which attack forest trees are similar to , or even identical with, those which attack agricultural crops, whilst in other cases they are widely different from any we have to deal with. In any case, we shall all be very interested to hear about them, whether they are old friends or new ones.

Section III was intended for Medical and Veterinary Entomology, and in the preliminary provisional programme which I circulated last October it was presumed that this subject would be arranged by the Imperial Pathological Entomologist. It has now been decided to omit this subject from the present conference.

Section IV deals with Household and Store Pests, and we have a few papers on these. The subject of household and store pests is one that badly requires working on in India and might perhaps be taken up more fully at the next Meeting.

Sections V (Bee-kceping) and VI (Lac) will not detain us for very long. I do not think there is much new to say about either. Regarding Bee-keeping, however, I should like to warn any of you, who may think of doing so, against importing European bees at present, owing to the grave danger of introducing bee diseases, particularly Isle of Wight disease, into India. It may be necessary to restrict the importation of bees and foundation-comb, as is done in South Africa.

Under Subject VII (Silk) Mr. De will tell you something of what we have been doing in the way of attempts to improve the multivoltine races of silkworms, and will also glve a paper on the methods of combating pebrine. Mr. C. M. Hutchinson, the Imperial Agricultural Bacterio- 
logist, has also very kindly promised to tell us something about his work on pebrinc, and his paper will be given in the form of an evening lecture.

Subject VIII (Life-histories and Bionomics) calls for little remark, as the titles of the papers are self-explanatory, and the same applies to Subject IX (Collection and Preservation of Specimens). Under the latter subject we have one paper which was received too late for inclusion in the printed programme and that is one by Dr. Darid Sharp, F.R.S., on the importance of collecting insects. Dr. Sharp's name is well known to all of you as the author of the two volumes on Insects in the "Cambridge Natural History" and we are greatly indebted to him for contributing this paper to our Meeting.

Subject X (Systematic Entomology) has brought us several interesting papers, amongst which I shall call your special attention to the one by Mr. E. Meyrick, F.R.S., on our present knowledge of Indian Microlepidoptera. Mr. Meyrick, as you know, has been working on our species for the last fifteen years, during which he has described over two thousand novelties from India, and we are greatiy indebted to him for sending us a very raluable and interesting note on his special subject.

Captain de Mello is giving us a paper on some Trichonymphid parasites of Indian Termites. This is a subject which lies, strictly speaking, beyond the borderland of Entomology but which is yet of considerable interest to us from an entomological point of view. These curious protozoan parasites which infest the interior economy of some (but by no means all) termites seem to be restricted to those temites belonging to the more primitive groups. Why this is so, it is difficult to say, but it is possible that further investigation of these Trichonymphid parasites may throw some light on the past history and relationships of their hosts. Captain de Mello is describing a new species of Nyctotherus also found in an Indian termite. Now, it is quite intcresting, as Dobell has pointed out in the case of Nyctotherus termitis (found in Calotermes mititaris at Peradeniya), to note that the only other known host of a Nyctotherus is a cockroach, Stylopyga orientalis, and as we know on other grounds that the termites and cockroaches are groups not remotely allied to one another it is decidedly a matter of entomolocical interest for us to hear something about these parasites and to see how a small fact of this nature fits into its natural place in our knowledge of the relationships of their insect losts. It is only one more example of the fact that an accurate observation apparenty trivial in itsclf so long as it is isolated, when added to other similar observations, joins up with them to build up a coherent whole.

The question of preparing and issuing a general Catalogue of all known Indian insects also comes under this Section. The need for such 
a Catalogue is very great, as I think that you will all admit, and it remains to be seen whether we are in a position to meet our requirements in this matter.

Under Subject XI (Publications) we have a paper by Mr. Slater on the preparation and reproduction of scientific illustrations. The making of drawings from which blocks are to be made for purposes of illustrationwork is not quite the same thing as the making of drawings which are to be looked at as originals. This is a point which is often overlooked, and I thought it would be useful if we had a paper on the subject and on the methods by which prints are made and accordingly asked Mr. Slater if he could give us a paper, which he has very kindly done.

Subject XII (Miscellaneous) is meant to include any subjects not fitting into the other Sections. I have prepared a note on Plant Imports, showing what has been done to keep pests out of India on plants imported from overseas. Entomological Education in Agricultural Colleges has also been included as I thought it would be a good thing if the teachers in the various Agricultural Colleges discussed, amongst themselves at first and afterwards at the full Meeting, any points about the courses in Entomology at some Colleges which might be interesting or useful to others. I have also asked each teacher to bring a syllabus of his course, any diagrams or models used for class-work and a rough estimate of the number of coloured plates required annually. The question of the organization and expansion of entomological work in India will also be discussed, at first in Committee.

I doubt whether it will be possible to make, or adhere to, a daily programme. The first week will mostly be taken up with discussions on crop-pests but papers on cognate subjects (for example, life-histories) will be taken at the time the insect concerned is under discussion. Mr. Burt will be here only from 12 th to 15 th and especially wishes to be present at discussions on cotton-pests, so we will probably take bollworm papers on 13th. If any delegates wish to have any particular papers taken on particular days, I will try to fit these in as far as possible. It is really immaterial in what oider papers are read or discussed, as they can be placed in proper order afterwards when the Procecdings are made up.

As indicated in my Address, I propose to appoint Committees to Mr. Fletches consider three subjects, namely, the proposed Catalogue of Indian Insects, Entomological Education in the Agricultural Colleges in the Provinees, and the Organization of Entomological Work in India. The Committees will consider these subjects and draw up short reports which will be circulated and then discussed at the General Meeting. The terms of 
reference and membership of the Committees will be as follows, and, if anyone else feels that he can usefully serve on a Committee or has any suggestions to make, I shall be glad if he will say so now.

\section{Commitees.}

(1) Catalogue of Indian Insects.

Terms of reference. To consider the desirability and practicality of the preparation and publication of a general Catalogue of all described Indian insects and to formulate proposals :-

C. Beeson.

E. A. Andrews.

T. V. Ramakrishma Ayyar.

R. Senior-White.

T. Bainbrigge Fletcher (Chairman).

(2) Entomological Education in Agricultural Colleges.

Terms of reference. To consider the methods adopted in Provincial Agricultural Colleges in India for teaching Entomology to the Agricul. tural Students and to make any recommendations :-

H. I. Dutt.

Ramrao S. Kasergode.

J. L. Khare.

T. V. Ramakrishna Ayyar.

K. Kunhi Kannan.

S. Higginbottom (Chairman).

C. Beeson.

C. S. Misra.

T. Bainbrigge Fletcher.

(3) Organization of Entomological Work in India.

Terms of reference. To consider the scheme put forward by Mr. Bainbrigge Fletcher (Appendix $\mathrm{K}$ of the Indian Industrial Commission's Report) and any alternative proposals, and to make any recommendations :-

E. A. Andrews.

C. Beeson.

L. H. Gough.

* C. A. Bentley (Chairman).

* These delegates did not serve on the Committee as they were unable to be present at the Meeting during a suffieiently long period. 


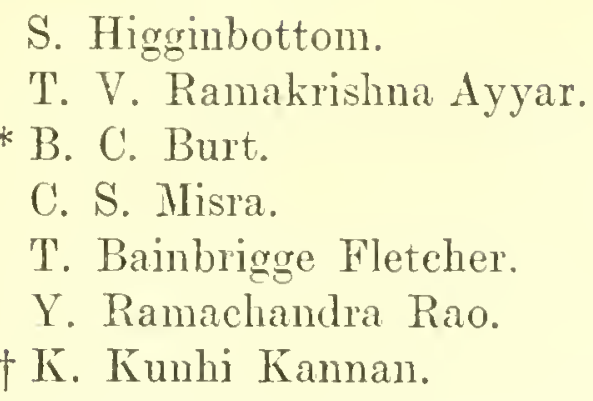

The first paper which we will take is that by Mr. E. A. Andrews on wr. Fletcher. Insect Control. As we shall have to deal with various methods of control when we take the next paper on crop-pests, it will be better to take Mr. Andrews' paper first in order to save time later on when we come to deal with these control methods. Mr. Andrews, as you know, is the Entomologist to the Indian Tea Association and requires little introduction from me.

\section{1.-INSECT CONTROL.}

By E. A. Andrews, B.A., Entomologist to the Indian Tea Association.

At the previous meeting we diseussed under each insect control or preventive measures tried against that insect. This method of dealing with the subject, while excellent in that it gave to any one interested in one insect an opportunity of ascertaining which remedies could be used against it, yet had this drawback that it left one with a rather vague idea as to the respective values of different methods of insect control in India. Were one to prepare a catalogue of the various methods for dealing with insect pests which have been put forward from time to time such a catalogue would be very extensive. Many of these methods are of value, others of no value, while some are effective under certain circumstances, but not under others, and my idea in suggesting that inseet control be treated as a special subject was to ascertain if possible what methods had been found to be of practical value in India so far and what methods have been found to be of very little value. This is a side of the work which interests me to a very great extent. I am especially concerned with one serious pest. The serious nature of this pest you can never realize until you travel all round the tea districts and see it for yourselves. Now the community by whom I am employed are not greatly interested in the investigation of minor pests, but anxi-

* These delegates did not serve on the Committee as they were unable to be present at the Mceting during a sufficiently long period.

$f$ Added to the Committee at the request of the delegates from Native states. 
ously desire a cure for the tea mosquito. I cannot therefore give much time to the investigation of the life-histories of the various pests of tea, but must confine my energies to the search for a cure for one particular pest, and, as you all know, though there are difficulties in the investigation of insect life-histories, the search for a cure presents greater difficulties still. I believe that I have had opportunities which many of you have not had of going into the question of insect control from a particular point of view, and I think it would be of interest to the meeting for me to give some of my experiences in this matter, and to give you an idea both of methods which I have found to be of value and of those that I have found to be of no value, under the conditions prevailing in tea, and I think that if other gentlemen would give an account of their experiences when working on the question of insect control it might lead to an exceedingly helpful discussion. Now the first point I want to emphasize with regard to insect control is this, that you must know your insect-and you must lnow it inside out. It is not enough to know its species; it is not enough to be able to recognize the various stages; you must know everything about it. It pays in my opinion to sit down amongst the bushes and watch every peculiarity of its behaviour, no matter how trivial it seems at the time, for the more you lnow of the insect's peculiarities the more likely are you to be successful in finding a remedy. Until we possess an intimate acquaintance with every phase of the economy of an insect we cannot hope to get very much further in the control of that insect and I think Mr. Fletcher is quite right when he says that we must get all the information we can about these insects before we can hope to devise adequate means of control. Another point I wish to emphasize is that if you are going to deal with an insect pest of any particular crop you must know all about the crop too. The methods of propagation, cultivation, and so on must be at your fingers' ends. You must be thoroughly conversant with the factors affecting the growth of the plant and of their respective effects before you can expect to form an accurate opinion with regard to the factors governing the attack by the insect. These are the two points which, in my opinion, should be borne in mind by all engaged in the investigation of problems in insect control. Before going further I may say that the title of this paper is rather misleading. I do not intend to go fully into the principles of insect control as they apply to all insect pests. That is a very broad subject with which I am not qualified to deal because my sphere has been limited to the investigation of the pests of a single plant. You will find adequate discussions of the subject in Mr. Fletcher's book on South Indian Insects and in other publications. I propose to discuss some of the work that I have been doing and to give you some of my experiences 
on insect control in India. Insect control, as we all know, is effected in various ways - there are natural means and there are artificial means of control. Insect pests are likewise controlled also by many natural factors-the climate, the nature of the plant attacked, the enviromment, the presence or absence of parasites, and so on. Now in dealing with. an insect all these factors have to be taken into consideration and yon must be thoroughly conversant with the effect of these on the insect in all stages before you can hope to estimate the value of your control methods and, in view of the practical difficulties which may be experienced in applying recognized remedial measures under different circumstances, it seems to me that general methods of control are very far away and that successful control is a question of adopting a method adapted to each partieular instance.

Take the case of insecticides. It does not follow that an insecticide which has once been successful will always be so, nor does it follow, because an applieation of insectieide is 'once' ineffective, that it may not be used effectively under proper conditions. A case of this kind can be instanced in connection with the tea mosquito, and it shows the imperative necessity for close observation of the habits of the pest. The tea mosquito can be killed by soap solution or by lime-sulphur if it is kept in them for a sufficient time, but this time is too great to render the substances of much value as an insecticidal application in the ordinary way. Now the tea mosquito has the following habit. It feeds on the young shoots of the bushes in all stages, sitting on the leaves and sucking them. When the bush is disturbed the adults apparently drop to the ground. They do not, as a rule, however, drop quite to the ground, but drop almost to the ground and then fly away into another bush. The young forms, which cannot fly, run down the stems of the bushes and conceal themselves at the nodes where the leaves or branches come off from the stem. The bush is sprayed, the insects being thereby disturbed. The adults drop and fly away elsewhere and escape the spray ; the young forms run down the stems and branches to the nodes. The fluid falls on to the leaf, runs down the stems and collects in drops at the nodes, and the young inseet is caught in a drop of fluid which is too big for him to be able to break through, and is held in the liquid for a sufficient period to allow of his being killed. Therefore, if the insecticide is applied when the bulk of the inseets are in the young stages one may have great success with it, and if applied when the majority are in the adult form no success. The result is that of tea planters to whom. recommendations of this nature have been made, some say it is no good, while others say that it had excellent results. The fact of the matter is that, whereas the substances cannot be recommended for general use 
against the pest, they can be made to give good results by one thoroughly conversant with the habits of the insect.

Another difficulty arises in connection with the treatment of this insect-a difficulty which is only apparent after close observation of the habits of the insect. The efficacy of insecticidal treatment depends, amongst other things, upon two factors-the killing power of the insecticide and the efficiency with which it can be applied. Helopeltis can only be treated by means of contact insecticides, which must be applied to the insect. This is in itself a difficulty except in the case of young forms, as described above. But supposing this difficulty be overcome, and that the adult tea mosquito be covered with a drop of the insecticide, and a drop of such a size that it would take considerable time to evaporate. One might suppose that that would kill him, but it does not, for the reason that he cleans it all off, just as a cat if covered with treacle would clean itself. For this reason any insecticide which has not sufficient penetrating power, even though properly applied to the insect, does very little good, and since insecticides with a sufficient corrosive power burn the young shoots spraying to kill the adults presents insuperable difficulties. Spraying against the tea mosquito therefore boils down to this, that until a substance is discovered which exerts a powerful penetrating action on the insect and at the same time is harmless to the young shoots, we must confine ourselves to applying spray fluids with a high surface tension at a time when the bulk of the insects are in the young stages, and the spraying should consist of a thorough soaking of the bush, to ensure that it will run down the branches and form drops at all the nodes. Otherwise no beneficial results can be anticipated.

We have another case-based on rather different lines. This is a case too where an intimate knowledge of the behaviour of the insect was necessary. The red spider of tea (Tetranychus bioculatus W.-M.) in North-East India lives for the most part on the upper surface of the leaves of the plant. Many sprays have been applied with the hope of dealing with red spider without success. The reason for their nonsuccess was in many cases due to the fact that the red spider lives under a web, which is very fine and almost invisible, but which is nevertheless of considerable strength. It is very close to the leaf, but at the same time the dimensions of the red spider are so small that nothing above the net or web will touch it, and I found that after spraying for red spider the insecticide rested in drops above this net while the insects ran about happily underneath. In treating red spider it is therefore necessary to break down this web, and we find that limesulphur, which generally contains much suspended matter, will break down this web, and in many cases differences in the action of different 
lime-sulphurs can be traced to the presence or absence of suspended matter. Thus in spraying for red spider with lime-sulphur it is not advisable to filter away all the suspended matter, and the lime-sulphur concentrates on the market will therefore sometimes fail when a homemade mixture will succeed. This is again a question of detail, which may make all the difference between success and failure, and which could be easily overlooked by one not thoroughly conversant with the behaviour of the pest. There was one other case in which spraying was. effective, but I cannot tell you much about that because it ras a proprietary insecticide made in Switzerland and I never knew the composition of it. This was an insecticide which we used against Thrips (Physothrips setiventris, Bagn., and Haplothrips temipennis, Bagn.) in Darjiling. Spraying is often said to be useless in Darjiling beeause. of the amount of rain, but we found that Thrips conld be sprayed: with this substance during fine periods with sucess.

Tea is grown mainly for the young shoots, and we find that in the case of most of our insect pests the young shoots are damaged by the insecticide at a weaker concentration than is necessary to kill the insect, which, of course, puts spraying out of the question, and here the importance of knowing all about the plant comes in.

Spraying is of course one of the mechanical methods of control. The methods of control which have given the best results in my experience are cultural methods of control. You all know what I mean by cultural methods of control. They consist of adaptations of existing agricultural practices to meet the necessities which are brought into existence by the presence of the insect pest. You yourselves advocate such methods in the case of many pests, as for instance digging up the stumps of plants after the crop has been removed, in the case of cane-borers, etc., and such recommendations enme under cultural methods of control. Now in tea we have had successes by the application of these methods, much more success in fact than in any other way, but if such methods are to. be successfully worked out the investigator must possess not only an intimate knowledge of the insect he is dealing with, but also an intimate knowledge of the plant that is being dealt with, of all practices followed in connection with its cultivation, etc., and of the way in which the plant responds to different treatments.

Termites oecur all over the tea-districts, and do a great deal of damage to tea. We have tried fumigation, we have tried insceticides in the soil, we have tried deterrents of one sort or another, and all without success. Sometime ago I spent a short time in South Sylhet investigating white ants and their behaviour in tea. I found, after cxamining a large number of bushes, that the white ants always get into the 
bush above ground and that they do not as a rule go below the collar of the bush. In that part of the world there is a system of pruning by which the plants are cut at 12 inches and plucked somewhere above that. This results in the formation of a high central stump in which the termites can find lodgment. By working there they can cut off the supply of sap to the upper portions of the bush, and can only be eradicated by cutting away the whole bush. We advoeated collar-pruning, i.e., pruning the bushes to the ground. By this means a bush is formed which consists of a circle of branehes arising directly from the collar of the bush. There is no central stump to afford a lodging to the Termites, and as they do not work below the collar they cannot affect the several branches until after some years, when they are becoming moribund. When this occurs a number of the branches ean be cut back in successive years-an operation which must be carried out in any case in order to get leaf, and the bushes thus consist always of strongly-growing branches which are not attacked by termites. This method of prevention has proved entirely successful. There is another case in which methods of cultural control are successful and that is in dealing with Melolonthid and other beetles. These beetles invariably attack new tea wherever jungle land is cleared and freshly planted. When the jungle is eleared, and the tea planted, the grub is still there, and the beetles attack the bushes, but in four years' time practically no damage can be seen. Contimed hoeing and forking, given year after year, five or six times during the year. gradually kills out the insects, until they are present in such small numbers as to be ineapable of doing any appreciable damage. We have another instance, which I gave you last year, in which such methods have been successful in the case of the looper eaterpillar.

Another question which must be considered is that of the relation between the insect and the plant plus the relation of the plant to its environment, and this is a line of inquiry which I think must always be followed. I ean give you an instance of this in the case of red spider. There are certain places in which tea is always attacked by red spider, others in which it is never attacked. Of two gardens adjoining one another red spider may be serious in the one, and none may oceur in the other, although, so far as the insect itself is concerned, the conditions are exactly similar. What causes the difference? Probably it is in the nature of the bushes. If that is so, then if we ean by any means alter the condition of the bushes which are attacked and bring it into line with the condition of the others which are not being attacked, we may reasonably hope for success in control. We find that in the case of red spider drainage has considerable effect. We linow that bad 
drainage causes weakening of the bushes, we know that weakening of the bushes may cause red spider. By improving the drainage we have been able to get rid of the red spider. I can give you one instance, which perhaps takes us ontside the realm of entomology, but which, since it is a case in which control of a pest was effected, is important. I was once called into a garden in Sonth Sylhet where they had put out some young tea, and for some reason it was badly attacked by red spider. Now, there was no red spider on the bushes round it, and yet there was no apparent reason why the pest should have chosen this area in preference to the surrounding areas. During this particular season there had been very wet weather, and an excessive rainfall for that part of the world. Now. when rain falls on to the ground it washes the fine particles down into the soil, the result being that a layer of fine particles is formed which holds up moisture, and produces a temporary condition of bad drainage. Such a layer is known as a pan. There was a pan about 6 inches down, which would be probably 4 inches above the bottom of the lowest of the roots of tea of that age. This means that the roots were in a layer of soil from which water could not get away. We therefore trench-hoed the area to a depth of 9 inches, to break this pan and allow the excess moisture to get away through the soil, and the result was entirely successful. By this means we had removed the cause of the susceptibility of the bushes to attack, and the red spider, which had resisted all attempts to remove it by insecticides, was thrown off. Occasionally red spider reappears on this area. When this occurs the manager of the estate puts in a shallow trench-hoe instead in place of an ordinary round of light hoeing, and the pest is thrown off.

My paper has consisted of a series of disconnected instances, rather than a discussion of the principles of insect control as a whole, because my activities have been restricted to a small sphere, but I wish to emphasize that I do not think that one can expect to devise effective means of control except by a thorough acquaintance, not only with the lifehistory of the insect, but with its relation to the plant attacked in all circumstances, and of the behaviour of the plant under different methods of cultivation, and the nature of its response to envirommental conditions, and to modifications of existing agricultural practices.

I should like to thank Mr. Andrews on bchalf of the Meeting for his Mr. Fletcher. very interesting paper which he has given us. I may say that I quite agree with all that he has said. It is an undoubted fact that, before taking up the application of control measures, it is essential to know every single thing we can know about the insect concemed and the crop which it damages. There is one point in the paper about which I should like some further information. Mr. Andrews said that, by giving several 
hoeings, the tea gardens are cleared of Melolonthid grubs. I should like to know how far that is true.

Andrews.

Fletcher.

Andrews.

Fletcher.

Andrews.

Fletcher.

Andrews.

Senior-White.

Andrews.

Senior-White.

Andrews.

Inglis,

Ordinarily tea is not very badly attacked but, when forest areas are cleared and new bushes of tea are planted, these grubs come up and the beetles that emerge from them eventually attack the bushes.

Do they feed on the tea-bushes?

The adult beetles riddle the leaves during the first two or three years, but later on no serious damage is done as all the grubs in the soil. are killed off by the frequent hoeings that are given.

In the case of fruit gardens in Shillong, the areas around the trees are constantly hoed and Melolonthid grubs are collected in very large numbers, and the beetles also are collected by hand from the leaves of the fruit-trees in the evening, but constant collecting of the grubs and beetles seems to exercise little permanent effeet on the numbers of the insects, which undoubtedly breed and come in from surrounding areas, so I am rather doubtful whether constant hoeing by itself would have such a permanent effect as is described.

In the case of fruit gardens, the conditions arc perhaps rather different, as the fruit and flowers are disturbing factors.

It is, therefore, another case in which a thorough knowledge of the crop is essential.

Quite so.

You have said nothing about the control of insect pests by means of their parasites. We in Ceylon have, for instance, a parasite on the Tea Tortricid [Homona coffearia, Nietn.] which keeps it down.

We have a parasite on the Tea Looper [Biston suppressaria] which was bred in cages and liberated in enormous numbers, but it did not keep the pest under control. Similarly there is a parasite of the Tea Mosquito [Helopeltis theivora] but this parasite is already existing all over the Tea Districts, so there is no question of introducing it; but something appears to keep this parasite down, as only about one per cent. of the bugs are found to be parasitized. Parasite distribution requires skilled men to carry it out.

Were you not able to find any hyperparasites that were keeping this parasite down?

No; but we have not studied the question scriously. In the case of some Tea Insects the percentage of parasitization may be quite large. In the case of Gelatine Grubs [Belippa sp.] for example, as many as eighty per cent. of the larræ are found parasitized.

With regard to collar-pruning, could this be done on a large scale? 
Yes; it is done to a large extent. If the tea has been properly collar-Mr. Andrews pruned once, you can cut out one branch at a time afterwards and get a new bush in a few years without any serious loss of crop. Tea is collar-pruned in the best practice. Sometimes cases occur where tea is not collar-pruned although the manager knows that it should be done. The immediate effect of a first collar-pruning is a loss of crop to a considerable cxtent, and when it is a case of losing crop for the benefit of his successor a manager who has been out some time may often leave tea up which ought to come down. In the case of tea owned by big Companies a certain percentage is cut down every year without reference to white ants, etc. In Sylhet collar-pruning was found to give no useful results, so it was not done there, but we did it.

We are very thankful to Mr. Andrews for his interesting paper. Mr. Famakrisuna He is in a very good position, as he has to deal with only one crop and Ayzar. has got intelligent men to carry out his instructions. In our work, on the other hand, we have to find out in the case of each crop what it will be advantageous to do and often we get information regarding the appearance of a pest too late to be able to do anything at all. We realize the truth of all that Mr. Andrews has said, that knowledge both of the insect pests and of the crops is essential. We have to consider local conditions also. As a rule we do not deal with crops of such a high value as tea, coffee and rubber, but with staple crops which do not allow of very high profits. Next we have to take into consideration the point of view of the raigat. Spraying with insecticides can only be applied to paying crops such as fruit-trees, cotton, etc., but with regard to staple crops I feel that spraying cannot be done for some time to come. Our hope lies in the direction of finding out different baits and working on the physiological aspect of insect-life. Then we shall be able to deal with pests of such crops as paddy, sorghum and wheat.

In Madras we tried spraying against Mango Hopper [Idiocerus spp.]. We sncceeded in checking it and the people became interested in this method of control, but we could not get the right sort of sprayers nor could we get the insecticides at the time we wanted them and the prices also went high just at the time when we could have demonstrated with some success.

Regarding parasites, to which a previous speaker referred. we know very little about parasites. We want to know their original home. There is some danger in working with parasites especially in the case of their introduction from other countries. We must first know what parasites we have already got in this country and their hosts.

We are thankful to $\mathbf{M r}$. Andrews for his interesting paper. He has Mr. Mira struck out a line of his own and lays great stress on cultural methods.

VOL. I 
We at Pusa have been working on Cotton Bollworm, Earias fabia and $E$. insulana, and find that cultural methods surely go a long way in protecting the plant. One year [1911] our plants were attacked by "Red Spider" ; we sprayed with crude oil emulsion and, as Mr. Andrews has pointed out, we had no success. Then we sent around boys with brooms to rub the webbing off the plants. Next we tried spraying with a forcepump so that the liquid might reach the underside of the leaves. Next year we increased the distance between the plants to be three feet apart so that the plants got plenty of light and air. Thus cultural methods were found useful. We also found that inter-cultured plants were able to throw off the attack. There is scope for work along the lines suggested by Mr. Andrews.

Andrews.

Gibosh.

Ramrao.

Fletcher.

\section{Chilomenes sex-maculatus eats the Red Spider.}

Mr. Andrews has said that termites attack tea-bushes at the collar. Here at Pusa they attack the roots of trees also. In Assam it may be the specialized habit of those termites not to go below the collar.

I have had some experience with sugarcane in which the setts were put down six inches below the soil. When we cut out the dead-hearts we find that the setts are attacked by termites. This shows that the termites of Assam have a special habit of not going down below the soil.

It merely shows, what I have pointed out before, that different species of termites have very difierent habits.

If there are no further remarks on Mr. Andrews' paper, we will go on to the Annotated List of Indian Crop-pests, with which we will take the paper on Indian Fruit-pests in order to save time, as many general crop-pests attack fruit-trees also and there will be no object in dealing with such insects twice over. We have been through the list of our insect pests on previous occasions. Fonr years ago we dealt with them according to the Orders and Families of the insects concerned. Two years ago we went over them according to the crops which they attack, and the whole information up to then is on record in the Report of the Proceedings of our Second Mecting, and there is therefore little need to, go in to too great detail; so at this Meeting we will give only a summarized account of these insects, adding especially any new information which we have been able to obtain about them during the last two years, and, instead of discussing the whole papers after they have been read, I will ask you to give any further remarks on each insect as we deal with it. We will now run briefly throngin these insect pests, taling them in systematic order and commencing with the Hymenoptera. 


\section{2.-ANNOTATED LIST OH INDIAN CROP-PESTS.}

By T. BaInerigge Fuetcher, R.N., F.L.S., F.E.S., F.R.S., Imperial Entomologist.

HIMENOP'IERA.

FORNICIDA.

The Hormicidic comprise the Ants, of which comparatively few species Mr. Fletcher. do damage directly to cultivated plants although numerous species do indirect damage by protecting Scale-insects and other noxious Phynchota which such plant-juices and exude honey-dew, and also other insects . such as Lycænid Jarve.

\section{Ecophylla smaragdina, Fb. \\ F. I., Hym. II., 311, f. 83.}

Occurs throughout the whole of the Plains of India, Buma and Ceylon, wherever trees grow, and is often a source of considerable annotance to fruit-gatherers, especially in the case of mango trees. It is also a decided pest by its habit of protecting noxious scale-insects. On the other hand, it is extensively insectivorous and does some good by destroying large numbers of caterpillars, beetles, etc. On the whole it, seems to do more harm than good and must certainly be included here as a pest. The nests may be bumt off the trees but it is very difficult to reduce their numbers permanently.

\section{Holcomymex scabriceps, Mayr. \\ F. I., Hym. II., 282-283, f. 84 .}

This spceses occurs irresularly throughout the Plains of India (except Assam), but is not recorded from Burma or Ceylon. Te have specimens from Pusa, Lyallpur, Peshawar, Gujranwala, Lahore, Kasur, Chakwal, Shahpur, Zafiarwal Tehsil (Punjab), Hangu (X.-W. F. P.), Chakradharpur and Coimbatore.

This is the common Harvesting Ant of India and in some wheatgrowing districts it does a certain amount of damage by carrying off ripe grains and storing these in its nest below ground. Indeed, in such areas, in times of famine, it is usual to dig out these nests and to recorer the grain, which is stored away in some quantity. 
Meranoplus bicolor, Guer.

F. I., Hym. 1I., 168-169, f. 66.

Occurs thronghout the Plains of India (except in hot, dry districts), Burma and Ceylon.

In the Pusa collection we have speeimens from Pusa, Bihar; Tranquebar, Madras; Minbu, Lower Burma ; Ranchi (Kanley Farm).

At Padu Farm, in Burma, this ant was noted as biting holes in leaves of Crajanus indicus. Otherwise, we do not know it as a pest.

Solenopsis geminala, $\mathrm{Fb}$.

F. I., Hym، II., 158-159, f. 64.

Occurs throughout the Plains of India, Burma and Ceylon. We have specimens from Calcutta, Chakradhaipur, Madura, Coimbatore, Mandalay and Tatkon.

At Calcutta the workers have been found destroying brinjal seedlings, and at Mandalar, biting holes into the leaves of Cajanus indicus.

Senicr-Whib. We have tried with snccess the banding of plants with a rag and tar just at the collar.

Fleichec.

Can you do this in the case of young plants, such as brinjal seedlings. for instance?

Serior-White. Yes.

Ciemastogaster-hodgsoni, Forel.

F. I., Hym. II, 131-132.

At Pusa this is a distinct pest on Citius trees by protecting Icerya aysptiace and other Rhynchota. In the "Fauna" volume it is only" recorled from Burna but our specimens appear to be hodgsoni.

Mymicaria brumea, Saunders.

F. T., Hym. IT., 118-119, f.55.

Ocenrs alnost everwhere in the Plains of India, Buma and Ceylon, except in dry areas. We have males from Chapra and Peradeniya, and workers froni Belgaum, Trichinopoly, Tanjore, Sidapur (Coorg) and Pegu.

At Bangalore thic ant was found attacking garden plants of Arctolis. grendis and doing some damage by biting the leares. 
Dorylus orientalis, Westw.

F. 1., Hym. II., pp. 4-г̃, fi. 6-7.

Occurs throughout India, Burma and Ceylon in the Plains, and frequently does damage by attarking the underground portions of plants. At Prisa it damages roots and underground parts of plants such as potato, cabbage, canliflower and vegetables generally. It Cawnpur also it has been found damaging potato. At Shahabar, in the Lnited Provinces, it has been noted as damaging early-sown groundnuts and at Cadag Fam it was found to eat ont gromdnut kemels when the nuts were lying in a heap after harrest. In ('eylon, both at Peradeniya and Dikoya, the workers have been observed to be destructive to the roots of potato and other regetables.

Mr. Andrews.

Mr. Eletcher.

It may be controlled by the use of erude oil emulsion applied to the soil around the plants. It is misually only young plants that are attacked.

Have you tried lime?

No; we have not tried lime at Pusa as there is already an excess of lime in the soil here. A few years ago we had a bad attack of this ant on young cabbages and I tried varions repellents, including apterite, naphthaline, and phenyle, and found that crudc oil emulsion was the most successful.

\section{Dorylus labintus, Shuck.}

$$
\text { F. I., Hym. II., pp. 2-3, ff. 1-3. }
$$

Occurs throughout India, but not known from Ceylon, Assam or Burma. Is apparently carnivorous as a rule, attacking ants (Pheidule). Has only once been sent in as a pest, when it was attacking potato tubers minderground at Sidapur, Coorg.

\section{ÁPID.E.}

Negachile anthracina, Smith.

F. I., Hym. I., 473-474, f. 157.

Occurs throughout the Plains of Northern India and Bengal. We have it from Pusa, Chapra and Cawnpur.

It is a leaf cutting bee; at Pusa it cuts leaves from tur (Cajauns indicus) and rose plants. It has been noticed taking leares from a ber tree also and from Cassia.

It is scarcely a pest but sometimes disfigures rose-plints by cutting circular patches out of the leaves. 
Megachite disjuncta, Fabr.

F. I., Hym. I., 480.

Occurs throughout India and Burma. We have it from Pusa, Chapra, Jagi Road (Assam), Belgaum and Lower Burma.

This is also a leaf-cutting bee, and remores leaves from un and rose plants, in the same way as $M$. anthracina.

\section{VESPIDE.}

Tespa basatis, Smith.

F. I., Hym. I., 403-401.

Widely distributed in India, Burma and Ceylon.

We hare had this species sent in to us from Dehra Dun, where this hornet was noticed removing the bark of young Eucalyptus stuartiana trees growing in the Cantonment of Dehra Dum. The bark was removed clean to the rood, the thickness of the bark being $\frac{1}{1}$ to $\frac{1}{2}$ inch and the widh of the eaten part about the same.

Do they damage the trees very high above the ground?

I camot say. The specimens were sent in to is and we hare only receired this one report about this insect.

At Dehra Dun I have notieed ants remoring the bark from these trees.

Possibly the trees were dead. It seems rather unlikely that these hornets should strip living bark from Eucalyptus trees. I included this insect in the list because it was sent in to us as doing damage and possibly someone else might be able to corroborate damage to living trees by hornets.

\section{Chatcididid.}

\section{(Unidentified Exrytomine.)}

This is the insect which damages apricots at Haripur Hazara in the North-West Frontier Province, by ovipositing in the young fruit. The grub bores into the kernel inside the stone, the result being that the fruit shrivels and falls off the tree before it is fully developed. The larva lives inside the fallen stone until the next spring, when it pupates and emerges as an adult. It is probable that in some cases it may lie over for more than one year.

Collection and destruction of the fallen funits and stones is the obvious. remedy for control. 


\section{(Undetermined Eurytomine.)}

Another species of Eurytomine, as yet undetermined, has been fcund to attack dhaincha pods at Pusa. We referred to this in our Annual Report for 1917-18 and have figured the various stages [figures exhibited]. Mr. Ghosh, will you tell us something about it?

The eggs are laid in the pods and the seeds are attacked. In each Mr. Ghosu. seed attacked there is one grub which eats the cotyledons and then pupates in the seed, the adult wasp gnawing its way ont through the shell of the seed and then through the wall of the pod. There is one grub in each seed and each adult wasp gnaws a hole of exit for itself. The only satisfactory method of control is the destruction of the affected pods. Vie tried spraying the plants with crude oil emulsion to deter the adults from ovipositing, but this did not keep them away. Picling oit the dried pods reduces the number of the wasps.

\section{Eurytoma indi.}

This Eurytomine has been found at Coimbatore, the larva boring Mr. Fieicher. and eating seeds inside agathi and dhaincha pods. It is apparently distinct from our species in dhaincha at Pusa but works in a similar way.

Megastigmus indi.

This also occurs at Coimbatore in agathi and dhaincha pods. batore. I have nothing new to add about these two Eurytomines from Coim- Mr. Ramakriskna
Aygar.

\section{TeNTHREDINide.}

Athatia proxima, Filng.

Athatia proxima is widely distributed in the Plains of India and is Mr. Fietclece. usually a minor pest, sporadically bad, on cruciferous plants. We have records from the following localities and food-plants:-

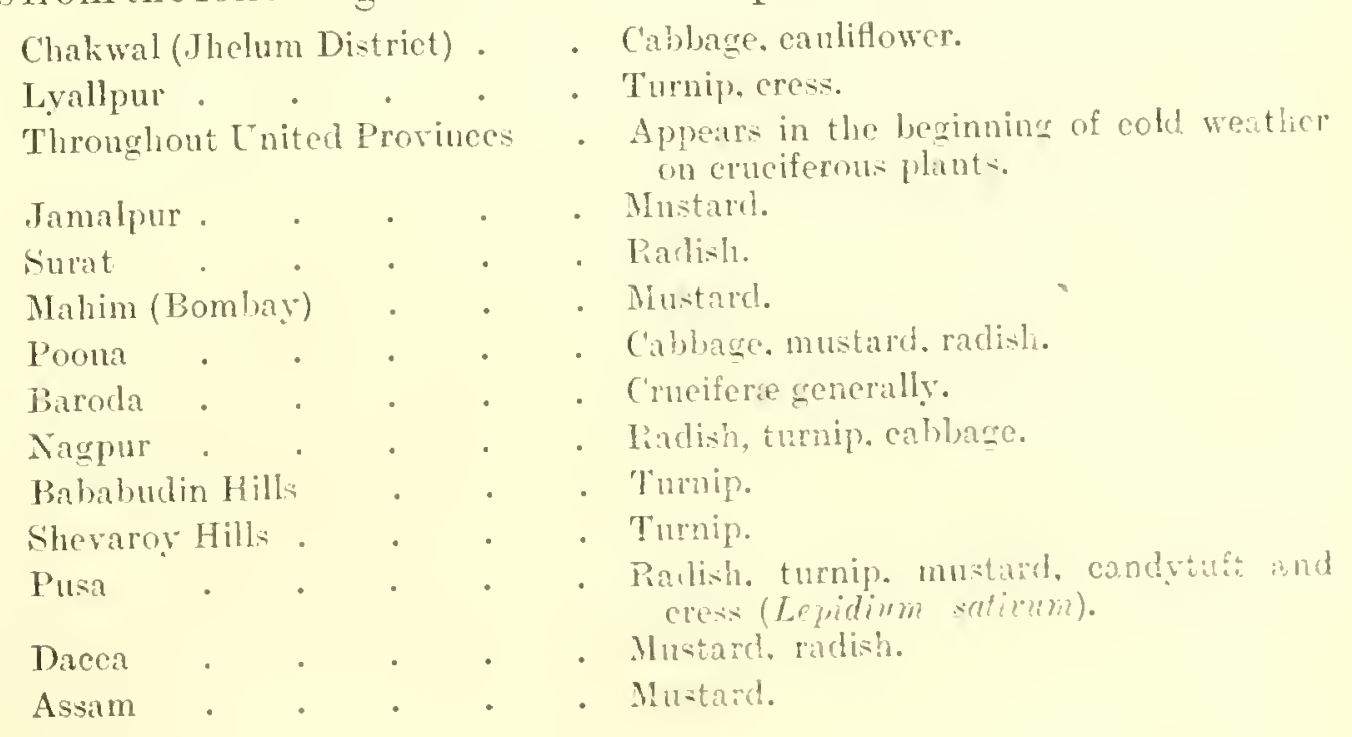


Ramaknisbua

yar.

. H. L. Dutt.

- Eamrao.

Ramachazdra

Fletcher.

Ramiao.

Gupta.

Fletcher.

Misra.

. Inupi Kaznan.

Gupta.

Fletcher.

Ghosh.

F'letcher.
We find it at Coimbatore also.

This year it was bad in Bihar.

We find Athalia proxima [at Poona] all through the summer and monsoon months.

I found it in July in Bellary.

At Pusa it appears active only during the winter and rests throughout the summer, from about April to Oetober inclusive.

At Poona it is bad on cruciferous plants in the middle of the monsoon [about Angust].

It is a bad pest in Assam.

Has anyone any control measures to suggest?

We usually dust the attacked plants with lead arsenate, road-dust and kerosinized ashes.

We shake the plants and the larve fall off and they are either swept away along the rows or squashed.

At Jorhat we sprinkle lime mixed with soil on to the plants, but this is not possible over large areas.

Has anyone tried turning chickens into the affected fields to eat up the caterpillars?

No.

It would seem worth while trying.

Athalia leucostoma, Cam.

We only know this insect from Hangu, in the North-West Frontier Province, where it was found on mustard. It probably replaces $A$. proxima in the North-West.

\section{(Unidentified Tenthredinid.)}

This sawfly occurs commonly at Shillong between May and October and often completely defoliates cultivated rose trees. The eggs are deposited in a long slit ent by the female through the bark of a young stem and, on the larve hatching out, this slit expands until its sides are flattened and lie parallel with the surface throngh which the slit was originally made, causing a characteristie malformation of the stem. The larvæ feed on the leaves, at first gregariously but later on, as they become nearly full-fed, they tend to become solitary. The attacked rose trees are often completely defoliated. Pupation takes place in a rough silken cocoon, which is probably formed on or beneath the surface of the soil, but cocoons have not been noticed under natural conditions. There seem to be four or five broods during the season, but adult flies 
and young and full-grown larre can usually be found at any time, so that the broods are not clearly defined.

Control is easy. The adult females may be caught as they are oripositing, or the positions where eggs have been laid may be seen and the eggs destroyed, or the larve may be hand-picked.

The life-history and damage done are shown in a coloured plate [enibibicd].

\section{(Unidentified Tenthedinid).}

This species is distinct from the Shillong rose sawfly, having a reddish thorax (black in the Shillong species) but acts in an exactly similar manner, the eggs being thrust into tender stems of cultivated rose, whose leaves are defoliated by the larve. This species is common at Dehra Dun, and at Ramgarh (Kumaon District) in Lugust 1918 I found a rose-twig which had had eggs deposited in it in the mamner characteristic of these species, so that the Dehra Dun species probably occurs along the central Himalayas generally.

In Dehra Dun this sawfly is scarcely a pest, as we have to cut Mr. Beeson. back the rose-bushes periodically.

It certain'y seemed to occur in large numbers when I was at Dehra Dun Mr. Fletcher. last August. In the case of the Shillong species, whose habits seem cxactly similar, certainly every leaf on a rose-bush may be eaten and the whole bush left leatless.

\section{DIPTERA.}

\section{Muscid 玉.}

Pycrosoma Raviceps, Nacq.

S. I. I., pp. 34S-349, f. 208.

This fly, as noted in the reference given, has occurred in South Kanara and Malabar as a pest of toddy, spoiling the juice.

\section{Anthonyiade.}

\section{(Cholam Fly).}

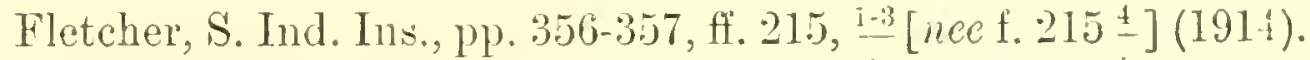

Proc. Second Entl. Meeting, pp. 178, 188, 202 (1917).

This species has been recorded from Nagpur, larva in juar stem, and from Coimbatore, larva in juar, wheat, varagu (Paspalum scrobiculatum), Panicum frumentaceum, maize and broom corn (a kind of cholam). 


\section{Ramakrishna} Tar.

Fletcher.

This was discussed at our last Meeting and I do not think there is: anything new to add.

$$
\text { (Cumbu Fly.) }
$$

Proc. Second Entl. Mecting, pp. 178, 202, (1217).

This fly also occurs at Coimbatore, the larra boring in cumbu and Panicum miliaceum.

To me this seems to be the same as the Cholam Fly.

Mr. Ballard studied these Anthomyiads and concluded that the cholam and cumbu flies were distinct.

\section{(Undetermined? Anthomyiad.)}

We have an undertermined fly which was sent in to us from Toong in the Darjiling District by the Manager of Margaret's Hope Tea Co. (letter of 27 th August 1915); the larræe were reported to be boring into healthy lime and orange fruits. Probably the same fly is also found boring into orange fruits in the Nilgiris.

This is probably the same as the "Tomato fly" referred to Proc. Sccond Entl. Neeting, p. 178 (1917), as attacking rotting fruits and regetable matter generally.

Senior-White. In Ceylon I have also bred an Anthomyiad from brinjal.

Tripaneid

Dacus (Leptoxyda) longistylus, Wied.

Bezzi, Bull. Ent. Res., VII, 101 (Oct. 1916).

Proc. Second Entl. Meeting, p. 137 (1917).

Fieccher.

Occurs at Combatore, Nagpur, Bellary and Puri, and probably throughout the Plains of India, the larra boring in the fruit of Calotropis and da maging the floss.

Dacus breristylus, Bezzi (1903).

Bezzi, Bull. Ent. Res., VII, 101 (Oct. 1916).

Proc. Second Entl. Meeting, pp. 243, 304.

Recorded by Bezzi from Hagari, Cuddapah, and Coimbatore. Attacks melons, water-melons and cultivated Cncurbits. We have this species from Triplicane, Madras, larra in bitter gourd fruit; Siddhout, Cuddapah, larva in melons; Nagpur, larra in Lagenaria velgaris.

Control may be attained by picking and destroying the early attacked fruits. 
Dacus olece, $\mathrm{Fb}$.

This well-known serious pest of cultivated olives in Southern Europe is known to occur in wild olives at Cherat, North-West Frontier Province, and probably throughout North-West India. So far as we know, it has not yet been noted to attack cultivated olives in India but the olive industry is as yet a very young one and there is little doubt but that we shall have trouble with this olive fruitfly.

Chatodacus ferrugineus fermgineus, Fb. (1791).

Bezzi, Bull. Ent. Res., VII, 104 (Oct. 1916).

Recorded br Bezzi from Peradeniya, Katihar, Pusa, fruits of guava. (Psidium guyara) and loquat (Eriobotrya japonica). Also known from Mandalay, on mango: Myitlyina, larra in peach and pomelo; Maymyo, larra in mango.

C'hetodacus fermgineus dorsatis, Hendl. (1912).

Bezzi, Bull. Ent. Pes. VII, 104-105 (Oct. 1916).

This species is known from the following localities and food-plants :-

Peradeniya.

Pusa; in loquat (Eriobotiya japonica).

Coimbatore: on mango.

Taru ; larra in peach.

Mandalay; larra in mango and chilly (Capsicum fiutescens).

Myitkyina; larra in pomelo and guara.

Tashio; $\}$ larra in Solanum verbascifolium fruits.

Naymyo; larra in American chillies (Capsicum sp.), pear (Pyrus commumis) and peach (Promus persica).

At Matale, in Ceylon, I have reared it from larve in Solamm melon-Mr. Sexicr-Wisi gene.

That is new record, but hardly unexpected as we already have it Mr. Fietches recorded from a wild Solanum.

Chetodacus ferrugineus incisus, Wik. (1860).

Bezzi, Bull. Ent. Res. VII, 105 (Oct. 1916).

This fruitfly is known from the following localities and food-plants :-

Kumaon; Pollibetta, larva in jak (Artocurpus integinfolia): Santikoppa, larva in fruit of Careya arborea; Bangalore 
adult on mango leaves, larva in guava fruits; Coimbatore, larva in mango fruits; Tatlion and Lashio, larva in Solanum verbascifolium fruits; Taung-gyi (adult).

Chatodacus ferrugineus versicolor, Bezzi (1916).

Bull. Ent. Res., VII, 105 (Oct. 1916).

We have the following records:---

Peradeniya; Pusa, larva in guava and Achras sapota fruits;

- Coimbatore, larva in mango fruits.

ミenjor-Trbite.

At Hatale, in Ceylon, I have reared it from mango fruits.

Chrotodacus zonutus, Saunders (ISt1).

Dacus squalidus, Wik. (1860).

, peisicre, Bigot (1859).

. mangifere, Cotes (IS93).

Bactiocera mangifere, Bezzi (1913).

Chatodacus zonatus, Bezzi, Bull. Ent. Res. VII, 105 -106 (Oet. 1916).

Chatodacus sonatus, Proc. Second Entl. Meeting, pp. 216, 226, 241, 219, 307 (1917).

Eletcher.

In his paper in Bull. Ent. Res. Bezzi gives the following records :-

Ranchi, "Ranchi peach pest."

Pusa, larva in peach, fig. (Ficus sp., cultivated), Achras sapota, ripe bael fruit.

Santikoppa, larva in Careye arborea fruits.

Amroha, Moradabad, larva in mango fruits.

Pachmarli, larva in peach fruits.

Nagpur, in bottle gourd (Lagenaria vulgaris) VIII, 1913, Ratiran. [?]

Taru, larva in peach VIII-IX. 1914.

The Pusa collection also contains specimens from Coimbatore and Tranquebar.

At Poona it is bad on mango, fifty per cent. of the fruit being attacked. It has a number of parasites but they do not seem to eheek it.

At any rate, we should like to see some of those parasites.

Chatodacus tuberculatus, Bezzi.

Bull. Ent. Res. VII, 106-107 (Oct. 1906).

Proc. Second Entl. Meeting, p. 241.

This is known from Taung-gyi (adults), and Myitkyina (larvæ in peach, May-June). 
Chectodacus correctus, Bezzi.

Bull. Ent. Res. VII, 107 (Oct. 1916).

Proc. Second Entl. Meeting. pp. 226, 241, (1917).

Bactiocera sonata, Bezzi (nee Saunders), Mem. Ind. Mus. III, 91, t. 8, f. 4 (1913).

We have records of this from Pusa, larva in peach; Coimbatore, on mango: Guindy, adults attracted to opened termitarium, and Hagari, adults.

\section{Chctodacus duplicatus, Bezzi (1916).}

Bull. Ent. Res. VII. 107-108, (Oet. 1916).

Proc. Second Entl. Meeting. p. 241.

This species seems to be known only from Pachmarhi, whe:e specimens were bred from larve in peach fruits by Ratiram in May 1303.

Chetodacus diversus, Coq. (1901).

Dacus sp.. Howlett, Ind. Ins. Life, t. 66, f. 2 (1909).

Bactrocia diversa, Bezzi, Mem. Ind. Mus. III, $9 \pm$, t. 8, f., 2-3 (1913).

Chatodacus diversus, Bezzi, Bull. Ent. Res. MII, 108-109 (Oct. 1916).

Chatodacus dicersus, Proc. Second Entl. Meeting. p1. 213,307 (1917).

Thes species was original'y bred from oranges (Chrus artinumu).

In his paper Bezzi gives the iollowing records:-

Pusa, adults: Bangalore, adult ; Hachararam. Crodavari Di-tric ;

Combatore: Nagpur, larva in bottle-gourd; Dehra Dun.

The Pusa collection contains specimens reared at Peradenirit from larve in mango and at Handalay from larve in plantain.

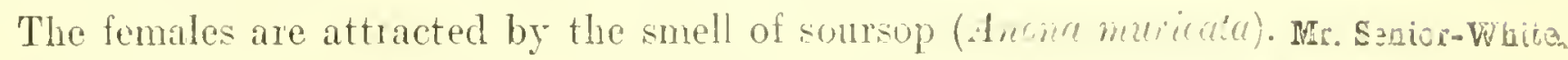

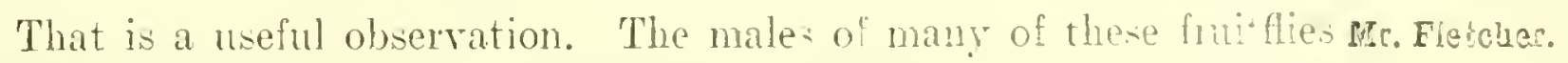
are readily attracted to smells, but that provides no means of control as it is the females which do the damage. If we can attract the females, the case becomes difierent. 
Chotodacus cucurbita, Coq. (1899).

Dacus cucurbita, Coq.

, Howlett, Ind. Ins. Life, p. 633, f. 418 (1909).

Bactrocera (ucubita, Bezzi, Mem. Ind. Mus. III, p. 96, t. 8, f. $T$ (1913).

Dacus cucurbita, Fetcher, S. Ind. Ins. p. 354, t. 16.

Chatodacus cucubita, Bezzi, Bull. Ent. Res. VII, 109-110, (Oct. 1916).

Chatodacus cucurbita, Proc. Second Entl. Heeting, pp. 11, 304, 305,307 (1917).

Occur's throughout India, Burma and Ceylon.

The Pusa collection contains specimens from the following localities and food-plants:-

Peradeniya, pumpkins ; Coimbatore, cucumber, pumpkin, melons ; Attur, water-melon; Pusa, Luffa cegyptiara, pumpkins, cucumber, Trichosanthes dioica fruits, Cephalandra indica stem (making galls), in wild small fruits and cultivated large fruits of Cucumis irigonus, Homordica charantia fruits, Trichosanthes anguina fruits, galls of Vitis trifolia; Peshawar, melon shoots; Maymyo, Luffa cegyptiaca; Tatkon, Trichosanthes cucumerina.

We discussed this species (as well as those other fruitflies also) at the last Neeting and I need only call your attention now to Mr. Fullaway's paper on the control of this fruitfly in Hawaii by means of a parasite. [See page 625.]

Jamakzisbra 7ar.

We have bred parasites from it [at Coimbatore].

Chatoducus caudatus, Fb. (1805).

Bactro e:a caudata, Bezzi, Mem. Ind. Mus. III, 97, t. 8, f. 8 (1913).

Chatodaius caudatus, Bezzi, Bull. Ent. Res., VII, 110 (Oet. 1916).

Chotodacus caudatus, Proc. Second Entl. Meeting, p. 213 (1917).

In his paper, Bezzi gives the following localities and food-plants :-

Dehra Dun; Shevaroys; Coimbatore, on snake gourd; Bababudins; Lashio; Tatkon, larva on fruits of Trichosanthes palmata; Myitkyina, on pomelo ; Taung-gyi.

The Pusa collection contains specimens reared at Peradeniya from pumpkins, and adults taken at Jeolikote, on mulberry fruit, and at Taung-gyi. 


\section{[Chatodacus hageni?}

At Matale, in Ceylon, I have reared from larvæ in Citrullus fruits Mr. Senior Wri.e. a fly which I believe to be C. hageni.]

Mellesis cumenoides, Bezzi (1916).

Bull. Ent. lies. VII, 119 (Oct. 1916).

Proc. Second Entl. Meeting, p. 307 (1917).

This species is so far only known from Burma, where it has been reared at Tatkon from larvæ in Trichosanthes cucumerina fruits and at Myitkyina from larvæ in cucumber.

\section{Myiopardalis carpatina.}

Cleghorn, Agl. Jour. Ind. IX, 124-140, t. 13-15 (A pril 1914).

Proc. Second Entl. Meating, p. 306.

This fruitfly is well-known in Baluchistan as attacking melons and a long account of it was given by the late Mr. J. Cleghorn in the Agricultural Jourmal of India. So far as we know it has never been reported from the Plains of India, but in August 1915 we reared it at Pusa in some numbers from larva found in fruits of Cucumis trigonus.

\section{Carpomyia vesuviana.}

Proc. Second Entl. Mleeting, pp. 11, 251 (1917).

This species has been reared from ber (Zisypius jujuba) fruit at Coimbatore, Hadagalli (Bellary District), Pusa, Poona and Baroda.

At Poona last year it was very bad on ber. The pest was so bad that Mr. Ramrao. no fruit could be had during the monsoon.

It is parasitized extensively at Pusa by Biostcres carpomyia, Silv., Mr. Fletcher. and Bracon fietcheri, Sily. If these do not occur at Poona you might perhaps try introducing them there.

Stictaspis ceratitina, Bezzi.

Proc. Second Entl. Meeting, p. 20.t (1917).

This species is common at Pusa, the larva boring into bamboo shoots during the rains. It seems probable that it does a great deal more damage to young shoots than is generally realized.

\section{Stictaspis striata, Frogg.}

Proc. Second Entl. Meeting, p. 20.4 (1917).

This species has similarly been bred at Peradeniya from larve attacking shoots of giant bamboo (Dendrocalamus strictus) but has not been found in India so far as I lnow. 


\section{[Ceratitis capitata.}

Fietcher.

Gough.

Fletcher.

Gough.

Fletcher.

Golig?.

Fietcher.

Gough.

Fletcher.

The Mediterranean Frnitfly, C'eratitis capitata, has not yet been found in India, but it is very widely distributed now and it is quite possible that it may be introduced some time, so perhaps Dr. Gough will tell us something about it from his experience in Egypt.

It is very bad in Egypt in gardens where several kinds of fruit are grown, such as oranges, gnava, apricot and peach. In such cases it has the ehance of passing through a generation in each of these fruits. If there is only one lind of fruit, for example, if only oranges are present, there is not much damage done. We have also taken it from dates. At present nothing is done to eontrol it and no parasites are known.

Have you any other fruitflies in Egypt besides Ceratitis?

No ; Ceratitis capitata is the only fruitfly so far known to attack cultivated plants in Egypt.

You onght to be careful not to get Chcetodacus cucurbitce introduced from India. It might easily be carried from Bombay or other ports in the larval state in vegetables or as an adult on board ship.

We ought to be quite safe, becanse we have twenty miles of desert in the Suez Canal region and Port Said is also separated from Cairo by a. belt of desert.

The adult fly is very long-lived provided it can obtain food. It can live for two or three hundred days or more under favourable conditions.

Whilst I was in Bombay I had some oranges which were probably Egyptian oranges; so, if these oranges are imported, there is danger of the introduction of Ceratitis capitata from Egypt into India. It will pay the Indian Government to stop the importation of Egyptian fruit altogether. It is not much of a trade. Quarantine is of no arail ; entire prohibition is needed.

There certainly have been importations of oranges from Egypt into Bombay in the past. We are indebted to Dr. Gough for ealling our attention to the danger of importation of Ceratitis capitata into India by this means.]

\section{Psilide.}

\section{(Til-Root Fly.)}

? Psita sp., Howlett, Ind. Ins. Life, p. 629, f. 415 (19n9).

? Psita sp., Proc. Second Entl. Heeting, p. 85 (1917).

This fly, which is supposed to be a species of $P$ sila, bores in the larval state in the roots of Sesumum indicum. It is said to be a serious pest, at Hoshangabad and has been noticed at Nagpur and Pusa. 


\section{MICROPEZID E.}

\section{Calobata sp.}

Fletcher, S. Ind. Ins., p. 355, f. 213.

Proc. Second Entl. Meeting, pp. 294, 295, (1917).

This species occurs throughout the Plains of India, the larva boring into the rhizomes of turmeric and ginger, but it is not definitely known whether it is a real pest or merely attacks rotting rhizomes. It has been noted at Coimbatore. Samalkota and Hopin (Upper Burma).

\section{Nerius sp.}

This is an undescribed species, which will be described by Mr. Brunetti in his second volume on Diptera in the Fauna of India Series. We have it from Pollibetta in South Coorg, from Lashio in the Northern Shan States, and from Myitkyina (Upper Burma) where the adults were found in numbers on stored potatoes and on rotten potatoes which had been thrown away. Like the Calobata, it is doubtfully a pest and may only breed in rotten vegetable matter; on the other hand, it may attack sound tubers or may assist decay by carrying spores of rot-diseases from rotten to healthy tubers.

I have bred it from brinjal also at Matale.

It seems definitely attached to Solanaceæ.

Mr. Fletcher.

Chloropide.

Oscinis thea.

Indian Insect Life, p. 626, f. 412.

This species has been reported as mining in tea-leaves, but is not a pest so far as we know.

\section{(Cruciferous leaf-miner.) \\ Indian Insect Life, p. 623, fig. 411.}

This is another species of which we know nothing regarding its status as a pest.

AgroMYZIDÆ.

$$
\text { (Red-gram Agromyza.) }
$$

S. I. Ins., p. 357, f. 216.

Proc. Second Entl. Meeting, p. 44.

Andrews, Q. J. Ind. Tea Assoc. 1918, 34. [Tur-pod Fly.]

This species has been bred from Cajanus indicus at Coimbatore and in Bombay and the Central Provinces, and at Tocklai and Borbhetta (Assam) the larva was found feeding on seeds of Cajamus indicus in April. 
As regards control, the only method that can be suggested is the selection of resistant varieties.

\section{Agromyze sp.}

"Cowpea Agromyza", S. Ind. Ins., p. 358, f. 217, (1914).

Agromyza sp., Proc. Second Entl. Meeting, pp. 52, 56, 59, (1917).

We now come to one or more species of Agromyza, one of which may possibly be $A$. phaseoli, which bore into the stems of pulse crops. In Ceyion and at Nagpur the larva have been found in the stems of French beans and considerable damage may be done. At Koilpatti, Coimbatore and Tinnevelly the larva bore into the stems of young plants of cowpea, lablab and green gram, the plants withering as the result of attack, and pupation taking place in the larval burrow. At Pusa we have a species referred to on pages 62 and 65 of the Proceedings of the Second Entomological Meeting and possibly distinct from the foregoing, whose larra bores in the stems of peas and cxotic field-beans.

It is quite possible that several distinct species may be concerned. Certainly there seem to be differences of food-plant and habit. At Pusa, for example, the larre in peas occur near or below soil-level; whitst at Sabour they have been noted high up in cowpea stems. So it looks as if we have sereral species mixed up here but I cannot undertake to differentiate them.

\section{(Batila Stem-fly).}

Proc. Second Entl. Meèting, p. 62, (1917).

A fly, which may be an Agromyzid, has been reported by Ratiram. us attacking stems of $\mathrm{T}$ icia faba in the larval stage in the Chanda District of the Central Provinces, but I have seen no specimens and know no more about it.

\section{(Clina stem-fly).}

Proc. Second Entl. Meeting, p. 202, (1917).

This is another unidentified species found at Pusa, the larva attacking the stem of China (Paspatum mitiaceum) before the ear ripens. The effect of attack is like a borer, the ear drying without forming any grain. The affected plants are easily spotted in the field. This fly was first noticed at Pusa in September 1916. 


\section{(Unidentified Agromyzid.?)}

This fly was found at Pusa in March and April 1918, the larva boring into lucerne stems in small numbers. It has not been noted as a pest but might become so.

\section{Cecidomyiade.}

Parhydiplosis oryzce, Wood-Mason.

Proc. Second Entl. Meeting, pp. 169-170, tab. (1917).

This Cecidomyiad occurs commonly in Madras, Orissa and Bengal but does not seem to have been noticed elsewhere so far. It attacks the r.ce-plant, the larva causing the formation of a long white gall which has earned the name of "elephants tusk disease" in some districts. We rent into this insect fairly fully at the last Meeting. Has anyone anything new to say about it?

It is still very bad in Marras.

Mr. Ramakrishna Ayyar.

The flies are attracted to light.

The flies are attracted to light in fairly large numbers. The specimens were sent to Dr. Felt, who has confirmed the identification.

Light-traps are of little use as a control measure because, by the time Mr. Fletcher. the adult flies emerge, the damage has been done.

It is rery bad in Ratnagiri district, but on the monsoon crop only. Mr. Deshpande. It is not found on summer or winter rice.

We have not had it reported from Bombay before.

Mr. Fletcher.

"Gingelly Gall-fly", S. Ind. Ins. p. 364, ff. 224, 225, (1914).

Asphondylia sesami, Felt, Canad. Entom. (1916).

$$
\text { , } \quad \text {, Proc. Second Entl. Meeting, p. 84, (1917). }
$$

This species has been found at Coimbatore, the larva'in buds of Sesamum indicum, and at Nadiad and Surat, the larva in immature pods of Sesamum indicum.

At Coimbatore it has also been reported as attacking flowers of cluster bean (Cyamopsis psoralioides) [Proc. Second Entl. Meeting, pp. 60-61] but it seems doubtful whether this is the same species.

Dasyneura gossypii, Felt.

Contarinia sp., S. I. Ins., pp. 363-364, f. 223, (1914).

Dasyneura gossypii, Felt, Canad. Entom. 1916, pp. 29-30, (1916). , $\quad$, Proc. Second Intl. Meeting, p. 103, (1917).

This species was found in 1913 at Coimbatore, the larva boring into cotton buds, pupation taking place in the withered bud. It was then $\Omega$ 
minor pest but does not seem to have been noticed since then, so is probably only sporadic. In Mysore the larva has also been found in cotton buds, but there also it is sporadic, although considerable damage was done one year in a small area.

Mr. Kunhi Kannan. Mr. Fletcher.

Dr. Gough.

In Mysore it is doing damage but not over a large area.

Dr. Gough, have you found any Cecidomyiad attacking cotton buds in Egypt?

No, we have never noticed any in Egypt.

\section{(Cholam Cecidomyiad.)}

Proc. Second Entl. Meeting, p. 183, (1917).

This is an midentified Cecidomyiad which has been found attacking cholam at Coimbatore and Udumalpet in Madras. The egg is thrust in under the glumes when the seeds are about half-ripe and the larva bores in the seeds of plants in the field. Damage may be considerable. It has also been noticed in Mysore, where the damage done was considerable in one year.

\section{(Juar Cecidomyiad.)}

Proc. Second Entl. Meeting, p. 183, (1917).

This Cecidomyiad was found attacking juar at Poona in December 1916. The larva destroys the ovary of the flower of Andropogon sorghum, pupating inside, so that no grain is developed. This fly is extensively parasitized by a Chalcidid.

Have you found this Cecidomyiad again, Mr. Ramrao ?

It was not found this year although I made several searches for it. Most of these Cecidomyiads seem rather erratic in their occurrence.

\section{(Cumbu Cecidomyiad.)}

Proc. Second Entl. Meeting, p. 188, (1917).

This species has been found at Coimbatore and Mettupalaiyam, where the larva bores in seeds of cumbu (Pennisetum typhoideum) plants in the field, the eggs being laid at night. During the day the flies hide away among the sheathing leaves at ground-level. The damage may be very considerable.

\section{(Mango-leaf Cecidomyiad.)}

At Pusa we have a Cecidomyiad which makes numerous globular galls on mango-leaves. It is as yet unidentified although specimens were sent to Dr. Felt three years ago. We do not look on it as a pest, but last year I had a letter from the Government Entomologist in Mauritius, saying that this insect had been introduced with mango plants imported 
from India and was becoming a bad pest in Mauritins, and asking for help in procuring parasites to check it. So, if any of you come across this Cecidomyiad and can get parasites, you might remember that Mr. d'Emmerez de Charmoy would be glad to have some.

In Mysore we have one species making galls on mango leaves.

Mr. Kunhi Kannan.

\section{TIPULIDE.}

Conosia irrorata, Wied.

Brunetti, F. I., Nemat. pp. 497-499, f. 43, t. 10, f. 5, (1912).

Proc. Second Entl. Meeting, p. 175.

Conosia irrorata occurs throughout the whole Oriental Region and is Mr. Fletcher. commonly found in rice areas in India and Burma. We know nothing about its early stages but I shall not be surprised to find that the larva may feed at the roots of paddy.

\section{INCERT SEDIS.}

The following Diptera, which have been reported as pests, cannot be placed in their Families.

\section{(Safflower Stem-fly.)}

Proc. Second Entl. Meeting, p. 97, (1917).

This has been reported by Ratiram from Mandla, in the Central Provinces, the larva boring in the stems of Safflower and killing the plants.

\section{(Safflower Shoot-fly.)}

Proc. Second Entl. Meeting, p. 97, (1917).

This fly has been reported by K. D. Shroff as attacking shoots of safflower at Mandalay.

$$
\text { (Safflower Seed-fly.) }
$$

Proc. Second Entl. Meeting, p. 97, (1917).

The larva of this fly has been reported by Ratiram as attacking safflower seeds, when on the plants, in the Central Provinces.

$$
\text { (Juar Stem-fly.) }
$$

Larvæ of this fly were found at Pusa in August 1917 by Ram Saran, boring in young juar stems. This is not the same as the Anthomyiad found in juar, but has not been definitely named as yet. 


\section{LEPIDOPTERA.}

\section{Amatide (Syntomide).}

Euchromia polymena, Linn.

Hmpsn., F. I., I, 227, f. 143, Cat. I, 297-299, f. 137 ; I. I. L., p. 434, t. 34, f. 6 ; Entl. Note 61 ; Proc. Second Entl. Meeting, p. 291.

This species has been reported by the Entomological Assistant, Travancore, as an occasional minor pest of sweet potato, destroying the leaves. It was also found by Green at Peradeniya in Jannary 1903 defoliating various garden varieties of I pomcen.

It is widely distributed within our limits. We have it from Bassein Fort (Bombay), Dacca, Rangpur, and Coimbatore.

Mr. Pillay.

The eggs are laid on the leaf and the whole life-history is passed on the leaf. It is not so common on the cultivated sweet potato as on the wild variety, but it does do some damage.

\section{[Amata passalis, Fb.]}

Syntomis passatis, Hmpsn., F. I. Moths, I, 219, Cat. Phal. I, 86. Amata passalis, Hmpsn., Cat. Phal. Suppl. I, 13.

Mr. Pillay.

In Travancorc we found Syntomis passalis this year on Vigna catjang. There were only two or three caterpillars on each plant.

Syntomis passatis is common in Quilon, Travancore.

On the 31st of August at about 7-30 A.M. a female adult was found resting on the stem of a coconut palm at a height of say 3 feet above the ground-level. There were a few male moths flying about this female probably for mating. At 8 A.m. one of the males mated with this female. Mating was done end to end. While these were in cop. another male came and attempted to mate the female under observation. Finding it is impossible he also left the place. At 2 P.M. the male severed its connection. At about 5 P.M. on 31st of August the moth commenced to lay eggs and the major portion of the eggs was laid by the next morning. This female continued to lay eggs till the 3rd of September.

The eggs were laid on the sides and bottom of the cage in 2 layers one over the other. The egg is soft and round withont any ornamentations. The colour of the egg is white when newly laid. The total number of eggs laid by this single female was 258. The first lot of eggs laid on the 31st of August changed colour to dark and at about 11-30 A.M. on 6th September 1918, eggs latched and the young larve commenced to come out. The top portion of the eggs before hatching became darker still. The young larva came out of the lids on the top portion of the eggs. 
The larva measures nearly $8 \mathrm{~mm}$. in length, a fer hours after emergence and is dull white; head round and shiny ; body is thinly hairy with dark hairs: As the larvæ are growing the bodily colour is changed to brown. The caterpillar when full-grown measures little more than $25 \mathrm{~mm}$. in length and is deep brown in colonr.

The insect feedsopenly on Cowpea (Vigna catjang) and is a very slow eater. They destroy the leaves. It is only a very minor pest. The full-grown larve conld be found in nature wandering in the fields. When disturbed the larva falls down from the foodplant and curves itself. A few larvæ were found dead in the cage, and it was observed that other larve were eating the dead body of their own species. The larva in nature is as a rule found isolated and not in gronps.

The insect commenced pupation on the zind of October. The newlyformed pupa is very soft and pink in colour and towards the close of the pupal period the colour bccame nore pinkish. Abdominal spiracles and wing parls are very black. Pupa measures about $12 \mathrm{~mm}$. in length and $3.5 \mathrm{~mm}$. across the body.

The insect makes a slight cocoon with silken threads and remnants of the foodplant. It makes its cocoon on the foodplants in nature.

The moths commenced to come out from 16 th October and continued for 2 days more.

Eggs lain on 3ist dugust 1918.

Eggs hatched on 6th September 1918.

Pupated on 2nd October 1918.

Moths emerged on 16 th October 1918.

The adult is found throughout the year.

[Amata passalis is widely distributed throughout India (except the Mr. Fletcher. North) and Ceylon, but we have not had it noted before as attacking any cultivated crop.]

\section{ArCTTAD正.}

Celame internella, Wlk.

Hmpsin., Cat. II, 13-14, f. 6.

Has been reared at Pusa from larvæe eating grains of bajra (Pennisetum typhoideum) and at Mandalay on Crjanus indicus.

We have it from Pusa, Chapra, Dhamai (Bengal), Bassein Fort (Bombay), Bellahunisi (Bellary District), Mandalay and Meiktia (Tpper Burma).

Not a pest. 
Celama squalida, Stdgr.

Hmpsn., Cat. II, $24-25$; Proc. Second Entl. Meeting, p. 71.

Reared at Pusa in December 1914 from larvæ found on pods of sann hemp (Crotalaria juncea), but only found in small numbers. It has also been reared at Pusa from fallen fruits of Ficus glomerata and from larvæ on flowers of Bombax malabaricum. We also have it from Peshawar.

Diacrisia nigrifroms, Wlk. (?)

Hmpsn., F. I. II., 12, Cat. III, 263.

Reared in January 1908 at Poona on cotton.

Not known to be a pest.

\section{Diacrisia obliqua, Wlk.}

Hmpsn., F. I., II, 7, Cat. III, 289-291 ; I. I. L., pp. 437-438, t. 35 ; Proc. Second Entl. Meeting, pp. 47, 51, 54, 58, 61, $64,65,83,86,89,91,95,101,126,127,129,132,237,263$, $270,274,283,291,294,295$.

A common and destructive pest in most parts of India with the exception of North-Western India. Our specimens are from the following localities and foodplants :-

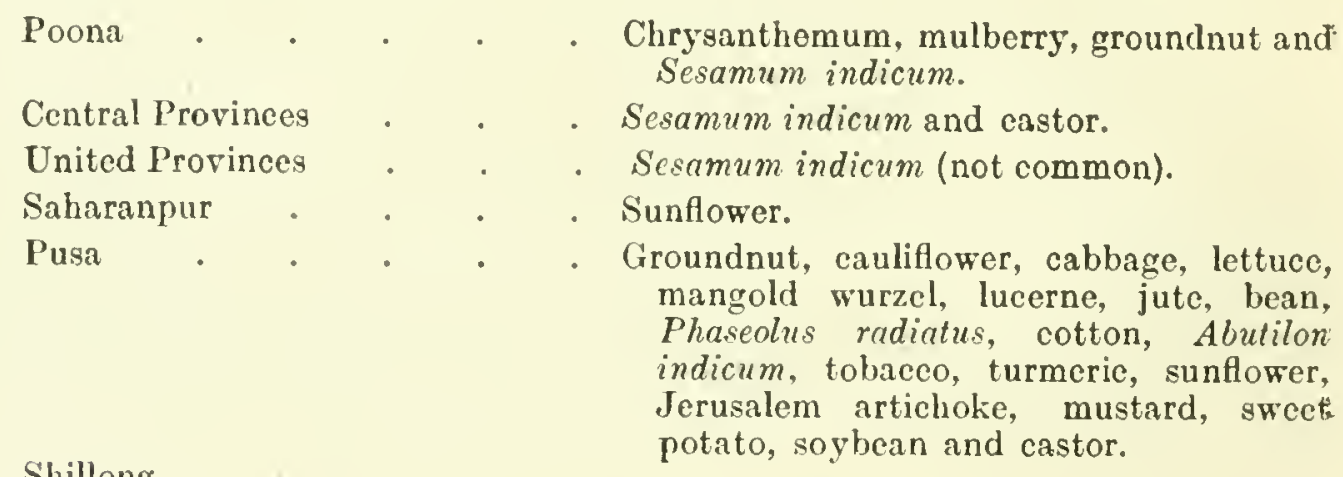

Shillong.

Darjiling.

Bliagalpur . . . . Phascolus radiatus.

Nadia District . . . . Jute.

Control :- Hand-picking of larvx in early stages when clustered.

r. Ramakrishna yyar.

r. Kunbi Kannan. In Mysore it is very serious on castor, ragi, etc. It occurs there in the cold weather from October to January, but is not a regular visitor. We control it by hand-picking the caterpillars in the early stages when they are feeding gregariously on leaves. 
It was bad [at Pusa] on white nettle, but not for the last four years. Mr. Misra.

There is one peculiarity that we have noticed about this insect in Mr. Kunhi Kannan. Mysore. It lays eggs on the more shady crops first and then moves on to the others. It attacks castor by preference.

When it occurs in large numbers we find eggs on all sorts of plants Mr. Ghosh. and in all places whether shady or otherwise.

That may be so in Pusa, but in Mysore we first find it on castor.

Mr. Kunhi Kannan.

Diacrisia montana, Guer. (suffusa, Wlk.).

Hmpsn., Cat. III, 302.

Has been reported (I. M. N. II, 47) as defoliating plantain and (I. MI. N., I. 54-55) on jute. Probably an error for D. obliqua.

\section{? Diacrisia sp.}

Bred from larvæ found feeding on rice-leaves at Ranchi in September 1915 .

The moth is a small, stoutly-built, immaculate, ochreous species, which has not yet been identified.

\section{Estigmene lactinea, Cram.}

S. I. I., p. 368, f. 230 ; Proc. Second Entl. Meeting, pp. 28, 57, 96, 101, 187, 189, 199, 291.

A common and widely-distributed species throughout India (except extreme North) and Lower Burma. Its incidence as a pest appears to vary largely according to locality; in Baroda, for example, it is stated to be a serious pert every year, whilst in the Central Provinces it is not common. In most districts it seems to be sporadic and scarcely a pest as a rule.

Piepers and Snellen have described the larva on numerous plants in Java (Tijds. voor Ent. XLVIII, 187-188 (1905)) and figure it (t. 7, ff. 1-3). At Pusa it has been found on sunflower, jute, castor, sann hemp, Abutilon sp., maize, sweet potato and Phaseolus mungo, and in Southern India on cumbu, ragi, coffee, horse-gram, etc.

\section{Amsucta lineola, $\mathrm{Fb}$.}

Hmpsn. Cat. III, 324-325 ; Hmpsn., F. I., II, 28 (Creatonotus emittens, Wlk.); Proc. Second Entl. Meeting, p. 96.

Common and widely-distributed throughout India and Burma, the larva occurring on most low-growing crops, especially on Graminex, 
but not a pest as a rule. In Baroda it is stated to occur on all growing crops, and the Pusa collection contains examples reared at Balaghat (Central Provinces) on rice, at Pusa on tobacco, at Ranchi on rice, and at Palur (Madras) on varagu (Paspalum scrobiculutam).

\section{Amsack moorei, Butl.}

Hmpsn., F. I., II, 27, Cat. III, 329 ; Proc. Second Entl. Meeting, pp. 47, 53-5๊, 68, 83, 87, 91, 99, 179, 187, 189, 199, 203.

Occurs, together with $A$. albistriga, in Mysore and Madras, principally in the South Arcot district, on all low-growing crops. Also recorded from Sind by Hampson.

\section{Amsacta moorei sara, Swinh.}

This form, sara, occurs in Bombay, where the larvæ attack maize at Dohad, and in the Punjab, where it has been reared from larvæ on Phaseolus radialus at Jagadhri. A few of the specimens from Dohad have the abdomen yellow. We have reared this at Pusa from Bombay materialand have prepared a coloured plate showing the life-history [exhibital. I am inclined to think that sara is a good species, distinct from moorei, although I cannot give any morphological distinctions but the male genitalia have not been compared.

We find it on the Bombay side also. We have used light-traps and caught a large number of moths. We, however, still got a large number of caterpillarsattacking plants. Wealso found Tachinid and Hymenopterous parasites on these caterpillars.

IMr. Kunhi Kannan. Did you find out the proportion of males and females attracted to the light-traps?

Yes; we did count these. The following are the details :- In the year $1917,7,581$ moths were caught and out of these 3,336 were females loaded with eggs and 4,245 were males. For the greater attraction of the moths powerful lights, like Kitson lamps, were also used. In this way a large number of moths was caught before they could lay eggs, and as a result of this measure very much fewer caterpillars were found later on in our experimental fields than in the cultivator's areas. During the season 1918 we caught 3.192 moths by means of light-traps and of these 1,227 were females and 1,965 were males.

The difference in attraction to light in this Bombay form and in that found in Southern India secms to indicate that we are really dealing with different species. 
Amsacta albistriga, Wlk.

S. I. I., p. 369, t. 17 ; Proc. Second Entl. Meeting, pp. 55, 91, $179,187,199$.

Occurs in Southern India, especially in the Soutl Arcot and Salem districts in Madras and in Mysore, as a serious and destructive pest of almost all local crops, e.g., cholam, cumbu, groundnut, pulses, castor, etc. Also stated to occur in Baroda, but I have not seen specimens, and the species concerned here will probably turn out to be $A$. lineola.

For control measures see South Indian Insects, pages 85, 135, and 369.

In the Mysore Agricultural Calendar for the year 1915, the life-Mr. Kunhi Kannan. history and simple method of controlling Amsacta albistriga was described. It was stated there that Kumblihulas are the offspring of a kind of moth with white wings and golden banded body, which comes out in the field during the rains and lies helpless until nightfall, when it begins to fly about. As each female lays about 1,000 eggs it was explained that, if the few thousands of motlis that emerge in a village are hand-picked and killed, their offspring (the Kumblikulas) will not appear and the crops will be saved from devastation. The value of the remerly has been repeatedly demonstrated in several villages where its adoption by the raigats has yielded very satisfactory results. Nevertheless there are a few raingats in-every village who refuse to co-operate with the rest in picking work. From this want of co-operation the whole village suffers for the moths are prolific and it is enough that a few moths are left unpicked for Inumblitulas to arise in large number's and these will be the cause of the pest the following year, whereas if all the moths are picked regularly for three or four years then the chances are that the village should be rid of the pest for a very long time. A whole village is therefore made to suffer for the neglect of a few.

To avoid this possibility a Pest Act was passed in 1917 and it was applied last year to two Hoblis, viz., Santebenumr in Chennagiri Taluq and Burmanayakandrug Hobli in Holalkere Taluq. The following regulations were drawn up under the Act:-

(1) As soon as the earliest mungar rains have fallen a diligent search is to be made daily in the morning or evening for the Kumblitula moths which are to be picked and placed in a vessel containing water with a small quantity of kerosine floating on the surface. All moths so collected will be handed over to the headman of village for inspection by the ficldman in charge of operations in the village. 
(2) Each raiyat or landholder must arrange for a daily collection of moths on his own lands.

(3) The work in each village will be under the charge of a fieldman of the Agricultural Department who will keep a record of work done on each holding and of the number of moths picked.

(4) In cases where raiyats or landholders neglect to carry out the above operations a report will be made to the Amildar unless delay is likely to prejudice the operations in which ease the fieldman in charge of operations in the village will make the necessary arrangements to pick the moths and intimate the cost to the Amildar. The Amildar will arrange to get the work done by the raiyat concerned but if he fails this may be done by Government Agency and the expenses incurred will be charged to the raiyats or landholders concerned and collected as arrears of land revenue.

(5) Payments will be made for the moths picked at rates fixed by the Director of Agriculture but the total amount paid for picking work in any one village shall not exceed Rs. 20.

(6) Picking will continue for 45 days or until such time as in the opinion of the officer in charge there is no danger of further emergence of the moths.

(7) Villages in these hoblis which are in the opinion of the Director of Agriculture not likely to suffer from the pest will be excluded from the operation of the Regulation.

(8) Copies of a circular giving full information with regard to the pest and the measures to be taken against it will be distributed to the raiyats of the villages concerned not later than the 10th May 1918.

(9) The officer in charge of the operations will be stationed at a central place (Sasalu) throughout the period during which combative measures against the pest have to be continued. $\mathrm{He}$ will visit the villages and will explain to the raiyats in detail the requirements for effectively dealing with the pest, the labour required, the period during which operations will have to be carried on and all other information necessary for the efficient control of the pest.

Work has already been done in previous years, in several of the villages in these two hoblis so that raiyats were familiar with the operations. Nevertheless, well in advance of the picking season, eirculars on the pest and the regulations were printed in Kamnada and circulated in all the villages. What the Department proposed to do and what help was 
expected was further explained by officers of the Department. Temporary fieldmen were appointed and put in charge of the picking work in the various villages and two officer's were stationed-one at Sasalu and the other at Santebennur to organise and supervise the whole work.

In spite of these elaborate preliminaries it was some time before the raiyats realised fully the intentions of the Government and the extent of the powers vested in them by the Act. The almost complete failure of the early rains was another obstacle, for it indisposed them to exertions against a pest which they said would die out of itself from the want of crops to feed on. There was however no active opposition and no penalties were imposed on any one even though the cases deserving of these were not a few. In all about 10.000 moths were collected representing nearly five million caterpillars. But for the Pest Act it is certain no picking work would have been done even in villages in the hoblis where work had been done previously and where the raiyats knew very well the advantages of the remedy.

\section{Creatonotus gangis, Linn.}

S. I. I., pp. 369-370, f. 231 ; Proe. Second Entl. Meeting, pp. 28, $91,133,206$.

A minor, polyphagous pest, occurring throughout India and Burma. Mr. Fletcher. Piepers and Snellen have described (Tijds. voor Ent. XLVIII, 188-189 (1905)) the larva from various wild plants in Java. In Southem India it has been found on coffee, groundnut, lucerne, etc., and we have spec:mens reared at Pusa on marua, grasses, and Mimulus gracilis, at Lyallpur on sweet potato, maize, urid and lucerne, and at Mandalay on seedling paddy.

\section{Pericallia ricini, $\mathrm{Fb}$.}

S. I. I., pp. 370-371, f. 232 ; P oc. Second Entl. Meeting, pp. 75, $84,86,101,237,267,298,299,303$.

As is implied by its specific name, this insect is usually found on castor, but it is polyphagous and has been noted in Madras on plantain, pumpkin, gingelly (Sesamum indicum), cotton, agathi, Calotropis, Moringa, oleander, and Colocasia. The Pusa collection contains specimens reared at Coimbatore on plantain, at Tynampet (Madras) on castor, at Calcutta on sweet potato, at Howrah on Cucurbita pepo, at Pusa on castor and Commelina, and at Nagpur on brinjal. We have no examples from Burma or from India north of the United Provinces.

A minor pest of eastor and of garden crops. The larvie may be hand-picked. This species is attacked by a Tachinid parasite. 
Utetheisa pulchella, Linn.

S. I. I., pp. 371-372, f. 233 ; Proc. Second Entl. Meeting, pp. 66 (tab), 71 .

Occurs commonly everywhere as a serious pest of Sann Hemp (Crotalaria juncea), the larvæ cating the leaves and contents of pods. It has also been reared on a wild Crotalaria and at Pusa on Heliotropium indicum.

\section{Noctuid}

Heliothis (Chloridea) obsoleta, Fb.

S. I. I., pp. 373-374, f. 235 ; Proc. Second Entl. Meeting, pp. 44, 49 (tab), 56, 58, 71, 80, 88, 90, 91, 96, 97, 115, 124, 188, 191, 206, 212, 265, 272, 273, 274, 289.

This species is the cotton bollworm of America but is rarely found on cotton in India, where, however, it is a serious pest, principally of gram. Its range of foodplants is very wide. It has been reared at Pusa on gram, tur (Cajanus indicus), oats, indigo, lucerne, Malachra capitate, rose-leaves, cotton-bud, cotton-boll, maize cob, safflower, bajra pod, marua ear, tobacco, tomato, carrot flowers, onion flowers, mangold, castor leaves and capsules, val and sunflower. We have also examples reared at Coimbatore on safflower, at Madras on Indian hemp, at Surat on gram, at Khandesh and Dhulia on cotton-buds, at Anand on tobacco, at Hoshangabad on wheat ears, at Nagpur on gooseberry [probably Cape gooseberry], cotton boll, tur and gram, at Patna on gram, in the United Provinces on poppy heads, at Lyallpur on Kusumba (Carthamus tinctorius) and on pea-pods, at Peshawar from larva boring young orange fruit, and at Hangu, in the Kohat Valley, North-West Frontier Province, from larvæ boring into rose-buds.

Control is difficult, owing to the wide range of foodplants and to the larral habit of eating into the pods of gram, which is the crop most seriously attacked-so much so that in some districts gram cannot be grown on account of this insect. In the case of young gram plants, bagging with a bag-net may be tried. Spraying is hardly practicable on a field-scale and is of little use when gram-pods are formed and are being attacked. Fields which have been badly infested with larvæ should be ploughed immediately after harvest to destroy the pupæ in the soil and prevent the resulting moths from ovipositing on other crops.

Dr. Gaugh.

Mr. P. C. Sen.

Mr. RobertsonBrowr.
We get it occasionally in Egypt, but very rarely on cotton.

It occurs on ganja at Nowgaon in the Rajshahi district. Handpicking is done to cheek this pest.

In the North-West Frontier Province it is impossible to grow gram on irrigated land on account of this pest. 
Heliothis (Chloridea) assulta, Guen.

S. I. I., p. 374 , f. 236 ; Proc. Second Entl. Meeting, pp. 270 (tab), 271.

Widely distributed in India (except extreme North) and Burma. A minor (occasional major) pest of tobacco, the larve eating holes in the leaves. We have specimens reared on tobacco at Pusa, Nadiad (Bombay), Anand, Madras, and Amarapur (Burma). It has also been reared at Pusa from larvæ on tur pods, Physalis minima, and on a wild Physalis.

In Ceylon also the larva attacks Physatis perwiana and is found Mir. Senior-White. inside the calyx.

In the case of tobacco, the larvæ are fairly easily found and hand- mr. Fletcher. picked.

$$
\text { Adisura alkinsoni, Mioore. }
$$

Himpsn., F. I., II, 173-174, f. 113, Cat. IV, 120, f. 39 ; Proc. Second Ent. Meeting, pp. 54, 56.

Has been reared at Pusa from larva on Blumea sp. and at Coimbatore in January and February from larvie boring lab lab pods, on red gram (Cajanus ndicus) and on field beans.

A sporadic local pest of pulses. The pupal period is a long one and cultural methods at this time offer the best chance of checking it.

$$
\text { Euxoa spinifera, } \mathrm{Hb} \text {. }
$$

Hmpsn., F. I., II, 182 [biconica], Cat. IV, 177-179, f. 60; Lefroy, Ent. Mem. I, 253-257, t. 14, f. 10 ; Proc. Second Entl. Meeting, pp. $203,273$.

Occurs throughout India, Burma and Ceylon, the larva usually feeding at roots of grasses, especially dubh grass. It was also reared at Pusa in February 1915 from a larva found on leaves of sweet potato and has been sent in from Gujrat (Punjab) as attacking young cotton plants. Usually a very minor pest, it occurs sporadically in enormous numbers at roots of grass.

\section{Euxoa segetum, Schiff.}

S. I. I., p. 375, f. 237 ; Proc. Second Entl. Meeting, Pp. 29, $208,280,284$.

Occurs throughont India, Burma and Ceylon, more commonly in the Hill Distriets, in which it is a major pest of garden erops. We have examples from Mysore reared from larve destroying coffee seedlings in the Coffee Districts, from Ootacamund reared from larve injuring garden 
Mr. Ramakrishna

Ayyar.

and vegetable crops, from the Shevaroy Hills where the larva were very destructive to potato in 1912, and from Gulmarg (Kashmir) from larvæ attacking potato tubers; at Pusa this species has also been reared from larvæ found on sugareane roots and on gram, at Rangpur on tobacco, at Nagpur on clover, and at Lyallpur on beetroot and gram.

A serious pest of potato in the Hills. Control is difficult, the best remedy being to grub up the larvæ which lie hidden by day in the earth around attacked plants. Spraying is not effective in the case of potato as the larvæ prefer to feed on the roots and tubers below ground-level.

At our suggestion one European planter in the Shevaroys tried sliced potatoes covered with a mixture of Paris Green and sugar as a bait, but it did not prove successful.

\section{Agrotis ypsilon, Rott.}

Hmpsn., F. I., II, 182, Cat. IV, 368-369, f. 71 ; Lefroy, Ent. NIem. I, 259-274, t. 14, ff. 1-8; A. J. I., VIII, 343-354, VIII, 372-389 ; Bengal Qrly. Agrl. Jl., IV, No. 4 ; Bihar Agrl. Jl.. I, 1-19, 78-104, II, 16-35, III, 1-14, ; Proc. Second Entl, Heeting, pp. 8, 48 (tab), 80, 90, 206, 269, 273, 279, 28, $284,297$.

Occurs throughout Northern India and mostly in a belt of about one hundred miles wide and parallel with the Himalayas, straggling as far as Nagpur and Jessore. Also in Ceylon. Not known in Western or Southern India.

We have examples reared at Pusa on gram, tobacco, groundnut, sweet-potato, celery, cauliflower, cabbage, lucerne and wheat leaves; at Lyallpur on bectroot, at Shahabad on opium poppy, at Nagpur on clover, at Jabbalpur on potato, at Gaya on gram, at Rangpur on tobacco, and at Jessore on mustard and linseed.

It occurs regularly every year on the tal lands at Mokameh and has been effectively controlled there by the use of Andres-Maire traps. (See literature cited above.)

Mr. H. L. Dutt.

I have a few more details to add to the account given at the last Heeting. We have found four or five parasites of which two or three are Tachinids and two are Braconids. One Braconid is very promising. It appears along with the pest but the parasitization percentage is about five per cent. in the begimning and later it rises to thirty-two per cent. In 1918 it rose so high as seventy-four per cent. The parasitic grub restivates from Nareh to September. By the middle of September or early in October cocoons kept in the insectary dry up and we cannot get the parasites out of these. Those that remain in the field get submerged during flood time and remain under water in some cases for a couple of 
months, the result being that we get very few parasites when the pert appears in the fieid at the beginning of the rabi [cold weather] reason. If the parasite could got a good start in the beginning of the season, we might succeed in controlling the pest. Agiotis is found in the Hills and we might be able to get parasites from there in September.

Do you find any difficulty in breeding these parasites?

Mc. Fistchar.

We breed this Braconid quite well in the insectary up to a certain ar. E. L. Dutt. time.

To have it in sufficient numbers when required, in Seprember, it would M:. Fietchor. seem necessary to have a regular Hill Station to breed it.

When doe, the parasitic grub commence to astivate?

E. Gough.

In March or April.

Mr. E. L. Dutt,

The Andres-Maire trap has given very good results in India. It Mr. Fietcher. seems strange that it did not succeed in Egypt.

The Andres-Haire trap was tried and discredited in Egypt. In Egypt Dr. Gough. Agrotis ypsiton is found also on wheat, grass and bersim, but chiefly on wheat. It is found in the basin area. It's habits in Egypt are exactly the same as in India.

[See also page 6:2].

Agrotis c-nigrum, Linn.

Hmpsn., F. I., II, 188, Cat. IV, 389-391, f. 76 ; I. I. L., t. 31

ff. 10, 11 ; Proc. Second Entl. Meeting, p. 281.

Occurs at Jabbalpur, usually annually, as a pest of potato. Recorded by Hampson from the Himalayas and Nilgiris.

Control :- Hand-picking of larræ.

Agiotis fummatia, Schiff.

Hmpsn., F. I., II, 189, Cat. IV, 393-391; Lefroy, Ent. Mem. I, 258-259; Proc. Second Entl. Meeting, pp. 48, 63, 91 1, 12:2.

Occurs throughout Northern India, Pusa being apparentiy its most southern lim t as far as records go. As a pest it is rery minor and sporadic in most localities but it is stated to be a very serious pest of almost all low-growing plants (tobacco, gram, etc.) in the spring at Lyallpur and throughout the Punjab.

The Pusa Collection contains examples reared from larre on gram and tobacco at Pusa, on gram and piazi (Asphodelus fishulosus) at Lya!lpur and on poppy at Gondra (Oudh) in March 1820. 
Nir. F. C. Sen.

\section{[Agrotis sp.}

[An Agrotis was found doing considerable damage to ganja plants in Nowgaon (Rajshahi $D^{\prime}$ strict) last year. Irrigation and hand-picking were found useful in its cont.ol. I cannot say definitely what species it was.]

$$
\text { Polia consanguis, Gn. }
$$

Hmpsn., Cat. Lep. Phal. V, 102-103, f. 23.

Recorded by Hampson from Sultanpur, Simla, Dharmsala, Sikkim, Nilg ris, Ceylon.

At Pusa it has been reared in some numbers on Gramineæ. (C. S. 1366 and C. S. 1527).

Tiracola pragia:a, Wlk.

Hmpsn., Cat. Lep. Phal. V, 258-259, f. 51.

Recorded by Hampson from Sikkim, Bombay, Kanara and Ceylon. It is a common species at Darjiling.

At Shillong in 1918 one larva was found on apple, eating leaves. It pupated on 11-12 July and emerged on 2nd August. This species has also been found on tea in Assam, but is not known to be a pest.

\section{Brithys crini, Fb.}

Glottula dominica, Cr. ; I. I. L., p. 445.

Brithys crini, Hmpsn., Cat. V, 448, f. 125 ; Piepers and Snellen,

Tijds. voor Ent. XLIX 37 (1906) ; Proc. Second Entl. Meeting, pp. 266,268 (1917).

Occurs throughout India and Burma and is an occasional pest of cultivated lilies. We have specimens reared on lilies at Pusa, Shillong, Daltonganj and Mandalay. Piepers and Snellen describe $(l . c$. $)$ the larva, found on Crinum and Cro us in Java.

It has the habit of boring in to the plants attacked.

Mr. Senior-Whit?. Mr. Fletcher.

I have not noticed that in cases where I have come across the larvæ. They were feeding much like those of Polytela gloriosa.

\section{Polyt la gloriosa, Fb.}

S. I. I., pp. 375-376, f. 238 ; Proc. Second En l. Meeting, pp. 266, 268.

D stributed widely thronghont the Piains of India, Burma and Ceylon. The blackish white spotted larva feeds on Gloriosa superba and on lïies (Amaryllidacex), often occurring in large numbers and proving a pest 
in gardens. They are easily hand-picked in the early morning and evering.

Cirphis in ularis. Buti.

Hmpsn.. Cat. V, 486-487. t. 91, f. 22, F. I., II, 280 [Leuraria irro ata part]: Proc. Second Entl. Neeting. p. 162.

Has been bred at Pusa from larvæ on Dubh grass and in some numbers from larve found on rice leaves but has never been recorded as a pest.

$$
\text { Cirplies lorryi, Dup. }
$$

Hmpsn., F. I., II, 274-275 [Lencaniu loreyi], Cat. V, 492, f. 153 ; Piepers and Snellen, Tijds. vor En!. XLIX, 38-39; Proc. Second Entl. Meeting, pp. 49, 162 (tab.),179, 189, 195, 198.

Occurs thronghout India as an occasional pest of most Gramineæ, -often occuring together with $C$. mipuncta and hence liable to be overlooked. We have (or I have seen) examples reared at Coimbatore on cholem, at Kirkee (Poona) on juar, at Jalalpur (Bombay) on sugarcane, at Surat on majze, at Jabbalpur on gram leaves, at Cawpur on wheat leaves, at Peshawar on wheat and oats, and at Pusa on bajni (Penniscum typhoideum), maize, rice, kanni (Selaria italica), sugarcane and guineagrass.

We had a few Cirphis loreyi attracted to andres-Maire trap at Mr. Misra. Pusa. At least, they appeared to be $C$. loreyi; it is difficult to identify insects that fall into this trap. We were using ethyl acetate.

Country liquor and molasses makes just as good a bait.

Cirplis compta, Ho.

Hmpsn., F. I., II, 272 [Leuania compta], Cat. T, 531-532 ; Proc. Second Entl. Meeting, p. 163.

The larva is said to have been found on paddy in Southern India (Coimbatore, Madras), but does little damage. It may be a sporadic local pest. There are no specimens of this species in the Pusa or Coimbatore collections except one from Kandy and one worn and doubtful example found as an imago on a paddy-stem at Melrosepuram, Madras, in October 1907.

Cirphis albisligma, Mo.

Hmpsn., F. I., II, 275 [Leucania loreyi, part], Cat. V, j43-544, t. 93, f. 23 ; Proc. Second Entl. Meeting, p. 162.

Has occurred at Manganallm (Tanjore District) on paddy just ripe for harvest, the larva cutting off the ear-heads; it was in large numbers 
Mhi. Ramalroishma

Aysur:

and did considerable damage. This species has also been bred at Puia from a larra on rice leaves and on Graminese [species not specified. We also have mothe collected in the Shevaroy Hills and at Pusa.

It did not appear in 1918. I have had a coloured plate of this dono. [crhitited].

\section{Cirphis fragitis. Butl.}

Hmpen. F. I., II, 275 [Leucanin fragilis], Cat. V. 546, t. 93. f. 26 ; I. I. L., p. 446 : Proc. Second Entl. Meeting, p. 195.

The larva is said by Hampson to do "much damage to wheat in Chhindwara District, Central Provinces," but it is not known to have: occurred as a pest of late years. It is probably a sporadic local pest.

\section{C'implis unipuncla. Haw.}

S. I. I., p. 376 . t. 18: Proc. Second Entl. Meeting, pp. 161, 179, $189,195,198,202$.

Occurs commonly throughout India as a major pest of Gramines. especially juar and rice. We have examples from the following localities. and food plants :-

\begin{tabular}{|c|c|c|c|}
\hline \multicolumn{4}{|c|}{ Palur (Madras) } \\
\hline Dharwar. & & & - Juar. \\
\hline Poona & . & & . Juar, maizc, rice. \\
\hline Manjari ( $B$ & $a y)$ & & . Juar. \\
\hline Surat & . & & - Jucr. \\
\hline Peshawar. & . & & - Wheat, oats. juar. \\
\hline Puse & . & & - MLaize, juar, wheat, ricc. \\
\hline Sadar Iha & iittagong & & . Rice. \\
\hline Mymensing & 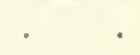 & & - Rice. \\
\hline Lakhinpur & alpara & & - Rice. \\
\hline Dibrugarh & $\therefore$ & & - Sali dhan (paddy). \\
\hline Kamrup (A & n) & & - Rice. \\
\hline
\end{tabular}

Inis R. C. Sous.

Mir. Bonare.

Mic. E. L. Ouit.

liór. Fleicher.
It is a very bad sporadic pest of rice in Bengal, cutting the ripening eare by night. It was reported from several districts last year. The period of activity of the caterpillars is not long. Reports are usually received only after the outbreak has subsided.

Does this species come in to the And:es-Maire trap?

Ye:

It is not attracted in sufficient numbers to hope for any contro! by this means. At Peshawar the caterpillars of this and allied species of Chiphis are extensirely preyed on by the larve and adults of Calosoma indica, a large Carabid beetle, which frequents the places where the 
Cirphis larve hide away by day. I do not think we have mart to add to what was said at the last ileetingregading control of this insect.

\section{Borolin remibs. Ilr.}

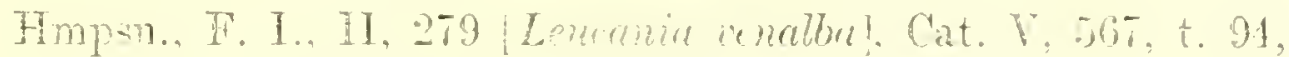
f. 32 ; Proc. Second Entl. hleting. p. 163.

Widely distributed and an occarional pest of wice e-pecially in Southern India. Has been found feethug on rice at Puca. Mascanshur

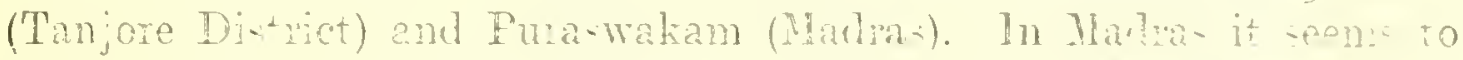
occur chiefly in May and Oeteber. Induly 1902 it was and ?t tut re to rice at Tangalla. Coyon.

$$
\text { Perigete eaprasis on. }
$$

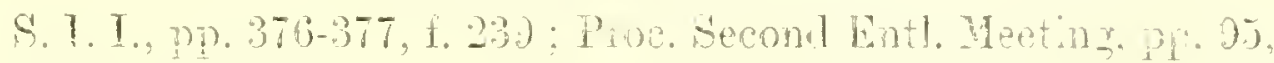
(Tab.) 134 .

Widely distributed throughout India as a poralic de-trcire pe-t of Sattower. We have examples reared on satlowei (Crithmons tho-

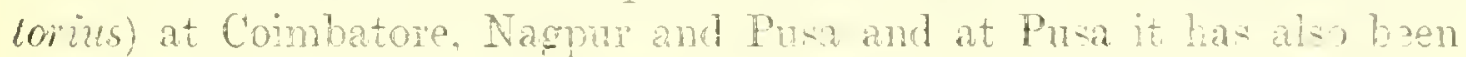
reared on jute. Niger-seed. Corenpsis. Artomisin and Bhmed i.t. zmifera.

\section{Prot nia liners. Fh.}

S. I. I.. pp. 377-378. t. 19: Proc. Seend Ent]. Meeting, 19). 49, 51, 53,59,61.75,80.86, 89, 31.127, 133, 179, 189, 203, $206,237,261,271,279,280,253,289,291,298$.

Cccurs commoniy throughout India, Buma and Coyon. The larva is reinartably polyphagous but this upecies in expecially a major pent of tobacco and castor. The Pusa collection contains examples from the following localities and reared on the foodplants specified:-

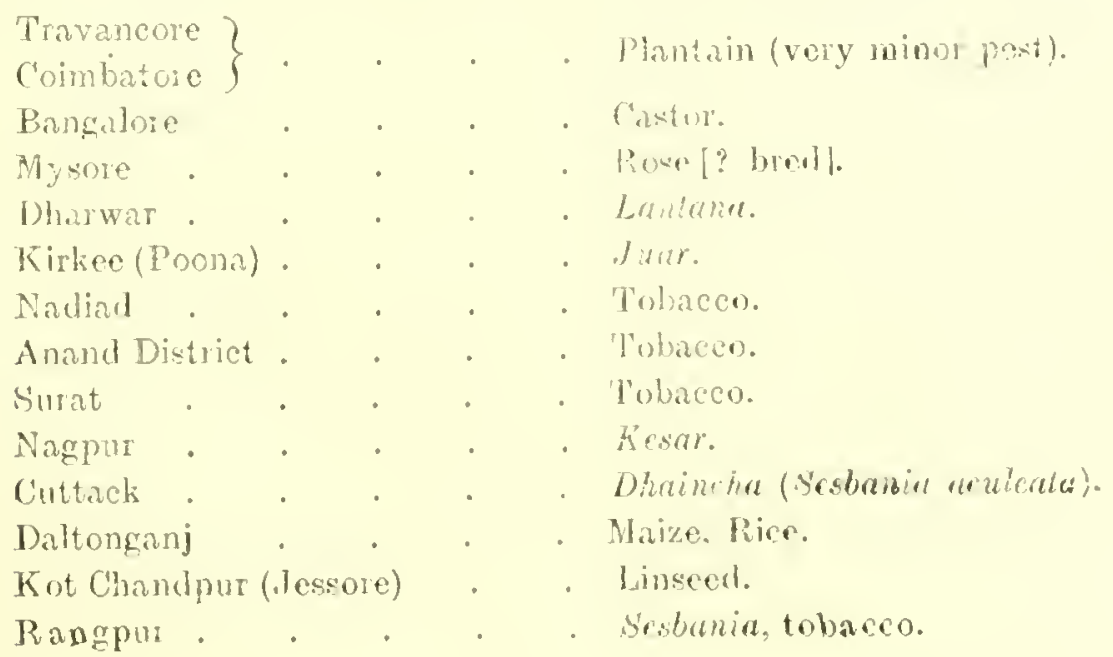


Max. Aadrews.'

Mx. Ex marristona Aysyar.

Mr. Fletcher.

D.. Gough.

Mr. Seuior-WLite.

Mx. Fletcher.

M. C. R. Dut

Mc. Kunhi Facnan. Mc. Fletcher.

South Bihar : $\quad \cdot \quad \cdot$
Bankipur .
Muzaffarpur
Pusa $\quad$ :

Chazipur (Uniled Provinces) Kumaon
- Rabi cropa on chars.

- Cauliflower.

- Tobacco, cabbage, cauliflower.

Cabbage, potato leaves, castor leaver. sunflower, rice leaves, jute, radish leaves, sweet potato, urid (Phaseolus radiatus), lucerne, Jasminum, groundnut, sugarcane. Colevs, tobacro, cotton (very rarely), ur (Cajanus indicus), Panicum. sp., rose, celery.

- Opium-poppy leares.

Apple,

The moth is attracted to Andres-Maire traps.

It rid extensive damage to tea in 1918 in the Eastern Duars.

In Madras we find it on onions also.

We find it very rarely on cotton in India, but I understand that it is a regular cotton pest in Egypt.

In Egypt it occurs mainly on cotton and bersim, but from Asiatic records we find that it is rarely found on cotton in Asia. In Egypt it occurs on bersim for the first two broods and, if we can arrange that the bersim is not watered, then the subsequent attack on cotton is lessened. We find it also boring into potato tubers underground; it is also found on tomato fruits and it is rery bad on lucerne. It is not found on castor in Egypt. As regards attraction to the Andres-Maire traps, we find that the female moths only go to the traps after depositing their eggs, so that this is useless as a means of control.

In Ceylon it is also found on Hibiscus.

Have any parasites been reared?

We have bred a Braconid and a Tachinid.

We have a Tachinid in Mysore also.

The differences in foodplants exhibited by Prodenia Iitura in India: and Egrpt raise a suspicion that different species are really implicated. It would be interesting to compare the male genitalia of Indian and Egyptian specimens.

\section{Spodoptera pecten, Gn.}

Hmp-n., I. I, II, 264 [Caradrina pectinata], Cat. VIII, 252-253, f. 63.

Has been reared at Pusa from larve on dubh and other grasses and from a larra found on maize leares. We have also moths from Peshawar, Comilla and Lashio (Upper Burma), so that it is widely distributed and likely to be found anywhere on cereal crops. Hitherto, however. it has not been reported as a pest. 
Spodoptera abyssinia, Gir.

Hmpsn., F. I, II, 259-260 [cilium], Cat. VIII, 254-255, f. 64 ; Proc. Second Entl. Meeting, p. 163.

Larvæ were found attacking paddy at Coimbatore in Angust 1316. The Pusa collection contains moths from Peshawar, Pusa and Coimbatore, and the species occurs throughout Peninsular Ind a. Far al:o been reared on Cyperus rotundus leares at Pusa.

\section{Spodoptera mauritiu, Boisd.}

S. I. I, p. 378, t. 20 ; Proc. Second Entl. Heeting, pp. 15:, $179,194,199,203$.

Widely distributed thronghont India, Burma and Ceylon, the larva feeding on varions Gramineæ and often a serious pest, especially of seedling rice-plants. The following licalit es and food-plants will indicate its range in India :-

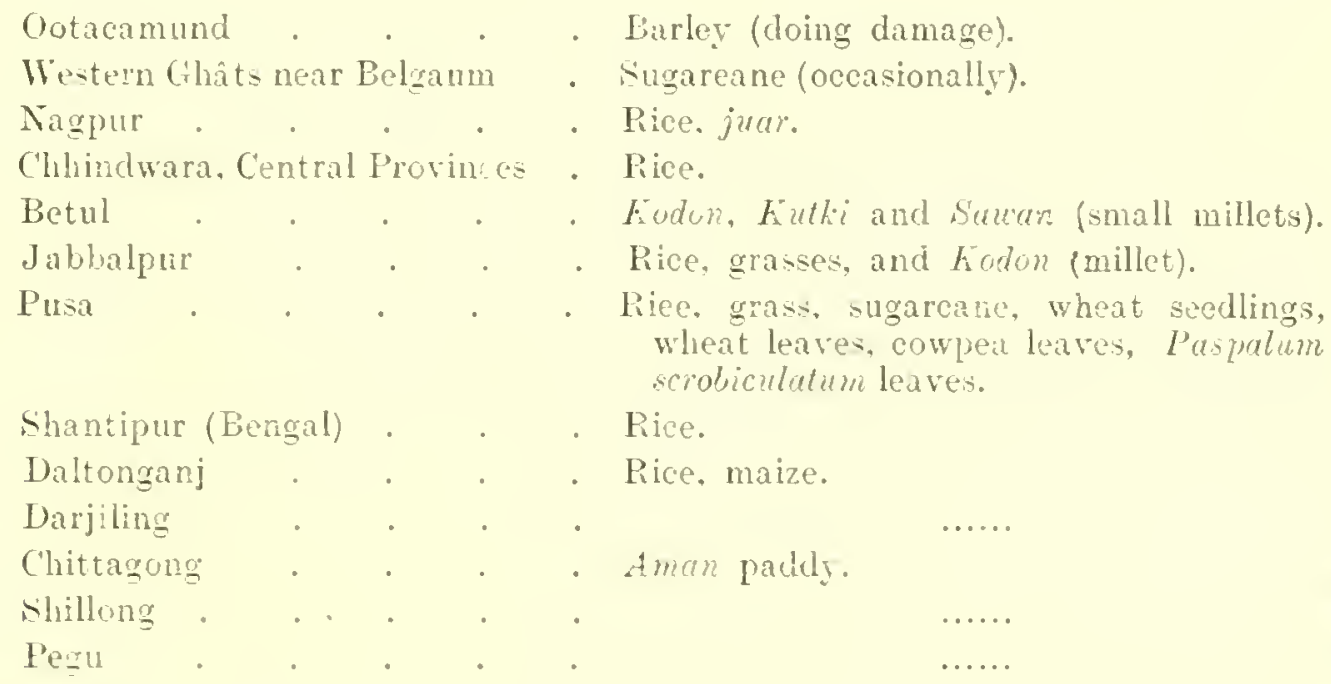

In addition to the control methods indicated in South Ludran Insects ploughing should, if possible, be done immediately after any outb:eali of larræ, to destroy the pupæ. Trenches may also be provided with pots of oil and water sunk level with the Hoor of the trench.

Spodoptera manitic is a rery serion pest in Travancore, where it pros. Pillaw. occurs annually, but it is only in some years that it is rery bad. Treating the fields with kerosine oil, when the caterpillar is in its carly stage, las been found useful as a means of control. We pour kezosine un to the water at the rate of four bottles to an acre. Andiallus spinidens has been fond predaceous on these caterpillars.

In Ceylon it is bad in rice-fields when the crop is lialf-grown. Mr. Senior-White.

We have caught the moths in the Andies-Maire trap. MIr. Misra. 
Mir. H. L. Datt.

N.r. Fletcher.

We had a huge swarm in 1918 but only on grass and the caterpillars did not attack the cultivated crops.

As I have said before, it will be very useful to accumulate exact records of these outbreaks, as, by correlating these, we may be able to discover some underlying cause.

Laplugma exigue, $\mathrm{Hb}$.

S. I. I., pp. 378-379, f. 240 : Proc. Second Entl. Meeting, pp. $59,75,80,84,89,97,98,132,189,206,208,209,283,287$, 290, $296,297$.

Occurs everywhere throughout India, Burma and Ceylon, the larvæ often joining swarms of larvæ of Spodoptera mauritia. The life-history is very short so that large broods are built up rapidly under favourable conditions and considerable damage may be done, especially to luceme and occasionally to indigo. In Egypt this speces has been noted as a cotton pest, but has not been found to attack cotton in India. The Puwa collection indicates the following range of localities and foodplants :-

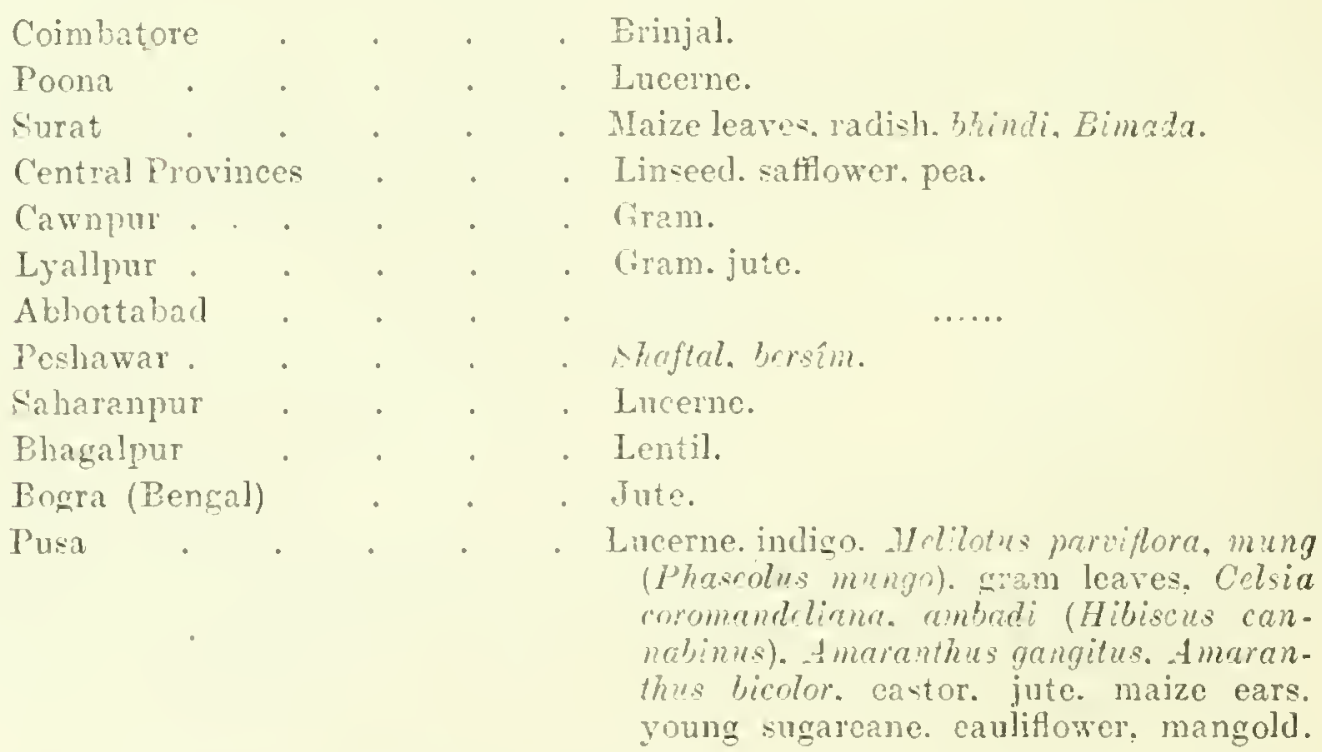

Control :s dfficult, owing to rap:d increase and range of foodplants. In the case of crops such as lucerne shefftal, bersim and indigo, cutting may be adjusted to check damage, presautions being taken to prevent swarming into adjacent areas. At. Iokameh and Pusa this species has been found attracted to the Andres-Maire traps put out for Agrotis ypsiton.

Mr. Ramakrisbna Ayyar. Mr. Jhaveri.
We bave found it on cor:ander in Madras.

It occurs on maize in Surat. 
Once it was found bad on roung jute plants on the Dacca Farn. Mr. P. c. Sen. Handpicking was commenced but fortunately there was a heary howe n of rain soon afterwards, and this cleared of the pest.

We got a mumber of moths attracted to the Andres-Haire trap. Eir. risia.

In Egrpt it feeds on cotton and bersim. Ir. Goug.

With us it feeds freely on bersim where this crop is grown. but, is Nr. Fletcher. not known to ocenr on cotton at all in Inclia. This is another care of a pronounced difference of habit between what is sunposed to be the ane insect in India and Egypt. It is possible that we may be dealing with two or more insects which are really distinct although they may look alike. In this comection I may call your attention to a recent papar by Colonel Swinhoe in the Ammals and Maga:me of Taluml Histony in which he shows that the moths hitherto known as Amphipugre pyoumber and supposed to occur in Europe, North India and Japan, really comprice no less than four speces. the true pyarmidea from Enope heing replaced in the Punjab by magna and in Japan by two distinct rpectes. smmia and yama, these distinctions being based on differences in the male genitalia. These four moths all look much alike and can only be distinguished by making microscopic preparations of the male genitalia. This shows us, I think, that we must not be too ready to as-ume that the species we are dealing with are necessarily identical with others apparently similar, especially when we get differences of habit as we have already seen in the case of Amsacta moorei and rara, and in $P$ rodonia litura and Laphygma erigua in Egypt and India. I shall be glad to give Dr. Cough some Indian male specimens of our Prodenia litura and Laphygma exigua and it would be interesting if he would compare their genitalia with thore of Egyptian specimens and lot ns know the result.

I shail be rery glad to do so.

Dr. Gorg

Muderia comifroms, Ho.

Moose. Ind. Mnc. Notes, III, 69 figs.; Hupen., F. I., II, 245. f. 1.26, Cat. IX. 2026, f. 87 ; I. I. L., p. 4t. f. 307 ; Proc. Second Entl. Heeting, p. 131.

Larve are conmon at Pnsa in Manch-April in pods of Silk-eotton Wr. Fletcrer. (Bombar ma'al a icum), devouring the seads and spoiling the lint. A minor pest in cases where the pods are collected for the cotton. 
Sesamia inferens, Wlk.

S. I. I., pp. 379-380, t. 21 ; Entl. Note, 62 ; Proc. Second EntI. Meeting, pp. 145, 152, 174, 182, 18i, 191, 196, 200, 204.

Widely distributed in the Plains of India and an important pest of cultivated Graminex, the larva boring in the stem and, in the case of paddy, sometimes deep into the roots. We have specimens reared in the following lccalities from the foodplants specified :-

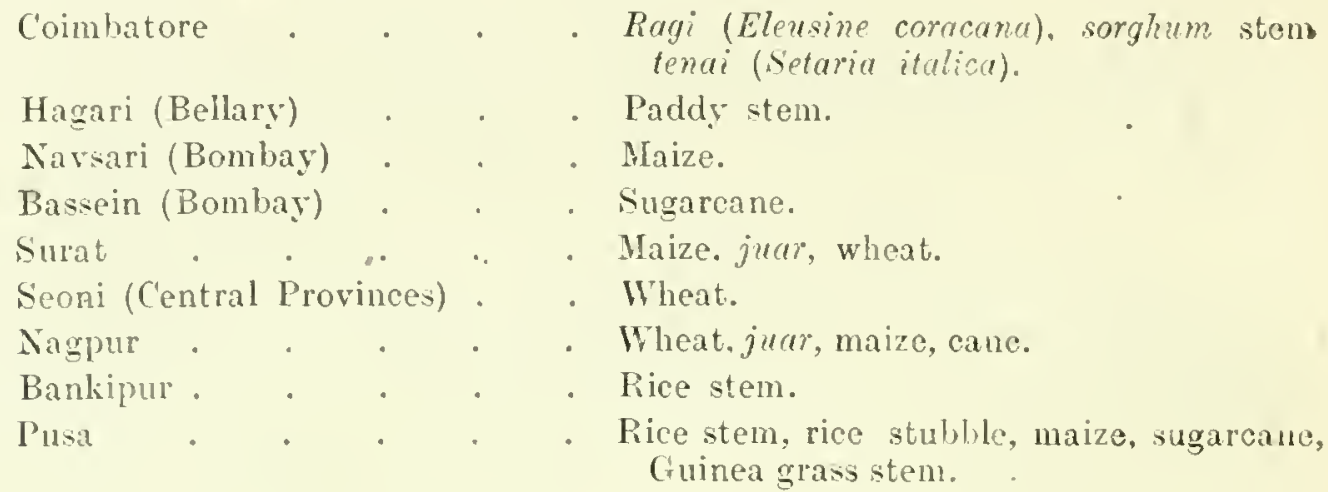

Sesamia uniformis, Ddgn.

Dudgeon, B. J. XVI, 402 [Nonagria]; Hmpsn., Cat. IX, 332, t. 144, f. 25 ; I. I. I., t. 37, f. 7 ; Ent. Note 62 ; Proc. Second Entl. Meeting, p1. 145, 191.

Apparently not very common in India. We have examples reared at Lyallpur from sugarcane and maize, and at Pusa from maize and young sugarcane. Attaclied canes show only one hole, plugged with frass.

Lefroy apparently interchanged this species and the more common S. inferens (Indian Insect Life, p. 448). The differences are indicated, in the case of the moths, in $m y$ "First Hundred Notes," and the pupre a:e easily distinguishable by the spines on anal abdominal segments.

Inc. Eenir-White. Have any parasites been found on the eggs? In Jara and Mauritius Sescmin nonagrioides is attacked by a Proctotrypiu parasite that keeps it in check. [There would seem to be some error in this last observation. Hampson (Cat. Lep. Phat. II 324-325) records S. vuteria (nomgrioides from Europe and Africa, including Madagascal and Bourbon, so that this species presumably occurs in Mauritius, but not in Java. Editor.]

Mr. Eunhi Eanann. Do these Sesamia larra attack the plant in all stages of growth?

Mr. Crost. Jes.

Mr. Kuni Kanan. What is the percentage of plants attacked?

Mr. Ginosu. Less than one per cent. At Pusa Sesamia inferens occurs more commonly in rice than in any other crop 
Eublemma dimidialis, Fb.

Phalona dimidialis, Fb.. Ent. Syst. III, ii, 224 (1791); Hmpsn., Cat. X, 797 [Eublemma].

Anthophila secta, Guen., Noct. II, 249 (1852); Hmpsn., Cat. X, 77, f. 35 [Eublemma].

Micra hemirhoda, Wlk., Cat. XXVIII, 799 (1865); Hmpsn., F. I., II, 342 [Eublemma]; Fletcher, Rept. Impl. Entom., $1917-18$, p. 104, t. 20 [Eublemma].

We have two specimens labelled "Coimbatore; on cholam" and Mr. Fleicher. one from Travancore labelled "on cowpea," but it is not apparent that these examples were bred. Specimens from Palur, S. Arcot, were noted as "flying in numbers in the groundnut fields" on 21 th April 1907. The moth is common at Pusa and has been bred from larvæ eating mmo flowers. We have it also from Gauhati.

\section{Eubleman olivacen, Wik.}

S. I. I., pp. 380-381, f. 241; Proc. Second Entl. Heeting. p. 287 (tab.).

Occurs throughout India as a pest of brinjal. Our specimens are from Pusa and Dhawar, and I have seen it from Lyallpur. It is u-ually a minor pest, occasionally rery destrinctive. The larva rolls brinjat leaves; it does not "bore in the green shoots" as stated (Indian Irsect Life, p. 451) by Lefroy, who has apparently described the larva of this species under the name Plotheia nephelotis (i. c., p. 449).

\section{Eublemma siliculu, Swinh.}

Swinhoe, A. M. N. H. (6) NIX, 167 (1897); Hmp-n., Ca九. X, 128-129, t. 152, f. 19: Proc. Second Entl. Meeting. p. 20.2.

Reared at Pusa from larræ in flowers of Nyctanthe; arbortristis and from mango buds and inflorezcence. from castor fiuit and from larve eating grains in bajia heads. at Nagpu. from mango flower- and from larse in juar heads, and at Coimbatore from larre in cho' am earheads.

It is found also on Lantana camara.

Mr. Ramachandea R30.

Cietonia vegeta, Swinh.

Himpsn., F. I., II, 325, f. 175 [Swinhan], Cat. X, 338-389, 1. 123.

Widely distributed throughont India, Burma and C'ey'on. Has Mr. Fletcler. been reared at Pusa from a larva found on rice leares, but is not known to be a pest. 
Amyna octo, Gn.

Hmpsi., F: I., II, 251, f. 142, Cat. X, 168-470, f. 132 ; I. I. L. p. 418 ; Proc. Second Entl. Meeting, p. 68.

Occurs commonly throughout India, Buma and Ceylon. Has been reared at Dharwar from a larva found boring potato [stem or tuber not stated] in the field, at Palur, S. Arcot, from larve on sam-hemp, and at Pnsa from larve on indigo and incerne leaves, on jatadhari leaves (Celosia cristata), on Pluseolus aconitifolius (boring pods), on leaves of sannhemp.

Usually a very minor and occasional pest of the crops indicated, but sporadically in large numbers on indigo. Lefroy stated that the larva has been reared on sweet potato also.

Amyna prenctem, Th.

Himpsn., Cat. X, 472-471, f. 133.

Amyna setenamplo, Gren.; Hmpsn., T. 1., II, 250; I. I. L., p. 418.

The larva is described by Fampion (Cat. X. 174) as feeding on Crolon tiglium (Croton ail plant) and C. aromaticum in Ceylon, sometimes a seriou: pest of the former (Green). Not noticed as a pest in India, but the pecies is abundant almost ererywhere and the moths often occur in swains, especially in the Hills.

\section{Lithacodiu signifera, Wlk.}

Hmpin., F. I., II, $304[$ Hyclopsis], Cat. X, 504-505; I. I. L., p. 455 [Hyelopsis].

Widely distributed throughout India, Buma and Ceylon. Has once been bred at Pusa from a larva on leaves of a millet (Panicum, sp.) and once from a larva on rice-leaves. Not known to be a pest.

Narainga diffusa, $\mathbb{T}^{\top} \mathrm{lk}$.

Hmpsil., F. I. II, 33.3-334, f. 177, Cat. X, 0.31-632, f. 167 ; I. I. L., p. 456 .

Has been bred at Pusa on two occasions from larra found feeding on leaves of rice, but is not known to be a pest in India. It has been recorded as found on paddy in Formosa by Shiraki, who figures the lifehistory. The female moths come to light freely, but the males rarely. 
Tarache mamoralis, Fb.

Himp-n.. Cat. X. T+7-749, f. 209.

Tarache tropica, (iner.; Hmpsn., F. I., II, 314, f. 170 ; I. I. L., p. 456. t. 37. Af. 1-4.

Has been reased at Pusa on leaves of bariar (Sida rhombifolia). May occasionally attack malraceous crops but not yet noted as a pest.

\section{Tarache crocatu, Guen.}

Hmpsn. F. I. II, 314-315, Cat. X, 751-755, t. 172, ff. 15, 16; Proc. Second Entl. Meeting, p. 133.

Widely distributed thronghout the Plains of India, Burma and Ceylon. The larra is sometimes found on jute but is scarcely a pest.

A female, captured in a jute-field at Samalkota on 17 th June 1903, is noted by $\mathrm{Y}$. Ramachand a Rao as having laid 220 eggs.

\section{Tarache niildula, $\mathrm{Fb}$.}

S. I. I., pp. 381-382. f. 243 ; Proc. Second Entl. Meeting. p. 101.

Occurs commonly throughout the $\mathrm{P}$ 'ains of India and is an occasional minor pest of cotton.

\section{Tarache opalinoides, Guen.}

S. I. I, p. 382, f. 244; Proc. Second Entl. Meeting, pp. 101, 129.

Occurs in Central and Southern India as a very minos pest of cotson. Also on Abution indicum. at Pusa. (C. 581.)

Taiache natabilis, Wlk.

Hmpsn., F. I., II, 311, Cat. X. 783-784, t. 173, f. 24; Proc. Second Entl. Meeting, p. 101.

Occurs throughout the Plains of India as a very mino: pest of cottun. Has al:o been reared on brinjal at Nagiur.

\section{Bombo'elia jocosativ, Cuen.}

S. I. I., pp. 382-383, f. 245; Proc. Second Entl. Meeting, 1). 218.

We have specimens from Chandragini, Koilpatti and Coimbato e in Madıs. from Poona and Pura, reared from larve on mango leaves. A sporadic minor pest of mango. 


\section{Bombotelia sp.}

Larva were found at Pusa, feeding on tender mango leaves in some numbers in May 1917.

This species is very close to $B$. jocosatrix but is distinct and is apparently undescribed.

\section{Chlumetia transiersa, Wlk.}

Hmpsn., F. I., II, 376, f. 207, Cat. XI, 68, f. 25; I. I. L., p. 450 ; Proc. Second Entl. Meeting, p. 220.

A nimor pest of mango, the larva boring the shoots and sometimes feeding on the leaves and inflorescence. Stated to be a bad pest of young grafted mangoes at Poona, boring the shoots. Occasionally on litchi also. Our specimens are from :-

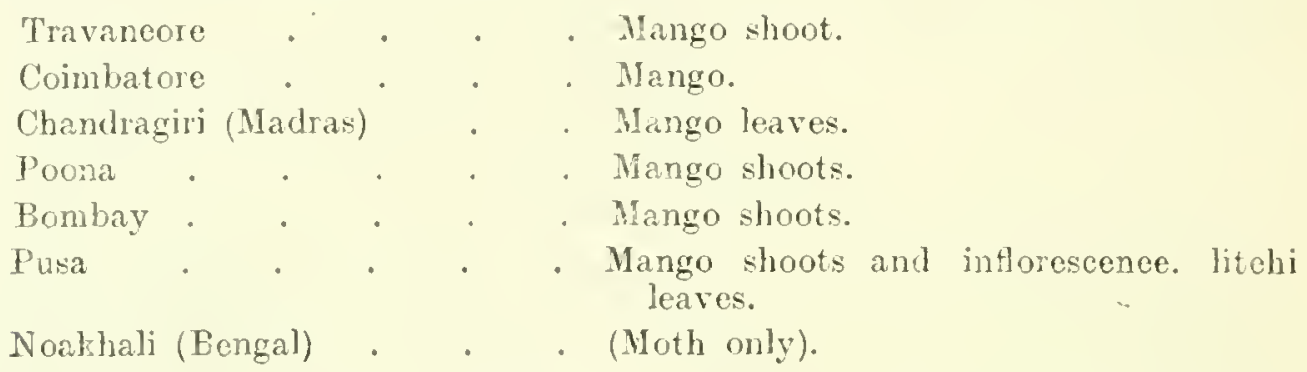

Mr Ramrac.

Nir. Fletcher.
Chlumetia transversa is a bad pest of mango in Poona. The caterpillass bore into the shoots and the attacked shoot dues not flower the next season even if the larva is extracted. The method of cutting back to the point of injury does not seem helpful. We have reared parasites from this species but they do not check it effectually. The younger grafted plants suffer seriously from the atack; the older plants need not be taken into account as the damage in their case is negligible.

\section{Symitha nolalella, Wlk.}

Hmpsn., Cat. Lep. Phal., XI, 244, f. 86.

Hampson gives the distribution of this species as, Calcu ita, Ka? war, Ceylon, Java. At Pusa the larve were found in numbers defoliating Langerstramia flosregina in August 1917.

Nanaguna breviuseula, Wlk.

Hmpsn., Cat. XI, pp. 252-253, f. 90.

Cletthare valida, Wlk.; Hmpsn., F. I., II, 384.

Bred at Mandalay in January 1910 from larvæ on Cajanus indisus and at Pusa in April 19]6 and May 1917 from larvæ on mango inflores- 
cence. We have a!so a spccimen from Peradeniya and the species is widely distributed throughout India, from Kashmir to Sikkim and in Southern India and Ceylon.

Giaura septica, Swinh.

Hmpsn., Cat. XI, 283 ; I. I. L., p. 450 [Cletthara]; Proc. Second Entl. Meeting, p. 47.

Has been reared at Pusa and Surat from larræon velvet bean and soy bean, of which it is a sporadic minor pest. Also at Puca from larva on Butca frondosa flower. Widely distributed throughout India, Buma, Ceylon and the Andamans.

Selepa celtis, Mo.

Hmpsn., Cat. XI, 298, f. 105; Proc. Second Entl. Meeting, pp. 218, 229, 246, 264.

Plotheia celtis, Hmpen., F. I., II, 370 ; I. I. L., p. 449, f. 308.

The Pusa collection contains reared examples from Coimbatore on Odinu wodier and from Pusa on litchi leaves, mango leaves and buds, rose leaves, Teminalia cutappu leaves and Loranthus leaves. Other recorded foodplants are Ficus glomerata and Gmelina arborea.

The species occurs throughont India and Burma as a sporadic pest (sometimes serious) of the plants and trees mentioned.

\section{Plotheia nephelotis, Meyr. MS.}

Proc. Second Entl. Meeting, p. 287.

A minor pest of brinjal, on which it has been reared in Travancore and at Calicut, Coimbatose, Tiruvallur and Melro:epuram (Madras), Nagpur, Lyallpur and Pusa ; also at Hagrari (Bellary District) on a wild solanaceous plant.

The larva attributed to this species by Lefroy (Indian Inseat Life, p. 449) is probably the larva of Eublemma areacea.

Tne specific name nephelotis is an umpublished manuscript name.

$$
\begin{aligned}
& \text { Brinjal Sarrothripine. } \\
& \text { S. I. I., p. } 383 \text {, f. } 246 .
\end{aligned}
$$

Has been reared at Coimbatore and in Halabar on brinjal and at Hagari on Solanum xanthocarpum. 'This is probably the same as the preceding. 
Eligma narcissus, $\mathrm{Cr}$.

S. I. I., pp. 383-384, ff. 247-248: Proc. Second Entl. Meeting, p. 263.

Occurs throughout Southern India on Ailanthus, which is sometimes comple-ely defoliated by the larve.

\section{Earias insu'ana, Boisd.}

S. I. I., pp. 384-385, t. 22; Proc. Second Entl. Meeting. pp. $104,122,123,127.129,130$.

Occurs throughout the Plains of India and Burma as a serious pest. c. cotton. Also attachs bhindi (Hibiscus esculentus) and has been reared at Pusa from buds and flowers of Hibiscus rost-sinensis and on langhani (Abutilon indicum).

Dr. Gough.

Earias insulana has become are in Egypt since 1912. We ascribe th:s to the plant legislation against Pink Bollworm. Exrias was a major pest at one time; but now it does not trouble us.

Earias cupreoviridis, Wlk.

Xanthoptera cupreociridis, Wlk., T. E. S. (3) I, 92 (1862).

Earias cupreoviridis, Hmpsn., C.at. XI, 505-506 ; S. I. I., t. 22,

f. 7 ; Proc. Second Entl. Meeting, pp. 127, 135.

Earias chromataria; Hmpsn., F. I., II, 133 ; I. I. L., p. 456.

Occurs in most parts of the Plains of India. Our specimens are from Hazara District, Bassein Fort (Bombay), Nagpur, Pusa, Chapra, Cuttack and Dacca. Has been reared at Pusa on bariar (Sida cordifolia) and at Nagpur on wild malraceous plants. At Cuttack also the larra has. been found boring into jute capsules as a very minor pest.

IIr. Senior-White.

Mr. Fleicicer.

Dr. Gought.

M. P. C. Een
In Ceylon it occurs on garden hollyhocks.

\section{Earias fabia, Stoll.}

S. I. I., p. 385, t. 23 ; Proc. Second Entl. Meeting. pp. 101, $122,123,127,129,130$.

Occurs throughout the Plains of India and Ceylon as a serious pest of cotton, boring the young shoots and bolls and sometimes feeding on the flowers. Also on bhindi, boring the pods, and has also been reared at Pusa on Hibiscus a'elmoschus and from flower bud of $H$. rosa-sinensis.

Earias fabia does not occur in Egypt. We only get $E$. insulana.

Last year Earias fabia was found bad on shoots and bolls of cotton grom on the Dacca Farm. 
We shall defer discussion on these Cotton Bollworms until we take Mr. Fletches. the papers dealing specifically with Cotton Pests.

Carea subtitis, Wlk.

Hmpsn., F. I., II, 422, Cat. XI, 542-543, f. 208.

Has been reared at Coimbatore on Ficus and Eugenia jambolana. Not known to be a pest.

I have found Carea subtilis commonly on Eugenia jambolana at Coim- Mr. Ramakrishna batore.

Ayyar.

Beara dichromella, Wlk.

Hmpsn., F. I., II, 428, Cat. XI, 581-582, f. 227.

Widely distributed in India and Ceylon. Has been reared at Pusa Mr. Fietcerer. from larre on leaves of Trema sp. and ber (Zizyphus jujuba), but is not a pest.

Acontia transversa, Guen.

Hmpsn., F. I., II, 323, f. 173, Cat. XI, 654-655, f. 268 ; Proc. Second Entl. Meeting, p. 123.

Has been reared from larva on bhindi leaves at Surat, Nagpur and Pusa, but is scarcely a pest. We have it also from Rangoon.

Acontia transversa occurs on hollyhock in Ceylon.

Mr. Senior-White.

Acontin intersepta, Guen.

Hmpsn., F. I., II, 323, Cat. XI, 656-657, f. 270 ; I. I. L., t. 37 ,

f. 9 ; Proc. Second Entl. Meeting, pp. 101, 123.

Has been reared at Nagpur on bhindi and at Pusa on Sidn, but is not Mr. Fletcier. known to be a pest. Occurs throughout India, Burma and Ceylon.

Acontia malve, Esper.

Hmpsn., F. I., II, 322, Cat. XI, 658-659, f. 271 ; Proc. Second Entl. Meeting, pp. 101, 123, 129.

Occurs throughout India, Burma and Ceylon. Has been reared from bhindi at Surat and Nagpur and on Abutilon indicum at Nagpur, but is scarcely a pest. We also have it from Serai Salah (Hazara) and Myingyan (Lower Burma). 
Acontia graellsi, Feisth.

S. I. I., pp. 385-386, f. 249 ; Proc. Second Entl. Neeting, p. 101.

We have reared examples from the following localities:-

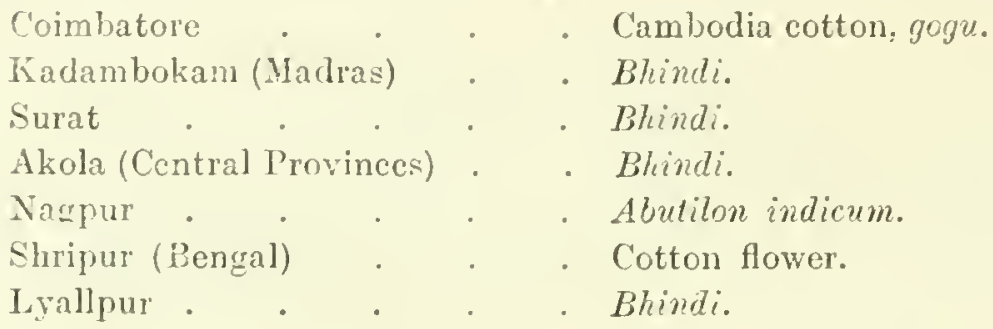

It is a minor pest of cotton and bhindi.

\section{Anua coronala, Fb.}

Hmpsn., F. I., II, 502-503 [Ophiusa], Cat. XII, 427-428, f. 101.

The larva is found commonly on Quisquatis and may be a minor garden pest. We have it from Pusa. Chapra and Darjiling, Insein and Minbu, and the moth is widely distributed in India, Burma and Ceylon.

\section{Achcea janata, Linn. (=Ophiusa melicerta, Drury).}

S. I. I., pp. 386-387, f. 250 ; Entl. Note 63 ; Proc. Second Entl. Meeting, pp. 86, 232, 235, 265.

Occurs throughout india and Ceylon as a serious pest of castor. Has also been reared at Pusa on rose and dudhi (Euphorbia pilulifera) and at Nagpur on rose.

Mr. Senior-White.

Mr. Fletcher.

Mír. Misra.
Achoca janala is a bad pest of rose in Ceylon.

In India it occurs occasionally on rose but has never been noted as a pest. With us it is a major pest of castor and we always have trouble with it every year at Pusa on the castor grown for the eri silkworms. It is controlled by hand-picking.

There is a parasite which attacks it, but this appears late in the season.

\section{Parallelia analis, Guen.}

Hmpsu., F. I., II, 501 [Ophiuscu], Cat. XII, 586, t. 221, f. 1.

Was sent in in October 1913 from Mow Bazidpur, Darbhanga District, Bihar, as defoliating Phyllanthus emblica. Widely distributed throughout India, Burma and Ceylon, but not otherwise known as a pest. 
Parallelia algiva, Lim.

Hmpsn., F. I., II, 500-501, f. 280 [Opliusa], Cat. XII, 596-598, f. 133.

Occasionally found teeding on castor together with Achace janata. We have a specimen bred from a larva found on castor at Cuttack and it was recorded as defoliating castor at Peradeniya in July 1903 and is likely to occur as a sporadic pest on castor throughout the Plains of India, Burma and Ceylon.

Grammodes. geomeirica, Fb.

Hmpsn., F. I., II, 531, f. 296, Cat. XIII, 18-20, f. 4 ; I. I. L., p. 451.

Occurs throughout India, Burma and Ceylon. The larva is stated (Indian Insect Life, p. 451) to feed on rice and we have a specimen from Balaghat (Central Provinces) labelled "on rice," but it is doubtful whether this was actually bred. Stated to feed on grasses at Nagpur. Hampson gives Polygonum persicaria and Cistus salvifolia as the foodplants in Europe. The larva is figured by Hofmann (Raupen, t. 36, f. 24).

Grammodes stolida, $\mathrm{Fb}$.

S. I. I., pp. 387-388, f. 251 ; Proc. Second Entl. Meeting, p. 89.

Widely distributed throughout India and Burna and is an occasional minor pest of linseed in Madras.

Chalciope hyppasia, Cr.

Hmpsn., Cat. XIII, 27-29 ; Proc. Second Entl. Meeting, pp. 80, 206. Trigonodes hyppasia, Hmpsn., F. I., II, 527 ; I. I. L., p. 451, f. 311.

Common thronghout India, Burma and Ceylon, but no $₫$ known as a pest except on one occasion when it was found defoliating indigo at Champaran on 1st April 1901; the Pusa Collection contains one of these moth; reared on indigo and the identification is certain. It also feeds on lucerne.

$$
\text { Pe'amie frugatis, } \mathrm{Fb} \text {. }
$$

Hmpsn., Cat. XIII, S7-89, f. 23 ; S. I. I., pp. 388-389, f. 253 [Remigia].

Occurs abundantly throughout India, Burma and Ceylon. The larva feedis a: a rule on wild giasses but occasionally invades cultivated areas as a minor pest of Graminee. It has been reared at Kannapuram (N. Malabar) on paddy, at Nagpur on juct and grasses, and at Pusa on paddy, sugarcane, Cypreres rotundus and Phuseolus mungo radiatus.

In Ceylon it attacks Guinea-grass.

Mr. Senior-White. 


\section{Pelamia unda!a, $\mathrm{Fb}$.}

S. I. I., p. 388, f. 252 [Remigra] ; Hmpsn., Cat. XIII, 91-93, f. 25 ; Proc. Second Entl. Meeting, pp. 80, 102.

Remigia archesia, Cram.; Hmpsn., F. I., II, 526, f. 293;

I. M. N., V, 159 ; I. I. L., pp. 450 451, f. 309.

Mr. Fletcher.
Occurs abundantly throughout India, Burma and Ceylon and is a minor pest of pulses as a rule, feeding mostly on the lower leaves, but is sometimes extremely abundant on indigo. The Pusa Collection contains examples from the following localities and reared on the foodplants noted :-

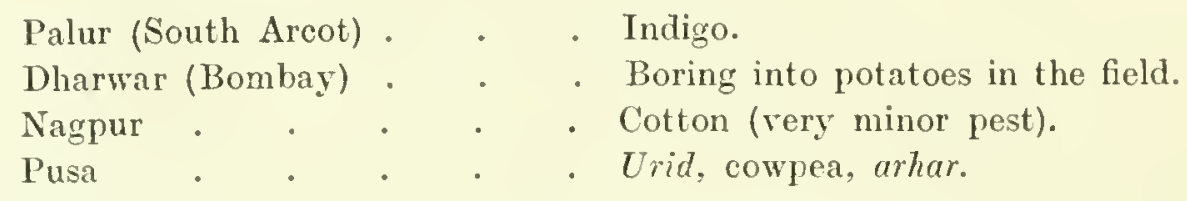

Pericyma glaucinans, Guen.

A minor pest of Sesbania spp. We have it from Rangpur on Sesbania, from Cuttack on Dhaincha (Sesbania aculeata), and from Coimbatore on Sesbania cegyptiaca.

\section{Plusia ni, $\mathrm{Hb}$.}

Hmpsn., Cat. XIII, 468-470, f. 121 [Phytometra]; Proc. Second Entl. Meeting, p. 282.

Occurs throughout India. We have it from Pusa and Lahore on cauliflower and from Surat and Kumbharia (Bombay) on cabbage. Other larval foodplants include safflower, nettle and Solonum, and in the United Provinces and Gujarat it is said to occur on opium poppy also. It is scarcely a pest.

\section{Plusia limbirena, Guen.}

Hmpsn., Cat. XIII, 472 [Phytometra] F. I., II, 568 ; I. M. N., V, 162 ; I. I. L., p. 452 ; Ent. Mo. Mag. 1900, 127 ; Proc. Second Entl. Meeting, p. 80.

Has been recorded as feeding upon indigo in Bihar. Possibly the identification is incorrect, as this species is recorded only from the Nilgiris and Ceylon in Hampson's Catalogue. 


\section{Plusia daub?: Boisd.}

Hmpsn., Cat. XIII, 477-47s [Phytometra]; Proc. Second Entl. Heeting, p. 50.

Has been reared at Pusa from larræo on mint leaves and from pupæ found on cress, but is not a pest. Occurs throughout India.

Plusice chalcytes, $\mathrm{Fb}$.

Hmpsn., Cat. XIII, 484-486, f. 122 [Phytometra]; Proc. Second Entl. Neeting, pp. ๖̄1, 5̈3, 68, 306.

Plusia eriosoma. Doubl.; Hmpsn., F. I., II, 569-570, f. 321.

Occurs throughout India and Ceylon. The Jarva is polyphagous and is a minor pest of various crops. The Pira Collection contains specimens from the following localities and foodplants:-

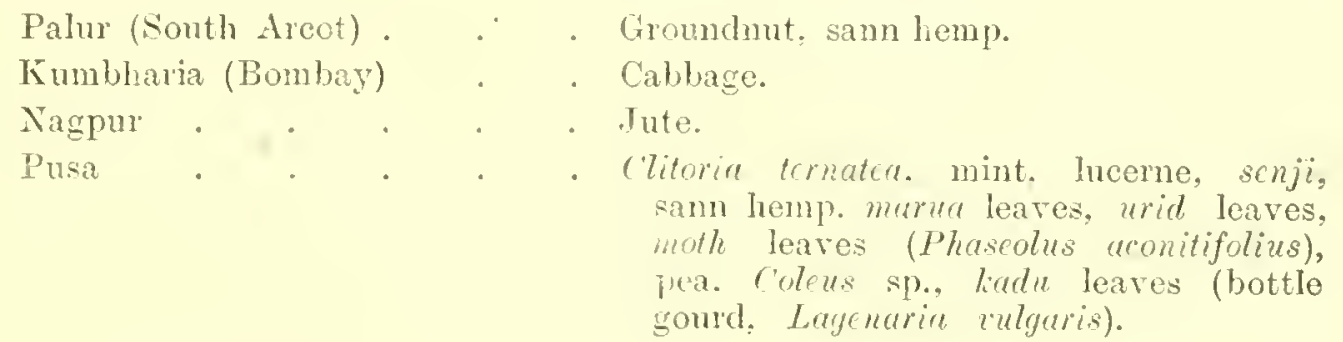

It has also been recorded on indigo in Champaian in September 1901 and at Kotagala (Ceylon) as defoliating tomato plants in January 1905.

In Ceylon we get it on onion and brinjal.

Mr. Senior-White.

Plusia signate, $\mathrm{Fb}$.

S. I. I., pp. 392-393, f. 259 ; Hmp *n., Cat. XIII, 491, t. 237, f. 24, [Phytometia]; Proc. Second Entl. Meeting, pp. 68, 91, $271,282$.

Recorded on cabbage, as an oceasional pest in Bihar (Lefroy), on Mr. Fletcher. tobacco, groundnut, green gram and sann-hemp in Southern India. There is, however, some doubt regarding identification. (See also P. (halcyles).

Plusia albostriata, Brem. and Grey.

Hmpsn., Cat. XIII, 496, t. 237, f. 29 [Phytometra].

Plusia oxygramma, Hmpsn., F. I., II, 575.

Found in August 1913 in some number on cultivated asters at Hebbal Farm, Bangalore. Also occurs at Pusa but not bred there. 
Plusia nigrisigna, Wlk.

Hmpsn., F. I., II, 570, Cat. XIII, 536-537 [Phytometra] ; Proc. Second Entl. Meeting, pp. 49, 271.

Occurs throughout India and is a sporadic minor pest, chiefly of gram. We have examples from:-

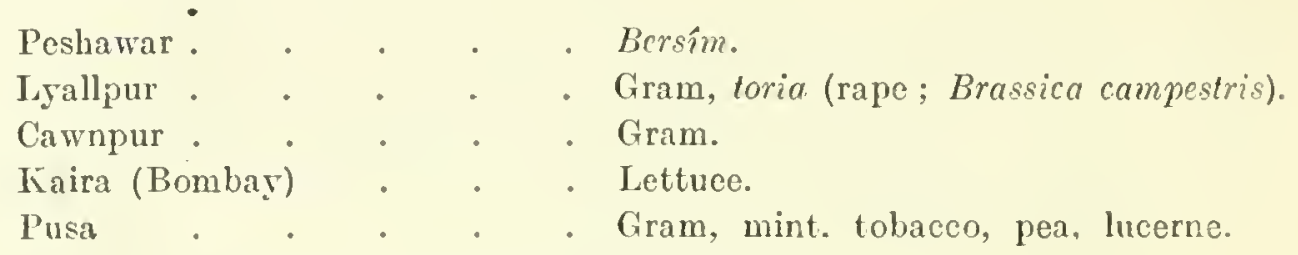

Plusia peponis, Fb.

S. I. I., p. 394, f. 261 ; Hmpsn., Cat. XIII, 573-574 [Phylometra]; Proc. Second Entl. Meeting, pp. 50, 303, 307.

Plusia agramma, Guen.; Hmpsn., F. I., II, 574; I. I. L. p. 452 , t. 37, f. 11 .

Occurs throughout India, Ceylon and the Andamans and is a minor pest of gourds. We have it from Pusa on bottle gourd and from Pusa and Coimbatore on snake gourd.

\section{Plusia orichalcea, Fb.}

S. I. I., pp. 393-394, f. 260 ; Hmpsn., Cat. XIII, 580-581 [Phylometra]; Proc. Second Entl. Meeting, pp. 47, 59, 63, $80,89,95,280,282,283,285,298$.

Occurs throughout India and Ceylon; apparently not recorded from. Burma, although it occurs in Assam and probably in Burma also. The larva is polyphagous and is a minor pest of garden crops especially. Our examples are from:-

$$
\begin{aligned}
& \text { Palur (South Areot) . . . Indigo. } \\
& \text { Poona . . . Cabbage. } \\
& \text { Nagpur . . . . Cabbage, radish. } \\
& \text { Jallandhar . . . Caulitlower. } \\
& \text { Iyallpur . . . . . Turnip. } \\
& \text { Patna . . . . Pea. } \\
& \text { Muzaffarpur . . . Brassica sp. } \\
& \text { North Bihar . . . Flax. } \\
& \text { Pusa . . . . Pea leares, linseed, carrot, senji, lucerne }
\end{aligned}
$$


Plusia orichalcea is one of the few insects that feed on umbelliferous Mr. Senior-White. plants, such as carrots and aniseed. It is highly parasitized.

Rivula bioculalis, No.

Hmpsn., F. I., II, 334-335, f. 178.

Widely distributed throughout India, Burma and Ceylon. The Mr. Fletcker. larva has been found at Pusa on leaves of rice and Panicum, but it is not known as a pest.

\section{Cosmophila fulvida, Guen.}

Hmpsn., F. I., II, 409-410, f. 226 ; I. I. L., p. 453 ; Proc. Second Entl. Nieeting, p. 129.

Oceurs throughout India, Burma and Ceylon. Has been reared at Pusa on Abutilon indicum and Sida sp., and Hampeon gives Waltheria indice as a food-plant. Not yet noted on cultivated plants but may be expected to be found on Malvacer (cotton, hollyhock, etc.).

\section{Cosmophita sabulifera, Guen.}

S. I. I., pp. 390-391, f. 256 ; Proc. Second Entl. Meeting, p. 133.

Occurs in all jute-growing districts as a major pest of jute. It is known from South Areot, Godavari District, Samalkota, Dhairrar, Belgaum, Poona, Nadiad, Nagpur, Pusa, Dacca and throughout Bengal.

If the plants are sufficiently young and water is standing in the field, control may be effected by running a film of kerosine over the water and disturbing the plants, when the larvæ drop.

Cosmophila sabulifera is a regular bad pest of jute in Bengal du ing Mr. P. C. Sen. the rainy season. As far as remedial measures are concerned, on the Dacea Farm hand-picking is done although it is tedious. Dragging a rope slightly moistened" with kerosine so that it may not injure the plants was also tried but was not found to be of much use, as the eaterpillars, which fall down at the time of operation, crawl up the plants again and feed on the leaves. This, of course, disturbs them when feeding.

\section{Cosmophila indica, Gn.}

S. I. I., p. 391, f. 257 ; Proc. Second Entl. Meeting, pp. 100, 123, 125, 126. [C. erosa, nec $\mathrm{Hb}$.$] .$

Occurs throughout India as a sporadic pest of cotton. We have Mrr. Fletcher. examples reared on cotton from Dharwar, Poona, Jalgaon (Khandesh), 
Mr. Senior-White.

Mr. Pillay.

Mr. Fle.cher.

Bassein Fort (Bombay), Surat, Ajmer, Narsingpur, Cawnpur and Pusa. It has also been found on bhindi (Hibiscus esculentus) at Lyallpur, Pusa and Surat, and at Pusa on ambadi (Hibiscus cannabinus), bariar (Sida cordifolia), hollyhock, wid and Bombax malabaricum.

The larvæ are best controlled by hand-picking.

In Ceylon it occurs in the North-East but not in the South-West. It breeds in October.

In Travancore it occurs on Hibiscus.

\section{Lyncestis amphix, Cram.}

Hmpsn., F. I., II, 479, f. 267 ; I. I. L., p. 447, f. 306 [Euscotia sp.].

Has been found at Pusa feeding on Ocimum sanctum and $O$. canum but is scarcely a pest.

Catephia inquicta, Wlk.

Hmpsn., F. I., II, 484 ; I. I. L., p. 45t, t. 28, ff. 4, 5 ; Proc. Second Entl. Meeting, p. 291.

A minor sporadic pest of sweet potato in North Bihar. Also reared at Pusa on young sugarcane. We have also moths from Myingyan (Upper Burma) and from Coimbatore and Siruguppa (Bellary).

\section{Azazia rubricans, Boisd.}

S. I. I., p. 389, f. 254 ; Proc. Second Entl. Meeting, pp. 51, 59.

A minor and sporadic pest of pulses in Bihar and Madras. Has been reared at Pusa on cowpea, wid, guar, and moth (Phascolus asonitifolius).

Ophideres fullonica, Linn.

Hmpsn., F. I., II, 560-561, f. 317 ; Entl. Note 64 ; Tryon, Queensland Agricl. Journ. II, pt. 4, t. 18, 20, 21, 22 (April 1898) [Otheis]; Proc. Second Entl. Mceting, pp. 212, 235.

The moths have been recorded (Indian Museum Notes, V, 118) as piercing pomelo fruits at Tardeo, Bombay, causing a loss of 25 to 33 per cent. of the fruits, which drop off the trees. Also stated to damage orange fruits around Poona and at Nagpur, and to suck grape-fruit in the Punjab. The species is widely distributed throughout India and is undoubtedly a pest in all fruit-growing districts.

Mr. Ramrao.

At Poona I have not been able to find the larve although the adults come in large numbers and puncture the fruits at night. We burn the moths off by means of torches and collect them by means of a small 
hand-net by the light of a lantern. I have tried to trap the moths with fermented toddy but only caught one specimen in fifteen days.

The early stages were described and figured in Moore's monograph of Mr. Fletcher. the Ophiderine of the Indian Region in the Transactions of the Zoological Society and also by H. Tryon in the Queenstand Agricultural Joumal, Vol. II, t. 18, 20, 21, 22' (April 1898); Tryon states that the larva feed on several distinet species of Menispermacex.

How did you try the trapping of the moths?

I placed the fermented toddy in narrow-monthed earthen vessels, Mr. Ramra. one jar to every five trees.

What is the percentage of loss to oranges at Poona?

Mr. Fletcher.

I have calculated that on an avelage, taking one season with another, Mr. Ramrao. from twenty to forty per cent. of the fruits drop off when nearly ripe. Pinctures are made by these moths and only occasionally fruit-flies lay eggs in the wounds so caused. Fruit-flies do not harm oranges in Poona to any extent, as out of several hundred fruits examined only a few were found to contain fly maggots.

Perhaps oil of bergamot might be used to attract these moths. Dr. Gough.

At Nagpur we tried spraying the trees with phenyle as a deterrent Mr. Khare. but I am not sanguine of the results.

What is the nature of the injury caused?

Mr. Ramakrishna

Ayyar.

The moths probably inoculate some bacillus whilst sucking the fruit Mr. Ramrao. and this sets up fermentation from the point of puncture and this extends right up to the stalk, so that the fruit drops down within three days of the puncture.

Uninjured fruits also drop down. There is some relation between Mr. Kunhi Kannan. the watering of the orange plants and the falling of the fruits.

I have not been able to find the caterpillars so that I do not know Mr. Ramrao. where the moths come from.

The caterpillar feeds on jungle creepers and is not easy to find, as a Mr. Fletcher. rule. I doubt whether much can be done to check it in the larval stage.

Similar fruit-piereing moths have been noted in Sonth Africa. Did you ever come across any when you were in South Africa, Dr. Gough?

No; I never heard of any there.

Dr. Gough.

$$
\text { Calpe ophideroides, Guen. }
$$

Hmpsn., F. I., II, 564, Entl. Note 64; Proc. Second Entl. lleeting, pp. 240-250.

Has been recarded as a destructive pest of nectarines and peaches Mir. Fieicher. in the Kumaon Government Gardens, the moths piereing and sucking the fruit in exactly the same way as in the case of $O$. fullonica. 
Raparna nebulosa, Mo.

Hmpsn., F. I., III, 25 ; I. I. L., p. 457 ; Proc. Second EntI. Meeting, p. 80.

Recorded by de Niceville as found abundantly on indigo in Champaran during the rains, but not noted of late years. Perhaps a sporadic pest.

Simplicia robustalis, Guen.

Hmpsn., F. I., III, 36, f. 16 ; S. I. I., p. 395, f. 262.

Widely distributed thronghont India, Burma and Ceylon. Not a pest of growing crops, the larva feeding on dry vegetable matter, but it occasionally does some damage to house-thatching and may also attack crops (e.g., cholam) if stacked after harvést. Has been reared at Pusa on rice and on dry leaves of sissu (Dalbergia sissu), at Coimbatore on roof-thatching, and at Baddagama (Ceylon) on dry tea-prunings.

Nodaria externalis, Guen.

Hmpsn., F. I., III, 56.

Has been reared at Pusa from larvæ on rice leãves. Not a pest.

Hyblace puera, Cram.

S. I. I., p. 392 , f. 258.

A serious pest of teak (Tectona grandis) in all teak-growing districts. Ha; also been seared on Millingtonia a Bombay and Kodanur (Kurnul District, Madras).

\section{LYMANTRIAD压.}

Orgyia postica, Wlk.

S. I. I., pp. 395-396, f. 263 ; Proc. Second Entl. Meeting, pp. 77, 87.

Occurs throughout India except the North-West. The larva is polyphagous and has been found at Coimbatore on castor and Erythina. indica and at Pollibetta (Coorg) on Erythrina lithosperma and geranium. Also recorded on rose (B. J. XIII, 412). A sporadic minor pest of the plants mentioned.

Mir. Ramakrishna Ayyar.

It damages castor at Coimbatore. We have done a coloured plate. showing its life history [exhibited]. 
Latia devestita, Mlk.

Hnipsil., F. I., I, 441.

Has been reared at Pusa in small numbers from larve found on Mr. Fletcher sugarcane and Guinea-grass. Not a pest.

Thiacidas postica, Wik.

Hmpsn., F. I., I, 445-446, f. 307 ; I. I. L., p. 459, f. 313 : B. J. XVI, 199 [lanva]; Proc. Second Entl. Meeting, p. 253.

Occurs throughont India and Burma. The larva is common on Zisyphus but is scarcely a pest. Our examples axe from Pusa. Bilaspur and Coimbatore.

Dasychira horsfeldi, Saund.

Hmpsn., F. I. I, 448, f. 309 ; B. J., XIII, 414 [larra].

Occurs throughout India, Burma and Ceylon. The larva feeds on tea and sometimes becomes a pest in the Tea Districts. One specimen reared from apple leaf (withont locality).

Dasychira mendosa, $\mathrm{Hb}$.

S. I. I., p. 396, f. 264 ; Proc. Second Entl. Meeting, pp. 21, 28, 87.

Widely distributed throughout India, Burma and Ceylon. The larra is polyphagous. Our records show the following localities and foodplants :-

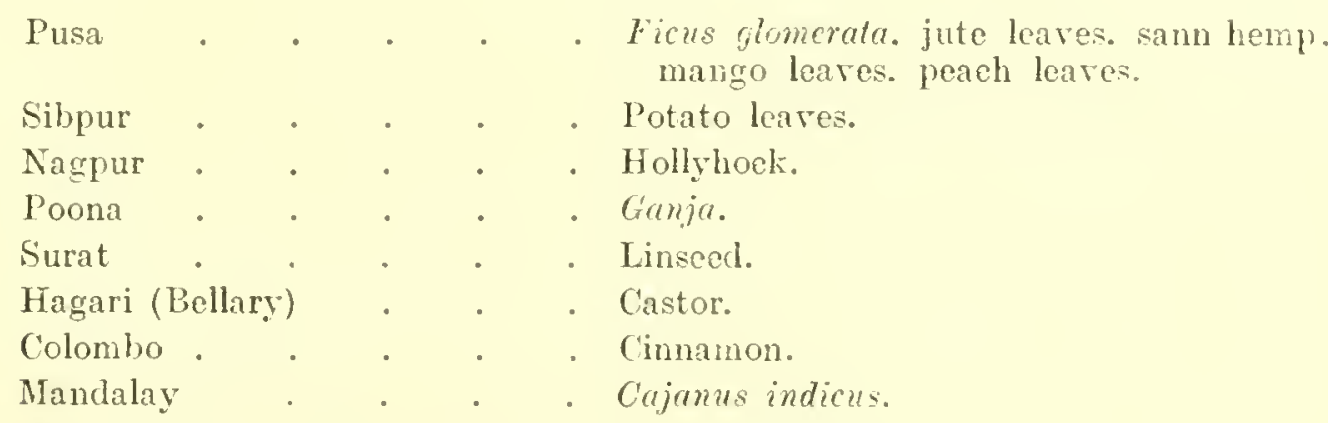

Also recorded from coffce in Southern India and on Teimina'ia catappa by de Niceville.

A minor pest, of little importance, as a rule. The larva can be handpicked.

In this case probably at least four species are mixed up under the Mr. Senior-White name mendosa. The foodplants and larvæ differ in the various forms.

That is quite possibly the casc. There may be several species mixed Mr. Fletcher. up under mendosa. 
Dasychira securis, $\mathrm{Hb}$.

S. I. I., p. 397, f. 265; Proc. Second Entl. Meeting, pp. 148, 163 (tab.), 179, 195, 199, 204.

Oceurs thronghout India and Burma as a minor pest of cereals and sugarcane. Kobus has also reeorded it as a pest of sugareane in Java and described and figured the life history (Tijds. voor Entom. XXXIX, 121-125, t. 4, ff. 1-7 (1896) ). The Pusa Collection contains examples from the following localities and foodplants:-

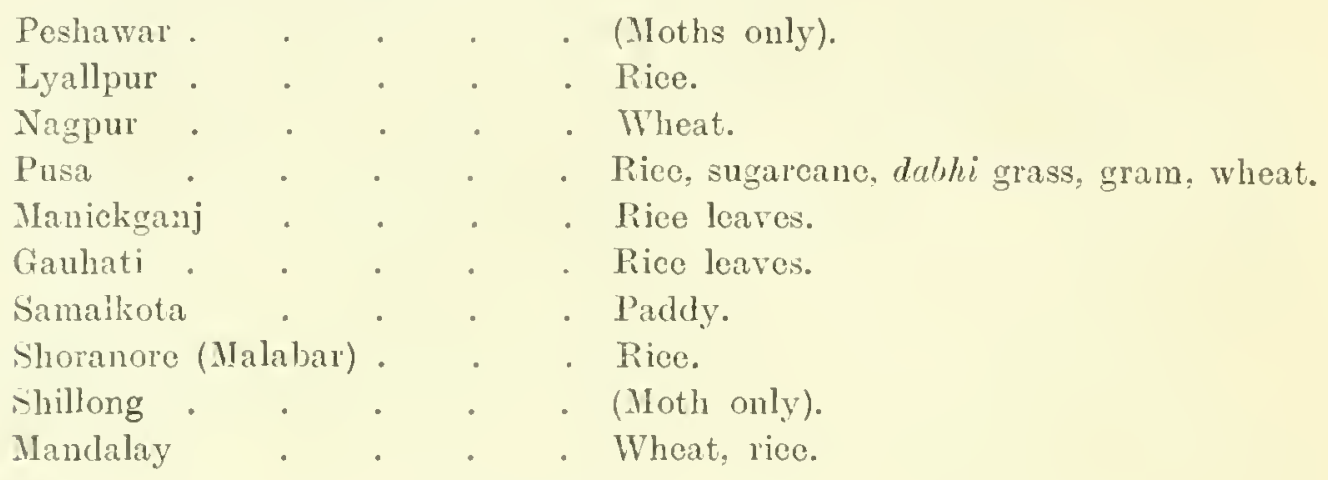

The larva may be hand-picked.

In Travancore $D$. securis has been reared on gram.

\section{Dasychira sp.}

This is an mnidentified species which was reared from larvæ found on apple leaves at Jeolikote by Mr. N. Gill. I do not know how far it is a pest.

\section{Lymantria obfuscata, Wlk.}

Hmpsn., F. I., I, 460-461.

Specimens (in poor condition but probably of this species) were received in July 1916 from the Director of Agriculture, Kashmir, the larvæ being stated to damage apple, apricot, poplar and willow. The larvæ rest during the day time in cracks and holes in the trunks of the trees on which they are feeding and may be sought ont and killed off. Artifieial hiding places may also be provided by placing bands of sacking, etc., on the trees affeeted

\section{Lymentria beatrix, Stoll}

Hmpsn., F. I., I, 463-464; Proe. Seeond Entl. Meeting, p. 218.

Oeeurs throughout India and Ceylon. The larva has been found feeding on mango at Poona and Pusa, but cannot be eonsidered a pest.

At Poona I have found the larvæ feeding on mango flowers.

Mr. Ramrao. 


\section{Lymantria concolor.}

We have moths from Turzm and Shillong. It is probably this Mr. Fleicber. species whose larvæ occur on apple at Shillong. The Jarvie are at present under rearing. January 1919, from eggs laid by a female caught at Shillong.

\section{Euproctis latifascia, Wlk. \\ Hmpsn., F. I., I, 472.}

The larva has been recorded as found on tea (B. J. XIII, 420). The species occurs all along the Himalayan region, from Kashmir to Manipur.

$$
\begin{gathered}
\text { Euproctis subfasciuta, Wlk. } \\
\text { Hmpsn., F. I., I, } 472 .
\end{gathered}
$$

Has been reared at Pusa in small numbers from larre found on castor leaves; also once from a larva on Tropcolum. Not yet noted in d-structive numbers.

\section{Euproctis Tunata, Whi.}

Hmpsn., F. I., I, 472-473; Proc. Second Entl. Meeting. p. 218.

Occurs throughout India and Ceylon. Our records show the following localities and foodplants:-

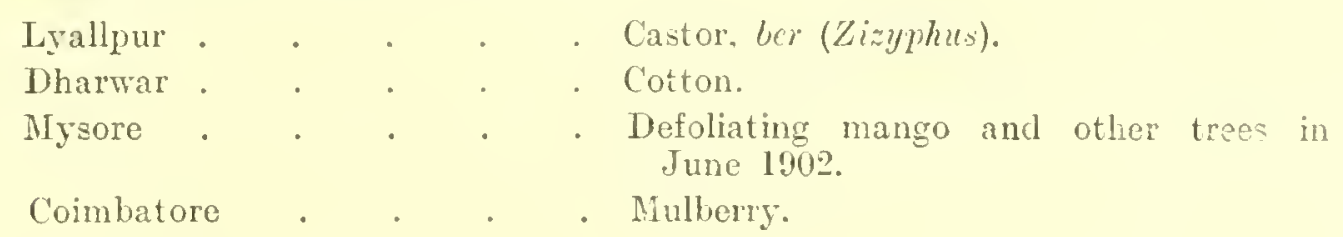

Usually a very minor pest.

$$
\text { Euproctis fraterna, Mo. }
$$

S. I. I., pp. 398-399, ff. 266, 267 ; Proc. Second Entl. Meeting, pp. 87, 102, 23:2.

Occurs throughout India, Burma and Ceylon. The Pusa Collection contains examples from the following localities and foodplants:-

$$
\begin{aligned}
& \text { Peshawar . . . Pear. } \\
& \text { Lyallpur . . . . Castor, cotton. rose. } \\
& \text { Poona . . . Rose, cotton. } \\
& \text { Dharwar . . . . Castor. } \\
& \text { Coimbatore . . . . Tylophora asthmatica. }
\end{aligned}
$$

A sporadic major pest of castor. 
IIIr. Ramakrishna Ayyar.

Mr. Senior-White.

Mr. Fletcher.

Mr. Pillay.

Mr. Senicr-White.
We have had a coloured plate done showing the life-history. [Exlibited.]

In Ceylon it is found on Rutacere and does some damage to various species of Citrus, but it prefer's Feronia elephantum.

We have not found it on Citrus in India. This seems to be another case of a difference in locality meaning a difference in food, with the implication that we mày not really be dealing with the same species of insect.

In Travancore we find it on sunflower, castor, plantain, croton, and Vigna catjang.

With us the larvx prefer Feronia and, if these trees be planted in orange gardens, damage to oranges will be reduced.

\section{Euproctis scintillans, Wlk.}

S. I. I., p. 399, f. 268 Proc. Second Entl. Meeting, pp. 68, 87, 90, 126, 221 ; Andrews, Q. J. Ind. Tea Assocn., 1918, pp. $31-32$.

Occurs throughout India, Burma and Ceylon as a sporadic minor pest of linseed. The larva is, however, polyphagous and has been reared at Pusa on linseed, castor leaves, Loranthus leaves, cowpea leaves, til (Sesamum indicum) leaves, pumpkin leaves, pomegranate and Ficus bengalensis; at Jerruck (Sind) on babul (Acacia arabica); at Nagpur on linseed; on leaves of Cassia fistula at Tocklai (Assam) in June; at Poona on charli (Vigna catjang) and bajri; at Saidapet on mango, at Shillong on apple, and at Coimbatore on jute.

The larra may be hand-picked.

It is found throughout the Ratnagiri district feeding on mango flowers.

It is found on castor on Gujarat.

\section{Porthesia xanthorhaa, Koll.}

İmpsin., I. 1., I, 485, f. 322 ; I. I. L., pp. 460-161; Proc. Second Entl. Meeting, p. 204.

Occur's throughout India, Burma and Ceylon, and in Java. It is often abundant but does not seem to do much damage as a rule. Has been reared at Nagpur on castor and cholui, and at Pusa on castor, Sorghum, grass, and marua (Eleusine coracana) ear-head. Lefroy also gives sugarcane, bajra: juar and Guinea-grass as foodplants. 


\section{Perina nuda, $\mathrm{Fb}$.}

Hmpsn., F. I.. I., 4S6, f. 323 ; I. M. N., IV, 14 [larva]; Proc. Second Entl. Heeting, p. 251.

Occurs throughont India and Ceylon, and in China. The larva is sometimes found in small numbers on leaves of mango, Ficus and Arto. culpus integrifolia but is scarcely a pest.

\section{HYPSID 玉.}

Hypsa complana, Wlk.

Hmpsn., F. I., I, 500-501.

Has been reared at Coimbatore from larva on Ficus glomerata and may occasionally be a pest of other species of Ficus. We have it from Kotmalie (Ceylon), Chapra and Darjiling. It occurs throughout India (except North-West), Burma and Cey!on.

\section{Hupsa alciphron, Cram.}

Hmpsn., F. I., I, 502-503 ; I. I. L., t. 39, f̂. 3, 4 .

Occurs throughout India, Buma and Ceylon, the larve feeding on various species of Ficus. A minor pest of Ficus carica in Bihar and has been reared at Pusa on $F$. bengalensis and $F$. glomerata and at Abbottabad on wild fig leaves.

Hypsa ficus, $\mathrm{Fb}$.

S. I. I., p. 400, f. 269.

Occurs throughout India and Ceylon. The larva feeds on Ficus-spp. and may sometimes strip even large fig-trees (see South Indian Insects, fig. 57). Not yet noted as a pest of cultivated figs but is likely to occur thereon. Our records are from :--

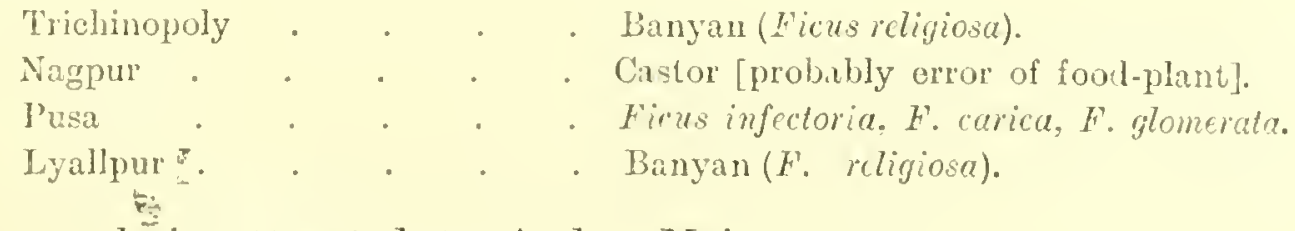

The moth is attracted to Andres-Haire traps. 


\section{Argina argus, Koll.}

Hmpsn., F. I., II, 51 ; I. I. L., p. 463, t. 39, ff. 8, 9 ; Proc. Ent]. Meeting, p. 68 ; Andrews, Q. J. Ind. Tea Assoen., 1918, 30-31.

Occurs throughout Inda and Ceylon. The larva is occasionally found on pods of sann-hemp (Crotalaria juncea) but is scarcely a pest. Also boring in pods of Crotalaria sericea in April and on leaves on $C$. striata and $C$. sp. in May-June at Tocklai (Assam).

Mr. Ramrao.

IIIr. Ramakrishna Ayyar.

IrI. Fletcher.

\section{Argina syringa, Cram.}

S. I. I., p. 401, f. 271 ; Proe. Second Entl. Meeting, p. 68.

Occurs principally in Sonthern India and Bombay as a minor pest of sann-hemp, occasionally abundant. Stated to be a serious pest every year around Poona where samn-hemp is grown as a green-manure crop.

Argina syringa is a serious pest of samn-hemp in the Decean, where it takes the place of Utetheisa pulchella. We also find A. cribraria on sann-hemp, but our worst pest is $A$. syringa.

In Madras we get all the three speeies of Argina but none of these approaches Utetheisa in the extent of the damage done.

We do not get $S$. syringa at all at Pusa and our collection is very poor in material of this species. Perhaps some of your may remember that when you next find it abundantly.

\section{Argina cribraria. Clerek.}

S. I. I., pp. 400-401, f. 270 ; Proc. Second Entl. Neeting, p1. 67, 71 ; Andrews, Q. J. Ind. Tea Assocn., 1918, 31.

Occurs throughont India, Burma and Ceylon as a serious pest of sann-limm, the larva derouring the pods and leaves. We have it from Coimbatore, Poona, Bassein Fort (Bombay), Surat, Balaghat (C. P.), Gorakhpur and Pusa-in all cases reared on sann-hemp. Attacking leaves of Crotalaria sericen at Tocklai (Assam).

Mir. Ghosh.

At Pusa Argina cribraria is a pest of samn-hemp, but inferior to Utetheisa pulchella.

Mr. P. C. Sen.

It was found bad on atashi (Crialaita sp.) grown for seed last year. Hand-piéking was found useful to eheck it.

The life-history has been worked ont at Pusa and is shown on a coloured plate [exhibitsd]. 
Sphinginæ.

Herse convolvuli, Limn.

S. I. I., pp. 401-402, f. 272 ; Proc. Second Entl. Mceting, pp. 51, 291 (tab.) ; Roths. and Jord., Rev. Sphing, pp. 11-15.

Occurs throughout India, Burma and Ceylon. A minor pest as a mule, occasionally in large numbers on sweet potato and pulses. Our records include the following localities and foodplants:-

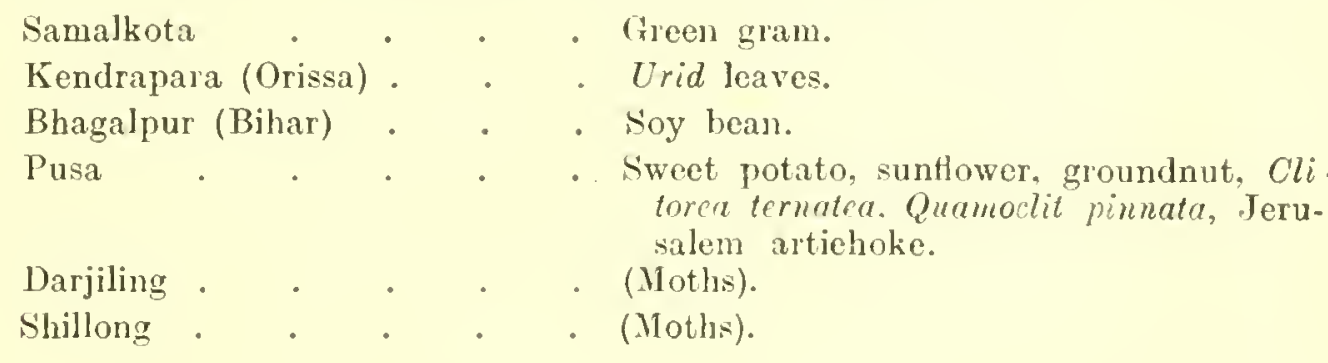

Acherontia lachesis, Fb.

Hmpsn., F. I., I, 67-68; Roths. and Jord., Rev. Sphing, pp. 17-18; Proc. Second Entl. Meeting, p. 77.

Occurs throughout India, Burma and Ceylon, but more common in the Hills where it tends to replace $A$. styx. The moth is sometimes found in bee-hives, robbing honey.

The larva may be a pest of Erythrina where this is grown for greenmanure or shade (as amongst tea and coffee). In such cases the larvæ may be hand-picked.

\section{Acherontia styx, Westw.}

S. I. I., p. 402, t. 24 ; Proc. Second Entl. Meeting, pp. 55, 81 . 287 ; Roths. and Jord., Rev. Sphing, pp. 21-23.

Occurs throughout the Plains of India, Burma and Ceylon. The moth is often found in bee-hives, robbing honey and disturbing the bees. The larva is a minor pest of Sesamum indicum (til; gingelly), brinjal and lablab. The Pusa Collection contains examples from the following localities and foodplants:-

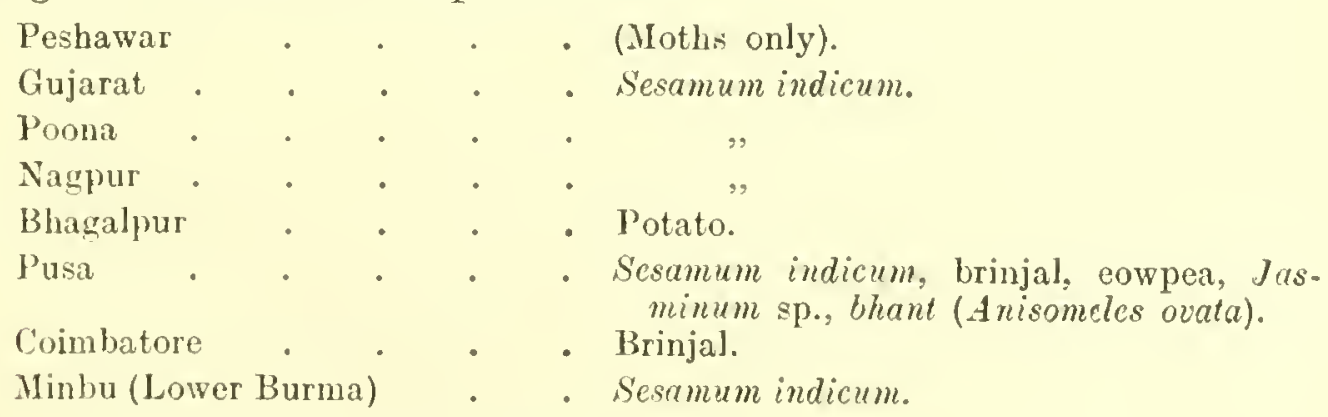

The larve may usually be hand-picked. 
Oxyambulyx sericeipennis, Butl. (Plate 2, fig. 1.)

Roths. and Jord., Rev. Sphing, pp. 195-196, t. 9, f. 2.

At Shillong the larva occurs in July on walnut (cultivated) in some numbers, but each larva defoliates considerably, so that the damage may be fairly considerable in the case of young trees.

The larva is shown in the accompanying photographs and the larva, pupa and moth on a coloured plate [exhibited].

\section{Leucophlebia lineata, Westw.}

Hmpsn., F. I., I, 74-75, f. 46 ; Entl. Note 65 ; Proc. Secondi Entl. Meeting, p. 149 ; Roths. and Jord., Rev. Sphing, pp. 230-231.

Occurs in the Plains of Southern and North-Eastern India, Burma and Ceylon. The larva has been reared on sugarcane but has not been noted to do any damage in India.

\section{Polyptychus dentatus, Crr.}

Roths. and Jord., Rev. Sphing, pp. 240-241.

Recorded by Rothschild and Jordan from Ceylon and South India, as far north as Karachi and Caleutta; the larva on Cordia sebistena.

At Coimbatore the larvæ have been found on Cordia subcorda'a.

[Mr. T. V. Ramakrishna Ayyar read a paper on this species, which is. printed separately.]

\section{Cephonodes picus, Cram.}

Hmpsn., B. J. XV, 645; Roths. and Jord., Rev. Sphing, pp. $469-470$.

Apparently confined to Ceylon and Southern India. The larva occurs on coffee but is not a pest.

We have examples from Ceylon (Trincomali and Diyatalawa), Coimbatore, Nellikuppam, and Bilaspur.

$$
\text { Deilephila nerii, Linn. }
$$

S. I. I., pp. 403-404, ff. 273, 274 ; Proc. Second Entl. Meeting, p. 267; Roths. and Jord., Rev. Sphing, pp. 507-509.

Occurs throughout India and Ceylon as a minor pest of ornamental oleanders. Also reared at Nagpur on Jasminum sambac and at Pusa on Tabernamontana wallichii. 
Deilephila hypothous, $\mathrm{Cr}$.

Roths. and Jord., Rev. Sphing, pp. 509-510.

Occurs throughout India and Ceylon. The larva sometimes does considerable damage to Cinchona, stripping the leaves.

We have specimens from Darjiling.

\section{Hippotion celerio, Linn.}

Hmpsn., F. I., I, 87 ; Roths. and Jord., Rev. Sphing, pp. 751-753 ; Proc. Second Entl. Meeting, pp. 235, 297.

A minor pest of the grape-vine in most parts of India. Has also been reared at Pusa on a wild Vitis and on Beta vulgaris, and at Poona was found in October 1916 feeding on the leaves of Rumex vicicarius (a vegetuble grown extensively for the Bombay markets).

In Egypt it is a minor pes: of cotton.

In India we do not know it on cotton at all.

Dr. Gough.

Mr. Fletcher:

Hippotion echeclus, Boisd.

Roths. and Jord., Rev. Sphing, pp. 754-755.

Charocampa eson; Hmpsn., F. I., I, 85; B. J. XVI, 142.

Stated to be found on til (Sesamum indicum) as a minor pest in the Central Provinces. Not otherwise known as a pest in India.

\section{Theretra gnoma, Fb.}

Hmpsn., B. J. XVI, 145 ; Proc. Second Entl. Meeting, p. 298 ; Roths. and Jord., Rev. Sphing, p. 770.

Has been reared at Pusa and Poona on leaves of 'Elephant's foot,' to which it is stated to do considerable damage at Poona. Also found on grape-vine at $\mathrm{Pusa}$ and Jeolikote, and is a regular feeder on vine.

\section{Theretra alecto, Linn.}

Hmpsn., F. I., I, 85, B. J. XVI, 145; Proc. Second Entl. Meeting, p. 335 ; Roths. and Jord., Rev. Sphing, pp. 776778 ; Scott, B. J., XXVI, 299-300 (1918) [Early stages].

Has been reared at Pusa on grape-vine, a wild Vitis, and on Boerhaavia, but is not known to be a pest.

Eggs and larre were found on cultivated vine at Rac Bareli (United Provinces) at the end of October and in November 1917 by Captain F. B. Scott. (B. J., XXVI 299-300.) 
Theretra oldenlandice, $\mathrm{Fb}$.

Roths. and Jord., Rev. Sphing, pp. 781-783; Proc. Second Entl. Meeting, p. 268.

Has been reared at Pusa on balsam, a wild Vitis, sweet potato and bansal (Ariesema tortuosum). A pest of Balsamifera impatiens in Bihar.

We have it from Abbottabad, Pusa, Darjiling.

Theretra pallicosta, Wlk.

R. and J., Rev. Sphing, p. 788.

Recorded from Ceylon to Burma and Hongkong by Rothschild and Jordan.

Major F. C. Fraser informs me that this species is common in every vineyard in Sind, the larva feeding on leaves of grape-vine, of which it is a decided pest.

It has, however, never been reported as a pest.

Rhyncolaba acteus, Cram.

Roths. and Jord., Rev. Sphing, pp. 789-790; Proc. Second Entl. Meeting, p. 298. Theretra actoa; Hmpsn.; F. I., I, 100, B. J. XVI, 147.

The larva is recorded (B. J. XI, 415) to feed on Colocasia but is not known as a pest of cultivated plants. We have it from Pusa, bred from larvæ on Chakirt, Commelina bengalensis and Pythonessa wallichii.

Mr. Senior-White.

Mr. Fletcher.
In Ceylon the larva attacks varieties of Caladium and unfortunately prefers the best kinds. It is parasitized by a Tachinid.

\section{Rhagastis albomarginatus, R. \& J.}

Roths. and Jordan, Rev. Sphing, p. 798, t. 14, f. 8.

At Shillong the larva is a serious pest of Hydrangea, often completely defoliating the plants. Pupation in a slight cell of net-like silk threads. There seem to be two broods of larvæ, in June-July and SeptemberOctober.

We also have a moth in the Pusa Collection from Turzum, Darjiling.

\section{[Undetermined Sphingid.]* (Plate 2, fig. 2).}

At Shillong, the larva is a serious pest of apple, and to a less extent of pear, about the end of June. It does considerable damage, as the larvæ are not easy to see in spite of their size, and one larva will strip

\footnotetext{
* This species has since been deternined as Langia zenzeroides, Mo.-Editor.
} 


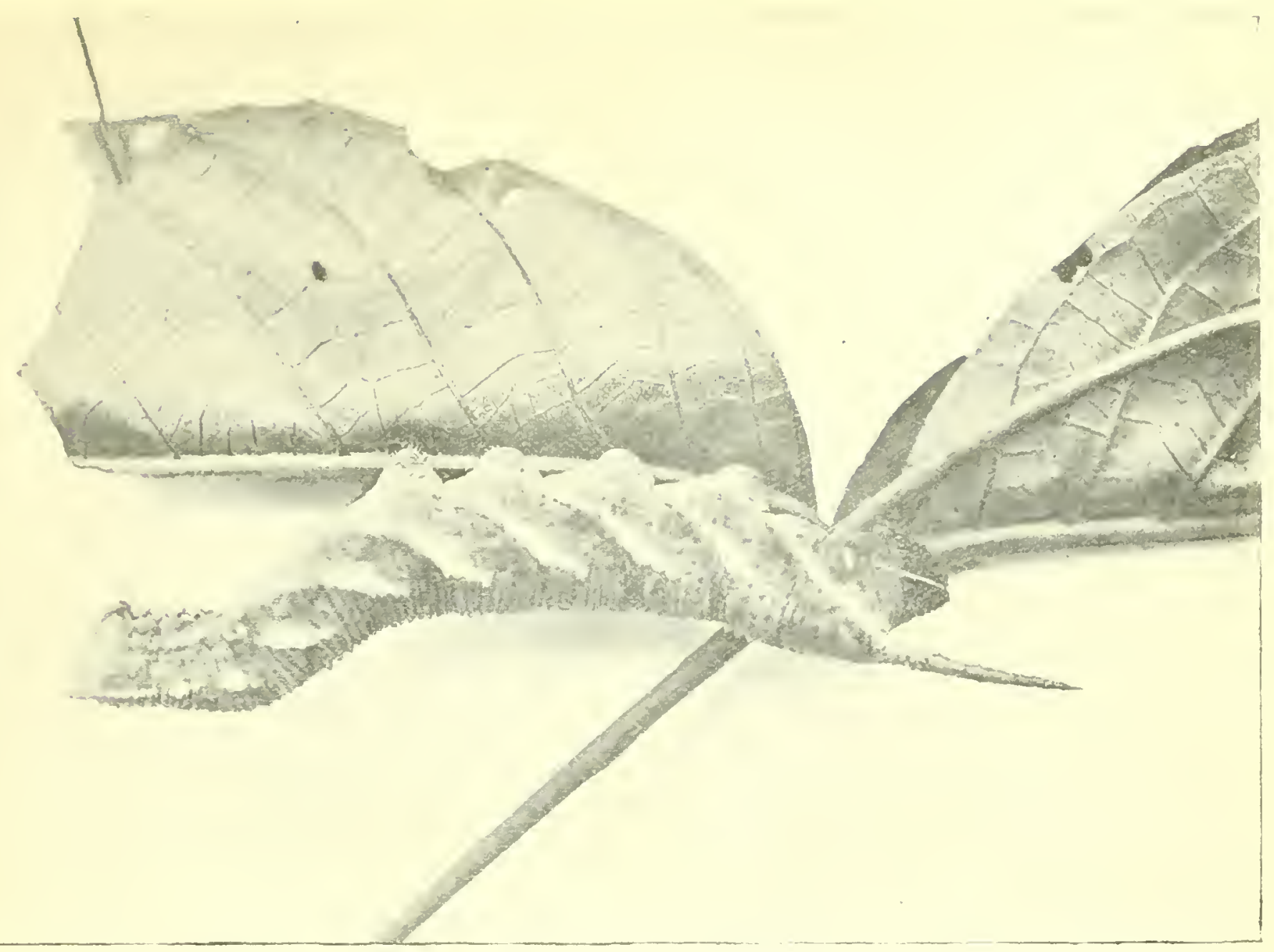

Fig. 1.-Larva of oxyambulyx se'je'cipemis on walnut at Sñillong.

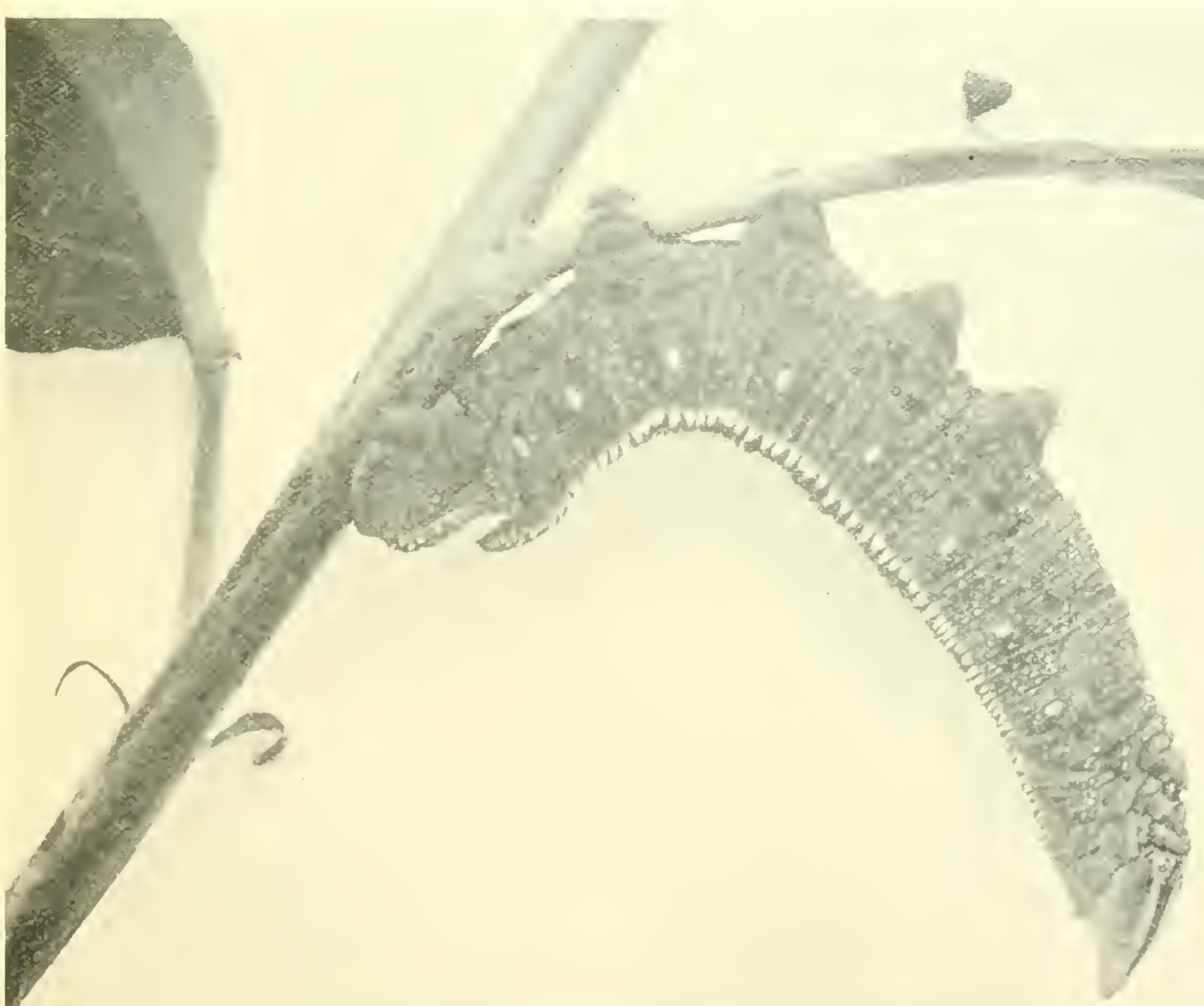

Fig. 2. - Sphingid (Lungia zenzeroides) larva on apple at Shillong. 




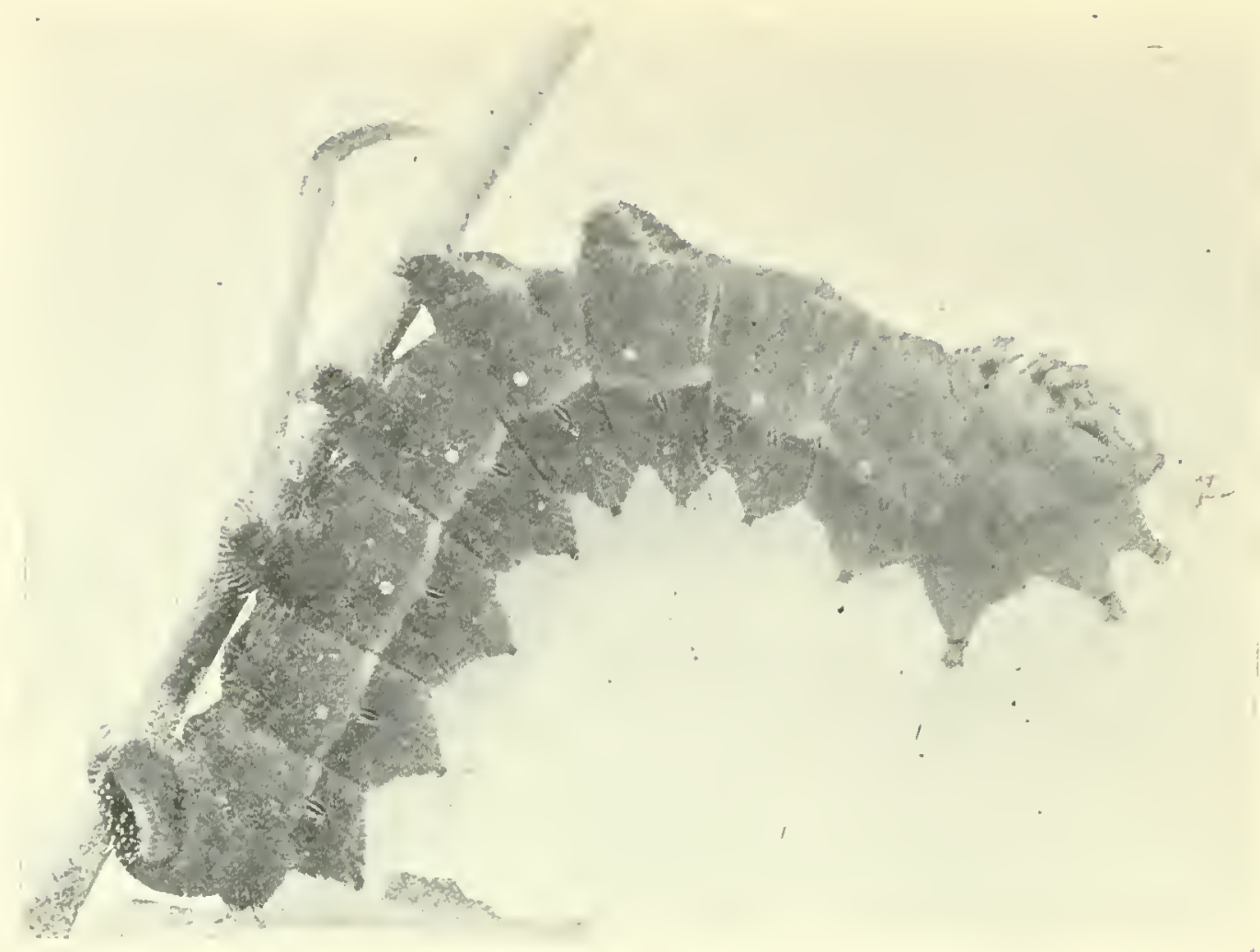

Fig. 1.-Larva of lefires seleme.

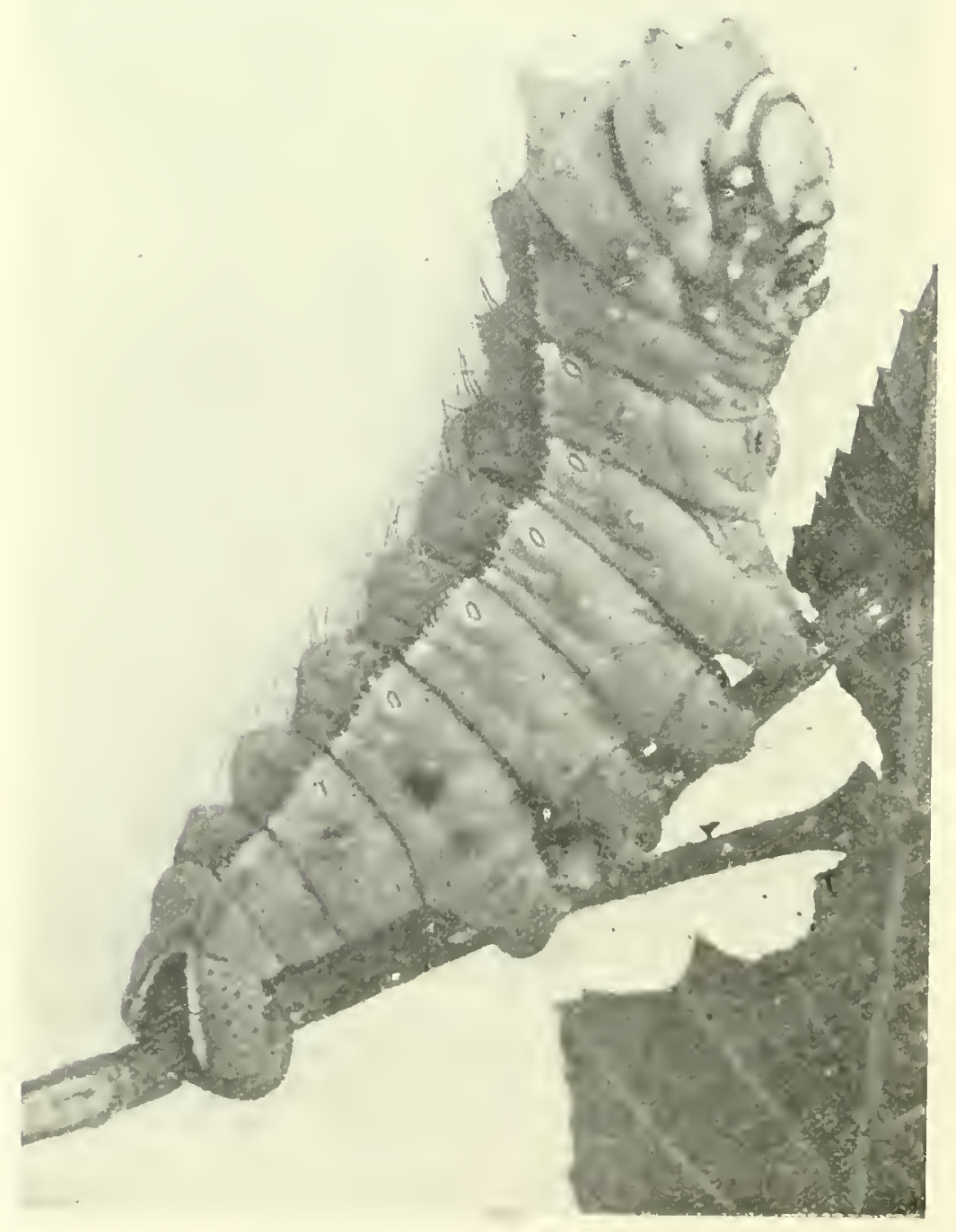

Fig. 2.-Laiva of Amlherade mollei. 
a whole branch of leaves. Pupation probably takes place under dead leaves in natural conditions; no cocoon is formed and larve refused to enter soil. There is only one brood annually, the pupæ hibernating. Larvæ (in spirit) have been sent in as infesting apple at Kulu also.

The moth has not been reared out as yet.

\section{Eupterotida}

\section{Eupterote mollifera, WIk.}

S. I. I., pp. 404-405, f. 275 ; Proc. Second Entl. Neeting, p. 299.

A pest of Moringa pterygosperma at Coimbatore and Chingleput. The larvæ may be bunt off when clustered on the tree-trunk during the day time.

\section{Eupterote geminata, W1k.}

Hmpsn., F. I., I, 60 ; Proc. Second Entl. Meeting, p. 163.

The larvæ occurred in destructive numbers on Hibiscus rosa-sinensis at Peradeniya in March 1902. It has been reared at Coimbatore on Moringa leaves.

At Matale it is bad on Cajanus indieus and also on young leaves of Mr. Senior-White. caca o.

$$
\text { Nisaga simplex, Wlk. }
$$

$$
\text { Hmpsn., F. I., I., 63, f. 36, B. J. XV, } 630 \text {; I. I. L., p. } 471 .
$$

Occurs in most grassy areas in Western and Central India. Our Mr. Fletcher. examples are from Belgaum, Poona, Pachmarhi, Ranchi and Pusa. The larvæ are found on wild grasses and sometimes occur literally in millions, but seem to do little harm to crops. Occasionally they have been known to invade paddy areas and to do a litt'e damage.

\section{SATURNIADæ.}

Actias selene, $\mathrm{Hb}$. (Plate 3, fig. 1).

S. I. I., p. 405 , f. 276.

Occurs throughout India, Burma and Ceylon, more especially in submontane districts, but it is not very common as a rule. The larva feeds on various shrubby plants and small trees. It is recorded on " wild cherry" (R.J., XI, 242) and has occurred as a pest defoliating Odina wodier at Coimbatore (B.J., XXIII, 792-793); also found on Moringa pterygosperma. At Shillong it occurs on Betula alnoides, apple. pear, walnut, ete. It is a decided pest of apple in the Khasi Hills and Kumaon.

It occurs regularly every year on Odina wodier at Coimbatore. We Mr. Ramakrishna have shown the stages on a coloured plate [exhibited]. 
Anthercea roylei. (Plate 3, fig. 2.)

Hmpsn., F. I. Moths, I, 18 ; B. J., XI, 243.

Ir. Fletcher.

Hampson records this from Masuri, Kangra, Sikkim, and Khasis; larva on "Mahowah," oak and birch.

At Shillong the larva feeds on Betula alnoides and less commonly on apple and pear, when it does some damage by defoliating branches.

Cricula trifenestrata, Helfer.

S. I. I., pp. 405-406, f. 277 ; Proc. Second Entl. Meeting, pp. 218, 255.

Occurs throughout Sonthern and North-Eastern India and in Burma, usually on mango but also on various wild trees (Terminalia, etc.). In Assam it occasionally strays onto tea. In Eastern Bengal it is a serious pest of mango.

The hairs of this caterpillar cause irritation. Hand-picking is consequently out of the question. In Eastern Bengal the people light a bundle of straw and hold it below the leaves on which the caterpillars are feeding gregariously. The caterpillars are crushed when they fall down.

\section{BOMBYCIDÆ.}

Ocinara varians, Wlk.

S. I. I., p. 407, f. 278 ; Proc. Second Entl. Meeting, p. 251.

Occurs throughout India, Burma, and Ceylon as a minor pest of figs (Ficus spp.) of various sorts, sometimes repeatedly stripping every leaf in the case of young trees and so stunting growth.

\section{Andraca bipunctata, Wlk.}

Hmpsn., F. I., I. 40 f. 23 ; Proc. Second Entl. Meeting, p. 21.

Occurs in Assam, Cachar and Sylhet as a serious pest of tea. There are two broods, in January-February and in April-May. The whole of the tea-leaves may be eaten off. The larvæ cluster conspicuously and are easily hand-collected.

\section{NOTODONTID王.}

Dinara combusta, Wlk.

$$
\text { Hmpsn., F. I., I. } 145 \text { [Anticyra]. }
$$

Has been reared at Pusa in small numbers on maize but is not known to be a pest. In Java the larva is common on sugarcane and the life 

TLATE 4.

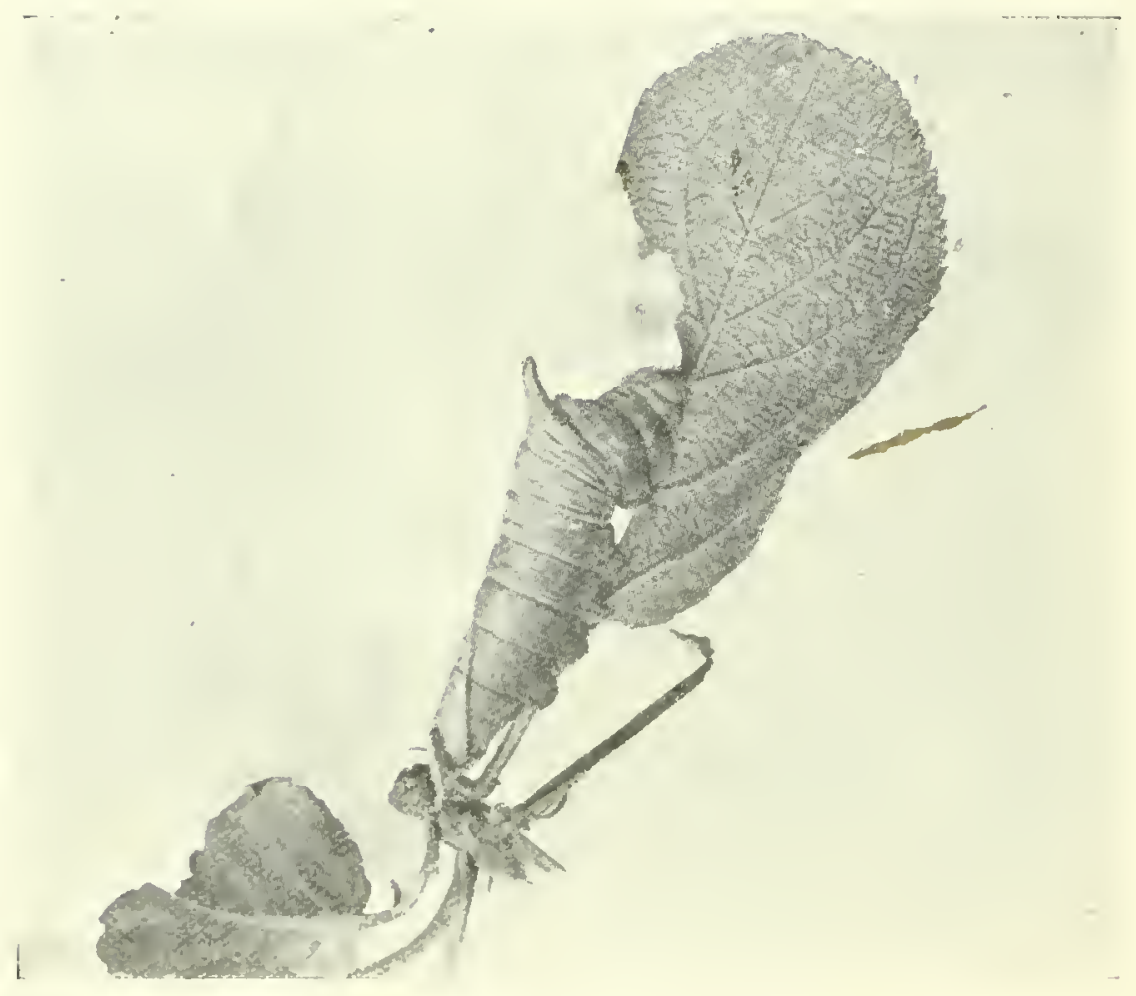

Fig. 1.- Notodontid larva on apple at Shillong. 



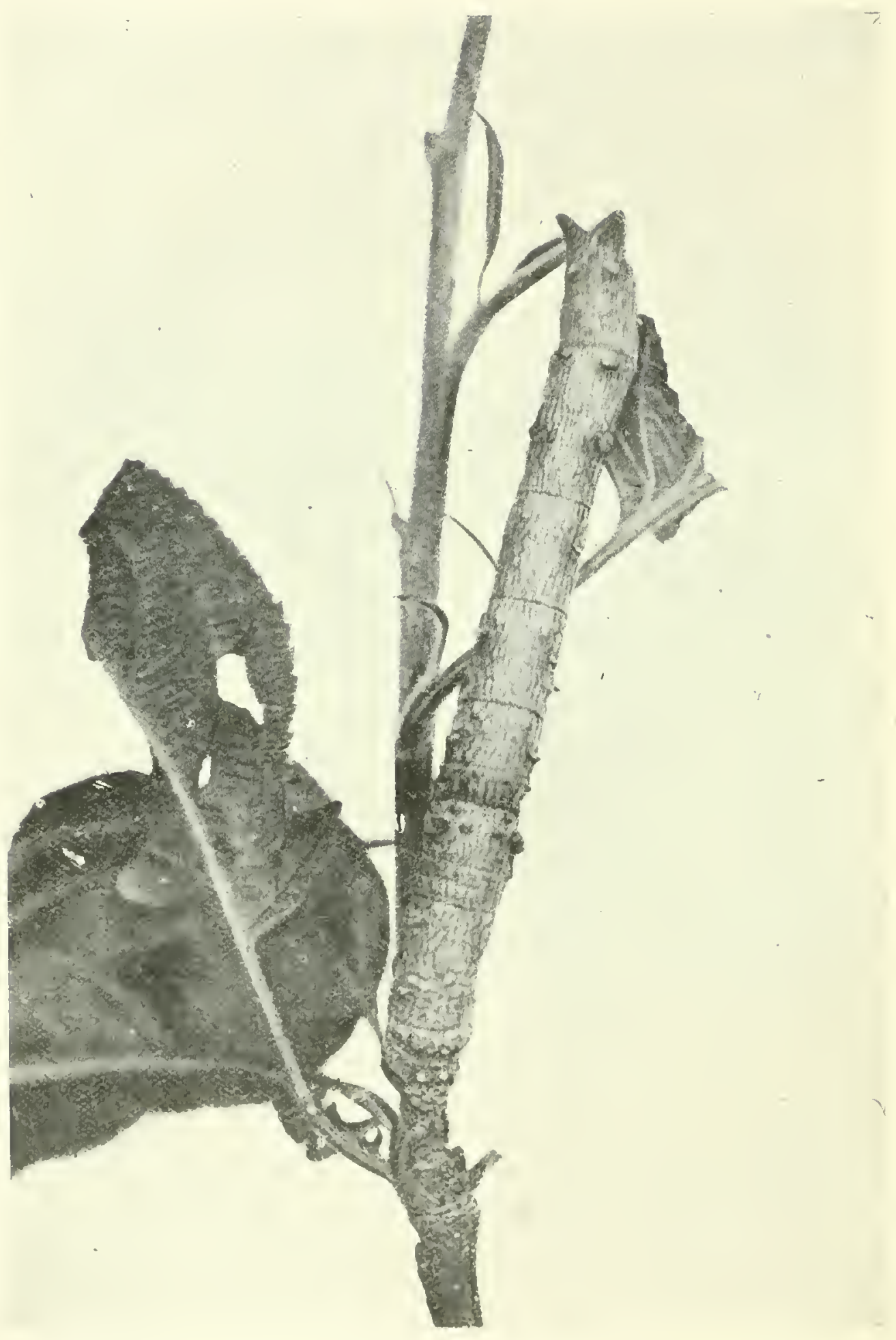

Fig. 2.-Boarmiane (No.2) larva on apple at Shillong. 
history has been described and figured by Kobus (Tijds. voor Ent. XXXIX 125-129 t. $5 \mathrm{ff.} 1-5(1896))$.

\section{Stauropus alternus, Wlk.}

S. I. I., p. 408 ff. 279, 280; Proc. Second Entl. Meeting, pp. $18,42,257,264$.

Cccurs throughout India and Ceylon, but is rather scarce as a rule, odd examples of larvæ being found on Cajunus indieus, tamarind, Trewia mudiflora, tea, rose, etc. It has once occurred in Ceylon on tea in alarming profusion; in Assam only odd specimens are found on tea.

We look on it as a curiosity in Assam.

Mr. Andrews.

\section{(Undetermined Notodontid.) (Plate 4, fig. 1.)}

The larvæ are found at Shillong on apple in small numbers at the Mr. Fletcher. end of June. Pupation takes place in a slight cocoon in which hibernation occurs in pupal state. The larvæ eat the leaves from one side and are very difficult to detect, as their coloration is highly procryptic, resembling a withered edge of the leaf attacked.

The caterpillar is shown in the photographs and colomed sketch [exhibited], but the moth has not emerged as yet.

\section{Geometrid}

\section{(Undetermined Boarmiane.)}

The larvæ of this feed on apple leaves at Shillong in June. They occur in small numbers and this species is scarcely a pest. The moth has not yet been determined but seems to be allied to Hyperythra.

\section{(Undetermined Boarmiane, No. 2.) (Plate 4, fig. 2).}

Another undetermined Boarmiane was found at Shillong, the larva feeding on apple in small numbers, but it does a good deal of damage, as the larvæ are stick-like and large and not easy to see.

\section{Biston suppressaria, Guen.}

S. I. I., p. 409 f. 281 ; Proc. Second Entl. Meeting, p. 18.

Occurs in the 'Tea Districts of Assam, South India and Ceylon, usually as a minor pest of tea and Cassia auriculata. In Assam it is sometimes a serious pest of tea, three broods occurring ; the control-method usually employed is to hand-fork around the base of the bushes in the cold weather to collect the pupæ, and this is stated to be quite successful. 
Mr. Andrews.

Mr. Fletcher.

Mr. Ramrao."

Mr. H. L. Dutt.

Mr. Fletcher.
The moths are killed in Assam as they sit on the bark of trees. Children go round with a long stick and tap the moths and kill them. It is becoming quite a rarity with us now.

\section{Sterrha sacraria, Linn.}

Hampsn., F. I. III, 424, f. 199 ; Proc. Second Entl. Meeting, p. 297.

Occurs commonly throughout the Plains of India. In October 1916 the larvæ were found feeding in large numbers on and destroying the leaves of Rumex vesicarius (a leafy vegetable grown extensively for the Bombay markets) at Poona.

Craspedia defamataria, Wlk.

Hmpsn., F. I. III, 435 ; Proc. Second Entl. Meeting, p. 207.

Occurred at Pusa on lucerne in some numbers in 1906. Not known otherwise as a pest.

Thalassodes quadiaria, Guen.

Hmpsu., F. I. Moths III 507, f. 225.

The larva occurs, usually in small numbers, on mango and Polyalthia longifolia at Pusa.

It occurs on mango at Poona.

I found it in numbers last year on mango at Sabour.

Thalassodes veraria, Gn.

Hmpsn. F. I. Moths. III, 508.

Lefroy, I. I. L., p. 475, f. 325, t. 41, f. 7 [quadraria, nec Gn.]

The larva occurs usually in small numbers on mango, litchi, rose, and Lagerstromia flos-regina at Pusa, where in January 1909 it occurred in large numbers on mango.

This species has hitherto been confused with quadraria, which is the scarcer species of the two at Pusa. They may be distinguished by the colour of the frons, which is green in veraria and red in quadraria.

\section{IJASIOCAMPID $\approx$.}

Taragama siva, Lef.

Hmpsn., F. I., I. 405-406 ; I. I. L., p. 497 , t. 41 ff. 8-11.

Occurs throughout the Plains of India and is a sporadic pest of various. trees It has been reared at Coimbatore on mahogany, when it did. 
PROCELDINGS OF TIE THIRD ENTOMOLOGICAI, MEETING $10 \%$

slight damage to young trees, and at Pusa on Acacia arabica, rose Zizyphus jujuba, Polyalthia longifolia, and Tamarix gallica.

\section{Metanastria hyrtaca, Cram.}

S. I. I., pp. 409-410, f. 282 ; Entl. Note 66 ; Proc. Second Entl. Meeting, pp. 38, 249.

Occurs throughout the Plains of India (except in North-West). The larva is polyphagous and is scarcely a pest as a rule, but occasionally occurs in large numbers, when it strips even large trees. The Pusa Collection contains examples from the following localities and foodplants :-

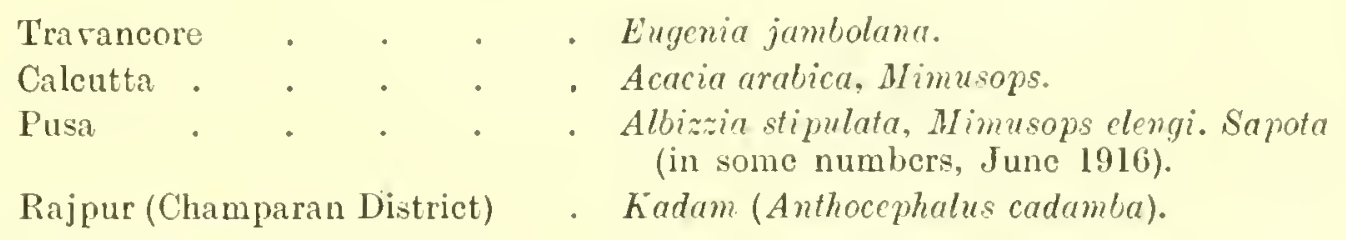

The larva has also been recorded on Schima wallichii (B. J. XIII 407 ).

$$
\text { Trabala vishnu, Lef. }
$$

Hmpsn., F. I., I. 421-422, f. 293 ; I. M. N., V. 107 ; I. I. L., p. 498 t. 46 ; Proc. Second Entl. Meeting, pp. 87, 246.

Occurs throughout India and Burma as a sporadic pest of castor. The larva also feeds on Eugenia jambolana and Tarminalia catappa and has been reared at Pusa on Quisqualis and at Shillong on rose, geranium, and other garden plants.

The egg-clusters and larræ may be hand-picked.

\section{LIMACODID A.}

Natada nararia, Mo.

$$
\text { Hmpsn., F. I., I. 381-382. }
$$

Occurs in Southern India and Ceylon. Recorded by Rutherford on tea in Ceylon (Trop. Agric., July 1914) and at Coimbatore has occurred as a pest on Sideroxylon subsilatum and Pithecolobium dulce. Spraying with Lead Arsenate was found successful at Coimbatore.

$$
\text { Nalada velutina, Koll. }
$$

I. I. L., p. 500 f. 335 ; Proc. Second Entl. Meeting, p. 218.

The larva sometimes ocçurs on mango but is not a pest. 


\section{Contheyla rolunda, Hmpsn.}

Hmpsn., B. J. XVI, 196 ; Proc. Second Entl. Meeting, pp. $20,259$.

This species, originally described from Kanara, occurred as a pest of coconut in S. Malabar in February and March 1916, the larvæ damaging the foliage and sometimes the flower-shoots and rinds of young nuts. When full-fed, the larva pupates in a small, oval, hard, shell-like cocoon, numbers of which are found on badly attacked tree-fronds. Spraying with Lead Arsenate was tried but found impracticable, and the preventive measures of cutting off first-attacked fronds and the destruction of the shell-like cocoons found on the trees before an outbreak raiyats were suggested and taken $u p$ by the raiyats (Madras Monthly Report for March 1916).

It lias also recently been reported as doing some damage to tea in the Wynaad.

\section{Parasa lepida, Crani.}

S. I. I., pp. 410-411, ff. 283, 284 ; Proc. Second Entl. Meeting, pp. 19, 28, 87, 217, 232, 234, 258, 262, 299.

Occurs throughout India (except North-West) and Ceylon as.a sporadic major pest of mango, Ficus spp., coconut, rose, plantain and various other plants. The young larvæ are gregarious and may be destroyed en masse; later on, they scatter and feed solitarily. The round shelllike coccons are often seen clustered in large numbers on tree-trunks and the enclosed larvæ and pupæ may be destroyed by crushing. Unless the hands and body are covered whilst doing this, an irritation is caused. The larval spines are highly poisonous and the larvæ should not be handled.

Phycita dentilinella was found predaceous on this insect at Coimbatore.

Our records include the following localities and foodplants :-

Mr. Ramakrishna Aysar.

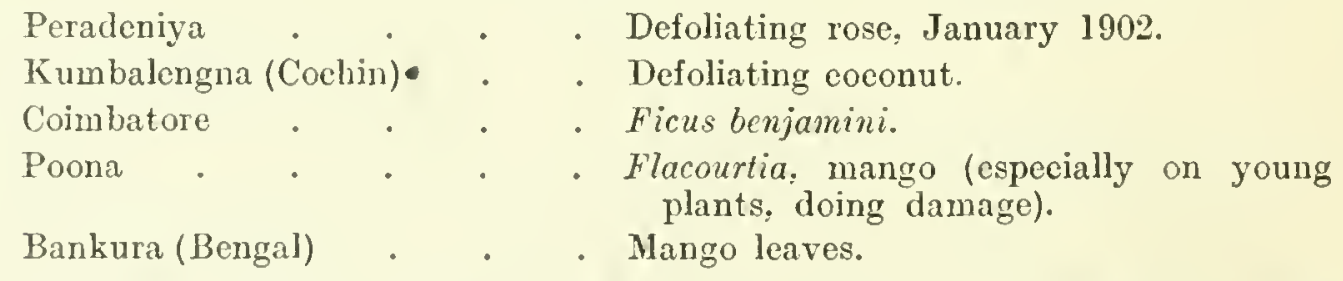

Parcasa lepida is pretty bad on young mango trees in Madras. We have done a coloured plate of it [exhibited].

Altha nivea, Wlk.

S. I. I., pp. 411-412, f. 285 ; Proc. Second Entl. Meeting, p. 87.

Occurs throughout India as a very minor pest of castor. 



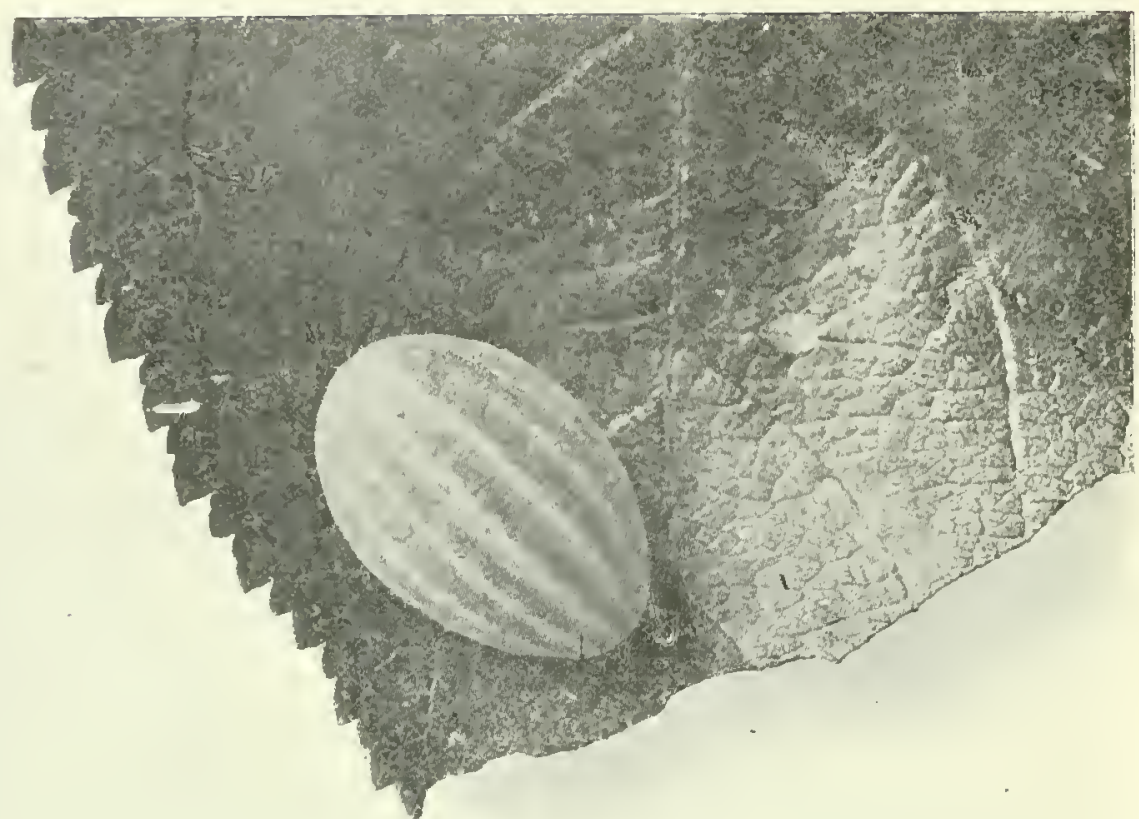

Fig. 1. Ineliplul Iarva on apple at Shillong.

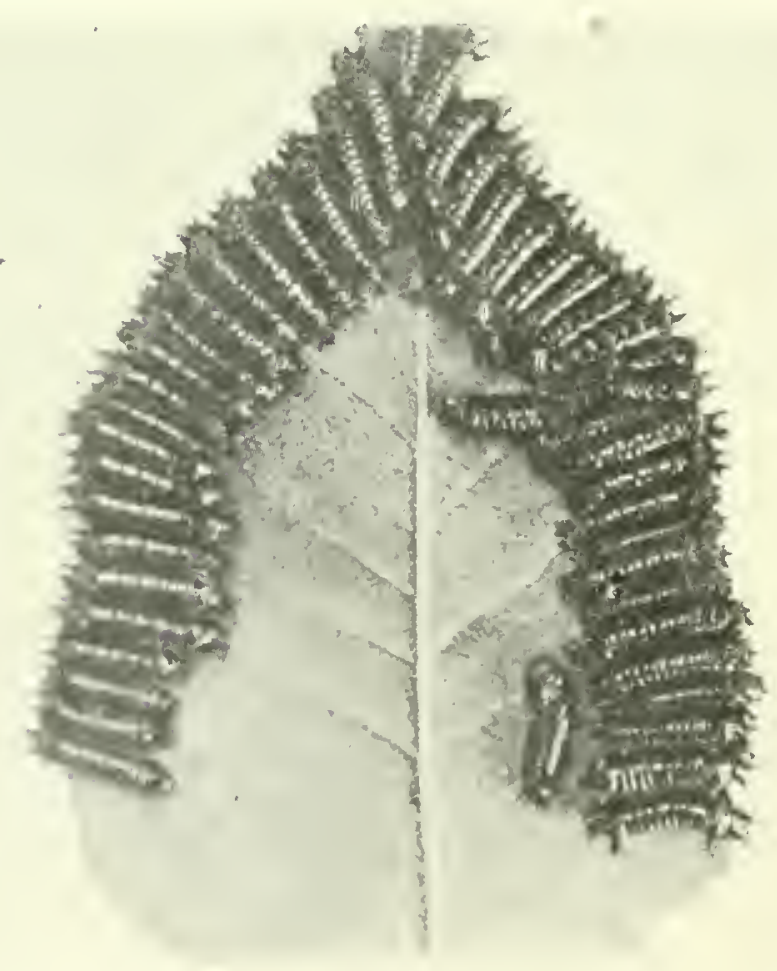

Fig. 2.--Limacodid larva on apple at Shillong. 
Belippa Taleana, Mo. (Plate 5, fig. 1.)

I. I. L., p. j01, t. 28, f. 14 ; Proc. Second Entl. Meeting, p. 28.

The fat slug-like, palc-green, yellow-dotted larva is common on coffee in South Coorg, but is scarcely a pest. Also occurs on apple, pear, walnut and other fruit-trees at Shillong and does slight damage by feeding on the leaves.

In Assam about eighty per cent. of the larvæ are parasitized.

Mr. Andrews.

\section{(Unidentified Limacodid.) (Plate 5, fig. 2.)}

At Shillong in June 1918 the larvæ occurred on apple in some numbers, Mr. Fletcher. but the moth could not be reared out.

Several different species of Limacodids attack apple and other fruittrees in Shillong.

\section{NyMphaldD玉.}

Mycalesis perseus, Fb.

Bingham, F. I., I. 57-58, f. 17 B ; Proc. Second Entl. Meeting, p. 163.

The larva is sometimes found in small numbers on rice at Pusa, but is not a pest.

Mycalesis mineus, Linn.

Bingham, F. I., I. 58-59, f. 17-A, t. 2, f. 8 ; Proc. Second Entl. Meeting, p. 163.

Pupæ have been found at Gauhati on rice-leaves. Not known to be a pest of rice.

\section{Melanitis ismene, Cram.}

S. I. I., p. 412, t. 50, ff. 7-9; Entl. Mem. V, 3-7, t. 1 ; Proc. Second Entl. Meeting, pp. 163, 180.

Occurs throughout India, Burma and Ceylon and is a minor pest of rice. The larvæ are also less commonly found on juar and marua; also on various wild grasses.

In Java the larva is noted, under the name Cyllo leda, by Kobus as found on sugarcane (Tijds. voor. Ent. XXXIX, 129-130, t. 6 ff. 1-5 (1896).

Elymias undularis, Dr.

Moore. Lep. Ind. II, 145-148, t. $133 \mathrm{ff} .1$ (larva), 1 A.C ; Bingham, F. I. Butt. I., 171-172.

This species occurs along the Himalayas from Masuri to Bhutan in Assam, Lower Bengal, C. India, Burma to Malaya. 
Mr. Pillay.

Mr. Fletcher.

The larva feeds on palms, often doing some damage to ornamental: specimens. It is usually extensively parasitized.

Euthalia garuda, Mo.

Bingham, F. I., I. 282-283 ; I. I. L., p. 411, t. 30 ; Proc. Second Entl. Meeting, p. 218.

Occurs throughout India and Burma. We have it from Dehra Dun, Pusa, Rajapatti, Burdwan, Insein and Myitkyina. The larva feeds on leaves of mango, at times in some numbers, but does little damage and cannot be considered a pest.

In Travancore the larva occurs on mango leaves but it is not a pest.

\section{Junonia lemonias, Linn.}

Bingham, F. I., I. 357-358 ; I. I. L., p. 413, f. 283.

Occurs commonly throughout India, Burma and Ceylon. The larva. has been found at Pusa on Sida rhombifolia and at Nagpur on jute, but has not yet been noted as a pest.

\section{Junonia orithyia, Limn.}

Bingham, F. I., I. 358-359.

The larva has been found on sweet pofato on two occasions at Pusa and also at Coimbatore. Also reared on Justicia at Pusa. Not a. pest.

\section{Junonia almana, Linn.}

Bingham, F. I., I. 361-362 ; I. I. L., p. 413, f. 282 ; Proc. Second Entl. Meeting, p. 163.

Occurs throughout India, Burma and Ceylon. Has been reared from larvæ found on rice and on Mimulus gracilis.

Scarcely a pest of paddy as a rule but has been found in la rge numbers destroying rice-fields together with larve of Spodoptera mauritia.

Lallima inachus, Boisd.

Bingham, F. I., I. 395-397, t. 10, f. 76 ; Proc. Second Entl. Mecting, p. 244.

The butterfly is said to suck peach fruits at Pachmarhi, Central. Provinces, but the record seems doubtful. 
Argynnis hyperbius, Johannsen.

Bingham, F. I., Butt. I., 438-440, t. 5, f. 36 ; Proc. Second Entl. Meeting, p. 268.

Occurs throughout N. India (replaced in S. India by castetsi).

Larva on violet and pansy, sometimes doing considerable defoliation to cultivated plants. Found in numbers at Shillong in October 1918, and at Pusa in February 1919 defoliating Viola odora.

\section{Ergolis merione, Cram.}

Bingham, F. I., I. 462-463 ; I. I. L., p. 415, t. 31 ; Entl. Mem. V, 8-15, t. 2 ; Proc. Second Entl. Meeting, p. 87.

The typical form merione occurs throughout the Northern half of India, in Assam and Burma. The larra feeds on castor and as a rule is of very minor importance as a crop-pest, but is often found on isolated self-sown plants which may be almost completely defoliated.

In Southern India and Ceylon it is replaced by the form taprobana, Westw., which has not been noted as a pest of castor.

\section{Telchinia viola, $\mathrm{Fb}$.}

Bingham, F. I., I. 471-472, f. 85 ; I. I. L., p. 415 ; Proc. Second Entl. Meeting, p. 126.

The larva has been found on Hibiscus cannabinus in Bibar as an occasional minor pest. It also feeds on wild Passion-flower (Modecca palmata) and has been reared at Cuttack on mustapat (H. cannabinus).

\section{PAPILIONIDæ.}

\section{Papilio machaon, Linn.}

Bingham, F. I., II, 36-38 f. 6.

The larvæ were found in small numbers on cultivated fennel at Hangu, Kohat District, North-West Frontier Province, in May 1916. Not a pest.

Papilio demoleus, Linn. (erithonius, Cram.).

S. I. I., pp. 412-413, t. 25 ; Entl. Mem. V, 33-48, t. 6 ; Proc. Second Entl. Meeting, pp. 210, 216.

Occurs throughout the Plains of India, Burma and Ceylon. The larva feeds on various species of Citrus and is sometimes a serious pest, stripping the leaves. It has been reared at Pusa on lime, orange, bacl 
(Egle marmelos) Psoralea corylifolia and Murraya Koenigi. The eggs and larvæ may be hand-picked and in small areas catching the butterflies in hand-nets has been found practicable.

Mr. Senior-White.

The larva of Papilio demoleus prefers Feronia elephuntum to species of Citrus.

Mir. Robertson-

Brown.

Papitio demoleus is found to attack Malta orange rather than other varieties in the North-West Frontier Province. Hand-netting of the butterflies has not been found effective at Peshawar.

\section{Papilio helenus, Linn.}

Bingham, F. I., II. 41-43, f. 8 ; Proc. Second Entl. Meeting, p. 210.

Mr. Fietcher.

The race daksha, Hmpsn., which is confined to the Hill Districts of Southern India, is sometimes a serious pest of orange trees in South Coorg (fide Hannyngton). The typical form helenus is also a minor pest. of orange at Shillong.

Davidson and Aitken give $X$ anthoxylon rhetsa as a foodplant.

Papilio memnon, Linn.

Bingham, F. I., II, 47-49, f. 9; Proc. Second Entl. Meeting, p. 210.

Butterflies were observed to be ovipositing on cultivated pomelo trees at Myitkyina, Upper Burma, in September 1914. Probably a very minor pest of Citrus.

\section{Papilio polymnestor, Cram.}

Bingham, F. I., II, 50-51, t. 12, f. 85; Proc. Second Entl. Meeting, p. 210.

The larva is sometimes a serious pest of orange in South Coorg (fide Hannyngton).

Davidson and Aitken give Atalantia sp. and Garcinia xanthochrymus as wild foodplants, but it may be noted that Moore quotes Citrus decumana as the food of the Sinhalese form parinda, Mo.

Mr. Pillay.

Mr. Ramakrishna Ayyar.

Mr. Senior-White.

Mr. Fletcher.

At Quilon Travancore, Papilio polymnestor occurs on orange and Murraya lioenigi.

We have found Papilio polymnestor and P. helenus on wild Citrus trees on the Western Ghats.

\section{Papilio agamemnon.}

In Ceylon Papilio agamemnon occurs on Anona muricata.

The larva is figured by Kershaw (Butt. Hongkong, p. 114 t. 4a ff. 10) who says that in Hongkong it feeds on Uvaria microcarpa and Unona 
discolor (Anonaceæ), Michelia champaca and the eustard apple (Anona reticulata). We have however, no record of its having damaged any cultivated plant in India.]

\section{Papilio polytes, Linn.}

Bingham, F. I., II, 61-63, f. 13 ; Entl. Mem. V, 33-42, 48-52.

t. 7 [pammon]; Proc. Second Entl. Meeting, pp. 210, 216.

Occurs throughout the Plains of India, Burma and Ceylon. The larra feeds on various species of Citrus (orange, lemon, etc.) and is oceasionally a minor pest of cultivated Citrus. It has also been reared at Pusa on Murraya kæenigi.

\section{Pieride.}

Pieris brassicce, Linn.

Bingham, F. I., II, 170-171, f. 43 ; I. I. L., p. 418 ; Agr. Jl. Ind. Jan. 1912, t. 1 ; Entl. Mem. V, 20-26, t. 4 ; Entl. Note 68 ; Proc. Second Entl. Meeting, pp. 9, 269, 279, 282, 284.

Found all along the Himalayan Region from Chitral to Bhutan and Assam, penetrating into the Plains in the winter months in an area about one hundred miles wide and parallel with the Hills, straggling as far South as Cuttack. At Pusa adults appear regularly about Ist February and two or three broods occur in February and March, the butterflies all disappearing by the end of April. At Peshawar the butterflies appear in October and are on the wing and breed until about the end of May.

Our specimens are from Bhagalpur, Pusa, Lyallpur, Akalgarh (Punjab), Peshawar, Abbottabad, and Shillong.

Larva on cabbage, cauliflower, mustard, Tropcolum (nasturtium) and other Cuciferæ. A serious pest of cabbage and cauliflower.

Control:-Hand-picking of the yellow egg-masses and of the young larvæ whilst these are still gregarious.

This year I saw P. brassicce at Laheria Serai on 8th and 9th January Mr. Inglis. 1919.

\section{Pieris canidia, Sparman.}

Bingham, F. I., II, 172-173 ; Proe. Second Entl. Meeting, p. 279.

Occurs commonly in the Hills (Himalayan Region, Southern India, Mr. FletckeiAssam, Upper Burma). We have it from Peshawar, Simla, Ootacamund, Shillong, and Lashio (N. Shan States). 
The larva is said to damage cabbages at Maymyo, Upper Burma, but the record seems doubtful.

\section{Catopsilia pyranthe, Linn.}

S. I. I., p. 413, f. 286 ; Entl. Mem. V, 29-32, t. 5, ff. 7-11; Proc. Second Entl. Meeting, pp. 72, 75, 76.

Occurs throughout India, Assam and Burma, mostly in the Plains. The larva feeds on Cassia fistula. C. tora and C. occidentalis and has been found at Pusa on Sesbania [sp.] flowers.

Scarcely a pest as a rule but may do damage to species of Sesbania and Cassia when these are grown as ornamental or shade trees.

Mr. Andrews.

Mr. Ramakrishna Ayyar.

Mr. Fletcher.
In Assam Catopsilia pyranthe sometimes does considerable damage to Cassia fistula trees, which are planted along roadsides for shade purposes.

We find it in Madras damaging dhaincha which is grown for greenmanure.

$$
\text { Colias hyale, Linn. }
$$

Bingham, F. I., II, 234-235; Proc. Second Entl. Meeting, p. 208.

Said to be an occasional minor pest of clovers (Trifolium spp.) at Peshawar, but there seems to be no exact record.

Colias croceus, Fourcroy, race fieldi, Men.

Bingham, F. I., II, 243-244, t. 15, f. 103 ; Proc. Second Entl. Meeting, p. 208.

Said to have occurred as an occasional minor pest of clovers (Trifolium spp.) at Peshawar, where the butterfly is common in April. The butterfly penetrates into Bihar in the cold weather but is a scarce visitor as a rule.

Terias hecabe, Linn.

S. I. I., p. 414, f. 287 ; Proc. Second Entl. Meeting, pp. 72, (tab), 75, 76, 79 .

Occurs throughout India, Burma and Ceylon. Larva on thaincha, agathi and various species of Sesbania and Cassia. Our records include-

\begin{tabular}{|c|c|c|c|c|c|}
\hline Poona & - & - & - & - & - Common on Sesbania. \\
\hline Coimbator & & . & . & - & - Dhaincha. \\
\hline Cuttack & . & . & - & - & - Dhaincha \\
\hline Pusa & . & . & - & • & - Cassia tora. \\
\hline Rangpur & . & - & . & . & - Sesbania aculeala. \\
\hline Duars & . & . & . & . & - Sesbania sp. (in large numbers in 1912). \\
\hline
\end{tabular}


Sometimes in large numbers on species of Sesbania when grown for green manure.

Terias silhetana, Wallace.

Bingham, F. I., II, 257-258, ff. 65, 66; Proc. Second Entl. Meeting, pp. 72, 75, 79.

Occurs in Sikkim, Assam, Burma, and Central and Southern India.

In November 1915 I found the larvæ defoliating Sesbania grown for green-manure amongst coffee in Coorg. The gregarious larvæ are green, with a black head. Pupa blackish; pupation in a cluster on stem. (In T. hecabe larva has green head, pupa greenish, not clustered gregariously).

\section{LYOENID א.}

\section{Zizera lysimon $H b$.}

Bingham, F. I., II, 357-358 ; I. I. L., p. 426 [Z. karsandra.]

"Breeds frequently on lucerne (Medicago sativa) in the Plains where this is grown . . . . Davidson and Bell reared it on a vetch, Zornia diphylla" (Lefroy, l.c.). Not known to be a pest.

\section{Chitades laius, Cram.}

Bingham, F. I., II, 365-367, t. 19, f. 135 ; I. I. L., p. 426 ; Proc. Second Entl. Neeting, p. 210.

Occurs practically throughout India, Burma and Ceylon. Larva on orange, lemon, lime, pomelo. Has been, reared at Pusa on several occasions from larve on topshoots of orange, but is scarcely a pest.

In the Godavari distriet we once had it very bad on orange shoots.

Mr. Ramakrishara Ayyar.

Chilades trochilus putti, Freyer.

Bingham, F. I., II, 367-368 ; I. I. L., p. 426 ; Moore, Lep. Ceylon I, 77, t. 35, ff. 4, 4a IC. [putli] ; Proc. Second Entl. Meeting, p. 80 .

Occurs throughout India, Burma and Ceylon, mostly in the Plains. Mr. Fletcker. The foodplants include Heliotropium strigosum, Zomia diphylla and indigo.

It has been reared on several occasions from larvæ found on indigo leaves in North Bihar, but can scarcely be considered a pest. Also reared at Pusa from larvæ boring pea pods. 
Lyconesthes emolus, Godt.

Bingham, F. I., II, 373-374.

Occurs in Sikkim, Assam, Burma, Bengal, Bihar, Orissa and North Kanara.

De Niceville gives the foodplants in Calcutta as Nephelium litchi, Cassia fistula and Heynea trijuga. It has been reared in small numbers at Pusa from larvæ feeding on mango leaves, but is not a pest.

\section{Lampides elpis, Godt.}

Bingham, F. I., II, 407-408 ; Proc. Second Entl. MIeeting, p. 37.

Occurs throughout the Hills of Southern India, Ceylon and Burma.

The larva feeds on the flowers and fruits of the cultivated cardamom and also on those of Kaempfaria pandurata; pupa in the fruit or in cluster of dead flowers above the fruit.

A decided pest of cardamoms in distriets where these are grown.

Mir. Andrews.

Mr. Fletcher.

\section{Euchrysops cnejus, $\mathrm{Fb}$.}

S.I.I.,pp.414-415, t. 26 ; Entl. Mem. V, 59-66, t. 8 [Catochrysops]; Proc. Second Entl. Meeting, pp. 44, 52, 56, 58, 60, 65.

Occurs thronghout India, Burma and Ceylon. The larva has been found at Pusa on tur (Cajanus indicus), mung, urid, moth, Vigna catjang and Sword-bean (Canavalia ensiformis). It may occur on practically any pulses and when in numbers (as it often is) may do serious damage, the contents of the pods being eaten out.

At Jorhat I found it on Phaseolus radia'us.

\section{Catochrysops pandaca, Horsf.}

Bingham, F. I., II, 413-415; Rutherf., Trop. Agric., Sept. 1914 ; Proe. Second Entl. Meeting, p. 266.

Occurs in most parts of the Plains of India, Burma and Ceylon.

The larva feeds on Cycads. De Niceville found it on Cycas revoluta in Calcutta and it has been sent to us from Bombay as damaging Cycas circinalis, and Rutherford found it as a pest of Cyeads at Peradeniya.

It disfigures ornamental Cycads but is otherwise scarcely a pest.

[See also pages 897-898.] 
Polyommatus beticus, Limn.

S. I. I., pp. 415-116, 1. 288 ; Proc. Second Entl. Meeting, pp. 44, 56, 58, 61, 71; Andrews, Q. J.. Ind. Tea Assocn., 1918, 29-30.

Occurs abundantly throughout India, Burma and Ceylon. Larva on Crotalaria striatu, Dolichos lublab. Cujamus indicus, Pisum and other Leguminosæ. It has been reared at Coimbatore from larræon pods of Cajanus indicus and flower's of Bulea frondosa. It may be a serious pest of Crotalaria when this is grown for seed.

In Assam we had it on gram last year and the attack was rather bad. Mr. Andrews.

I have had a request from Java for egg-parasites of $P$. boticus; so, Mr. Fletcher. if anyone comes across any Trichogramma or other parasite of the eggs, I shall be glad to be informed.

\section{Taruces theophrastus, $\mathrm{Fb}$.}

Bingham, F. I., II, 417-419, t. 20, f. 151; Pruc. Second Entl. Meeting, p. 253.

Occurs practically throughont India, Burma and Ceylon. The larva feeds on the young leaves and buds of Zizyphus jujuba. It is scarcely a pest as a rule but is stated to be a minor pest of grafted bea-trees in the Central Province:

Deudorix epijarbas, Mo.

Lep. Indica IX, 33-34, t. 711, ff. 3, 3 a-c; I'roc. Second Ent!. Meeting, p. 233.

The larva are destructive to pom agranate fruit in Kumaon in June and July, so that "in some years scarcely a pomegranate escapes their attacks" (Hannyngton, B. J. XX, 369-370).

It is common as a borer of pomegranate fruits in the Dehra Dun IIr. Beesoz. district.

Virachola isocrates, $\mathrm{Fb}$.

S. I. I., p. 416, f. 289 ; Lep. Indica IX, 61-69, t. 719, ft. 3, $3 a-b$; Bell, B. J. XXIV, 181 ; Proc. Second Eutl. Hecting, pp. 213, 231, 232, (łab.) 231, 215, 250, 257.

Oceurs throughout the Plain of India (? except northrards of United im. Fletcher. Provinces). Not noted in Burma. 
Mr. Sen.

Mr. Fletcher.

A major pest of pomegranate, the fruit being bored by the larva, which also occasionally attacks guava, orange and other fruits. Our records include the following localities and foodplants:-

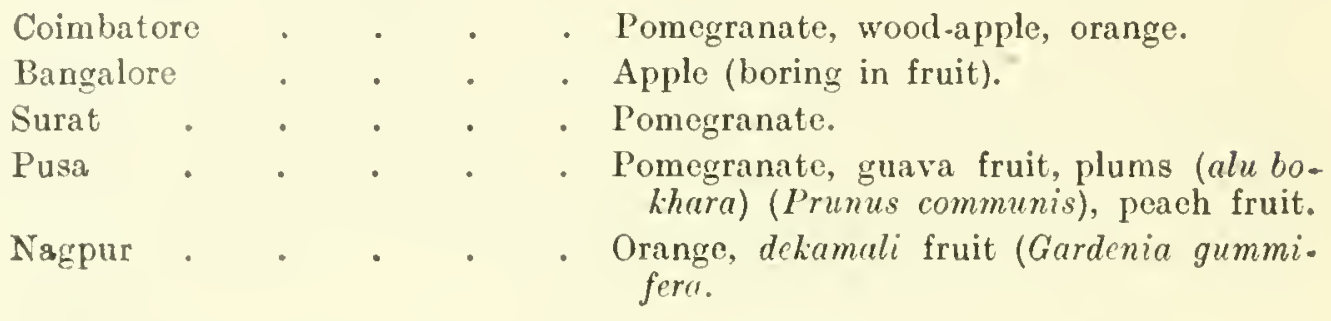

Also attacks tamarind fruits and Bell gives fruits of Gardenia and Randia and Strychnos nux-romica.

In Bengal it is a very common pest of pomegranate. The caterpillars are found on guava also, but in very small numbers.

\section{Hesperiade.}

Parata alexis, Fb.

Lep. Indica IX, 253-255, t. 752, ff. 3, 3a-d.

Widely distributed in the Plains.

Has been reared at Coimbatore and Chepank from larvæ on leaves of Pongamia glabra and also on castor and at Nagpur from larvæ on "Kanji.",

Not known to be a pe-t.

Spialia galba, Fb.

Lep.. Indica X, 99-101, t. 781, ff. 1, 1a-c.

Widely distributed throughout the Plains.

Has been reared at Pusa from larvæ on Sida rhombifolia, on hollyhock leaves, and on soybean (Glycine hispida). Davidson, Bell and Aitken bred it from Walthesia indica.

Not a pest.

\section{Ampittia d'oscorides, $\mathrm{Fb}$.}

Hesperia dioscorides, Fb., Ent. Syst. III, 329, (1793); Swinh., Lep. Indica X, 125-126, t. 786, ff. 1, 1a-d [Ampittia]; Proc. Second Entl. Meeting, p. 164.

Hesperia maro, Fb., Ent. Syst. Suppl. p. 432, (1798).

Occurs in Sikkim, Burma, South India and Ceylon.

It was reared by Davidson, Bell and Aitken from larræ on rice and grasses and has been reared on paddy at Coimbatore and Samalkota:

Probably a vely minor pest of rice. 
Suastu; gremiu;, $\mathrm{Fb}$.

S. I. I., pp. 418-419, f. 293 ; Lep. Indica X, 152-151, t. 793, ff. 1, 1 $a-c$; Proc. Second Entl. Meeting, 1pp. 258, 262.

Widely distributed in the Plains, the larva feeding on various palms, mostly on palmyra, also on coconut and date.

A minor pest, sometimes occurring in considerable numbers.

\section{Gangara thyrsis, Mo.}

S. I. I., p. 417, ff. 290-291 ; Lep. Indica X, 161-163, t. 795, ff. 1, 1a-c; Proe. Second Entl. Meeting, p. 258.

A common species throughont the Plains of India, Burma and Ceylon:

We have this from Coimbatore and South Coorg. The larva feeds on palms of various kinds and may do some damage to omamental plants and in nurseries of young coco-palms, ete.

Gangara thyrsis is a pretty bad pest of nurseries of young coconut- Mr. Ramakrishna palms in South Kanara. Ayyar.

\section{Matapa aria, Mo.}

I. N. N. V, 115 ; I. I. L. p. 431 ; Lep. Indica X, $171-172$, t. 797, ff. 1, la-c; Proe. Second Entl. Meeting, p. 201.

A common species in most parts of India, Burma and Ceylon. It Mr. Fletcher. occurs commonly at Pusa, the larva rolling bamboo leaves, but is scarcely a pest.

It is found at Coimbatore also.

IHr. Ramakrishna Agyar.

\section{Udaspes folus, Cram.}

S. I. I., p. 420, f. 295 ; Lep. Indica X, 205-207, 1.805, ff. 1, 1a-c; Proc. Second Entl. Mecting, pp. 294, 295.

Widely distributed in the Plains-we have it from Pusa, Rangpur, Mr. ontelier. Nepal, Hopin (Upper Burma), the Northern Circars of Madras, and Coimbatore; not common as a rule but sporadically abundant, when it may be a serious pest of turmeric and ginger. Davidson, Bell and Aitken found the larva on Curcuma aromatica.

In Travancore it is a very minor pest of ginger.

The caterpillars are generally parasitized.

As a rule it is of no importanee, but occasionally it occurs in very large numbers and does a good deal of damage to ginger and turmeric.

Mr. Pillay.

Mr. Ramakrishma

Myr. Flotcher. 
Telicola augias, Linn.

S. I. I., pp. 419-420, f. 294; Lep. Indica X, 246-247, t. 813, ff. 2, 2a-c; Proc. Second Entl. Meeting, pp. 149, 164, 204.

Common throughout the Plains of India. We have it from Pusa, Cuttack, Palur and Coimbatore, in all cases reared from sugarcane.

The larva feeds commonly on cane-leaves, and is also said to feed on bamboos and rice rarcly, but is scarcely a pest.

Calloris colaca, Mo.

S. I. I., p. 413, f. 292, [Parnara]; Lep. Indica 316-317, t. 831, ff. 1, la-c; Proc. Second Entl. Meeting, p. 164.

Common throughout the Plains. Our specimens are from Pusa (larra on rice), Chingleput (larva on paddy) and Bassein Fort, Bombay (larva on grasses).

Scarcely a pest of paddy.

Caltoris bevani, Mo.

Lep. Indica X, 318 t. 831, ff. 2, $2 a-b$; Proc. Second Entl. Meeting, p. 164.

Occurs throughout the Plains of India (except South) and Burma. We have examples reared from larvæ found on rice leaves at Pusa and Samallota.

Not known as a pest.

Chapramathias, Fb.

S. I. I., pp. 417-418, t. 27 [Pamara]; Lep. Indica X, 320-321, t. 831, ff. 3, 3a-c; Fntl. Mcm. V, 67-72, t. 9 ; Proc. Second Entl. Meeting, pp. 164, 180.

Occurs throughout India, Burma and Ceylon. We have butterflies from Peshawar, Bassein Fort, Pollibetta, Coimbatore, Ootacamund, the Anamalai Hills, Mandalay, Maymyo, and Myitkyina, as well as examples bred from larvo on rice at Nagpur, Pusa, Daltonganj, Poona and Thana District. It has also been reared at Pusa on juar and once on sann-hemp leaves (collected on sann-hemp in field).

A minor pest of paddy as a rule, and sporadically bad in most districts.

Mir. Ghosh.

Mir. Fletcher.
I found one caterpillar on a leaf of sann-hemp.

Sann-hemp is a very unusual food-plant. Possibly it had wandered off grass. 
Parnara bada, Mo.

Lep. Indica X, 329-330, t. 834, ff. 1, 1a-c ; Proc. Second Entl. Neeting, p. 164.

Common throughout the Plains of Southern India, Burma and Ceylon. We have this from Pusa, Ootacamund, Bassein Fort and Laymyo, and also examples bred from larræo on rice leares at Ranchi, Daltonganj and Karwar.

Not hitherto recorded as a pest of paddy, but often occurs on this crop in large numbers; probably overlooked and confused with other species.

That brings us to the end of the butterflies, unless anyone has any Mr. Fletcher. more butterflies to bring forward?

\section{[Delias aglea,}

There is a wild mistletoe, a species of Loranthus, which is a pest on Mr.Andrews. tea, in so far as it checks its growth. It is especially bad on tea-bushes reserved for seed and planters have to spend a lot of money in cutting this ont. The larva of Delias aglea eats this parasite right down and as such it is a beneficial insect.

At Pusa we have Delias encharis which feeds on Loranthus in a similar Mr. Fletcher. way, but I am afraid it does not check the Loranthus very much. Indeed, I hare never seen so much Loranthus as there is bere just at present on the mango and Sissu trees.]

\section{Prralide.}

Trachylepidia fructicassiella, Rag.

$$
\text { Hmpsn., F. I., IV, 4, f. } 2 .
$$

The larva bores commonly in pods of Cassia fistula at Pusa.

Stenachroia elongella, Hmpsn.

Hmpsn., B. J. XII, 94 fig. ; S. I. I., p. 421, f. 296 ; Prcc. Second Entl. Neeting, p. 183.

Has been reared in Madras from larræ on cholam ear-heads at Coimbatore and Hagrari and at Pusa from larvæ on Sorghum ear-heads and stems, maize cobs and marua ear-heads. A sporadic pest of these crops in Madras and Bihar. Apparentiy not known in Western or Northern India. 
Tirathaba sp. nov.

Annl. Rept. 1917-18, p. 98, t. 14, ff. 2 (1918).

Larvæ were found at Pusa boring young coconut fruits in the bunch on the tree and causing the young fruits to drop off.

Tirathaba (Wlk., Cat. XXX, 961) is the Mucialla of the Fauna volume (IV, 5).

A very similar species of this genus has been recorded to attack young coconut fruits in Fiji in a similar way and it is probable that this Indian species is widely distributed in India and does more damage than is at present suspected. Here at Pusa we are not in a coconut-growing district, and have only a few odd cocomut palms here at all; so we have little opportunity of going into this question. But those of you who work in coconut districts might look to see whether this insect is not present.

\section{Ramakrishna} Aуyаr.
Mr. Sampson was telling me some time ago about an injury to very tender coconuts which was very similar to that described just now. The young fruits had punctures in them and all such punctured fruits dropped down. This insect may have been responsible for the damage.

\section{Diatrae saccharatis, Fb.*}

Hmpsn., B. J., XII, 306 fig.

Recorded by Hampson from Ceylon. This is the species notorious as a cane-pest in America and the West Indies. It seems very doubtful whether it really occurs in India.

\section{Diatraea venosata, WIk.}

Diatraea venosata Wlk., Cat. XXVII, 14t; Hmpsn., P. Z. S. 1895, 954 ; Proc. Second Entl. Meeting, p. 142 ; Annl. Rept. 1917-18, pp. 90-93, t. 5 .

Diatraea striatalis, Snell., Tijds. voor Ent. XXXIV, 349, t. 19, ff. $1-1$.

Prubably occurs everywhere in the Plains of India, the larva boring in sugarcane and less commonly in cereals such as juar, maize and rice.

We have specimens of the true $D$. venosata from Pasoeroean, Java, and these appear very similar to Indian examples reared at Pusa from sugarcane and less commonly from maize and juar stems, at Ramnad from sugarcane, at Jalalpur (Bombay) from sugarcane and juar stems, at Surat from sugarcane and maize, and at Cawnpur from juar.

* Note.-The discussion on this and the following species of cane-borers will be found on pages 387 et seq. 
The nomenclature of this species is doubtful. It is perhaps sacchariphagus, Bojer, described from Mauritius (whither it was imported from Ceylon); if so, Bojer's name antedates those of Walker and Snellen (assuming that these tro belong to the same species, which is also doubtful).

Diatrca sp. (C. S. 1610).*

Annl. Rept. 1917-18, pp. 90-92, t. 6.

We have this from Sylhet, Dacca and Pabna. It is injurious to cane at Dacca and was sent in August 1911 from Pabna (cane).

Diatraa sp. (C. S. 1674).

Annl. Rept. 1917-18, p. 90-92, t. 7.

Annl. Rept. 1917-18, p. 90 [? Chilo in rice (C. S. 1768).]

Dacca.-Injuriously prevalent in cane in July 1917.

Pusa.-Larra in rice-stem (C. S. 1768), once only.

Diatrca auricitia, Dudgeon.

Chito auricitia, Ddgn., B. J. XVI, 405.

Diatraa auricitia, Annl. Rept. 1917-18, pp. 90-92, t. 4

Diatrca suppressalis, nec Wlk.,'Proc. Second Entl. Heeting, p. 142 .

Pusu.-The larva boring cane. This is probably the commonest species at Pusa and we have numerous examples from other localities which are probably the same but requine further study before venturing an opinion.

Diatraa sp. (C. S. 1769).

Annl. Rept. 1917-18, p. 90.

Pusa.-Larva in Saccharum anthinaceum, moth emerged 29, III, 18; only a single specimen reared so far.

\section{? Diatraa sp. (C. S. 1835).}

Pusa.-Larræ in Sccchom fuscum, moths emerged 25, VIII.3, IX, 1918.

Pupa with strong row of spines on all abdominal segments.

* Since described as Argyria tumidicostalis, Hmps. 
Chito simplex, Butl.

S. I. I., pp. 422-424, ff. 299, 300 ; Proc. Second Entl. Meẹting, pp. 143, 174, 181 (tab.), 187, 191, 200 ; Ann. Rept. 1917-18, pp. $90-92$, t. 3 .

Occurs everywhere throughout the Plains as a major pest of maize and juar, less commonly in rice and sugarcane, the larvæ boring in the stems.

In Western India, where seed is sown in excess and thinning practised, the first-attaclied plants may be thinned out.

Chilo oryzce, n. sp. (M. S.).

Ann. Rept. 1917-18, pp. 88-89, 90-92, t. 8 [" Rice Chilo"].

The larva occurs in rice at Pusa, boring stem.

? Chilo sp. (C. S. 1795).

[? Chilo suppressalis, W1k.]

Pusa; larva in Saccharum fuscum, moth emerged 29, IV, 18 ; only one bred so far.

$$
\text { ? Chilo sp. (C. S. 1831). }
$$

Pusa; larræ in Saccharum spontancum stem; moths emerged 21, VIII-18, IX, 18.

Ancylolomia chrysographella, Koll.

S. I. I., pp. 424-425, f. 301 ; Proc. Second Entl. Mecting, p. 165.

Occurs throughout India and Ceylon as a minor pest of paddy, the larve living in silken tubes usually constructed at about ground-level. Has been reared on paddy at Pusa, Nagpur, and in North Malabar, and at Pusa also on dabhi grass. The life-history has been worked out at Pusa and shown on a coloured plate [exhibited].

Specimens of moths from the Hills of Southern India and from Ceylon

Mr. Fletcher.

Mr. Ramakrishna Ayjar.

Mr. Fletcher. usually have the hindwings dark fuscous (form teprobancnsis, Z.).

Have you found it again in Madras?

No ; we had trouble from it only once.

Scirpophaga xanthogastiella, Wlk. (= aurifua, Z.).

S. I. I., pp. 425-426, f. 302 ; Entl. Note 69 ; Proc. Second Entl. Neeting, p. 144.

Occurs in most parts of the Plains of India as a pest of sugarcane, the larra boring the stems. Also in shoots of Saccharum arundinaceum. 
Usually not very serious but a major pest of cane at Sindewahi, Central Provinces. Apparently unknown in Bombay. Our specimens are from Cawnpur, Saran, Chapra, Dumraon, Pusa, Sindewahi, and Hagari (Madras).

Control methods include prompt cutting out of dead-hearts and collection of egg-masses. In the Central Provinces early planting of setts in October-November, instead of in February-March, has been found effective in mitigating attack.

\section{Scirpophaga monostigma, Z.}

S. I. I., p. 426, f. 303 ; Proc. Second Entl. Meeting, p. 144.

Widely distributed in the Plains and is occasionally a minor pest of sugarcane but not common as a rule. Our specimens are from Pusa and Saran in Bihar.

Scirpophaga gileiberbis, Z.

Hmpsn., F. I., IV, 46 ; Proc. Second Entl. Meeting, p. 174.

Found very commonly in paddy areas in Lower Burma where it will probably prove to be a specific pest of paddy.

Specimens also from Pusa, Bengal and Assam.

Schonobius immeritalis, Wlk.

Hmpsn., F. I., IV, 47 ; Proc. Second Entl. Meeting, p. 174.

Reared at Trivandrum, Travancore, from larvæ boring in rice-plants. This species does not seem to have been bred otherwise. It is widely distributed and may prove to be a minor pest of paddy.

Schocnobius bipunctifer, Wik.

S. I. I., pp. 426-427, t. 29 ; Proc. Second Entl. Meeting, pp. 171-174.

Occurs throughout India, Burma and Ceylon as a major pest of paddy, the larva boring in the stem.

This is the most important insect pest of paddy in India and Burma, usually destroying about ten per cent. of the total crop and doing damage totalling hundreds of millions of rupees annually. The female moths are attracted to light in large numbers but systematic trials of lighttraps have shown the inefficacy of this method as a means of control. The hand-picking of egg-masses and first attacked shoots is not practicable on a large scale over extensive areas, and hardly feasible in small plots. In districts where this can be done the growing of pulses or 
Mr. Ghosh.

Mr. Deshpande.

Mr. Ramakrishna Ayyar.

Mr. Fletcher. shaftal under irrigation over the rice stubble helps to check this pest by rotting the rice stubble. The destruction of stubble by fire after harvest is probably the most efficacious control-measure that can be recommended at present and this should be combined with the control of wild grasses on field-bunds and areas adjacent to paddy lands; this last measure will also be effective against Leptocorisa.

Our experience is that Schonobius and other borers of rice occur in large numbers at the time when the plants come into ear. All the borers put together damage rice in this district to the extent of about four per cent.

At Ratnagiri our chief pest of rice is Schonobius and the damage done by this insect is about seventy-five per cent. of the crop.

In Madras Schonobius is our chief rice-borer and the damage during its worst attacks is as much as ninety per cent.

The damage done around Pusa is certainly very low but then this is not much of a rice-growing district. Taking the Indian Empire as a whole I should certainly say that Schonobius destroys ten per cent. of the whole rice-crop on a general average. I consider it is far and away the worst pest we have so far as loss to the country is concerned. The loss caused by this one insect must run into several hundreds of millions of rupees annually. I might also draw your attention to the interesting monograph on this species by Dr. T. Shirali, issued since our last Meeting.

\section{Raphimetopus ablutella, Z.}

Hmpsn., F. I., IV, 56 ; I. I. L., p. 512 , t. 47, ff. 8, 11 ; Proc. Second Entl. Meeting, pp. 146 [Anerastia].

Hmpsn., P. Z. S., 1918, 78.

Has been recorded as a cane-pest in North Bihar but is probably sporadic and does not seem to be known as a pest in normal years.

Only once bred at Pusa from larva boring cane shoots (C. S. 1801). Old records probably refer to $E$. depressella. Said to have been reared from Cyperus rotundus.

\section{Saluria inficita, Wlk.}

S. I. I., pp. 427-128, f. 304; Proc. Second Entl. Meeting, pp. $200,201$.

Occurs commonly in ragi-stems at Coimbatore about August, the larve boring low down in the stem, near the roots. Probably widely distributed but not yet noticed elsewhere. Also bores into tenai. 
Emmalocera depressella, Swinh.

Polyocha depressella; Hmpsn., F. I., IV, 63, B. J. XXI, 1251.

Polyocha saccharella, Ddgn., B. J. XVI, 405 ; I. I. L., p. 512 , t. $47 \mathrm{ff} .7,12,19$.

Papua depressella ; Entl. Note 70 ; Proc. Second Entl. Meeting, pp. 141, 145, 182.

Emmalocera depressella, Hmpsn., P. Z. S., 1918, 128.

Widely distributed in Northern India. We have specimens from Pusa, Saran, Tharsa, Jehanabad (Bengal), Cawnpur, and Lyallpur, in all cases bred from borers in sugarcane roots; from Lyallpur also in Sorghum and maize.

A very minor pest of sugarcane as a rule, chiefly found in roots of ratoon cane. Occasionally, as at Pusa in 1916 and subsequent years, boring into new shoots of young cane and doing considerable damage.

\section{Heterographis bengalella, Rag.}

Hmpsn., F. I., IV, 70, B. J. XII, 313 ; Proc. Second Entl. Meeting, p. 257.

Recorded from Bhutan and Calcutta.

The larva tunnels into fruits of Custard Apple (Anona squamosa) and occurs at Pusa about September-October, but is not common as a rule and can scarcely be called a pest.

At Dacca it is a pest of custard-apple and bullock's-heart.

Mr. P. C. Sen.

\section{Euzophera perticella, Rag.}

S. I. I., p. 428, t. 30, ff. 1-4 ; Proc. Second Entl. Meeting, pp. 289, 290.

Occurs commonly throughout the Plains of India and Ceylon. We Mr. Fletcher. have examples from Pusa, Penukonda (Anantapur District), Bellary, Coimbatore, Dharwar, Poona, Surat, Baroda and Peshawar, all bred from larvæ boring stems of brinjal; also from Pusa and Coimbatore, boring in stems of Chilli plants; and it has also been found boring potato tubers at Coimbatore and Ranchi, in stems of a wild Physalis at Pusa, and in tomato at Surat.

A common pest of brinjal, often doing serious damage.

Destruction of affected plants or attacked portions, easily recognizable by the wilted appearance caused by the larva boring inside, is the only remedy. 
Euzophera punicaella, Mo.

Hmpsn., F. I., IV, 73; I. M. N., II, 28.

Recorded as boring fruits of pomegranate in Baluchistan. Apparently not kuown elsewhere. No specimens in the Pusa Collection.

\section{Euzophera plumbeifasciella, Hmpsn.}

Hmpsn., F. I., IV, 73.

Bred commonly at Pusa from bael fruits (Egle marmelos) and at Coimbatore from fruits of Wood-apple. Scarcely a pest.

Mr. Senio -White.

\section{Mr. Fletcher.}

\section{Mr Senior-White.}

\section{Nephopteryx eugraphclla, Rag.}

Hmpsn., F. I., moths, IV, 77.

Recorded by Hampson from Punjab and Calcutta, larva on cured tobacco [?] and Mimusops elengi.

Pusa.-Reared in numbers on Achras sapota leaves and once on Mimusops.

$$
\text { Nephopteryx minutella, Rag. }
$$

Hmpsn., F. I., IV, 81-82 ; Proc. Second Entl. Meeting, p. 288.

Recorded from South India, Burma and Ceylon.

We have specimens reared at Pusa from larvæ on brinjal leaves; it was bred in small numbers in August and September 1912.

Not a pest.

In Ceylon the larva webs together the topshoots of brinjal.

\section{Nephopteryx semirubella, Scop.}

$$
\text { Hmpsn., F. I., IV, 84-85. }
$$

We liave specimens reared at Pusa on Sij leaves (Euphorbia sp.), on Jatropha and on the green bark of Pedilanthus tithymaloides, from Nagpur on "raubatama," from Surat on maize leaves, and from Mandalay on Jatropha glandulifera. According to Hampson, the larva feeds on Lotus, Hippocrepis, Trifolium, etc.

Not a pest.

Myelois pectiniconella, Hmpsn.

Hmpsn., F. I., IV, 88-89, f. 55, B. J. XV, 29.

Originally described from Bhutan but since found in Ceylon, where the larva bores in cacao pods after attack by squirrels. Also bred by 
Green from pods of sword-bean (Canacalia ensiformis) at Peradeniya in July 1903.

\section{Phycita infusella, Meyr.}

S. I. I., pp. 428-429, t. 31 ; Proc. Second Entl. Meeting, pp. 100, 125, 126.

Probably occurs throughout the Plains of India. The Pusa Collection contains examples bred at Pusa, Surat and Lyallpur on cotton and at Pusa on top-shoots of Malvastrum tricrepidatum. Also reared in Madras on Hibiscus spp.

A minor pest of cotton, the larvæ sometimes doing appreciable damage to young shoots, especially in the Surat District.

The affected shoots should be picked off and destroyed.

At Surat we find it every year as a serious pest.

Mr. Jhaveri.

At Pusa it is controlled by an unidentified parasite.

Mr. Misra.

\section{Phiycita clientella, Z.}

Hmpsn., F. I., IV, 94 ; Proc. Second Entl. Meeting, p. 288.

Recorded from Calcutta, Bombay and Ceylon. We have specimens Mr. Fletcher. reared at Pusa and Hagari (Bellary District) from castor fruits and at Pusa from larvæ rolling brinjal leaves.

Scarcely a pest.

$$
\begin{aligned}
& \text { Rhodophaa heringi, Rag. } \\
& \text { Hmpsn., F. I., IV, 39, f. } 58 .
\end{aligned}
$$

Recorded from the Nilgiris and Ceylon, in which island the larva has been found destructive to foliage of Erythroxylon coca at Matale. We have specimens from Gammaduwa, Ceylon.

Cryptoblabes ephestialis, Hmpsn.

$$
\text { Hmpsn., B. J. XV, } 32 .
$$

Originally described from Matale in Ceylon. It has also been bred by Green from larve in fruit-capsules of castor at Peradeniya and is likely to be found under similar circumstances in India. 
Etiella zinckenella, Tr.

S. I. I., p. 429, f. 305 ; Proc. Second Entl. Meeting, pp. 44, (tab.), 57, 58, 60, 64, 71 .

Occurs throughout India, Burma and Ceylon, and is a destructive pest of sann-hemp and pulses, the larvæ boring in the pods and devouring the seeds. Our records include :-

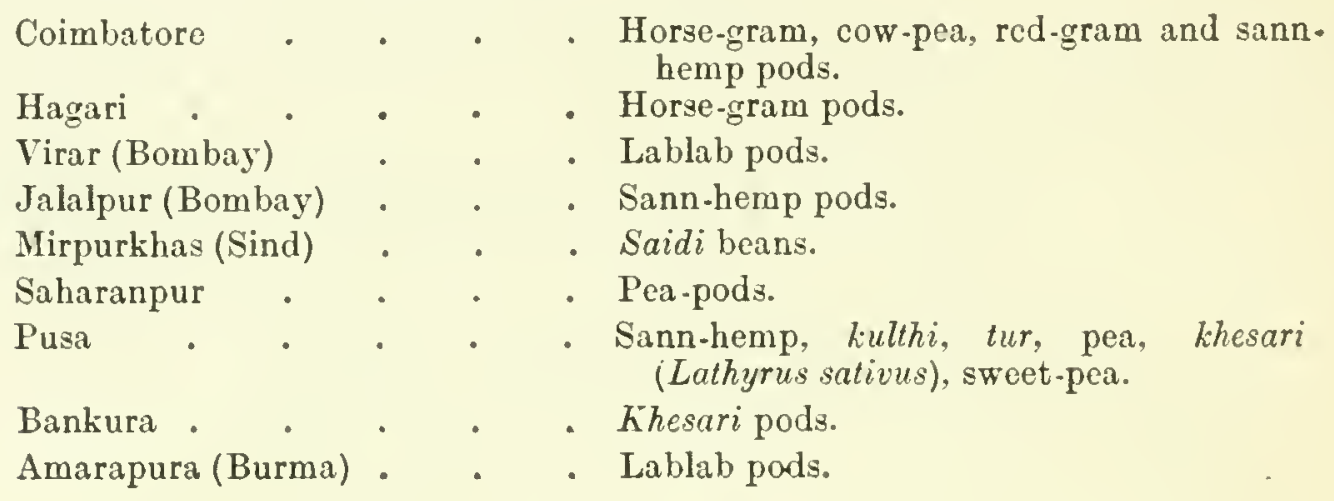

Macalla moncusalis, Wlk.

S. I. I., pp. 429-430, f. 306 ; Proc. Second Entl. Meeting, p. 218.

The larva has been found webbing mango leaves and shoots and des. troying the young leaves at Coimbatore, Salem, Madras and Samalkota, also said to occur on sal in the United Provinces. It has been bred at Pusa on Lagerstromia flos-regince and we have it from Nagpur also.

A minor pest of mango.

The webs are conspicuous and the enclosed caterpillars easily collected: and destroyed.

Nymphula fuctuosalis, Z.

Hmpsn., F. I., IV, 193-194, f. 115 ; Proc. Second Entl. Meeting, p. 165.

Occurs throughout India, Burma and Ceylon, but has apparently only been bred at Taliparamba, Malabar, when it was reared from a pupa found on paddy.

It is perhaps a pest of paddy, together with $N$. depunctalis, but has not been definitely recorded.

Nymphula depunctalis, Guen.

S. I. I., pp. 430-431, t. 32 ; Proc. Second Entl. Meeting, p. 164.

Occurs throughout India, Burma and Ceylon, usually as a minor pest of paddy, sometimes serious. Said to have been bred in the Central Provinces from larva on leaves of garari (Lebidieropsis orbicularis). 
The larvæ may be controlled in some cases by spreading a film of kerosine oil over the water in the paddy-fields and dragging a rope or bamboo over the crop.

In Mysore we have tried the kerosine treatment with success. Plants Mr. Kunhi Kannan. should not touch the kerosinized water.

\section{Hymeniu fascialis, C'ram.}

S. I. I., pp. 431-432. f. 307; Proc. Second Entl. Neeting, p. 296.

Occurs commonly throughout India, Burma and Ceylon. We have wr. Fletcher. examples reared on Amumothus at Pusa. Cuttack, Surat and Trivandrum; at Coimbatore on Trimthynu monogyma and Silver Beet; at Pusa on mangold wurzel leares. on mug, on Coleus and on jutadhari (Celosia cristata) leaves; at Poona on beet; and at Niandalay on White Beet.

Usually a minor pest of Amaranthes, sporadically serious in gardens.

Cnaphalocrocis medinalis, Guen.

S. I. 1., p. 4:2, f. 308 ; Proc. Second Entl. Meeting, p. 166.

Occurs commonly throughont India, Burma and Ceylon. We have examples reared on paddy from Pusa, Poona, Surat, Belgaum. Palur and Parlakimedi (Ganjam District).

A minor pest of paddy, sporadically rather serious.

Marasmia renilialis, Wlk.

Hmpsn., F. I., IV, 276, f. 167.

Occurs throughout India, Burma and Ceylon. Has been reared at Pusa from larvæ rolling Guinea-grass leaves and on Punicum sp.

Scarcely a pest. Probably feeds on wild grasses normally.

Marasmiu bilinealis, Hunpsn.

Hmpsin., F. I., IV, 277.

Occurs in Assam, the Nilgiris and Ceylon. It was bred at Peradeniya from larve on rice-plants in November 1902. Not noted in India but; likely to be found on paddy.

\section{Marasmia trapesalis, Guen.}

S. I. 1., pp. 432-433, t. 33 ; Proc. Second Entl. Meeting, pp. 119, $180,187,190,199$.

Occurs throughout India, Burma and Ceylon, the larva rolling and feeding upon leaves of variuus Graminex. 
The Pusa Collection contains examples from Pusa, on maize, sanai, juar, bajra and kauni (Selavia italica), from Nagpur on juar, from Surat on maize, and from Coimbatore on sugareane.

A minor pest as a rule, sporadically serious. Pieking of rolied leaves is the only practicable means of control.

\section{Pilocrocis barcalis, Wlk.}

Hmpsn., F. I., Moths IV, 313 [A Aacoleia].

Bred at Pusa in sonne numbers from larr rolling Cassia fistula leares.

Occurs throughout India and Ceylon.

Caprinia conchylalis, Gnen.

Hmpsn., F. I., IV, 295, f. 174.

Distributed throughout. India (except North-West), Burma and Ceylon. In Ceylon the larva has been found by Green at Peradeniya defoliating Kiclisia africana (Kickxia rubber), Ponllandia grantiflora and Funtumia.

\section{Dichocrocis pumctiferalis. Cuen.}

S. I. I., p. 433, t. 34 ; Proe. Second Entl. Meeting, pp. 37,88 , $221,231,240,294,295$.

Oecurs commonly throughout the Plains of India, Burma and Ceylon. The larva is polyphagous, boring into various fruits, but is a specific pest of castor, often serious. Our records include the following localities and foodplants :-

\begin{tabular}{|c|c|c|c|c|}
\hline \multicolumn{2}{|c|}{ Peradeniya . } & & & - Cacao pods. castor seed-capsules. \\
\hline \multicolumn{2}{|c|}{ North Malabar. } & - & & Arrow-root. \\
\hline \multicolumn{3}{|c|}{ 'T'aliparamba (Malabar') } & e & . Ginger stem. \\
\hline \multirow{2}{*}{\multicolumn{2}{|c|}{$\begin{array}{l}\text { Coimbatole } \\
\text { Saidapet (Madras) }\end{array}$}} & 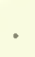 & . & - Jurmeric stem, guara fruit. \\
\hline & & - & ${ }^{\circ}$ & - Castor seed-consules. \\
\hline Bangalor & - & • & - & - Mulberry fruit. \\
\hline Poona & . & . & & - Boring pomegranate fruits. \\
\hline Surat & . & - & • & - Castor seed-capsules. \\
\hline Nagpur & . & & - & $\begin{array}{l}\text { - Costor capsules, mango flowers, juar ear- } \\
\text { l.cad. }\end{array}$ \\
\hline Pusa & . & & & 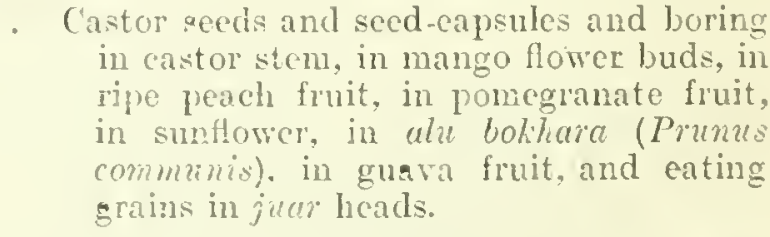 \\
\hline
\end{tabular}

Hopin (C'pper Burma) In vild turmeric stems.

Fin. Senior-White. In Ceylon it attacks Sorghum heads. 


\section{Lamprosema indicata, $\mathrm{Fb}$.}

S. I. I., pp. 433-434, f. 309 [Nacoleia]; Proc. Second Entl. Meeting, p]). 51, 57, 207 [Nacoleia].

Occurs throughont India, Burma and Ceylon as a minor pest of various Mr. Fletcer. pulses, etc. We have it from Saidapet on horse-gram leaves, from Nagpur on Chrysanthemum leaves, and from Pusa on mid leaves, bean leaves, soy-bean, moth leaves, lucerne (rolling top-leaves), groundnut (pupa on leaf), snake-gourd, samn-hemp, Justicia, and Florida Beggarweed (rolling leaves).

\section{Lamprosene dicmenalis, Guen.}

S. T. I., f. 310 .

Occurs probably throughout the Plains of Central and Southern India, in Burma and Ceylon. It has been reared at Pusa from larræ rolling Florida Beggar-weed, whor and wrid leaves, on soy-bean leares and on "chimiri," but is not known as a pest.

\section{Sylepta derogata Fb.}

S. I. I., pp. 434-435, t. 35 ; Proc. Second Entl. Meeting, pp. 100, $123,125,130$.

Occurs throughout India, Burma and Ceylon as a minor pest (:ometimes serious) of cotton and other Hrilucea. We have examples from practically all districts, bred from cotton and bhindi, and it has also been reared at Pusa on hollyhock, Sida sp., Hibiscus pariformis, Abutilon indicum, Corchorus leares, Urima Tobata and jatadhari (C'closia cristata). The larva roll the leaves and may be hand-picked.

Whenever cotton is introduced into Trarancore, it is badly attacked Mr. Pillay. by Sylepta.

At Dacca it was very bad on cotton last year. Hand-picling was Mr. P. C. Sen. done and this liept the pest in great check. It is found on bhindi also.

In Cawnpur it is bad, so much so that we cannot experiment with Mr. David. American cottons. Even netted plants do not escape injury. sites.

It is bad in Bombay too, but in Khandesh it is controlled by para- Mr. Jhaveri.

It is fairly easily controlled by picking off the rolled leaves or eren Mr. Fletcher. by squashing the larre inside the rolled leares. 
Sylepta Tunalis, Guen.

Hmpsn., F. I., IV, 339 ; Proc. Second Entl. Meeting, p. 235.

Occurs throughout India, Burma and Ceylon. Our examples are from Pusa and Shripur, Bihar, bred from larve on grape-vine leaves and from Bassein Fort (moths). It also occurs on grape-vine at Coimbatore.

A minor pest of grape-vine, the larva rolling the leaves into a funnel and dropping to the ground on the least disturbance.

\section{Margaronia negatalis. Wlk.}

\section{Hmpsn., F. I., IV, 347 [Glyphodes].}

Found throughout India, Burma and Ceylon. The larva feeds on various species of Ficus but is not known to be a pest.

Margaronia marginata, Hmpsn.

Hmpsn., F. I. IV, 348-349 [Glyphoctes].

Hmpsn., B. J., XV, 216 [Larva].

Occurs throughout North-Eastern and Southern India and Ceylon. Has been bred at Pusa from larvæ on leaves of Bombax malabaricum, from larvie boring galls on leares of chatuan (Alstonia scholaris).

Not known to be a pest.

\section{Margaronia vertumnatis, Guen.}

Hmpsn., F. I., IT. 349 [GTyphodes].

Occurs throughout India, Burma and Ceylon. Our records include the following localities and foodplants:-

$$
\begin{aligned}
& \text { Pusa . . . . Gárdenia forida. Tabrnamontana wallichii } \\
& \text { and on an Apocynaceous plant. } \\
& \text { Sabour . . . . Tabernamontame sp. } \\
& \text { Mandalay . . . Tabernemontemu cretsen. }
\end{aligned}
$$

Not known to be a pest.

Margaronia stolatis. Cinen.

Hmpsn., F. I., IV, 354 [Glyphorles].

Found throughout India (? except North-West), Burma and Ceylon. The larva rolls leaves of rarious species of Ficus, but is not linown to be a pest. 
Margaromia bivitralis, Guen.

Glyphodes bivitialis: Hmpsn., F. I., IV, 35.5.

Glyphodes alitalis, Hulst, Tr. Am. Ent. Soc. XIII, 158.

Has been reared at Pusa in February 1915 from larvæ on pods of arhar (Cajume indicus), but is not known to be a pest. We have specimens also from Peradeniya, Chapra and Tumding. Hampson describes the larva and gives Ficus oppositifolia as a foodplant.

In Ceylon it is bad on species of Ficus.

Mr. Senior-White.

Hargaronia casalis, Whi.

S. I. I., p. 435, f. 311 [Glyphodes]; Proc. Second Entl. Meeting, p. 252.

Occurs throughout India (except North-West), Burma and Ceylon. Mr. Fletcher. The larra bores in the flower-buds and young fruits of jak and feeds on the leaves also.

A minor pest of juli in Southern India and Assam.

Margaronia cronthusalis, Wlk.

Hmpsn., F. I., IV, 357 .

Common throughout India (except North-West). We have it from Pusa and Chapra in Bihar, and from Coimbatore where it was bred from larvæ on Ficus religiosa.

Not known to be a pest, but likely to occur on Ficus spp.

Margaronin imdica, Saund.

S. I. I., pp. $435-436$, f. 312 [Glyphodes]; Proc. Second Entl. Meeting, pp. 303 (tab), 307.

Occurs abundantly everywhere in the Plains of India, Burma and Ceylon. The larva feeds on various cucurbitaceous plants and is a minor pest of such. The Pusa Collection contains examples from the following localities and foodplants:-

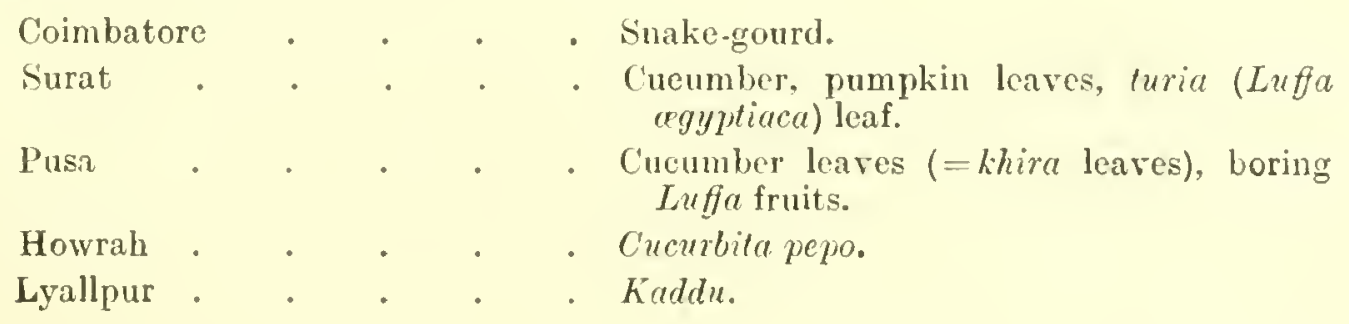


Leucinodes orbonalis, Guen.

S. I. I., p. 436, t. 30, ff. 5-9; Entl. Note 71 ; Proc. Second Entl. Meeting, pp. $286,288$.

Occurs throughout India, Burma and Ceylon and is a pest (sometimes serious) of brinjal, the larva boring in the growing topshoots, causing them to wilt, and in fruits. At Poona and Dharwar the larva was also found boring in potato shoots and at Coimbatore it was reared on Solanum nigrum and S. xanthocaipum.

\section{Crocidolomia binotalis, $\mathrm{Z}$.}

S. I. I., p. 437, f. 313 ; Proc. Second Entl. Meeting, pp. 276 (tab), 277, 280, 282, 284.

Occurs throughout India, Burma and Ceylon, usually as a minor pest (sometimes serious) of cruciferous crops. It may be a serious pest of mustard, the larve webbing and destroying the flowers and leaves of the whole plant and boring the pods and eating the green seeds. Our records include the following localities and foodplants :-

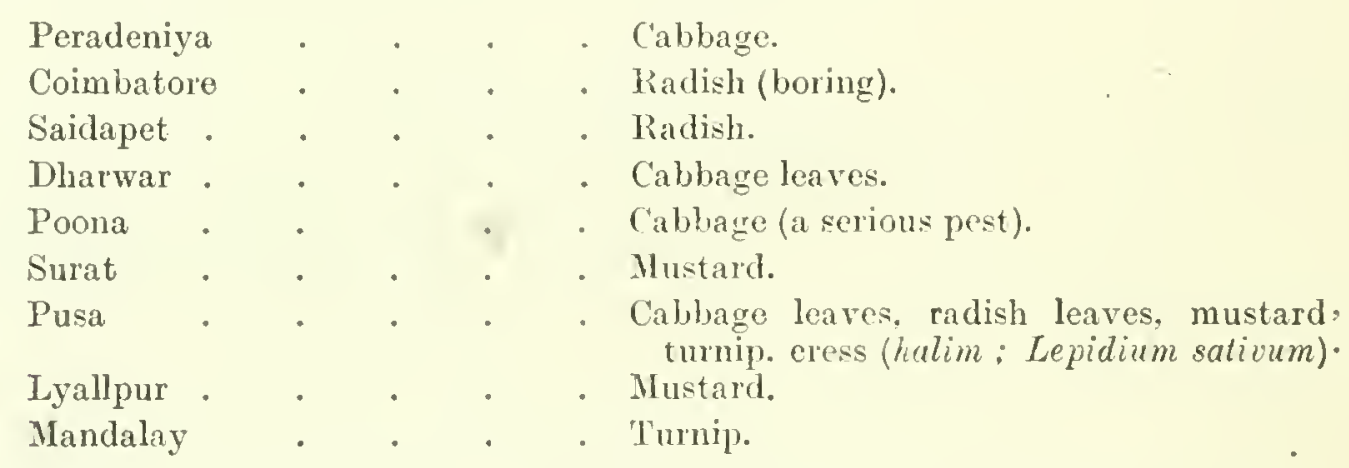

Mr. Senior-White. In Ceylon I had an extraordinary experience once when chilli plants, on being transplanted, were attacked by this pest.

\section{Hellula andatis, $\mathrm{Fb}$.}

S. I. I., pp. 437-438, f. 314 ; Proc. Second Entl. Meeting, pp. 276 (tab), 280, 282, 283.

Mr. Fletcher.

Occurs throughout India, Burma and Ceylon as a minor pest of cruciferous crops. We have examples from :-

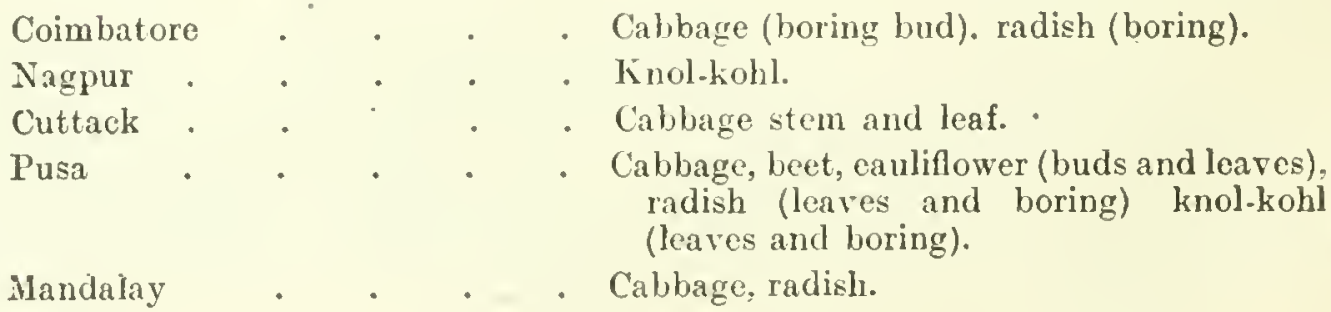


In Egypt Hellula undulis is common with us on young cabbages. Dr. Gough. When the damage is noticed it is too late to take any control measures.

With us it comes late in the season on cabbage.

Mr. Gbosh.

They have a boring habit. I have seen then boring right through Mr. Ramrao. the lleads of cabbages and it is very diffonlt to reach them.

\section{Terastia maticulosalis. Guen.}

S. I. I., pp. 438-439, f. 315 ; T'roc. Second Entl. Mceting; p. 77.

Recorded from Ceylon. The larva is common at Coimbatore, boring IIr. Fletcher. shoots of Erythina indice, and may be a bad pest, checking new growth. Probably throughout South India. Also occurs at Poona.

At Poona it is found damaging the shoots.

Mr. Ramrao.

Terustia egialeutis, WIk.

Hmpsn., F. 1., Hoths, IV, 381.

Andrews, Q. J. I. T. A., 1918, 33-34.

Hampson gives the distribution as Dhammala, Sikkim, Java. Mr. Fletcher.

The larva bores into young stems and shoots of Erythrina indica in January at Tocklai (Assam).

Omphisa anastomosalis, Guen.

S. I. I., pp. 439-440, f. 316 ; Proc. Second Entl. Meeting, p. 292.

Recorded from Sikkim, Khasis, Burma, Andamans; Nilgiris and Ceylon. Bred at Coimbatore from larva in stem of Ipomoes and has occasionally occurred as a pest of sweet potato, boring the main stem.

Crocidoptiora ptyoptiora, Hmpsn.

Hmpsn., F. I., Moths, IV, 389, f. 210.

Pusa.-Has been reared in small numbers from larve rolling leaves of bamboo.

Maruca testulatis, Geyer.

S. I. I., p. 440 , t. 36 ; Proc. Second Entl. Meeting, pp. 44, 52, 56, 60, 65.

Occurs throughout India, Burma and Ceylun as a pest of pulses of various kinds. Not noted in Bombay. In Assam the larvæ have been found on pods of sword-bean, and at Pusa they have been bred from dhaincha flowers, soy-bean, velvet-bean, tur (Cajanus indicus) buds, flowers and pods, mung pods, Vigna caljang pods and cowpea pods. On cowpea it is sporadically a serious pest. 
Mr. Senior-White.

Mr. Pillay.

Mr. Fletcher.
Mr. Senior-White.

Mr. Fletcher.
It is sporadically bar in Ceylon.

I have bred a hymenopterous parasite from it.

Collection and destruction of affected pods effects the most practicable means of control.

\section{Psara bipmenctatis, Fb.}

Pachyzancla bipuncalis, Fb.; Hmpsn., P. Z. S., 1899, 204; Entl. Note 72 ; Proc. Second Entl. Meeting, p. 288. Pachyzancla agrotalis, Z., S. I. I., pp. 440-441, f. 317.

Occurs throughout India (except North-West) and Ceylon. Has been bred at Pusa on Altermanthera sessitis and on croton, and at Coimbatore on brinjal and in brinjal shoots. It does not seem to have been noted as attacking any crop-plant except in Southern India.

In Ceylon it is found on brinjal, but prefers the wild Solanum indicum.

\section{(Undetermined Pyranstine.)}

Reared at Pusa in numbers from larvæ rolling Amaranthus leaves. This was placed in the collection under Psara bipunctalis, but is distinct.

\section{Loxostege massalis, Wlk.}

Hmpsn., F. I., IV, 408, f. 221 [Phlyctcenodes].

Occurs throughout the Plains of India and Ceylon. The larvæ have been found at Pusa feeding on tender top-leaves of maize, but this species. is not known to be a pest.

\section{Antigastia celalamalis, Dup.}

S. I. I., p. 441, t. 37 ; Proc. Second Entl. Meeeting, p. 84.

Occurs throughout India, Burma and Ceylon as a regular minor and occasional major pest of Sesamum indicum. (til ; gingelly), the larva rolling and webbing the leaves and boring in the shoots and pods. We have it, reared on Sescmum, from practically all districts.

\section{Noorde blitealis, Wlk.}

S. I. I., pp. 441-442, f. 318 ; Proc. Second Entl. Meeting, p. 229.

Occurs throughout the Plains of India, Burma and Ceylon as a very minor pest of Moringa, the larva attacking the leaves, shoots and small pods. We have it from Hagari (Bellary District) on Moringa, from Nagpur on "Munga" [probably intended for Moringa], and moths. from Puasa nd from Myingyan, Upper Burma. 
Melasia comiolatis, Hmpsn.

Hmpsn., B. J., XV, 220 ; I. I. I., p. 520, t. 52, ff. 1-4; Proe. Second Entl. Meeting, p. 293.

Recorded from Tibet, Kashmir, Simla, Ferozepur and Pusa. At Pusa it was found as a pest in March 1907, the larvæ boring into sweetpotato tubers underground. It has not since been noted to do damage although moths occurred in July 1910 and Mareh 1915.

Hapalia fermgatis, $\mathrm{Hb}$.

Hmpsn., F. I., IV, 422-423, f. 234 [Pionea].

Occurs throughout India, Burma and Ceylon. Reared at Pusa from larve on eabbage, violet. and kulivamida (Blumea balsamifera).

Not a pest.

Pyransta mactiaratis, Wlk.

S. I. I., pp. 442-443, f. 319.

Oceurs commonly throughout the Plains as a pest of teak. We have it from Dariling, Pusa and Nagpur on teak and it has also been reared at Pusa on Plumeria aculifolia.

\section{Pyrausia mubitalis, $\mathrm{Hb}$. \\ Hmpsn., F. I., IV, 435.}

This speeies is recorded from the North-West Himalayas, Siklim, Khasis and Manipur. In Russia it has been recorded (Rome Bull., Dee. 1912 , pp. 2767-2768), under the name silacealis, Hb. (quoted as a synonym of nubilalis in the "Fauna" volume), as very injurious to maize, hemp and millet. It may therefore be expeeted to occur as a pest of cereals in the montane districts of Northern India, but has not yet been recorded as a pest in India.

Pyrausta nubilalis oeeurs in Egypt, but we do not know it as a pest Dr. Gougb. there.

Pyrausta coclesalis, Wlk.

Hmpsn., F. I., IV, 441, f. 235.

Occurs throughout India, Burma and Ceylon as a minor pest of bamboo, the larva rolling the leaves. We have it, reared from larrie on bamboo, from Coimbatore, Poona, Nagpur and Pusa, and at Pusa it has also been reared on sugarcane. 


\section{Pyrausta bambucivora, Mo.}

Hmpsn., F. I., IV, 442.

Recorded from the Khasis, Jubbulpur and Ceylon. The larva "lives in rolled-up leaves of bamboo" (Hampson).

Not known to be a pest.

Mr. Ramakrishna

Ayyar.

Mr. Fletcher.

\section{[(Undetermined Pyralid. $)$}

There is another Pyralid which is very bad on cultivated chrysanthemums in the Madura district.

Possibly it is Hapalia ferrugalis.]

\section{Pterophorid}

Diacrotricha fasciola, Z.

Pusa.-Larva, Averhoa carambola. Bores into flowers and destroys them.

Galle-Larva, Averrhoa bilimbi. Bores into flowers and destroys them.

$$
\text { Sphenarches caffer, Z. }
$$

S. I. I., pp. 443-444, f. 320 ; Proc. Second Entl. Meeting, pp. 44 , 56,306 (tab.).

Occurs throughout India, Burma and Ceylon as a minor pest of cucurbits and pulses. The larva is polyphagous and feeds on various wild plants, e.g., Biophytum sensitivum. The Pusa Collection contains examples from the following localities and foodplants :-

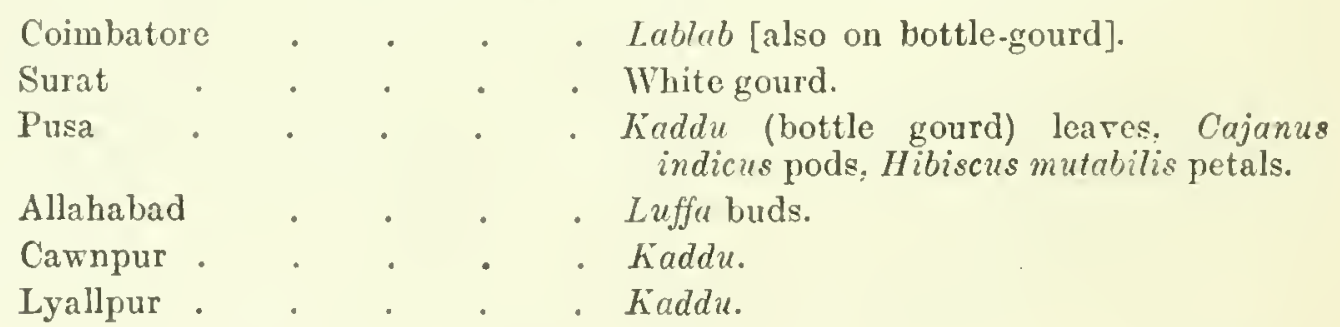

Has also been reared at Galle from larvæ on flowers of Averrhoa bilimbi.

Mr. Senior-White. At Hatale I have reared it from larvæ on young shoots of cacao and on cultivated Geranium flowers.

\section{Oxyptilus lactuca, Fletcher MS.}

Mr. Fletcher.

Reared in small numbers on lettuce at Dehra Dun by Mr. Ollenbach in October 1906. 
Exelastis atomosa, Wlsm.

S. I. I., pp. 444-445, t. 38 ; Proc. Second Entl. Nceting, pp. 44, ว6.

Occurs throughout Madras, Bombay, Baroda, the Central Provinces and Bihar. I have not seen any specimens from Northern India, Assam, Burma or Ceylon (previous records from Ceylon probably all refer to E. phlyctcenias, Meyr.).

An important pest of Cajanus indicus and Dolichos lablab, the larva eating the flower-buds and flowers and boring in to the pods and devouring the seeds.

In the Sholapur District control is practised by shaking the plants over baskets and a small proportion of larvæ and pupre is collected in this way.

\section{Pterophonus lienigianus, Z.}

S. I. I., p. 445, f. 322 ; Proc. Second Entl. Meeting, p. 288.

Occurs throughout India, Burma and Ceylon. Has been reared on brinjal at Coimbatore and in the Godavari District but is scarcely a pest. We have moths also from Ootacamund, Peshawar, Naymyo, Shillong, and Bankipur, and it has been reared at Pusa on leaves of "Khagra." ["Khagra" is given in Watt's Dictionary as Saccharum spontcneum, but this seems unlikely.]

\section{Psychide.}

Mahasena graminivora, Hmpsn.

Hmpsn., T. E. S., 1895, 286; F. I., IV, 472-473 ; I. M. N., IV, 18-19, t. 3, ff. $1 a-c$.

Originally described from Calcutta as destructive to thatching grass. Occasionally occurs on paddy in some numbers as a minor pest in Bihar, Orissa and Bengal. We have it, reared from larvæ on Saccharum spontaneum, from Pusa and Mukhtapur. in North Bihar.

\section{Mahasena theivora, Ddgn.}

Acanthopsyche (Metisa) theivora, Ddgn., B. J., XVI, 400 fig. Mahasena theivora, Hmpsn., B. J., XX, 96-97.

Occurs in Sikkim, the larva on tea in a case composed of fragments and whole leaves attached to a rather soft case. Apparently not a pest. 
Clania crameri, Westwd.

S. I. I., p. 448. f. 325; Proc. Second Entl. Meeting, pp. 19, 87, 274.

Occurs commonly in the Plains of India, usually on Acacia arabica and sometimes on castor. Dudgeon $(B . J$. XII, 643) records the larva on tea and it is said to be a destructive pest of tea in Assam, where it is controlled by hand-picking.

Clania destructor, Ddgn.

Mahasena destructor, Ddgn., B. J., XVI, 401 fig.

Clania destructor, Hmpsn., B. J., XX, 95.

Dudgeon states that this is the most destructive tea Psychid in the Darjiling and Terai Districts, often confounded with $C$. crameri but distinguished "by the forewing wanting red markings and by the position of the elongate pale marginal or submarginal spot, a conspicuous one filling the the whole fork between veins 4 and 5 in crameri, whereas destructor has the largest conspicuous pale spot between veins 3 and 4 and has only a marginal speck between reins 4 and 5." Also a pest of tea in Chittagong. Known to occur in Sikkim, Bhutan, Chittagong and: Borneo.

Clania antrami, Himpsn.

Hmpsn., B. J., XX, 96.

Recorded from Cachar. Larra on tea in a case covered with fragments of dry leares.

Acanthopsyche bipars, Wlk.

$$
\text { Hmpsn., F. I., I, 293, f. } 202 .
$$

The larva has been recorded as a tea-pest in Sikkim (B.J., XII, 611). Also known from Bombay. Also found iceding on apple leaves at Shillong.

Acanthopsyche (Brachycyttarus) subteralbata, Hmpsn.

Hmpsn., Ill. Het. IX, t. 159, f. 23 (male), t. 176, f. 12 (case),

F. I., I, 295, B. J., XI, 281.

The larva has been recorded as destructive to tea in Chittagong. Originally described from Colombo.

$$
\begin{aligned}
& \text { Psyche vitrea, Hmpsn. } \\
& \text { Himpsn., F. I., I, } 299 .
\end{aligned}
$$

We have a single specimen reared on mango leaves at Bakerganj in February 1906. Probably not a pest at all, but most Psychids are liable 
to occur sporadically in large numbers and to do damage when they feed on leaves.

\section{Manatha scotopepla, Hmpsn.}

$$
\text { Hmpsn., B. J., XX, } 96 .
$$

Has bcen recorded from Cachar, the larva on tea in a case covered with scales of bark.

$$
\text { (Psychid-on Palms.) }
$$

Proc. Second Entl. Neeting, p. 263.

We have specimens of an unnamed Psychid reared from larvæ sent in June 1910, as destructive to palms in Calcutta. Larræ were also noticed as destructive to ornamental palms in Calcutta in September 1916.

In the case of small ormamental plants, the larval cases are easily seen and picked off. In the case of large trees, spraying with a stomachpoison, such as Lead Arsenate, may be done.

$$
\text { (Psychid-on Orange.) }
$$

A second unnamed Psychid was reared at Pusa in April 1913 from larvæ feeding on orange twigs. Scarcely a pest as a rule.

$$
\text { (Psychid-on Rose.) }
$$

Sent in by Superintendent of the Gardens, Fyzabad, as feeding on rose in 1918.

\section{[(Undetermined Psychids.)}

We get two more Psychids, one on Achras sapota and the other on Mr. Ramakrishna castor. The former is very bad but the latter appears only sporadically.] Ayyar.

\section{ZYG.ENID王.}

Heterusia magnifica, Butl.

Hmpsn., F. I., I, 261 ; B. J. XVIII, 431 tab.; Proc. Second Entl. Heeting, pp. 19-20.

A sporadic pest of tea in the Duars and Assam. Infested patches of Mrr. Fletcier. bushes may be isolated by means of lines of fresh wood-ashes, which the larve will not cross; but of course in wet weather this method is ineffective. 


\title{
Heterusia edocla, Doubl.
}

\author{
Hmpsn., F. I., I, 261, B. J., XII, 298.
}

The larva occurs on tea, as a sporadic pest, in Assam, Sikkim and Cachar.

Antram (B. J., XVIII, 431) suggests that this species is identical with magnifica.

\section{Heterusia virescens, Butl.}

S. I. I., pp. 448-449, f. 326 ; Proc. Second Entl. Meeting. pp. 19-20.

A sporadic pest of tea in the Nilgiris and Wynaad.

\section{Soritia leptatina, Koll.}

$$
\text { Hmpsn., F. I., I, 252, f. } 168 .
$$

The larva occurs on rose, tea, etc., in Sylhet (B. J. XII, 296). We have specimens from Dungagali (Hazara District), Masuri, Darjiling, Khasis and Haymyo and also one spccimen labelled "Pusa " [probably by error]. Also on apple at Shillong in some numbers.

\section{ZEUZERID A.}

\section{Zeusera coffece, Nietn.}

S. I. I., p. 446, f. 323 ; Proc. Second Entl. Meeting, pp. 21, 34, 121.

Occurs in most parts of India and has been recorded from Siklsim, the Naga Hills, Rangoon, Nilgiris and Ceylon. In Assam the larva is said to be a bad pest of tea, boring the stems and branches, and is controlled by cutting back the affected parts. In Southem India the larra attacks tea and coffee bushes and seems to be not uncommon in coffee bushes. In Burma the larva has been found boring cotton plants.

\section{Phragmatecia sp.}

Proc. Second Entl. Meeting, p. 152.

Ins been reared at Pusa from larve boring in stems of Saccharum spontanem. Not known to be à pest.

\section{Arygophleps scalaris, $\mathrm{Fb}$.}

S. I. I., pp. 416-447, f. 324; Proc. Second Entl. Meeting, pp. 73, $75,76$.

Occurs in the Plains of Southem India and Burma as a pest of agathi (Sestaniu grandiflora), dhaincha (S. aculeata), and chithagathi ( $S$. 
agyptiaca). Te have cxamples reared from agathi at Hagari and Nandyal, and from dhainchat Palur, Cuttack, Pusa and Mandalay.

\section{TERAGRIDE =ARBELID \\ "Abetr" tetranis, Mo.}

S. I. I., pp. 453-45t, t. 41 ; Proc. Second Entl. Heeting, pp. 211 , $227,230,231,244,252,251$

Widely distributed in the Plains, the larva boring into various trees and feeding on the bark under cover of a gallery composed of silk and fragments of wood. On records inchde the following loealities and foodplants :-

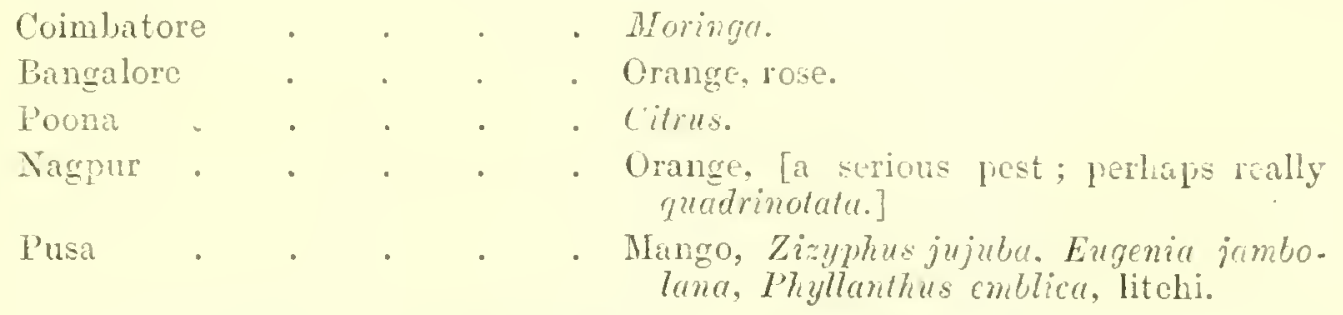

Note.-The elosely allied $A$. quadrinotuta (I. I., I, 315, f. 215) has been recorded as tumnelling in the angles of caeao branehes in Ceylon and it is probable that some of the Indian records also refer to quadrinotata. We have quadrinotata from Dharwar and from Coimbatore, where it bores in stems of the Rain Tree (Pithecolobium saman).

In one garden we pomed petrol in the galleries and found this treat- Mr. Khare. ment quite successful.

At Poona we tried spraying with Paris Green, using twice the usual Mir. Ramrao. strength after removing the webbing. We noticed that several caterpillars died when they came ont at night to feed on the bark. The trees treated were those of Bassia latifolia on the roadside and the treatment was quite successful.

What time of the day do you spray?

Mr. Ramakrishua

You can spray at any time. The larra comes out at night, feeds on Mr. Ramrao. the bark and dies.

How high do you find the larra in the trees?

Mr. Fletcher.

Whole stems up to twenty feet from the grourd were covered Mr. Ramra. with webbing. This webbing was brushed off before spraying.

$$
\text { "Arbela" dea, Swinh. }
$$

Hmpsn., F. I., I, 315 ; Proc. Second Entl. Meeting, p. 22.

The larva has been recorded as eating tea bark in Sylhet and Cachar. 
"Arbela" theivora, Himpsn.

Hmpsn., B. J. XX, 97, t. G. f. 1.

Occurs in Assam. The "larva bores in the bark of tea and the smaller branches of mango, feeding under a web."

\section{Cossine.}

Cossus cadamber, Ho.

Hmpsn., F. I., I, 306, f. 209.

Described from Calcutta. Fairly common in Bihar, the larva boring in stems of Ficus spp. (? and mango), usually in old trees and probably doing little damage.

Duomitus ceramicus, Wlk.

Hmpsn., F. I., I, 307.

Said to attack Fig trees of mały species in Westem India $(B . J$. XXIII, 765), but this is probably an error for leuconotus. Stebbing (Indiun Forest Insects, Coleoptera, p. 14) says that the larva feeds on the bast of teak, tumnelling into the wood to pupate and thus ruining it for timber purposes.

We have no specimens in the Pusa Collection, and it is probably ronfined to Burma.

Duomitus leuconotus, Wlk.

Hmpsin., F. I., I, 308, f. 210.

Recorded from Simla, Sikkim, Calcutta and Ceylon. We have this from Belgaum and Belgachia. The larva bores in various trees and may do considerable damage. It was found boring Cassia fistula at Rangoon.

\section{Duomitus mineus, Cram.}

$$
\text { Hmpsn.. I. I., I, } 309 .
$$

Widely distributed in India and recorded from Sikkim, Sylhet, Calcutta and Ganjam. We have moths from Pusa and Chapra, in North Bihar, but this insect does not seem to be common. The larva does not appear to have been noted but will probably turn ont to be a pest owing to its large size.

\section{[Duomitus sp.}

Mr. Ramakrishna Ayyar.
We have a caterpillar of a species of Duomitus which damages the main stem of Cassia in the Nilgiris.] 


\section{Carposinide.}

Meridarchis scyrodes, Meyr.

Meyr. Exot. Micr. II, 30 (1916) ; Entl. Note 74: Proc. Second Entl. Mecting, p. 254.

The larva has been found at Pusa, Surat, Nagpur and Coimbatore Mr. Fletcher. boring the fruits of ber (Zizyphus jujuba).

Status doubtful; probably scarcely a pest.

\section{Meridarchis reprobata, Meyr.}

Reared at Nagpur and Surat in fruits of Eugenia jambolana. It has also been sent in to us fom Kashmir as boring and damaging cultivated olive fruits.

\section{Phaloniade.}

\section{Clysia ambiguella, Hb.}

This insect is well-known in Europe as an injurious pest of the grapevine, the larva feeding in the flower-buds. It occurs in the Hills of Assam and Burma, but has not been recorded as a pest in India, although it will probably prove to be so as cultivation extends in these Hill tracts.

\section{TORTRICIDA.}

Capua incalidana, Wlk.

Wlk., Cat. XXIIII, 327 (1863) ; Proc. Second Entl. Meeting, p. 300.

Bred at Nagpur in December 1915 from larvæ on leaves of Piper betle (J. L. Whare).

May be a local minor pest. Also occurs in Ceylon.

\section{Homona coffearia, Nietn.}

S. I. I., pp. 45.2-453, f. 330 ; I'roc. Second Entl. Meeting, pp. $20-28$.

Said to occur in the Tea Districts of Southern India, but the only specimens I have actually seen were collected by myself at Pollibetta, in South Coorg, amongst cofiee, and reared on Lantana by Y. Rachandra Rao at Kallar and Sidapur. It is, of course, a well-known pest of tea in Ceylon. Also said to occur in the Assam Tea-districts, but I have seen no specimens from Assam.

\footnotetext{
* See also Laspeyresia leucostoma (page 147).
} 
Mr. Senior-White.

Mir. Fletcher.

Mr. Andrews.

Mr. senior-White.

Mr. Andrews.
It is a bad pest of tea in Ceylon, so much so that one of our entomologists, Mr. Jardine, has been working especially on this insect and has recently issued a Bulletin on it.

No Bulletin on Homona coffearia has been received at Pusa as yet.

Have rou noticed any effect on three years' pruning?

None. There seem to be three species concerned in the attack.

Homona coffearia occurs occasionally in Assam and almost invariably on the new flush which comes up after the plants have been' cut back.

Cacacia micaceana, Wlk.

Wlk., Cat. XXVIII, 314 (1863).

Bred at Mandalay in January 1909 by K. D. Shroff, from larvæ found on broad bean and on guava. We have also moths from Minbu, in Lower Burma, and from Peshawar.

Not known to be a pest.

\section{Cacacia epicyrta, Meyr.}

We have specimens from the following localities and foodplants:Madulsima (Ceylon).

Coimbatore, larva on green chillies, Duranta shoots, webbing Lantana flowers.

Shevaroys, larva on Lantana flowers.

Palnis.

Bangalore, larva on Lantana.

Sidapur, larra on Laintane fruits.

Solan, larva on orange leaf.

Pusa, larva boring guara fruit.

Darjiling.

Eucosmina.

Spitonota rhothia, Meyr.

Meyr., T. E. S., 1910, 368.

Probably widely distributed in the Plains of India. The larva rolls young leaves of guava. Eugenia jambolana and mango, but is not a pest. We have it from Pusa on guava and Eugenia, from Koilpatti (Madras) on tender mango leaves, and from Coimbatore.

\section{Ancylis lutescens, Meyr.}

Meyr., Exot. Micr. I, 32 (1912).

The larva rolls tender leaves of Zizyphus jujuba fairly commonly at Pusa and has once been found boring in the fruit. Scarcely a pest. 
Eucosma critica, Neyr.

Eucetis critica, S. I. I., p. 450, t. 39 ; Proc. Second Meeting, pp. 12,42 .

Eucosma luticra, Meyr., B. J., XXI, 867, Exot. Micr. II, 19 (1916).

Eucosma trichocrossa, Meyr., Exot. Nier. I, 563-564; Entl. Note 76, [Laspeyresio.]

Originally described from specimens reared from larvæ in spun-up shoots of Cajanus indicus at Surat. Said to occur at Poona as a minor pest and in the Central Provinces on young plants. The larvæ have been found at Pusa boring the pods and eating the seeds of arhar (Cajanus indicus) in April and May and also on the flower-buds and top-leares. Also at Coimbatore on Crijams indicus.

Puemoval of affected top-shoots should provide control.

\section{Eucosma melanaula, Merr.}

Meyr., Exot. Micr. II, 17-18 (1916).

Bred at Coimbatore, 3rd March 1915, from a larva on green-gram pods. Also reared as Pusa, 4th Narch 1913, from flower of Cajamus indicus; 11th October 1907, from top-shoots of urid; 30th June 1911, from mung pod. Since found at Pusa in numbers boring top-shoots of Phaseolus aconitifolius and Florida Begger-weed and in mung flowers and pods. We have also moths collected at Pusa in Jamary-March, and it is also known from the Khasi Hills.

Probably widely distributed but hitherto mixed up with Eucosma critica.

\section{Eucosma zelota, Meyr.}

Proc. Second Entl. Meeting, p. 264.

Has been found at Abbottabad, where the larvæ spin and bunch together young rose leaves. A garden pest.

\section{Lobesia colopa, Meyr. \\ Meyr., B. J., XVTI, 976.}

This species has been bred in Ceylon from Cajamus indicus. It is commoniy and widely distributed in India and Burma and has been reared in India from Lantama flower heads and from castor. Aiso recorded from Reunion and Cape Colony.

Not known as a pest. 
Argyroploce illepida, Butl.

S. I. I., pp. 449-450, f. 327 ; Proc. Second Entl. Meeting, pp. 230,234, 257.

Widely distributed in the Plains of India and Ceylon, the larva boring in various fruits and seeds. Our records include the following localities and foodplants:-

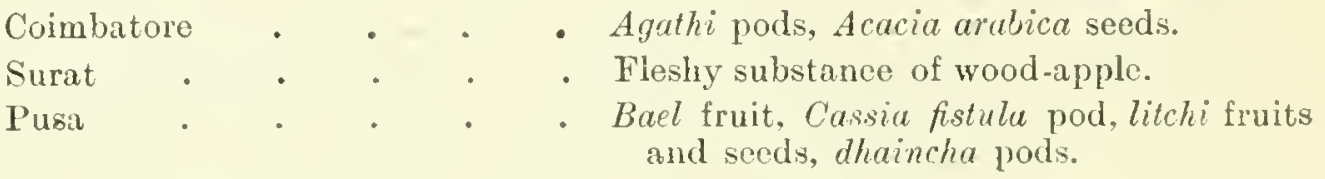

Argyroploce aprobola, Meyr.

Meyr., T. E. S. 1886. 275 [Eccopsis]; Proc. Second Entl. Meeting, pp. 219, 230, 267.

Widely distributed throughout the Plains. The larva is a very minor pest of mango and litchi, rolling the leaves, but is polyphagons. It has been reared at Coimbatore from larva boring rose-bud, at Poona and Bassen Fort on mango, at Pusa on mango, rose, and litchi leaves, rose flower, Cassia tora and Polyalthia longifolia leaves, and at Kallar on Lantana. It is also said to have been reared on Dahlia at Nagpur, but this record reouires confirmation.

Argyroploce erotias, Meyr.

Meyr., B. J. XVI 584-585 (1905) [Platypeplus]; Entl. Note 75; Proc. Second Entl. Meeting p. 219.

The larva has been found at Pusa rolling tender mango leaves and feeding on them; also reared in Bombay from larva boring in mango shoots. At Pusa it has also been reared from larva rolling Loranthus leaves [probably ou mango] and from a larva wiebbing Cynoglossum leaves. Also occurs in Ceylon.

Argyroploce leucaspis, Meyr.

Meyr., Gardiner's Fauna Geogr. Maldives I 126 (1902) [Eucosma]; Proc. Second Entl. Meeting, p. 229.

Has been bred at Pusa in some numbers from larvæ rolling litchi leaves but is scarcely a pest. Also reared at Nagpur from larva on "Kanji" (? Malva syluestris) [perhaps error in labelling]. We also, have moths from Kandy and the Khasi Hills. 
PROCEEDINGS OF THE THIRD ENTOMOLOGTCAL MEETIYG 147

Argyroploce paragramma, Meyr.

Report of Impl. Entom. 1917-18, p. 102, t. 17 ff. 1 a-d (1918).

The larre are common at Pusa in Jnly and August boring into new shoots of bamboo, completely hidden under the protection of the leaf-sheaths. They seem to damage the young shoots to some extent.

I took a moth at Gauhati in May 1918, so that this species is probably widely distributed in the Plains.

Laspeyresia hemidoxa, Meyr.

Meyr.. B. J. XVIII 145; Proc. Second Ent]. Meeting, p. 300.

A single specimen was reared on 2nd Angust 1909 from a larra found boring in pepper-vine shoots at Taliparamba, Malabar.

The species is otberwise only known from the Khasi Hills.

Laspeyresia lencostoma, ileyr.

Meyr., B. J. XXI 876; Proc. Second Entl. Meeting, p. 20.

Larre were found at Hillgrove, Nilgiris, in May 1915, in some numbers, rolling tea leaves. Also from Mmnar rolling tea leaves.

The species is also known from Ceylon (Maskeliya), the Palnis and Khasis, and occurs in Assam.

\section{Laspeyresia tricentia, Meyr.}

S. I. İ. p. 451 t. 40 ; Proc. Second Entl. Neeting, p. 70.

The Pusa Collection contains moths from Surat, Bassein Fort and the Sheraroy Hills. Also reared at Coimbatore from larræ in cow-pea pods. This species apparently accompanies $L$. pseudonectis as a pest of Crotalaria in Western (and Sonthern ?) India.

\section{Laspeyresia pseudonectis, Meyr.}

Nieyr., B. J. XVIII 146-1-i; Proc. Second Entl. Meeting, p. 69.

Widely distributed in the Plains of India as a pest of sann-hemp (Crotalaria juncea), the larra tumelling in the stem and webbing topshoots. Originally recorded from Surat. We have examples, bred

- from larrac in sann-hemp stems, from Pusa and Coimbatore. Also moths from Pesharar. 
Laspeyresia torodelta, Neyr.

S. I. I. p. 451, f. 329 ; Proc. Second Entl. Meeting, p. 56.

Apparently confined to Southern India, where it is a minor pest of Dolichos lablab, the larva boring into the shoots, especially of young: plants. The affected top-shoots may be picked off.

\section{Laspeyresia pomonella, Linn.}

Proc. Second Entl. Meeting, p. 249.

This insect, the notorious Codling moth of Europe, North America and Australia, has been recorded from Dras Ladak (7,000 feet) in Kashmir, but $I$ have as yet been unable to obtain any evidence of its occurrence in any apple-growing districts in India.

Dr. Gougb.

Mr. Fletcher.

Dr. Gough.

Mr. Senior-White.

Mr. Fletcher.

Dr. Gough

Mr. Fletcher.

Mr. Fletcher.
I have found this insect in Syria and the Greek islands and also in South Africa. These places are worth guarding against in India. But we do not find it in Egypt.

It occurs also in Australia and there is some importation of Australian apples into India and I think, Ceylon also. There is some danger of the importation of this insect with fruit but it is probably very slight as there is little chance of this infected fruit being sent to any of our apple-grcwing districts.

It might be brought in from the Levant.

Is it a specific pest of apples? If it has any alternative foodplant, it may crop up in Ceylon.

It occurs principally in apples and pears but attacks many other fruits also. It is a very bad pest in apple-growing districts. In America it causes a loss of two to three million sterling a year, what with damage and control. We do not want to get it in India.

Does it occur in quince?

In America it has been found in fruits of peach, prune, plum, cherry, quince and apricot.

\section{[Unidentified Tortricid.]}

Whilst discussing Laspeyjesia pomonella, I may mention that when I was in Kumaon last year I found a Tortricid larva boring into apple fruits. It was said to be common at Ramgarh in one orchard but I was only able to secure one larva, which was brought back to Pusa but which we were unable to rear out. I cannot therefore say definitely what this is, but I had a drawing made of the larva and the arrangement of the tubercles is different to that found in pomonella and so we may presume that it is not pomonella although the type of damage done is almost exactly similar. 
Laspeyresia ptychora, Meyr.

Meyr., B. J. XVIII $14 \pi$.

Reared at Coimbatore in February 1915 from larva on pods of Cajanus indicus. Alkn known from Nonth Cowro, Queenstand a! it South Africa; in Rhodesia it has been reared from larve feeding in pods of Vigna sinensis.

\section{Cosiopterigide.}

Anatrachyntis simplex, Wlsm. (coriacella, Snell.)

S. I. I. pp. 458-459 f. 334 ; Proc. Seconi Entl. Meeting, p. 114.

Occurs thronghont the Plains of India and Burma. Has been reared in some numbers from cotton-bolls at Pusa, Coimbatore, Chidambaram (Madras), Shibpur Farm (Bengal) and Surat, and more occasionally from cotton-leaves at Pusa, from maize cobs and stem of Capparis dicersifolia at Coimbatore, from mango inflorescence at Pusa, from palus lac in Berar, from a rotten pomegranate at Crobichettipalayam (Madras), from rotten bamboo stalk (Pusa), juar ear-heads (Pusa), dry Trigna catjang pods (Pusa).

It seems rather doubtful how far this is a pest of cotton bolls and seeds. Perhaps it occurs only on dried-up bolls and leaves. At present it appears to be a general feeder on dry vegetable refuse and hardly a pest.

Anatrachyntis falcatella, Stt.

Gracilaria? falcatella, Stainton, T. E. S. (n.s.) Y 121 (1859).

Pyroderces spodochtha, Meyr., B. J. XTI 607 (1905).

Anatrachyntis falcatella, Proc. Second Entl. Meeting, p. 11 .

Has been bred in small numbers at Pusa from larve on cotton shoots "on Dactylopius on cotton" [probably eating the dried dead scales?, and from a rotten pomegranate at Gobichettipalayam (Madras). Has also been bred from lac.

Probably a rubbish-feeder and not a pest.

Anaturactis plumigera, Meyr.

Mieyr., Exot., Nicr. I. 565-566; Entl. Note 83; Proc. Second Entl. Nleeting, p. 81.

Reared at Pusa and Coimbatore from larve feeding in galls produced in stem of Indigotera.

Not known to be a pest. 
Pyroderces semicoccinea, Stt.

Cosmopteryx? semicoccinea, Stainton, T. E. S. (n. s.) V, 123 (1859).

Bred at Pusa from galls in stems of tur (Cajanus indicus), but other moths, including Phycitines, were also bred from these stems, and this species was perhaps only a scavenger.

Pyroderces albilineella, van Dev.

Has been reared at Coimbatore from indigo pods in some numbers. Also from Virajpet (S. Coorg).

\section{Pyroderces promacha, Meyr.}

Pyroderces promacha, Meyr., Proc. Limn. Soc, N. S. W. 1897. 351.

Said by Lefroy (Indian Insect Life, p. 536) to have been "reared from a leaf-mining larva found in Phascolus mungo; the orange larra pupates in a thin cocoon of white silk." This is probably an error, the leaf-miner being perhaps Cyphosticha corulea. P. promacha seems to be a rubbish-feeder and is not a pest, so far as is known. We have it from Pusa, Coimbatore and Peshawar.

Cosmopteryx bambusc, Meyr.

The larra mines blotches in bamboo leares at Pusa. It is scarcely a pest.

\section{Cesmopteryx phacogestra, Meyr.}

Has been reared at Pusa in some numbers from larræ mining bean leaves, but is not a pest.

\section{Gelechiade.}

Sitotroge cerealella, Oliv.

S. I. I. p. 456, f. 331 ; Entl. Note 79 ; Proc. Second Entl. Meeting, p. 183.

Occurs throughout India, Burma and Ceylon. Usually a pest of stored grains but also occurs in the field on ripe ears of paddy, cholam, etc.

Phthorimaa heliopa, Low.

S. I. I. pp. 454-455 t. 43 [Gnorimoschema]; Entl. Note 81; Proc. Second Entl. Necting. p. 272.

Decurs throughout the Plains of India (except North-West) and Ceylon as a minor (major in some districts) pest of tobacco, the larva boring in the stems. We have records from Hanguranketa (Ceylon), 
Coimbatore, Shevaroy Hills, Hagari, Penukonda (Anantapur Distriet), Tharsa, Cujarat. Anand District. Pusa and Rangpur.

Control is best effected by removal and burning of all attacked plants in nurseries and by careful cleaning up of all stumps and stray plants after harrest. Slitting the galls with a knife is useless as a rule as it is only by chance that the larva is killed in this way.

It is an important pest in some districts of the Madras Presidency.

It is a bad pest in Gujarat also.

Mr. Ramakrishna

Ayyar.

Mr. Jhaveri.

In the lankas [islands in the Godavari delta] there is a lot of tobacco Mr. Ramakrishna cultivation. This pest occurs chiefly in the seed beds. The cultivators Ayyar. recognize the attacked plants and these are not transplanted but are collected and destroyed.

How are these roung attacked plants recognized?

Mr. Fletcher.

The leaves fade and the characteristic swelling is seen on the tender Mr. Ramakrishna stem.

Ayyar.

Do not these islands go under water in flood time?

Mr. Fletcher.

Tobaceo is grown only during the cold weather and the land is then Mr. Ramakrishna imigated. These islands go under water very rarely and then silt is Ayyar. deposited and makes the soil very fertile.

We have tried making slits in the affected plants to kill the eater-Mr. Jhaveri. pillars but it has not been found successful as there may be several caterpillars in one plant. We finc the pest present right up to the harresting-time and then it remains in the stubble. The removal and destruction of the stubble has been found very useful.

We also find it in the stubble. Has it been found in any other plant? Mr. Ramakrishna

It is only known from tobacco so far. Ayyar.

It is a regular pest of tobacco, but is not found in the nurseries at Mr. Misra. Puca.

The cultirators reject the seedlings if they find a swelling on the Mr. Ghosh. stem.

Tobacco is a very thin crop and if at the time of transplanting a Mr. Misra. swelling comes up. the cultivator takes out the grub and kills it.

Very probably they reject the seedlings.

Mr. Ghosh.

In Gujarat also they reject the affected seedlings.

Mr. Jhaveri.

The stem is also used for smoking and therefore it is not thrown Mr. Misra. away.

As far as my experience goes the swelling stunts the growth of the Mr. Ramrao. plant and, if once the swelling comes up, the plant is useless, whether you cut open the swelling and kill the grmb or not.

The plant is useless, but not quite so.

Mr. Misra. 
Mr. Fletcler.

\section{Mr. Ramakrishna} Ayyar.

Mr. Fletcher.

Dr. Gough.

Mr. Ramrao.

Mr. Kunhi Kannan.

MIr. Ramrao.

\section{Phthorimau blapsigona, Heyr.}

Meyr., Exot. Micr. I, 569 ; Proc. Second Entl. Meeting, p. 288.

Has been reared at Coimbatore, Saidapet and Nagpur from larvæ boring and feeding in flower-buds of brinjal. Probably widely distributed in the Plains as a minor pest of brinjal.

Five per cent. of brinjal buds are attacked by this insect.

\section{Phthorimcea operculella, Z.}

S. I. I. p. 455, t. 44 ; Entl. Note 77 ; Proc. Second Entl. Meeting. pp. 286,288 .

Introduced with potatoes into Bombay, this moth has spread until it is now found in practically all papts of India. It is a serinu pent of stored potatoes and the larvæ were found at Dharwar mining leares of brinjal. It is likely to be found as a leaf-miner in tobacco plants.

In Egypt it was introduced by the military authorities, but with us it remained restricted to the plants in the field. We store no potatoes in summer, so it died out again.

We find it attacking the crop whilst it is still standing in the field. The larvæ work as leaf-miners to begin with and later on attack the tubers.

It is very rare in the tubers in Mysore.

When there is a break in the monsoon, the soil cracks and the larre get down into the cracks and attack the tubers.

$$
\text { (See also page 763.) }
$$

\section{Phthorimaea ergasima, Neyr.}

Mieyr. Exot. Nicr. I. 568-569; Proe. Second Entl. Meeting; p. 288.

Nr Fleturer.

The larvæ mine brinjal leaves at Pusa in February and Mareh. Probably widely distributed in the Plains as a minor pest.

Stomopteryx nerteria, Meyr.

S. I. I. pp. 45i-158 f. 333 ; Proe. Secolnu intl. Meeting, pp. 43, 47, 42: [Aproarema.]

Widely distributed in most parts of the Plains of India but apparently not known in Bombay. Well known in Madras, under the name Surulpuchi, as a serious pest of gromndnut; also ocenrs on Cajunus indicus: 
soy-bean, and Psoralea corylifolia. Our records include the following localities and foodplants :-

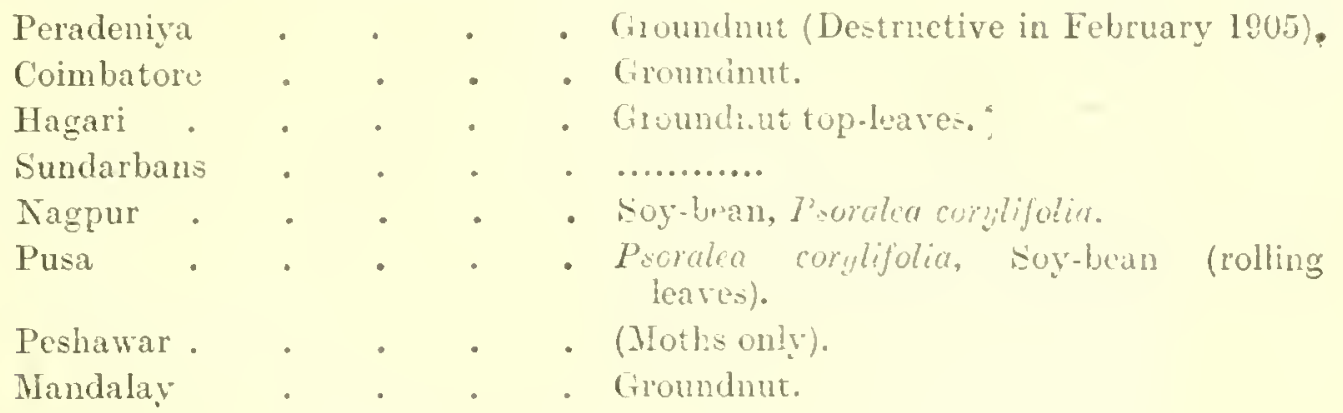

This moth comes to light in large number's.

Mr. Ramakrishna

Ayyar.

Mr. Ghosh.

\section{Platyedra gossypiella, Saund.}

S. I. I. p. 4jt, t. 42, Proc. Second Entl. Meeting. pp. 10, 111 $114,127,129,130$ [Gelechir].

Occurs throughout the Plains of India, Burma and Ceylon as a pest Mr. Fletcher. of cotton, serious in most localities, especially so in the United Provinces. In all districts exotic varieties seem to be most subject to attack. The larva bores into the bolls, feeding on the seeds and spoiling the lint, and also does some damage to buds and flowers.

As regards control it is important to sow uninfested seed. The seeds should be fumigated or spread in a thin layer in the sun to drive out or lill any larvæ contained in them.

(See also pages 172 et seq.)

\section{Brachmia arotica, Merr.}

Meyr., T. E. S. 1894. 15 (Cluilodes) : Proc. Second Entl. Mieeting. p. 16 t.

Bred in small numbers from larvio on rice leaves at Pusa and Katni (Central Provinces). We have it also from Cuttack and Palamau. Also occurs in Burma and Ceylon.

Not a pest.

Brachmia idiastis, Meyr.

Meyr., Exot. Micr. I. 577 (1916).

Bred at Pusa from larre feeding on leares of Punicum in June. Not a pest.

\section{Brachmia insulsa, Meyr.}

A very common species at P'usa. Has been reared from larvæ found at the base of juar shoots. Also from Peshar war. 
Brachmia engrapta, Meyr.

Has been reared at Lahore from larvæ on sweet potato. Not known to be a pest.

Brachmia effera, Meyr.

Has been reared at Coimbatore from larvæ on sweet potato leaves. Not known to be a pest.

Helcystogramma hibisci, Stt.

Gelechia hibisci, Stainton, T. E. S. (n. s.) V 117 (1859).

Brachmia hibisci; I. I. L. p. 533.

Helcystogramma hibisci, Proc. Second Entl. Neeting pp. 123, 265 .

Has been reared at Pusa from larvæ on leaves of bhindi (Hibiscus esculentus), at Nagpur on rose, and at Pollibetta (S. Coorg) the moths were found associated with Hibiscus rosa-sinensis. We also have it from Shillong.

Not a pest.

$$
\text { Paraspistes palpigera, WIsm. }
$$

Originally described from S. Africa.

We have it from Pnttalam, Pollibetta, Coimbatore and Bhamo.

At Coimbatore it has been reared from pods of indigo, Cassia flora and C. corymbosa.

Also on lablab at Coimbatore. Also at Nanganallur, reared on mild indigo.

\section{Dichomeris ianthes, Meyr.}

S. I. I. pp. 456-457, f. 332 ; Proc. Second Entl. Neeting, pp. 61, 80 (tab), 207.

Occurs throughont the Plains of Ceylon, Madras, Bombay and Bihar - probably throughout India. We have examples reared on indigo from Palur (S. Arcot), Champaran, Muhammadpur, Pusa, Gondra and Dalsing Serai in North Bihar. Also reared at Pusa on lucerne and guar bean (Cyamopsis psoralioides).

A sporadic pest of indigo and lncerne. 
Anarsia ephippias, Meyr.

I. I. L. p. 534, t. 56 ; Proc. Second Entl. Meeting, pp. 51, 53, 91.

Occurs probably thronghout the Plains of India as a very minor pest of pulses. We have it from the following localities and food plants :-

$$
\begin{aligned}
& \text { Coimbatore . . . Red-gram (Cajanus indicus). } \\
& \text { Virajpet (Coorg) . . . Wild Acacia flowers. } \\
& \text { Nagpur . . . . Urid. } \\
& \text { Gondra (Bihar) . . . . Indigo. } \\
& \text { Pisa . . . . Groundnut leaves and top-shoots, moth }
\end{aligned}
$$

Control :--Hand-picking of spun-up leaves and shoots.

Anarsiracerata, Meyr.

Meyr., B. J. XXII, 169 (1913).

Bred at Saidapet in October 1906 from larva on Red-gram (Cajanus indicus). Not a pest.

Anarsia melanoplecta, Meyr.

Meyr., B. J. XXII 774 (1914) ; I. I. L. p. 534 ; Entl. Note 78; Proc. Second Entl. Meeting, p. 221.

At Pusa the larva burrows in young mango shoots but it is not common as a rule and scarcely a pest. Also reared at Nagpur from mango flowers [? from twigs in cage with the flowers].

Anarsia omoptila, Meyr. MS.

Bred at C'oimbatore in October 1908 from larva folding leaves of Red-gram (C'ajanus indicus). Not known to be a pest.

Anarsia cxallucta, Meyr. MIs.

Bred at Pusa, 7 October 1912, from larva in top-leaves of C'ajanus indicus.

Anursia sagittaria, Meyr.

Meyr., B. J. XXII, 774-775 (1914).

Bred at Pusa in June-August from larve in top-slroots of ber Zizyphus jujubu). Not a pest. 
Chelaria spathota, Meyr.

Meyr., B. J. XXII, 165 (1913) ; Entl. Note 82 ; Proc. Second Entl. Neeting, p. 219.

The larva has been found eating tender mango leaves at Pusa and Koilpatti. It is not common, however, and not yet noted as a pest.

Chetaria thicnota, Meyrr.

Meyr., Exot. Micr. I. 580-581.

Bred from larva in mango flowers at Panapakam, Chittur District, in February, 1914. Also recorded from the Sheraroy Hills. Not known to be a pest.

CEOPHORIDÆ.

Tonica niviterana, Wlk.

Binsitta niviferana, Wlk., Cat. XXIX 832; I. I. L. p. 535 ; Proc. Second Entl. Meeting, p. 131 (tab).

Has been reared fairly common at Pusa and Chapra from larvæ boring young shoots of Bombax malabaricum, of which tree it is a very minor pest. Probably widely distributed in the Plains, but overlooked. I have seen a moth from Nagpur.

\section{Tonica zizyphi, Stt.}

S. I. I. p. 459, f. 335 ; Proc. Second Entl. Meeting, p. 211.

Occurs throughout the Plains of India as a minor pest of orange and lemon, the larra rolling the young leaves. It also feeds on Mumaya koenigi. We have it from Coimbatore, Nagpur, Pusa, Chapra and Peshawar.

Mir Ramrao.

At Poona it occurs on orange in large numbers rolling the voung leaves. We find the caterpillars particularly on young trees when they are putting ont new leaves.

\section{Porthmologa paraclina, Merr.}

Meyr., Exot. Micr. I. 261 (1914).

Mir. Fletcher.

Has been reared at Pusa from larvæ rolling leaves and boring shoost of ber (Zivyphus injuba). Not a pest. 


\section{Irloryctide.}

Procometis trochala, Meyr.

Pnsa. The larva usually feed on dry sugarcane stems, dry arhar stalks, etc. Once bred at Pusa (C. S. 1708) from a larva found boring into stem of sugarcane.

Probably not a pest.

\section{Nephantis serinopa, Meyr.}

S. I. I. p. 460. f. 336 ; Proc. Second Entl. Meeting, pp. $259,262$.

Occurs throughout the Plains of Ceylon, Southern India, Bengal and Burma as a pest of palms, often serious, especially on coconut and palmyra.

In Travancore it was very bad Jast year on coconut palms. Nearly Mr. Pillay. 5.000 tre?s were attacked. It spreads very rapidly and completes its whole lifehistory on the leaf. Cutting and burning the affected branches has been found very effective. We engaged a temporary fieldman and treated the whole lot in this way.

\section{Ptochoryctis simbleuta, Meyr.}

Meyr., B. J. XVIII 150-151 ; I. I. L. p. 535 [Metathinca].

Recorded from Gazepore (Assam). The brick-red larva feeds, beneath Mr. Fletcher. a web covered with refuse and pieces of bark, on bark of tea-shoots, eating right through the cambium and thus killing the branch or plant.

\section{Stenomide.}

Symchalara rhombota, Meyr.

Meyr., B. J. XVII 982 [Agriophara].

Occurs in the Khasis, Silchar, and Assam Tea Districts. The larra is yellowish-red, sides yellow-orange, subdorsal stripe broad, blackish, head and prothoracic segment black; it feeds between spun leaves of tea and, when foliage is stripped, will attack the bark, doing great damage (Antram).

Control consists in leaving leaves on the bushes when pruning. All prunings should be buried or burnt immediately.

For the last three years we have had no trouble from this insect. Mr. Andrews. It can be controlled by collecting the pupa. 


\section{Blastobaside.}

Blastobasis crassifica, Meyr.

Meyr., Exot. Micr. I 595-596.

Mr. Fletcher.

Bred at Pusa in March from pods of Crotalaria juncea. Probably a refuse-feeder, eating dried seeds rather than attacking the crop in the field. Not noted as a pest. Also occurs at Coimbatore.

\section{Prosintis forivora, Meyr.}

Meyr., Exot. Micr. I. 598.

Bred at Pusa in June and August from larvæ feeding on mango inflorescence. Not noted as a pest.

\section{Hetiodinid é.}

\section{Stathmopoda theoris, Meyr.}

Meyr., B. J. XVII, 410-411 (1906) [ALoloscelis] ; I..I. L. p. 537 ; Proc. Second Entl. Meeting, p. 96.

Reared at Pusa from sunflower-heads. The larvæ are probably merely rubbish-feeders, eating the dried remains of the flowers and not: the seeds. Also reared at Coimbatore from palm-fibre chewed by Oryctes grub, from rubbish, and from cholam heads.

Not a pest.

Stathmopoda sycastis, Meyr.

Proc. Second Entl. Meeting, p. 251.

The larva of this species occurs in cultivated figs in the Peshawar Valley in May and June, the moth emerging in July. The larva are well-known locally, so much so that the comtry-folk are chary of eating the fruit on account of the presence of the larvæ.

\section{Eretmocera impuctella. Wik.}

Proc. Second Entl. Meeting P. 296.

Occurs throughout the Plains of India, Burma and Ceylon.

In Bihar the larva webs up Amaranthus plants, especially single plants, sometimes badly, and eats back the tops. 


\section{EGERIADE.}

Egeria ommatiaformis, Mo.

Trochilium ommaticeforme Noore. I. M. N. II. 16, figs. (1891) ; Hmpsn., Moths. Ind. I. 189 , fig. (1893).

This species has been recorded as doing extensive damage by boring willow trees in Baluchistan.

\section{Melittic enrytion, Westw.}

Hmpsu.. F. L. L. 203, f. 131.

Bred at Pusa in small numbers from stems of snake-gourd (Trichosanthes anguina) in which the larva bores and forms an elongate gall. Also bred from stems of Cephalandra indica.

Scarcely a pest.

\section{GLYPHIPTERYGIDE.}

\section{Hilarographa caminodes, Meyr.}

S. I. I. p. 464 ; Proc. Second Entl. Meeting, p. 37.

Occurs in Ceylon as a pest of cardamoms, the larva boring in the bulbs. Likely to occur in Southern India also, although not hitherto noted.

\section{Phycodes minor, Mo.}

Moore, P. Z. S. 1881. 378; Proc. Second Entl. Meeting, p. 251.

Apparently widey distributed in the Plains of India and Burma. We have examples from Lahore. Pusa, Gauhati, Nowgong, and Minbu (L. Burma). The larva rolls and spins up leaves of various species of Ficus. It occurs as a rule on wild species but may attack cultivated varieties, especially in the Punjab, in which case it is decidedly a pest.

\section{Phycortes radiata. Ochs.}

S. 1. 1. p. 463, f. 339 ; Proc. Second Entl. Heeting, p. 251.

Occurs probably throughout India. Our examples are from Peshawar, Kulu, Gurdaspur, Pusa, Gauhati, Nagpur and Hagari. Has been reared at Pusa on wild figs (Ficus religiosa, $F$. glomerata, etc.), at Gauhati on Ficus indica and at Hagari on Ficus tisela. It also occurs on cultivated fig ( $F$. carica), the larva rolling the leaf, and is sometimes a serious pest of young fig-trees.

VOL. I 


\section{HyPONOMEUTID瓜.}

$$
\text { Prays citri, Mill. }
$$

Entl. Note 89 fig. ; Proc. Second Entl. Meeting, pp. 17, 212.

A well-known pest of various species of Citrus, the larva devouring the flowers, boring in the shoots and tunnelling in the rind of fruits. Has been recorded as a pest in S. Europe, E. Australia and the Philippines. It occurs in Ceylon and Coorg and at Pusa, but has not yet been noted as a pest in India, although it probably is so.

\section{Atteva fabriciella, Swed.}

S. I. I. pp. 461-463, f. 338 ; Proc. Second Entl. Meeting, p. 263.

A common pest of Ailanthus at Coimbatore, the larvæ living in a common web. Also reared at Nagpur on sulai (Boswellia serrata).

Also from Ahmadabad on Ailanthus.

Attera niveigutla, Wlk.

Wlk., Cat. II 526-527 (1854); Proc. Second Entl. Meeting, p. 263.

The larva has been recorded as webbing and defoliating Ailanthus in Sikkim and Srlhet.

\section{-Etherastis circulata, Meyr.}

Bred at Trivandrum, Travancore, in May 1914 from larvæ found making galleries on the bark of Eugenia jambolana. Not known to be a pest.

\section{Mr. Pillay.}

Mr. Fletcher.

Mr. Pillay.

İ̃r. Fletcher.
The caterpillars are found feeding on the bark of Eugenia making galleries on the stem.

Do you find them in any numbers?

Yes, $\mathrm{I}$ have found in some numbers.

\section{Comocritis pieria, Meyr.}

Meyr., B. J. XVII, 416 (1906).

Recorded from Ceylon and Assam, the larva in galleries on bark of Para Rubber (Hevea brasiliensis). Its status as a pest seems doubtful. [See also Mr. Senior-White's paper on this species (No. 53 of these Proceerlings.)] 
GrRAILLARIAD E.

Lithocolletis triarcha, Meyr.

Meyr., B. J. XYIII 811 (1908); I. I. L. p. 537 ; Proe. Second Entl. Meeting, p. 102.

The larva mines leaves of cotton (not only tree-cotton as might be implied from the statement in Indian Insect Life). Not common and not yet seen in sufficient numbers to do damage. We have examples from Pusa only.

\section{Lithocolletis ganodes, Meyr.}

This has been found at Parachinar where it was reared from apple leaves collected on 17th September 1917.

It is not known how far it is a pest.

\section{Phrixosceles plexigrapha, Meyr.}

Veyr., Exot. Micr. I. 623.

Bred at Coimbatore in March 1915 from red-gram (Cajanus indicus) pods. Also occurs at Pusa.

Not known to be a pest.

\section{Acrocercops ordinatella, Meyr.}

Entl. Note 85 ; Proc. Second Entl. Meeting. p. 38.

Occurs in Ceylon, Mysore, Coorg and Burma. the larva mining leaves of camphor and sometimes a considerable pest.

$$
\text { Acroceicops supplex. Meyr. }
$$

At Pusa the larra mines Terminatia catappa leaves in small numbers.

Acrocercops prosacta. Meyr.

At Pusa the larva has been found mining leares of Ipomaca batatas in small numbers.

$$
\text { Acrocercops phaspora. Meyr. }
$$

At Pusa the larva has been found mining Eirgenia jambolana leares.

$$
\text { A erocercops terminalice, Stt. }
$$

Stainton, T. E. S. (3) I 298-299, t. 10, f. 8 (1862) [Gracilaria].

Reared at Calcutta from leaf-miner on Country Almond (Teminatia cratapa) but not known as a pest. 
Acrocercops cathedrax, Meyr.

Entl. Note. 84 .

Probably widely distributed in the Plains. We have it from Coimbatore, Pusa and Rajshahi. The larva mines mango leaves but is. scarcely a pest. Also reared from larvae mining leaves of "chichri" (Achyranthes aspera).

\section{Acrocercops gemoniella, Stainton.}

Has been reared at Pusa from larva mining Achras sapota leaf. Not a pest.

Acrocercops hierocosma, Meyr.

Entl. Note 86.

Reared at Pusa in September and October from larvæ mining leaves. of Nephelium litchi. Described from Queensland, so that the species. is probably widely distributed in India.

\section{Acrocercops auricilla, Stn.}

Bred in September 1915 from leat-miners received from Belgachia where they were doing considerable damage to leaves of mahogany. Also at Pusa from miners in Swietenia mahogani leaves.

\section{Acrocercops telestis, Meyr.}

\section{Entl. Note 87.}

Reared at Pusa from larvæ mining leaves of Eugenia jambolana and Gmelina arborea. Also reared at Coimbatore from larvæ on Trewia. We also have it from Moumcin.

\section{Acrocercoiss syngramma, Meyr.}

-Enti. Note 84.

Reared at Pusa. Saidapet, Coimbatore and Chittur from larve mining young mango leaves. We also have it from Bankipur. Scarcely a pest.

\section{Acrocercops sonoma, Meyr.}

Meyr., Exut. Micr. I 625 ; Entl. Note 84.

Once reared at Pusa in May from larva mining mango leaves. Not. known as a pest. 
Liocrobyla paraschista, Meyr.

Meyr., Exot. Micr. II 5 (1916).

Reared at Pusa in February 1916 from leaf-mining larvæ on tur (Cajanus indicus). Not a pest. Also reared from Desmodium gangetirum.

\section{Cyphosticha comlea, Meyr.}

Meyr., Exot. Micr. I. 26 (1912); Proc. Second Entl. Meeting, pp. 42, 56.

Bred at Coimbatore from larræ mining leaves of Dolichos lablab and at Pusa from leaf miners on cowpea, mung, sem. Dolichos lablab, Cajanus inticus and Vicia fabe.

May at times be a minor pest of pulses. Probably widely distributed in the Plains, but overlooked.

\section{Gracillaria sachrysa, Meyr.}

Proc. Second Entl. Meeting, p. 248 [Apple Gracilariad].

A decided pest of apple, the larva at first mining in young leaves and afterwards tying up the leaves. fastening the edges together and living inside, guawing the green substance on the upper side of the leaf. Sometimes practically all young leaves may be destroyed in this way.

Has been found at Parachinar, Abbottabad and Peshawar and also at Shillong, so that it is probably widely distributed along the Hill districts of Northern India.

Gracillaria theivora, Wlsm.

\section{M. N. II 49 ; Meyr.. B. J. XVIII 829.}

Common in the tea Districts of Ceylon but apparently scarcely a pest. We have an example from Lebong. Darjiling District. The larva mines and rolls leaves of tea.

Have you come across this as a pest of tea?

I have never had it from tea gardens except those situated near Mr. Andrews. Dehra Dun and from these it has twice been sent in to me as doing damage.

$$
\text { Gracillaria soyella, van Dev. }
$$

Entl. Note 88 ; Proc. Second Entl. Meeting, p. 42.

Has been reared commonly at Pusa and Coimbatore from larvæ rolling ledves of Cajanus indicus and at Pusa also on Phascolus mungo. It may also be expected to occur on soy-bean in India. 


\section{Plutellide.}

Plutella maculipennis, Curt.

S. I. I. p. 464, f. 340 ; Proc. Second Entl. Meeting, pp. 276 $277,280,282,283$.

Occurs everywhere, both in the Plains and Hills, throughout India, Burma and Ceylon. The larva gnaws holes in leaves of cabbage, cauliflower, radish, mustard, turnip and other Cruciferæ.

\section{LYONETIADE.}

Phyllocnistis toparcha, Meyr.

Proc. Second Entl. Meeting: p. 235.

Mr. Ramakrishna Ayzar.

Mr. Fletcher.

Mr. Eletcher.

\section{Phyllocnistis citrella, Stt.}

S. I. I. p. 465, f. 341 ; Proc. Second Entl. Meeting, pp. 209, 210, 216. Occurs in every locality where species of Citrus are cultivated in India. We have no specimens from Burma. The larvæ may occur in large numbers, especially in young plants, mining the leaves and the epidermis of green shoots, and doing considerable damage.

Also bred from larræ mining leaves of bael (Eigle marmelos) at Pusa and Sibpur, and on Murraya koenigh.

Control-spray of Crude Oil Emulsion mixed with tobacco extract.

In the Central Provinces we get it, but it is never bad.

In some districts it may be quite a bad pest, especially of young plants. I have seen young plants with every leaf badly mined and containing four or five or more larvæ.

\section{Bucculatrix loxoptila, Meyr.}

Meyr. Exot. Micr. I 209 ; Proc. Second Entl. Meeting, p. 102.

Reared at Attur, Madras Presidency, in June 1907 from larvæ found eating small holes in leaves of Caravonica cotton. Not otherwise known in Jndia as yet, but likely to prove a pest. Originally described from Zanzibar, where the larra was found damaging cotton. 
PROCEEDINGS OF THE THLRU ENTOMOLOGIC.L MEETHC 16 Ǵ

Petasobathra sirina. Mevr.

Meyr., Exot. Micr. I 355 ; Entl. Note 91.

Found on indigo at Gorakhpur and Dalsing Serai, N. Bihar. in September, the larva webbing the top-shoots and nibbling the leaves. A very minor pest so far as is known.

TINEIDE.

Dusyses migosellus. Stt.

Stainton, T. E. S. (n. S.) V 113-114 (1859) [Cerosioma]; Proc. Second Entl. Meeting, p. 257.

Reared at Pusa and Combatore from larvæ in stems of Papatjo carica. The larra usually feeds on dead wood but may bore in below the bark of old living stems; the direct damage done is slight but the indirect damage, by admission of disease. may be more serious. The larval workings are easily seen and can be cut out and the wound tarred.

Trocherdade.

Tischeira piarmica, Mieyr.

Meyr. Rec. Ind. Mus. II 399 ; T. I. L. p. 540.

Found mining leaves of ber (Zizyphus jujuba) in Orissa. May accur in very large numbers constituting a minor pest.

HePIALID E.

Phassus malubaricus, Mo.

S. I. I. pp. 467-468, f. 344 ; Proc. Second Entl. Mleeting, p. 22.

Reared at Ootacamund from a pupa found in tea-stem. Also known from Bangalore In the Bombay Presidency the larva sometimes does much damage by boring in ronts of Trema orientalis (B. J. XXIII 765).

It is only occasionally found on tea in Assam.

It occurs in Burma, probably on teak.

Mir Andrews,

Mr. Beesou.

\section{COLEOPTERA. \\ Melolonthide.$$
\text { Antosericu sp.* }
$$

Ann. Rept. Impl. Entom. 1917-18, p. 93, t. 12, f. 1 (1918).

This species has been reared in small numbers at Pusa from larve Mr. Fletcher. at roots of lemon and sugarcane. It is probably a minor pest.

* This has since been identified as a t. insunabilis, Brencke. 
Serica assamensis, Brsk.

I. M. N. IV 176 (1899), V 14-15; Stebb., Ind. Forest Insects, pp. 74-75.

Recorded by Stebbing as serionsly defoliating tea in the Duars tea gardens close to the Bhutan Hills, larva also at roots of tea. Larva also at roots of sal trees in Bengal Duars.

We have this from the Duars, but have no further information regarding it.

$$
\text { Serica marginella, Hope. }
$$

We have this from Gauhati and from Shillong, where it was found on cherry in May 1905.

Serica maculosa, Brenske.

This species was also found at Shillong on cherry in May 1905.

Serica clypeata, Brenske.

This species was also found at Shillong in May 1905 on cherry.

Serica calcuttce, Brenske.

I. M. N., IV 176 t. 13, f. 3 ; IV 243 ; V 130.

Recorded from Calcutta, the adult beetles eating rose-leaves in the Indian Museum compound.

Serica nilgiriensis, Shp.

This species occurs at Ootacamund in the beginning of April. It

Mr. Ramakrishna Agyar.

Mr. Fletcher.

Mr. Ramakrishna Agyar.

Mr. Fletcher. occurs on Cinchona leaves to which it does a little damage.

It is found on Cinchona leaves. Probably there are two species concerned.

Does it do much damage?

No ; it does not do much damage.

\section{Serica pilula, Shp.}

This species occurs in numbers at Ootacamund in the beginning of April. It is not definitely known to do damage but may be assumed to be at least a minor pest.

Serica pruinosa, Burm.

Proc. Second Entl. Meeting, p. 29.

We have this from Derikulam (5,000-6.000 feet), Travancore, where it is reported to have done a considerable amount of damage by defolia. 
ting coffee bushes. (I. M. N. III, iii, p. 117 (1892)). Stebbing (Ind. For. Ins. p. 75, f. 40) also refers to the above record and records it from Trevandrum also.

\section{Melaserica barberi, Shp.}

This is one of the small cockchafers occurring at Ootacamund in numbers in April. The beetles occur on Cinchona there in small numbers.

\section{Brahmina coriacea. Hope.}

Proc. Second Entl. Meeting, pp. 234, 245, 247, 248.

This species has been sent in to us from Chavai, Kulu District, where it was defoliating apple and pear trees by night in August 1915; from Jeolikote, where it was attacking rine and fig leaves by night in June 1910 and vine, apple, pear and plum in July 1912; we also have a speciinen taken on pear at Jeolikote on 3rd May 1915. This species occurs at Pusa also, and has been found attracted to the Andres-Maire traps There.

\section{Apogonia proxima. Waterh.}

We have this from Calcutta, Chapra and Pusa. At Pusa the adults are found in very large numbers on Ficus religiosa leaves in July, eating the leaves in the evening. A pupa and many adults have also been found at Pusa amongst roots of Saccharmm spontancum. It is not definitely known to be a pest but probably feeds on cane roots during the larval stage.

Apogonia ferruginen, $\mathrm{Fb}$.

Proc. Second Entl. Meeting, p. 131.

We have this from Pusa, and from Hopin and Tatkon in Upper Burma. It is very abundant in the adult stage at Pusa in June and July, resting in the evening on leaves of Bombax and Ficus spp., which they damage considerably.

\section{Holotrichia conterta, Shp.}

Proc. Second Entl. Meeting. p. 29.

We have this from Pykara and Ootacamund in the Nilgiris, from Coorg and Santikoppa (N. Coorg). Said to damage coffee roots in the larval state. The adult bectles appear during the first half of April. 
Mr. Ramakrishna

Ayyar.

Mr. Fletcher.

\section{Holotrichice repetita, Shp.}

This cockchafer beetle appears in large numbers at Ootacamund in April. This insect damages cinchona to some extent.

It is found on einchona in small numbers.

\section{(Unidentified Melolonthid).*}

This cockchafer was sent in to us from Ranchi, the adult damaging rose leaves, in swarms at night, 6 July 1916. (Mrs. Maude.)

\section{(Unidentified Melolonthid).}

Sent in from Upper Shillong, 29 September 1904, the adult beetles found on fruit-trees.

\section{(Unidentified Melolonthid).}

The adults swarm at dusk in May in Shillong and eat Rubus leaves.

\section{(Unidentified Melolonthid).}

A second species found at Shillong in May 1918, the adult beetles swarming at dusk and destroying leaves of Rubus spp.

Mr. Fletcher.

The habits of all these Melolonthids are almost similar. The beetles all hide away in the day-time and come out at night just at dusk, and feed upon leaves. Individual specimens probably do comparatively little damage, but if many species appear together in large numbers (as they usually do), considerable damage may be caused. The ordinary remedy is to collect the adult beetles by hand or by light-traps.

Mr. Beeson.

Is there any method of preventing the beetles from ovipositing in cultivated areas?

It is not possible to do so. In cultivated areas hoeing provides a good remedy because it brings the grubs to light and is also good for cultivation.

Mr. Ramakrishna Ayyar:

Light-traps are effective. The life-cycle of these beetles is one year.

Spraying with Bordeaux mixture may be tried. We found that. in a garden where the grape-vines were attacked by a fungal diseise for which Bordeaux spray was given, a particular patch was left unsprayed by mistake and this plot was found to be very badly attacked by cockchafers whilst the treated vines were quite untouched.

Mr. Fletcher.

In most districts spraying is impracticable because of the area to be covered and because of the occurrence of rain. The cockchafers Pusa.

* This has since been identified a s Schizomelde roficollix, l'. We have it alsu from 
generally hateh out with the first rains, about June in most parts of India.

In the case of cinchona in the Nilgiris; thousands of grubs are collect-Mr. Ramakrisha ed by hand. Coolies are offered money for their collection.

In Shillong a fungus attacks the beetles. which are seen fixed on to Mr. Ramachandra leaves, dead.

Rao.

The fungus that attacks these beetles is not effective as a check Mr. Fletcher. because it apparently only attacks them when their activities are almost over. and the beetles must occur in very large numbers for this fungus to be of any use.

We have some trouble with cockchafers in the forest areas. Seedling Mr. Beeson. trees are attacked. The total damage to seedlings is sixty per cent.. of which nearly a half is due to cockchafer grubs and the remainder to root-borers. I would like to know whether the method of collecting and killing them whilst hoeing is based on the lnowledge of their lifehistory or is only an empirical method.

It is only empirieal. But it is practical, as it fits in with the cultiva-Mr. Fletcher. tion methods, and it is successful to some extent.

How does the migration of the grubs take place in relation to the Mr. Beeson. season; that is to say, how do they come to the surface?

We know very little about them but, as far as I know they spend Mr. Fletcher. their whole life-cycle fairly near the surface. Certainly, they are not found at any great depth when hoeing.

\section{Rutelide.}

$$
\text { Popillia cupricollis. Hope. }
$$

Arrow, F. I. Rutel, pp. $73.74 ;$ Entl. Note 25.

We have this from Kumaon (I. R. 651 of 4th September 1909), Gopaldhara (Sikkim) Turzum. Lebong, Masuri, Lansdowne, Simla, and Shillong. Arrow also records it from Kangra Valley. Naini Tal, Nepal, Sikkim. At Shillong in September 1917 the adults were found destroying flowers of rose; Dahlia, and garden plants generally.

\section{Popillia fece, Kraatz.}

Arrow, F. I. Rutel. p. 80 ; Proc. Second Entl. Meeting, p. 240.

We have this from Maymyo, where the adult beetles were found on peach trees in May 1909 by K. D. Shroft. Arrow also records it from Nepal, Sikkim, Sadiya. Sylhet, Karen Hills, Ruby Mines. Mergui, Siam and Malaeca. 


\section{Popillia chlorion, Newm.}

Arrow, F. I. Rutel. p. 82 ; Proc. Second Entl. Meeting, p. 300.

This species is common at Ootacamund at the beginning of April. We have a single specinen from Coimbatore recorded as having been

Ar. Ramakrishna Myjar.

Mir. Fletcher.

found on betel leaves; but it is probably mis-labelled.

It is doubtful whether it occurs at Coimbatore.

\section{Popillia histeroidea, Gyll.}

Entl. Note 24 ; Proc. Second Entl. Meeting, p. 240.

Adult beetles were found on peach (Prums persica) leaves at Maymyo in May 1909 by K. D. Shroff.

Anomala dorsalis, $\mathrm{Fb}$

Arrow, F. I. Rutel. pp. 136-137, f. 32.

The Pusa Collection contains examples from the following localities :-

Coimbatore

Chapra . . . . .

Pusa . . . . Adults abundant in June and attracted to Andres-Naire trap.

Ambala . . . Adult on bhindi flower. July 1906.

Dehra Dun . . . . September 1906.

Igatpuri . . . . . July 1904.

Lyallpur . . . . . 28 July 191․․

Surat . . . . June 1904, adult at light.

Arrow also records it from Bangalore, Khandesh, Nagpur, Calcutta, Chota Nagpur, Sikkim, Sibsagar, Andamans, Simla, Secunderabad, Khulna, Gwalior.

This is a common and widely-distributed cockchafer, not vet defi; nitely noted as a pest, but likely to be so.

\section{Anomala transversa, Burm.}

Arrow, F. I. Rutel. pp. 142-143, f. 33 ; Entil. Note 13 ; Proc. Second Entl. Neeting, p. 250.

Found at Shillong in May 1905 in numbers on cherry leaves, also on white flowers, roses, Spiræas, ete. In May 1918 at Shillong in large numbers inside lily flowers in daytime, devouring pollen and petal:. Also occurs at Gauhati in May.

Arrow also records it from Ruby Mines, Tharrawaddy, Maymyo and Tonkin. 
Anomala bengalensis, $\mathbf{B l}$.

Arrow. F. I. Rutel. p. 143, f. 34; Proc. Second Entl. Meeting, p. 14t; Anmual Report 1917-18, pp. 93-94.

Hitherto mixed with polita. 'This is one of the three species hitherto mixed up under the name varians; it is distinguishable by the incised clypeus.

It has been reared at Pusa from larre found in leaf-mould and at Pusa and Dacca from larve gnawing sugarcane stems below ground. At Pusa the adult beetles have been taken at light and are also freely attracted to the Andres-Maire trap. in larger numbers than those of polita.

Also recorded by Arrow from Calcutta, Chota Nagpur, Malda, Murshidabad, Golconda (Vizagapatam), Bangalore, Coimbatore and Mandalay.

This species is undoubtedly a pest although we have as yet few records of it as actually doing damage.

\section{Anomala olivieri, Shp.}

Arrow, F. I. Rutel. p. 1tt.

We have this from Taduvatum (Nilgiris), May 190t, and from Ootacamund (9 April 1901 ; C. A. Barber) where it occurs in numbers.

Arrow also records it from Cochin.

It is not common as a rule.

Mr. Ramakrishna

Ayyar.

Anomala elata. $\mathrm{Fb}$.

Alow, F. I. Rutel. 1. 145, f. 35.

This species apparently represents polite in the Sonth Indian Hills. Mr. Fletcher. The hind tibia and tarsus are dark and the latter very thick (in polita slender and not rery dark).

It is represented in the Pusa Collection from Pollibetta and sidapur ne Coorg and from the Bababridin Hills.

\section{Anomale polita, Blanch.}

Arrow, I'. I. Rutel. p1. 146-147, t. 2, f. 24; Proc. Second Enti. Meeting, pp. 146, 174, 192, 245.

This is one of the species hitherto mixed up under the name varians; it resembles bengalensis closely but has the clypeus straight (incised in bengalensis). 
At Pusa the larva has been found in leaf-mould and also at the roots of rice and grass. At Muzaffarpur and Nadia the larvæ have also been found at the roots of rice-plants. At Jeolikote (Kumaon) the adult beetles were found damaging apricot shoo's and on apricot tree. and at Zhob (Baluchistan) the beetles were attacking geengage fruits in Iuly 1918. The Pusa Collection also contains examples from Coimbato a, Kanara. Baroda and Kashmir, and Arrow also records it from Agra, Dehra Dun. Khandech. Bolganm. N. Kanara, Jaintia Hills.

\section{Anomala varicolor, Gyll.}

Arrow, F. I. Rutel. pp. 152-153, f. 41.

At Pusa the adult beetles are attracted to the Andres-Maire trap in numbers in Nay and June; the larva has been reared from Saccharum spontaneum (under C. S. 1744: biharensis), and the pupa has been found at roots of oats (C. S. 1209). At Dacca the beetles have been found in small numbers attacking mango blossoms, and at Jeolikote (Kumaon) the beetle was found damaging plum leaves on 20th May 1915 by H. H. Prasad. We also have it from the Buxar Duars and from Peradeniva, and Arrow also records it from Gopaldhara, Sarda (Bengal), Parlakimedi

Mr. P. C. $S \in \mathbb{n}$, Mr. Fletcher. Mr. P. C. Sen. (Ganjam District), Bangalore, South Arcot, and the Palnis.

At Dacca the adults occur on mango blossoms at night.

Do they do any damage?

I found them only in small numbers and have not observed them doing any appreciable damage.

Anomala variirestis, Arr.

F. I. Rutel. p. 156, t. 3, ff. $20,21$.

This species was found at Shillong. 23-26 June 1918, defoliating fruit trees (apple principally) at night. Arrow also records it from Manipur and Maymyo.

\section{Anomala biharensis.}

Arrow, F. I. Rutel.. pp. 166-167 ; Ann. Rept. Impl. Entom. 1917-18, p. 93. t. 10, ff. a-d.

This species has been reared at Pusa from larva found at roots of sugareane and roots of Sacharum spontaneum. Larve and adults have also been found around roots of gular and banyan trees.

It is apparently not a very common species. 
Anomala antiqua, Gryll.

Arrow, F. I. Rutel. pp. 167-168.

This is a large dark green Anomala which has been found at Tatkon, Burma, on maize and Sesamum by K. D. Shroff. We also have specimens from Minbu, Sale, Mandalay, Myingyan and Tharrawaddy. Arrow also records it from Nepal, Hainan. Hongkong, Siam to Borneo and N. Australia.

\section{Anomala ignicollis, Blanch. \\ Arrnw, F. I. Rutel. p. 178.}

This species occurs at high elevations $(\pi, 000$ feet and over) in the Nilgiris. It is one of the abundant species found at Ootacamund in the beginning of April and we also have it from Naduratam (7,000 feet) in May 1904 and from Pykara (7,000 feet).

\section{Anomala amora, Arr.}

Arrow. F. I. Rutel. p. 185; Proc. Second Entl. Meeting, p. 240.

This species was found by K. D. Shroft at Maymyo on peach leaves in May. Arow also records it from the Ruby Mines.

Anomala pallidospila, Arr.

Arrow: F. I. Rutel. p. 195, f. 48 ; Proc. Second Entl. Meeting, p. 240.

Also found by K. D. Shroff at Maymyo on peach leaves in May.

Anomala lineatopemis, Blanch.

-Arrow, F. I. Rutel., pp. 212-213 ; Proc. Second Entl. Meeting, p. 245.

This is a dark-green species with yellowish-brow elytra. The beetles were found at Jeolikote (Kuman) attacking phm leaves on 20th May 1915 by H. H. Prasad, and we also have it from Buxar Duars. Arrow also records it from Dehra Dun, Masuri, Ramgarh, Ranikhet, Naini Tal, Kulu, Simla, Bhutan and Nepal.

\section{Anomala decorata, Kirsch.}

Arrow, F. 1. Rutel. p. 216 ; Proc. Second Entl. Meeting, p. 240.

This is a shining brown species with chestnut markings on the elytra. It has been found on peach at Maymyo and Arrow also records it from Perak. 
Anomala dimidiata, Hope.

Arrow, F. I. Rutel., pp. 232-233.

This is a large bright-green species, which is common at Pusa at light and has also been taken in the Andres-Maire trap. At Chawai, in the Kangra Distriet, it appears during June and July every year and is found abundantly on berberry trees in sunny places, completely defoliating the trees, and by night it attacks apple and pear, damaging the fruits chiefly. At Zhob (Baluchistan) the beetles were found attacking greengage fruits in July 1918. At Daltonganj it has been found on Butea frondosa. At Darbhanga the beetles were reported to be damaging garden plants in the Rajbagh in the beginning of July 1906. Arrow also records it from Nepal, Campbellpur (North-West Frontier Province). Kulu, Simla, Naini Tal, Malda, Ranikhet, Sikkim, Shillong and Manipur.

\section{Anomala dussumieri, Bl.}

Arrow, F. I. Rutel., p. 2’3, t. 2, ff. 9, 10 : Proc. Second Entl. Meeting, p. 219.

This is a very large shining green species which has been found in the adult state as a minor pest of mango leaves and sweet-potato stems in Travancore. We also have it from Helem (Assam) and Peradeniya. Arrow also records it from Colombo, Cochin, and S. Kanara, and states that it is said to be destructive to leaves of Cinchona succimbra in Ceylon.

Mr. Senior-White. I have seen it in the centre of a rose flower in Ceylon. It was only chewing the petals.

Mr. Fletcher.

Mr. Pillay.

There is a specimen which was found on the stem of sweet-potato at Trivandrum. What was it doing, Mr. Pillay?

I found it in very small numbers. It is a very minor pest.

\section{Anomala ruficentris, Redt.}

Arrow, F. I. Rutel., pp. 236-237 ; Proc. Second Entl. Meeting, p. 254.

Mr. Fletcher.

This is a large shining blackish-green species which was sent in to us in August 1915 from Chawai (Kulu) as attacking apples and pears, defoliating the trees, no trace being found of it in the daytime but emerging by night and doing a great deal of damage. We also have it from Simla (July 1909), Lansdowne (October 1909), Masuri (August 1906) and Nagri Spur (Darjiling District). Also recorded by Arrow from Ranikhet, Manipur, Khasis, Jaintias, and Bhutan. 


\section{Anomala regina, Newman.}

Arrow, F. I. Rutel., p. 252, t. 3, ff. 37, 38.

This species occurs in both light-green and dark-blue forms. It occurs at Ootacamund in numbers at the beginning of April and we also have it from Neduvatam (Nilgiris) in May 1904 and from Coimbatore (3 October 1917).

Adoretus lobiceps, Arrow.

F. I. Rutel., pp. 303-304, f. 67.

We have this from Surat, Jabalpur and Nagpur, where the beetles were found on rose-trees in June by Mr. D'Abreu.

Adoretus bicaudatus, Arr.

F. I. Rutel., pp. 310-311, f. 68, t. 5, ff. 15, 16 ; Entl. Note 17 ; Proc. Second Entl. Meeting, p. 264.

We have this from Fenchuganj (C. Presley coll.) where it was found damaging rose-leaves and other garden trees. Also known from Sun. darbans, Dacca, Berhampur, Trincomali, and Nirodhumunai (Ceylon). At Dacca it was found on bark of a mango tree (Arrow).

\section{Adoretus ovalis, $\mathrm{Bl}$.}

F. I. Rutel., p. 338, t. 5, f. 28 ; Entl. Note 16.

This species is only known from Ootacamund, where it occurs in numbers at the begimning of April. The statement in South Indian Insects that this species was found in other localities damaging grapevine and mango, is based on a misidentification and the figure given represents $A$. lasiopygus.

\section{Adoretus durauceli, Bl.}

F. I. Rutel., pp. 343-344, t. 5, f. 43 ; Entl. Note 21 ; Proc. Second Entl. Meeting, pp. 234, 251.

This species was sent in from Jeolikote (Kumaon) in June 1910 as damaging vine and fig leaves by night and again in July 1912 as damaging vine, apple, pear and plum leaves. It was received from Begum Serai in July 1904 as damaging vines by cating the leaves and in Calcutta Dr. Gravely has found the adults damaging leaves of Lagerstroemia and Cassia. We also have it from Chapra and from Pusa, where the adults occur from June to September. 
Adoretus horticola, Arr.

F. I. Rutel., p. 344 , t. 5, f. 34 ; Entl. Note 22 ; Proc. Second Entl. Meeting, pp. 234, 245, 247, 248, 251.

This speeies was sent in to us from Jeolikote (Kumaon) in June 1910 as damaging leaves of vine and fig by night and again in July 1912 as damaging leaves of vine, apple, pear and plum by night.

Adoretus bicolor, Brenske.

Arrow, F. I. Rutel., p. 347.

Recorded by Arrow from Kurseong, Sarda (Bengal), Caleutta, Pusa, Jabalpur, Surat, Berhampur (Ganjam), Bangalore, Coimbatore, Kodumor, and Kurnul.

At Bangalore it was found attacking rose-bushes. (I. M. N., V. 2, p. $38(1900))$.

Adoretus lasiopygus, Burm.

Arrow, F. I. Rutel., 348-349, t. v. f. 36 ; Entl. Note 18; Proc. Second Entl. Meeting, pp. 234, 264.

Adoretus ovalis (part), Fletcher, S. Ind. Ins. p. 287, f. 127.

This species was sent in from Begum Serai in July 1904 as damaging grape-vines. This is also the speeies referred to in South Indian Insects as ovalis as damaging grape-vine and mango in Southern India. We liave it also from Pusa, where the beetles occur from June to September, from Calcutta, Rewari (Punjab) on 4th October 1905, from Jorhat (23th June 1907) and from Palaman in September 1906, and Arrow also records it from Allahabad, Sikkim, Tejpur, various localities in Bengal, Ranchi, Coimbatore, S. Arcot, Godavari, Trichinopoli, and Anuradhapura.

Mr. Pillay.

Mr. Fletcher.

Mr. Pillay.

In Travancore it damages coeonut seedling one-and-a-half year's old and three to four feet high. It completely defoliates the plants.

On a big scale?

More than one hundred plants were destroyed. The leaf blades vere eaten and only the mid-ribs left.

Adorelus versulus, Har.

F. I. Rutel. pp. 350-351, ff. 73, 74 ; Entl. Note 2 J ; Proc. Second Entl. Meeting, pp. 234, 245, 247, 248, 251, 264.

Mr. Fletcker.

A. versutus was sent in to us from Jeolikote (Kumaon) in June 1910 as lacerating leaves of vine and fig, and again in July 1912 as damaging leaves of vine, pear, apple and plum, whilst on $20^{\text {th }}$ May $1915 \mathrm{H}$. H. 
Prasad found it at Jeolikote on apple seedlings and on a loquat tree. The arlult beetle has a partiality for rose leaves and has been noted specially on rose at Pangalore, whilst in Calcutta it also attacks leaves of Lagerstromia and Cannas. In Samoa the adult is a pest of cacao and the larva feeds on roots of grasses, etc. At Pusa the larva was found at roots of oats and the adnlt beetle reared ont ennerged on 1st May 1915: a pupa was alio found at Prsa underground in an indigo field and from this the adnlt emerged on th September 1917. The Pusa Collection also contains examples from Murshidabad, Buxar Duars, Sylhet, Tejpur (Assam), Cumbatore and the Nilgiris. It is a very widely distributed species.

Adoretus caliginosus, Burm.

F. I. Rutel. pp. 355-356 ; Entl. Note 19; Proc. Second Entl. Meeting, p. 264; Ann. Rept. Impl. Entom. 1917-1918, p. 93," t. 11, ff. a-d (1918).

This species has been reared at Jusa from larve found at roots of grasses. rice, sugarcane and Saccharum spontanewm, the adult beetles emerging at the end of April. We have it also from Surat (5th Mav 1904), Bababudin Hills (Narch to April), Santikopja (N. Coorg: 4th10th Mlay 1914), Jornat (29th June 1907) and Tharrawaddy.

Arrow also records it from Kangra Valley, Sikkim, Sarda (Bengal), Belgaum, Bandra; Nilgiris (3.500 feet) and Rangoon.

\section{C'etoniade.}

\section{Heterrorhina elegans, $\mathrm{Fb}$.}

Arruw, F. I. Ceton. pp. 93-94; Proc. Second Entl. Neeting, p. 182.

This is a large metallic green or blue species which occurs on cholam flower-heads in small numbers at Coimbatore, eating the pollen, but it is not looked on as a pest. We also have it from Chapra and Arrow -also records it from Malda, Chota Nagpur, Mysore, Trichinopoly. Nilgiris and Ceylon.

I teats the pollen but does not do appreciable damage as it does Mr. Rama ivina not occur in large numbers.

$$
\text { Anthracopteon coucifera, Oliv. (=atromaculata. Fb.) }
$$

Arrow, F. T. Ceton. pp. 110-111; Proc. Second Entl. Meeting. 1. 18:2.

This species has been found at Coimbatore on cholam and Lamoun Mr. Flewcbor. but is not looked on as a pest. It is widely distributed and the Pusa 
collection contains spccimens from Dehra Dun, Pusa, Chapra, Igatpuri. Surat, Betul, Trivandrum, Pollibetta and Sidapur in S. Coorg, and from S. Kanara, whilst Arrow also records it from Sahibganj (Bengal). Purneah District, Bangalore and Ceylon.

\section{Anatona stillata, Newm.}

Arrow, F. I. Ceton. pp. 114-115 ; S. I. I. p. 282, f. 122 ; Proc. Second Entl. Meeting, pp. 182, 188, 200, 201.

This species seems to be confined practically to the Western Ghats. and Deccan and surrounding tracts and has been recorded from Khandesh, Poona, Nagpur, Bellary and Bangalore. In Bellary and Bangaiore. it occurs on cholam and ragi and at Poona it occurs on bajra earheads, feeding on the pollen and unripe grains. It occurs at Poona every year but was particularly bad in 1918. At Poona control by means of light-traps has been tried, but these were found to be useless. The. l'usa collection contains one poor specimen.

\section{Protetia fusca, Hbst.}

Arrow, F. I. Cet. pp. 154-155, f. 34.

We have this from Insein and from Pusa, where it was bred from, larve found in farmyard manure.

Also known from Calcutta, Chapra, Cachar, Bhamo, Mandalay; Rangoon and ranges through Tenasserim and Siam to S. China, the: Malay Peninsula and Archipelago, Polynesia, N. Queensland and Mauritius (Arrow).

Ridley says that at Singapore the larvæ are very injurious to Cannas. and other cultivated plants, on whose roots they feed. In Queensland the adult beetle attacks nests of a Trigona, probably for the sake of the stored honey (Arrow).

\section{Protatia alboguttata, Vig.}

Arrow, F. I. Ceton. p. 162-163 ; Proc. Second Entl. Meeting, p. 182.

At Coimbatore and Bangalore the adult has been found on earheads: of cholam to which a little damage is done. At Pusa the adult beetle has been found at roots of Panicum. We also have it from Kanara. Belgaum, Mrsore, Surat, Chapra and Dehra Dun and Arrow also records it from Panchi and Kandy. 
Oxycetonia versicolor, $\mathrm{Fb}$.

Arrow, F. I. Ceton. pp. 164-166, ff. 35, 36 ; S. I. I. p. 284, f. 123 ; Proe. Second Entl. Neeting, pp. 90, 123, 182.

This species has been reared at Pusa from larve in farm yard manure. The adult beetle has been found in South India on flowers and shoots of groundnut, doing some damage at times, also eating flowers of bhindi and cotton in West Khandesh, and attaeking flower-lreads of cholam in South India. It is a widely distributed species which we have from Chapra, Pusa, Murbhanj and Kanti in Bengal, Bombay, Andheri, Nasik, W. Khandesh, Bangalore, Combatore and Palur.

\section{Oxycetonia albopunctata, $\mathrm{Fb}$.}

Arrow, I. I. Ceton. p. 166-167; Proe. Second Entl. Neeting, pp. 123, 212.

This speeies has also been reared at Pusa from larve in farmyart manure. The adult beetles appear at Pusa from the end of July to the beginning of November and feed in numbers on bajra, maize, juar and rice ears and have also been noted as feeding on cotton [? flowers], Hibiscus mutabilis flowers, and lemon Howers. At Combatore it has also been found on cholam. We have it also from Kanara, Chapra, Dehra Dun, Lebong, the Khasi Hills and Helem (Assam).

Lefroy reports the adult as feeding on pollen of cotton flowers, and aiso found on rice, jute, cane and other erops (Arrow) and Mr. C. M. Inglis reports the adults as damaging Lagerstromia at Laheria Serai.

I found this on heads of wheat. In Ceylon we carried on wheat- Mr. Sezior-White. growing experiments but this beetle gave us much trouble by damaging the earheads.

\section{Chiloloba acuta, Wied.}

Arrow, F. I. Ceton. p. 172, t. 2, f. 4 ; S. T. T. p. 284, f. 124 ; Proe. Second Entl. Meeting, pp. 178, 183, 188, 264-265, $278,281$.

At Pachmarhi the larva has been reported to damage seedlings of cabbage, eauliflower, artichoke, ete. The beetles often occur in large numbers and have been reported to damage rice flowers at Cuttack and Nagpur. At Virajpet, in S. Coorg, the beetles were found on paddy and on a wild grass (Pernisetum alopecurus). At Nagpur the beetle has also been found on juar heads and at Pusa on rose leaves and florrers. In Kashmir the adult was noted in very large numbers on flowers of bhang (Cannabis sativa) on the road to Srinagar, and Mr. E. A. Andrews reports it as having oecurred on tea in the Bengal Duars in considerable 
Mre. Inglig.

Mr. Andrews.

numbers, eating the young leaves and doing considerable damage.. We also have it from the Punjab (on bajra), Garhwal, Dehra Dun, Nasik, the Shevaroy Hills and Maymyo. Lefroy has also reported it as injurious to juar and kuthi [Panicum miliare; a small millet], whose flowers it damages (Arrow).

I have found it on flowers of thatehing grass.

In the Bengal Duars the adults were eating the leaves of young tea-bushes and doing considerable damage. This tea was planted on new land which had just been cleared of jungle.

\section{Epicometis squalida, Linn.}

Arrow. F. I. Ceton. p. 174, f. 40 ; Proc. Second Entl. Meeting. p. 268.

This has been sent in to us from Quetta, the adult beetles occurring on hyacinth, crocus, violet, and narcissus and destroying [the flowers?] in April 1910. It also occurs in W. Asia, Europe, N. Africa, where it. injures peach blossoms by destroying the stamens and in Greece, Corsica, Algeria and other vine-growing countries damages buds of growing: vines.

The larra is said to bred in manure (Arrow).

\section{Agestrata orichalcea, Linn.}

Arrow, F. I. Ceton. pp. 192-194, f. 2.

Oecurs in Ceylon, Travaneore. Bombay, Sylhet, Tenasserim, Anda. mans, Malay Peninsula, Sumatra, Bormeo, China, etc.

The larva bores into Pandanus. the woody stem being tunnelled through just below the point of origin of the branches, causing them to die off. At Singapore it is very destructive to ornamental Pandaners growing in tubs. The larva is preyed on by Scolia mbiginosa, Fb. (Arrow). This has not yet been noted as a pest in India but is likely to be found damaging ornamental Pandames.

\section{Spilophorus crelosus, Hope.}

$$
\text { Arrow, F. I. Ceton, Lp. 201-202, f. } 45 .
$$

We have specmens from Coimbatore, where it was found on cumbu ou 21st September 1909 and on Cordia subcordata, from Chapra, and from Halegaum in Bombay where the adult beetle was found in a nest of ('remaslogaster sp. Also known from Malda, Berhampore, and Western Provinee of Ceylon (Arrow). 
Macroma melanopus, Sch.

Arrow, F. I. Ceton, p. 219.

Adult beetles were found at Shillong in May and the beginning of June 1918 on Rubus spp., usually on wild Rubus but also attacking cultivated species. Damage slight.

Arrow also records it from Manipur, Sylhet, Jaintias, N. Kyen Hills (Burma) and Siam.

\section{DYNaSTID五.}

Xylotrupes gideon, Linn.

Arrow, F. I. Dyn.; pp. 262-265, ff. 59.

Recorded from Calcutta, Kurseong, Shillong, Sibsagar, Cachar, Bombay, Travancore, Ceylon (Arrow).

The Pusa Collection contains specimens from Dehra Dun, Mereara (Coorg), Dacca, Tezpur, Khasi Hills (1,000-3,000 feet), Shillong, Helen (Assam), and the Philippines. At Tezpur the adult beetles were found damaging seed indigo plants by gnawing and stripping the bark.

\section{[Eupatorus hardwickei, Hope.}

Arrow, F. I. Dyn., pp. 268-269.

While staying with Mr. J. R. P. Gent of the Forest Service in the Mr. Inglis. Kurseong Division (elevation 6,000 feet) he brought in one of each of Eupatorus hardwicliei and E. hardwickei cantori which he found stripping the bark from an Alder (Almus nepalensis). As far as I remember, he said the beetles were working vertically and doing a good deal of damage by stripping off about four feet of the bark all round the tree.]

\section{Oryctes nasicornis, L.}

Arrow, F. I. Dynast., pp. 275-276; Proc. Second Entl. Meeting, p. 262.

We have specimens from Quetta and had for determination from Mr. Fletcher. Mr. Milne one specimen captured by him at Dalhousie.

Recorded from Baluchistan, Kashmir, S. W. Asia, S. \& S. E. Europe (Arrow).

This species is not definitely known as a pest but probably attacks date-palms in North-West India. 
Orycles rhinoceros, $\mathrm{L}$.

Arrow, F. I. Dynast., pp. 278-281, ff. 6, 63 ; S. I. I. p. 285, t. 3 ; Proc. Second Entl. Meeting, pp. 135, 145, 259, 262.

Throughout Southern India and Ceylon as far north as Pusa and Bandra, apparently not found in the United Provinces and we have no records from the Central Provinces. The larva occurs in farmyard manure, coffee pulp, rotting aloe stems and decaying vegetation generally, the adult beetle boring into crowns of palm trees, occasionally into sugarcane. It has been found in sugarcane at Coimbatore, and in Travancore is said to occur rarely in cane when 3-4 feet high.

The Pusa Collection contains specimens from Pusa, Bangalore, Kanara, N. Coorg (larva in rotten coffee pulp), Virajpet in S. Coorg (damaging coco palms) and Trichinopoly.

Mir. Fletcire:

The northern limit of the distribution of Oryctes rhinoceros in India does not seem to be definitely known. We have no records from the United Provinces and no specimens from the Central Provinces.

Nir. David.

It is not found at Cawnpur.

IIIr. Fibare.

IMr Ramakrishna Ayyar.

Mr. Fletcher.

Mr. Ramakrishna

Ayyar.

MY. Kunhi Kannan.

Mir. Eletcher.

In the Central Provinces we find it breeding in manure heaps. It is found throughout the Central Provinces.

A new control method has been tried in Travancore. A powdered oil-cake is prepared from a plant called marrali (? Hydrocarpus sp.) and placed in the crowns of the palms. This has a strong smell and a bitter taste and probably acts as a repellent.

How far is it actually practical ?

I do not know. I have only lieard of it.

Fermented ragi water was tried in Mysore and found to attract the beetles in large numbers.

Do the people keep pigs in these coconut-growing districts in Southern India?

Mr. Ramakrisbna No ; but they make pits filled with rubbish and when the beetles Ayyar.

Mr. Senior-White. have collected they are lilled off.

In Ceylon, in the low-country at an altitude of about 400 feet, the Singhalese keep pigs and, so far as I know, they do not have much trouble with Orycles.

\section{Heteronychus sacchari, Arrow.}

Arrow, F. I. Dyn., p. 297, f. 69.

Recorded by Arrow from Rangpur (Bengal) and "reported as causing considerable injury to sugarcane."

No specimens in Pusa Collection. 
Allissonotum piceum, $\mathrm{Fb}$.

Arrow, F. I. Dynast., p. 299 ; Ann. Rept. Impl. Entom, 1917-18, p. 93.

Recorded from Darjiling, Sundarbans, Dacca, Malabar, Ceylon (Arrow).

The Pusa Collection contains specimens from Dacca, Chapra, and Pusa, where the larva was found boring into sugarcane shoots, and the adults occur at roots of Saccharmm spontaneum in sone numbers from July to September.

\section{Alissonotum simile, Arrow.}

F. I. Dynast., p. 300-301 ; Ann. Rept. Impl. Entom. 1917-18, p. 93.

Recorded from Assam (Dilkoosha), Sylhet and Pusa (Arrow).

The Pusa Collection only contains examples from Pusa, where the adults occur at light in June and July, and the larva has once been found in a sugarcane field in May. The larva probably eats roots in the same way as A. piceum.

\section{Pentodon bispinifrons, Reitter.}

Arrow, F. I. Dyn., p. 303 ; Proc. Second Entl. Neeting, p. 146.

Recorded from Banmu, Baluchistan, Karachi, Persia and Turkestan (Arrow). The Pusa Collection contains specimens from Lyallpur, Baroda (adult, labelled "sugarcane" 17 August 1907), Pusa (adults at light), Simla (adult, July 1909), and Chapra.

This species probably bores into cane in the same way as $P$. bengalense.

\section{Pentodon bengalense, Arr.}

Arrow, F. I. Dyn., p. 304, f. 71 ; Proc. Second Entl. Meeting, p. 146.

Recorded by Arrow from Pusa and Rajmahal. The Pusa Collection contains specimens from Chapra, Pusa (larva at roots of sugarcane) and Peshawar, where the adult has been found destroying sugarcane shoots by burrowing in below ground.

\section{Pleyllognathus diomysius, $\mathrm{Fb}$.}

Arrow, F. I. Dynast., pp. 307-308, f. 73 ; Ent. Mem. II, 139143, t. 13 ; Proc. Second Entl. Meeting, p. 174.

The Pusa Collection contains specimens from Simla, Dehra Dun, Pusa, Chapra, Hoshangabad, Seoni, Igatpuri, Belgaum, S. Kanara and Coimbatore, whilst Arrow also records it from Kinseong, Purnea District, 
Chota Nagpur, Calcutta, Mysore and Ceylon. The adult beetle was: found in S. Kanara cutting stems of young rice-plants on one occasion, and the larvæ were found in numbers at roots of rice-plants at Belgaum. It is apparently a sporadic pest of paddy.

\section{LUCANIDÆ.}

Lucanus lunifer, Hope.

Stebbing, Ind. For. Ins. Col., pp. 70-72, ff. 37, 38.

This species occurs throughout the Himalayan region, the larva feeding in rotten wood. We have it from Dehra Dun and Ramgarh.

At Ramgarh, Kumaon District, two male specimens were given me in August 1918 by Mr. N. Gill as having been found boring into peach fruits about the middle of July. The beetles are said to do considerable damage in this way and to bore into sound ripe fruits.

\section{SCOLXTID瓜.}

\section{Xyleborus fornicatus, Eich.}

This Scolytid is the well-known and destructive "shot-hole borer" of Ceylon and has been reported as found in Travancore also, but this latter reeord appears to be uncertain. At Bangalore it has been reared from bored castor stems.

Mr. Pamakrishna Aygar.

Mr. Senior-White.

Plants over a year old were attacked. The whole stem was bored. All stages were found in the stem-eggs, grubs and beetles.

Mr. Speyer states that castor is the normal food of this insect. He came to this conchusion by a comparison of the galleries in castor and tea. He believes that it comes into tea as an overflow when its numbers have inereased too much on castor. In the Tea districts of Ceylon the planting of castor has been prohibited. It is extending its range in Ceylon.

Mr. Fletcher.

It is strange that it is such a bad pest of tea in Ceylon but not in Sontli India.

Mr. seric-White. Mr. Speyer is now recommending fish-oil paints on the tea-bushes. His Bulletin on the subject is expected shortly and will contain all the information.

\section{[Xyleborus sp.}

Ir. ¿'haveri.

Another speeies of Xyleborus was found in and around Surat damaging date and coconut palms. This appears to be a new pest in this locality and has been noticed to spread gradually into the surrounding gardens at Surat. This insect was found to damage the tree by making very small holes of the size of the head of an ordinary pin. The damage 
commences from a foot or two above ground-level and goes upwards. It appears to be a serious pest in this limited area.

See also the Scolytid on coconut in Madras. Possibly both species are identical.-Editor.]

\section{(Undetermined Scolytid.)}

S. I. I., pp. 344-345, fig. 203; Proc. Second Entl. Meeting, p. 37.

This Scolytid occurred very abundantly in cardomom capsules in Mr. Fietcher. Coorg in 1913 and damaged a large percentage of the crop, but has not been reported again.

\section{(Undetermined Scolytid.)}

Proc. Second Entl. Neeting, p. 261.

An undetermined Scolytid has been reported to bore in the stems of coconut palms at Negapatam and in the Godavari district, killing the attacked trees. It is also reported to be a bad pest of coconut in $\mathrm{N}$. Kanara, but very little seems to be lnown about this insect.

\section{(Undetermined Scolytid.)}

Another undetermined Scolytid has been reported as damaging Hevea rubber trees, by boring the bark, on the Moopli Valley Estate. It is said to attack healthy trees.

\section{Platypodida.}

\section{[? Crossotarsus, sp.}

A Platypodid has been reported as attacking Hevea rubber trees in Irr. Ramakrishna Travancore also.]

\section{Curculionid}

Blosyrus asellus, Linn.

Nshll., F. I. Curc., I. p. 33 ; Proc. Second Entl. Meeting, p. 292.

The Pusa Collection contains specimens from Simla, Chapra, Muzaft-Mr. Fletcuer arpur and Pusa and Marshall also records it from Bengal, Assam, Burma, Andamans, Cambodia, Malacca, Sumatra, Borneo and the Philippines.

At Pusa the adults have been found on cotton and on sweet-potato in small numbers. but it is probably not a pest. 
Blosyrus inaqualis, Boh.

Mshll., F. I. Cure., I, pp. 35-36 ; Proc. Second Entl. Meeting, pp. 61, 81.

This species seems to be restricted to Sonthern India. We have it from Yemmiganur, Adoni and Hadagalli (all in Bellary), Coimbatore, and Nellikuppam (S. Arcot) and Marshall also records it from Sampgaon, Belgaum, Mysore, Bangalore, Pondicherry, Nagodi (S. Kanara), N. Coorg, and Anuradhapura.

At Adoni the adults were found on gingelly, at Hadagalli on cluster beans, and at Nellikuppam in August 1912 on indigo in some numbers.

\section{Tamymecus sciurus, Oliv.}

Mshll., F. I. Curc. I, pp. 76-78, f. 24v ; Proc. Second Entl. Meeting, p. 149.

We have this from Eastem Bengal and Assam (I. R. 357-V of 1 Angust 1907), Chapra and Pusa, and Marshall also records it from Chota Nagpur and Patna. At Pusa it has been found on sugarcane on two oceasions and in small numbers on cotton.

Mr. P. C. ฐeท.

I found it doing a certain amount of damage to sugarcane at Rangpur. It eats the soft leaves of the young shoots.

\section{Tamymecus princeps, Fst.}

Mishll., F. I. Curc., I, 97, f. 24l ; Proc. Second Entl. Meeting, p. 103.

Mir. Fletcher.

We have this from Surat, where it was found "on cotton leaves," from Hoshangabad, and from Palaman, where D. P. Singh found it commonly in October 1906. It is also recorded by Narshall from Nagpur, Belgaum, and N. Kanara. At Belgaum it was found on beans or other plants bordering rice-ficlds (Marshall).

Tanymecus hispidus, Mshll.

F. I. Curc. I. 95, f. 24t; Proc. Second Entl. Neeting, pp. 103, $149,168,190,207,254$.

The larva has been found at Pusa in sugarcane fields. The Pusa Collection contains specimens from Rohtak (Punjab), found on cotton, from Pusa, Dholi and Cooch Behar, and Marshall also records it from Rampurchaka, Bijnor District, United Provinces, and Jallandhur. It is of very minor importance as a rule, occurring at Pusa on maize, rice, sugareane, lucerne and leaves of Dalbergia sissu and Zizyphus jujuba, but at Dholi [near Pusa] in Jume 1909 it was reported to be attacking maize and in March 1918 it was sent in to us by Messrs. Turner, Morrison $\&$ Co. as found in fairly large numbers on a sugarcane plantation in Cooch Behar. 
Tanymecus indicus, Fst.

Mshll., F. I. Curc., pp. 99-100, f. 32 ; Proc. Second Entl. Meeting, pp. 69, 81, 96, 97, 134, 168, 180, 186, 190, 193, 273, 283.

Our records include the following localities and foodplants:-

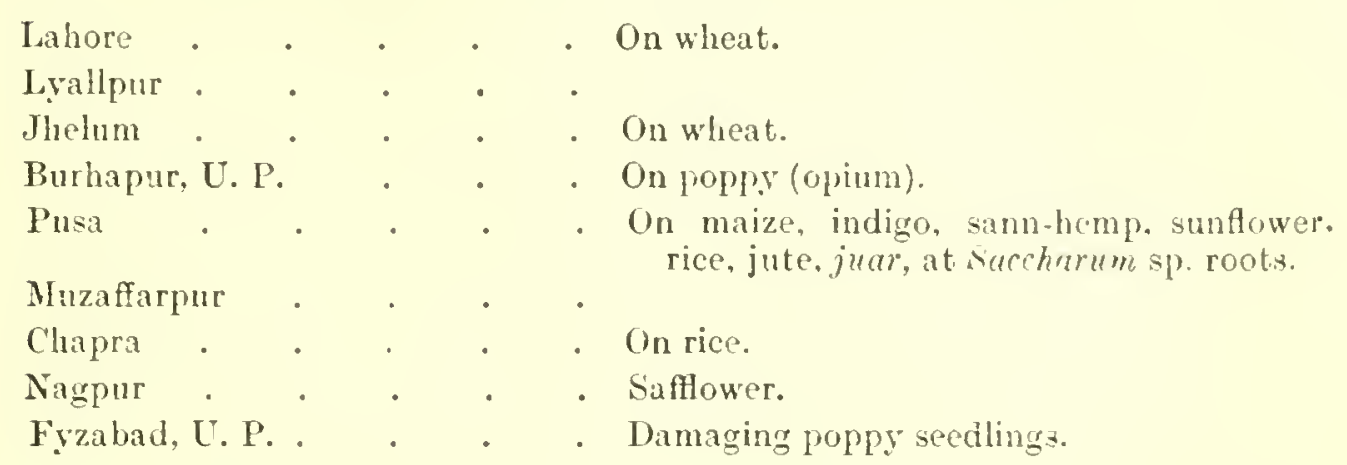

It is an occasional bad pest of young wheat (when 5-6 inches high) in the Punjab and once occuured in numbers on beetroot at Pusa. Split pumpkins, placed at dusk and examined before sunrise, may be used as traps for the beetles. Marshall also records it as a pest of gram and barley, and at Surat the adults attack juar seedlings and do some damage.

I found it a serious pest of juar seedlings at Surat last year. A Mr. Juaveri. bait of cut pumpkins and heaps of uprooted weeds, put in the rows, attracted large numbers of beetles. It is also found on cotton.

In Madras it is found on cotton.

Mr. Ramakrishna

Ayyar.

Atmetonychus peregrimus, Oliv.

Mshll., F. I. Curc., I. pp. 112-113, f. 37 ; Proc. Second Ent?. Meeting, pp. 123, 253, 273, 285.

We have this from Amballa, Fyzabad, Chapra, Pusa, Cuttack and wr. Flocker. Eastem Bengal and Assam. At Pusa the adults have been found on jute and on two occasions on ber, at Amballa on bhindi. at Cuttack on potato leaves, whilst at Fyzabad it was reported on opium poppy on 16th December 1904 and again as damaging poppy seedlings on 14th January 1918.

\section{Hypomeces squamosus, $\mathrm{F}$.}

Mshll., F. I. Curc., I. pp. 116-117, f. 39 ; Proc. Second Entl. Neeting, pp. 128, 296.

This species is apparently common in Burma and we have it frum Myitkyina, Mandalay, Tagunding, Minbu and Moulmein. At Myitkyina the adults occurred on orange and on Hibiscus rosasinensis, and at Mandalay K. D. Shroff found it on Amarenthus.

In South India and Assam it defoliates teak, etc.

Irr. Beeson. 
Dereodus pollinosus, Pedt.

Mshll., F. I. Curc., I. 121 ; Proc. Second Entl. Meeting, pp. 136, 248.

Mir. Fletcher.

Marshall records this from Kumaon, Nepal, Kashmir and Baluchistan, and we have it from Masuri, Simla, Kulu, Amritsar, and Dera Ghazi Khan (I. R. 86-V, 12 May 1908).

At Amritsar it was found on Calotropis and at Kulu it was found attacking and defoliating wild apples.

Astycus lateralis, $\mathrm{Fb}$.

Mshll., F. I. Curc., I. pp. 139-140 ; Proc. Second Entl. Neeting, pp. $42,61,103,149$.

Marshall records this as widely distributed in India, Burma, Siam and Malay Peninsula, and in Ind. Mus. Notes, IV, 181 (1899) it was reported as attacking tea plants in Assam and defoliating. mulberry bushes at Rangoon.

Our specimens show the following localities and records :-

Pusa, on cluster bean, jute, marua, sugarcane, bhindi, juar, and Erythrina indica leaves. It occurs mostly during the Rains and is sporadically abundant on cotton;

Cawnpur, on cotton;

Dehra Dun ;

Chapra ;

Tatkon, on sugarcane;

Lashio;

Maymyo ;

Insein ;

Myithyina, Hibiscus rosa-sinensis leaves;

Nagpur, does a little damage to cotton and tur;

Kliasis;

Travancore, on Amaranthus;

Mercara;

Multan;

Belgachia ;

Narayanganj;

Cuttack.

Mr. Misra

Sporadically it occurs in large numbers on cotton, particularly in the rains.

Mr. Ghosh

It is quite common on sann-hemp also. 
Tylopholis ballardi, Mshll.

F. I. Curc. I. 157-158, f. 50 ; Proc. Second Entl. Meeting, p. 50.

This species was found in the Bellary District, at Yemmiganur, Mr. Fletcher. attacking stems of Bengal gram. I have no further information about it.

Sympiezomias frater, Mshll.

F. I. Curc. I. 164 ; Proc. Second Entl. Meeting, p. 29.

Recorded by Marshall from the Nilgiris, Balur, Yercand, and Coorg. At Yercaud, in April-1lay 1913, it occurred on coffee in some numbers, but is probably only a very minor pest; it was also taken by C. W. Mason on coffee in the Shevaroys, in August 1907. We also have specimens from Sidapur (May 1914) and Pollibetta (September 1903).

\section{Sympiezomias cretaceus, Fst.}

Mshll., F. I. Curc. I. 167 ; Proc. Second Entl. Meeting, pp. 29, 255.

This species has been found on mulberry at Bangalore on 26th August 1913, and on coffee at Hillgrove (Nilgiris) on 3rd September 1908. We also have it from Bailur Forests, Coimbatore District, on 23rd November 1913, and from the Nilgiris. It is doubtful how far it is a pest.

\section{Sympiesomias decipiens, Mshll.}

F. I. Curc. I. 167 ; Proc. Second Ent. Meeting, p. 37.

This species was reported in May 1913 as injuring young Java Ledger Cinchona in the Kukal Orange Valley, Nilgiris, by eating the leaves. The leaves sent were seriously injured. It is recorded by Marshall as occurring in the Nilgiris (1,000-6,000 feet) and in Pirmaad, Travancore.

\section{Episomus lacerta, Fb.}

Mlshll., F. I. Curc., I. 223-225, f. 66k ; S. I. I. pp. 327-328, f. 184 ; Proc. Second Entl. Meeting, pp. 42, 56, 77, 121, 187.

This is a South Indian species, which we have from Surat, Cuttack, Samalkota, Bellary, South Arcot, Coimbatore, Pollibetta and Mercara. At Surat it was found on bajra, at Samalkota on tur, and in Bellary, S. Arcot and Coimbatore on julses. At Coimbatore it has been found eating field bean leaves in numbers. Throughout Coorg it is common on Erythina, eating the leaves.

It is recorded by Lefroy (Ind. Ins. Life, p. 384) as eating cotton barl; but this is perhaps an error of determination. 
Mr. Ramakrishna Ayyar.

Mr. Fletcher.

\section{Mr. Ramalsishna} Ayyar.

Mr. Fle`cher.
It is very common in Southern India, especially on leguminous. crops.

\section{Emperorrhinus defoliator, Mshll.}

Mshll., F. I. Curc., I. 286-287; Proc. Second Entl. Meeting. pp. $240,245,247,248,250$.

This species occurs in Kulu, Kurseong, Darjiling and the Khasi Hills. At Kulu it appears first on Alnus nitida, and then attacks peach, then apricot and pear, apple being touched last. It is a serious local pest of fruit-trees in Kulu.

\section{Myllocerus viridanus, Fb.}

Mshll., F. I. Curc., I. 301-303, f. 93 ; Proc. Second Entl. Meeting, pp. $81,88,92,123,134,231$.

This small greyish or pale-greenish weevil seems to be confined to South India and Ceylon. We have it from Madura, on castor; Tanjore ; Manaparai; Palur, on guava leaves and in numbers on groundnut; Coimbatore, on castor; Chepauk, on groundnut; Shoranur (Malabar), on bhindi; Kumbakonam, on jute ; Nellikuppam, on indigo ; and Trichinopoly, on groundnut in numbers in August 1908.

It is sometimes a bad pest of groundnut in Southern India.

Myllocerus setu'ifer, Desb.

Ind. Mus. Notes, IV, p. 111, t. 8, f. 2 (1899); Mshll., F. I. Curc., I. 312-313.

This species has been recorded from Dehra Dun where the adults were found damaging rose flowers in the Forest School Garden. The Pusa Collection contains no specimens.

\section{Myllocerus dorsatus, $\mathrm{Fb}$.}

Mshll., F. I. Curc., I. 320-321 ; Proc. Second Entl. Meeting, pp. 65, 92.

We have this from the following localities and foodplants:-Kumbalionam (Madras), sword-bean leaves; Trichinopoly, on Margosa [Melice asadirachta] leaves; Tranquebar; Villupuram (Madras), on groundnut; and Nanaparai. Marshall also records it from the Nilgiris, Pondicherry, Bangalore, Belgaum, Nagpur, Calcutta and Pusa. 
Myllocerus blandus, Fst.

Mshll., F. I. Curc., I. 333-334, f. 101; Proe. Second Entl. Meeting, pp. 69, 96, 123, 141, 168, 180, 190, 195, 256, 287.

Marshall gives the distribution of this species as Godavari District, Pusa, Dacca, Siripur, Sarda, Prome, Nandalay and Yenangyaung.

The Pusa Collection contains specimens from :- .

Pusa, on bhind, sunflower, rice, cane, carrot, strawberry plant, sissu, sann-hemp, maize, wheat leaves, Tumarix, cucumber leaves, eating guava and pumpkin leaves, pupa underground in indigo field; Sirsiah (N. Bihar); Lyallpur, on brinjal; and Fyzabad, damaging poppy seedlings.

\section{Myllocerus sabulosus, Mshll.}

Mshll., F. I. Curc. I. 336-337; Proc. Second Entl. Meeting, pp. 102, 219, 231, 254, 292.

Marshall records this from Chota Nagpur, Purneah, Ranchi, Dehra Dun and Madras. The only specimens that we have are from Pusa, where it has been found in some numbers on Zizyphus jujuba, on cotton and sweet-potato and devouring young mango leaves.

\section{Myllocene transmarinus, Hbst.}

Mishll., F. I. Curc. I. 337-338, f. 102 ; Proc. Second Entl. Meeting, pp. 102, 254 .

Marshall records this from the Punjab, United Provinces, Calcutta, Chota Nagpur, Central Provinces, and along the Western Ghats to Bellary.

We have it from Chapra and Pusa. At Pusa it occurs mostly on Zizyphus jujuba and has also been found on cotton and eating young leaves of Dalbergia sissu. It is not a pest as a rule.

\section{Myllocerus subfasciatus, Guer.}

Mshll., F. I. Curc. I. 345-346; Proc. Second Entl. Meeting, pp. $285,287$.

This species occurs in Madras. S. Bombay, Central Provinces, Burma and Ceylon. We have it from the Nilgiris, Ootacamund, Saidapet (Madras), Coimbatore and Virajpet (S. Coorg). At Saidapet and Coimbatore it has been found eating brinjal leaves and at Ootacamund on potato leares, and it is sometimes a bad pest of these crops. buds.

In Cevlnn it does some damage to brinjal, attacking the flowers and Mr. Senior-White. 
Mr. Fletcher.

Mr. Misra.

\section{Myllocerus dentifer, $\mathrm{F}$.}

Mshll., F. I. Curc. I. 347-348; Proc. Second Entl. Meeting, pp. 92, 168, 201.

This species occurs in Ceylon (low country), throughout Madras and Orissa to Palamau and Chota Nagpur. We have it from Colombo ; Palamau; Shoranur (Malabar), on paddy; and Palur (S. Arcot) on groundnut and tenci.

It is probably quite a minor pest, often found intermixed with other species of Myllocerus.

\section{Myllocerus discolor.}

Ishll., F. I. Curc. I. 348-350, f. 106 ; Proc. Second Entl. Neeting, pp. 92, 102, 126, 134, 141, 146, 168, 192, 195, 216, $219,231,250,254$.

M. liscolor has been reared at Pusa from larvæ found at roots of sugarcane and maize. It is a widely-distributed species, which we have from the following localities and foodplants:-Simla; Patiala; Pusa, adults on Eribotrya japonica (loquat), lucerne, guaví, sugarcane, wheat, ber (Zizyphas jujuba), young mango leaves, jute, rice, bael, and cotton; Kanti (Bengal), on cotton; Jamalpur (Bengal), on grass and ber ; Comilla ; Cuttack; E. Bengal and Assam ; Bangalore; Coimbatore, adults on wheat and Hibiscus cannabinus, larva at roots of tenai (Setaria italica); and Palur, on groundnut.

It is a common species, often occurring in sufficient numbers to constitute it at least a minor pest.

It is found on every crop but is not serious to any as a rule. In one year, however, it was a pest.

\section{1yllocerus 11-pustulatus, Fst.}

Mshll., F. I. Curc. I. 350-352. [Includes vars. pistor, maculosus and marmoratus]; Proc. Second Entl. Meeting, pp. 42, 72, 96,102 (tab), 121, 123, 126, 141, 180, 187, 190, 192, 200, $202,219,231,232,248,254,256$.

This Myllocerus is a common and widely-distributed species and a general feeder on almost all plants. It has been reared at Pusa from larva found at roots of cotton and maize. The Pusa Collection contains the following records of adults:-Multan ; Amritsar, on cotton; Lyallpur, on cotton; Lahore, on cotton and bajra; Dehra Dun; Cawnpur, on cotton; Baktiarpur, on tender mango leaves; Pusa, on cotton, maize, sunflower, ber, tur, bhindi, mango, sugarcane, pomegranate, 
guava, strawberry, Panicum frumentaceum, marua, and ambadi; Dacca; Kanti (Bengal), on cotton; Manjri (Bombay), on cotton; Surat, on maize; Poona, on ambadi, bhindi, cotton, maize and millets; Bangalore, on apple shoots and branches; and Coimbatore, on cholam. Especially a pest of cotton, but often of other plants also.

Has any one any remarks to offer on the control of these species of Mr. Fletcher. Myllocerus generally?

We tried dusting the attacked plants with lead arsenate and a number Mr. Ramakrishna of beetles were killed; but this is a measure which we should not Ayyar. advise on any large scale to the raiyats.

\section{Sitones crinitus, Oliv.}

Proc. Second Entl. Meeting, pp. 81, 207, 208.

This species has been found in Champaran and at Dalsing Serai (N. Bihar) on indigo and at Pusa on lucerne in some numbers and also on senji, cabbage. wheat-ear, jute and ber. It is not a pest as a rule.

It can be controlled by shaking it off with brushes made of twigs.

Mr. Misra.

Peltotrachelus pubes, Fst.

Proc. Second Entl. Meeting, p. 211.

We have this from Goraklipur, Pusa, Cuttack, the Nilgiris and the Shevaroys. In the Shevaroy Hills it occurred on orange and is a minor pest. At Pusa it lias been found on Zizyphus jujuba in small numbers, whilst the specimens from Cuttack were found in Termites' nests [!].

\section{Platymycterus sjöstedti, Mshll.}

We have this from Dehra Dun, Chapra, Pusa and Daltonganj. At Pusa it has been found on grass, Dalbergia sissu, tender mango leaves, sann hemp and jute, and at Daltonganj on ber. It usually occurs in small numbers and has not yet been noted as a pest.

\section{Phyloscaphus triangularis, 01.}

We have this from Pusa, on bamboo, pear, cotton leaf, sann hemp, ber, rice, cane leaves, indigo, jute, sweet potato, dhaincha, tur, and maize; from Cawnpur, on groundnut; Pratapganj (Bengal); and from Daltonganj.

It occurs as a rule in small numbers and has not been noted as a pest. 
Phytoscaphus dissimilis, Mshll.

Bull. Ent. Res. V. iv fig.; Entl. Note 26 ; Proc. Second Entl. Meeting, p. 21.

This species has been found in Assam, nibbling young tea-shoots.

Amblyrrhinus poricollis, Boh.

Proc. Second Entl. Meeting, p. 219.

This has been found at Pusa, on tender mango leaves, bael, Albizzia lebbek, sissu leaves, litchi, and mango inflorescence ; at Cuttack, on ber; at Pithapuram (Godavari), on country almond leaves (Terminalia); and at Hagari, on agathi.

\section{Hypera medicaginis, Mshl.}

Proc. Second Entl. Meeting, pp. 207 (tab.), 208.

This has been reared at Pusa from larræ on lucerne, pea, senji (Melilotus alba), Lathyrus hirsuta, and a weed locally called akta. It is a sporadic minor pest of these plants when cultivated.

Mr. Misra.

The pupæ are prominent on the leaves and may be picked off. Spraying is out of the question.

\section{Hypera variabilis: Host.}

Mr. Fletcher.

We have this from Tarnab and Charsada in the North-West Frontier Province; Lyallpur, on lucerne leaves; Jallandhar; Lahore, on senji ; and from Pusa, larræ on lucerne. It is a sporadic minor pest of trefoils.

\section{Xanthotrachelus faunus, Oliv.}

Entl. Note 27 ; Proc. Second Entl. Meeting, pp. 96, 253.

We have this from Chapra, Pusa, Khandala, Cuttack and Maymyo. At Pusa the adults occur commonly on ber and have been found attacking sun-flower heads, whilst a few have also been taken on rice and grass.

Xanthotrachelus perlatus, Fb.

Entl. Note 27 ; Proc. Second Entl. Meeting, p. 96.

We have this from Masuri, Dehra Dun, Lahore, Muzaffarpur, Pusa and Daltonganj. At Pusa the adults were found attacking newly-formed sun-flower heads and a few have also been taken on castor and cotton. At Daltonganj this weeril was found on Butea frondosa. 
Xenthotrachehus supercitiosus, Giyll.

Proc. Second Entl. Meeting, p. 96.

We have this from Belgaum, Chapra, Pusa and Tharrawaddy. At Pusa it has been found on ber and a few adults were also found attacking sunflower heads in company with the two preceding species.

Atactogaster finitimus, Fst.

S. I. I., p. 333, f. 191 ; Proc. Second Entl. Heeting, pp. 98, 102.

We have this from Nathampatti (Ramnad) and Koilpatti, where the adults were found devoming young cotton plants. In Ind. Iusem Notes (Vol. IV, pt. III, p. 112 (1899)) this species is also recorded as damaging young cotton and gram shoots at Tinnevelly.

During the last two or three years we have found it in small numbers. Mr. Ramakrishna

Have you found it at Coimbatore?

A ууат.

It is found, but not as a pest.

Lixus brachyrrtinus, Boh.

S. I. I., pp. 331-332, f. 189 ; Proc. Second Entl. Meeting, p. 296 (tab.).

Lixus brachyrrinus is a widely distributed species, contained in the rur. Fletchor. Pusa Collection from:-Lahore, on Amaranthus; Cawnpur, on Niger seed; Nagpur; Balaghat (Central Provinces); Igatpuri; Surat; Poona; Bangalore; Coimbatore, on Amaranthus; Erode, on Amaranthus: Trichinopoly; Manaparai; Chingleput, on Amaranthus; Cuttack; Chapra; Pusa, on indigo, larva on Amaranthus; Daltonganj, on ber leaves; Nandalay, on Amaranthus and ber; Meiktila (Upper Burma); and Mimbu (Lower Burma).

It is a specific pest of Amaranthus, the larva boring in the stem and causing a gall-like swelling, but the attack usually takes place at a time when the plant is past the period for consumption.

Paramecops farinosas, Wied.

S. I. I., pp. 332-333, f. 190 ; Proc. Second Entl. Meeting, pp. $136,137$.

We have this from Taru (North-West Frontier Province), on Calotropis; Lyallpur, on Calotropis; Lahore; Igatpuri; Bor Ghat; Coimbatore, on Calotropis; and Pusa, on Calotropis.

It is a specific pest of Calotiopis, although adults have been taken on rice at Pusa on two occasions. 
Apoderus tranquebaricus, $\mathbf{F}$.

S. I. I., pp. 335-336, f. 193 ; Proc. Second Entl. Meeting, pp. 219, 246.

We have this from Saidapet, Chepauk, Chittur, and South Arcot. It occurs on country almond (Terminalia catappa) and less commonly. on mango, twisting the leares, but it is scarcely a pest.

\section{Cylas formicarius, $\mathrm{Fb}$.}

S. Ind. Ins. pp. 334-335, t. 12 ; Proc. Second Entl. Meeting, p. 293.

This weevil occurs abundantly in all districts south of the United Provinces and is a very serious pest of sreet potato. We discussed this fairly fully at the last Meeting and I do not think there is much to add. The best preventive method that we can recommend at present is early harvesting.

Mr. Ghosh.

Mr. Fletcher.

Mr. Misra.

Mr. Fletcher.

Mr. Misra.

Mr. Fletcher.

Mr. Ramrao.

Mr. Ghosh.

Mr. Fletcher,

Mr. Ramrao.

At Pusa it only damages the July crop and not the winter crop. The only possible remedy is the use of early harvesting varieties.

In the winter there are no beetles about at Pusa and so there is no damage.

Deep-rooting varieties are not so badly attacked.

But later on the beetles get down even into deep-rooting varieties.

Is it recorded that the beetles are attracted to light?

They come in to light commonly but not in large enough numbers to use that as a means of control.

Has anyone reared any parasites from this species? If anyone comes across any effective parasite, we should like to know about it.

\section{Balaninus c-album, $\mathrm{Fb}$.}

Ann. Rept. Impl. Entom. 1917-18, p. 102, t. 18, f. 1 ; Proc. Second Entl. Meeting, p. 247.

We have this from Pusa and Eastern Bengal and Assam (probably Dacea). It also occurs at Poona. The life-history, damage, and control were treated of in my last Annual Report and we have no more to add to that.

It was reared in Poona from seeds of Eugenia jambolana. In our district most of the fruits are attacked. Is there any remedy?

The collection and destruction of the seeds is the only measure that is possible.

Has the life-history been worked out in Bombay and, if so, is it the same as at Pusa?

It is the same as at Pusa. 


\section{[Balaninus sp.}

In 1917 a large number of jamun fruits which had a pitted or distorted Mr. Kbare. appearance were examined. It was thought first of all that each of the pits might have been a passage through which the egg was deposited. The pulp of the fruit was carefully examined, but no trace of any insect could be got. When the entire pulp was scraped off some brownish scars were noticed on the skin which was peeled off and the scars were noticed deep in the seed. On cutting open the seed, a whitish grub was found either in the centre of the seed or in the deep scars. Usually one grub is found in each seed, but sometimes more than one may be got. The pits on the fruits must have been made by the adult by thrusting their proboscis to feed on, which ultimately never heal up. The grubs remain inside, eat up, make the seed hollow and fill up with excreta, etc. These do not come out of themselves by biting a way through, but wait till the fruits drop on the ground. The fruits drop in large numbers on the ground and rot. The upper skin and pulp are all removed and the seeds are exposed. The seeds of Jamun fruits germinate very quickly and in such process the two cotyledons split up and liberate the encased grub. The grubs later on get into the moist soil, prepare several small earthen chambers, many of which are found lumped up together. If these chambers are periodically opened, one sees the grub lying inside. This shows that restivation of the grub takes place in the soil. till the following April or May when they pupate and emerge as weevils, but in some cases weevils emerged in August, i.e., within three months. This weevil is of the same shape and size as the one described in the report of the Imperial Entomologist of 1917-18, p. 102, but in colour it is uniformly brown and does not possess the whitish lines on the elytra. Mr. Naoroji kindly identified the specimens and put them under the genus Balanimus.]

\section{Eugnamptus marginatus, Pasc.}

S. I. I., pp. 329-331, ff́. 186-187 ; Ann. Rept. 1917-18, p. 99, t. 16, f. 1 ; Proc. Second Entl. Meeting, p. 219.

Our records include the following localities and foodplants:-Dehra Mr. Fletcher. Dun, adults defoliating Butea frondosa; Poona, mango leaves; Nagpur, young mango leaves; Pusa, mango leaves, the young leaves being completely eaten at times; Sabour, mango leaves; Maymyo, tender mango leaves.

The life-history has already been described and figured.

At Dehra Dun it defoliates Butea frondosa.

At Dacea it does slight damage by cutting the soft leares of mango. Mr. P. C. Sen. 
Mr. Fletcher.

Mr. P. C. Sen.

Mr. Misra.

Mr. Fletcher.

\section{Apion sp.}

Proc. Second Entl. Meeting, p. 134.

This species occurs throughout the jute-growing districts of Bengal and Bihar as a minor pest of jute, sporadically serious. The larva bores just at the junction of the leaf-petiole with the stem and cuts through a good many of the fibres. The attacked leaf withers and droops and this indicates the presence of the grub. No control measures can be suggested at present.

It was found doing considerable damage to jute plants grown in pots [at Dacca]. Though it is common in jute fields, it has not been found doing much damage. When it attacks the tops of young plants, it does considerable damage, but when it attacks side-shoots of old plants the damage is not appreciable. Cenerally the young affected plants, which are not too many, are uprooted at the time of weeding and thimning. In the pot-culture house the affected shoots were removed and the grubs destroyed.

Once I found it very bad on jute at Munshiganj. The plants were riddled and the fibre unfit for use. It is not known to occur every year. No remedy has been tried.

\section{(Jute Apion.)}

S. I. I., p. 331, f. 188; Proc. Second Entl. Meeting, p. 134.

This occurs in Godavari and Bellary, in May and June, the larva boring stems and shoots of jute. It may be identical with the preceding, but we have no specimens in the Pusa collection for comparison.

\section{Apion sp.}

Proc. Second Entl. Meeting, p. 45.

This species attacks Cajanus indicus in Burma, but we have no further information about it.

\section{Alcides bubo, $\mathrm{Fb}$.}

S. I. I., pp. 337-338, f. 96 ; Proc. Second Entl. Meeting, pp. 61,73, 75, 81.

We have this from Bhor Ghat, "on grass (Dixon)"; Chapra; Cuttack, thaincha stem ; Pollibetta (South Coorg); Podanur, on agathi; Madura; Saidapet, agathi stem; Palur, on indigo ; Villapuram and South Kanara, on cluster-bean. It is especially a pest of species of Sesbania, the larva boring in the stem and causing a gall-like swelling. Cutting of the bored stems, when these are in the top-shoots, seems the only practicable remedy. 
Alcides collaris, Pasc.

S. I. I., p. 337, f. 195 ; Proc. Second Entl. Meeting, pp. 46, 52, 56.

We have this from Sarai Saleh (Hazara district), Chapra, Pusa, Dharwar, and Hadagalli (Bellary District). At Dharwar it was reared from a pupa found in roots of Cajanus indicus and at Hadagalli adults were found on green-gram. It is apparently a minor pest of pulses.

Green-gram and lablab are attacked in Madras. A swelling in the Mr. Ramachandra stem is produced and the stem breaks down. It is only a minor pest. Rao.

\section{Alcides fabricii, Fb.}

Proc. Second Entl. Meeting, pp. 57,121.

We have this from Abbottabad; Dehra Dun; Bulsara (Bombay); Mr. Flecter. Nagpur. on cotton; Ranchi; Bankura; Coimbatore, on maize: Hadagalli, on horse-gram; Hagari, on paddy; Calicut; and Sairapet.

It is doubtful whether it is a pest.

\section{Alcides leopardus, Oliv.}

S. I. I., p. 338-399, f. 127 [? affaber]; Proc. Second Ent?. Neeting, pp. 121, 125, 126.

We have this from Pusa, Muzaffarpur and South Malabar. At Pusa the adults have been found on cotton, Cajanus indicus, samn hemp, and on sun-flower heads, the larva has been found boring in shoots and stems of cotton, and the pupa has been found in a bored stem of Cynoglossum lanceolatum. In South Malabar the larva was found in a wild malvaceous plant. It is apparently a sporadic minor pest of cotton.

I found it breeding in malvaceous plants in South Malabar.

Any cotton near by?

Mr. Ramakrishna Ayyar.

No.

At Pusa we get it on cotton but it is not bad. We found parasites Myr. Misra. which were sent to Dr. Howard for examination.

$$
\text { Alcides affaber, Fst. }
$$

Proc. Second Entl. Meeting, pp. 121, 126.

This species occurs at Coimbatore in December-Jamuary, the lar'va Mr. Fletcher. boring into the stems of cotton, bhindi, and gogu. It is distinctly a pest.

The account given of Alcides leopardus in South Indian Insects probably refers wholly or in part to this insect. 
Mr. Ramakrishna Ayyar.

Mr. Ramachandra Rao.

Mr. Fletcher.

Mr. P. C. Sen.

Mr. Fletcher.

Mr. P. C. Sen.

Mr. Fletcher.

Mr. P. C. Sen.

Mr. Fletcher.

Mr. P. C. Sen.

Mr. Ghosh.

Mr. Fletcher.

Mr. P. C. Sen.

Mr. Ghosh.

Mr. Fletcher.
It damages cotton in the same way as $A$. leopardus. It is distinctly a pest of Hibiscus camnabinus but not a serious pest of cotton.

At Palur and Saidapet tree-cottons were attacked.

Alcides frenatus, Fst.

Entl. Note, 28; Proc. Second Entl. Meeting, p. 221 ; Ann. Report, Impl. Entm. 1917-18, p. 103, t. 19, f. la-g (1918).

This species oceurs at Dacea in July as a decided pest of mango, the larva boring the top-shoots. Eggs are deposited in the shoots which are tumnelled by the larva, whose pellets of exerement are thrown out through small holes gnawed at the base of the tunnel. Pupation takes place inside the larval burrow, the adult weevil gnawing its way out through a large hole of exit. The adult weevils are found freely pairing and ovipositing on the shoots.

It is a regular pest of grafted mangoes in the Botanieal Garden at Dacca. It occurs every year and does much damage. The eggs and grubs are very commonly to be seen in the affected shoots.

Can you give us some idea of the pereentage of damage?

As many as seventy-five per cent. of new shoots are damaged.

Have you tried picking off the affected shoots?

We have tried pieking the affected shoots with the eggs and grubs in them and also the beetles which are seen on the shoots.

Were any effects noticeable the next year?

Next year it was not so bad.

It is possible to pick off the affected shoots, but the influence of pieking on future years is not definitely known.

Do you know its life-history throughout the year?

I have not studied it.

The seasonal life-history is not known. At Pusa we had pupæ in September. The beetles are only seen in July.

Probably it hibernates as an adult until the new shoots come out.

\section{Alcides mali, Mshll. MS.*}

This species has been found at Shillong, the larva boring shoots of apple, eausing a gall-like swelling. The adult weevil makes several, usually four, holes with its snout in a row in a tender shoot of apple and in one of these holes, and only in one, it deposits an egg. The larræ tunnel in the stem, which becomes swollen in consequence. Pupation takes place in the larval tunnel. The life-history is shown on the coloured plate [exhibited]. Control is practised by collecting the adult beetles as

\footnotetext{
* Since described in Bull. Entom Res. IX, pp. 276-277, t. 17 f. 3 (July 1919).
} 
they rest on the twigs and by cutting off the twigs which show the punctures or the swelling caused by the enclosed larva.

\section{Metialma balsamina, Mots.}

Proe. Second Entl. Meeting, p. 268.

We have this from Pusa, Matheran and Poona. The larvæ bore in the stem of garden Balsams which show a characteristic gall-like swelling and ultimately droop. Choice imported varieties seem more subject to attack. Specimens which may belong to this species liave also been reared at Pusa from larve in stems of Anisomeles ovalu, but the identity of the weevil is not certain. M. Lalsumince is scarcely a pest as a rule, except of choice varieties of Balsams.

On the Bombay side the balsam plants are attacked and at the place Mr. Ramrao. where the grubs are situated the growth is stmuted and the stem becomes weak; the slightest wind then breaks off the plants.

Do you get many complaints about it around Poona?

Mr. Fletcher.

Yes, we get many complaints.

Mr. Ramrao.

Have you anything to say about it, Mr. Ghosh?

Mr. Fletcher.

At Pusa we get it, but the effect of attack takes place late in the Mr. Ghosh. season.

In 1917, I got some seed of especially good varicties of balsam from Mr. Fletcher. Poona and, when the plants came up, they attracted more weevils than the local varieties and were very badly attacked.

White-stemmed balsams are mọe attractive than red-stemmed, probably because the white-stemmed varieties are softer.

Does it attack wild balsams?

Mr. Ramrao.

We do not know of its occurrence in any but cultivated balsams.

I may say that swellings on the plants do not always contain a grub.

Mr. RobertsonBrown.

Mr. Fletcher.

Mr. Ghosh.

\section{Pachylychius mungonis, Mshll.}

S. Ind. Ins. p. 336, f. 194 ; Proc. Second Entl. Meeting, pp. 52, 60, 73.

This species is at present only known from Southern India where it Mr. Fletcher. has been found to attack pods of mung (green-gram), cowpea, and dhaincha.

Ceuthorhynchus asperulus, Fst.

S. Ind. Ins. pp. 328-329, f. 185 ; Proc. Second Entl. Meeting, p. 43.

This small weevil has been found in flowers of Cajanus indicus, in both larval and adult states, at Nagpur, in Gujarat, at Poona, Coimbatore, and in the Godavari district. I do not think there is more to add to what has already been said about it. 
Mr. Ramrao.

Mr. Fletcher.

Mr. Ramrao.

Mr. Fletcher.

Mr. Jhaveri.

Mr. Fletcher.

Mr. Ramrao.

iin. Fletcher.

I found it in Poona doing damage to the tur flowers which drop down with the grubs in them. The beetle wanders in unopened flowers, punctures them and lays eggs inside. The grubs eat the pollen and stigma, and, before the ovary develops, the flower falls off.

What is the proportion of damage done?

A very large number of flowers is destroyed. It is not possible to state the exact amount of damage done. A very large number of weevils is found if the plant is shaken; they drop to the ground and afterwards climb up again.

We have not found this weevil at Pusa hitherto.

It is also found in Gujarat and was a very serious pest last year.

Are any control measures practised?

The only method to apply is the collection of the beetles; but it is difficult to check them under field conditions.

\section{Rhynchonus mangiferce, Mshll.}

S. Ind. Ins., p. 334, f. 192 ; Proc. Second Entl. Meeting, p. 220.

This species occurs as far north as Pusa, where it is not common, but in Southern India it is sometimes a bad pest of mango, whose tender leaves are damaged by the mining of the larvæ. It has been noted at Pusa, Peddavadlapudi (Guntur), Coimbatore, and in Mysore, and is probably widely distributed, although overlooked on account of its small size.

Inr. Kunhi Kannan. Rinynchenus mangiferce is bad in Mysore and we have not done anything for it.

Mr. Ghosh.

Mr. Fletcher.

We bred it here. We do not find it every year and, when it does occur, it is found only in small numbers.

Probably Pusa is at the extreme northern limit of its distribution and the conditions here do not suit it very well, and so it does not do much damage.

Mr. Kunhi Kannan. The adults feed gregariously on the leaves in Mysore, and the leaves assume an appearance like tissue-paper.

Mr. Fletcher.

If you get them in numbers together like that, you might be able to control them.

\section{Pempheres affinis, Fst.}

S. Ind. Ins., p. 339, ff. 198, 199 ; Proc. Second Entl. Meeting, pp. $120,125,126,274$.

This species has been reared at Pusa from larvæ in stems of cotton, bhindi, Cannabis [? Hibiscus cannabinus] and Triumfetta sp. It is also common in cotton and gogu at Coimbatore and has been recorded from 
Cuddapah. The distribution scems curious, as it is difficult to see how a pest of this kind conld have been overlooked in the areas from which it is not known. The larva bores in the stem and produces a gall-like swelling at or usually just above ground-level; the plant is weakened and, especially in the case of Cambodia cotton, may be broken off by the mind. Rigid climination of all attacked plants seems to be the only practicable means of control.

Pempheres affinis is not found in Bombay.

Mr. Ramrao.

There is no record of it in the Central Provinces.

Mr. Khare.

In Madras we find that its distribution is extending. It is the Cam-Mr. Ramakrishna bodia cotton which is generally attacked and, as the cultivation of this Ayyar. cotton is spreading, the insect is also getting into new localities.

Is it already present in these districts or is it going with the Cambodia Mr. Fletcher. cotton?

It is already present and probably breeding on some wild plant, Mr. Ramakrishna as it is found where there is no cotton.

At Pusa it has been found on a species of Trimette. Ayyar.

We have worked out the life-history and we are trying to get it pub- Mr. Ramakrishas lished in Nadras.

What is the effect of the destruction of affected plants?

Some good would result only if all the people do it.

But has the complete removal of all the attacked plants had any Mr. Fletcher. effect on the Farm at Coimbatore?

No appreciable difference has been noticed; but, if all do it, it might nir. Ramakrishra have some effect. Ayyar.

I understood that the regular remoral of affected plants on the mir. Fletcher. Coimbatore Farm had had some effect on lessening the incidence of attack over a term of years. But whether this was due to any lessening of the numbers of beetles present or to the gradual evolution of a more resistant variety of plant, by continual selection from the non-attacked ones, is another question. It seems to me that a possible solution of the difficulty with regard to Cambodia cotton may be attained by getting a resistant race.

The worst of it is that this Cambodia cotton is liept on in the fields Mr. Ramakrisuna for two or three years, so it is difficult to get rid of this beetle. That is Ayyar. because the insect biceds throughout the rear and the cotton is there for it to breed in. If there were an arrangement to uproot all cotton plants before a certain date, it might prove useful.

Is any variety of cotton more affected? Tree cotton was tried at Mr. Misra. Pusa but was not immune.

That was before my time. What height was the tree cotton when it Mr. Fletcher. was attacked? 
Mr. Misra.

Mr. Fletcher.
Four or five feet. The majority of the plants all fell down. In our experiments it was very bad, so much so that in one plot not a single plant was left.

\section{Aclees cribratus, Gyl.}

This was found at Shillong in June-July 1918, the larva boring into the main stem of Ficus carica, doing eonsiderable damage.

The adult beetles occurred on the stems by day, and could be collected by hand, although they readily drop to the ground when disturbed.

Specimens were sent to Dr. Marshall who informs me that it is a variety of Aclees cribratus, Gyl.

\section{Cryptorrhynchus mangiferce, Fb.}

S. I. I., p. 341, f. 200 ; Proe. Second Entl. Meeting, p. 225.

This species seems to be confined to Southern India so far as its actual breeding-area is concerned. We have reeords from Trivandrum, Travancore, Naduvatam (Nilgiris), Coimbatore, Palur (South Areot), Lahore and Rangoon. The Lahore specimen is definitely noted as " in imported mango."

In some years ninety per cent. of the mango-stones may contain this insect in some stage, but the adults usually emerge after the fruit is ripe and so do comparatively little damage.

Mr. Kunbi Kannan. At Bangalore I had adult weevils which remained alive in the stones until the following July and they never left the stones.

\section{Cryptorrlynchus gravis, Fb.}

Ann. Rept., 1917-18, pp. 100-101 ; Proe. Second Entl. Meeting, p. 225.

Mr. Fletcher.

This species seems to be confined to Bengal, Assam and Burma. We have specimens from Pusa (on Bombax stem), Dacea, Rangpur, Silehar, and Maymyo. The Pusa record is of a single adult individual which almost certainly came from a mango fruit imported from Bengal, as it is not known to occur naturally in the Pusa distriet.

Unlike C. mangiferce, the larva of $C$. gravis bores in the pulp of the mango fruit so that the fruit is badly damaged and in some districts the damage done may be very serious, a large proportion of the erop being destroyed. We have prepared a coloured plate [exhibited] showing the life-history of this insect but, as it does not oceur at Pusa, we have not been able to follow the life-cycle throughout the whole year. It is probable that the insect hibernates as an adult in Bengal, but this requires local investigation. 
Can you tell us something more about it, Mr. Sen?

Cryptorhynchus gravis does great damage to mango fruits in Bengal. Mr. P. C. Sen. The grub bores into the fruit and makes it useless, eating its way through the pulp. In some trees all the fruits are attacked. It is a regular pest attacking the same tree every year. The early maturing varieties of mango are more attacked than the late ones.

Life-history.-Early in April the female weevil lays small white eggs (about $0.5 \mathrm{~mm}$. long) on the surface of the fruit when it has attained nearly half its size. The egg is covered by a coating of black hard substance giving the appearance of a black spot which is about $1 \mathrm{~mm}$. long. From the egg hatches out a tiny white legless grub in a week or so which bores into the fruit and feeds within. The black coating then falls off and the wound also heals up to such an extent as not to be easily detected. The grub has 11 body segments. It continues to feed within till it is fullgrown in about a month. It then pupates inside and subsequently the weevil emerges by cutting its way out of the fruit. The life-history occupies about a month and a half. It has only one brood in the year. Immediately after the mango season and during the rains it has been found to hibernate in the bark of the affected tree either in its natural cracks or amongst the roots of epiphytes growing on them.

It is a very bad pest in Eastern Bengal and Assam; but does not Mr. Ghosh. occur in Western Bengal although fruits from Eastern Bengal are carried all over the country. I brought some infected fruits to Pusa and found that the grubs did not live here after September.

It is peculiar that, although these fruits are exported in such quantities, Mr. Fletcher. this weevil does not spread into adjacent mango-growing areas.

It is believed in Sylhet that the same trees are attacked year after Mr. Ghosh. year and that neighbouring trees are not affected. But that is not a fact, for all trees are attacked indiscriminately. I found wild mango trees growing isolated in the jungle and these trees bore very small fruits, but even in these the weevils were present. This is an insect which requires working out.

It is a bad pest throughout Assam.

Mr. Gupta.

\section{Cryplorrhynchus poricollis, Fist.}

Entl. Note 28 ; Proc. Second Entl. Meeting, p. 225.

Specimens of this weevil were found under bark at Dacca on 27 th Mr. Fletcher. July 1911 by Mr. Nowroji who was sent to investigate the damage done by $C$.gravis. It has also been found underground in the adult state by Mr. Sen at Dacca. It is not definitely known that this species attacks mango. 
Mr. P. C. Sen.

Mr. Nowroji.

Mr. Fletcher.

Mr. Inglis.

Mr. Fletcher.
I have found them in numbers underground around the trunks of mango trees but have never found them breeding.

I found it at Dacea under the bark of a mango tree.

\section{Pachyonyx quadridens, Chevr.}

At our First Meeting, in February 1915, this species was reported as found on Butea frondosa in the Northern Circle of the Central Provinces and was said to kill the trees. We have adults from Khandesl and from Banga (Punjab); these latter were taken on Butea frondosa on 19th September 1905. We have no further information about it, but it would appear that this weevil is a pest of Butea which, I may remind you, is an important host-tree of lac in many distriets.

\section{Desmidophorus hebes, $\mathrm{Fb}$.}

Ind. Mus. Notes I 58, II vi 151, III i 23 ; Proc. Second Entl. Meeting, pp. 128, 131.

We have this from Dehra Dun, Pusa, Darbhanga, and Nongpoh (Khasi Hills).

In Indian Museum Notes this species is recorded as attacling young Hibiscus plants in the Rajbagh, Darbhanga, eating the young stems and in some cases causing the young plants to die. On 9th July 1906 the Superintendent of the Rajbagh sent us further specimens and wrote:"they have been damaging plants and are particularly fond of eating the new tops and chewing the lower parts of almost all the shoots. I get them caught by hundreds every morning and evening."

This species was also sent in to us, the adult beetles damaging Bombax seedlings, defoliating those of one to two years old ; these beetles appeared in the third week of April 1904 in the Tista Forest Division.

It has not been noted as a pest at Pusa.

I have only seen this in one year when this weeril appeared in millions in one local area and attacked the garden Hibiscus and did mich damage.

Acythopeus citrulli, Mshll.

Proc. Second Entl. Meeting, p. 306.

This species was reported from Hagari (Bellary) as a bad pest of water-melons in April 1908, the grubs boring into the side in contact with the ground; the larva tunnels in the fruit, filling its passage with excrement, and causes decomposition. It apparently occurs regularly in Bellary as a pest of water-melon, and is also known from Tinnevelly. We have also one specimen from Nagpur labelled "fruit of Kakarulu, IX, 1915." 
Cyrtotrachelus dux, Bol.

Stebbing, Ind. Forest Ins. Col., p. 443 ; Proc. Second Entl. Meeting, p. 204.

We liave this from Nongpoh (Khasi Hills). Stebbing records it from Darjiling. The larva bores in bamboo shoots and does some damage at times.

\section{Ciyrtotrachelus longipes, $\mathrm{Fb}$.}

Stebbing. Ind. Forest Ins. Co!., pp. 440-443, t. 38 ; Proc. Second Entl. Meeting, p. 204.

We have this from Lebong (Darjiling). As in the case of C. dux'. the larva of $C$. longipes bores in the growing shoots of bamboos and does some danage at times.

\section{Polytus mellerborgit. Boh.}

We have this from Pusa where it was reared from rotten plantain rhizome and found "boring plantain root, 9th May 1907." We do not. know this as a pest in India as yet, but in the Philippines it has been found to do damage by boring into plantains and it is probable that it is a pest in India also. The adult is a small black weevil, about the size of Calandra oryzce, with a strongly punctured thorax and striated elytra.

\section{Rhynchophorus fermgineus, $\mathrm{Fb}$.}

S. I. I., p. 343, t. 14 ; Entl. Mem. 11, pt. 10 ; Proc. Second Entl. Meeting, pp. 259, 261. 262.

This species occurs throughout the palm-growing districts of India, and also in Sumatra, the Philippines, etc. In India it attacks coconut. date, palmyra, areca and practically all palms. We discussed this fairly fully at the last Meeting and I do not think there is much to add. It can be controlled by regular destruction of all attacked, dying and dead palm-trees.

I have found Rhynchophoms fermgineus attacking trees which had Mr. Pillay. neither been tapped nor attacked by Oryctes.

It does serious damage to date palms in Surat.

Mr. Jhareni.

Do the weevils vary in colour?

Yes, the colour and markings vary considerably.

Mr. Ramrac.

Palms are also attackied in Ceylon.

Mr. Fletcher. 
Mr. Fleteher.

\section{Mr. Ramrao.}

Mr. Senior-White.

irr. Fletcher.

Mr. Ramakrishna Ayyar.

Mr. Fletcher.
Odoiporus longicollis, $\mathrm{Ol}$.

Proc. Second Entl. Meeting, p. 238 (tab.).

We have this from Pusa, Munshiganj, Buxar. Duars and Jorhat, and the form planipennis, Gyll., from Munshiganj, Buxar Duars, Helem (Assam) and Naymyo. The larva bores into the stem of plantain and kills the tree. Destruction of the attacked and wilting stems is the only practicable measure; in any case, the plant will be destroyed by the beetle grubs, which occur in numbers. The adult beetle is very longlived and may live for one or two years.

\section{Cosmopolites sordidus, Germ.}

S. I. I., pp. 342-343, f. 201 ; Proc. Second Entl. Meeting, p. 238.

We have this from Mahim (Bombay), Poona, Tellicherry and Mayanad, and doubtfully from Baroma (Assam). The larva bores in plantain stems, low down and in the roots. It is a decided pest and may be introduced in planting setts. It does not occur at Pusa and we have nothing new to add to what was said at the last Meeting.

I have found eggs laid in leaf-sheaths. They are cylindrical. They have not been found before. No wound is made, but the eggs are simply pushed under the sheath.

In Ceylon, when a fruit-bearing stump is cut away, the stool is simply riddled by the weevils; but, when you thin a clump and remove the stumps that have not yet borne fruit, you find them quite healthy.

Has anyone found any parasites of this weevil ?

No.

We should like to know of any parasites if anyone should find any, especially as we have not this weevil at Pusa. It has been introduced with plantain setts into several other parts of the world and has proved a bad pest, notably in Fiji, so that other countries are keenly interested in knowing about anything that will check it.

\section{Calandra stigmaticollis, Gyll.}

Annl. Rept. Impl. Entom. 1917-18, pp. 98-99, t. 15, f. 1.

We have this from Malvan (Ratnagiri) and Tamarasseri (Malabar), where it was found in both cases boring stems of coconut in the larval stage. Specimens were reared at Pusa from a sample of attacked wood from Ratnagiri and we found that they were able to breed in sugarcane under insectary conditions.

It is a very bad pest in the Ratnagiri district. 
What percentage of trees is damaged?

IIr. Fletcher.

Two trees in erery one hundred to five hundred are damaged every Mr. Deshpande. year.

The proportion does not seem very high but it soon mounts up in the Mr. Fletcher. course of a few years in the case of a permanent erop like cocomut.

The larvæ tunnel under the bark and the stem bleeds.

Is the attack associated with any fungal disease?

Mr. Ramachandra

Rao.

Mr. Fletcher.

That is not known. It is very widely spread. No remedial measures Mr. Deshpande. have been adopted. An attacked tree is bored and riddled from top to bottom.

It also bores into the leaf-petioles at the top of the tree.

Only a few trees were found attacked in a coconut garden on the Nalabar coast, and these trees were seattered about.

Did you get any idea as to why partieular trees were attacked?

Probably those trees were unhealthy. A single tree may harbour 1,000 grubs but the number of attacked trees is not great.

Mr. Ramrao.

Mr. Ramacinandra

Rao.

Mr. Fletcher.

Mr. Ramachandra Rao.

If the attacked trees are cattered about and not near one another, Mr. Fletcher. it looks as if the weeril attacked sickly trees.

$$
\text { Deiradolis (n. g. Mshll. Ms.) n. sp. }
$$

This weeril was found at Shillong in June-July 1918. the adults on mulberry, apple, pear and fruit trees generally, nibbling holes in leaves and doing considerable damage, being present in very large numbers.

In the case of fruit trees, control was practised by collection by hand of the adult beetles.

\section{(Undetermined Curculionid.)}

The adults were found at Dohad on maize leaves in numbers on 16 th August 1917. It is apparently a minor pest.

\section{(Undetermined Curculionid.)}

This weeril was reported from Poona in August 1915 by Ramrao S. Kasargode, the larva boring in fruits of Zizyphus jujuba of a variety called Ahmedabad ber. They change the shape of the fruits. The natural shape of the fruit is long, but attacked fruits are always round berry-like.

There were about half-a-dozen trees in the Ganeshkhind Gardens IIr. Ramrao. at Poona and this weevil attacked the fruits very badly. This, however, is not a generally distributed pest. 
Mr. Fletcher.

\section{(Undetermined Curenlionid.)}

This weeril was found at Pusa, the larra boring in samn-hemp stems in the field, 15th August 1916, the adults emerging in the middle of September 1916.

The larva bores the central pait of the stem and when full-grown forms a sort of pupal cell at the end of its burrow just below the bark of the stem. It is doubtful how far it is a pest.

\section{(Undelermined Curculionid.)}

The weevil was found at Abbottabad, at the beginning of June 1916. The adults occurred in numbers on apple, rose, Rubus spp. and thistles. eating the leaves.

\section{Dyscerus fietcher, Mishll. MS.** (Plate 6.)}

This weevil was found at Shillong, the larra boring into apple fruits. in June 1918. It is a reddish-brown species with scattered patches or duts of grevish scales. It is rather larger than the next species but attacks apple fruits in exactly the same way, but pupation seems to take place sometimes outside of the fruit. The egg is about $1 \mathrm{~mm}$. in diameter and rather dull-brown in colour. The larva seems quite similar to that of the next species. The adults seem long-lived, as an individual caught at Shillong about 15 th June, and brought to Pusa, lived in the insectary. until 15th October.

Dr. Marshall has identified this as a new species of Dyscerus.

\section{Dyscerns malignus, Mshll. HS.† (Plate T.)}

This weevil was found at Shillong in June 1918. It is brownishblack with a conspicuous grey patch on posterior portion of elytra. The adult weevils feed on apple fruits, eating small patches into them, and oriposit in excarations along the edge of such patches. The eggs art large for the size of the insect, about $1.25 \mathrm{~mm}$. in diameter and pearl. white in colour. The grub bores about in the interior of the fruit and damages it considerably. Pupation takes place inside the attacked fruits which in the initial stages of attack are externally searcely distinguishable from healthy fruits, but the invariable presence of a number of small whitish dots on the surface of the infested fruits marks these as attacked. These small dots are really holes through which the timne!s of the grubs communicate with the open air, and as a rule these tunnels originate at the apical end of the fruit. somewhere near the flower scar, whence they ramify throughout the interior, branches being

* Since described in Bull. Encm. Res. IX, pl. 274.275 t. 17 f. 1 (July 1919), where. it $i_{i}$ also recoried from Alnora.

+ Since described in Bu!l. Entom. Res. 1X, pp. 275.27t t. 17 f. + (July 1919). 

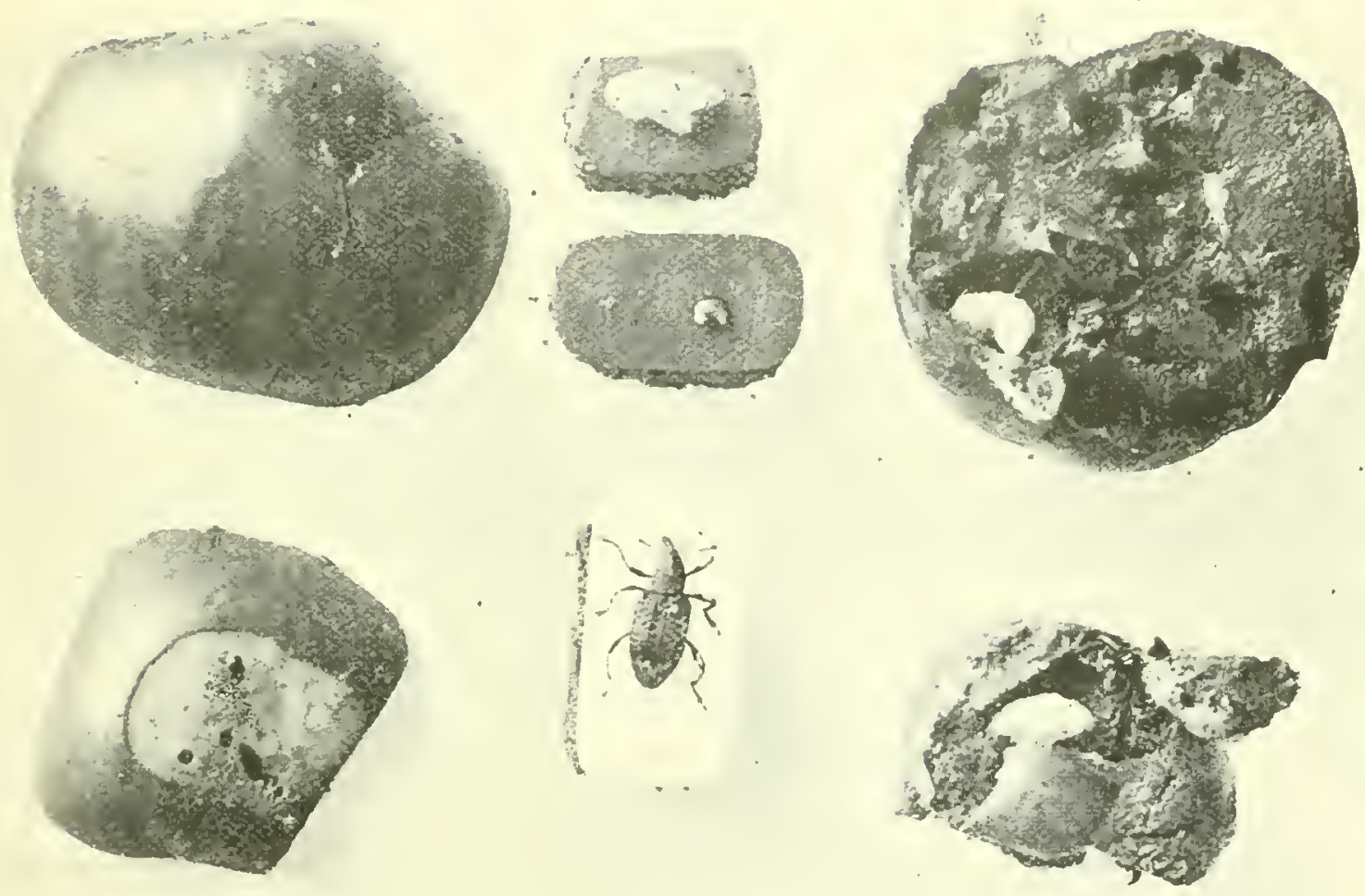

Stages of 1 !yscerms fletelleri in apple fruits at Shillong. 




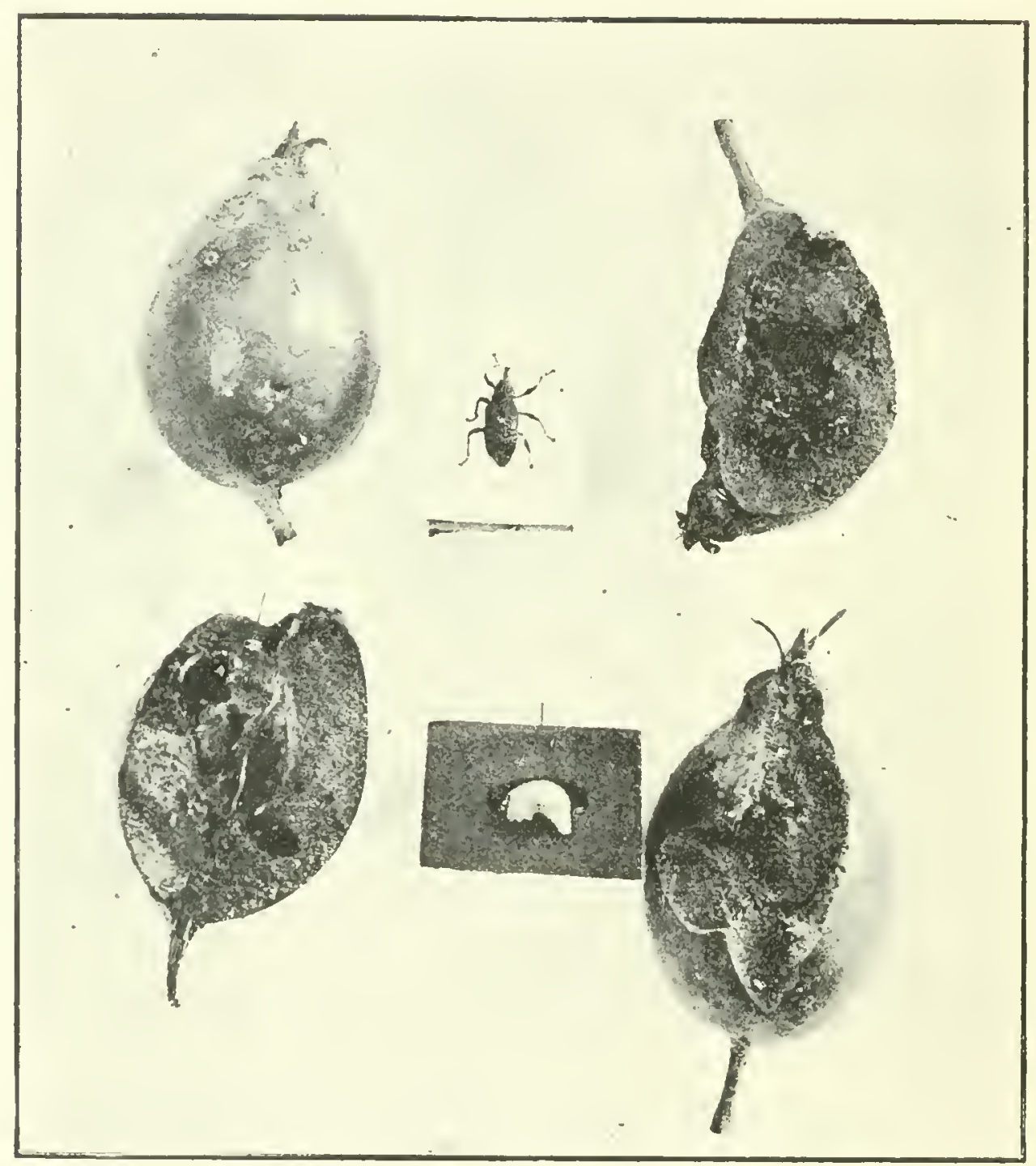

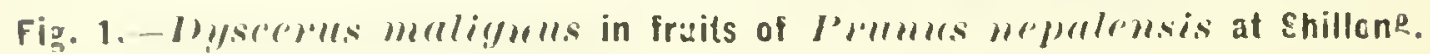





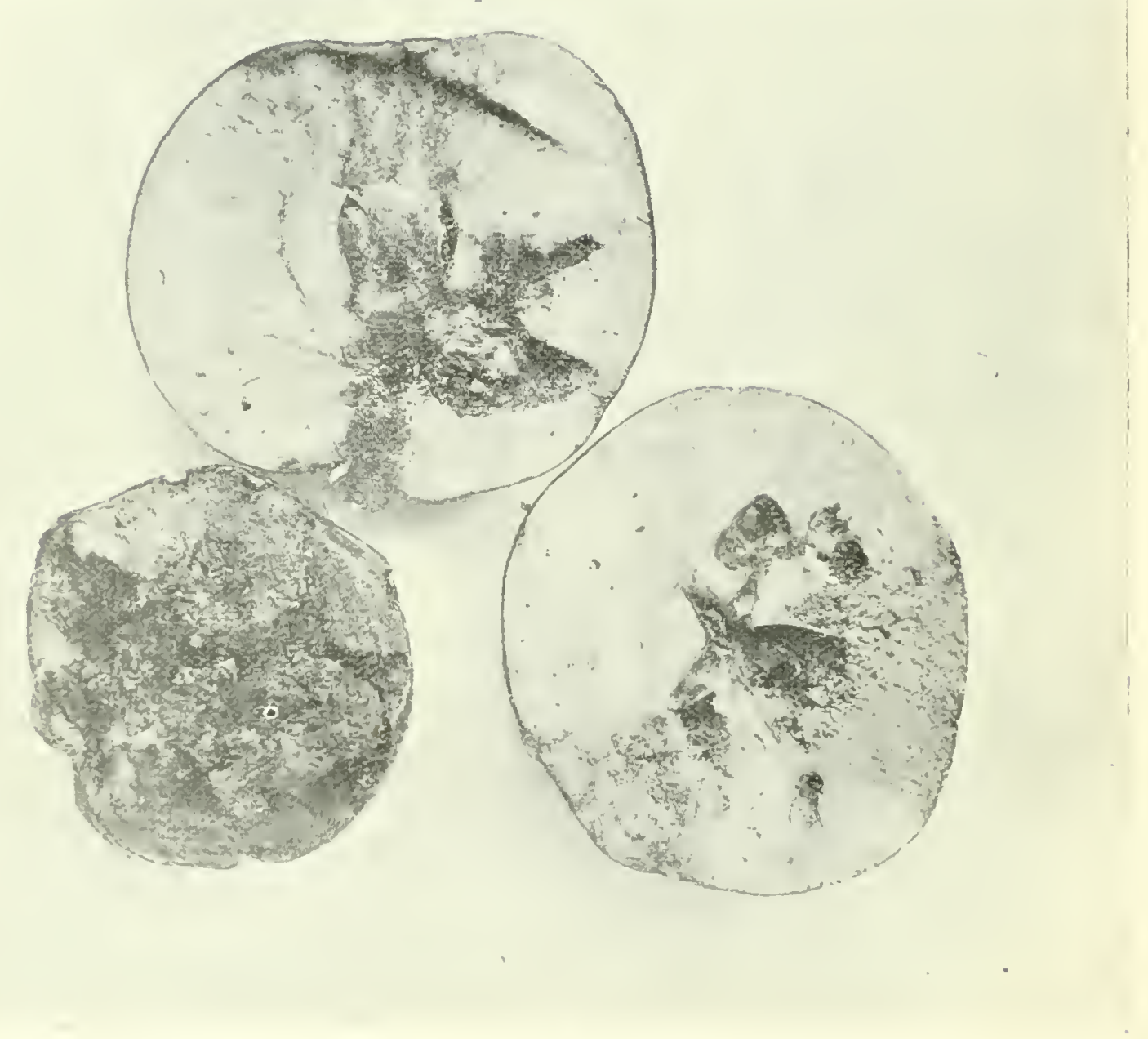

Fig. 2.-Apple fruits attacked by grubs of I"yscerus muli!/nus at Shillong. 
yiven off at intervals towards the surface where their termination is marked by the small dots mentioned above. In the later stages of attack. these holes become much larger and often exude a frothy liquid which attracts Sarcophagid flies.

This weeril was also found breeding in the fruits of Pmus nepulensis, a wild indigenous plum whose fruits are edible when ripe.

Dr. Marshall has identified this as a new species of Dyscerus.

$$
\text { Corigetes bidentules, Mshll. }
$$

Entl. Note 26 ; Proc. Second Entl. Neeting, p. 21.

This pecies occurs in Assam as a serious pest of tea. It has also been found in Upper Burma.

\section{[(Unidentified ('ureuliomil.)}

In September last year I happened to examine several stems of sann- Mr. Kbare. hemp which were stunted and had small curled up leaves. In all cases I found some indications of an insect attack, i.e., a meagre passage cut through between the pith and wood quite a long way up and down the stem. In the passage at intervals very small whitish grubs were found embedded in the pith-a little. Similar grubs were found in the healthy stems as well, so that peculiar leaf growth could not be attributed to this insect. On examining the stem from outside some black scars were noticed in the axil of the leaves from about 12 to 18 inches to about 3 feet above ground. If the outer bark is scraped off then distinct injury to the rook is seen, thus showing that the grubs enter at such places and that the eggs mist have been laid in the axil. (The eggs of the weevil are not found.) The height where the black sears are noticed suggests that the weevils appear some time in July and remain active, depositing eggs up to September.

The grubs are about $3 \mathrm{~mm}$. long, $0.5 \mathrm{~mm}$. broad, whitish, fleshy, tumnel between the pith and the wood, but never go right into the root. The tumelled portion is filled loosely with the frass or pellets excepting a little portion above the pupal chamber which is stuffed closely. The grub on attaining full growth prepares a small oval chamber by cutting into the wood, thus the pupal chamber is not straight along the stem, but a little transverse, extending both in the pith and wood as rell. The grub bores a small round hole before pupating, for the emergence of the weevil; this I was led to conclude from the fact that a number of small holes were found outside on the bark and; on cutting open, weevils freshly come out of the pupe. were seen.

The weevil is very small, brown, about $1.5 \mathrm{~mm}$. long and has a fairly long snout and long antenna; when torehed, it curls up with the snout 
and antenne bent inward and, like several other weevils, shams death.

In two cases I found hymenopterous grubs attached to the weevil grubs and some parasitic pupx in the pupal chamber of the weevils. I could get only one adult parasite and it is shown with the weevil. I could not yet work ont exact life-history of this weeril but so far as I have observed this weevil begins to emerge from September to Norember. In the month of December I cut open sereral dried stems of sann-hemp, but could not find a single one. Alternative food plant is not yet known. This weevil practically does no harm to the plant and thus cannot be included as a crop pest.]

\section{LAMIADE.}

Batocera rubus, Linn.

S. Ind. Ins. p. 324. f. 129 ; Proc. Second Entl. Meeting. pp. 36 , $131,227,251,299$.

Mr. Fletcher.

We have this from the following localities and foodplants:-Peshawar, adult eating shoots of Ficus carica and larva boring into stems of $F$. carica; Laksar (Grwalior), (IR. 912 of 12 th October 1912); Dehra Dun; Muzaffarpur district, larra boring into mango roots. March 1915 ; Pusa, larva in rotten papaya stem, boring sissu wood, in Bombax stem, and boring Erythrinc indica stem; Khasi Hills; Western Ghats, in Para rubber stump; Kanara and Madura. It is widely distributed and is often a pest of cultivated fig.

As regards control, collection of the adults and injection of a mixture. of chloroform and creosote into the larval galleries have been found successful.

Mr. Seaior-White.

In Ceylon I have found the larva boring into a live stem of Ficus religiosa some way abore ground-level.

Mr. Fletcher.

At Pusa it is a common species and probably lives mostly in the rarious species of wild figs. We have reared it and found that there is only one generation in the year here.

Mr. Beeson.

It attacks dead trecs.

Mr. Fletcher.

Mr. Robertson-

Brown.

Mr. Inglis.

Mr. Senior-White

Certainly not alwars. It is often a bad pest of cultivated fig-trees.

Some time ago all the fig-trees in the Peshawar district were bored. Nothing was done and the pest has quite abated now.

I have found it boring in a living tree of Ficus religiosa.

It has not been seen in living rubber trees but attacks dead rubluer trees. Of course, it may work below ground-level in the case of living trees. 
This is another species about whose parasites we know nothing but Mr. Fletcher. would like to have some information. It has been introduced into the West Indies and is doing a lot of damage there and I have been appealed to for parasites to help them; but we do not know of any parasites in India.

I have bred a laige number and found an absolute absence of para-Mr. Beeson. sites.

They lay a very large number of eggs. In the Insectary more than Mr. Ghosh. 200 eggs have been laid. The female goes on laying eggs for fourteen days.

Then what kecps it in cheek!

Mr. Fle'cher.

Probably desiccation of the wood as a result of the egglaying and Mr. Beeson. working of the grubs is an important check.

What about those larvx that are boring in living wood? - Mr. Fletcher.

There is no check on those.

Mr. Beeson.

Do wood-pechers help at all to check them?

Mr. Fietcher.

The larvæ have enomons vitality. Toung larræ are probably Mr. Beeson. killed off by cannibalism.

We have not noticed any camibalism.

Mr Ghosh.

\section{Apriona germari, Hope.}

Stebbing, Ind. For. Ins. Col., pp. 371, 372, 374, f. 249 ; Proc. Siecond Entl. Meeting, p. 25\%.

This spccies has been recorded from Shahdera (near Lahore), the Mr. Fletcher. larva boring into mulberry, into the main trunk, and doing considerable damage.

We have no specimens of this at Pusa.

It is a shoot-girdler of mulberry and Ficus.

Br. Beeson

Apriona cinerea, Cher.

Stebbing, For. Ins. Col.. p. 374 ; Proc. Second Entl. Meeting, p. 255.

Stebbing records this from Dehra Dun, the adult beetles stripping nir. Fietcher. off the bark off the leading shoots and young twigs of Morus indicu.

The Pusa collection contains specimens, identified as A. cinerea with some doubt, from Jammu, larva boring mulberry stem; Kumaon Hills, larva boring fig tree; and Jeolikote (IR.,306; 29. III, 12).

\section{? Apriona sp.}

We have this from Chandinagar (Sylhet), where the larra was found boring stems of jak; the adult emerged at Pusa, 6th August 1918. 
Mr. Ghosh.

Mr. Gupta.

IMr. Fletcher.

Mr. Ramrao.

Mr. Ghosh.

Mr. Ramakrishna Ayyar.

Mr. Fletche?.

Mr. Ghosh.

Mr. Fletcher.

Mr. Beeson.

Mr. Ghosh.i

IVr. Fletcher.

Both young and old trees are attacked. Young trees are hollowed out from top to bottom. The grub throws out dust from its galleries. We tried to probe a gallery but the probe went upwards. Kerosine does not kill the grub; we gave one grub three dippings in kerosine and yet it survived and pupated. In one locality there are 3,000 jak trees and all are affected by this beetle.

I have found it spreading throughout the valley in some parts of Sylhet. The older trees can withstand the attack but the young trees do not grow. We find fifty per cent. of the trees attacked. The trees are not killed but are damaged severely. The tumnels of the grubs are very peculiar. I tried the effect of carbon bisulphicle on five trees and it was very satisfactory. I closed the side holes with mud and injected the carbon bisulphide through one hole. This remedy, however, cannot be adopted by the cultivators. Kerosine is not effective.

Kerosine is not sufficiently volatile. You might try benzine, as that is more volatile and it is readily obtainable from Digboi.

I tried phenol and carbon bisulphide in the case of a borer in lime.

One could use a White Ant Exterminator and pump in the gas.

Or you could use chloroform and creosote and inject it with a longnozzled syringe.

Any rolatile liquid of that kind should be effective.

With a White Ant Exterminator we can inject fumes of sulphur and arsenic and then see where the gas comes out and close the holes and then pump more gas in.

I do not think the White Ant Exterminator wonld be a practical proposition. For one thing the gas must be injected hot or it will all condense without doing any good.

What girth are the trees attacked?

Various girths. The grub bores down the stem and in big trees the young branches are attacked and the grub works its way down. The grub comes to maturity after two years.

\section{Calosterna sp.}

This insect was reported to us from Manipur State, where considerable damage was done to mulberry on one plantation. "A quantity of wood-chist accumulated around the roots. Holes appeared here and there in the stem. Now when the tree is cut down it is found to be hollow and to contain these beetles and larvæ." (Letter from Vice-President, Manipur State Darbar, Imphal ; 27th April 1914.) No specimen, however, is traceable.

An ummanned Coolosterna is also referred to in Ind. Wus. Notes. V, iv, 213 as doing much damage to mulberry at Shahdera, near Lahore. 
Coclosterna scabrator, $\mathrm{Fb}$.

South Ind. Ins., pp. 325-326, f. 181 ; Stebbing, Ind. Forest Ins. Col., pp. 358-362, t. 25 ; Proc. Second Entl. Meeting, pp. 22, 121, 248, 254, 265, 275 [scabrator and spinator].

We have this from Peshawar, Bhangaon Forest (Berar), Poona, Charodi (Bombay), Belgamm, the Shevaroy Hills and Shembaganur (Madura). At Peshawar the adult was found gnawing the bark of a branch of Tamarix indica on 21st Oetober 1914; in the Bhangaon Forest it was reported as " doing very serious damage to sowings of babul, the larva boring into the stem and the adult eating the bark, often completely ringing the shoot" (letter from Conservator of Forests, Berar Circle, 14th September 1910); at Poona, the adult was found on Ziayphus, lst Jume 1910 ; and at Charodi "on cotton."

Stebbing states that it attacks Acreia arabica and Shorea iobusta in Berar, Casuarina equisetifolia in Oudh, and that it oceurs also at "Kandiduppa, Madras."

Watt and Mann include it as a pest of tea in Assam, but I have never Mr. Andrews. known it on tea.

Aristobia approximator, Thoms.

We hare this from Nongpoh (Khasi Hills), and from Paungde, Taung- Mr. Fletcker. gyi and Lashio in Burma. At Taunggyi the larva was found by K. D. Shroff boring the stems and branches of cherramoya.

It girdles forest trees.

Mr. Beeson.

Epepeotes uncinatus, Gahan.

Adult beetles were found at Shillong in July 1918 resting on the Mr. Fletcher. twigs of Ficus carica and the larva probably bores into this tree as this beetle belongs to a group which is usually attached to species of Ficus and a young longicom larva was found boring in the stem of one of these trees.

\section{Monohammus nivosus, Wh.}

Stebbing, Ins. For. Ins. Col., pp. 357-358, f. 243.

Stebbing gives its distribution as the Sub-Himalayan tract from Ganges to Nepal. Central and South India; Burma; Ceylon.

The larva bores in stems of Calotropis gigantca.

We have specimens from Pusa, bred from larvæ in Calotropis, and from Poona labelled "Woodfordia, 12th June 1910." It is apparently a very minor pest of Calotropis. 


\section{Monohammus versteegi, Rits.}

This species occurs in Assam, where the larra bores in the pith of young stems of orange trees, the result of the attack being that the leaves turn yellow and the branch withers. We have specimens from Khowang and Haflong, in both cases reared from larve boring orange stems, and also from Nongpoh.

Mr. Gupta.

Mr. Ghosh.

IYr. Fletcher.

It is found in some districts of the Suma Valley. There are three borers of orange, one in the shoots and two in the stem. The two latter differ in the nature of the damage they do to the stem.

One of these is M. rersteegi and the other is a Buprestid. The egg; are laid just above the ground and the places of deposition may be seen by the slits made in the bark.

If the eggs are always deposited near the base of the stem it should be possible to protect this portion by smearing on some repellent or applying some mechanical preventive such as by tacking on oiled paper.

\section{[Dihammes fistulator, Germ.}

Mr. Senior-White.

At Hatale a rubber tree nine years old came down in a wind and from above five feet upwards the trunk was hollowed ont by this beetle. It is said to be a pest of cacao also.

Under the name Monohammus fistulator Mr. Froggatt has recently described [Agrict. Ga . N. S. Wales XXX, pp. 3--38, tab. (2nd January 1919)] this species as damaging passion-fruit vines in New South Wales and states that he has also found it boring in stems of cultivated figtrees at Sydner. It is widely distributed in India, Cerlon, the Malay Archipelago. Java, Quecnsland, Victoria, New South Wales and South Africa, but we do not have any record of it being a pest in India.]

\section{Linda nigroscutata, Fairm. (Plate 8.)}

This species was found in 1918 at Shillong, where the adults occurred. fairly commonly on apple trees in June and July and were generally found resting on the shoots or leaves and occasionally feeding on the latter. In captivity the beetles fed on the leaves and also on the bark of apple twigs, but did not oriposit. Under natural conditions, however, the beetle girdles the twig more or less (usually rather less) completely, makes a slit at right angles to the girdling and abore it. slightly detaches the bark on one side of this slit and thru-ts in an egg under this loosened bark. The larva on hatching bores upwards into the twig and thrusts its longish pellets of frass out through holes cut in the twig. which of course dies off and shrivels up. This is a serious pest, doing considerable damage. The only control method possible is hand-collection of the 


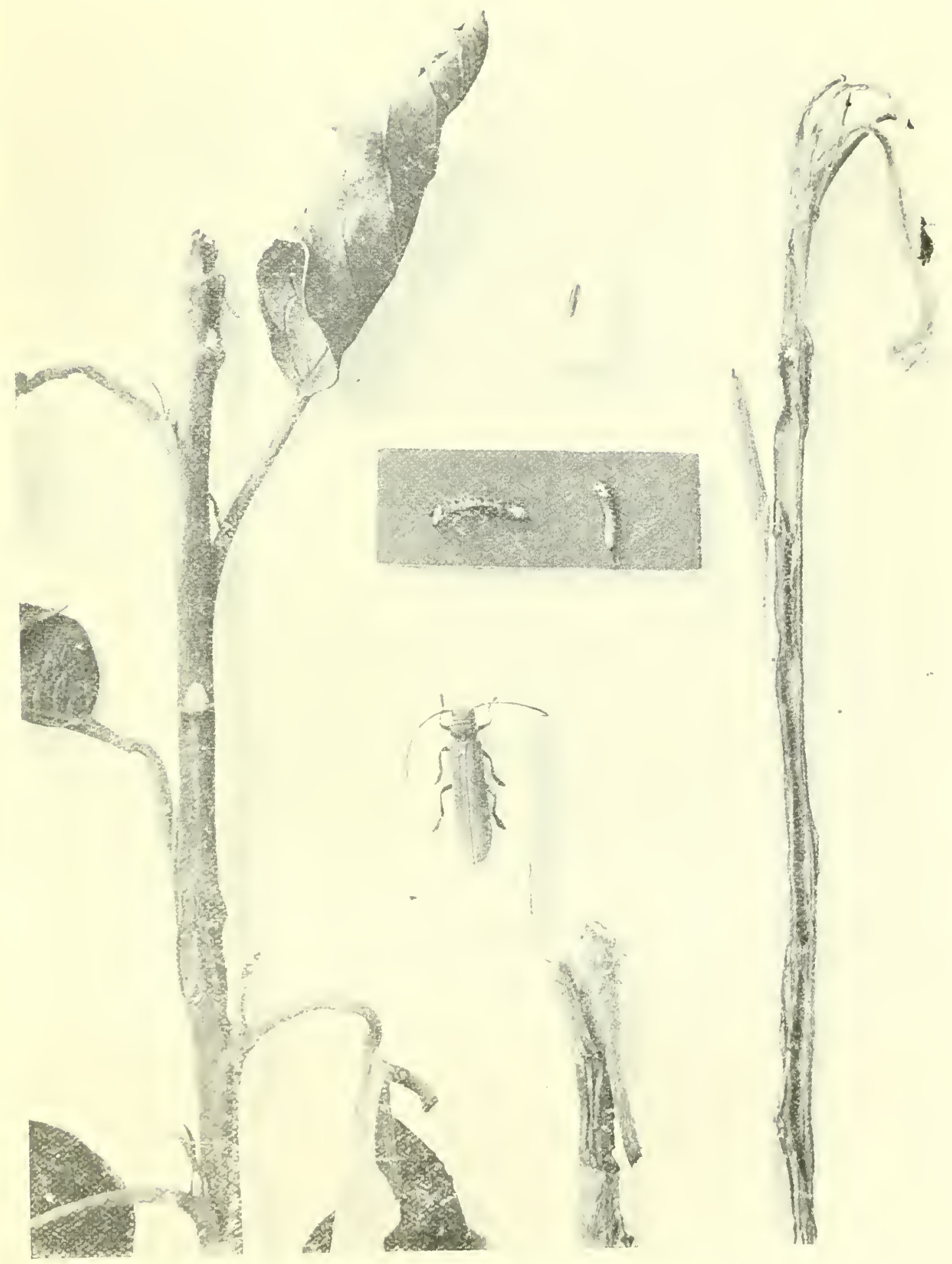

Limlle mignosemtula, girdling apple twigs at Shilleng. 

beetles and cutting out of attacked twigs. No alternative foodplant is known as yet.

The adult beetles can easily be hand-picked and the places where the Mr. Ramaciandra eggs have been deposited can also be spotted easily and these branches Rao. cut off and destroyed.

Sthenias grisator, Fb.

S. I. I., p. 326, f. 182 ; Stebling, Ind. For. Ins. Col., pp. 37т-378, f. 252 ; Proc. Second Entl. Meeting, pp. 75. 235, 25., 265, $267,268$.

We have this from Palitana State, on grape-vines, oleander and other Mr. Fletche:. flowering plants; Nasik, on grape-vines; Bangalore, adults girdling rose-bushes; Pollibetta (South Coorg), adults girdling Erythina; and Coimbatore, adults girdling mulberry and Bougainzillea. Stebbing also records it as girdling Tabemomontana alba in Kurnul.

We discussed this fairly fully at the last Meeting and I do not think there is much to add.

At Coimbatore it is a serious pest of mulberry. The stages have been Mr. Ramakrishna drawn on a plate [exhibited], but the length of the life cycle is not linown.

In Mysore it is not serious on mulberry.

Ayyar.

Mr. Kunhi Kannan

At Poona it is rery bad on grape-vine, girdling branches as thick as Mr. Ramrao. one's thumb.

\section{Apomecyna peitigera, Thoms.}

S. I. I., p. 327. t. 11 ; Proc. Second Entl. Meeting, pp. 303, 307.

This has been reared at Pusa from larve in Luffu stem, bottle-gourd. Mrr. Fietcher. snake-gourd. and pumpkin stem, and the a duit beetles have also been found eating cucumber fruits. At Mandalay it has been noted to bore pumplins, and we also have it from Chapia, Jorhat and Coimbatore. It is a minor pest of cucurbit, the larva boring the stems and the adults: eating the young fruits. It may be controlled by destruction of affected stems and collection of the adult beetles.

$$
\text { Aponecyna listrio, ib. }
$$

Proc. Second Entl. Meeting, pp. 304, $30 \%$.

This has been reared at Pusa from larræ in stems of Luffu, Cephalandra and gurrach (Tinospora cordifolia). We have it also from Chapra and Laheria Serai. It is a pest much in the same way as is A. pertigera but does not seem to be so widely distributed. 
Mr. Ghosh.

Mr. Ramakrisboa Ayyar.

Iir. Fletcher.

Mr. Ramakrishna Ayyar.

Mr. Fletcher.

IIr. Ramakrishna Ayyâr.

Mr. Pillay.

IMr. Fletcher.
It hardly occurs in young plants but the adult beetles may gnaw young shoots. The larvæ occur late in the season at Pusa. It is difficult to say whether it is a pest.

The grub kills the plants which it attacks.

\section{Apomeeyna perotteti.}

Proc. Second Entl. Meeting, pp. 304, 307.

This species is apparently confined to Southern India. We have it from Kanara, Madura and Pollibetta (South Coorg). The life-history is not known but is likely to be the same as in $A$. pertigera and A. histrio and the Pollibetta specimens were collected by myself around cultivated cucurbits.

\section{Olenecumptus bilobus, $\mathrm{Fb}$.}

Stebbing, Ind. For. Ins. Col.. p. 375 , f. 250 ; Proc. Second Entl. Neeting, p. 251.

This is a widely-distributed species attached to fig-trees. At Trivandrum, Travancore, it has been found in banyan, and at Surat, Combatore, Salem, and in the Krishna district it has been found damaging Ficus curica, the larva boring into the solid rood. At Pusa it does not seem to have been bred, but probably breeds in the wild fig-trees; our Pusa examples were all taken as adults on gular (Ficus giomerata), teak and jak trees, or at light. In Java and Sumatra it has been recorded by Dammerman as boring in Fieus elastica. In India it seems to be mainly a pest of cultivated fig in Southem India.

In Madras it does a good deal of damage to cultirated figs. The larve are found right inside the wood of the stem.

Have you tried any treatment in the case of afiected trees?

We cut ont the old stem and affected branches. That is the only thing that can be done.

The artult beetles are attracted to light.

Yes; they come in to light sometimes at Pusa.

Nupserhabicolor, Thoms.

Dutt, Bihar Agricl. Joumal; Proc. Second Entl. Meeting, p. 47, 70; Ann. Rept. Impl. Entom. 1917-18, p. 98, t. 14, ff. $1 a-d(1913)$.

This species is apparelitly only known so far from Bihar, where it has been reared at Sabour on soy-bean and sam-hemp and at Pusa from soy-bean, sam-hemp, Vigna catiang, Phascolus aconitifotius and Phradiatus. 
The eggs are laid on young shoots, which have previously been girdled by the adult beetle. The larra bores down to the root and goes from one branch to another, killing the plant. Hibenation takes place in the larral stage in the stumps. The larva occur in the rains and the beetles emerge at Pusa in August (mainly) and September. A Chalcidid parasite has been reared. At Pusa the "bermeli "rariety of soy-bean (from Sabour) was attacked especially, other varieties growing alongside this escaping attack almost wholly. It may be controlled by destroying the affected tips, which droop, and by buming the stumps after harvest.

\section{Oberea sesami.}

Proc. Second Entl. Meeting, 1. 85.

This species only seems to be known in Baroda. The egg is laid on the midrib of a leaf of Sesamum indimm, and the larva bores into the midrib and stem, and then down into the roots and pupates in the roots. Hibernation takes place in the larval stage. Tein to twelve days elapse before the larra bores into the stem and yellow blotehes appear on the attacked leaves which ma be collected at this stage of the attack. It in usually a minor pest of young Sesamum plants, but does very serious damage sporadically.

In Bellary I once found a very few Sesamum plants attacked in this Mr. Ramachanara way but I cannot say whether this was due to Oberea sesami.

Rao.

It is a regular pest in Baroda. Plants in the early stages of growth Mr. Patel. are killed but grown-inp plants do not suffer so mueh.

It has not been found in Surat.

Mr. Jhaveri.

\section{Oberea sp.}

This species was found at Pusa. the larva boring Phaseolus aconitifolins ive. Fletcrer. [molli] (C. S. 428). The eggs were laid at the end of September 1906, and hatched after 5 dars. the larra pupated at the end of June. and the adult beetle cmerged after twelve days (in the begimning of July). The eggs were laid in the stems within a portion enclosed by two girdlings. The larra freds on the pith and part of the woody tissues. The aftected girdled stems droop and are easily seen. The larva feeds until November, then rests in the larval state mutil the end of June. Larvo often emerged from stems hefore hibernation and attempted to go into earth. There is only one eycle anmually.

Specimens were sent to Dr. Gahan some years ago, but no identification has yet bern received.

There is an Cbereu in Travaneore which attacks Vigna catjang.

Mr. Pillay. 


\section{(Unidentified Lamiad.)}

This was found in the adult stage at Moulmein in September 1914 on sweet-potato and had apparently been breeding on this plant.

\section{(Unidentified Lamiad.)}

Ann. Rept. Impl. Entom., pp. 17-18, f. 99, t. 15, ff. 2 $\iota-c$ (1918).

This species was sent to us from Latu (Sylhet) by S. R. Gupta, the larva boring and killing orange shoots. The larva bore into the new shoots which appear in spring and cause them to wither. The beetles emerged at Pusa in March and April. We liave an apparently similar specimen taken in the Buxar Duars in May 1907.

M:. Gupta.

Mir. Andrews.

I found it common in the Surma and Assam Valleys. The grub bores in young orange shoots which wither. The tree is never killed but it bears less fruit. I have found this borer wherever I have searched for it. We have cut out the withered shoots. but the pest was found again. The orange-garden at Latu is isolated from other orange gardens but is alongside a big forest and very probably this pest comes in from the forest plants; but this is not known definitely. In one plot we cut oft almost all the withered shoots but the insect was still prèsent after a time.

It is difficult to grow orange trees in Assam. This insect is known to do damage in a garden where there are only a few orange trees.

\section{(Unidentified Lamiad.)}

Mr. Fie'cier.

This was sent in to us from Bengal by $\mathrm{D}$. N. Pal with the information that it was reared on 12 th September 1907 from a larva in jute stem and that it is said to do damage. We have no further information about it.

\section{Ceranbycide.}

\section{Lophostermus hugelii, Redt.}

Crahan, F. I. Cer̃amb., pp. 11-12; Stebb., Ind. For. Ins. Col., pp. $274-275$, t. 17 ; Proc. Second Entl. Meeting, p. 248.

We have this from Simla, Dehra Dun and Chaubattia (Kumaon). At Chaubattia the larva was found attacking roots and trunks of apple trees.

Gahan gives the distribution of this species as Kashmir, the NorthWest Frontier Provinces, Punjab and Assam. Stebbing states that the larra feeds on Quercus incana and probably Q. Cilatatu. 


$$
\text { Xystocera globosa, Oliv. }
$$

Gahan, F.I. Ceramb.. pp. 106-107. f. 42 ; S. I. I., p. 321, f. 174; Proc. Second Entl. Heeting, p. 79.

We have this from Coimbatore. Nagpur and Tatkon (Upper Burna). It has not yet been noted as a pest in India but in Coiro it has prored a serious pest of Albisia lebbek when grown as shade-trees and it is apparently associated with $A$. lebbek in India also so that it may be expected to prove a pest of this tree.

In Egypt it is a pest of old Albiaia lebbek trees.

In India it damages Albisia pracera.

Dr. Gough.

Was it introduced into Egypt?

Fr. Beeson.

I do not know.

$$
\text { Ginatiolea cburiferit. Thoms. }
$$

Mr. Fletcher.

Dr. Gough.

Gahan F.I. Ceramb.. p. 111 ; Proc. Second Entl. Meeting, p. 211.

This has been noted by $\mathrm{K}$. D. Shrofi at Noulmein boring orange Mir. Fletcher. stem and at Kya-in, Karen Hills. as boring stem and branches of orange, the adult emerging on 1 th January 1908.

\section{Stromatium barbatum, $\mathrm{Fb}$.}

Cahan. F. I. Ceramb. pp. 114-115, fig. 45; S. I. I., pp. 321-322, f. 175: Troc. Second Entl. Neeting, pp. 205, 211, 275; Khare, B.J. KIT, 610-612.

We have this from Dehra Dun; Arrah, larra in dry wood of a case of cutlery; Thapra: Pusa. larva boring in sissu wood, bamboo, furniture, on one oceasion boring a sissu-wood table for three years, the adult emerging in July 1909: Calcutta, larra in piano wood (Entl. Note 32); Nagpur, larva boring dead parts of orange trees, especially parts affected by "Arbela"; Poona, on Acecia arabica; Kanara; North Coorg; and Hagari (Bellary). larva boring in dry bamboo.

It is a common household pest. the larva boring into wooden furniture, picture-frames and so on; and Mr. Khare says that he has found it boring into Citrus trees in the Central Provinces. It seems doubtful, however. how far it may really be regarded as a pest of living trees, although there is no doubt that it bores into many trees that are dead or perhaps dying from other causes.

In Patiala this beetle does a lot of damage to living orange and Malta Harchand Singh. orange trees.

In the Central Provinces I found orange trees in a garden very badly Mr. Misra. affected by "sibelq" and these trees were afterwards attacked by Stromatimen. 
Mr. Sen.

Mr. Fletcher.
[Plocculeins pedeslins. White.

Gahan, F. I. Ceramb. p. 123.

Ploccelerus pedestris is found boring into mango trees in Dacca. Last. year in February grubs, pupe and beetles were found in numbers in a dead tree. As regards its habits, the grub feeds on the portion between the bark and the wood and goes upwards or downwards. When full. grown, it makes a big slanting hole in the wood and pupates in a yellowishwhite hard cocoon inside the hole. The life-history has not been studied in detail.

We have $P$. pedestris from Pusa, but it is not common here and it is not recorded from anywhere East of this by Crahan. The Dacca species is more likely to be $P$. obesus, Gahan. Dut it is impossible to say without seeing the specimens.]

\section{Eolesthes holosericea, Fb.}

Gahan, F. I. Ceramb., pp. 127-128; Stebbing. Ind. For. Ins. Col., pp. $301-30.5$, fi. $208-210$, t. 19.

Gahan gives the distribution as North-West India, Bombay: Nilgiris, Ceylon. Assam. Tenasserim, Andamans, Nicobars, Siam and Malay Peninsula.

We have it from Khedut (Baroda) [labelled Poona on specimen] reared from a larva in guava stem, the adult emerging on 4th April 1907. This stem was also infected with Belionota prasina, and it is doubtful how far $E$. holosericea is a pest of living trees so far as non-forest trees are concerned.

? Rhylidodera robustu.

Gahan. F. I. Ceramb., p. 14i, f. 59.

This was reared by K. D. Shroff on th April lits from a larva boring Ficus caricri at Mandalay, and has also been noted at Thaton in mango.

The identification of this species is uncertain.

\section{Chloridolum alcmene, Thoms.}

Gahan, F. I. Ceramb., 1). 199-200; S. Ind. Ins., p. 323, f. 177 ; Proe. Seeond Entl. Meeting. p. 211.

We have specimens from Pollibetta and Virajpet, in South Coorg. This insect occurs in the orange-growing tracts in the South Iidian. Hills and does serious damage to C'ilms trees by its larva boring in the stems and large branches. It seems to be rather sporadic in its appearance, and has only been noted as a pest in Coorg. 
In Coorg I collected beetles from lemon aud Citins trees. They mere Mr. Ramaclandra resting on the leaves and, when disturbed, they fly about actively.

\section{Chelidonium anctum, Guer.}

$$
\text { Gahan, F. I. C'eramb., p. } 210 .
$$

This was sent in to $n$ in 1918 from Bangalore by Mr. Anstead who Mr. Fletcher. found the larva boring into orange branches. Nr. Anstead states that the eggs are deposited in Jume in the axils of young living twigs and never on dead wood or old branches. The eggs are covered with a sort of yellow transparent vamish. As soon as the eggs hatch the young larra bores into the twig and works upward for about half-an-inch to an-inch-and-ahalf and then makes two tiny holes abont the size of a pin's head. It then turns back and bores domn the trig, occasionally making small openings. Finally it gets into the main branches where it makes tunnels a quarter-of-an inch in diameter. The young twigs that are bored at once die and turn black so that they are conspicuous and they can be cut off with the larvx inside them. By doing this and by hand-collection of the adult beetles the attack can be controlled to a large extent. The eggs appear to take about two weeks to hatch out.

\section{Xylotrechus quadripes, Chevr.}

Gahan, F. I. Ceramb., pp. 245-246, f. 90 ; S. Ind. Ins., pp. 323 324, f. 178 ; Proc. Second Entl. Meeting, pp. 30-34.

We have this from North and South Coorg and the Nilgiris. It is the rell-known "Coffee-borer" of South India, which was discussed fully at the last Meeting in 1917. Since then I have not risited the Coffee Districts and have therefore no more to add.

The length of the life-history is one year but it may vary. The Mr. Kunbi Kannan. bushes may be infected with eggs laid by the April brood. The method of egg-laying is very interesting. The egg is always laid in a crevice; if it is laid anywhere else, the grub fails to penetrate into the wood. Scrubbing the plants is successful to prevent egg-laying and to destroy the eggs when laid. The eggs are never laid loose on the tree. The larve take from two to two-and-a-half months to eat into the wood. To check them in this stage Brunolinemm has been nsed. The larral excrement in the tumnels is not very compact so that the fumes enter the gallery and kill the larva. This chemical might be tried on all sorts of borers in fruit-trees. It is not known exactly what it is but it is perhaps a tar distillate.

What does it cost?

M:. Fietcher. 
Mr. Kunhi Kannau. One Rupee per gallon. Even when used at full strength, one gallon will treat 200 trees. But now the price has gone up, so we are using an emulsion with soap.

Mr. Fletcher.

MIr. Senior-White.

It might be worth trying an emulsion of soap and creosote.

There is some description of this Brunolinem in a Bulletin lately issued by the Ceylon Agricultural Department. Just before I left Ceylon, about 25th January, the beetles emerged in large numbers. I have found a predaceons Carabid grub which follows up the track of the boring larva and kills it. Another interesting fact is that the attack depends on the weather conditions. Probably these influence emergence and oviposition, rainfall records and the number of trees taken out bearing a close relation to one another. There are two or three species of parasites.

\section{Chrysomelide.}

Sagra vigrita, Oliv.

Jacoby, F. I. Chrysom., p. 5; Proc. Second Entl. Meeting, p. 56. IMr. Fletcher.

This species was reared by Mr. E. Ernest Green at Peradeniya, where the larva was found boring in stems of Dolichos lablab, causing large gall-like swellings in the stems. It occurred abundantly and did considerable damage. We have not noted it in India as a pest as yet, but it is quite likely to occur.

\section{Sagra femorata.}

This was found in some numbers by Y. Ramachandra Rao "on bean creeper" at Sidapur, South Coorg. I do not know how far it was damaging any cultivated crop, but, in view of the record of $S$. nigrita on Dolichos lablab, it seems better to include it for the present.

\section{Lema downesi, Baly.}

Jacoby, F. I. Chrysom., p. 43.

At Pusa the eggs have been found laid singly or in rows, usually on the upper surface of leaves of Panicum sp., the larva eating one epidermis and the mesophyll substance of the leaf, and leaving the other epidermis intact. Pupation takes place in soil in a slight cocoon. The life-cycle from egg to adult is about 17 days at the end of August. One female laid 227 eggs between 19th and 30th August and was then lost. We have it also from Chapra.

This species is not known as a pest, but might easily be one. 


$$
\begin{aligned}
& \text { Inopristis bimuculutu. Jae. } \\
& \text { dacoby. E. 1. ('hrysoms. pp. 39-100, fig. 21. }
\end{aligned}
$$

The adult beetles have been found at l'usa in small numbers atmes Howers of rice on Sth October 1917, and have also been found on cotton leaf and on grass. Wo have it aleo from ('hajura. It is probably not. enmmon enough to do any real damage.

\section{Diapromoryhu melanopms, Lac.}

Jacoby, F. I. Chrysom1.. pr). 168-164, tig. 04.

In Intian. Museum Noles. I, ii, p. 106 (1889) this speeies is recorded as reeeived in 1885 from Sibsagar from S. E. Peal who noticed it as " eating the stems of tea-shoots so that they wither and droop."

The Pusa Collection eontains specimens from the Khasis (1000-3000), and Shillong. Buxar Duars. Maymyo. Lebong. Palamau. Chapra, Inmshiganj and Pusa. At Pusa the adult has been taken on Bombar malubaricum, but we do not know it as a pest here.

In Assam it oeeurs every year as a very important pest of tea all irr. Andrews. over the tea districts. especially along the edges of jungles. It bites half-way through the stem which droops and withers. Every planter knows it and it is destroyed by hand-pieking.

In Assam this insect is apparently called the Orange Beetle on aecount Mr. Fletcher. of its colour. and it is so referred to in Watt and Mamn's "Pests and Blights of the "Tea Plant:" As you know, before the appointment of any regular Government Entomologists in India. information about. insect pests, along with various other matters, was dealt with under a scissors-and-paste method in the office of the Reporter on Economic Products and these files on insect pests were finally transferred to Pusa. On looking up the file on this insect I find that the name "Orange Beetle" proved too much for the Office Staff of the Reporter on Economic Products, with the result, that this beetle was solemnly filed under the heading "Pests of Citrus trees."

Cryptocephalus dodecaspilus, Sulẗ.

Jacoby, F. T. Chrysom., pp. 252-253, fig. 97 ; Hroc. Second Entl. Meeting, ]). 264.

The adult beetles were found in some numbers damaging rose-leaves at Abbottabad on 10th June 1916. We also have it from Maymyo, taken in June 1910. 


\section{Norina rufipes, Jac. \\ Jac., F. T. Chrysom., p. 293.}

We have this from Moulmein and also from Maymyo, where K. D. Whrof found the adults on Prames persicre on 18th Mlay 1909. Jacoby records it from Momeit.

\section{Nodostoma subcostatum, Jac}

Jac., F. I. Chrysom, p. 384 ; Proc. Second Entl. Neeting, p. 237.

This occurs at Pusa as a regular pest of plantain, the beetles feeding on the leaves and fruits, eating patches which spoil the appearance of the fruits and it is also said to spoil the flavour of the fruits. In October 1917 the adult beetles were also found at Pusa eating and damaging grape-vine leaves. The larva has been found underground, near roots of grasses. Control may be attained by spraying or by collecting the adults by hand.

It is curious that this beetle has never been noted as a pest except in Pusa, although Jacoby records it from Assam and Burma. It only shows how very little we know as yet regarding even our commonest: insect-pests.

\section{it}

Pagria signata, Mots.

Jac., F. I. Chrysom. pp. 356-357, f. 125.

Jacoby records this from South India, Nilgiris, Burma, Ceylon, China. and Japan, and the Pusa Collection contains specimens from the Nilgiris, Pusa and Jorhat.

At Jorhat at the end of September 1913, it did great damage to cowpeas in the field, completely destroying a crop somn for seed in about 4 bighrs of land and also invaded a "mashkolai" [Phaseolus mungo roxburghii] crop adjacent. The "Mashlolai" was sprayed twice with kerosine cmulsion and the insects then disappeared. (Farm Superintendent, Jorhat, lettor of 9 th December 1913.)

Scelodonta strigicollis, Mots.

Jac., F. I. Chryson., p. 386 ; South Ind. Ins., p. 309, f. 158; Proc. Second Entl. Mecting, pp. 234-235.

We have this from the following localities and foodplants:--Peshawar, adults on grape-vine; Jeolikote (Kumaon), adults on grape-vine ; Poona, achults on grape-vine; Nasik, adults on grape-vine; Nagpur, on grapevines; Pusa, adults on mango inflorescence; Combatore; Dacca; Tharrawaddy; and Minbu (Lower Burma), adults on wild Vitis. 
It is at times a serious pest of grape-vine, especially around Peshawar and Ponna, the adults destroying the tender shoots of the vines. Collection of the adults, either by tapping the bushes or by means of the plantain brooms used at Nasik, is the best method of control and this shonk be supplemented by leaving three or four buds, instear of only one or two, when pruning and hy removal of all loose bark. The life-history is as yet unknown.

- At Peshawar we shake then ofi the vines into kerosinized water. Mr. RobertsonThe beetles are not found in very large numbers.

\section{Brown}

\section{Colasposoma semicostatum, Jac.}

Jac., F. I. Chrys., p. 443 ; Proc. Second Entl. Heeting, p. 212.

Jacoby records this from Sikkin, Mungphn, and Cachar, and the Pnsa in. Fretcher. Collection contains specinens from Chapra and the Khasi Iills. In the Khasis the adult beetles destroyed flowers and loaves of orange trees in March and April 1916 at Randait "Alakha." The leaves were eaten near the stalks. It is said to have done considerable damage to oranges during the preceding three years, appearing in Hareh and April and then disappearing again. (S. R. Gupta's letter of 12th May 1916.)

It is very bad on olanges and ants away the flowers.

Is it found in any other prat of Assan!

I have not seen it anywhere ase.

iir. Fletcher.

Mr. Gupta.

\section{Pachephorns bretinghami. Baly.}

Jac., F. I. Chrysom, pp. 460-461; Proc. Second Entl. Neeting, pp. 140, 180, 294.

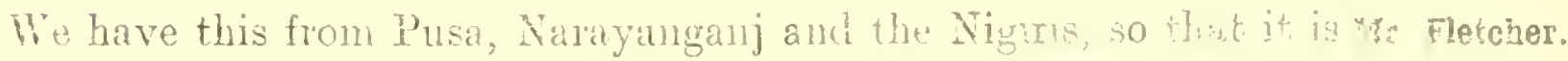
widely distributed. At Pusal the artult hav heen forme ir antichere.

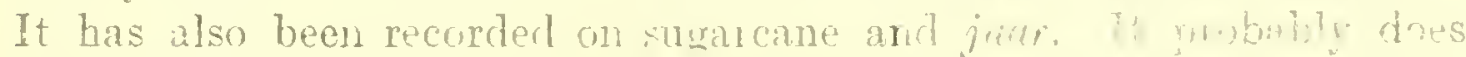
damage in the same way a- P. impressus int dees nom ceres. to have uctually been noted as a pest.

$$
\text { Pachuephorus improssus, Rosenh. }
$$

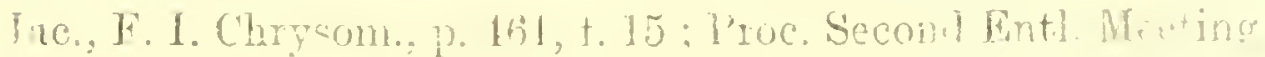
пр. 83, $122119,181,192 ;$ Fint. Note 33.

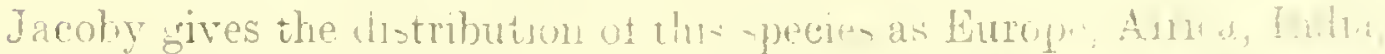

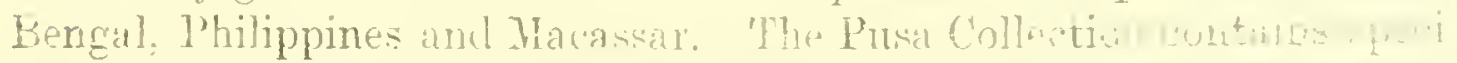

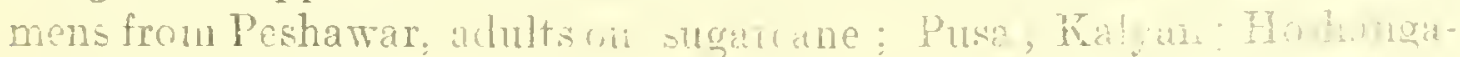

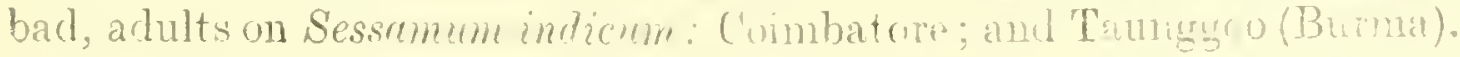
At Peshawar the beetles necur in numbers and eat small looles in the 
Mr. Anảrews.

Mr. Fletcher.

Mr. Ramakrishna Ayjar.

Mr. Fletcher. leaves of young sugarcane. At Pusa the larva has been found amongst maize roots and the adults have been noted on young bhindi. At Hoshangabad it is said to be a bad pest of til, eating the leaves and pods. Collection of the adults seems to be the simplest remedy.

\section{Phadon brassica, Baly.}

In Indian Museum Notes, III, v, p. 44 (1896) it was reported under date of 28th December 1893 by the Sub-Divisional Officer, Golaghat, that the mustard erop in part of the Sub-Division was infested by $P h$. brassice and the beetles were identified by Jacoby who records it also from China and Japan. It has not been reported again as a pest, but it is said to be common throughout Assam and presumably does some damage.

In Assam it comes to light but I have never noticed it in large numbers.

\section{(Unidentified Chrysomelid.)}

This species was found at Mandalay by K. D. Shroff on 12th May 1909, the adult beetles occurring on guara.

\section{Oides affinis, Jac.}

South Ind. Ins., p. 313, f. 164 ; Proc. Second Entl. Meeting, p. 168.

This species was found in large numbers on rice-plants at Shoranur (Malabar) on 31st July 1907 and we have it also from Taliparamba (Malabar), where it was found on grass, and from the Nilgiris. It is very doubtful how far it is a pest. At any rate, it seems to be sporadic and local.

We have not found it again. On the one occasion when we did find it, it was in numbers, nibbling the plants.

\section{Aulacophora stevensi, Baly.}

South Ind. Ins., pp. 312-313, f. 163 ; Proc. Second Entl. Meeting, pp. 303-307.

This species occurs on cucurbits generally and has been noted on snake-gourd, bottle-gourd and bitter-gourd, the adult beetles being especially destructive to the flowers. It does not seem to occur in North India, but is abundant in Southern India and Burma. Our specimens are from Ceylon, Trichinopoly, Saidapet, Kistna district and Tatkon (Buma) and it is also recorded from Coimbatore, Chingleput and Godavari. 
Aulacophora atripemis, $\mathrm{Fb}$.

South Ind. Ins., p. 312, f. 162 ; Proc. Second Entl. Meeting, pp. 303-307.

Aulacophora atripennis (excreata), a ferruginous species with blueblack elytra, is common in most parts of India except the extreme North and occurs on all cucubitaceous plants but is hardly a pest as a rule. We have it from Dehra Dun; Chapra; Pusa; Buxar Duars; Jorhat; Silchar; Mandalay; Hopin (Upper Burma); Pyinmana; Moulmein, on cucumber ; Surat; Poona, on gourd leaves; Pollibetta (South Coorg); Manganallur; and Peradeniya, on cucumber.

\section{Aulacophora abdominalis, $\mathrm{Fb}$.}

South Ind. Ins., p. 311, f. 161 ; Proc. Second Entl. Meeting, pp. 207, 302 (tab.), 306, 307.

Aulacophora abdominalis (forcicollis) occurs abundantly throughout India and Burma as a bad pest of all cultivated cucurbits, and it feeds on wild species also. We have it from Kohat. Peshawar, Haripur Hazara, Lyallpur, Zaffarwal Tahsil (Punjab), Jallandhar, Gwalior, Bilaspur, Balaghat (Central Provinces), Belgaum, Kanara, Coimbatore, Samalkota, Pusa, Dacca, Jorhat, Manikganj (Assam), Tharrawaddy and Meiktila (Burma).

At Pusa it has been noted especially on bottle-golird, at Lyalipur on pumpkin and in Gwalior the adult beetles were eating holes in cucumber leaves. At Jallandhar both larvæ and adults were found boring into the underside of melon fruits lying on the ground and at Peshawar I found it doing serious damage to melons in the larval stage in May by boring into the roots.

Control was discussed at the last Meeting and there is nothing to add.

Do the grubs usually breed in roots?

Mr. Ramrao.

They are not found inside the roots but underground feeding on roots. Mr. Ghosh.

At Peshawar I found them actually boring inside melon roots.

Mr. Fletcher.

I cannot find the larva, although I have tried.

Mr. Ramrao.

At Pusa it took us five years to discover the early stages.

Mr. Fletcher.

\section{Galerucella singhara, Lefroy.}

Entl. Nem. II, Pp. 146-119, t. 15; Proc. Second Entl. Meeting, p. 254.

This species occurs principally in the United and Central Provinces where it is a bad pest of water-nut (Trapa bispinosa). We have it from Campur, Shakartala and Bhadra (Central l'rovinces), Muzaffarpur and 
Mr. David.

Mr. Fletcher.

Pusa. At Pusa the adult beetles have been taken at light. As regards control, collection by hand and crushing the insect in all stages is the only satisfactory remedy.

It is a bad pest in the United Provinces, where we control it by collection in handnets.

\section{Galerucella sp.}

Proc. Second Entl. Mleeting, p. 250.

This species was found on loguat (Eribbotrya japonica) by K. D. Shroff at Maymyo on 17th May 1909.

\section{Himastra cyanea, Hope.}

Ind. Museum Notes IV, iv, 217 ; Proc. Second Entl. Meeting, p. 247.

The Pusa collection contains specimens with the following data:Jeolikote, adults on apricot fruit, chestnut, apple fruit; Solan, adults defoliating pear trees, 29th Nay 1916 (H. P. J. Peake); Dehra Dun; Abbottabad; Hills near Simla, adults defoliating mulberry and apple (inlcludng wild Pyrus Pashia), occurring annually at end of May, Aying in morning and late afternoon, resting at midday (I. H. Burkill, letter of 28th May 1906); Sambli (near Murree Hills) 4,000 feet, adult beetles in enormous numbers in June 1918 defoliating pear, apricot and grape-vine.

It has also been recorded as injurious to Growia asiatica in the Dun Forest (Ind. Mus. Notes, l.c.).

\section{Honoleptu signata, Olir.}

South Ind. Iiss., p. 310, f. 159; Proc. Second Entl. Meeting, pp. $42,61,81,190,195,200,207,280,282,283,290,298$; Am. Rept. Impl. Entom., 1917-18, p. 93, t. 12, ff. $2 a-c$ (1918).

This is a common and widely distributed insect with a very wide range of foodplants. The Pusa Collection contains examples from Pusa on grass, Polygonum, heerne, indigo, arhar, maize, abbage; Chapra; Jeolikote (Kumaon), on grape-vine leaf; Tharsa Farm (Central Provinces) on maize, 3rd January 1913; Patna district, on pea ; Poona ; Coimbatore, on ragi, grass, wheat, and vegretahles; Nilgiris; Samalkota; Dacca; Raniganj (Bengal); Buxar Duars; Jorhat; Minbu (Lower Burma); Tharawaddy; Miyitkina; and Maymyo. In Burma it is a minor pest of tur. In India it seems to be scarcely a pest as a rule although it is sufficiently common at times, especially on maize, to do a small amount of damage. It has been reared at Pusa from larve found feeding at the 
roots of sugarcane but it is probable that the larvo are general feeders on roots of Graminex and do some harm in this stage.

\section{(Undetermined Galerucine.)}

This was found in the Shevaroy Hills ( 1,000 feet) on mustard by Y. Ramachandra Rao on 26th August 1907.

\section{(Undetermined Galerucine.)}

This species was sent in to us from Solan by Mr. H. L. J. Peake, who in his letter of 30 th July 1915 states that it " attacks almost every plant, and is specially partial to fruit trees, such as apples, pears and apricots, also roses; the latter they completely destroy. May attack and completely iuin leaves of large apricot trees."

It also attacks rose leaves, completely ruining them, and also attacks rose flowers, both when in full bloom and in bud.

\section{(Undetermined Galencine.)}

This was sent in to us on 29 th March 1907 by Nr. J. Harold Mitchell, from Helem (Assam), the adults attacking leaves and unlipe fruit on plum trees in large numbers.

Nisotra madurensis, Jac.

South Indian Ins., pp. 310-311, f. 160 ; Proc. Second Entl. Neeting, pp. 126, 134.

We Lave this from the Nilgiris, Malabar, Kundapur (Sonth Kanara) and Trichinopuly. It is apparently confined to Southern India, where it is a minor pest of jute and an oceasional major pest of Hibiscrs comnabines.

$$
\text { Psylliones tenebrosus, Jac. }
$$

Proc. Second Ent1. Meeting, pp. 278, 281.

This secies ras sent in to us from Jeolikote (Kumaun) as cansing trat damage to cruciferou seedlings in Normber 1909. It was also - eut in te nem Bhin Tal by Mr. C. F. Ruxton who wrote in a letter, diated 2ne Irarch 1912. that these beetles "have devastated my gardeu in the last four days. They hare practically cleared ererything except jeats, which they have not touched....... They seem to prefer mustard seed." 
Clitea picta, Baly.

Proc. Second Entl. Meeting, p. 215.

We have this from Tharrawaddy (Burma) and Pusa. At Pusa it is a decided pest of bael (Egle marmelos). the larva boring into the leafpetioles and shoots and the adult beetles eating the leaves so that they are riddled with small holes in June and July.

\section{Haltica eyanea.}

This was sent in on 14th December 1911 by the Superintendent of the Victoria Gardens, Bombay, as very badly infesting Ruellia amcena and $R$. formosa and Cuphea ignea. It has been reared at Pusa from larvæ on Ammania sp.; pupation took place in earthern chambers in the soil.

At Taru the adult beetles were found in numbers in May 1916 on cauliflowers, eabbage, lettuce, sugar beet (especially on flower-heads) and also spread on to shaftal and bersim.

The Pusa Collection contains specimens from Pusa (abundant); Nainpur (Central Provinces); Balaghat (Central Provinces); Surat; Nuwara Eliya; Tranquebar; Coimbatore; Samalkot; Munshiganj; Cuttack; and Nepal.

\section{Chatcenosoma metallicum, Jaic.}

Proc. Second Entl. Meeting, p. 267.

This is a medinm-sized, globular, bright metallic green and blue Halticine which was found in numbers injuring garden lilies at Ootacamund in December 1912 and 1913. The beetles may be collected by hand.

\section{Phyllotreta vittata, $\mathrm{Fb}$.}

Proe. Second Entl. Meeting, pp. 280, 282.

'I'his species was found by K. D. Shroff on cabbage at Kaltha (Burma) on 2nd February 1907.

\section{Phyllotreta chotanica, Duviv.}

Proc. Second Entl. Meeting, pp. 280, 282.

This species was found in small numbers on cabbage at Pusa, on 4th March 1916 and we also have it from Mandalay (13th December 1910). 
Chetocnema basalis, Baly.

Proe. Second Entl. Meeting, p. (6s.

We have this from Ranchi, Dharwar and Tharrawaddy. At Dharwar it was found in February 1913 at the roots of withering rice plants. There are also old records on cards of the oceurrence of adult beetles on sann hemp at Pusa in April 1906 (on stray plants), and in August 1905 ("some"), at Raipur in August 1907 (" a good deal "), at Jallandhar in September 1905 and at Surat in September 1904; but we have no specimens with these data and it is very doubtful whether these records really belong to $C$. basalis at all-more probably they belong to the unidentified Halticine dealt with later on.

\section{Podontia 14-punctata, Linn.}

We have this from the Khasi Hills, Helem (Assam), Jalpaiguri, and Bassein (Burma). It has been noted to attack fruit-trees at Jalpaiguri and, in his letter of 29th August 1908, Mr. I. H. Burkill reports that these beetles "have almost defoliated some imported fruit trees in the Jalpaiguri District."

\section{(Unidentified Halticine.)}

This speeies was found at Cawnpur on 15 th October 1905 by Mr. C. S. Misra, the adults attacking groundnut and sweet potato.

\section{(Unidentified Halticine.)}

'This species occurs at Pusa on sann hemp, generally in July on young plants, often in large numbers, eating the leaves into holes. On 15th Deeember 1915 it was found on sann hemp at Pusa by Tahl Ram.

It is often a bad pest of young sann hemp and the records on sann hemp quoted under Chatocnema basalis (supra) probably belong to this species, which is distinct from C. basalis.

In the ease of young plants, the beetles can be caught in bag-nets swept over the plants or may be dealt with by spraying the plants.

The larve feed on roots of sann hemp but we have not been able to Mr. Ghosh. trace it through all its stages.

At Coimbatore we also have a flea-beetle which is very bad on sann Mr. Ramakrishna hemp, but I do not know whether it is the same species.

It is not safe to assume that it is the same species because it feeds on Mr. Fletcher. the same plant. There are so many of these small flea-beetles and their identification is hopeless at present. There is a very wide field in the Haltieina for anyone who wishes to take up systematic work. 


\section{(Unidentified Halticine.)}

This was found on sam hemp at Handalay by K. D. Shroft on 10th Hay 1909. It is apparently distinct from the preceding species; it is larger and more stontly built and rather redder in colour.

\section{(Unidentified Halticine.)}

The adult beetles have been found at Pusa, on brinjal leaves in August 1912 and on sweet-potato leaves in September 1915, eating small holes in the leaves.

The beetles were also found nibbling the surface of brinjal seedling leaves in the seed-bed on 25th August 1915, producing yellowish markings all over the leaves. In many cases the entire tissue of the leaf is eaten and holes are produced. The beetles are a pest of the seedlings, eating both the upper and lower surfaces of the leaves. Adult beetles were also found at Muzaffarpur on brinjal, 10-20th January 1905.

\section{(Unidentified Halticine.)}

This species was reported by ${ }^{\prime}$ T. N. Jhaveri, in his letter of 7 th February 1913, as occurring at Dhulia, East Khandesh, and attacking a young germinating crop of rabi juar.

\section{Aspidomorpha mitiaris, $\mathrm{Fb}$.}

Ind. Mus. Notes III, i, 24 (1893) [Aspid. initituris]; South Ind. Ins. pp. 316-317, f. 168 ; Proc. Second Entl. Meeting, p. 291.

This is a widely distributed speeies which we have from Bassein Fort; Poona, on Gmelina ; Kanara ; Hunsur (Mysore), on wild I pomoar ; Coimbatore, on sweet-potato; Hadura; and Ceylon. It is an occasional very minor pest of sweet-potato, the larva feeding ou the leaves.

$\therefore$ Ramrao.

ir. Fleteler.

\section{Aspidomorphla foveata, Thubg.}

We have this from Tharrawaddy and IIoulmein, where it was tound on sweet-potato.

\section{Aspidomorpha indica, Boh.}

Proc. Second Entl. Meeting, p. 292.

We have this from Chapra, Pusa, Betul, Khasi Hullo (1, ) (6)-3,000 leet). the Anamalai Hills and Tatkon (Burma). Lt Betul it was tound "on salad, 9th December 1915," at Tatkon the adults wciurrel un Trichosanthes cucumerina, and at Pusa it has been reared from the egg on sweet-potato leaves. 
It is perhaps an occasional pest of sweet-potato, but as a rule the damage done is negligible.

From a long scries reared from the egg, it would appear that indica, Boh., and fovertu, Thulgg., are identical; at least, I fail to see any distinction.

$$
\begin{aligned}
& \text { Pilemostoma trilinectu, Hope. } \\
& \text { Proc. Second Entl. Neeting, p. } 292 .
\end{aligned}
$$

Vie have this from Masuri, Chapra, Pusa, Lebong (Darjiling), and Tation (Burma). At Tation the adults were found on Trichosanthes cucumerina and at Pusa the larre have been found on sweet-potato leares. It is searcely a pest of sweet-potato, bat may do a little damage at times.

\section{Metriona circumdata, Hbst.}

Metriona sp., S. I. I., p. 318, f. 170 ; Proc. Second Entl. Meeting, p. 292.

We have this from Surat, Chapra, Pusa and Dacca. At Pusa it Las been reared from larvæ on sweet-potato and in South Arcot and Tinnevelly it has also been found on sweet-potato, of which it is scarcely a pest.

\section{(Unidentified C'assidine.)}

This was found on sweet-potato at Moulmein in September 1914. the adults occurring in small numbers.

\section{Leptispa pygmaca, Baly.}

South Ind. Ins., pp. 313-314, f. 165 ; Proc. Second Entl. Meeting, p. 168 (tab.).

'This species seems to be restricted in its distribution to Southern India, occurring as far North as Londa in Bombay and Godarari in Madras. We have it from Bassein Fort (Bombay); Alibagh (North of Bombay) ; Hassan (Mysore) ; Mercara (Coorg), on paddy, 17 th November 1915 ; Ottapalam, Nalabar ; South Malabar, on rice, 23rd October 1911 ; and Travancore.

It is a serious pest of paddy in Southern India, especially in districts with a heary rainfall.

We find it in Bombay, especially near the coast.

Mr. Ramrao.

How far north do you get it?

Mir. Fletcher.

From Ratnagiri to Surat; but in the Upper Konkan (i.e., in Thana Mr. Ramra. and Alibagh Districts) we have only Hispa, and in the Lower Konkan (i.e., Ratnagiri and Karwar) we have Leptispa.

We do not find it at all at Pusa.

Mr. Fleicher. 
IIr. Pillay.

IIr. Fletcher.

Mr. Pillay.

IIr. 'haveri.

Mr. Fletcher.

It is a serious pest in Travaneore.

Do you do anything against it ?

Nothing.

We have found the grubs parasitized at Surat.

The parasite is probably not very successful.

\section{(Unidentified Hispine.)}

This speeies was found by K. D. Shroft on 7th September 1908 at Hmawbi (Lower Burma) boring into plantain stems.

\section{Wallacea sp.}

Proc. Second Entl. Meeting, p. 262.

'This species has been found at Pusa, the adult on top-leaves and the larva on top-shoots of the date palm (Phoenix sylvestris). The larvæ and adults eat the epidermis of young leaflets.

\section{(Unidentified Hispine.)}

This species has been found in some numbers at Pusa on Succharum srundinaceum. On 21st June 1918 the larvæ were found living gregariously inside rolled leaves, nibbling the epidermis, and on 10tl July 1918 the adults were found in the field nibbling the leaves. The larvæ collected in June emerged on 25 th July 1918.

\section{Oncocephala tuberculata, Oliv.}

Proc. Second Entl. Meeting, p. 292.

We have this from Bulsar (Bombay), in numbers on 20th May 1904; from Coimbatore, on sweet-potato; and from Moulmein, adults on sweetpotato. It is not known to be a pest.

\section{Oncocephala sp.}

This was reared at Pusa from larvæ found in September 1915 on sweetpotato leaves, mining them, September 1915. It is not known to be a pest.

\section{Platypria andrewesi, Weise.}

Proc. Second Entl. Meeting, p. 253.

This species occurs on ber (Zizyphus jujuba), the larva damaging the leaves to a small extent. We have it from the Punjab, Surat, Pusa, Sripur, and Coimbatore. 


$$
\text { Platypria echidna, Guer. }
$$

Proc. Second Entl. Aleeting, p. 77.

We have this from Matheran, Belgam, the Nilgiris, and Pollibetta (South Coorg). It lives on Erythrine lithospermen and is a minor pest of this, the leaves sometimes being damaged to a considerable extent.

$$
\text { Platypria hystrix, } \mathrm{Fb} \text {. }
$$

South Ind. Ins., p. 316, f. 167 ; Proc. Second Entl. Meeting, pp. 56, 74, 77.

We have this from Calicut and 'Tanjore. It ocen throughout Southern India as a local and minor pest of lablab, ayathi irythrima.

\section{Hispa armigera.}

South Ind. Ins., pp. 315-316, t. 10; Proc. Second Entl. Meeting, p. 167.

Hispa armigera (anescens) occurs in practically all rice-growing areas in Southern and Eastern India as a serious pest of rice, usually on young rice plants. North Bihar seems about its northern limit, and at Pusa it is sometimes a pest of nurseries. Our records include the following data:-Champaran, on rice; Pusa, usually in small numbers, occasionally destructive to seedling rice-plants; Kidderpur; Hidnapur; Noakhali, on rice, 11th September 1913; Harra (Bankura), breeding in aus paddy leaves, July 1917 ; Bakerganj (Bengal), on paddy in numbers, September 1905 ; Sylhet, on paddy, 10th June 1912 ; Cuttack, occasionally serious; Ellore; Salem, on paddy; South Kanara, on paddy; Lonavla (Bombay), on rice.

The life-history in known and the main difficulty in control is the sporadic manner in which this pest usually appears in destructive numbers. Collection of the beeties in hand-nets has been found useful in Madras, and perhaps oiling of the water and dipping the plants by dragging a rope over them might be useful in the case of seed-beds.

Can anyone give us an account of practical experience in control measures?

Cutting off the tips of the plants is effective. When the pest appears Mr. Ramrao. in large numbers, cutting the tips oft the plants reduces the pest considerably, but this must be done before the flowering shoot comes up.

In Madras it is the custom to bundle the seedlings together and to Mr. Ramakrishna cut off the tops whether the beetles are present or not. We tried this Ayyar. and found it successful.

In Travancore we tried hand-netting. If this is done twice or thrice Mr. Pillay. after the rains it is successful. Rain is essential for hand-netting, because 
Mr. Ramakrishna

Ayyar.

Mr. Pillas.

Mr. P. C. Sen.

Mir. Gupta.

Mr. Ramakrishna Ayyar.

Mr. Pillas.

Mr. Gupta.

Mr. Pillay.

Mr. Ramakrishna Ayyar.

Mr. Pillay.

Mr. Glosh.

Mr. Piliay.

Mr. Ghosh.

the mire in the fields gets sticky and the beetles that fall in get stuck there.

We find this pest very bad in cases where fields are irrigated from tanks.

It does not occur until forty-five days after transplantation.

It is bad in flooded areas in Bengal and nothing can be done there to check it. When it attacks aus paddy, bagging is possible.

In Assam there is no hope of checking the pest by bagging or netting.

Will Mr. Pillay say whether it was a bag-net or a hand-net that he tried?

Hand-netting.

We did bagging, but it was no good.

The fields must be muddy and then the insects fall into the mire.

Paddy is grown under swampy conditions, and bagging or netting seem impossible.

We do netting two or three times.

Do you get the beetles by bagging? They seem to sit tight on the leares.

The insect occurs in patches where the paddy is about two feet high.

Some varieties of paddy are more affected than others and work might be done on the sclection of resistant varieties.

Phidodonta madesta, Wied.

South Ind. Ins., p. 315, t. 9 ; Proc. Second Entl. Meeting, pp. 149, $152,180,199$.

N.r. Fletcher.

Our specimens are from Chapra; Pusa, on sugarcane, Saccharum sponteneum, juar, oats and rice; Surat, on sugarcane and jucr; and Pyinmana (Burma), on sugarcane. It is a widely distributed species throughout the Plains of India and Burma and is a minor pest of sugarcine and juar. The larva mines the leaf and the beetle also eats the leaf. The mined leaves and adult beetles may be collected and destroyed.

It is uncertain whether we have one or more species on sugarcane under the name Ph. modesta. The Pusa specimens (as is shown in the -olourcd plate given in Indian Insect Life, tab. 23, and in South Indian Insects, tab. 9) have five pairs of thoracic spines, the first and second and the third and fourth comnate, the fifth frce. In the Surat specimens the first and sccond spines are connate, the rest separate at origin. The Burma form, as represented by a single specimen from Pyinmana, has the third and fourth thoracic spines on a distinct stalk and the clytra with accentuated colourless patches in rows between the spines. One Pusa specimen has the fifth thoracic spine double on the left side only. 
The original description of $P h$. modesta applies to the Surat form, whilst our colomred plate is taken from the Pusa form.

It is not a pest at Pusa.

Mr. Misra.

LARIADA: (BRUCHIDA).

This family includes a number of species which attack pulses. Most Mr. Fletcher. of them are pests of stored pulses, but a few attack the seeds in the field. The various species concerned are as yet very imperfectly known in India and further investigation will doubtless bring to light many more species which attack crops in the field. Besides those mentioned here we have various unidentified species from Sestania and Crolalaria seeds.

\section{Bruchus affinis, Frol.}

Proc. Second Entl. Meeting, pp. 64, 65, 308 ; Ann. Rept. Impl. Entom., 1917-18, p. 105.

This species has been found at Pusa and Poona attacking Pisum sativum seeds in the field. We have it also from Kanara.

We find it breeding in the field to a considerable extent. It has one Mr. Ramrao. brood in the year and cannot breed in the dry seeds later on.

\section{Bruchus theobromce, Linn.}

This species has been found at Poona, breeding in Pisum sativum Mr. Fletcher. seeds in the field.

We also have it from Belgaum, Matheran and Coimbatore, but it has not been found at Pusa.

\section{Pachymerus chinensis, Linn.}

S. I. I., pp. 306-307, f. 155 ; Proc. Second Entl. Neeting, pp. 45, 57, 60, 64, 308 (Bruçus) ; Ann. Rept. Impl. Entom. 1917-18, p. 105 .

Pachymerus (Bruchus) chinensis breeds both in the field and in stored pulses. At Pusa it is mainly a pest of stored seeds, but has been found to breed in the field in pods of cowpea (Tigna caljang). We have specimens from the following localities and foodplants, but not all of these latter are from growing plants:- Nagpur, larva in pea-seeds and Vignu catjang pods; Gaya, on Cajanus indicus; Pusa, eggs on pea-pords, larva in Vigna catjang pods in fields, sceds of Dolichos biflorus, arhar seeds, lentils in store; Mysore and Coimbatore, on Cajanus indicus.

The fact that these seeds may be infested in the field emphasizes the necessity for proper treatment before storage.

vOL. I 


\section{Meloide (Cantharide \\ Epicanda hirticomis badgleyi, Wellm. MS.}

This species was sent in by Dr. H. H. Mamn in June 1907 as damaging vegetable gardens in Assam and also serionsly attacking Sesbania aculeata (ahaincha) plants introduced for green manure on Tea Gardens. It.was also sent in on 21st September 1907 by the Head-Naster of the Dacca Training School as destroying leaves of dhaincha plants.

The Pusa Collection also contains specimens from Buxar Duars, Gauhati and Nongpoh.

$$
\text { Epicaula sp. }
$$

S. S. I., p. 306, f. 154.

This species was found at Puttur. South Kanara, on paddy, 3rd October 1909 .

It is a local pest of paddy, eating the flowers and also attacking the ripe ear-heads.

\section{Epicaulesp.}

Adult beetles were sent in to us on 17th June 1914 from Simla by Kishen Singh as "working havoc on all the potato and cabbage crops, and it swarms like locusts, eating up all the leaves. even of walnut and other trees."

\section{Zonabris phalerata, Pall.}

Proc. Second Entl. Meeting, p. 128.

Specimens were sent in to us by Messrs. Mitchell and Company on 23rd June 1915 from Garhi, Kashmir (3,000 feet) and were stated to be eating and destroying the olive fruits on the trees.

At Pusa the adults occur in November every year and destroy Hibiscus rosa-sinensis flowers.

We also have specimens of this species (identified by Dr. Creighton Wellman) from Helem (Assam), Belgaum, Sheraroys, Masuri, Surat,

Mr. RobertsonBrown.

Mir. Fletcres. Berar (Central Provinces), Hoshangabad, Saran (Bihar) and Cuttack.

It has not been noticed on olives in the North-IVest Frontier Province.

\section{Zonabris pustulata, Thunb.}

Proc. Second Entl. Meeting, p1. 43, 60, 128, 201.

We have two or three specimens named as pustulalu by Dr. Creighton Wellman but I cannot distinguish these from phaterata, which seems to be the commoner form. 
The name pustulate has generally been applied to the common large black red-banded species which is frequently destructive to Cajanus indicus, cowpea, Hibiscus rosa-sinensis and tenai.

$$
\text { Lytla tenuicollis, Pall. }
$$

S. I. I.. p. 302, f. 148 ; Proc. Second Entl. Meeting, pp. 178, 183, 188. 201.

We have this from Chapra; Pusa; Belgachia; Palamau; Bhandara (Central Provinces), on rice; Hoshangabad; Surat, on bajra and juar; Nadiad; Hagari (Bellary), on cholam ear-heads and paddy; Bezwada; and Coimbatore. In Southern India this species does considerable damage to ear-heads of cholam, cumbu, etc.

As in the case of all these Heloid beetles, the adults are easily collected by hand or in nets.

$$
\text { Lylla picla, C'ast. }
$$

Proc. Second Entl. Meeting, p. 207.

This has been found at Gurgaon (Punjab), the beetles eating bajra (Pennisetum typhoideum) flowers, 4th September 1906. Mr. T. N. Jhaveri has also found the beetles eating lucerne leaves in North Gujarat.

\section{Lytla ruficollis, Oliv.}

S. I. I., p. 30J, f. 153 ; Proc. Second Entl. Meeting, p. 201 (Cantharis).

This species seems to be confined to Southern India. It has been found in Coimbatore, Bellary, Kurnul, Tanjore, and Tinnevelly; the adult beetles damage cumbu, cholam and tenai ear-heads.

\section{Lylla actoon, Cast.}

Entl. Note 35 ; Proc. Second Entl. Mecting, pp. 149, 202, 207 (Cantharis).

We have this from Kasur (Punjab), Cawnpur, Surat, Khandesh, Pusa and Cuttack. At Pusa the adult beetles were found on rice-plants on 8th August 1905, on grass on 10th June 1907, cating lucerne on 2nd August 1913, on Setaria and Panicum miliaceum in large numbers on 17 th July 1915, and also appeared in the beginning of July 1916. At Cuttack the adults were found on aus paddy on 20th August 1907.

We find this in Madras also. 
Gnathospastoides rouxi, Cast.

South Ind. Ins., p. 302, f. 147 ; Proc. Second Entl. Meeting, pp. 51, 201.

Mr. Fletcher.

This is a widely-distributed species which we have from Fyzabad (United Provinces), Pusa, Seoni, Bhandra (Central Provinces), Hoshangabad, Surat, Dharwar, Kanara, Bezwada, Samalkota, Devanakonda (Kurnul), Beeravalli (Bellary) and Yemmiganur (Bellary). At Pusa it has been found on urid leaves. At Bhandara the adult beetles were found in a field of Kutki [Panicum mitiare]; they "ate up nearly twothirds of the whole crop, selecting the seeds which were just ripening and leaving those that were dry and perfectly mature." At Seoni on 7th September 1904 the adult was noted to attack the ear of young plants: of Kutki. At Dharwar on 21st September 1908 the beetles were found on juar ear-heads; "sweet" and "dwarf Milo" varieties of juar were attacked, whilst the "Sundhia" variety, grown close to the others, was quite free from attack. At Devanakonda the beetles occurred on cholam at the end of August 1913. At Beeravalli and Yemmiganur the adults appeared at the end of August 1913.

\section{TENEBRIONID $\approx$.}

Hopatroides seriatoporus, Fairm.

Specimens of adult beetles were sent to us on 29th July 1910 by the Superintendent of the Agricultural Station, Dharwar, who stated that they were "found in the surface of the soil and had done a lot of damage by cutting the tenderupshoots of potatoes, castors and groundnuts." Injured stems were sent for inspection. No attack of these beetles had hitherto been observed nor has it been reported subsequently.

\section{Gonocephalum brachelytra, Gebien.}

We have this only from Pusa, where it is abundant. On 18th January 1919 adult beetles were found in large numbers in recently transplanted beds of poppies, petunias, etc., in a garden, feeding on the plants. They were collected by hand and excluded from the flower-beds by a border of ashes mixed with kerosine. The larva has been found underground at Pusa in a gram field, where it was eating gram roots; in confinement it fed on fresh indigo leaves and decomposing leaves. The larva and pupa have been found.on 18th May 1914 underground in a field of paluat (Trichosanthes dioica). 
Gonocephalum depressum, $\mathrm{Fb}$.

Proc. Second Entl. Meeting, pp. 46, 50, 284.

This is a widely-distributed species which we have from Peshawar, Masuri, Cawnpur, Bundhilkhand (Central India), Pusa, Lebong (Darjiling District), Buxar Duars, Khasi Hills, Mandalay, Belgaum, Bangalore, Kanara, Trichinopoly, Iyerpadi (South India), Coimbatore, and Valparai (Anamalai Hills). In Bundhilkhand it was found at roots of gram and at Bangalore in March 1910, the beetles were noted by T. V. Ramakrishna Ayyar to damage grape-vines by nibbling the tender roots and scraping the fruits. Larvæ were sent in from Orai, near Cawnpur, by Mr. B. C. Burt and stated to be damaging gram roots in January 1909 ; "the larva remains underground, first eating the hairs of the roots, sometimes cutting roots through four or five inches below ground. Individual plants are attacked here and there; they yellow and dry up."

\section{Gonocephalum hofmannseggi, Steven.}

South Ind. Ins., p. 299, f. 143 ; Mysore Entl. Bull., No. 5 (1918).

We have this from Dehra Dun, Bangalore, Nilgiris, Kanara, Calicut, Coimbatore, Anamalais and Tinnevelly. It has been noted at Bangalore to do occasional damage to grape-vines, potatoes, etc., and in their recent Bulletin Messrs. Coleman and Kumhi Kannan record it definitely as a pest of potato and ragi (Eleusine coracana), and recommend control by attracting the adult beetles to bundles of weeds pulled out with their roots and laid down on the field bunds.

We have recently issued a Bulletin on $G$. hopmannseggi and $G$. depres-Mr. Kuabi Kanoa sum and remedial measures have been suggested there. This species attacks ragi seedlings and potato tubers in Mysore.

\section{Gonocephalum elongatum, Fairm.}

Proe. Second Entl. Meeting, pp. 46, 50, 94.

This is also a widely-distributed species and we have it from Cawnpur, Mr. Fletcher. Chapra, Pusa, Comilla, Buxar Duars, Lashio (Upper Burma), Nongpoh (Khasis), Chitrakote and Lalitpur (Central Provinces), and Belgaum. At Cawnpur the adult beetles have been found on groundnut and at Pusa on 18th January 1919 they were abundant in newly-transplanted beds of seedlings (poppies, petunias, ete.), in a garden, pairing, and apparently breeding and feeding on the plants. At Pusa the larra was foumd eating roots of gram in May 1915 and the insect has also been reared from ihe egg on dry indigo leaves. Like the preceding species, it probably feeds normally in the larval stage at the roots of grass but may do considerable 
MAr. Senior-White.

Mr. Fletcher.

Mr. Ramakrishna Ayyar.

Mr. Fletcher.

Mr. Beeson.

Mr. Ramakrishna Ayyar.

Mr. Fletcher. damage to cultivated plants at times and the beetles also attack cultivated plants, especially any that are at all sickly.

The beetles are gregarious in habit.

\section{Gonocephalum sp.}

The larvæ were found at Pusa in a gram field, and in confinement ate gram roots and also decaying leaves.

\section{Gonocephalum sp.}

The adult beetles were found in numbers at Moulmein in September 1914 on sweet-potato which certainly seemed to have been attacked by them, many plants being dying or dead and their stems eaten into.

\section{Elaterid}

\section{Drasterius sp.}

Elaterid grubs found at Pusa on 10th November 1914 were supposed to be damaging newly-grown wheat. The larvæ were supplied with roots but it could not be determined that they were eaten; they were probably predaceous, and it is doubtful whether they were actually doing damage.

We have found this species actually eating potato-tubers underground. We find it chiefly in the Hilly tracts.

All the Elatcrids that we have reared have been predaceous in the larval stage.

They live in wood in large numbers.

The grubs were fed on potato-tubers in our insectary.

\section{BUPRESTIDE.}

Sphenoptera gossypii, Kerr.

South Ind. Ins., p. 298, t. 8 ; Proc. Second Entl. Mecting, pp. $119,124$.

This species is widely distributed in India and we have it from Hissar (Punjab), Pusa, Nagpur, Anand, Surat, Baroda, and the Nilgiris. As a pest of cottons, however, its activities seem localized. In the Punjabs and at Pusa it is searce. In Berar it used to be a bad pest but the practice of removing and burning all attacked plants has apparently reduced the dämage to insignificant proportions. In the Surat District it is still very serious, especially in young cotton plants. In Baroda it is reported to occur especially on areas of black soil. In the Bellary district and the adjacent territories in Mysore it is an occasional pest of cotton. It is occasionally found in bhindi also throughout its area of occurrence. 
It is easily controlled by systematic destruction of all attacked plants.

In Bellary we found it in Egyptian cotton.

Mr. Ramakrishna

It is not found in cotton in Egypt. What chances are there of its Dr. Gough. importation into Egypt from India?

The chances are very small since the insect is not found in the seeds Mr. Fletchez, at all.

In Baroda it is bad in areas of black cotton soil.

Mr. Patel.

The same statement is true in Surat. With us it is controlled by Mr. Jhaveri. a parasite.

Sphenoptera arachidis, Lefroy MS.

South Ind. Ins., pp. 298-299, ff. 141, 142 ; Proc. Second Entl. Meeting, pp. 46, 48, 56, 57, 60, 70, 75, 93, 208.

We have this from Palur (S. Arcot) and Hagari (Bellary), reared Mr. Fletcher. from groundunt, of which this insect is a sporadic pest, and it has also been reported to occur at Nagpur on groundnut and soy-bean and in Baroda on tur. We have also specimens in the Pusa collection, placed under gossypii but which more probably belong to arachidis, from Nagpur, on soy-bean, from Hagari, on gronndnut, and from Pusa on sann-hemp and tur. S. arachidis has also been noted in lucerne at Bellary, in lablab at Nadiad, in horsegram in Madras, in cowpea, and in agathi in Madras; but it is possible that some these records do not really refer to this species.

In Madras it is a sporadic pest which has nevel been serious, at least Mr. Ramakrisuna not for the last two or three years.

Ayyar.

$$
\text { Psiloptera fastuosa, } \mathrm{Fb} \text {. }
$$

Stebbing, In. For. Ins. Col., pp. 199-200, t. XI ; Proc. Second Entl. Neeting, p. 275.

This species seems to oceur chiefly in Southern India, our specimens Mr. Fletcrer. being from Bassein Fort (Bombay), Malabar, Trichinopoly, Manaparai, Saidapet, Kumul, Yemmiganur and Beeravalli (Bellary). In Malabar it has been recorded on teak and at Saidapet the adult beetle was found on castor stems. The beetle is also recorded as stripping the bark off young stems of Acacia arabica. It seems doubtful whether it is a pest to any cultivated crop.

\section{Belionota prasina, Thunb.}

Stebbing, Ind. Forest Ins. Col., pp. 217-218, fig; Proe. Second Entl. Neeting, pp. 227-231; Ann. Rept. Impl. Entom. 1917-18, p. 103, t. 18, ff. 2 a-d.

We have this from the Khasi Hills, Pusa, Baroda, Surat, Poona and Kanara. At Pusa the adults oceur in August and September. At 
Poona it has been found boring into guava stems and at Surat the larvæ were found in August 1917 in numbers in a mango stem which had apparently been killed by them. Stebbing also records it in mango at Chicacole, and it may be looked on as a sporadic pest of mango.

\section{Julodis alkinsoni, Kerr.}

Ind. Mus. Noles IV, ii, 48-49, fig. (1896).

Reported as very destructive in June 1895 to the cotton and melon crops in the Lieah Tahsil of Dehra Ismail Khan.

There are no specimens in Pusa Collection and it has not since been reported as a pest.

\section{Trachys sp.}

Proc. Second Entl. Meeting, p. 134.

This species occurs as a pest of jute chiefly in Bengal and the adjacent parts of Bihar, the larva mining the leaves. At Pusa it is not common, whilst at Dacca jute plants left for seed have been noted to have been riddled with holes. It has also been noted on jute at Rangpur and Purnea but it is usually regarded as only a minor pest of jute.

Mr. P. C. Sen.

Mrs Fletcher.

Mr. Ramakrishna Ayyar.

Mr. Fletcler.

\section{(Unidentified Buprestid.)}

This species was sent to us from Simla by Messrs. W. M. Cotton \& Co., as boring cherry trees in the larval stage. These cherry trees had been imported and were five years old. The larra apparently hatched between the bark and the wood, and the pupa was embedded in the hard wood. The outside bark was riddled with oval holes as large as the head of a mateh, but these did not contain living insects.

\section{[Chrysochroa sp.}

Mr. Senior-White. This is an occasional pest of cultivated roses at Matale, the beetles getting into the middle of the flowers and eating out the flowers.] 


\section{[Agrilus acutus.}

In 1918 in the observation plots at the Nagpur Experimental Farm, Mr. Khare. some ambadi (Hibiscus cannabinus) plants were growing. These plants looked quite healthy, till the month of October, but later on put on a sickly appearance, so much so that in November many plants died and had to be uprooted: all the dead plants were examined, and found harbouring more than one grub of a Buprestid beetle. I first of all took that to be a Sphenoptera grub, but later on when the beetles emerged, those were no longer Sphenoptera but Agrilus acutus. The stems of ambadi apparently were all right excepting a few cuts on the bark here and there. The root system too was quite sound, unlike in cotton when the main root is hollowed by the Sphenoptera gossypii grub, and, when the plants are pulled up, always break at that point. The grub, when it enters the stem, makes its way up spirally by cutting the wood a little deep, behind the bark. When the grub is fully developed it cuts a chamber in the wood and remains doubled up in a resting condition. I have kept quite a large number of the affected stems in a cage. I got a couple of beetles emerged in December last, but the majority of the grubs are lying inactive in the stems. It is possible that these may emerge next May or June.

I could not find any reference to this beetle in any of the books like South Indian Insects, Indian Insect Life, or Indian Museum Notes. I think it worth recording that this beetle may turn out a serious pest of ambadi.]

\section{Melyride.}

\section{Idgia melanura, Koll and Redt.}

This species occurs commonly at light at Pusa in July-September, Mr. Fletcher. and in August-September 1905, the adults were found on maize in small numbers and in September 1908 on juar. We also have it from Chapra, Nasuri, Lebong (Darjiling), Khandesh, Belgaum and Coimbatore (at light), so that it is widely distributed in India. It may be looked on as a potential pest of cereals.

\section{Idgia cardoni.}

\section{Proc. Second Entl. Meeting, p. 188.}

This species is very similar to melamura but the femora are unicolorous testaceous, whereas in melanura the apices of femora are blackish. We have it from Lahore, Helem (Assam), Coimbatore, the Anamalai Hills, and Peradeniya. At Lahore it was found on one occasion in destructive numbers on bajra flowers and it may be looked on as a sporadic pest of cereals. 


\section{[Idgia belli.}

IMr. Ramakrisbna

Ayyar.

Mr. Fletcher.
Idgia belli was found in enormous numbers in October in the Wynaad, the adults attacking flowers of wild and thatching grass but not any cultivated crop. They occur in such enormous numbers that three or four baskets-full conld be collected in a couple of hours by one man.]

Hapalochrus fasciatus, $\mathrm{Fb}$.

Proc. Second Entl. Meeting, pp. 168, 207.

This species has been found on rice at Chapra, and at Pusa on rice in small numbers in July 1915, on grass and on lucerne. We have it also from Kasara (Bombay). It is not known as a pest.

\section{Cóccineluid a.}

Epilachna dodecastigma, Muls.

South Ind. Ins., p. 292, t. 6 ; Proc. Second Entl. Meeting, pp. 59, 285, 287, 289, 302, 307.

We have this in the Pusa Collection from Igatpuri, Pusa, Nilgiris, Tatkon, Jorhat, Chapra, Cheniot (Punjab) and Coimbatore.

At Pusa it occurs on leaves of Luffa agyptiaca, potato, brinjal, tomato and cucumber in all stages. At Tatkon the adults were found on Trichosanthes cucumerina. At Coimbatore it was reared on Solamum sp.

It also occurs less commonly on cowpea.

It is a decided pest of brinjal, potato and cucurbits, both the larra and adults feeding on the leaves. It may be collected in all stages or treated by spraying.

\section{Epilachna 28-punctata, $\mathrm{Fb}$.}

Proc. Second Entl. Neeting, pp. 59, 285, 287, 289, 302, 307.

This species occurs commonly throrghont the Plains and we have it in the Pusa collection from Belgaum, Jalpaiguri, Palur, Pusa, Baroma, (Assam), Jorhat, Nongpoh, Chapra, Tatkon.

At Pusa and in the Philippines it occurs on potato, brinjal, Ceplealandra indica, and it is regular pest of brinjal, potato and cucubits whenever it occurs. Life-history and control as in E. dodecastigma.

This beetle did enormons damage to desi varieties of potatoes at Solan and Kanda Ghat, near Simla. Scotch varictics, which were put down nearby, were untonched. 


\section{EROtylide.}

\section{Languria sp.}

Proc. Second Entl. Meeting, p. 201.

This species has been found at Coimbatore, where it bores into tenai (Setaria italica). The egg is laid in a hole cut by the adult in a stem, inside which the larva bores and pupates. This is at present only known from Coimbatore and the Pusa Collection contains no specimens.

Have you found it anywhere ontside of Coimbatore?

Mr. Eletcher

We have not found it anywhere ontside of Coimbatore.

IVIr. Isaac.

[See also papers Nos. 3 and 65 of these Proceedings.]

\section{Cicindelide.}

\section{Collyris sp.}

Fowler, F. I. Cicind, p. 515.

The larva of a species of Collyris has been noticed to bore into branches Mr. Fletcher. of tea in the Nilgiris. It is not sufficiently common to do much damage.

\section{HEMIPTERA (RHYNCHOTA).}

\section{Pentatomida:}

Brachyplatys pauper, Voll.

Dist., F. I. Rhyn. I. 9-10.

This species was found in large numbers on hemp at Rangpur on 21 st July 1905 and was said to have done some damage. It is scarcely a pest as a rule.

\section{Brachyplatys subaenens, Westwd.}

$$
\text { Dist., F. I. Rhyn. I. } 11 .
$$

This species was also found in large numbers on hemp at Rangpur on 21 st July 1905 , but is scarcely a pest as a rule.

\section{Coptosoma cribraria, Fabr.}

South Ind. Ins.. pp. 469-470. fig. 345; F. I. Rhyn. I. 22-23, fig. 11 ; Ind. Ins. Life, p. 612 ; Proc. Second Entl. Neeting, pp. $51,57,76$.

We have this from Seoni (Bhandara), on beans, 26th April 1912; Poona, on Cajanus indicus on 15th December 1908, and on val; Cuttack; 
Travancore, on cluster beans; Yercaud (Shevaroys); Coimbatore; Pusa, on beans ; Surat; Muzaffarpur ; Ranchi ; Nadiad ; Mahim; Jalalpore; and Jallandhar.

In Southern India it has been recorded as found on Dolichos lablab, Phaseolus mungo, Cyamopsis, agathi (Sesbania grandiflora), Leguminosæ and Compositæ. It is generally a minor pest of lablab and agathi. Control by catching in hand-nets.

\section{[Coptosoma nazira, Atk.}

Mr. Ramakrishna Aysar.

Mr. Andrews.

\section{Dist., F. I. Rhyn. I. 33.}

This species occurs in large numbers on brinjal, cluster-bean, etc., in South Kanara. It occurs on mango shoots also.

We have found it in enormous numbers in Assam, but have not noticed that it did any damage.]

\section{Coptosoma sp.}

This was found at Mandalay in August 1914 on Sesbania and Cajanus indicus, in some numbers.

\section{Coptosoma sp.}

This species was found in August 1914 at Mandalay on Sesbania aculeata, in some numbers.

\section{Coptosoma sp.}

This species has been found at Palur (S. Arcot) on Butea frondosa.

\section{Pacilocoris latus, Dall.}

Dist., F. I. Rhyn. I. 44, f. 19 ; Proc. Second Entl. Meeting, p. 23.

This species occurs throughout Assam on tea. The bug pierces into the lieart of umripe tea sced, and thus facilitates the entrance of fungus spores.

Mr. Andrews.

As regards control, we still rely on catching it by hand.

\section{Scutellera nobilis, Fb.}

Dist., F. I. Rhyn. I. 51-52; Proc. Second Entl. Meeting, p. 236. Mr. Fletcler.

We have this from Poona, on cotton and Phyllanthus; Pusa, on castor; and Carbwal. It was recorded in Indian Museum Notes V, iii, 119 as attacking grape fruits at Siripur Farm, Hutwa. 
Ochrophara montana, Dist.

Dist., F. I. Rhyn. I. 147 ; Anstead, Planters' Chronicle, Vol. XII, No. 47, 24 Nov. 1917, p. 594.

We have this from Aijal (Lushai Hills) on paddy; Sallebile Estate (Mysore), on Grevillea robusta, a shade tree to coffee; Hallery Estate, Santikoppa, N. Coorg; and Pollibetta, S. Coorg.

This species apparently lives normally on bamboo seeds, and when the bamboos have flowered over a large area, the bugs increase enormously so that they sometimes do damage to shade trees on coffee estates by breaking off the branches owing to the weight of the vast number of bugs congregated on the trees. They also occur on coffee in large numbers at such times but have not been noticed to attack coffee at all.

\section{Cappoca taprobanensis, Dall.}

Dist., F. I. Rhyn. I. 149, f. 88 ; Proc. Second Entl. Meeting, p. 213.

We have this from the Shevaroys, Coonoor, Bababudins and Malabar, in all cases found on orange trees.

It has also been found gregariously in Ceylon on the bark and trunk of orange trees (Distant). It is apparently a minor pest of Citrus trees.

\section{Codophila maculicollis, Dall.}

Dist., F. I. Rhyn. I, 158-159, f. 95.

We have this from Poona, on Solanum xanthocarpum.

\section{Dolycoris indicus, Stal.}

Dist., F. I. Rhyn., I. 160, f. 96 ; Proc. Second Entl. Meeting, pp. 82, 96, 97, 184, 198, 201.

We have this from Poona, on wheat; Lahore; Berhampore; Aska (Ganjam), aniseed; Chapra; Pusa, Cajunus indicus pods, indigo, wheat, lucerne, tobacco plants, sugarcane, cotton; Jallandhar; Gojra (Punjab). In Southern India it has been recorded as found on cholam, Pennisetum typhoideum, Setaria italica, safflower, sun-flower. It is a minor pest of the various crops attacked.

Eusarcocoris ventralis, Westwd.

Dist., F. I. I, 167 ; Proc. Second Entl. Meeting, p. 85.

This species has been found at Ganjam on gingelly, and we also have it from Pusa, Khasi Hills, Chapra, Raniganj, and Bangalore. 
Eusarcocoris gutliger. Thunb.

Dist., F. I. Ryn., I. 165-166; S. Tnd. Tns. p. 471, f. 348.

We have this from Surat, Belgaum, Bassein Fort. Pusa, and Chapra.

In the Plains of South India, it is a minor pest of Pennisetum typhoiderm.

Antestia cruciala, $\mathrm{Fb}$.

Dist., F. I. Rhyn., I. 185; S. Ind. Ins. p. 472. f. 350 ; Proc. Second Entl. Meeting. Pp. 36, 222; Planters' Chronicle, VIII, 37.

We have this from Nagpur, on lemon 16th June 1906. and tur Bth July 1906; Poona, on coffee 2lst May 1910; Chindwara, on mango inflorescence (sajd to be damaged); Kullakamby, on coffee; Calcutta, on Acanthus; Kasanli, on peach, apricot; Seoni (C. P.). on mango, peaches-sucks the juice of fruits which fall down.

It attacks young berries of coffee in Ceylon [Distant]. In the Nilgiris it has been found in large numbers sucking coffee berries and may be looked on as a sporadic pest of coffee in South India.

Apines concinma, Dall.

Dist., F. I. Rhrn. I. pp. 186-187, fig. 111.

Distant gives the distribution, Hardwar, Bombay: "reported as attacking Rabi (winter) crops in the North Western Provinces (Ind. Mus. Noles, Vol. II, p. 165)." Otherwise we do not know this as a pest.

Agonoscelis nubila, $\mathrm{Fb}$.

Dist., F. I. Rhyn., I. 189 ; South Ind. Ins. pp. 472-473, fig. 351 ; Proc. Second Entl. Meeting, pp. 184, 298, 301.

Our specimens are from Jabbalpur, on tobacco, 14th March 1906 ; Poona, on lucerne, 21st October 1909 ; C. P., carrot flowers; Pusa, on sunflower, Hibiscus sabdariffa, ber, Leucas sp.; Dacca; Naduvatum; Cuttack; Sitamarhi (N. Bihar); Munshiganj; Balaghat (C. P.) ; Jorhat (Assanı) ; Khasi Hills; Tatkon (Upper Burma), on cotton (K. D. Shroff) ; Shoranur (Malabar), paddy.

"At Bombay, generally found on Dolichos lablab; R. M. Dixon" (Distant). In the Central Provinces it is reported on carrot flowers and in South India it has been recorded on cholam, cumbu (Pennisetum typhoideum), wheat, various pulses, and aniseed. 
Bugrada preta, $\mathrm{Fb}$.

Dist.. F. I. Rhyn. I. 193-194, f. 116 ; South Ind. Ins.. p. 473, t. 2, f. 10 ; Proc. Second Entl. Heeting, pp. 277 (tab.), 281, 282. 283 .

We have this from Nagpur, on eabbage in December 1909: Poona on mustard, 18th September 1909; Coimbatore; Cotacamund, on turnips; Simla, on eabbage, eauliflower. radish, cress; Saharanpur on Cruciferæ; Bhim Tal (Kumaon), did eonsiderable damage to potato crop, 30th Nlay 1907; Naini Tal (Kumaon). cabbage-did considerable damage; Ramgarh (Kumaon). on crueiferous plants; Pusa. on sugarcane, rice [?], mustard, eabbage ; Kasauli (Punjab) ; Surat. on mustard; Bombay, on radish; and Chapra.

At Dalsing Serai it was found attacking Natal indigo by de Nicevile (Distant). It is a pest of Crueiferæ generally throughout India, occurring in verv large numbers in some years. As a rule. it occurs late in the season.

\section{Rhynchocoris humeralis, Thub.}

Dist.. F. I. Rhyn. I. 2]2-213, f. 133 ; Entl. Note 94: Proc. Second Entl. Meeting. p. 214.

We have this from Myitkyina (Upper Burma). on orange at end of August 1904; Jeolikote (Kumaon), on orange, did considerable damage; and the Buxar Duars. It is a minor pest of orange.

We find a bug, which is probably this one, in large numbers on Mr. Gupia. orange fruits in Assam. The small green oranges drop off the trees when attacked. We control these bugs by applying the milky juice of the jak fruit to the end of a long stick and touching the bugs with this sticky end.

Can the bugs be seen easily?

Mr. Fletcher

Yes; quite easily.

Mr. Gupta.

Rhynchocoris plagiatus, Wlk.

Dist., F. I. Rhyn. I. 213 ; Entl. Note 95.

This species was found in numbers on Coca (Erythroxylon coca) at Mr. Fetcher. Peradeniya in April 1914.

[Vitellus orientalis, Dist.

Dist. F. I. Rhyn., I. 214-215, f. 134.

It punctures the ripe fruits of oranges, particularly the sweet varie- Mr. Isaac. ties. The area around the puncture sinks down and the size of the 
pit thus formed may be as large as a four-anna piece. Probably this condition is brought about by a fungus which follows the puncture.]

\section{Nezara viridula, L.}

Dist. F. I. Rhyn. I. 220, f. 139 ; S. Ind. Ins., pp. 473-474. Proc. Second Entl. Meeting, pp. 52, 71, 89 (tab.), 130, 184, 187, 198, 200, 285 .

M. Fletcher.

This species has been reported from Akola (Berar), on Maghai Telli, 24th December 1909; Poona, on cotton (18th November and 19th December 1909), tur (15th October 1907); Pusa, on mung (Phaseolus mungo), potato leaves (in large numbers), cotton, millets, sun-flower; Simla ; Ging (Darjiling); Bassein Fort; Ganjam, on ragi ; Coimbatore, on wheat; Shevaroys (Yercaud), bad pest of potatoes; Hubli (Dharwar), on castor; Gadag, on Sesamum; Tinnevelly, reported bad on cumbu; Bangalore, on potato ; Dharwar, on til pods; Poona, on Cajanus indicus; Minbu (Lower Burma); and Rajshahi.

It is a regular minor pest of castor and the other crops named above and is sometimes serious on potato in the Hills. It is best controlled by hand-picking.

Mr. Isaac.

Dr. Gough.

Mr. Ghosh.

Mr. Eletcher.
It is a bad pest of potato in the Shevaroys.

In Egypt it is a pest of cotton and a bad pest of potato.

It is found on pulses also.

Nezara graminea, $\mathrm{Fb}$.

Dist., F. I. Rhyn. I. 221.

This species has been found at Dharwar, on juar.

Piezodorus rubrotasciatus, $\mathrm{Fb}$.

Dist., F. I. Rhyn., I. 224-225, f. 142 ; S. Ind. Ins., p. 474, f. 353 ; Proc. Second Entl. Meeting, pp. 39, 184.

We have this from Pusa, Bilaspur, Katni, Surat, Bassein Fort, Nadiad, Burdwan, Cuttack (on dhaincha), Mysore, and Godarari District.

In South India it is a minor pest of cholam, pulses and low growing plants. It has also been found on Lantana camara. 


\section{Menida histrio, $\mathrm{Fb}$.}

Dist., F. I. Rhyn., I. 228 ; S. Ind. Ins., pp. 474-475, f. 354 ; Proc. Second Entl. Meeting, pp. 175, 184.

We have this from Pusa, Chapra, Cuttack (on potato), Dacca, Raniganj, Trevandrum (on rice), Suri (Bengal) on rice, Penukonda (Madras) on paddy, and Kezanathum (Tinnerelly).

In South India it has been noted on paddy, wheat, cholam and pulses. It is scarcoly a pest.

Asopus malabaricus, $\mathrm{Fb}$.

Dist., F. I. Rhyrn. I. 255, f. 162.

This species has been found in the Central Provinces on cotton and we also have it from Pusa. It is not known as a pest.

\section{Tcsenratoma guadrata, Dist.}

Dist., F. I. Rhyn. I. 258, 1. 164 ; Proc. Second Entl. Meeting, pp. $230,247,249$.

This species was reported from Kalimpong in 1914 as damaging pears, apples and litchis. We have it also from the Buxar Duars and the Khasi Hills.

Cyelopelta siccifolia, Westw.

Dist., F. I. Rhyn. I. 280-281, f. 178 ; S. Ind. Ins., p. 476, f. 357 ; Proc. Second Entl. Meeting, pp. 45, 78, 299, 300.

We have this from Surat; Belgaum; Tellicherry, on Erythrina: Manjri, on C'yamopsis psoraloides; and Poona, on Sesbania cagyptiaca. and Horinge pterygosperma.

In South India it is a pest of Cajanus indicus, Erythina indica, E. lithosperma, and Piper belle, and at Poona it has been reported as infesting Erythrina spp. and Leguminose.

The bugs are easily hand-picked.

Aspongopus janus, Fb.

Dist., F. I. Rhyn. I. 281-282, f. 179 ; S. Ind. Ins., pp. 476-477, f. 358 ; Proc. Second Entl. Meeting, pp. 289, 304, 307.

We have this from Chakwal (Punjab) ; Poona, on Abutiton muticum; Muzaffarpur, on Cucurbitx ; Pusa, on pumpkin and bottle gourd; Adoni and Salem, on pumpkin; and Iravancore, on bottle gourd (Lagenaria). 
In South India it has been noted on brinjal, lablab, pumpkins, most low-yrowing plants, and it is a sporadic pest of cucurbits in most parts of India. The bugs may be hand-picked.

$$
\text { Aspongopus brunneus, Thunb. }
$$

Dist., F. I. Rhyn., I. 283-284; Proc. Second Entl. Meeting, pp. $30 \pm, 307$.

We have this from Siripur, Pusa (on pumpkin), Rangpur, Balur, and Myitkyina (Upper Burma). At Pusa it has occurred as a sporadic serious pest on pumpkin.

Mr. Ghosh.

It occurs mostly in the Rains but the adults can be seen throughout the year. They sometimes kill the plants attacked.

\section{Tetroda histeroides, $\mathrm{Eb}$.}

Dist., F. I. Rhyn. I. 199, f. 191 ; S. Ind. Ins., p. 477, f. 359 ; Proc. Second Entl. Meeting, p. 175.

Mr. Fletcler.

This species has occurred at Coimbatore and Salem as a sporadic minor pest of paddy.

\section{COREID玉.}

Anoplocnemis phasiana, $\mathrm{Fb}$.

Dist., F. I. Rhyn., I. pp. 346-347, f. 210 ; S. Ind. Ins., p. 477, f. 8; Proc. Second Entl. Meeting, pp. 45, 52, 76, 82, 184, 289 .

This species has been found in South India on brinjal, redgram, greengram, cholam, Erythrina and lablab. We have it from Shripur (Bihar); Chapra; Kanara; Coimbatore, on Odina wodier; and Pusa, on Sesbania agyptiaca.

This species is often a bad pest of Erylhrina and is less conmonly found on the other plants mentioned. Control, by hand-picking, is easy.

\section{Brachytes sp.}

$$
\text { Dist., F. I. Rhyn., p. } 353 .
$$

'This insect was sent in to us from Solan, (near Simla), Punjab, attacking Asparagus plants.

\section{Ochrochira sp.}

Dist., F. I. Rhyn., pp. 342-344.

This has been sent in to us from Jeolikote (Kumaon), where it attacks young growths of apple and cherry. 
Leptoglossus membranaceus, $\mathrm{Fb}$.

Dist., F. I. Rhyn., I. 382-383, f. 224; Green, Trop. Agric. XXY VIII, No. 6 (1912) ; Proc. Second Entl. Afeeting, p. 307.

We-have this from Tatkon (Burma) where it was found in some numbers on Trichosanthes cuchimerina. It has not been noted as a pest in India but in Ceylon it has occurred sporadically on orange, tree tomato, passion fruit, pear, plum, cape gooseberry, beans, peas, and vegetable marrow.

\section{Physoments sp. \\ Dist., F. I. Rhyn.. p. 38.3.}

This insect was sent in to us from Cooch Behar (Bengal) as found in large numbers on sugarcane, but we do not know how far it is a real pest.

\section{Clavigralla gibbosa, Spin.}

Dist. F. I. Rhyn., pp. 401-402, f. 235 ; S. Ind. Ins., p. 478, f. 361 ; Proc. Second Entl. Nleeting, pp. $45,57$.

We have this from Pusa, Jamuary to May, on mo and cowpea; Surat, December to April; Nagpur, on tu; Bilaspur, February 1907, on tur; Purulia, November 1906; Katni, February 1907; Lebong, September 1908 ; Buxar Duars.

It is a minor pest of tur, especially bad around Poona. Control by collection of the bugs.

Clavigralla horrens, Dohrn.

Dist., F. I. Rhyn., I. 402 ; S. Ind. Ins., p. 479, f. 362 ; Proc. Second Entl. Meeting, pp. 45, 118.

We liave this from Nagpur, on $l u r$, 11 th December 1905; and Coimbatore, on tur pods.

It is a minor pest of tur (Cajanus indicus), said to be a serious pest around Poona. Shaking the plants over vessels of oil and water or over oily cloths seems the most practical remedy.

\section{Leplocorisa varicormis, Fb.}

Dist., F. I. Rhyn., I. 409-410, f. 211 ; S. Ind. Ins.; pp. 479-480, f. 363 ; Proc. Second Entl. Weeting, pp. 175, 184, 192, 200, 201, 202.

We have this from Pusa, on rice, grasses, millets, sugarcane (odd specimens) ; Dacca, on rice; Bankura, on rice; Rangpur, on rice ; Comilla, 
Mr. Pillay.

Mr. Gupta.

Mr. Fletcher.

Mr. Jhaveri.

Mr. Andrews.

Mr. Jhaveri.

Mr": Fletcher. on rice; Siripur, on rice; Manickganj, on rice; Nagpur, on rice; Bhandara, on rice; Balaghat, on rice; Mayorbhanj, on rice; Trincomali, on rice; Partabgarh, on rice; Benipur (Bihar), on rice; Jhansi ; Cawnpur; Khunti; Bihta; and Lakhimpur. It is a serious pest of rice, especially in Assam, sucking the developing grain so that it is not formed. Control by keeping bunds and other areas adjacent to paddy fields clear of wild grasses and by use of hand-nets.

We get it generally on the borders of the paddy fields and we use hand-nets with advantage. Ten, twenty or thirty acres can be treated in this way. It usually occurs mostly along the margins of the fields and, when netting or bagging is done, there is a likelihood of its going right into the field. The cultivators are begimning to take up this method of control.

It is very bad in Assam and bagging. has been found to be very difficult. The bug is attracted to rotting flesh. We discovered a number of bugs clustering around a squashed frog, not only on the dead body but also on the juice which was oozing out. Both nymphs and adults were found in it. We tried frogs and found that decomposing frogs do attract the bugs.

At Pusa we found that the squashed bugs attracted a small fly in large numbers.

$$
\begin{aligned}
& \text { Leptocorisa acuta, Thnbg. } \\
& \text { Dist., F. I. Rhyn., T. } 410 .
\end{aligned}
$$

We have specimens, supposed to be $L$. acula, from Chapra, on rice; Kurseong; Khasis: Phoobsering (Darjiling); Bassein Fort; and Tatkon, on sugarcane.

In its habits it seems exactly similar to ravicomis and I cannot. di-tinguish it as distinct.

I found this insect clustering on guava leares between 9 and 10 A.M. at several places and on several occasions.

I have seen $L$. varicomis swarming at noon-time during the heat of the day, leaving the rice-fields then and flying about amongst gram. Mir. Jhaveri's case may be the same.

There were no rice-fields nearby.

$$
\text { Riptortus pedestris, Fb. }
$$

Dist., F. I. Rhyn., I. 414, f. 244 ; S. Ind. Ins., pp. 480-481, f. 364 ; Pros. Second Entl. Meeting, pp. 45, 48, 52, 57, 60, 307. We have this from Pusa, on tur, compea, val (Dolichos lablab), $P$. mungo, $P$. ratiatus; Lebong; Manikganj; and Coimbatore. It is a minor pest of pulses. 
Riptortus fuscu, $\mathrm{Fb}$.

Dist., F. I. Rhyn., I. 411-115; Proc. Second Entl. Meeting, pp. $45,57,60$.

We have this from Pusa, on Dolichos lablab, cowpea, and Phaseolus sp.; Cuttack; Lebong (Darjiling); Manikganj; Bassein Fort; and Coimbatore.

It is a minor pest of pulses.

Riptortus linearis, $\mathrm{Fb}$.

Dist., F. I. Rhyn., I. 415; Proc. Second Entl. Neeting, pp. 45, $48,57,60$.

We have this from Pusa, on sweet potato, Guinea grass; Bassein, October 1909 ; and Ganjam, on cholem.

Corizus rubicundus, Sign.

Dist., F. I. Rhyn., p. 417, f. 245.

This species occurs at Pusa in numbers on Abutilon indicum and sometimes also on hollyhock.

Serinetha abdominatis, Fabr.

Dist., F. I. Rhyn., I. 419, f. 246.

We have this from Bankura, Burdwan and Yercaud. At Yercaud it was found in numbers on coffee but it is not known to be a pest.

Serinetha augur, Fb.

Dist., F. I. Rhyn., I. 420 ; Proc. Second Entl. Meeting, p. 118.

We have this from Pusa, on cotton; Poona, on cotton; Dacca; and Coimbatore, on Treweia in large numbers.

It is scarcely a pest.

\section{Berytide.}

Metacanthus pulchellus, Dall.

Dist., F. I. Rhyn., I. 423, f. 248 ; Proc. Second Entl. Meeting, p. 306.

This species was sent in to us in March 1913 as damaging bottlegourds at Baroda by puncturing the young fruits. At Pusa it has been found on pumpkin, bottle-gourd, and tobacco. It is widely distributed in Incia but does not seem to be a serious pest as a rule. 
Mr. Andrews.

Mr. Fletcher.

I have found it on tea in the Duars. It was sent in along witk: Helopeltis.

\section{LYGæID}

Lygaus pandurus, Scop. (=militaris, Fb.)

Dist., F. I. Rhyn., II. 6 [militaris] ; S. Ind. Ins., p. 481, f. 365 ; Proc. Second Entl. Meeting, pp. 118, 137, 184, 290.

We have this from Pusa, on cotton, lur; Igatpuri; Bilaspur; Bankura; Surat; Lyallpur, on cotton; Purulia; Bhor Ghat, on Calotropis gigantea; Chetput (Madras); and Coimbatore.

It occurs at times in some numbers on cotton and Calotropis, but is hardly a pest.

\section{Lygares hospes, $\mathrm{Fb}$.}

Dist., F. I. Rhyn., II, 6-7, f. 3.

This occurs throughout India. We have it from Peshawar, on Calotropis; and Lyallpur, on cotton.

At times it occurs in numbers, but it is scarcely a pest as a rule.

\section{Graptostethus servus, $\mathrm{Fb}$.}

Dist., F. I. Rhyn., II. 8-9, f. 4 ; S. Ind. Ins., p. 482, f. 366 ; Proc. Second Entl. Meeting, pp. 46, 134, 294.

We have this from Pusa, on sun flower, cotton; Samalkota, on redgrain : Bilaspur; Surat; Chapra; Tation, on sugarcane; Chepauk, on cotton; and Monlmein, on sweet potato.

It is a very minor pest of the plants attacked.

\section{Nysius inconspicuns, Dist.}

Dist., F. I. Rhyı., II. 18-19; Proc. Second Entl. Mecting. pp. $84,272$.

We have this from Pusa, on tobaceo and grasses, and from Kasargode (S. Kanara) on gingelly. At Pusa the bugs have been found clustered in thousands on tobacco capsules and it is at times a decided pest. It may be controlled by tapping the bugs into pans of oil and. water.

It may be observed that the identification of this insect is doubtful. 
Macropes excaratus, Dist. (? raja, Dist.)

Macropes excavatus, Dist., F. I. Rhyn., II, 25 [Shillong]. Marropes raja, Dist., A. M. N. H. (8) III. 323 (1909), F. I. Rhyn., V. 19 [Calcutta].

We have specimens from Pusa, on sugarcane, grasses; and from the Naga Hills, on rice, Job's-tears.

At Pusa this insect appears occasionally in some numbers on cane, but is scarcely a pest.

The identification seems doubtful. The specimens in the Pusa Collection standing under the name of $M$. cxcaratus do not seem to have been named authoritatively. They differ from Macropes in pilosity and the fore femora not being spined. If it is a Macropes, it is probably 11. raja.

$$
\text { Blissus gibbus, } \mathrm{Fb} \text {. }
$$

Dist.. F. I. Rhyn. II, 28-29, f. 20.

Distant, on the authority of de Niceville, records the immature stages as having done "much damage to sugarcane at Cawnpur." This species has not been reported as a pest during recent years.

Chauliops fallax, Scott.

Dist., F. I. Rhyn., II. 36, f. 24.

This species was sent in to us on 22nd August 1913 from the Government Garden at Jeolikote (Kumaon) as attacking soy bean.

It is recorded from Ceylon and Japan. In Ceylon it punctures the foliage of Dolichos unguiculata and completely checks the growth of the plant; E. E. Green (Distant).

Oxycurenus latus, Kby.

Dist., F. I. Rhyn., II, 43, f. 31 ; S. Ind. Ins. pp. 482-483, f. 367 ; Proc. Second Entl. Meeting, pp. 116 (tab), 124, 126, 127, 129, 130.

We have this from Pusa, on cotton, Hibiscus esculentus, H. abclmoschus, Abutilon indicum, hollyhock, Thespesia populnea; Gojra (Punjab), on cotton; Belgaum, on cotton; Coimbatore, on cotton; Lyallpur, on cotton; Surat, on cotton; Saidapet, on cotton; Coimbatore, on cotton.

The bugs attack the seeds, especially of over-ripe bolls left on the plant, and probably have some effect on the vitality of the seed. They also do some damage by staining the lint when crushed. 
Control was discussed at the Second Entomological Meeting.

Oxycarenus lugubris, MIots.

Dist., F. I. Rhyn., II, 44.

We have this from Peradeniya where it occurred in April 1914 on Hibiscus sabdariffa in numbers. Distant states that it attacks cotton in Ceylon.

Aphanus sordidus, Fb.

Dist., F. I. Rhyn., II, 79-80, f. 62 ; S. Ind. Ins., p. 483 ; f. 368 ; Proc. Second Eintl. Neeting, pp. 85, 93.

We have this from Jallandhar, on tobacco, bonga [?]; Palaman ; Pusa ; Ranchi ; Belgaum ; Palur, on threshing floor (groundnut); Surat; Poona, on groundnut, Sescmum indicum; Taungtha (Burrna), stored Sesamum and groundnut; and Bezwada, on cumbu seeds (threshing floor).

This insect is sometimes a serious pest of Sescmum and groundnut by carrying off the seeds in large numbers from the threshing-floor. It hardly seems to be a pest in the field, although it has been noted to feed on groundnut pods on the ground when the soil is cracked. The bugs are easily swept up and destroyed.

Mr. Ramakrishna Ayyar.

Mr. Fletcher.
I have found these bugs on Cambodia cotton seed on the threshing floor after harvest.

\section{PYRRHOCORID E.}

Dysdercus cingulatus, Fb.

Dist., F. I. Rhyn., II, 118-119, f. 87 ; S. Ind. Ins., p. 484, t. 46 ; Proc. Second Entl. Meeting, pp. 115, 124, 126-130, 132.

This species occurs abundantly throughout the Plains of India, Burma, and Ceylon on cotton, Hibiscus esculentus, H. cannabinus, H. abelmoschus, H. rosa-sinensis, hollyhock, Abutilon indicum, Bombax malabaricum, Thespesia populnea, etc. At times it occurs in masses of individuals and at such times the bugs are sometimes predaceous on one another, newly-moulted individuals being attacked and sucked by the others. It is a bad pest when it occurs on plants in any numbers. It may be controlled by collection by hand or in bags provided with tin fumnels or by attraction to heaps of moistened cotton-seed placed amongst the plants or hung up on the bushes. 
TINGIDIDE.

Recaredus sp.

Dist., F. I. Rhyn., V, $10 t-105$ (1910); Dutt, Bihar Agricl. Journ. I, 139-141, tab. (October 1913).

This species occurs in North Bihar (Bettiah) as a pest of stored potatoes.

\section{Galeatus retiarius, Dist.}

Cadmilos retiarius, Dist., Amn. S. E. Belg. liii, 114 (1909), F. I. Rhyn., V, 107-108, f. 53 (1910).

Galeatus, Horvath, Ann. Mus. Hung. IX, 337 [Cadmilos is synonym].

This speeies was sent in to us from Allahabad by the Superintendent of the Government Gardens, on 12th June 1916, as attacking Chrysanthemum plants in May and June, disappearing during the Rains and giving no further trouble until next hot weather. It was found on plants in considerable numbers in the early morning, disappearing later on in the day. It has also been noted as common on chrysanthemums at Lahore.

\section{Stephanitis typicus, Dist.}

Dist., F. I. Rhyn., II, 132, [Cadamustus] ; Entl. Note 96, f. 20 ; Proc. Second Entl. Meeting, pp. 37, 239, 260, 295.

We have this from Pusa, on plantain leaf; Coimbatore, on plantain leaf; and Colombo.

It is a minor pest of plantain and turmeric, and has been recorded to puncture leaves of cardamom, Hedychium and allied Scytamineous plants in Ceylon.

\section{Stephanitis sp.}

This was found at Coimbatore, on the underside of young coconut leaves in small numbers. It is perhaps the same as the preceding.

\section{Urentius cchinus, Dist.}

Dist., F. I. Rhyn., II, 134, f. 97 ; S. Ind. Ins., p. 485, f. 370 ; Proc. Second Entl. Mecting, p. 289.

We have this from Surat, Dharwar and Belgaum, in all eases on brinjal leaves. At Dharwar and in Travaneore it is stated to be bad on brinjal, and in August 1915 it was reported to be damaging brinjal plants at Lyallpur. It is sometimes a serious pest of brinjal. It may 
be controlled by spraying and by picking off the affected leaves, which turn yellow and ultimately dry up and fall off the plant in any ease.

Tingis hystricellus, Richter (1869) seems to be a prior name of this species (see Dist., F. I. Rhyn. II, 141, f. 104).

\section{Monanthia globulifera, Wlk.}

Dist., F. I. Rhyn., II, 144, f. 107 ; S. Ind. Ins., pp. 485-486, f. 371 ; Proc. Second Entl. Meeting, pp. 97, 267.

We have this from Pusa, on croton, Ocimum basiticum, mint; and Yemmigannur, on Ocimum.

It has also been noted on mint in Travancore and on heliotropa in Madras and occurs in Ceylon also. Oceasionally it oceurs on safflower. Generally it is a minor pest of tulsi (Ocimum sanctum), causing the leaves to turn yellow.

\section{(Unidentified Tingidid.)}

Ann. Rept. 1917-18, p. 113.

This speeies has been found at Bankura, where it did severe damage to Jasminum sambac. Spraying with soap was effective.

Probably the same speeies has been found at Pusa and Lyallpur in large numbers on Jasminum sambac damaging the leaves, especially in company with Dialcurodes citri.

\section{Capsida.}

Megacolum straminem, Wlk.

Dist., F. I. Rhyn., II, 428 ; Proc. Second Entl. Meeting, pp. 184, 187, 192.

This species is recorded by Distant from N. Bengal, Kangra Valley and Pundahoya. At Coimbatore it is associated with Calocoris angustatus, laying its eggs in the surviving seeds of cholam after Calocoris has destroyed a certain proportion.

It has been found at Pusa on lucerne, peas, linseed and grass, but has not been noted on juar. It is probably widely distributed in India as a pest of cereals, but has been overlooked.

\section{A pollodotus prafectus, Dist.}

$$
\text { Dist., F. I., Rhyn. V, 247-248, f. } 135 \text { [II, 438]. }
$$

This species is recorded by Distant from Eppawela (Ceylon), and has been found at Pusa on plantain leares. It is not known to be a pest. 


\section{Helopeltis antonii, Sign.}

Dist., F. I. Rhyn, II, 440, f. 285 ; S. Ind. Ins.. p. 488, f. 374 ; Agr. Journ. Ind. X, 412-416 (Oetober 1915); Proc. Second Entl. Meeting, pp. 23, 26, 37, 25..

We have this from Kudua Kamam Estate, on tea on 13th September 1913, and from Pirmaad, on tea on 11th Angust 1913. In the South Indian Hills it is a pest of tea and cinchona and in Ceylon of cacao. In Coimbatore, and probably throughout the Plains of Madras, it attacks nîm (Melia azadirachta), as described by $\mathrm{Y}$. Ramachandra Rao in the Agricultural Journal of India, and in North Malabar, South Kanara and Bangalore it attacks shoots of cashew (Anacardium occidentale). It has also been recorded on annatto (Bixu orelluma). We seem to know remarkably little about it as a pest of tea and einchona in South India.

Has anyone found this on nim shoots?

Mr. Ramakrishna

Ayyar.

Yes; I have seen this insect on roadside nim trees, the topshoots $\mathbf{M r}$. Ramchandra of which get withered as the result of their attack.

Rao.

I have been examining these shoots for some time. I cannot find Mr. Ramakrishna the inseet and have some doubts as to whether the damage done is due Ayyar. to an insect or to a fungus attack.

I investigated this subject some years ago and published an account Mr. Ramchandra of it in the Agricultural Journal. I found the eggs as well as the nymphs Rao. on the new shoots. The reason why the insect is not seen on the damaged shoots is because it attains the adult stage and flies away before the damage becomes apparent.

\section{Helopeltis theivora, Waterh.}

Dist., F. I. Rhyn. II, 440-441 ; Proe. Second Entl. Meeting, pp. $23,26,37$.

We have this from Lower Ging (Darjiling District; October 1908) Mr. Fletcher. and from the Buxar Duars in May 1907. It occurs from Darjiling to Chittagong as a serious pest of tea.

[See also pp. 669-671].

\section{Disphinctus humeralis, WIk.}

Dist., F. I. Rhyn. II, 444, f. 286 ; Proc. Second Entl. Meeting, p. 23.

This species has been reported to oceur on tea in Assam in much the same way as Helopeltis and on einchona in Siklim. 
Mr. Andrews.

Iir. Fletcher.
It has been found in the Mangaldai district doing damage to tea in exactly the same way as Helopeltis theivora. The damage done by this bug is quite as much as by Helopeltis in districts where the latter does not occur.

\section{Disphinctus politus, Wlk.}

Dist., F. I. Rhyn. II, $444-445$; S. Ind. Ins., p. 489, f. 375 ; Proc. Second Entl. Meeting, p. 300.

We have this from Talegaon; Amraoti (Berar), on betel-vine leaves, 11th October 1907 ; Kasargode (S. Kanara), on betel-vines, 3rd October 1913 ; Bassein Fort, on betel-vine leaves, 21st July 1903 ; Dharwar, on betel-vine leaves, 4 th October 1903 ; Kirkee, on betel-vine.

It is also reported from Belgaum and Ahmednagar. It is a pest of betel leaves (Piper betle) chiefly in Madras, Kanara and Bombay and is especially noted as a bad pest in Berar.

In Ceylon Green gives its host-plants as Cuphea jorullensis (abundant, young shoots punctured and wilted), Solanum sp., young leaves and shoots of Peperonia sp., young leaves of Psidium guyava, and of Acalypha (Distant).

Hand-collection and crushing of the nymphs and adult bugs where these are accessible, combined with catching the adults in hand-nets and spraying of the immature stages, appear to be the best methods of control.

Calocoris angustalus, Leth.

Dist., F. I. Rhyn. II, 452 ; Bulletin No. 58 ; S. Ind. Ins. p. 490 , f. 376 ; Proc. Second Entl. Meeting, pp. 184, 187, 192.

We have this from Coimbatore and Yemmiganur (Bellary). In Madras it is a major pest of cholam, cumbe and maize, the damage done being usually associated with that done by Megacolum sliamineum. Mr. Ballard has worked especially on this insect and has given all the available information in a Bulletin. No effective means of control can be suggested at present.

\section{Gallobclicus crassicornis, Dist.}

Dist., F. I. Rhyn. II, 478, f. 310 ; S. Ind. Ins. pp. 490-491, f. 377 ; Proc. Second Entl. Meeting, p. 272.

We have this from Pusa and Coimbatore, in both cases found on tobacco leaves and seed capsules, and Distant records it also from Bhor Ghat and Tenasserim, so that it is very midely distributed. It seems to be a minor pest of tobacco, sometimes found abundantly on tender shoots, flower-heads and seed-capsules. 
The adults are fairly active and are probably best dealt with by catching in hand-nets and shaking the plants over pans of oil and water.

Ragmus importunitas, Dist.

F. I. Rhyn. V, 288-289, f. 159 ; South Ind. Ins., p. 491, f. 378; Proc. Second Entl. Mceting, p. 71.

We have this from Pusa, Nagpur, Samalkota and Palur (South Arcot), in all cases on sann-hemp, of which it is sporadically a serions pest, especially on young plants, whose leaves curl up and become paleyellow and finally drop oft in bad cases.

In Ceylon it has been noted by Mr. E. Ernest Green to puncture leaves of Crotalaria remosa and C . incarna [Distant].

As it is chiefly a pest of young plants, it may be controlled by bagnets or handnets.

\section{Halticus minutus, Rent.}

Dist., F. I. Rhyn. II, 480, f. 312 ; Ind. Ins. Life, p. 707, f. 479 ; Proc. Second Entl. Meeting, pp. 269, 286, 294.

We have this from Pnsa and also from Nonlmein, where it ras found in September 1914 in numbers on sweet-potato. It is sometimes a pest of tobacco seedlings and brinjal seedlings, and Distant records it as found on an Ipomoea at Peradeniya.

It may be collected in handnets when sufficiently abundant.

\section{FULGORIDE.}

Eurybrachys tomentosa, $\mathrm{Fb}$.

Dist., F. I. Rhyn. III, 222-223; S. Ind. Ins. p. 492, f. 379 ; Proc. Second Entl. Meeting; pp. 78, 118, 124, 136.

We have this from Surat (Athwa Farm), 5th December 1903; Surat, on cotton in 1903; Dhulia, 28th October 1908; Nagpur, 27th June 1905, on Zizyphus jujuba; Godarwada (C. P.), 15th October 1910; Madras, 28th September 1906 ; Penukonda, 30th March 1907, on Hibiscus esculentus ; Nagpur, on bhindi-imagines on flowers and tender shoots; Aurangabad, on bhindi tender shoots; Pollibetta, on Erythrina lithosperma.

This species occurs commonly in the Central Provinces, Bombay and Southern India on Calotropis and Erythrina and less commonly on bindi and cotton. It is scarcely a pest of cultivated plants. 
Dictyophora pallida, Don.

Dist., F. I. Rhyn. III, 243-244.

Distant gives a record from Indian Muscim Notes, V, 43 [destructive to cane in N. Areot], evidently a mistake for a species of Pyrilla. probably $P$. perpusilla. We have one of the specimens collected by Atkinson at Raniganj and identified as $D$. pallida by Distant. D. pallida is not a pest so far as we know.

\section{Oliarus sp.}

Dist., F. I. Rhyn., III. p. 256.

This was found on rice at Pusa on 10th November 1914. It is scarcely a pest, so far as we know.

\section{Assamia moesta, Westw.}

Dist., F. I. Rhyn., III, 296-297, f. 142 [Phenice]; South Ind. Ins. p. 193, f. 380 ; Proc. Second Entl. Meeting, pp. 150, 18t, 192.

We have this from Pardi (Bombay), 23rd September 1904; Mnzaffarpur, 15th October 1904 ; Pusa, on ber, Dracena, maize, Sorghum, Setaria italica, sugarcane; Coimbatore, 15th January 1913, on sugarcane, grasses, cholam, palms ; Tatkon (Upper Burma), 7th September 1914, on sugarcane.

This species is common in the Plains and the adults are often found in numbers on sugarcane and cereals, on which it does not seem to breed, however. It las not definitely been noted as doing any damage, but it often occurs in such numbers on cultivated plants that we may well remain suspicious of its doings pending further evidence.

Elasmoscclis platypoda, Kirby.

Dist., F. I. Rhyn., III, 318-319, f. 155.

We have this from Laksam (Bengal), on 26th January 1906 ; Pyinmana (Upper Burma), on sugarcane, 7th September 1914; and Distant also records it from Ceylon. This may turn out to be a minor pest of sugarcane but we know very little about it as yet.

\section{Jivatma sp.}

Dist., F. I. Rhyn., III, 328.

This insect was found at Pyimmana (Upper Burma), on sugarcane ov 9th September 1914. 
Ricania sp.

Dist., F. I. Rhyn., III, 375.

This inseet was also found at Pyimmana (Upper Burma) on sugar. cane on 9th September 1911.

\section{Pyrilla aberans, Kby.}

Dist., F. I. Rhyn., III, 326-327, f. 161 [Zamila], VI, 85 ; Ent]. Note 97 ; Entoml. Mem. V, 73-136, t. 10-15, figs. ; Proe. Second Entl. Meeting, pp. 150, 185, 192.

We have this from Akola, on sugareane; Cawnpur, on cane, 16th October 1905; Kasandra (Ahmedabad), on sugareane, 6th January 1915 ; Bassein Fort (Bombay), in Oetober 1909 ; and Pusa, on Sacchamm spontaneum, 13th September 1906, Penisetum typhoideum, 18th September 1906, grasses 20th September 1906, sugarcane, juar, wheat, oats and Setaria italica; and Distant has recoraed it from Chikkaballapurar (Mysore).

All the available information on this and the other two species of Pyrilla has reeently been given in Mr. Misra's Memoir.

\section{Pyrilla pusana, Dist.}

A. M. N. H. (8), XIV, 326 (1914), F. I. Rhyn., VI, 84; Entl. Mem., V, pp. 76-78; Proc. Seeond Entl. Neeting, p. 150.

We have this from Akola (Berar), on sugarcane, in December 1909; Talodi (Chanda District), on sugarcane, 9th October 1914; Pusa. on sugarcane, juar, and grasses; and Chapra. Distant also records this from Upper Burma.

In habits it is practically identical with $P$. aberrans.

\section{Pyrilla perpusilla, Wlk.}

Dist., F. I. Rhyn., III, 327 [Zamila], VI, 85 ; Sonth Ind. Ins., pp. 493-494, f. 381 ; Entl. Mem., V, p. 78 ; Proc. Second Entl. Neeting, pp. 150, 185, 192.

We have this from Pusa. on sugareane in March and April ; Cawnpur, on cane and juar; Coimbatore, on sugarcane, maize and cholam and Palur. It is a common pest of sugarcane and cereals, occurring more especially in Southern India. 


\section{Puncaluoya simplicia, Dist.}

Dist., F. I., III, 468-469, f. 255, VI, 134 ; South Ind. Ins., p. 494, f. 382 ; Proc. Second Entl. Meeting, pp. 185, 193.

We have this from Pusa, on maize, and from Coimbatore, on cholam and maize. It occurs probably throughout the Plains, but has been little noted, although it is a bad pest of sorghum and maize. The attack is usually localized in patches, the attacked plants assuming an unhealthy yellow appearance and producing practically no grain.

Control is very difficult, as the bugs live protected inside the leafsheaths, where it is practically impossible to get at them. They are usually attended by ants and one line of attack might deal with these ants' nests. Beyond that the only method is by cutting the attacked plants and using them for fodder.

\section{(Unidentified Fulgorid).}

Proc. Second Entl. Meeting, p. 216.

This insect has been found at Coimbatore in all stages in swarms on

Mir. Ramakrishna Ayyar.

MTr. Fletcher.

\section{Sogala pusana, Dist.}

Dist., A. M. N. H. (8), IX, 191 (1912) ; Dist., F. I. Rhyn., VI, 139-140, f. 100 ; Proc. Second Entl. Meeting, p. 177.

This insect has been found on rice-plants at Pusa, Bilaspur and Sambalpur, and has also been recorded from Calcutta, Berhampur, and Chikkaballapura (Mysore). It appears to be a minor pest of rice.

Sogata distincta, Dist.

Dist., A. M. N. H. (S), IX, 191 (1912); F. I. Rhyn., VI, 140 ; Proc. Second Entl. Meeting, p. 177.

This species has been found on rice at Pusa and has also been recorded from Chikkaballapura (Mysore) and Peradeniya. It occurs, together with $S$. pusana, as a minor pest of rice.

[Since this paper was read, Mr. F. Muir has stated (Canad. Entom. L'. P. S ; January 1919) that $S$. distincta is the sume species as Megamelus furcifera, Horv.Edilor.] 
Sogata pallescens, Dist.

Dist., A. M. N. H. (8) IX, 192 (1912) ; F. I. Rhyn., VI, 140; Proc. Second Entl. Mecting, p. 177.

This species has been recorded from Galle; Chapra; Madhupur District; Calcutta; Pusa, on rice; and Janjgri (Bilaspur district), on rice.

It occurs, together with the two preceding species, as a minor pest of rice.

[Note.-Since this paper was read, Mr. F. Muir I as stated (Canal. Entom. LI, p. 8 January 1919) that the type of $S$. pallescens, Dist., is really Hegamelus furcifera, Horv.Editor].

\section{Liburnia sp.}

Dist., F. I. Rhyn., III, 480-481 ; Proc. Second Entl. Meeting, p. 177.

This species has been found at Pusa, Burdwan, Hooghly, Bomchi (Hooghly), Alipur, Kandi (Murshidabad), Nadiad; in all cases on riceplants. It is reported to be an occasional serious pest of paddy in Bengal, but very little is known about it. Specimens have been sent to Mr. Distant, but the identification has not yet been received.

Libumia psylloides, Leth.

Dist., F. I. Rhyn., III, 484-485.

This insect has been reported as a pest but it is probably in mistake for Pundaluoya simplicia. We have no specimens of $L$. psylloides.

\section{MeMbraCid}

Oxyrhachis tarandus, Fabr.

Dist., F. I. Rhyn., IV, 4-5, f. 1 ; Proc. Second Entl. Meeting, p. 275.

We have this from Sitamarhi (Muzaffarpur), on tur (Cajanus indicus); Pusa, on tur, C'assia fistula, and Acacia arabica; Bombay, on Acacia richii.

It is common in the Plains and is a minor pest of Acacia arabica, occurring sometimes in some numbers on Cajamus indicus also.

VOL. I 


\section{Cercopide.}

\section{Macharota planitiox, Dist.}

Dist., F. I. Rhyn., IV, 84 ; Ind. Ins. Life, p. 733, t. 79 ; Proc. Second Entl. Meeting, p. 118.

This species occurs abundantly on cotton at Pusa and checks new growth. It is a serious pest at times.

[See also pages 556-559.]

\section{Macharota sp.}

This species occurs at Pusa on Phyllanthus emblica in some numbers, the nymphal cases being attached to the twigs. It has also been noticed at Lucknow and is probably widely distributed in the Plains.

\section{Macharota sp.}

The tubes of this species occur at Pusa on Egle marmelos shoots, which are sometimes considerably stunted.

\section{Callitettix versico'or, Fabr.}

Dist., F. I. Rhyn., IV, 113, f. 86 ; Proc. Second Entl. Meeting, p. 150.

We have this from Wahjain and Nongpolı (Khasi Hills, 1,000 to 3,000 feet) and Tatkon in Upper Burma. At Tatkon it was found in numbers on sugarcane on 7 th September 1914, but it is not known how far it is a pest of cane.

Abidama producta, Wlk.

Dist., F. I. Rhyn., IV, 114, f. 87.

We have this from Nongpoh (Khasi Hills), Shripur (Bihar), Pusa, Buxar Duars, and Pyinmana (Burma). At Pyinmana it was found on sugarcane on 7 th September 1914, but it is not known how far it is a pest of cane.

\section{Phymatostetha deschampsi, Leth.}

Dist., F. I. Rhyn., IV, 128, f. 94.

We have this from Paruthur (Nalabar), 15th November 1913, on plantain ; Trithala (Malabar), 12th November 1913, on plantain ; Someshwar (S. Kanara, 2,000 feet); 24th September 1913, on plantain; and Talivaramba (Malabar), 30th September 1913, on plantain.

It orcurs on plantain in some numbers along the Malabar coast but. is scarcely a pest. 
Cosmosecre relute, Dist.

Dist., F. I. Rhyn.. IN. 143; South Ind. Ins. p. 495, f. 383 ; Proc. Second Entl. Meeting: 1). 2.2.2.

This species occurs in South Mysore and in Coorg as a serious pest of jak, sucking the young shoots.

\section{Cosmoscata funeralis, Butl.}

$$
\text { Dist., F. I. Rhyn., IV, } 154 .
$$

We have this from Lebong (Darjiling), Nongpoh (Khasi Hills ; 1,800 feet) and Myitkyina (Upper Burma). At Myitkyina it was found on orange but it is doubtful how far it is a pest.

\section{JASSID}

Idincerus niveosparsus, Leth.

Dist., F. I. Rhyn. IV, 185, f. 121 ; South Ind. Ins., pp. 495496, f. 381 ; Proc. Second Entl. Meeting, pp. $222-224$.

We have this from Saharanpur, Pusa, Bangalore, and Coimbatore, in all cases on mango, and it is a serious pest of mango throughout the Plains.

It can only be controlled by spraying, which should start before the flowers open, as the eggrs may be laid on the young leaves which appear before the flowers, and should be continued until the fruits are well set.

\section{Idiocerus athinsoni, Leth.}

Dist., F. I. Rhyn., 1V, 186 ; Proc. Sccond Entl. Meeting. pp. 222-224.

We have this from Pusa, 3rd Nay 1906, on mango bark and leaves; Bombay, October 1905, on mango bark; Pratapganj, 18th June 1907 ; Jamalpur, 12th Derember 1905; Manickganj, 26th October 1906, on mango; Saidapet, 16th Mareh 1907, on mango leaves; Baliganj, Calcutta, mango; Bankipur, mango; Thar and Parkar (Sind), mango.

It is common together with $I$. niveosparsus and the same remark applies to both species.

\section{Idiocerus clypealis, Leth.}

Dist., F. I. Khyn., IV, 187, f. 122 ; Proc. Second Entl. Meeting, pp. 222-224.

We have this from Pusa, Combatore (27th May 1913), Shillong, Bombay, Alwar (Rajputana), in all cases on mango. It oceurs together with the two preceding species and the same remarks app'y to all. 
Mr. Kunhi

Kannan.

Mr. Ramakrishna

Ayyar.

\section{Mr. Kunhi}

Kannan.

Mr. Ramakrisbna Ayyar.

Mr. Andrews.

Mr. Senior-White.
I have found an egg-parasite on Idiocerus spp. on mango.

There are some important mango-growing tracts around Salem, Chittur, and Vizagapatam. These gardens contain trees from fifteen to twenty years old.

Spraying with fishoil soap has been found effective against this insect. The cost of spraying works out at eight to twelve annas per tree, may be a rupee, but it pays because a tree after treatment yields fruit worth fifteen to twenty rupees.

It is very important to know when the young nymphs appear, because it is very essential to know the right time to commence spraying. Once we know the time of the emergence of the nymphs we can reduce the number of sprayings to be given to the trees. Spraying is quite effective on young trees but is not so on old ones. Our present difficulty is to secure the spraying machinery.

The cost you have given seems much too low. Does this inelude labour charges and hire of machinery ?

No ; those items are not included. As was explained by me at the last Meeting, the labour is supplied by the watchmen who are maintained by the owners of the gardens to look after the gardens. I have not included cost of the spraying machines either.

In view of the difficulty experienced by entomologists in India in obtaining sprayers, I may mention that Messrs. Shaw Wallace \& Co. are putting on the market sprayers manufactured on the lines of Autosprayers. These sprayers are quite good ones, better than the Autosprayers, with all the modern improvements, and are quite cheapthirty rupees or so.

Mr. Speyer is also getting machines made in Colombo.

Mr. Fle ‘cher.

\section{Idiocerus sp.}

This insect was found at Yercaud on orange. It is not known how far it is a pest.

Tettigoniella spectra, Dist.

Dist., F. I. Rhyn., IV, 211-212, f. 137; South Ind. Ins., pp. 496-497, f. 385 ; Proc. Second Entl. Meeting, p. 177.

We have this from Pusa, 5th May 1914, on Saccharum spontaneum, paddy ; Penukonda, 27th March 1907, on paddy ; Gangajhari (Bhandara, C. P.), 10th November 1905, on paddy; Surat, 16th February 190.1; Laksam; Munshiganj, 16th February 1906; Lumding, 24th October 1911, at light; Comilla, 27th October 1911, at light; Chaumahani, 27th November 1911, at light; Muzaffarpur, 6th September 1910; Tellicherry (Malabar), 2nd July 1907, on paddy : Coimbatore, on paddy. 
It is an abundant species throughout the Plains and a minor pest of paddy, probably feeding on wild grasses also.

\section{Iolla mimica, Dist.}

Dist., F. I. Rhyn., IV, 225 ; Proc. Second Entl. Neeting, p. 177.

This species has been recorded by Distant from Calcutta and Pusa. At Pusa it was reared from eggs found laid in rice leaves in 1915 when attempts were being made to rear Nephotettix bipunctatus. It is probably a minor pest of paddy, but has been overlooked hitherto.

\section{Nephotettix bipunctatus, $\mathrm{Fb}$.}

Dist., F. I. Rhyn., IV, 359-360, f. 228 ; Soutlı Ind. Ins. p. 497, f. 386 ; Proc. Second Entl. Meeting, pp. 176-177.

We have this from Sakti, 3rd October 1914; Pusa, 3rd November 1912 ; Aijal (Lushai Hills), 10th December 1913; Penukonda, 16th March 1907; Hagari, April 1907; Janjgir (Bilaspur), October 1914; Raipur, October 1914; Balasore, September and October 1914; Chaumahani, 5th March 1911; in all cases on paddy. The adults also come to light in enormous numbers and form a large proportion of the swarms of "Green Fly" which come to light at Calcutta and other places towards the end of the Rains. [See pages 433-443.]

\section{Nephotettix apicalis, Mots.}

Dist., F. I. Rhyn., IV, 360-362, f. 229 ; Proc. Second Entl. Meeting, p. 177.

We have this from Chapra; Dacca, on paddy in October 1906; Aijal (Lushai Hills), on paddy, 10th December 1913; and Coimbatore, 15th April 1913. It occurs together with $N$. bipunctatus and is probably a pest of paddy also.

[See pages 433-443.]

Empoasca flarescens, Fb.

Dist., F. I. Rhyn., IV, 405-406; South Ind. Ins., pp. 497-498, f. 387 ; Proc. Second Entl. Meeting, pp. 26, 28.

We have this from Pusa and Coimbatore, in both cases found on castor as a minor pest, and in the Duars and Assam it occurs on tea. 
Empoasca thea, Dist.

Dist. Entom. XLIII 196 (1910), F. I. Rhyn. VII 91 (1918).

Destructive to tea in Cachar in company with $E$. favescens. Also from Calcutta.

Empoasca devastans, Dist.

Dist., F. I. VII 93 (1918); Proc. Second Entl. Meeting, p. 117. [Empcasca sp.]

We have this from :-Pusa, Sth August 1912, on cotton ; Coimbatore, 7th January 1914, on cotton; Taru (Peshawar), 26th September 1913, on cotton; Nagpur; Lyallpur, on cotton; Dhulia Farm, on .cotton; and Dharwar, on cotton. It is at times a bad pest of cotton, especially of exotic varieties.

\section{Empoasca sp.}

This was found at Peshawar in numbers on leaves of beetroot on 26th Septemis 1913.

\section{Empoasca sp.}

This species attacks grape-vine in numbers at Peshawar in August. It has not been identified as yet.

\section{Psylidide.}

Arytaina isitis, Buckt.

Psyllopa punctipennis, Crawf.

Psylla isitis, Entl. Mem. IV, No. 6 ; Agricl. Journ. Ind., VIII, 1-26, tab. 1-4 (Jan. 1913); Proc. Second Entl. Meeting, p. 81 .

This species occurs on indigo in most parts of the Plains of India, from the Punjab to Madras, but is a minor pest as a rule, occasionally serious, especially in North Bihar.

\section{Euphaterus citri, Kuw.}

Proc. Second Entl. Neeting, pp. 215, 216.

We have this from Cherat (North-West Frontier Province), Lyallpur, Pusa, Poona and Coimbatore. It is usually a minor pest of Citrus spp. (orange, lime, lemon, pomelo), sometimes occurring in large numbers and doing considerable damage, especially in the Punjab. At Pusa and Coimbatore it has been found on shoots of Murraya loenigii and at Coimbatore on Cordia cordifolia also.

Spraying with fishoil-resin soap is effective. 
Apsylla cistellut", Buckt.

Ind. Ins. Life, p. 742, ff. 514, 514 ; Proc. Second Entl. Mecting. p. 221.

This insect is found througlout Northern India on mango. Its early stages are passed inside a young shoot which becomes distorted and transformed into a cone-shaped gall. It is not common as a rule but occasionally becomes a pest.

\section{Aleyrodidæ.}

Aleurolobus barodensis, Mask.

Ind. Ins. Life, p. 749, ff. 524, 525 ; Proc. Second Entl. Meeting, pp. 150-151.

We have this from Cawnpur, Pusa, Sindewahi (Central Provinces), Bassein Fort and Baroda, in all cases on cane. It is a sporadic major pest of sugarcane, but is usually checked by parasites.

Beyond the utilization of such parasites and the cutting and destruction of badly infested leaves, no suggestion for control can be made at present.

Aleurocanthus spiniferus, Quaint.

Proc. Second Entl. Heeting, p. 214.

This species is widely distributed in the Plains as a pest, sometimes serious, of Citrus trees. It has been noted at Pusa, Surat, and in the Punjab.

It can be controlled by collection of the old leaves and regular sprayings (three or four, at intervals of a fortnight) of the new leaves with fishoil-resin soap.

The damage done is largely indirect, due to the honey-dew on the leaves.

Aleurocanthus mubilans, Buskt.

Ind. Mns. Notes, V, 36, t. 5, ff. 7-9 ; Proc. Second Entl. Meetin r, p. 301.

This species was originally described from Backerganj where it was reported to be doing considerable damage to "betel-leaves" [probably Piper betle]. It has not been noticed since on betel.

Aleurocanthus piperis, Mask.

This species has been found in Ceylon on pepper, and is likely to be found on pepper in India also. 


\section{Neomaskellia bergi, Sign.}

South Ind. Ins., p. 507, f. 394 ; Proc. Second Entl. Meeting, pp. 150-151.

We have this from Pusa on sugarcane and from Pusa and Tharsa (Central Provinces) on juar. It is widely distributed in the Plains as a pest of sugarcane and juar.

Dialeurodes citri, Riley and Howard.

Proc. Second Entl. Meeting, pp. 214-215.

We have this from Lahore, on Citrus, and from Pusa on Jasminum sambac. It is not usually regarded as a serious pest in India, where it is probably kept in check by predators and parasites.

Dialeurodes eugenice aurantii, Mask.

This species has been found on Eugenia jambolana at Pusa, Poona, Bangalore and Coimbatore; but it seems to be a very minor pest as a rule.

Bemisia leakei, Peal.

This species has been found at Pusa on indigo, but it is not known to be a pest.

Aleyrodes cotesii, Mask.

Proc. Second Entl. Meeting, p. 266.

This species was originally described from examples found on rose at Quetta, and is also known to occur on rose at Pusa, Alipur (Calcutta), and Pondicherry; but it is a rather minor pest as a rule.

\section{Aleyrodes sp.}

Ind. Ins. Life, t. 81 ; South Ind. Ins., p. 202, f. 89 [parasite]; Proc. Second Entl. Meeting, p. 88.

We have this from Pusa and it is known to occur in Burma, Baroda and Coimbatore also as a sporadic serious pest of castor, whence it is commonly referred to in India as Aleyrodes ricini, although that is an unpublished name.

\section{Aleyrodes sp.}

Proc. Second Entl. Meeting, pp. 233-234.

This species occurred in very large numbers on pomegranate at Dharwar in February 1912 and has also been reported to occur at Bangalore and Coimbatore. 


\section{APHIDID ж.}

[Note.-Our knowledge of Indian Aphids, even of those whieh are fests of eultivated erops, is woefully seanty. The following list has been eompiled almost wholly from the late Bashambar Das' paper on the Aphidide of Lahore.]

Macrosiphum pisi, Kalt.

= Siphonophora pisi (Kech-Buch.).

= Nectarophora destructor, Johnston.

Jour. Eco. Entom. Vol. IV, p. 384 (1911).

Jour. Eco. Bio. September 1913, p. 134.

Memoirs, Ind. Mus., Vol. VI, No. 4, pp. 157-158 (1918).

Has been found at Lahore on the following food plants:-Alkagi maurorum, Melitotus alba, Medicago sativa, Clianthus dampieri, Lathyrus odoratum, Dolichos lablab, Peganum harmala.

Macrosiphum rosaformis, Das.

Mem. Ind. Mus. VI, 4, pp. 158-162 (1918).

This has been found at Lahore on rose.

Macrosiphum granarium (Kirby-Pergande).

Buekton, Brit. Aphid., I, p. 114; Pergande, U. S. Dept., Agric. Div. Entom. Bull., 44 (1904); Theobald, Jour. Eco. Biol., VIII (1913); Mem. Ind. Mus., VI, 4, pp. 162-163 (1918).

This species has been recorded from Lahore on wheat, oats and barley and is a pest of wheat at Pusa and probably throughout Northern India.

Macrosiphum sanborni, Gillette.

Sanborn, Kans. Univ. Sc. Bull., Vol. III.

Gillette, Canad. Entom. L. ii, p. 65 (1908).

Jour. Eco. Entom., IV, p. 385 (1911).

Nem. Ind. Mus., VI, iv, pp. 163-164 (1918).

This species has been found at Lahore on cultivated Chrysanthemum.

Macrosiphum sonchi, Linn.

Proc. Second Entl. Meeting, p. 97.

This species-or, at least, the Aphid we know under this namehas been noted on safflower at Pusa, Dharwar and in the Central Provinces, and is sometimes a bad pest of safflower.

This Aphid does not appear to have been seen by Mr. Das in Lahore. 
Myzus persica, Sulz.

= Rhopalosiphum dianthi, Schr.

Gillette, Jour. Eco. Entom., I, p. 359 (1908) ; Ind. Mns. Notes, IV, i, p. 23 (1896); Lefroy, Ind. Ins. Life, p. 744 (1909); Mem. Ind. Mus., VI, iv, pp. 166-169 (1918).

This species is recorded from Lahore on rape, mustard, cabbages, cauliflowers, turnip, B. campestris, Raphanus sativus, Contolvulus mäjor, Ipomcea spp., Nicotiana tabacum, Datura stramonium, Prunus persica (often pinkish in colour; along with Aphis pruni). Pyrus communis, Dalbergia sissu, Solamm tuberosum, S. lycopersicum, Chenopodium, Viola tricols, Cineraria. It has been found at Berhampur on brinjal.

Stephensonia lahorensis, Das.

Mem. Ind. Mus., VI, iv, pp. 175-179 (1918).

This has been found at Lahore on cultivated Chrysanthemum.

Brevicoryne coriandri, Das.

Mem. Ind. Mus., VI, iv, pp. 180-183 (1918).

At Lahore this has been found on coriander (Coriandrum sativum). Occasionally also on F'eniculum sp. and C'arum copticum.

Brevicoryne chenopodii, Schrank.

Mem. Ind. Mus., VI, iv, pp. 184-187 (1918).

Has been found at Lahore on Chenopodium album.

Brevicoryne (Aphis) brassica, Linn.

Buck., Brit. Aphid, II, p. 33 (1875) ; Essig. Pom. Coll. Jour. Entom. III, iii, p. 323 (1911) ; Herrick, Jour. Eco. Entom., IV, pp. 219-224 (1911) ; Ind. Mus. Notes, II, ri, p. 167; Ind. Ins. Life, p. 747 (1909); Mem. Ind. Mus., VI, iv, pp. 187-188 (1918).

This species has been found at Lahore on cabbage and turnip.

Siphocoryne intobrassice, Das.

$=$ Aphis psculobrassice, Davis.

Mem. Ind. Mus., VI, iv, pp. 188-191 (1918).

Recorded by B. Das from Lahore, Java, America. Myzus persicce is also found along with this in varying proportions. A coloured plate - has been issued by Agricultural Research Institute, Pusa. 
We have it from Pusa, Poona, Ram Nagar (United Provinces), Fatehpur, in all cases on mustard.

Siphocoryne nymphace. Linn.

= Rhophalosiphum mymplecer.

Buck. Brit. Aphid, II, p. 12 ; Essig. Pom. Coll. Jour. Entom.

IV. iii, pp. 793-797; l'atch, Main. Agri. Expt. St. Bull. 202

(1912); Davis. Entom. News, p. 245 (1910); Cockerell,

Science, p. 764. (1905); Ind. Ins. Life, p. T47; Mem. Ind.

Mus., TI, iv, pp. 191-194 (1918).

Found on Lemna sp., Nelumbium speciosum and Scarpars lacustris at Lahore.

\section{Siphocoryne padi, Linn.}

= Siphocoryme avence. Fabr.

= Siphonaphis padi. Linn.

U. S. Dept. Agric. Bull.. No. 44 ; Essig. Pom. Coll. Jour. Entom.

IV, p. 791 ; Men. Ind. Mus., VI, iv, pp. $194-195$ (1918).

At Lahore this has been found on wheat, barley, Avena, rhizomes of Cynodon dactylon.

\section{Toxoptera graminum, Rond.}

Passerini, Aphidæ Italicæ, p. 28 (1863); S. J. Hunter and P. A. Glen, Bull. Kansas Univ., IX, ii (1909); Mem. Ind. Mus., VT, iv, pp. 196-198 (1918).

This species occurs in the Punjab on wheat, barley, oats, Cyperus yotundus. C'yperus niveus.

\section{Texoptere murabimyir, Das.}

Mem. Ind. Mus., VT, iv, pp. 198-202 (1918).

This species has been found at Lahore on Pyrus commun (pear), and Pymes sp. (wild pear).

\section{Toxoptera aurantii, Boy.}

=Ceylonia theaecola.

Ind. Mus. Notes, II, i, p. 40 ; Ind. Ins. Life, p. 748.

This species occurs at Pusa and in Bombay on Citins trees, but apparently does not extend so far Nortl as Lahore (Das; Mem. Ind. Mus., VI, 196). 
Aphis rumicis, L.

Schouteden, Cat. Aphides de Belgique, p. 277 (1906); Buck, Brit. Aphid, VII, pl. xiv; Ocstlund, Aphid Minn., p. 61 (1887); Gillette, Jour. Eco. Entom., III, p. 407 (1910): Patch, Maine Agri. Expt. Sta. Bull., 202 (1912).

This species has been found at Lahore on Solanum nigrum, Cnicus arvensis, Rumex dentata, Chinopodium ravely, Pyrus communis (pear).

Aphis medicaginis, Koch.

Aplis cardui.

Koch, Pflanzenläuse, p. 94, figs. 125-126 (1857); Gillette, Jour. Eco. Entom., I, pp. 177-178 (1908) ; Essig, Pom. Coll. Jour. Entom., III, iii, p. 527 (1911).

This species occurs commonly in the Plains on indigo and Cajanus indicus and has been noted at Pusa, Surat, and Ranchi on these plants, whilst it hias also been recorded on Dolichos, Dalbergia, Medicago, Vicia, Sesbania, Cassia, etc.

Aphis nerii, Boyer de Fonscolombe.

Fonscolombe, Ann. Soc. Ento. Fr. X, p. 157 ; Essig, Pom.

Coll. Jour. Entom., III, iii, p. 530 ; Ind. Ins. Life, p. 748.

This species has been found at Lahore on Calotiopis gigantea, $C$. procera, Hoya longifolia, Cryptostegia grandiflora, Asclepias sp., Cynanchum dalhousie, Draga volubilis.

Aphis sacchari, Zchntner.

Mem. Ind. Mus., VI, iv, pp. 206-208.

This species has been found at Lahore on Sorghum and Panicum colore. It has not been found hitherto on sugarcane in India, though it was first noticed on sugarcane in Jara. (Arch. Java Suiker-industrie Dl. IX, p. 674 (1901). 
Aphis maidis, Fitrh.

= Aphis adusta, Zehnt.

= Aphis sorghi, Theobald.

Fitch, Sec. Rept. on Insects of New York by State Entomologist (1856); Oestlund, Synop. Aphid Minn. (1887), p. 56 ; Webster, The Croton leaf Aphis, U. S. Dept., Agric. Circ. No. 86 (1907) ; Ind. Ins. Life, p. 747 ; Mem. Ind. Mus., VI, iv, pp. 208-213 (1918).

This species has been found at Pusa on juar and at Lahore on wheat, maize and Panicum colore (inflorescence only), oats, barley, maize, Sorghum, Pennisctum typhoideum, Panicum crusgalli, Cynodon dactylon.

A plate showing this insect under the name of "Wheat Aphis" has been issued by the Agricultural Department, India, but is of little scientifie value.

Aphis malvex, Koch.

$=$ A. cucurbiti, Buck.

Buck, Brit. Aphidæ, II ; Mem. Ind. Mus., VI, iv, pp. 213215.

This species has been found at Pusa on bhindi and at Lahore on cueurbits.

Aphis malvoides, Das.

Ree. Ind. Mus., VI, iv, pp. 215-216, 1918.

This has been found at Lahore on Malva sp., Malvastrum spp., Chrysanthemum, pear, pansy, Solanum spp.

Aphis durranti, Das.

Mem. Ind. Mus., VI, iv, pp. 217-219 (1918).

This species has been reported from Lahore on Duranta sp., Vilex negundo, Colocasia, ete.

This species was called durranti by Bashambar Das, but the name apparently should have been duranta. 
Aphis gossypii, Glover.

= A. citrulli, Ashmead, 1882.

= A. cucumeris, Forbes, 1883.

Glover, Pat. Off. Report, p. 62 (1854); Ashmead, Can. Ento., IIV, p. 91 (1882); Gillette, Jour. Eco. Entom., I, iii, p. 176 (1908) ; Essig, Pom. Coll. Jour., III, iv, p. 590 (1911); Ind. Ins. Life, p. 746 (1909) ; Mem. Ind. Mus. VI, iv, pp. 219220 (1918).

This species occurs commonly on cotton and is sometimes rather a pest of this crop. It has been found on cotton at Lahore, Muzafiarpur, Pusa, Dhulia, Shimoga, Bellary and throughout Southern India. At Lahore it has also been found on Capsella, Impatiens sp., Cryptostegia grandifora.

\section{Aphis nasturtii, Kalt.}

Kaltenbach, Pflanzenl. (1843), p. 76 ; Koch, Pflanzenl (1857), p. 136, fig. 125 ; Schouteden, Cat. Aph. Belg. (1906), p. 221; Mem. Ind. Mus. VI, iv, pp., $212-222$ (22).

This species occurs at Lahore on Nasturtium.

\section{Brachycaudus prumi, Koch.}

Koch, Die Pflanzenläuse; Buckton, Brit. Aphid, II, p. 64; Van der Goot, Zür Systematik der Aphiden, pp. 96-97; Stebbing, Ind. Mus. Notes, VI, 1913, p. 70.

This species occurs throughout North-West India on peach and is also found on Ageratum conyzoides.

It is one of the worst insect pests that the peach-grower has to contend against in Northern India. The leaves are contorted into pseudogalls and the trees become sickly and unsightly. The leares appear closely crowded and never expand fully. They turn whitish and in some cases pinkish. It is found with Myzus persice on the same plant.

\section{Lachme pyri, Buckt.}

South Ind. Ins., p. 503, f. 391 ; Proc. Second Entl. Meeting, p. 247.

This species occurs commonly on pear in Ootacamund and the Shevaroy Hills and Ceylon (Hills), but apparently does not extend into Northern India. It occurs in masses on the stems and branches and is easily dealt with by brushing or spraying. 


\section{Hyalopterus prumi, Fb.}

Buckt., Brit. Aphid, II, p. 110 ; Riley, Ins. Life, V, p. 236 : Gillette, Baili. Color. Expt. Sta. No. 133 (1908); Mem. Ind. Mus., VI. iv, pp. 2025-2027 (1918).

This species has been found at Lahore on Arundo donax, Phragmites kirki and Prunus persica (peach).

\section{Brachyunguis (?) carthami, Das.}

Mem. Ind. Mus., VI, iv, pp. 237-240.

This species has been found at Lahore on wild saflower (Carthamus oxycarpi).

\section{Callipterus trifolii, Monell.}

=Chaitophorus maculatus, Buckt.*

Monell, Canad. Entom. XVI, p. 14 (1882); Ind. Mus. Notes, IV, p. 277 : Ind. Ins. Life, p. 746 ; Davis, Ann. Ent. Soc. America. I (1908); B. Das, Mem. Ind. Mus., VI, iv, pp. 244-245 (19]8).

This species is found on lucerne and bersîm throughout Northern India.

$$
\text { Tuberodryobius persice, Chole dk. }
$$

Hcm. Ind. Hus., VI, iv, pp. 259-268 (1918).

This species occurs throughout North-Western India as a bad pest of peach. and it also occurs on plum, apricot and ahond.

The Aphids are present on the main trunk and branches of the fruit-trees mentioned above, more particularly the peach. The loss to the peach crop from an attack of this Aphid is immense. Tery few fruits mature and attain the normal size and colour.

$$
\begin{aligned}
& \text { Eriosome (Schizoneura) lanigera, Hausm. } \\
& \text { South Ind. Ins. pp. 500-501, f. } 389 .
\end{aligned}
$$

This species has been introduced into India with imported orchard stock and is now fairly established in all the principal apple-growing districts. We know it from Simla, Binsar (Almora), Ramgarh (Kumaon), Lucknow, Shillong, Taung-gyi (Southern Shan States), Bangalore and Coonoor, in all cases on apple.

At Ramgarh, where it is said to attack jungle plants also, the winged adults were found emerging towards the end of August 1918, and treat.

* Theobald states that C. maculatus is a synonym of Calli, terus ononicis, halt (Bull. Ent. Res II 134.138, ff. 25, 26 (1915); Entom. 191s, p. 28). Eaitor. 
ment at this time of all colonies on the trees is especially desirable to prevent spread of infection as far as possible.

(Unidentified Aphid).

"Ragi root Aphis," South Ind. Ins., pp. 502-503, f. 390 ; Proc. Second Entl. Meeting, p. 200.

This species occurs regularly every year at Coimbatore on roots of ragi and is a serious pest.

\section{(Unidentified Aphid).}

South Ind. Ins., pp. 506-507, f. 393 ; Proc. Second Entl. Meeting, p. 261.

This species was found at Coimbatore on young coconut palms which had been imported from Colombo.

\section{Oregma bambusa, Buckt.}

Soutlı Ind. Ins., p. 505 , f. 392.

This species occurs commonly at Coimbatore, and probably throughout Southern India, as a pest of bamboo.

\section{COCCID}

[NotE.-The Coccidæe form another group of which we know nothing in India and the following list, which is placed in the order of Fernald's Catalogue, is very incom. plete.]

\section{Monophlebus stebbingi var octocautata, Gr.}

Mem. Dept. Agric. India, II, ii, p. 16, II, ii, pp. 111-117 (1908).

This species has been found at Sitamarhi (Brhar), Fatehgarh (United Provinces), Bareilly, Lahore (Shalimar gardens), in all cases on mango. It is abundant at Pusa on practically all trees from December to April.

Monophlebus tamarindus, Green.

South Indian Coccidæ (MS.) ; Mem. Dept. Agric. India, II, ii, p. 17 (1908).

This species has been found at Agra, on tamarind leaves; and at Samalkota (Godavari), on garden crotons. 
Monophlebus sp. (near temarindus, Gr.).

This was found in May at Kohat (North-West Frontier Province) on mulberry.

$$
\text { Walleriana cincrea, Green. }
$$

Mem. Dept. Agric. India, II, ii, p. 17 (1908) ; l. c., iv, p. 121 (1908).

This species has been found in Western India, on Lawsonia alua; at Surat, on Acacia arabica; and at Vadanapalle (Malabar) on stem of Lausonia alba and on sandalwood tree.

\section{Irallieriana sp.}

This was found in Coorg on Tobernamontena.

$$
\text { Lerya agyptiace, Dougl. }
$$

Non. Brit. Cocci., II, p. 248 (1902); Sonth Indian Coceida (MS) ; Mem. Dept. Agric. India, II, ii, p. 118 (1908).

This species has been noted at Tadanapaile (\$. Maiabar), on Artocarpus incisa; Kallar (Nilgiris), on Artocarpus integrifolia; Simhachalam (Vizagapatam), on Ficus sp. leares; Pusa, on Citrus, guava, chillies (plants), jak; and at Ranchi, on rose leaves.

\section{Ícrye minor, Gr.}

Mem. Dept. Agric. India, II, ii, p. $118-121$ (1908), l.c., II, ii, p. 17 (1908).

This species has been found at Pusa, on mango leaf.

Icerya seychellarum, Westwd.

N. 7. Trans., p. 329 (1897) ; I. M. N., IV, i, p. 7 (1896) ; Mem. Dept. Agric. India, II, p. 18 (1908) ; Sonth Indian Coccida (MIS) ; Bom. Jour., XXIII, p. 137 (1914).

This specios has been found at Kottur (Bellary Dist.), on C'ussia tora: Bombay, on mango; Coromandel coast, on Casuarina; and in Western India, on Ficus bengalensis.

\section{Cerococcus hibisci, Green.}

Mem. Dept. Agric. India, II, ii, pp. 20, 122 (1908) ; Nerrstead, Bull. Ento. Res., VIII, 127 ; South Ind. Ins., p. 508, f. 395 ; Proc. Second Entl. Meeting, p. 118.

This species has been found at Coimbatore, Godavari, Madras, on cotton, Hibiscus rosa-sinensis; Guntur, on Solanum melongena; Lashkar FOL. I 
(Cwalior), on cotton; Rangoon, on cotton; Sabour, on cotton (1918) Bombay, on Hibiscus liliflorus; and at Pusa, on cotton.

\section{Dactylopius indicus, Green.}

Mem. Dept. Agric. India, II, ii, p. 28 (1908).

This species was found at Kangra, on Opuntia dillenii.

\section{Phenacoccus ballardi, Newstead.}

Bull. Ent. Res., VIII, p. 17 (Angust 1917) ; South Ind. Coccidæe (MS).

This species has been found on mango at Coimbatore and in South Kanara.

Phenacoccus hirsutus, Gr.

Bom. Tour., XXIII, p. 136 (1914) ; Mem. Dept. Agric. Ind., II, ii, 25.

This species has been found at Mrhol (Sholapur District), on Ficus bengalensis; Pusa, on mulberry, cotton shoots (very bad on mulberry, causing tulira disease); Malda, on mulberry shoots; Berhampore (Bengal) mulberry shoots; and Bankura, on mulberry shoots.

\section{Phenacoccus iceryoides, Gr.}

Mem. Dept. Agric. Ind., II, ii, pp. 26,129 (1908) ; South Indian Coccidæ (MS).

This species has been found at Coimbatore, on Odina wodier ; Palacole (Godavari), on Citius shoots; Alamanda (Vizagapatam), on mango shoots and fruits; Tanjore, on Boswellia; Calcutta, on mango; and at Surat, on Capparis horrida.

\section{Phenacoccus insolitus, Green.}

Mem. Dept. Agric. Ind., II, ii, p. 27 ; Bull. Ento. Res., VIII, p. 127 ; Proc. Second Entl. Meeting, p. 289.

This species has been found at Pusa, on Sida cordifolia ; Chingleput and Coimbatore, on brinjal plants; and at Saidapet, on Solanum melongena (Newstead).

Phenacoccus mangifera, Green.

I. M. N., IV, i, p. 7 ; South Indian Coccidæ (MS.).

This species has been found at Coimbatore, on mango. 


\section{Pseudococcus (Dactylopius) citri, Risso.}

Mem. Dept. Agric. Ind., II, ii, pp. 22, 122, 123-12t (1908); South Ind. Ins., pp. 508-509, fig. 396; Proe. Second Entl. Heeting, pp. 29, 36, 79, 256.

This species has been found at Kallar (Nilgiris), on cacao pods; in IIysore, on coffee, Cedrela, Ficus glomerata; in Coorg, on Erythrina. Ageratum; and in Ceylon, on coffee.

\section{Pseudococcus cocotis, Msk.}

Ind. Nus. Notes, II, p. 169 III, i, pp. 7, 66 (1893); South Indian Coecida (IIS).

This species has been found on coconut leaves in Malabar and the Laccadive Islands.

\section{Pseudococcus corymbatus, Green (MS). \\ South Indian Coccidre (IIS).}

This species is known from Palacole (Godavari District), on Cilrus shoots and fruits; Malabar, on jak; Coimbatore, on cotton shoot; and Pusa, on cotton shoot, soy beans.

\section{Pseudococcus longispinus, Targ.}

Cotes, Ind. Hus. Notes, II, vi, p. 169 (1893) [alomidum]; Barlow, Ind. Mus. Notes, IV, p. 75 (1897).

This species has been found at Vadanapalle (S. Milabar), on coconut leaves; in Nysore, on coffee and eedar; and at Calcutta on croton.

\section{Pseudococcus nipe, Mask.}

Mem. Dept. Agric. Ind., II, ii, pp. 23, 121; South Ind. Ins., p. 509, f. 397 ; South Indian Coccidx (IIS); Bom. Jour., XXIII, p. 136.

This species is known from Coromandel coast, on Casuarine stem ; Nortl India, on stored potatoes; Western India, on Cajumus indicus; and Pusa, on potato tubers in store, mulberry, cotton. [The Mealy-bug on cotton and mulberry has been identified by E. E. Green (1919) as Phenacoccus hirsutus.] 


\section{Pseudococcus sacchari, Ckll.}

Ind. Mus. Notes, V, iii, p. 102 ; Mem. Dept. Agric. Ind., II, ii, p. 23 ; Soutlı Indian Coccidæ (MS); Newstead, Bull. Ento. Res., VIII, 126 ; Proc. Second Entl. Meeting, p. 151.

This species has been found at Coimbatore, Trichinopoly and South Arcot, on paddy (a rather serious pest occasionally); Basscin; Poona; Bilaspur; and Rajnagar (Darbhanga), on sugarcane.

\section{Pseudococcus saccharifolii, Gr'.}

Mem. Dept. Agric. Ind., II, ii, p. 24 ; Proc. Second Entl. Meeting, p. 151. This species has been found at Pusa, on sugarcane.

\section{Pseudococcus thececola, Green.}

Nem. Dept. Agric. Ind., II, ii, p. 24.

This species was found in Darj:ling, on roots of tea plant.

\section{Pseudococcus virgalus, Ckll.}

Newstead, Ind. Mus. Notes, III, v, p. 24 (1895) ; Green, Ind. Mus. Notes, I, p. 7. (1896) [ialini] ; Mem. Dept. Agric. Ind., II, ii, pp. 127-128 (1908); South Ind. Ins., p. 510, fig. 398 ; Proc. Second Entl. Mleeting, pp. 124, 257, 268, 290.

This species has been found at Coimbatore, on croton, tomato; Palur (S. Arcot), on Cambodia cotton; Poona, on adventitious roots of banyan trec; Serampore, on violets; Poona, on croton; Bettiah, on cotton: Pusa, on cotton, mulberry, crotons, Draccuna, Hibiscus, violets, Acalypha, Cissus discolor.

\section{- Ripersia resinophita, Gr.}

Bull. Ent. Res., VI, pp. 395-397.

This species has been found in Kumaon and Kashmir (Kamraj Division), on Pinus longifolia and Pinus excelsa.

\section{Ripersia sacchari, Gi.}

I. M. N., V, ii, p. 37 ; South Indian Coccidr (MS) ; Mcm. Dept. Agri. Ind., II, ii, p. 25 ; Proc. Sccond Entl. Meeting, p. 151.

This species has been found at Coimbatore, on sugarcane; Gorakhpur, on cane; Pusa, on canc; and in Bengal, on rice plant. 
Ripersia sacchari oryse, Green.

Mem. Dept. Agri. Ind., II, ii, pp 12S-129.

This insect has been found at Balasore, Bankipur, Champaran, Gorakhpur, Moorla (Bihar), and Handia (Bihar), in all cases on rice.

Ceronema koebeli, Gr.

Bull. Ent. Res., V, p. 267, 1914.

This species has been found at Peradeniya, on Pithecolobium saman.

\section{Pulvinaria burkitli, Green.}

Mem. Dept. Agri. Ind., V, ii, pp. 31-32; South Indian Coceidæ (IIS) ; Bull. Ento. Res., VIII, 129.

This species has been found at Coimbatore, on Zisyphus jujuba leaves, and at Siugaing [?] (near Calcutta), on C'roton tiglium.

\section{Pulvinana maxima, Green.}

Ent. Mo. Mag., XL, p. 206 (1.01); South Indian C'occidæe (MS).

This species has been found at Coimbatore, on nîm trees, and in South India, on mulber'ry plants.

\section{Pulvinaria psidii, Mask.}

N. Z. Trans., XXV, p. 223 (1892); Ind. Mus. Notes, IV, i, p. 8 (1896); Mem. Dept. Agri. Ind., II, ii, p. 32, 131, 134 (1908); South Ind. Ins., p. 511, f. 399 ; Proc. Second Entl. Necting, pp. 34, 228, 230, 232, 250.

This species occur's in South India, on guava, mango, Morinda, tea, coflee ; at Coimbatore, on mango, gllava; in Nysore, on Ficus glomerata; in the Nilgiris, on guava, Eugenia, tea; at Koilpatti, on guava; in Western India, on mango, guava (very bad), Rassia latifolia; anc at Pusa, on mango leaves, litchi, and Ficus glomerata.

\section{Pulcinaria sp.}

This occurs at Pusa, on mulberry leaves. 
Ceroplastes actiniformis, Green.

Ind. Mus. Notes, IV, i, p. 8 (1896); Coccidx of Ceylon, iv, p. 275 (1909) ; B. J., XXIII, p. 136 (1914); South Indian Coccidre (MS).

This species has been found at Coimbatore, on coconut leaves and mango ; in Malabar, on coconut leaves ; at Samalkota (Godavari District), on Canna; Penukonda (Anantapur District), on Ficus sp.; Poona, on Loranthus sp., banyan; and in Ceylon, on coconut and other palms, Canna and Sapium.

Ceroplastes ceriferus, Anderson.

Ind. Mus. Notes, I, p. 89 (1890), III, v, p. 21 (1896) ; Coccidæ of Ceylon, iv, p. 270 (1909).

This species occurs at Coimbatore, on Lawsonia alba; Tanjore, on Boswellia [?]; and in the Central Provinces on Terminalia and Buchanania.

\section{Ceroplastes floridensis, Comst.}

Ind. Mus. Notes, V, i, p. S (1900); Coccidæ of Ceylon, iv, p. 277 ; Rept. U. S. Dept. Agri. 1880, p. 331 ; Mem. Dept. Agri. Ind., II, ii, p. 134 ; Proc. Second Entl. Meeting, pp. $228,251,255,257$.

This species has been found at Bangalore, on cashew (Anacardium occidentale); in Timnevelly District, on Michatia coutallum; in Ceylon, on tea and guava; and at Pusa, on Ficus carica, F. infectoria, Tamarix galiica, mango, guava, Hibiscus esculentus and Cyamopsis psoralioides.

Ceroplastes rubens, Mask. (myrica).

N. Z. Trans. XXV, p. 214 ; I. M. N., V, i, p. 8 ; Mem. Dept. Agri. Ind., II, p. 32 ; Bull. Ento. Res., VIII, 129.

This species has been found at Coconada, on Cycas revolula; Chicacole, on mango; Coimbatore, on Calophyllum; Palghat (Malabar), on jak; and in Ceylon, on tea. mango, cimnamon and Eugenia.

Vinsonia stellifera, Westwd.

Coccidæ of Ceylon, iv, p. 280 ; Proc. Second Entl. Meeting, pp. $228,260$.

This species has been found at Coimbatore, on mango; in Timmevelly, on nutmeg leaves; Malabar, on coconut palm; Godavari District, on rose-apple leaves (Eugenia jambos) ; South Malabar, on coconut; Ceylon, on mango and coconut; and at Bombay, on Garcinia indica. 


\section{Inglisia bivalvata, Green.}

Ind. Mus. Notes. V, iii, p. 95 ; South Indian Coccidæ (MS).

This species has been found at Mandapetta (Godavari District), on Cajanus indicus leaves.

\section{Ceroplastodes cajani, Mlask.}

Newstead, Bull. Ento. Res., VIII (1917); Mem. Dept. Agri. Ind., II, ii, p. 32 (1908); South Ind. Ins., p. 512, f. 400 ; Proe. Second Entl. Neeting, pp. 57, 267.

This species has been found in South India, on Cajanus indicus, Zizyptus jujuba, Ocimum senctum, and wild indigo; at Calcutta, on Ocimum; and at Surat, on Coleus.

\section{Ceroplastodes chiton, Gr.}

Iem. Dept. Agric. Ind., II, ii, p. 32 (1908).

This spccies has been found at Darjiling, on Cajemus indicus.

Coccus acutissimus, Gr.

I. M. N., IV, i, p. 10 (1896); Coccidæ of Ceylon, p. 218 (1899).

This species has been found at Coimbatore, on coconut leaf and mango leaf.

\section{Coccus hesperidum, L.}

Coceidæ of Ceylon, I, p. 188 (1899); Proc. Second Entl. Mleeting, p. 36.

This species has been found at Mandapetta (Godavari District). on Cimus shoots; and at Madaligam (S. Malabar), on coconut leaf.

\section{Coccus longulus, Douglas.}

I. M. N., IV, p. 8 (1896) ; Coccidæ of Ceylon, p. 221, t. LXX.

This species has been found at Mandapetta (Godavari District), on red-gram; and in Ceylon, on Acacia, Albizzia, Loranthus.

\section{Coccus mangiferce, Green.}

Mem. Dept. Agric. Ind., II, ii, p. 30 (1908).

This species occurs at Pusa, on mango. 
Coccus viridis, Green.

I. M. N., pp. 49-117; Coccidæ of Ceylon, p. 199, t. LXIX (1899) ; Ent. Mo. Mag., XXV, p. 248 ; West Ind. Bull., Vol. XII (1912); Mem. Dept. Agric. Ind., II, ii, p. 131 ; South Ind. Ins., p. 5I3, f. 401 ; Proc. Second Entl. Meeting, pp. 34, $36,37,232,250$.

This species occurs in the Shevaroys, Anamalais, Palnis, Nilgiris, Coorg, and Mysore as a pest of coffee. It has also been found at Bangalore, and in the Nilgiris, on Citrus; at Coimbatore, on Egle, Carissa; and in the Nilgiris, on tea, guava, Citrus, Plumiera acutifolia.

\section{Eulecanium caprece, Limn.}

Mem. Dept. Agri. Ind., II, ii, p. 29.

This species has been found on almond trees in Baluchistan, where it kills off the branches and lastly the trees.

\section{Eulecanium persick, $\mathrm{Fb}$.}

Mem. Dept. Agric. Ind., II, ii, p. 31 (1308).

This species has been found at Jhelum, on Morus indica.

\section{Paralecanium expansum, Green.}

I. MI. N., IV, i, p. 9 (1896) : Mem. Dept. Agri. Ind., II, p. 29 (1908); South Indian Coccidæ (MS).

This species has been found in Mysore, on Ficus retusa.

\section{Saissetia depressa, Targ.}

Targioni-Tozzetti, Coccidæ, p. 29 (1869); South Indian Coccidæ (MSS .

This species has been found at Coimbatore, on plantain leaf.

\section{Saissetia hemispharica, 'Targ.}

I. M. N., I, p. 117 [L. coffece]; South Indian Coccidæ (1IS); Bom. Jour., XXIII, p. 136 (1914) ; Mem. Dept. Agri. Ind., II, ii, pp. 129-130 ; Proc. Second Entl. Meeting, pp. 214, $232,246,250$.

This species has becn noted in South India, on coflee, ferms, tea, guava, Taberncemontana, loquat; at Thana (Bombay), and in the Konkan, in pomelo (very serious on pomelo plants at Rajapur, Ratnagiri Dis- 
trict); Manickganj, on Trichosanthes auguina; and in North India, on guava, Thunbergia, Trichosanthes anguina.

Saisselia (Lecanium) nigra, Nietn.

I. N. N., I, ii, p. 117 (1889) ; Coccidæ of Ceylon, p. 229 ; Hem. Dept. Agri. Ind., II, ii, pp. 31, 130 ; South Ind. Ins., pp. 514-515, f. 403 ; Proc. Second Entl. Meeting, pp. 36, 119, $124,230,256$.

This species has been found in South Mysore, on Juslicie; at Pusa, on cotton (at times bad), Ficus glomerala; at Calcutta, on Capparis sepiaria; at Coimbatore, on cotton, croton, H. esculentus, H. rosa-sinensis, Thespesia populneu, Hygrophila spinosa, sandalwood, Lausonia alba (News., Bull. Enl.Res., VIII, 130) ; in Timnevelly, on nutmeg shoots; at Ponna; and at Surat, on Capparis sepraria.

It is at times a bad pest of cotton and oceurs on castor also.

Saissetir olea, Bernard.

Coccidre of Ceylon, p. 227 (1899); Sonth Indian Coccidæ (ISS).

This species has been found at Coimbatore, on tamarind fruits Eimhth leaves and stem, IIygrophila spinose; in Coorg. on cofiee; and in Peliary, on Sesbania (aguthi).

\section{Arlenda japonica.}

Proc. Second Entl. Weeting, p. 152.

This species has been noted on sugarcane at Jabbalpur, Partabgarh and Foona.

\section{I.ecanium adeisi, Newst.}

Bull. Ent. Res., VII, p. 357 ; South Indian Coccide (NIS).

This species has been found at Coimbatore, on mango.

\section{Lecanium discrepans, Green.}

Coccida of Ceylon int. iii, p. 204; South Indian Coccida (MS).

This species has been found at Palacole (Godavari District), on mango :eaf.

\section{Lecanipm imbricans, Green.}

Ind. Mus. Nores, V, 94 (1903); Mem. Dept. Agrie. Ind., II, 130 ; South Ind. Ins. pp. 516-517, f. 406.

This species oecurs in the Hills of South India, on Cedrela loona. 


\section{Lecanium marsupiale, Green.}

Mem. Dept. Agri. Ind., II, p. 30 ; Coccidæ of Ceylon, pt. iii, p. 212 ; South Ind. Ins., p. 516, f. 405; Proc. Second Entl. Neeting, p. 300.

This species occurs in South Wynaad and Malabar, on pepper leaves; and in South Arcot, on Calophyllum.

\section{Lecanium mercarce, Green MS.}

South Ind. Coccidæ (MS).

This species has been found at Mercara (Coorg), on coffee.

\section{Lecanium signiferum, Gr.}

Coccidie of Ceylon, p. 197 (1899); South Indian Coccida (MS).

This species has been found at Golconda (Vizagapatam District). on plantain leaf.

Chionaspis decurvata, Cr.

Bom. Jour., XXII, p. 135 (1914) ; Proc. Second Entl. Meeting, p. 205.

This has been found on bamboo at Poona and on rice at Calcutta.

Chionaspis ditatata, Green.

Cocc. of Ceylon, pt. iii, p. 146, t. LI ; Mem. Dept. Agri. Ind., II, p. 36 ; Proc. Second Entl. Meeting, p. 228.

This species is recorded from Bangalore, on areca palms; Godavari, on leaf-sheaths of palmyra palm; Calcutta, on palms; and Poona, on mango and Ficus.

At Poona it is of common occurrence on mango, on both surfaces of the leaves.

\section{Chionaspis graminis, var divergens, Gr.}

Mem. Dept. Agri. Ind., II, ii, p. 37.

This was found at Bharwain (Hoshiarpur), on Andropogon sorghem.

\section{Chionaspis mami, Gr.}

=Chionaspis prunicola var theae, Mask.

Mem. Dept. Agri. Ind., II, ii, p. 37 ; Proc. Second Entl. Mecting. p. 26.

This has been found on tea in Assam and Darjiling and on Ficus sp. in the Kangra Valley. 
Chionaspis megaloba, Green.

Pusa, on Zizyphus jujubr leaves.

Chionaspis nilgirica. Green HS.

South Ind. Coceidx (MS).

This has been found in the Nigiris. on Lomillus.

Chionaspis varicosa, Gr.

I. M. N., I, p. 2. (1896); Coec. C'eylon, pt. ii, p. 146, t. L (1s69).

This has been reported from Sidapur (Coorg). on pepper stem, and from Ceylon, on Gelonimm lanceolatum.

\section{Chionaspis vilis, Gir.}

Ind. Mus. Notes. IV, i, p. 3 (1896); Coee. of Ceylon, pt. ii p. 140. t. XLVII (1899); Mem.-Dept. Agri. India, II. ii, p. 37 ; Proc. Second Entl. Mecting, p. 228.

This is known from Pusa and Bangalore, on mango; Kollegal: Coonoor, on Elcagnus; and from Ceylon, on T'itis lanceolaria and Loranthus sp.

Honcerdia biclaris. Comst.

Ind. Mus. Notes, IV, i, p. 2 (1896); Coce. of Ceylon, pt. ii, p. 152, t. LIV (1899); Mem. Dept. Agri. Ind. I, p. 354 (1907), II, p. 36 (1908); Mon. Brit. Coce., I, p. 190, t. XXI (1901) ; South Ind. Ins., p. 519, f. 410 (1914); Proc. Second Entl. Meeting, p. 37.

This has been recorded from the Nilgiris, on tea, and from Ceylon, on Cinchoma, coffee and Grevillea.

\section{Diaspis barberi, Green.}

Mem. Dept. Agri. India, II, p. 35; South Ind. Coecidx (MS).

This speeies has been found on Loranthus at Tanjore and Alamanda. (Vizagapatam District).

\section{Diaspis echinocacti, Bonehé.}

Ind. Mus. Notes, IV, 211 (1899) [D. calyptroides]; Mem. Dept. Agri. Ind. II, 36 ; Proc. Second Entl. Meeting, p. 41.

This species occurs in South India and at Manjri (Poona), on prickly pear (Opuntia sp.). 
Diaspis mangiferce, Green.

South Indian Coccidæ (MIS).

This species has been found at Alamanda (Vizagapatam District) on mango leaf.

\section{Diaspis rosce, Bouché.}

Ann. Soc. Ent. Fr., IX, p. 441 (1869); Brit. Cocc., I, p. 168, t. XIV [Aulacaspis].

This species has been found at Bangalore, on mango leaves.

\section{Hemichionaspis aspidistre, Sign.}

Ann. Soc. Ent. Fr. (4) p. 443 (1889) ; Ind. MIus. Notes, II, p. 17 (1891), III, V, p. 52 (1891) [brasiliensis]; Cocc. of Ceylon, pt. ii, p. 110, t. XXXII (1899); Mon. Brit. Cocc., I, p. 187, t. XX (1901) ; Proc. Second Entl. Meeting, pp. 262, 300 .

- This species has been found in Mysore, on areca, jak; Western Ghats (Maciras), on pepper berries; Nilgiris, on Ceara rubber ; Nalabar, on coconut leaves; Godavari District, on Citms leaves; Coimbatore, on Ficus leaves; and in Ceylon, on ferns, Acacir, mango, Capparis, and croton.

\section{Hcwichionaspis dracance, Cooley.}

Sepe. Bull. Mass. Expt. Sta., P. 57 ; South Ind. Coccidæ (IIS).

This species has been found at Vadanapalle (South Malabar), on areca palm; the young fronds are badly infested.

Hemichionaspis fici, Gr.

Mem. Dejt. Agri. Ind., II, ii, p. 38 (1908).

This species has been found at Pusa, on Ficus glomerata.

Henichionaspis minima, Cr.

Mem. Dept. Agri. Inc., II, ii, p. 38.

This species was found at Pusa on the underside of leaves of banyan (Ficus sp.). 
Hemichionaspis minor: Mask.

N. Z. Trans. XVII, p. 33 (1884) ; Coce. of Ceylon, ii, 1. 115, t. XXXIV (1899); Ind. Mus. Notes, V, iii, p. 128 (1903); Mem. Dept. Agri. Ind., II, Pp. 39-128; South Ind. Coccidie (MS).

This scale has been found at Cuddapah, on Agave; Bellary, on C'assire tora; Coimbatore, on tamarind; and Sibpur (Calcutta), on sann-hemp.

Hemichionaspis the Mask.

Ind. Mus. Notes, II, p. 60, t. I, fig. 2. (1891); Mem. Dept. Agri. Ind. I, p. 342 (1907); Sonth Ind. Ins.. pp. 520-521, f. 411 .

This species has been found at Coimbatore, on ponegranate leares in Ceylon, on tea; and in North and South India, on tea. Also on Psychoria and other plants.

\section{Jencespris irdice, Marlatt.}

B. J., XXIII, 135; Proc. Second Entl. Neeting. pp. 228-229.

This species has been recorded from Poona as occuring commonly on mango trees.

\section{Fioninia proboscidaria, Green. \\ Bull. Ent. Res., VIII, 133.}

This species was found in Jamaica, on Citnes imported from India.

Fiorinia thea, Gr.

Mem. Dept. Agri. Ind., II, ii, p. 39 (1808).

This species has been found at Calcutta, on C'itrus.

Aspidiolus (Sclanaspidus) arliculatus, Morgan.

Bull. Ent. Res., VIII, 133.

This species was found in Jamaica, on Citms imported from India. 
Aspidiolus camellia, Sign.

Ind. Mus. Notes, II, vi, p. 168 (1893) [Asp. flavescens]; B. J., XIII, p. 71 (1900) ; Mem. Dept. Agri. Ind., I, pp. 343, 353 ; Proe. Second Entl. Mecting, pp. 26, 37.

This species has been found in the Nilgiris, on tea; at Dodabetta (Nilgiris), on Ficus sp.; in Ceylon, on cinchona, Michalia, Acacia, Osbectiva and iry; and at Bangalore, on tea stems.

\section{Aspidiotus curcuma, Green MS.}

Bom. Jour. XXIII p. 135 (1914); Proc. Second Entl. Meeting, p. 295.

This species has been found at Poona, on turmeric rhizomes.

Aspidiotus cyanophylli, Sign.

Coce. of Ceylon, p. 51, t. IX ; South Ind. Coccidæ (IIS).

This species has been found in the Nilgiris, on plantain leaf, Ceara rubber; and in Ceylon, on tea, cinchona, palm [?].

Aspridiotus cydanice, Comst.

B. J. XIII, p. 71 (1900); South Ind. Coccidie (MIS).

This species has been found at Bangalore and Coimbatore, on grape, fig, pear; at Coimbatore, on fig fruit; and in Ceylon on Ficus carica, Citms decumena, Cycas, Cinctus, palms, tea steins.

It is widely distributed, being know 1 from Florida, Sandwich Islands, British East Africa, Uganda, Gold Coast, Jamaica, South India.

\section{Aspridiolus destivector, Sign.}

Ind. Mlus. Notes, III, i, p. 66 (1893); Bom. Jour. XIII, p. 70 (1900), XXIII. p. 134 (1914); South Ind. Ins., p. 518, f. 408 ; llem. Dept. Agri. Ind., II, ii, p. 33 (1908) ; Proc. Second Entl. Ileeting, pp. 229, 239, 260, 300.

This species has been found at Nadiad, on mango leares; Tinnerelly and Coimbatore, on coconut; Anantapur ; in the Laccadive Islands, on coconut; in Bombay, on mango; in Ceylon. on tea, pepper, Ceara.rubber, plantain leaf, Loranthus; in Cochin, on cuconut leaves; at Moorathi (Wynaad), on coconut; and at P'usa, on plantain leaves and mango leaves.

It oceurs commonly on coconut, mango, castor, banana, guava, screw-pine, Ceara rubber and Hcvea brasilensis, and is often a bad 
pest of coconut. It is very widely distributed and is known from British Guiana, Zanzibar, South Africa, Britislı East Africa, Uganda, and the Gold Coast.

$$
\text { Aspitiotus dictyospermi, Morg. }
$$

Ind. Mus. Notes, IV, p. 119 (1899) ; Bom. Jour. XIII, p. 68, XVI, p. 345 ; South Ind. Coccidæ (MS).

This species has been found at Bancalore, on Dendrobium Coconada, on Mimusops elengi; in Ceylon, on Cyeas, Opuntia and Calo. phyllum; and in North India, on tea.

\section{Aspidiotus hartii.}

Proc. Second Entl. Meeting, p. 295.

Specimens on turmeric rhizomes at Poona were identified by Mr. Green as $A$. hurtii, which is a West Indian species; and possibly the identification was a mistake for $A$. curcumce.

\section{Aspidiotus latanier, Sign. \\ A. cydonice, Gr.}

Mem. Dept. Agri. Ind., II, p. 33 ; Bom. Jour. XIII, p. 69 ; South Ind. Coccidre (MiS).; Proc. Second Entl. Meeting, pp. 214, 232, 239, 257.

This species lias been noticed at Combatore, on Ficus carica, sissal hemp, Carissa carandas; Hadras, on Nerimm orlomm; Coonoor, on peach ; Calcutta, on Pleanir sp., Bombay, on Citms, bamboo, Poinciana regia; Pusa, on Zizyphus jujuba, Xylophylla clongata, Dulbergia sissu; Bangalore, on guava leaves, tamarind fruit pods; Muzaffarpur; and Poona, on orange leaves.

It is also found on tamarind fruits, plantain leaves, Ficus curica, Dulbergia sissu, guava, Xylophylla elongata, Zizypleus jujuba.

\section{Aspidiotus orientulis, Newst.}

Ind. Mus. Notes, II, r, p. 26 (1894), IV, 4 (1896) [osbechice]; B. J., XIII, p. 69 (1900), XXIII. p) 135 (1914); Proc. Second Entl. Meeting, pp. 216, 234, 239, 257, 266.

This species has been found at Pusa, on plantain leaves, Cassin fistula, Ficus religiosa, Mclia azadiachta, Zizyphus jujuba, D. sissu; in South India, on tamarind fruits; Bombay, on roses; Ceylon, on Osbeckia sp.; Guntur, on Solanum melongena; Poona; Ahmadnagar, 
on roses, Cycus rcroluia ; Calcutta, on Phonix sp. ; Alleppey (Travancore), on coconut palm; Damda (C. P.), on rose; Bilaspur, on guava leaves, pomegranate leaves.

Also recorded on Aegle mamelos and Tamaindus.

Aspidiotus tamarindi, Green MS.

Proc. Second Entl. Neeting, p. 257.

This species occur commonly at Coimbatore, on tarnarind.

Pocridumidir Milobitifomis, Green.

Ind. Mus. Notes, IV, i, p. 41 (1896); Coce. of Ceylon, pt. i, p. 41, . IV (1896); B. J., XIII, p. 66 (1900): Bull. Ent.

Res. VIII, 132; Proc. Second Entl. Meeting, p. 229.

This species has been found at Vadanapalle (South Malabar), on 1.era; Coconada, on Mimusops elengi; Coimbatore, on mango; Pundaluoya (Ceylon), on Dalbergia champiomii and Ixora coccinea; and a: Pusa, on mango leares.

\section{Chrysomphalus aonidum (ficus).}

Ind. Hus. Notes, IV, ii, p. 69 (1896) ; B. J., XIII, 69 (1900) : Cocc. Ceylon pt. i, p. 43 (1896); Mem. Dept. Agri. Ind., II. p. 33 (1908); Proc. Second Entl. Meeting, pp. 211, 236 , 262 ; South Indian Coccidæ (MIS).

This species has been found at Pusa, on bamboo leaves; Penulionda (Anantapur District), on Ficus; Coimbatore, on mango rine (stems); Sonth Mlalabar and Nilgiris, on Citrus leaves; Cochin coast, on Pandanus; Calcutta, on Phomix sp., B Bombay, on Areca catechu and orange; Khed (Poona District); Sirsi (Kanara District); and at Poona, on palms.

\section{Chrysomphalus aurantii, Mask.}

N. Z. Trans. XI, p. 199 (1878) ; Coccidre of Ceylon, pt. i, p. 58 ; Bom. Jour., XIII, p. 71 (1900); Hem. Dept. Agri. Ind., II, ii, p. 134; Proc. Second Entl. Hecting, pp. 214, 266.

This species has been found at Palghat (Malabar), on rose bush: Godavari District, on jasmine leaves; in Nortil India, on rose bush; in Ceylon on agave, pomelo, oranges; in Jamaica, on Citrus imported from India; at Pusa, on rose stems, orange leaves and stems; Bombay, on Cycas circinalis, Cycas recurrata; Damda (Central Provinces), on rose; and at Myitkyina (Burma), on pomclo and orange leares. 
It is a widely distributed species, recorded from Australia, New Zealand, America, British East Africa, Sonth Rhodesia, South Africa, Tasmania, Fiji.

Chrysomphalus rossi, Msk.

Cocc. Ceylon, pt. i, p. 45, t. VI (1896); Proc. Second Entl. Meeting, pp. 232, 234.

This species has been found at Combatore, on Curissa carandas; Coco nada, on mango leaves; Poona, on Burringlonia aculangula; in Ceylon, on Cyees sp., Capperis: and at Bilaspur. (C. P.), on guava and pomegranate leaves.

Chrysomphalus triglendulosus, Gr.

Mem. Dept. Agri. Ind., II, pp. 33-34 (1908).

This species has been found at Hahableshwar (Bombay); and at Bangalore and Malabar, on jak leaf.

Lepidosuphes (Mylitaspis) beckii, Newst.

South Ind. Coccide (MS).

This species has been found at Trivandıum, on pepper leaf.

Lepidosaphes crythina. Rutherford.

Bull. Ent. Res., V, p. 264.

Lepidosaphes (Hytilaspis) lasianthi, Gr.

Men. Dept. Agri. India, II, ii, p. 134 (1908).

This species has been found at Calcutta, on crotons.

Lepidosaphes (Mylikspis ?) pallida, Green.

Ind. Mus. Notes, IV, p. 5 (1896); South Ind. Coccidæ (IIS).

This species has been found at Ramchandrapur (Godavari District), on guava leaí.

Lepidosaphes (Myilaspis) piperis, Green.

Mem. Dept. Agri. India, II, p. 34 (1908); South Ind. Insects, p. 519, f. 409; Proc. Second Entl. Mecting, p. 300.

This species occurs in the Wynaad and probably all along the V'estern Ghats as a local minor pest of pepper.

VOL. I 
Parlatoria catianthina, Berl and Teo.

Rev. Pat. Veg., III, p. 346 (1895); South Indian Coccidx (MS).

This species has been found in Madras, on oleander.

Parlatoria mangifera, Marlatt.

Bull. U. S. Bur. Ent. (T. S.) 16 pt. ii, p. 28 (1908); South Indian Coccidæe (MS).

This species has been found in the Godavari District, on a palmyra leaf-sheath.

\section{Parlatoria pergandii, Comst.}

Bull. Ent. Res., VIII, 133 ; Proc. Second Entl. Meeting, p. 299.

This species has been found in Jamaica, on Citrus imported from India; and in India at Bangalore, on grape vine stems; and Alwar (Rajputana), on mango leaves.

Parlatoria proteus, Curtis. var. mylilaspiformis, Gr.

B. J., XVI, p. 349 (1905); South Ind. Coccidæ (MS); Gard. Chron. p. 676 (1843) ; Mem. Dept. Agri India, II, ii, p. 35 (1908).

This species has been found at Bangalore, on a species of orchid; in the Konkan, on Garcinia indica; and in Bombay, on Cycas recurvata, Draccuna leaves, Kantia.

Parlatoria (Websteriella) zizyphus, Lucas.

Ind. Mus. Notes, III, p. 102 (1903); South Ind. Coccidæ (MS); Bull. Ent. Res. V, p. 233 (1914).

This species has been found at Coimbatore, on Citrus leaves; Calcutta, on Citrus; and in Jamaica, on Citrus imported from India. (Bull. Ent. Res., VIII 133).

\section{THYSANOPTERA.}

Nоте.-As this group is dealt with elsewhere in a paper by Mr. Ramakrishna Avyar (seo pages 618-621), it is not included here.]

\section{ORTHOPTERA.}

\section{ACRIDIID}

(Unidentified Tettigid).

This small Tettigid grasshopper occurs at Pusa as a minor pest of cabbage. 
Acride turite, Linn.

Kby., F. I. Aerid., p. 98 ; S. Ind. Ins., pp. 524-525, f. 416.

This species oceurs throughout the Plains and is found on miscelianeous erops, but is searcely a pest.

\section{Aswathamanus cylindricus, Kby.}

Kby., F. I. Acrid, pp. $101-102, \mathrm{ff} .82,83$.

This species is common at Pusa on grass, from July to November. It is doubtful whether it is really a pest.

Phlaroba cinctalis, Kirby.

Kby., F. I. Acrid, p. 105.

This species is common at Pusa on grass, sweet-potato, ete., in July and August.

Aiolopus tamulus, $\mathrm{Fb}$.

Epacromia dorsatis, I. M. N., III, v, p. 73, figs; Lefroy Ind. Ins. Life, p. 83, f. 21.

Epacromia tamulus, Fletcher, S. Ind. Ins., p. 525, f. 417 ; Proc. Second Entl. Neeting, pp. 72, 98, 160, 180, 186, 190, 191, 196, 199 .

Eolopus tamulus, Kby, F. I. Acrid, p. 122.

This grasshopper oceurs throughout the Plains of S. India and is especially common in the Tinnevelly, Ramnad and Madura distriets. It attacks ragi, cholam, cumbu, dhaincha, cotton, rice, maize, wheat, marua.

We have it from Peshawar, on maize; Munshiganj and Pusa, common on grass.

Aiolopus affinis, Bol.

Eolopus affuis, Kirby, F. I. Acrid., pp. 122-123, f. 92.

This species is recorded from Madura and Bandra by Kirby, and we bave it from Garlisankar (Punjab), on sugarcane; Pusa, comnon on grass; Nasirabad Tahsil (Baluchistan), great damage to juar, August 1917.

Stauroderus bicolor, Charp.

Kirby, F. I. Acrid., p. 127, f. 93.

This species occurs commonly throughout India and Burma, on grass, etc. 
Heteroptemis respondens, Wlk.

Kirby, F. I. Acrid., pp. 141-142, f. 101.

This species occurs throughout India, Burma and Ceylon and is presumably a minor pest of low-growing crops, although it never seems to have been reported as doing damage.

Edaleus nigrofasciatus, Sauss.

Kirby, F. I. Acrid., p. 143.

This species occurs throughout India and Ceylon. We have it from Pusa, on grass and juar; Dharwar ; and Trichinopoly.

Gastrimargus marncratus, 'Thnb.

Kirby, F. I. Acrid., p. 145, f. 94.

This species is recorded by Kirby from Baltistan, Nepal, Garhwal, Sylhet, Bengal and the Shevaroys. We have it from Pusa, Chapra, Surat and Bandra. At Pusa it has been found on paddy and lucerne.

Locustu danica, Linn.

Kirby, F. I. Acrid., pp. 146-147, f. 94.

This grasshopper occurs throughout the Indian Empire. We have it from Pusa, on paddy (in numbers), on grass and oats in November 1906 ; also a few at Pusa in February 1917.

Acrotylus inficila, Wlk.

Kirby, F. I. Acrid, pp. 152-153.

This species is recorded fiom North Bengal and Ceylon. It is a common species at Pusa and at hiuzaffarpur has been found injuring cabbage and caniflower. We have it also from Koilpatti, on cumbu.

\section{Chrologonus sp.}

Kirby, F. I. Acrid; pp. 161-167; S. Ind. Ins., pp. 528-529, t. 49 ; Proc. Second Entl. Neeting, pp. 49, 66. 79, 86, 90, $95,98,160,181,186,191,193,269,274$.

Species of Chrotogonus. (whether of one or more of of which species I cannot say) occur throughout the Plains of India, and are often serious pests of young crops (tobacco, juar: wheat, etc.). They are best dealt with by bagnets. 
Aularches miliaris, L.

Kirby, F. I. Acrid., pp. 168-169 ; S. Ind. Ins. p. 526, f. 418 ; Proc. Second Entl. Meeting, pp. 28, 77, 200.

Aul. punctatus, Drury; Kby., F. I. Acrid., pp. 169-170, f. 112. Aul, scabiose, Fb. ; Kby., F. I Acrid. p. 170.

Recorded from Nepal, Sikkim, Orissa, Bombay, Coonoor, Ceylon. We have it from the Shevaroys, Nilgiris, Vizagapatam and Coimbatore. It is found on coffee, coconut and Erythrina, but does little damage as a rule. According to Green, the form scabiosce has been found at Veyangoda (Ceylon) defoliating Erythrina, areca-nut, coconut and various shade trees. We have specimens of punctatus from Burdwan, on jute; and Lashio (Upper Burma).

Kirby splits this up into three species, miliaris, punctatus and scabiosce, but it seems impossible to separate them satisfactorily.

\section{Pocilocenus pictus, $\mathrm{Fb}$.}

Kirby, F. I. Acrid., pp 172-173, f. 113 ; S. Ind. Ins., pp. 526527. f. 419 ; Proc. Second Entl. Meeting, pp. 136, tab. etc.

This species is recorded by Kirby from Quetta, Karachi, Madras,

It occurs thronghout the Plains of India and is found on Calotropis especially. It has been found to damage young Ficus carica in Bellary.

Atractomorpha crenulata, $\mathrm{Fb}$.

Kirby, F. I. Acrid., pp. 181-182 ; S. Ind. Ins., p. 528, f. 421 ; Proc. Second Entl. Meeting, pp. 98, 270, 271, 288, 296, 298, tab.

This species occurs throughout the Plains of India, and is found especially on tobacco, brinjal, Amaranthus and other vegetable crops, of which it is often a decided pest.

\section{Atractomorpha scabra, Thub.}

Kirby, F. I. Acrid., p. 182.

This species is only recorded from Ceylon by Kirby. We have it from Hambantota (S. E. Ceylon) ; Tricomali: Pusa, on grass; and from Dacca (in numbers). 


\section{Orthacris sp.}

S. Ind. Ins. p. 527, f. 420 ; Kirby, T. I. Acrid., pp. 184-188; Proc. Second Entl. Meeting, pp. 90, 181, 187, 199, 288.

This species has been found in Coimbatore, Timnevelly, and Bellary and occurs probably throughout the Plains of South India. It is found on most low-growing crops, as a minor pest.

\section{Colemania sphenarioides, Bol.}

Kirby, F. I. Orth., p. 189 ; S. Ind. Ins., pp. 527-528, t. 48 ; Proe. Second Entl. Meeting, pp. 51, 59, 160, 181, 187, 201.

This species is found in Mysore, Bellary, Kurnul, and was a bad pest of most low-growing crops from 1910-1913, but lately it has been little heard of. It has been found in the Ahmednagar district, on bajra.

\section{Oxya velox, Fb.}

Kirby, F. I. Acrid., p. 199, f. 116 ; S. Ind. Ins., p. 533, f. 426 ; Proc. Second Entl. Meeting, pp. 148, 166, 181, 190, 202.

This species occurs throughout the Plains of India as a minor pest of paddy especially, but it is also found on juar, sugarcane, maize and other crops.

The eggs are laid on bases of Sorghum stems.

$$
\text { Hieroglyphus bilineatus, Kby. }
$$

Kby., F. I. Acrid., pp. 202-203.

"Bengal. Mr. Lefroy suggests that this is a micropterous form of H. banian" (Kirby).

Specimens from Mandevi, Surat District, on crops in October 1903, scem to agree with this description, but how far it is a distinct species * seems doubtful.

I do not know whether this is identical with the Hieroglyphus bitineatus, Sauss. MS., referred to by Bolivar (B. J., XXIII, 174); if so, it should apparently be placed in the genus Hieroceryx.

\section{Hieroglyphus nigrorepletus, Bol.}

S. Ind. Ins., pp. 531-532, f. 425; B. J., XXIII, 172-175, ff. 1, 2 (June 1914) ; Proe. Second Entl. Meeting. pp. 181, 201.

Hieroglyphus bettoni, Kirby, F. I. Acrid., pp. 203-204, ff. 118119.

This species oceurs in Bellary, Kurmul, and Guntur and is found on juar and tenci as a minor pest occurring in small numbers. We have 
it also from Barban (Bombay); Kaira (Bombay) "on crops"; and Lonavĩa, on rice, 21 st November 1905.

\section{Hicioglyphus banian, $\mathrm{Fb}$.}

Kirby, F. I. Acrid., p. 204: S. Ind. Ins., p. 531, t. 50, ff. 1-3 ; Proc. Second Entl. Meeting, pp. 147, 166, 181, 190.

This species occurs throughout the Plains of India as a pest of rice usually and in the United Provinces especially of sugarcane. It is possible that several distinct species are mixed up under this name. Faridpur specimens show very reduced black marks on the sutures on the sides of the prothorax.

\section{Hieroglyphus concolor. Wlk.}

Kirby, F. I. Acrid., pp. 204-205.

This species is recorded by Kirby from Kanara and Sylhet. It "appears to be commoner than banian, with which it is probably often confounded" (Kirby). According to Kisby, the antemw in banian are wholly green, in concolor black. pale at base and at ends of joints, and the pronotum is smooth in banian, finely punctured in concolor.

In spite of Kirby's assertion, we seen to have no specimens that can be separated as concolor, and I cannot distinguish this from banian. The antennæ seem variable in colour even in specimens of the same brood reared from the egg.

\section{Spathostermum prasiniferum, Wlk.}

Kirby. F. I. Acrid., p. 208 , f. 121.

According to Kirby this species is recorded from Bombay and Pusa and is very abundant and variable. We have it from Dacca.

Orthacanthacris agyptia, Limn.

Kirby, F. I. Acrid, p. 225.

This species is recorded from Quetta. We have it from the Punjab, on cotton.

Orthacanthacris flavescens, $\mathrm{Fb}$.

Kirby, F. I. Acrid., p. 225-226, f. 127.

This species is recorded by Kirby from Madras and Ceylon. 
Orthacanthacris succincta, Linn.

Kirby, F. I. Acrid., pp. 227-228, f. 125 ; S. Ind. Ins., p. 530, f. 423. [Cyrtacanthacris].

This species occurs throughout the Plains of India and Ceylon, and $s$ the well-known "Bombay Locust" dealt with in Entomological Memoir, Tol. I, No. 1.

\section{Cyrtacanthaeris ranacea, Stoll.}

Kirby, F. I. Acrid., p. 231 ; S. Ind. Ins., pp. 530-531, f. 424 ; Proc. Second Entl. Meeting, pp. 88, 90, 103, 199.

This specie; occurs throughout the Plains of India on almost all crops, but is usually found in small numbers only. It is a minor pest of cotton and other crops and has been reared from the egg on cotton at Pussa.

Schistocerca tatarica, Limn.

Kirby, F. I. Acrid., pp. 232-233, f. 128.

This species is recorded by Kirby from Sind, Nepal, Assam, and Ceylon. It occurs all along the. Western Ghats and the Himalayan Region, appearing in migratory hordes and doing immense damage.

\section{Teratodes monticollis, Gray.}

Kirby, F. I. Acrid., p. 235 ; Ind. Ins. Life, p. 88, ff. 28, 29 ;

Proe. Second Entl. Meeting, p. 235.

This species is recorded by Kirby from Bombay and Ceylon. It has been sent in to us from Bengal as attacking grape-vine leaves, but is probably a mere casual visitor or feeder on grape-vine. It seems to be commoner on the Bombay side.

\section{Eucoptacra pramorsa, Stal.}

Kirby, F. I. Acrid., pp. 240-241.

This species is recorded from Bandra, Madura, Bhamo and Tenasserim, by Kirby. It is apparently a common species and is probably at least a minor pest.

\section{Catantops sp.*}

Kirby, F. I. Acrid., pp. 246-254 ; S. Ind. Ins., p. 529, f. 422.

This species occurs in Tinnevelly and Ramnad as a local and sporadic pest of cotton (damaging bolls, flowers and leaves) and grasses. 
Heteracris illustris, Wlk.

Kirby, F. I. Acrid., p. 263.

This species is recorded from South India by Kirby. It occurs fairly commonly at Pusa, on grass.

\section{Heteracris sp.}

This species mas found at Pesharar, in numbers on maize in October 1914.

Chorocdocus capensis, Thnb.

Kby., F. I. Acrid., pp. 263-264.

This species is recorded by Kirby from the Himalayas, Calcutta, Coromandel Coast, Ceylon, Bhamo. It is a widely distributed and common species and is presumably a minor pest.

\section{Heteracris elegans, Wlk.}

Kirby, F. I. Acrid, pp. 264-265, f. 139.

This species is recorded by Kirby from North India. We have it from Surat.

\section{Tylotropidius raricornis, Wlk.}

Kirby, F. I. Acrid., pp. 265-266, f. 140.

This species is recorded by Kirby from S. India, Ceylon, Karen Hills. It is widely distributed and common and is probably a minor pest. We have it from Pusa.

GRYLLID E.

Gryllotalpa africana, Pal.

S. Ind. Ins., pp. 534-535, f. 428 ; Proc. Second Entl. Meeting, pp. $140,270$.

This species is apparently abundant throughout India. The Pusa collection contains specimens from the Palnis, Cuttack, Pusa, Rangpur, Rajapati, Khasis, Shillong, Abbottabad, Srinagar, Hoshangabad, Igatpuri and Bombay. Possibly more than one species i- included under this name. We have also a very much larger species from Shiraz, Persian Gulf, named by Lefroy as $G$. gryllotalpa and found damaging all forms of root crops and flowers by burrowing and destroying the points of the roots. 
G. africuna has been noted at Pusa to damage canc-shoots in February and March, gnawing into shoots at junction with sett; at Dacea and Pusa, shight damage to seedling tobacco; stated to damage opium poppy plants by cutting them off when considerably advanced in growth (Ind. Mus. Noles, II, vi, 172) ; Jorhat, damaged barley crop (Farm Supdt., letter of 8th December 1913); Kumowl Factory, Tirhut, reported to be doing great damage to newly-sown Natal indigo by burrowing around roots (letter from F. Murray, 3rd November 1906).

\section{Brachyliypes portentosus, Licht. (=achatimus).}

S. Ind. Ins.. p. 536, f. 430 ; Proc. Second Ent. Neeting, pp. 79, 83, 98, 132. 270, 278, 281, 290.

The distribution of this species appears to be rather restricted in India and the exact limits are not clearly known. It occurs abundantly throughout Bengal and Bihar, but in Madras only at Nellore, where it was found damaging Casuarina seedlings.

The young emerge during the first half of October at Pusa, and attain the adult stage about the middle of June.

It is a serious pest of indigo, Sescmum, cotton. jute, tobacco, cabbage, cauliflower, and chillies.

It did serious damage to rice-crops in Comilla in June 1893 (Ind. Mus. Notes, III, v. p. 78) and has been noted at Jalpaiguri, destroying cauliflowers at the Gaol, 22nd October, 1914: in Nepal, much damage to Residency lawns by burrowing, 3rd September 1912 ; Telhara Indigo Concern, Bairagnia, Champaran, indigo ravaged, 27th April 1911; Pabna, serionsly damaging crops, especially young jute, 27th April 1910 ; Nalda, young mango-graft shoots 2Sth May 1909; Dacca, much damage to jute and paddy, 23rd April 1907; Bogra, young jute plants much injured, 24th April 1906; Myitkyina, much clamage to gardens and forest nurseries, 2nd October 1903.

\section{Liogigllus bimaculatus, de Geer.}

S. Ind. Ins., p. 537, f. 431 ; Entl. Note, 99 ; Proc. Second Entl. Meeting, pp. 50,62.

This species occurs throughout the Plains of India. It is partly predaceous, fecding on caterpillars and grasshoppers, and partly vegetarian, feeding on decaying vegetation and growing plants. It has been found to gnaw into gram pods and eat the seeds, sometimes doing considcrable damage, and it attacks lentil pods in a similar way in the Central Provinces, eating the seeds. 
Tn Khandesh it was found destructive to potato plants, cutting stems near soil-level (Ind. Mus. Notes, III. ii, 97) [? Brackytrypes], and at Jabbalpur, attacking gram. masur and linseed and did 4 to 6 annas damage. (Mr. Misrais Note in File).

$$
\text { Gryllus viator. Kirby. }
$$

Kirby, Cat, Orth., II, 32 (1906).

Gryllus melanoceplualus, Sanss., Hem. Soe. Geneve, XXV, 174, t. 12 (x) ff. 1, 2 (1877) [nec Serv.].

Gryllus melanocephalus. Proc. Second Eutl. Meeting, pp. 98, 217.

[Note.-Serville's 6 . melanocephulus [O1th.. p. 34:2 (1839)] is also from Bengal. It is not quite eertain whether our species is saussure's or Serville's.]

This species occurs as a pest chiefly in the Punjab, attacking young cotton plants in May and June as a major pest. It is controlled by light traps and fires at night.

It is an occasional pest of young mango plants, and has also been reported from the Upper Sind Frontier, injuring young juar crops, July 1892. (Iml. Mus. Notes, III, v, 77); Orai (Bundelkhand), attacking young rabi crops (D. D. A.'s letter of Sth January 1909): Rajanpur Subdivison. l'mujab. attacking rap sced (Assistant Commissioner's letter, 25th May 1904) ; Mokameh Tal, erious pest of rabi clops, responsible fo damage of about 450 bighas of crop in 1912 (letter from $\mathrm{Mr}$. Woodhouse, ith June 1913).

\section{TSOPTERA.}

\section{TERMITIDE.}

\section{Microternes obesi, Holmgr.}

Holmgr, Entl. Mem. V. 159160 [obesi and anandi]; Proc. Second Entl. Meeting, pp. 194, 196, 281.

This termite is a scrious pest of wheat seedlings at Pusa, etc., and of wheat when coming into car at Hoshangabad. It also attacks cabbage and cauliflower at Pusa.

\section{Otontotermes parvidens, Holmgr.}

Entl. Mem., V. p. 154 ; Proc. Sccond Entl. Meeting, pp. 46-47.

This species was found on an estate on the Gauhati-Shillong road as a serious pest of Cajanus indicus, cating the roots. 


\section{Odontotermes bangatorensis, Holmg.}

Holmg. Entl. Mem., V, 151-152.

This species has been found at Hadagalli, nibbling roots of cholam.

Odontotermes obesus, Ramb.

Holmg., Entl. Mem., V, 146-149.

This species has been definitely noted from Quilandy (Malabar), damaging young coconut palms; Coimbatore, galleries on tree-trunks; Hadagalli, nibbling bark of small tree; Mysore City, on bark of Grevillea; Lyallpur, on tree trunk; Bankura, eating sugarcane setts.

\section{Proterimitide.}

Stylotermes fletcheri, Holmg.

Holmg., Entl. Mem., V, 142-143.

This species was found in the Shevaroys, burrowing in the rotten interior and in sound wood of a mango tree.

\section{Hodotermes viarum, Koenig.}

Hodotermes koenigi, Holmgren, Entl. Mem., V, 138.

This speeies occurs commonly at Coimbatore and sometimes does some damage to grass lawns by cutting of grass.

\section{3.-SOME INSECTS RECENTLY NOTED AS INJURIOUS IN SOUTH INDIA}

By T. V. Ramakrishna Aryar, B.A., F.E.S, F.Z.S., Acting Govemment Entomologist, Madras.

The latest connected record of the injurious insects of South India is the volume on Some South Indian Insects by Mr. Fletcher. In the preface to that publication the author writes thus:- "The list of croppests is not complete, and it must be clearly understood that it cannot be complete for many years, if ever. Every month new pests come to light, many of them altogether unknown even by name, and our lnowledge of old pests is augmented." These words are only too true ; for, since the publication of that volume in 1914, several new insects of economic importance have been noted in South India within the last three or four years. 


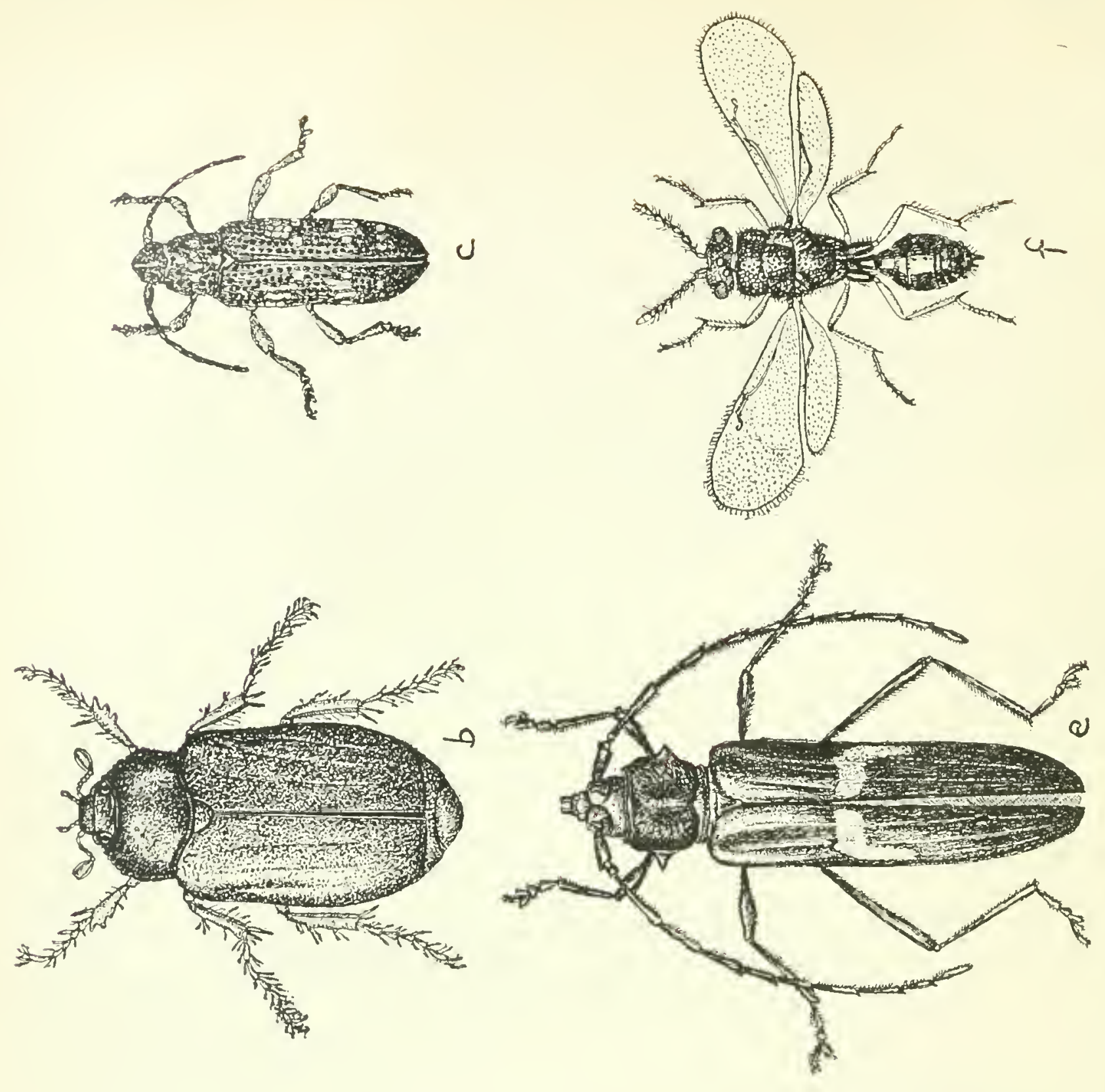

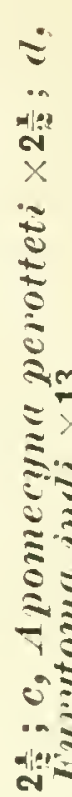

$x+$ c... ลั่ 잋 $0 \pi$ เป ะิ 도 $\leq \approx$ ำ x IU $\therefore$ हi $=\bar{\delta}$ $\frac{2}{2}$ ระ: 4
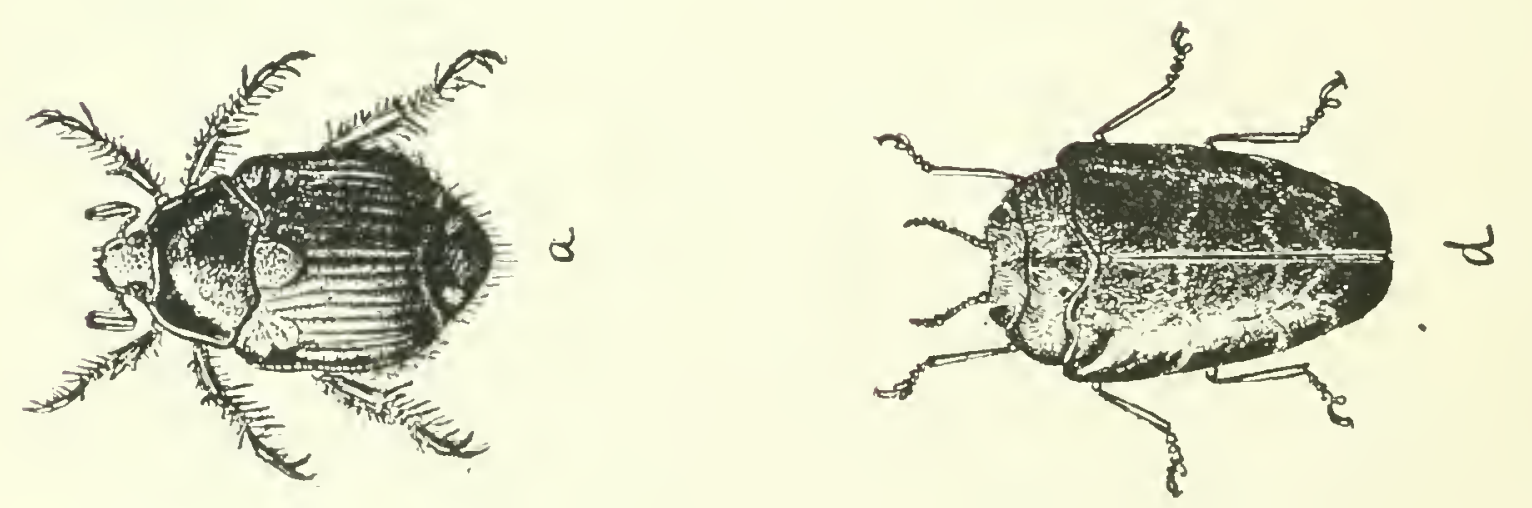

בิ 
In this paper I have attempted to bring together a very brief account of these recently noted forms. Of course, casual references and stray notes of some of these have appeared in reports and departmental papers but nowhere in a comnected and complete manner.

The list is neither complete (it can never be complete for many a long time to come), nor does it profess to give any detailed accounts of the different forms. It is more or less a skeleton list forming a sort of supplement to Mr. Fletcher's valuable volume, and the only reason for its publication is to bring together our scattered and necessarily incomplete knowledge of these forms into a connected shape as a sort of nucleus for future work. There is little doubt that, as our knowledge of these insects increases, it may be possible to bring out further papers containing detailed information on each of these forms. In the list, I have included not only those insects that have been recently noted as of some economic importance, but also others, which though already known and recorded, have not been sufficiently recognized as injurious in South India. The forms are arranged under their natural Orders and with regard to many which have not yet been scientifically identified, I have given popular names by means of which each might be recognized until it gets its scientific baptism.

\section{HyinenopterA.}

Eurytoma indi, Girault. (Plate 9, fig. f.) - This is a small wasp of the family Eurytomidxe inchuded in the large group of Chalcidid wasps. Nost of the insects of this group are parasitic on other insects and as such beneficial in many cases to the cultivator. This species, however, seems to be one among the exceptions. The adult insect is black with the abdomen shining: measures $2.25 \mathrm{~mm}$. It breeds inside seeds of dhaincha (Sesbunin agyptiaca) pods and destroys the seed. The insect was noted on the Coimbatore farm three years ago doing serious damage to a crop of dhaincha left for seed. A smaller insect, also a Chalcidid, Megastigmus indi, Gir., has been noted along with it and is believed to be a parasite on the seed-borer.

In general form and habits this borer appears very closely allied to the American 'Clover-seed Chalcid' (Bruchophagus funcbris, How).2

Philanthus rumakrishnce, Turner. (Plate 11, fig. 1.)--This fossorial wasp is one of the many insect enemies of the honey-bee (Apis indica) in the Hills of South India. I first noted this on the Bababudin Hills in

\footnotetext{
1 The name given to this inseet in the Report of the and Entomological Conference, Pusa, (p. 73), is a mistake.

¿Sco Monthly Bulletirs Calif. St. Com. Hort., Vol. II, p. 696 (1913).
} 
Nysore at an elevation of 4,000 feet. It has latterly been noted on the Palnis also. Numbers of the honey-bee are carried off by this wasp and stored in nests made in hard banks at the sides of hill roads. There is no doubt that hives of honey-bees are depopulated in this way by this insect. Interesting accounts of how species of these wasps hunt bees and store them, will be found in Fabre's interesting works.

Xylocopa temiscapa, Westw. In buildings where the roofing materials are of bamboo or weak and unseasoned wood this carpenter-bee causes considerable damage. The rafters and beams are riddled with holes inside which the insect breeds. Swarms of these insects are found hovering about the building all day long with their characteristic disturbing noise. I have collected the Meloid beetle Cissites debyi in the galleries made by this bee. This latter insect is beliered to be predaceous on the larvæ of the carpenter-bee.

Among other Hymenoptera already recorded as injurious, mention may be made of two well-known ants-Ccophylla smaragdina and Camponotus compressus. The former was recently found bad on the crowns of coconut trees in Sonth Kanara. It is found very hard to get rid of the nests on these trees; tree-climbers often suffer very much. The latter is chiefly found guilty of spreading colonies of scale-insects from tree to tree; this has been noted especially in the case of two Coccids on the Coimbatore farin, viz., Pulinaria maxima, Gr., and Anomalococcus indicus, Gr.

\section{Coleoptera.}

Holotrichia sp. (Plate 3, fig. b.)* This is a fairly big cockchafer beetle, chocolate-brown in colour. Mr. Arrow of the British Musenm, to whom it was sent, says that the species is new to the Museum. Thousands of these emerge from the soil at the hill-sides soon after the first summer rains on the Nilgiris. The grubs are generally found active from September to November. In certain years these do considerable damage to young cinchona seedlings. Thonsands of the adults may be caught at lights in May-June. Another known species, $H$.repetita, is occasionaly found with this species, but not in such numbers, on the Nilgivis.

I opillia chlorion, Newm. (Plate 9, fig. a.) 'This small pretty green insect is found in company with the big cockeluafer noted above, and the grubs too have the same habits, but are smaller in sire. Cockchafer grubs of sorts have now and then been observed also under cholam plants and other garden shrubs on the Coimbatore farm.

\footnotetext{
* Since described in Ann. Mag. Nat. Hist., July 1:19, p. 24, by Mr. Arrow as Rhizotrogus rufus.
} 
Anadasts ip. Within the past three or four yeurs the temi crop (Setaria ilatica) on the Coimbatore farm has been found subject to the attacks of a Languriat borer. The nature of the damage and the extemal srmptoms of the crop are similar to those caned by ordinary boress-the farling and gradual deatls of the shoots and ears, and leath of the plant. The beetle appears to be a species of Anatasus; another Frotylid which I lave noted as a borer till now is Fature lomgicomis, W.. breeding on dry and rotting Euphortia aniogurum plants (See Pletcher: p. 290). The lifo-history of this lemai beet lo has recently been worked out by my Assistant, Hr. P. I. Teaac." The egos are thrust into the stem at the nodes singly, a few inches abore the ground level. The grub feeds from inside and pupatos in the hollow: The beetle is small in size, about $6 \mathrm{~mm}$. in lengtl, and red and blue in colour.

Anthenus pimpinella, Fab., var. (Fig. 76 in Fleteher's book.) Silk and woollen goods are found subject to the attacks of a small Dermestid in South India. The beetle is very small, oval in shape and dark brown in colour with white patches on the elytra. The small dark hairy larva is found feeding on sills cocoons, woollens, brushes. ete. Anlinurs fuscialus has been reported more than once from Army clothing depôts.

Trachys bicolor. (Plate 9, fig. d.) The palas tree (Butea frondosa) is subject to the serious attacks of this Buprestid leaf-miner. In the montlis from December to March, when fresh leaves are put out by the bushes, every leaf is found mined and blistered by this borer. The beetle is comparatively small in size and dark bluish in colour. It is very crmmon in South Malabar.

A species of Trachys is referred to as a pest of jute in Bengal (vide Reporl of Second Entomological Meeting, p. 13t) but I do not know which species this one is.

Wire-Worms. Reports of Elaterid grubs attacking potatoes in the Hills have been recently received. The actual species concerned has yet to be bred out.

Th. Moringa stcm-borel. The larva, which in this case is a lengicorn borer, attacks the moringa tree (Moringa pterygosperma). The beetle is a typical Lamiad appearing more or less like one of the species of Monohammes. It is about $19 \mathrm{~mm}$. long and greyish-brown in colour. The insect is found occasionally serions. The life-history has recently been worked out by my Assistant Mr. T. V. Subramania Ayyar. [See paper No. 66 of these Proceedings.]

\footnotetext{
* Lee also Jir. Isaac's paper (No. 65 of these l'rocecdings).
} 
Chelidonium cinctum, Guer. (Plate 9, fig. c.) Mr. Anstead, the Deputy Director of Agriculture for Planting Districts, has recently found this insect attacking Citrus trees in the Mysore uplands. Probably it is similar in habits to the other well-known orange-borer of Coorg, Chloridolum alcmene. It may be the same or similar to one noted in Coorg by Fletcher (Sec Rept. of Second Entomological Meeting, p. 211).

The Morinda shoot borer. This insect is a very small pale-brown beetle, the whitish grubs of which are found attacking the growing terminal shoots of Morinda tinctoria plants. The presence of the pest is easily seen by the faded and drooping appearance of the young distal shoots; the latter turn black in course of time and drop down. The larva is a minute pale white grub; the pupa is also found in the same place. The bectle appears to be a Scolytid, having an oval prothorax and small brownish head tucked underneath the thorax.

The Kolingi pod beetle. (Plate 10, fig. g.) As a green-manure plant in wet areas, the kolingi or wild indigo (Tephrosice purpurea) is held in high esteem in South India. Seeds are regularly collected and even sold by the Department. The growing pods of this bush are attacked by a small beetle borer-an Anthribid, probably a species of Arcecerus - which eats away the seeds and makes the pod empty. The pupa is also found inside the attacked pod. The insect is found in Timnevelly, Tanjore and South Arcot districts. The adult bectle is very small in size, $2.5 \mathrm{~mm}$. long, pale greyish in colour and is almost similar in appearance to the kolingi seed. It is a very active creature.

Longitarsus nigripennis, Motsch. The grub of this small flea-beetle contributes a share to what is called the Pollu disease of pepper in North Malabar. The adult beetle is a very active small creature with the head and thorax ochraceous and the elytra bluish-black; the hind femora are extraordinarily thick. Eggs are thrust singly just under the rind of the growing pepper-berry; the small cream-white grub feeds on the inner contents of the berry and makes it hollow-this hollowing of the pepperberry, to whatever cause it is due, being called the Pollu disease of pepper. The mature grub drops down into the soil and pupates underground enclosed in an earthen cell. I am reading a separate paper on this inseet [Sec page 925].

There are also other species of flea-beetles which are often noted as sporadic local pests causing a certain amount of damage to crops in certain seasons. Of these the following are the chief :-

The Buel flea-beetle. This dark shining beetle has been noted in Coimbatore and Kollegal doing damage to the foliage of bael, Egle mamelos. They feed together in numbers and cause considerable 

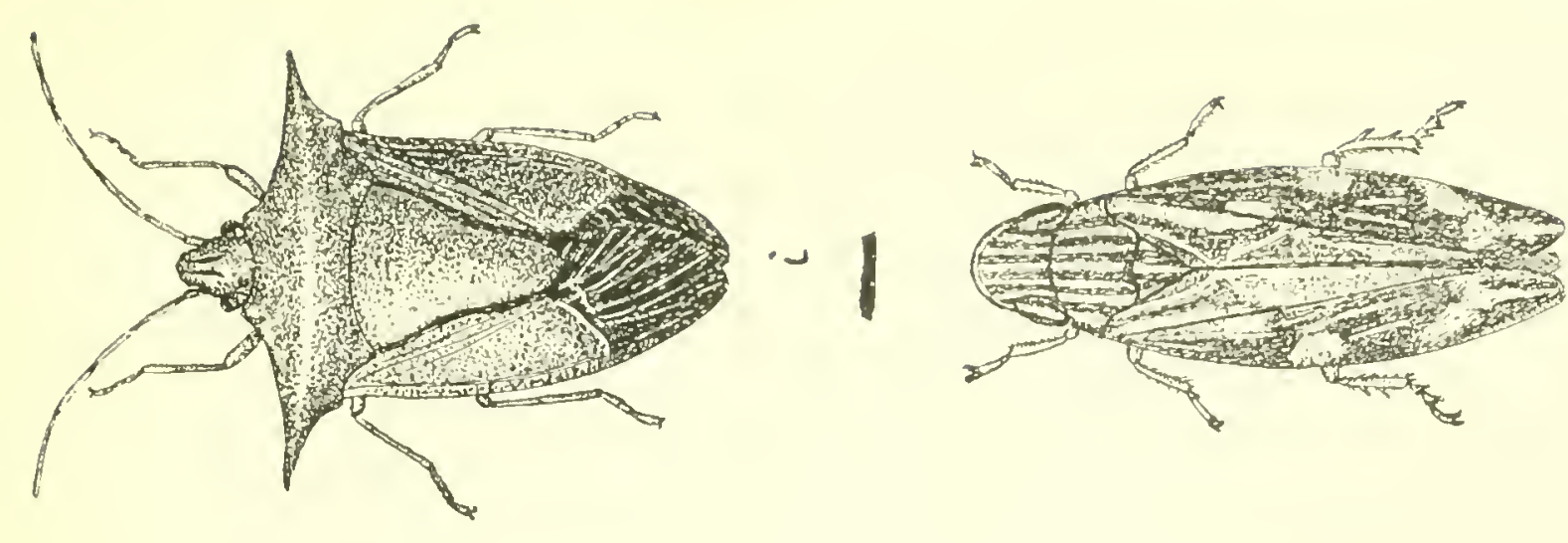

-
$\cdots$
$\cdots$
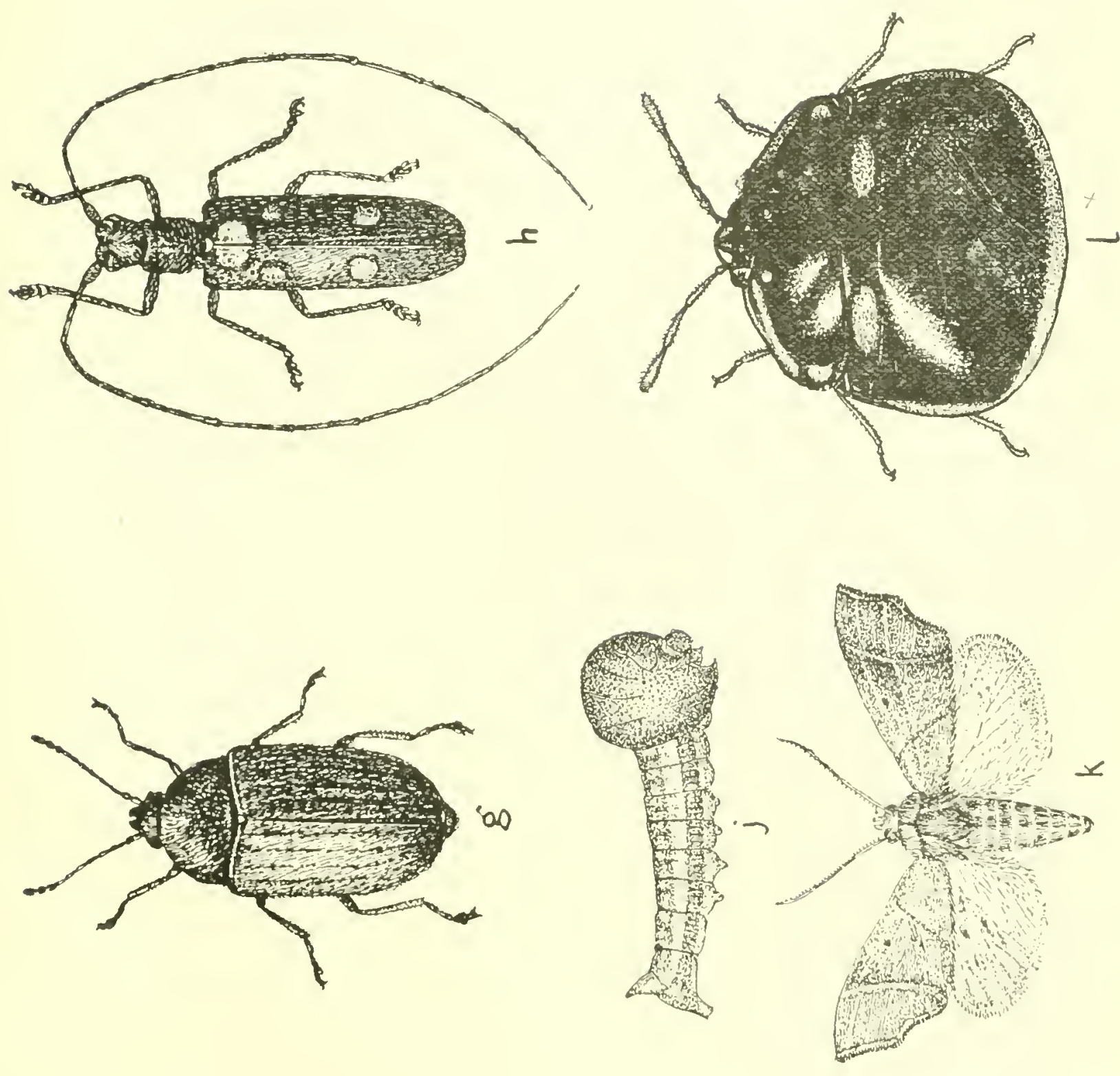

E

$\therefore$

$\ldots$

iv

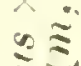

$\pm \approx$

$\equiv m$

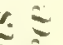

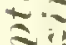

$\approx$

$=$

$\approx$

23

$\div \Sigma$

…

m-

$\bar{x} \cdot$

일

吾

흠를

ㅊ:

ㅊำ

紊

$\therefore \equiv$

क

क

$\div=$

次:

돌

들 



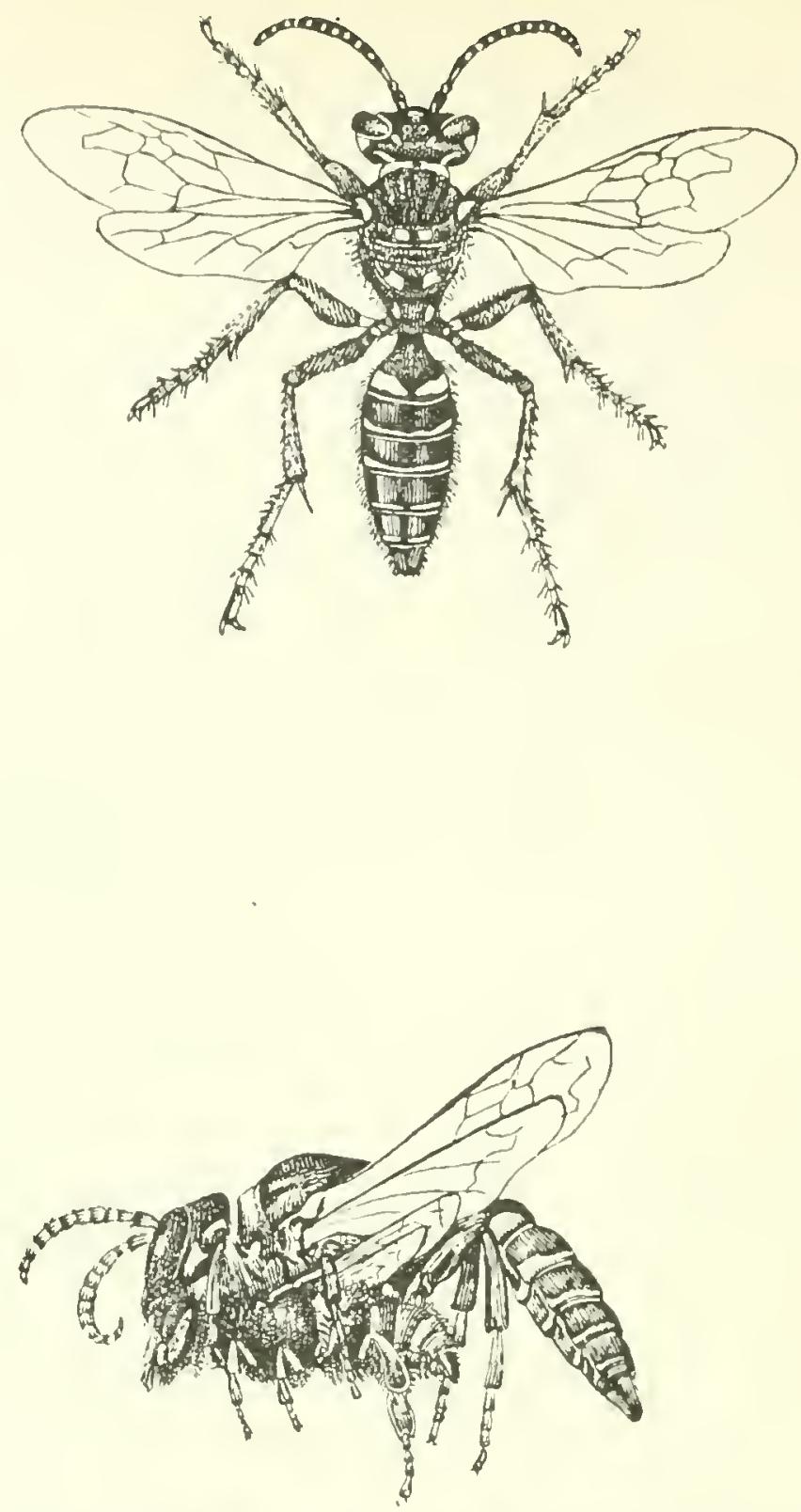

Fig. 1.-Philanthus belmalivishmox. Turner, $x 2$ ". The lower figure shows a specimen in flight, carrying off a honey-bee.

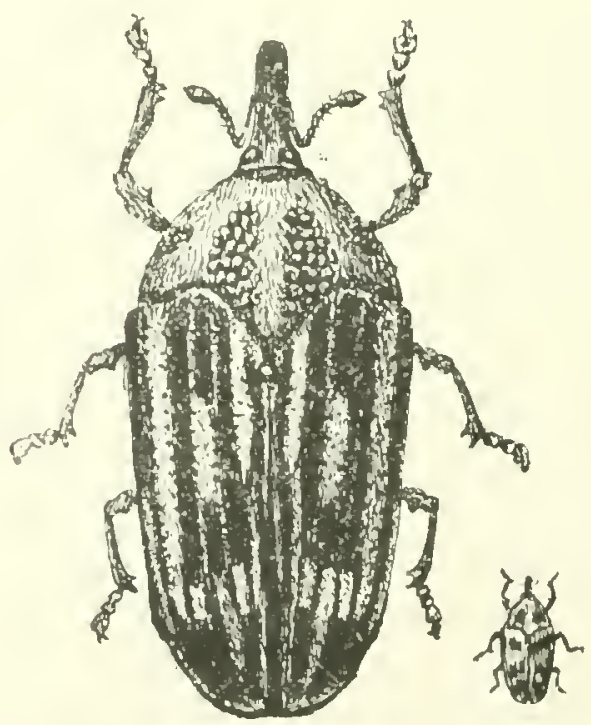

Fig. 2.-Ilrieles pictus, natural size and magnified $(\times 5)$. 
damage within a short period of time. It does not appear to be Clitea picte, Baly.

The Panivaragu flea-beetle. This small flea-beetle appears to be a specific pest of the millet Panicum miliare in Coimbatore; the larvio bore into the plant stem and often cause "dead hearts."

The Radish flea-beetle. This small very active bright-blue insect is found doing serious damage often to cabbage, radish and other eruciferous plants. It is also occasionally found on other irrigated crops but the insect is very partial to Crucifere. It appears to be similar to a flea-beetle which I remember to have collected on brinjal in Muzaffarpur' in October 1904.

Other flea-beetles are those found on sann hemp, castor, ete.

Green potato leaf-beetle. A shining green Galerucine beetle is found on the Nilgiris feeding on potato-leaves in some numbers. Similar beetles have also been noted on sweet-potato in Timnevelly and other places-but not as bad pests.

Several species of Myllocerus are now and then noted on varions cultivated crops but only a few of these species ever do any appreciable damage and even this is not of common occurrence. The following species may however be watched.

Myllocerus subfasciutus, Guer. This species is a grey insect commonly found on a variety of plants. Noted on brinjal, potatoes, apple, etc. Sometimes the insect causes serious damage to brinjal foliage in the Plains.

Myllocerus discolor. This weevil is the common greyish-brown species found on a variety of crops all over South India. It has been noted on maize, ragi, cholam, etc. In bad seasons and when the plants are young this weevil does appreciable damage to the crop, although in normal years the work of the insect is negligible.

Myllocerus dentifer, $F$. This pale-greyish beetle is occasionally found defoliating tenai (Selaria). cumbu, ete., in Sonth Arcot.

Myllocerus viridanus. This pretty green species is generally found on groundnut, castor, Hibiscus esculentus, etc. Stebbing notes this insect as a bad pest on teak in the Walayar forests. With this species is often found a smaller species, M. pretiosus, F.

Corresponding perhaps to the species of Myllocerus in the Plains we have one or two species of Sympiezomias on coffee, cinchona. etc., in the Hills. The species noted so far are S. fruter, S. cretaceus, and S. decipiens.

Alcides pictus. (Pl. 11, f. 2). This species of Alcides, which is not unknown in South India, has within the last two or three years taken to feed on lablab. The grubs and pupx are found infesting the main vines and some damage is done to the plant.

VOL. I 
Conarthrus jansoni, Woll. In the coastal tracts of Malabar a Cochin I have noted a small shining black beetle boring in numb into the bamboo framework of sheds and fences near houses. The sp bamboo pieces are badly tunneled in some cases. Fletcher has notec beetle of similar habits in Ceylon (Myocalandra exarata, Boh.), bu find that this inseet is not the same as the Ceylonese one.

The Jak-fruit weevil (Pl. 12, f. 1). In Malabar and the Mys uplands young fruits of jak trees are sometimes very badly damag by this insect. The weevil is a very small one, measuring abo $6 \mathrm{~mm}$. in length, and is pale-greyish-brown in colour. The snout prominent. Hundreds of the small cream-white grubs are fou riddling healthy tender fruits and as a consequence the fruits shri up and drop down. Dr. Marshall, to whom I sent specimen's so time back, tells me that the insect belongs probably to a new gen and that he would describe the same soon.

Calantra rugicollis, Fst. This small weevil has been noted as pest of sal (Shoiea robusta) seedlings in Ganjam. In appearance it more or less like the ordinary rice Calandra but slightly bigger. fallen sal seeds contain the grubs and pupæ of this weevil. This noted by a nephew of mine who is a Forest Officer. It appears clos allied to the acorn weevil ( $C$. sculpturata, Gyll.) mentioned by St bing, and is perhaps the same as the undermined 'Sal weer referred to by Stebbing on page 450 of his book on Indian Forest Insec

Rubber Scolytid.* (Pl. 12, f. 2). A small reddish-brown Scoly beetle (rery likely a species of Xyleborus) was recently sent up fr a rubber estate in Cochin as doing damage to Hevea bark.

Rubber Platypodid. (Pl. 12, f. 3). This was reported from Trave core doing the same kind of damage to rubber bark. The insect fr its structure appears to be a species of Platypodid.

Coconut Scolytid. A small Scolytid, said to damage coconut ster has been received two or three times from different parts of South Ind

The real bionomics of these Scolytids have to be studied to see whetl they are the cause or the effect in these different cases, since in the ce of rubber a fungus disease is often found mixed up.

Two weevils-Melon weevil (Acythopeus citrulli, Marsh) and a sm Apion (Apion cmplum, Fst.) may also be added to the list of weevils. T former was noted in Cuddapah and Bellary inside melons, and the lat has been collected on Anacardium fruits in Malabar and also breedi in green-gram pods in Coimbatore.

* Since named by Col. Winn Sampson as Ẍyleborus biporus, n. sp. 
l'ugro?
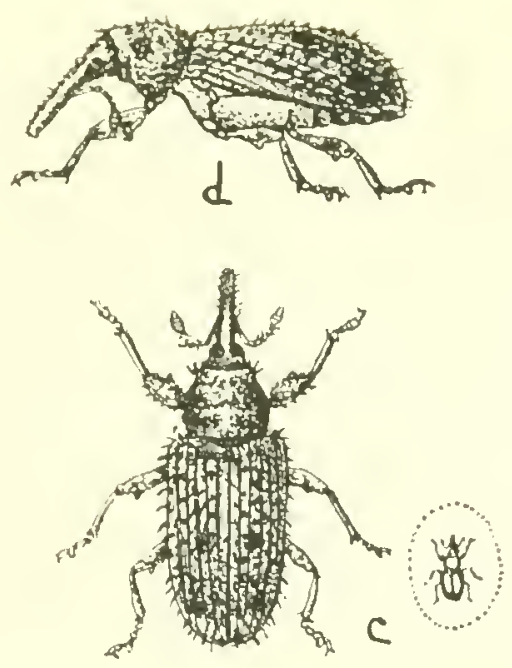

Fig. 1._-lak Weevil ; $几$, larva $>8$; 1 , pupa $8 ; c$. beetle, dorsal view, natural size and cnlarged ( 8$) ; 1$, beetle, side-view, $>8$.
PLATE 12.
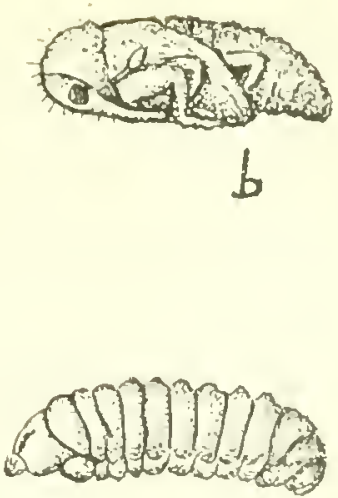

a

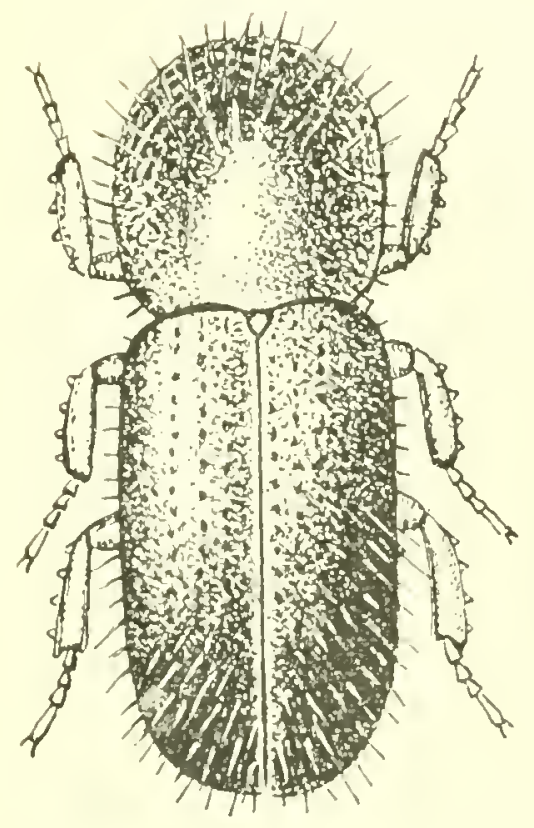

Fig. 2.-Rubjar Scolytid ( $\times 36)$.

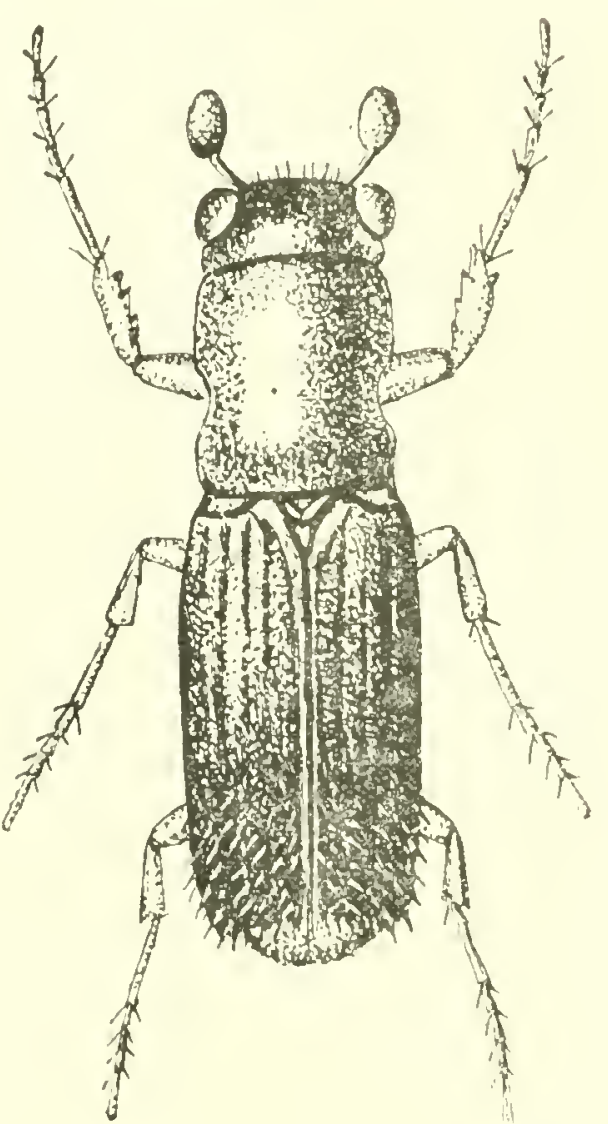

Fig. 3.-Rubber Platypodid $(\times 16)$. 



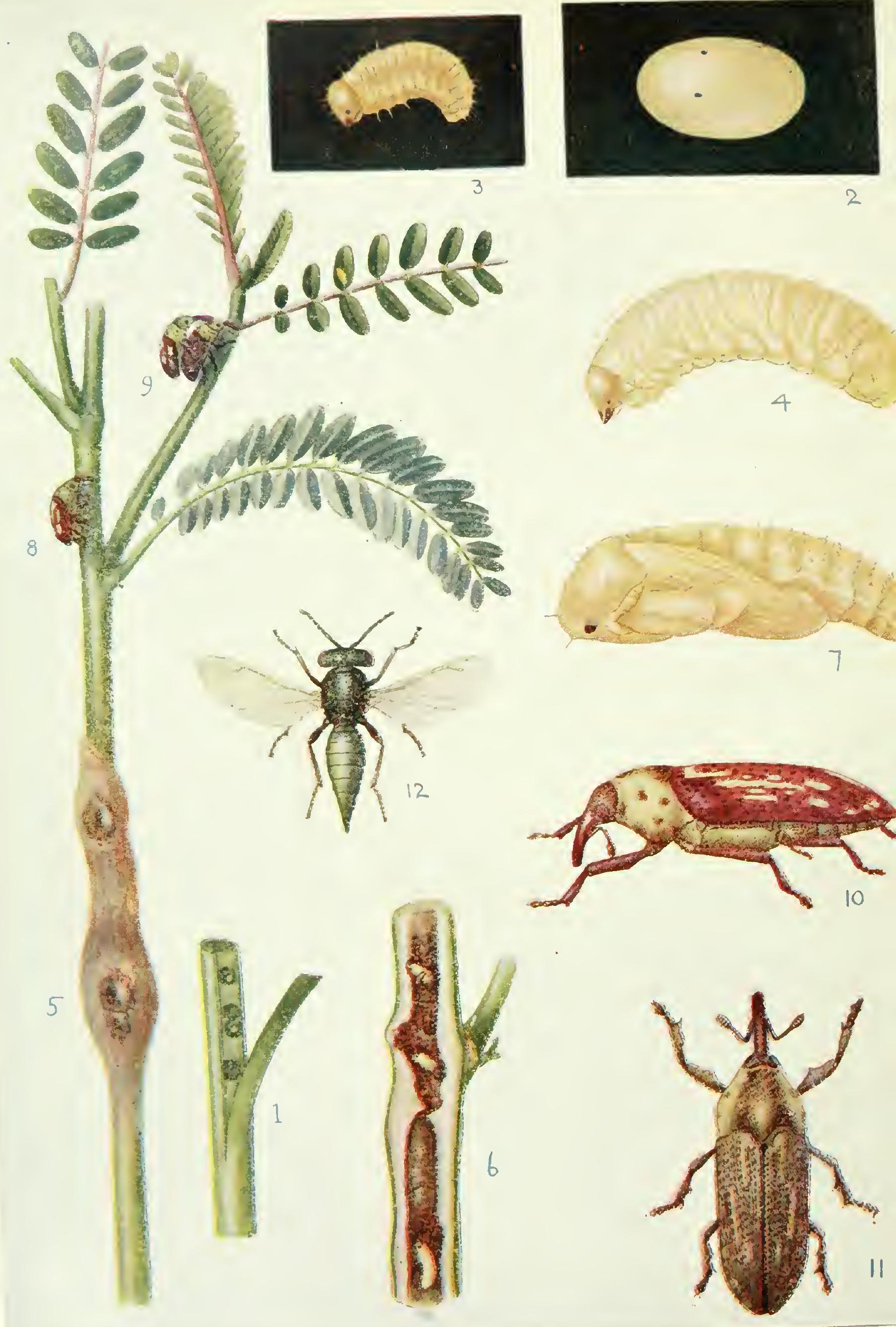




\section{EXPLANATION OF PLATE 13.}

\section{Alcides bubo.}

Fig. 1. Stem cut open. showing eggs deposited in it $\left(\times 1 \frac{1}{6}\right)$.

Fig. 2. A single egg, magnified ( $\times: 33)$

Fig. 3. Newly-hatched larva $(\times 30)$.

Hig. 4. Full-grown larva $(\times 10)$.

Fig. 5. Stem attacked by larva, showing galls.

Fig. 6. Stem sut open, showing larval workings $\left(\times 1 \frac{1}{3}\right)$.

Fig. 7. Pupa, magnified $(\times 8)$.

Fig. 8. Adult beetle $\left(\times 1 \frac{1}{2}\right)$.

Fig. 9. Pair of beetles $(\times 11)$.

lig. 10. Beetle, side-view $\left(x_{5}^{5}\right)$.

Fig. 11. Beetle, dorsal view $(x 5)$.

Fig. 12. Chalcidid parasite $(\times 10)$. 
Before leaving beetles, I may add a few remarks on the following insects which have already been noted as injurious. just to point out their present status in view of our further knowledge of these insects.

Pempheres affinis. This insect has within the past two or three years distributed itself with Cambodia cotton into tracts where it was not found till now-riz. Madura, Ramnad and Timnevelly districts. It appears that the weevil exists in diflerent parts where no cotton is grown -for I noted the weevil on Hibiscus esculentus in North Malabar-and makes itself prominent with the introduction of cotton cultivation. The life-history of the insect has been worked out and an account of it will be found in my paper on this insect in the Year Book of the Madras Department of Agriculture for 1918 (pp. 1-13) [Coloured plate exhibited].

Alcides bubo. (Plate 13). This insect continues to be a bad pest of Sesbania (agathi) in betel-rine gardens. The plants do not suffer much when they have grown 4 or 5 feet high; but during the younger stages very serious damage is done. Two or three applications of lead arsenate during the earlier stages at intervals of a fortnight checked the attack in the early stages. I an exhibiting a coloured plate showing the different stages of this pest. Two parasites Metastenomyia juliani, Gir., and Enrytoma pigra, Gir., have been noted on the grub; but not to any great extent. In page 97 of the Madras Departmental Year-Book for 1917 is a short paper of mine on the egg-laying habits of this insect.

Alcides affaber. This is a specific pest of gogu (Hibiscus camnabinus) and is also found on Hibiscus esculentus; pretty bad occasionally. Alcides lcopardus, 01., mentioned by Fletcher in his book, is apparently a wrong identification for $A$. affaber, for I have never seen $A$. leopardus anywhere in Coimbatore. I, however, got some specimens of this latter species breeding on a wild plant in South Malabar a couple of years ago.

Peltotrachelus pubes-a weevil noted in the Shevaroys on orange This is a minor pest only.

Apoderus tranquebaricus. Recently this insect has been noted in numbers on tender shoots and leaves of mango trees in Chittur and adjacent mango tracts. (Reference to my note in Bulletin of Second Hundred Notes).

Pachytychins mungonis, originally noted on green-gram, is also found on dhaincha as a pretty bad pest, causing prominent swellings of the stem.

Olenceamptus bilobus (Plate 10, figure h), though noted by Lefroy in his Indian Insect Life, is not in Fletcher's book. It is sufficiently important to be grouped as a pest. I have noted this doing damage to cultivated figs in Krishna, Bangalore, and other places. It was once noted on pomegranate also in Salem, Coimbatore. 
Apomecyna perotleti (Plate 9, figure c) has recently been noted in Godavari and Vizagapatam districts as a pretty bad pest of cucurbits, especially of the vegetable called dondekaya in Telugu.

Among Bruchids of economic importance the following might be noted.-

Bruchus analis-on stored pulses.

B. theobrome-breeding on red-gram in the fields.

B. chinensis-both in the fields and in the store room.

Other unidentified species are, one species breeding on lab lab in the fields, one on cow-pea also in the field, and another from agathi (Sesbania) pods in the field. The correct identification of these species is a matter of great importance, as confusion is sure to arise.

Tyleborus fornicatus (Pl. 14) was once noted pretty bad on a species of red garden castor plant in Bangalore. Being a well-known pest of tea and other plants in Ceylon, and this being the first record of it in the Plains. it is necessary that the progress of this pest should be watched carefully.

The Bostrichid, Rhizopertha dominica, which was till now considered a minor pest of stored cereals, has during the past two or three years proved a serious pest of stored paddy. This was the case in the Coromandel districts two years ago.

The weevil, Tylopholis ballardi, mentioned in Marshall's Fauna volume, has been noted attacking Bengal gram in Bellary, but has not been noted as serious.

\section{LEPIDOPTERA.}

Chitades laius. This tycænid is occasionally noted doing damage to Citrus shoots in the Northern Circars.

Parata alexis. The larva of this Skipper is found sporadically in numbers attacking the foliage of Pongamin glabra, a tree the leaves of which are largely used for green-manure in wet-lands.

Psychille. Among bag-worms wa often have souble with some species. One is sometimes found on castor in Coimbatore (probably Psyche vitrea). and another on funit-trees in the Northem Circars, especially on Sapota.

Contheyle rotunda. A sporadic serious pest of coconut trees on the South Malabar coast. It has also been noted by Mr. Ans ead as a pest of tea in the Hills. (See my paper on this insect, p. 91, Madras Departmental Year-Book 191\%.)

Natada nararia was once found as a bad pest of the garden hedge plant, Pithecolobium dulce, in Coimbatore. 

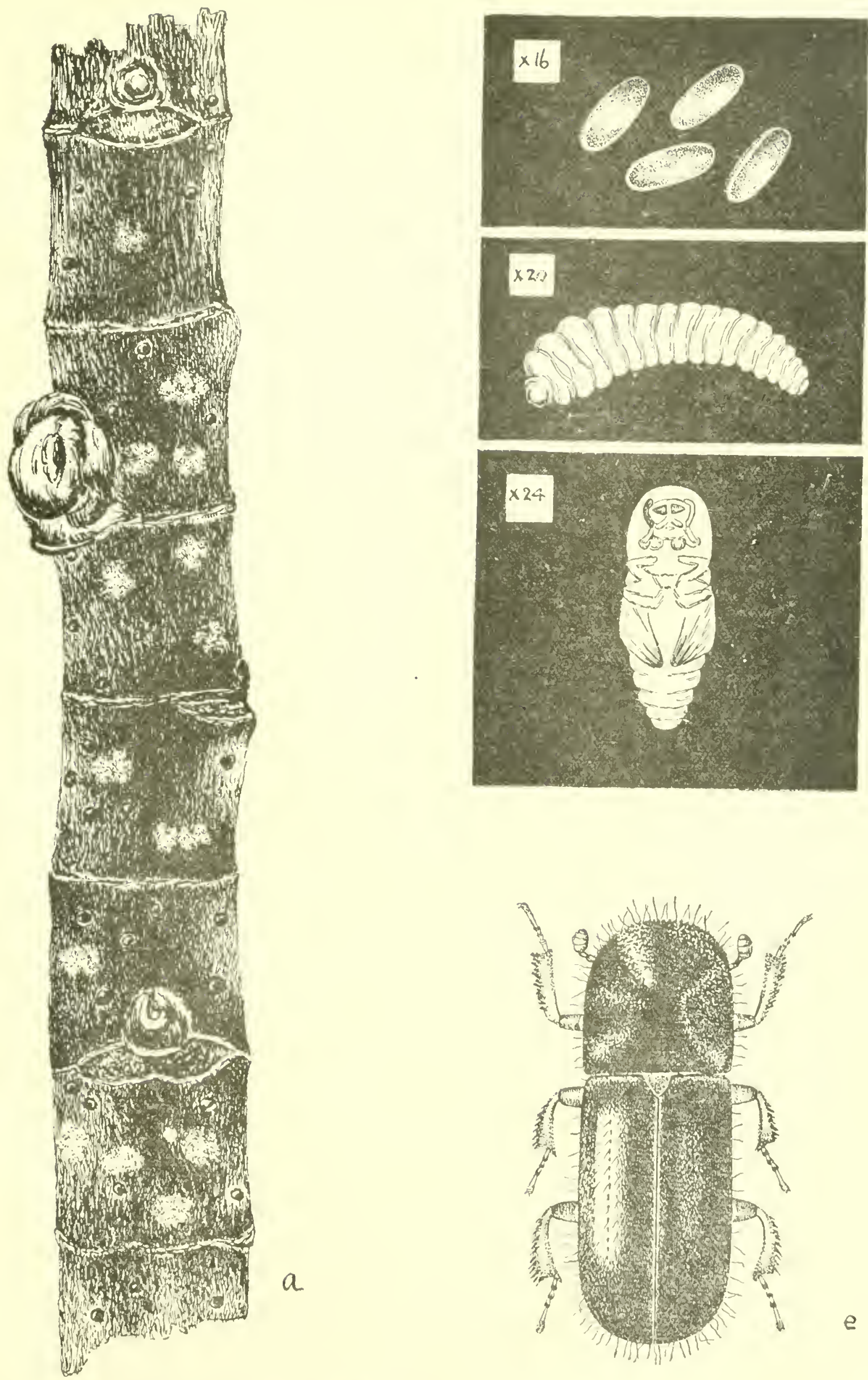

c

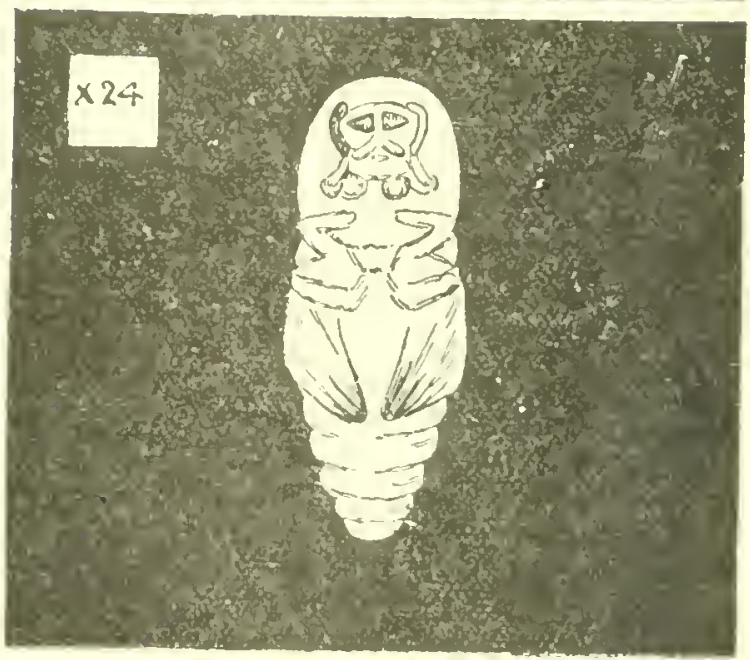

$d$

$a$

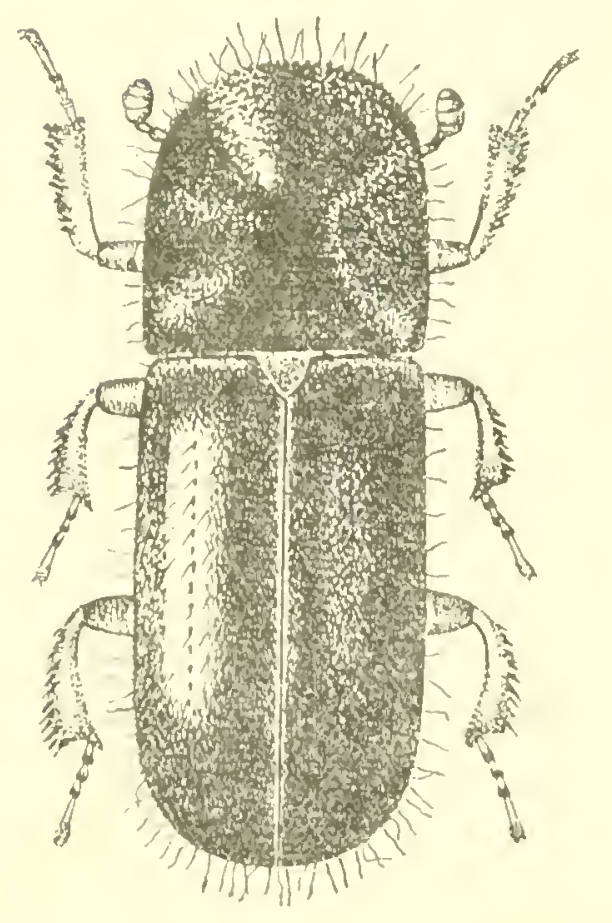

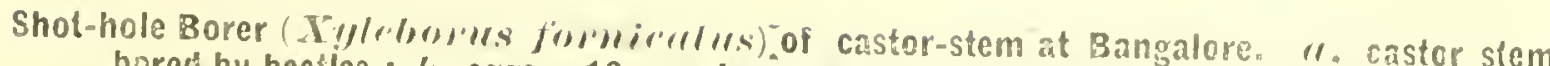
hored by beetiles; ", eggs, 16 ; ", larva 20 ; 11 . pupa, 24; ". beetle, ; 24. 



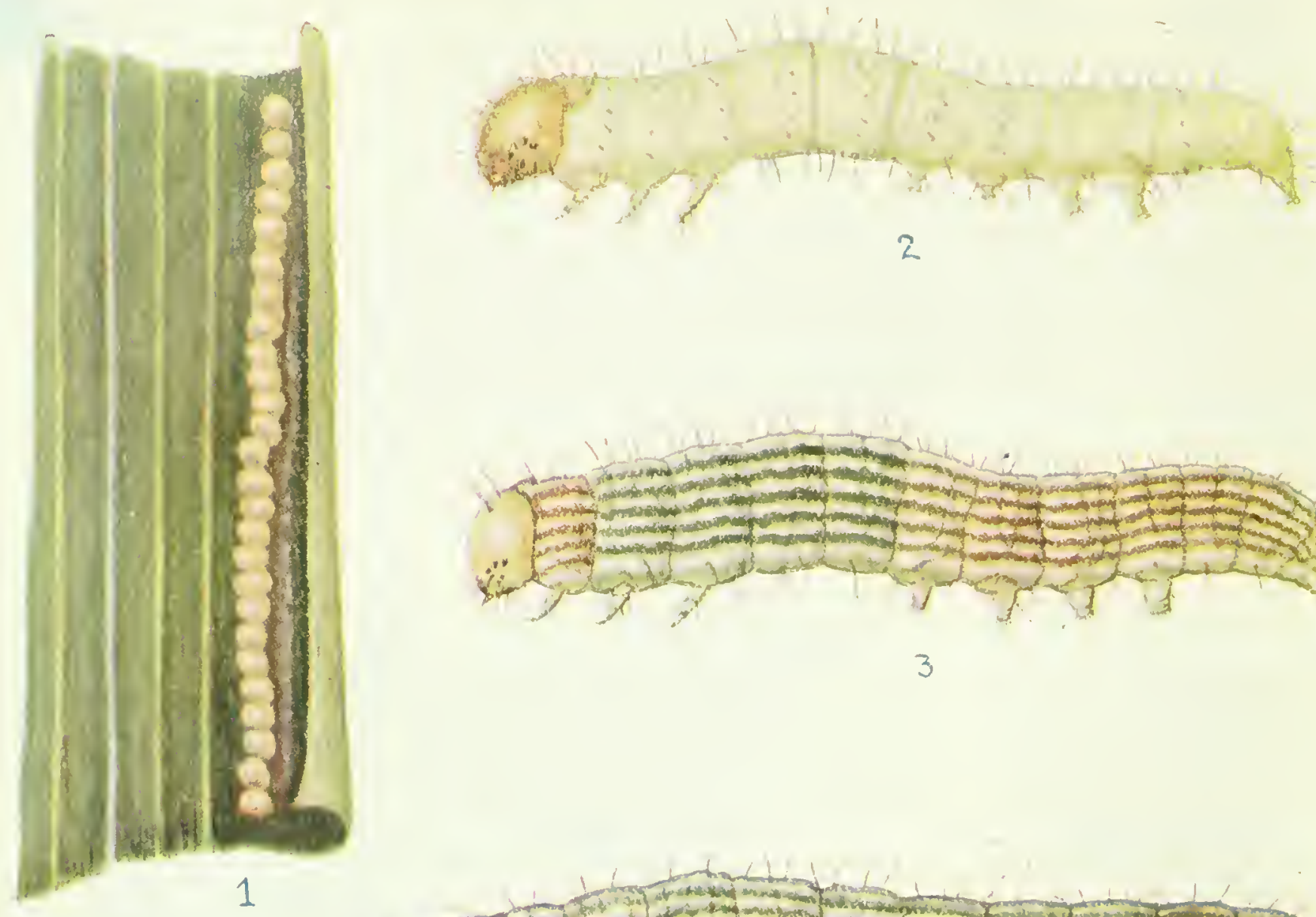

2

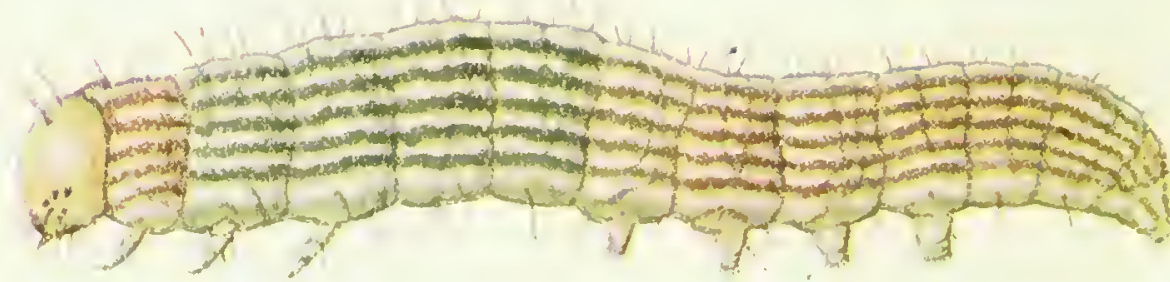

3

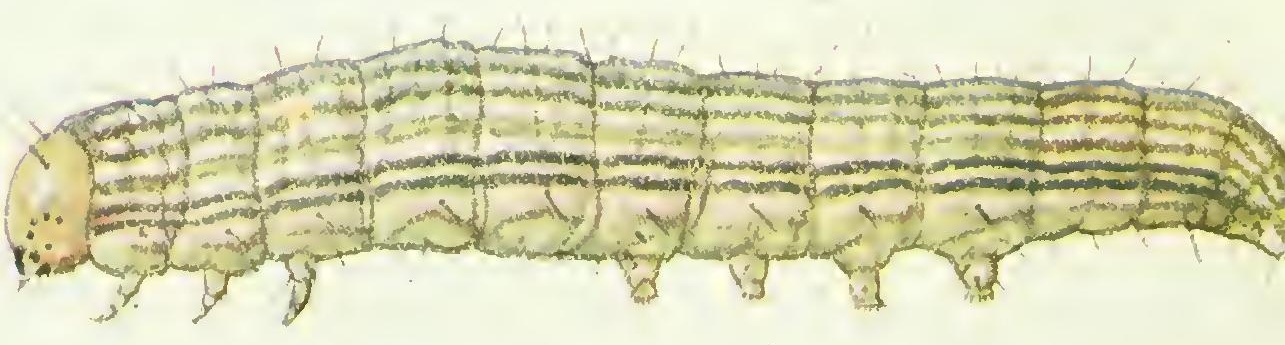

4
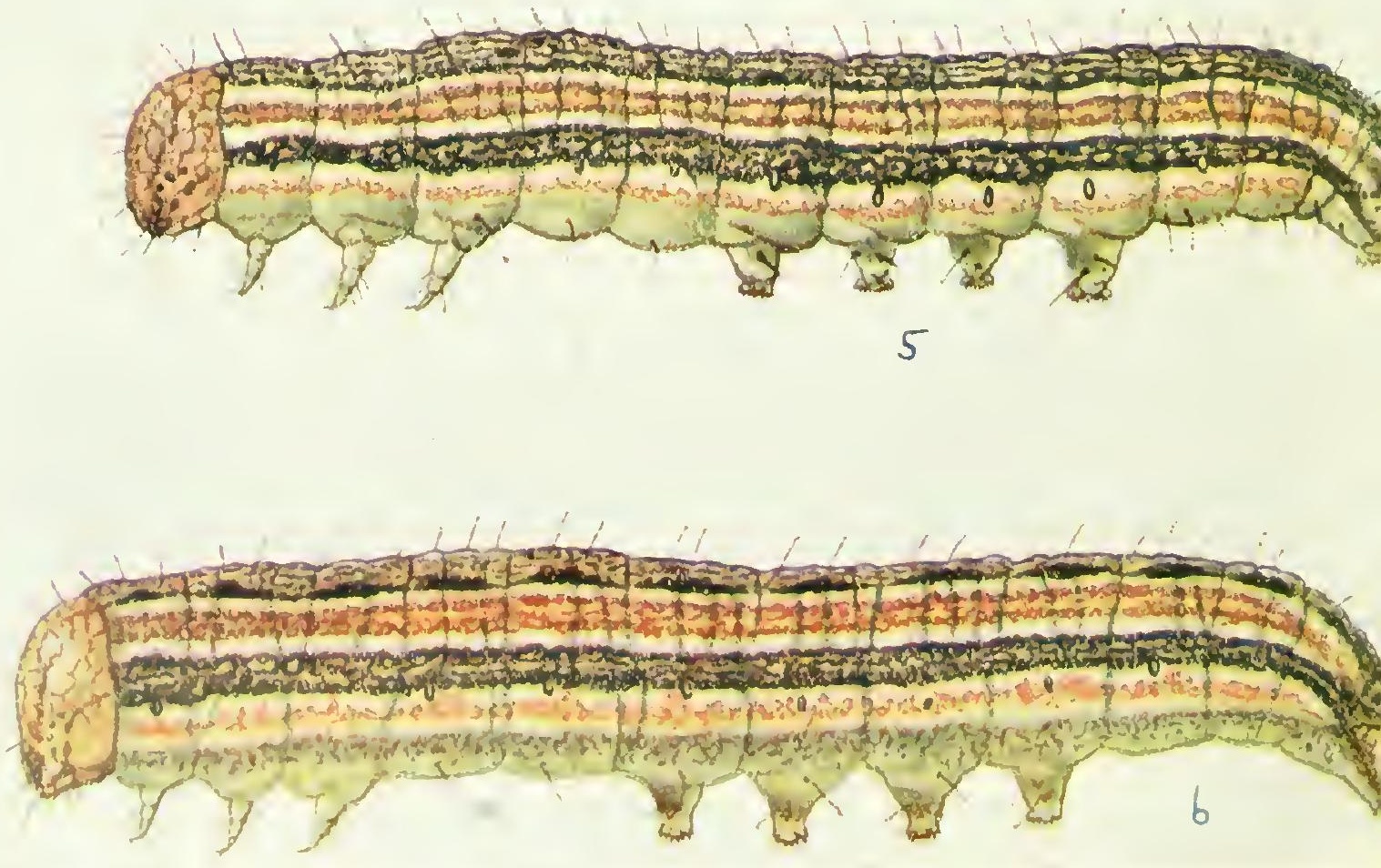
EXPLANATION OF PLATE 15.

Cirphis albistigme.

Yii.. 1. liggs laid on paddy leat, matnitied.

rig. 2. Larva, first instar $(x 45)$.

Fig. 3. Larva, second instar $(\times 25)$.

Jiz. 4. Jarra, third instar (Y13).

Fir. 5. Jarre, fifth instar ( $x 3$ ).

Fig. 6. Larva, sixt! instar $(\times t)$. 


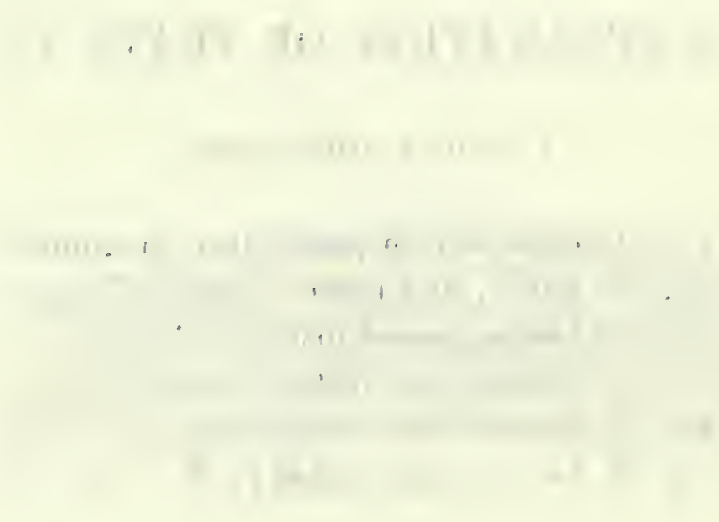



PLATE.16.
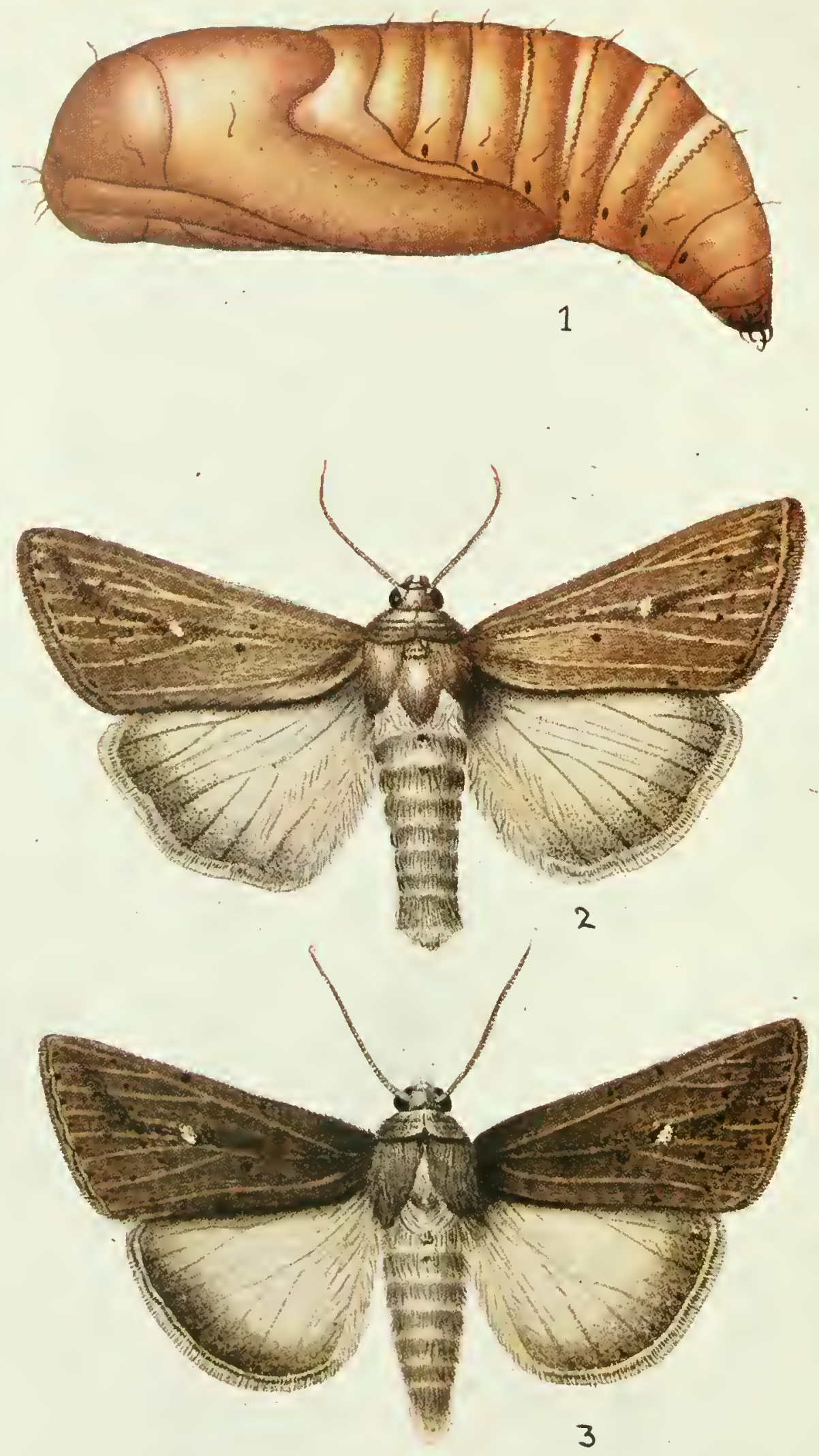

CIRPHIS ALBISTIGMA. 
EXPLANATION OF PLATE 16.

Cirphis albistigma.

Fig. J. Pupa, magnified $(x 5)$.

Fig. 2. Moth, mate, magnified $(x \geq 2)$.

Fig. 3. Moth, female, magnified ( $\left.x^{2}+1\right)$. 

Butea Limacodid. A stout spiny caterpillar similar to Parasa but bigger in size. Moth grey with ochraceous markings. Found defoliating Butea frondosa in the Bolampatty forests, Coimbatore.

Carea subtilis (Plate 10, figs. j, k) very common on Eugenia jambolana in different parts. The caterpillar with the swollen anterior portion is easily made out. A parasite has been noted on this, Tumidicoxoides jambolana, Gir MS.

Cirphis albistigma (Plates 15, 16). A pretty bad pest of ripening paddy. The caterpillar is the climbing caterpillar of paddy of the Coromandel coast, appearing generally after the heafy North-East Monsoons, January to February. The caterpillar cuts down the ripening ear-heàds.

Adisura attinsoni. A Noctuid borer of lab lab pods. Tery common in Coimbatore and the Northen C'ircar's during the cold weather. (See Tear Book of Hadras Department, 1917, p. S7, for Mr. I. Ramachandra Rac's paper on its life-history).

Euzophora plumbeifasciella has been found breeding inside woodapple fruits.

Ephestia cautella, on stored groundnut pods; the caterpillar bores into the pod and eats the reds. Often bad in stores of minhelled groundnuts.

Heterographis bengalella, a Pyralid with olive greenish upper wings. Larva found inside the fruits of custard apple.

Corcyra cephalonica. The stored rice meal-worm. Tery common in South India. Found on rice and meal of all cereals.

Chrysonthemum caterillar. A small green caterpillar was found once pretty bad on cultivated chrysanthemmm in Madura. The moth is of medium size and has ochraceous wings. Probably a species of Hypargyria (Pyralidx).

Brachmin effera, Heyr. The small caterpillar folds the leaf of sweetpotato; has not become serious yet.

Laspeyresia leurostoma. Found near Kateri and Coonoor on the Nilgiris. The caterpillar feeds on the leaf of tea.

Cyphosticha comlea. The pinkish small caterpillar mines into the leaf tissue of lab lab and produces a sort of prominent white blister en the leaf. Pretty bad in Coimbatore and Malabar.

Phthorima blapsigona. A common pest of brinjal buds in South India. A species of Microbracon is found as a parasite of this caterpillar.

Phyllocnistis toparcha, Meyr. The larva mines into grape-vine leaves and the mine is seen in the form of glistening wary lines on the leaf in Coimbatore.

Acrocercops syngramma, Meyr., on tender mango leaves, Madras. 
Sylepta lunalis was found in numbers on grape in November 1917 in Coimbatore. Pupa inside leaf fold.

The Ragi ear-head worm. This is a slender elongated caterpillar found on the ripening ear-heads of the ragi plant. Sometimes appreciable damage is done to the ears.

The Saturniad moth, Actias selene, has been noted as a regular pest defoliating Odina wodier trees in Coimbatore for the past two or three years. (See my note in the Bombay Joumal, XXIII, p. 792).

The following are already known pests among Lepidoptera; but I have added some extra information regarding their status.

Dicrisic oblique. This Arctiad has not been recorded till now from South India. It is found on sweet-potato and Lantena in Malabar. On the Wynaad Hills I found it on a variety of other plants.

Orgyia postica is found to be a pretty bad pest of castor in Combatore. A coloured plate of its stages is heremith exhibited. (Plate 17.)

Euproctis fraterna has been noted on rose. doing serious damage in South Malabar. It is also found on pomegranate. A coloured plate is exhibited herewith.

Prodenia litura. Noted bad on Colocusia in Tanjore and was recently noted on onions in Combatore.

Dichocrocis punctiferalis on arrow-root plant in North Malabar.

Hybloca puera is often serious on Millingtonia and Bignomia.

Laphygma exigua has been noted on coriander at Coimbatore.

\section{DIPTERA.}

Packydiplosis oryzce. This is noted as a rery important and serious pest, chiefly in the Northern Circars, Tanjore and Ramnad districts. The fly is found breeding on other Graminaex also. It is known as Ancikombu in Tamil districts.

Bittel-gourd gall-fly, (Pl. 18). The distal tender shoots of the bitter-gourd plant often derelop a long gall and the growth of the plant is much affected by the maggot found inside the gall.

The Cumbu fly. This is also a Cecidomyiad noted on cumbu in Coimbatore.

An Anthomyiad has been noted on tomato also.

Among fruit-flies we have a few species of Bactrocera, Chatodacus etc., affecting mangoes, guavas, etc.:-

Chatodacus jermginers incisus, on guava, Bangalore.

Bactrocera caudata. On snake-gourd, Coimbatore.

Dacus brevistylus, on water-melon, Cuddapah.

Dacus longistylus, on Calotropis.

Carpomyia resuviana, Coimbatore, on ber friit. 

EXPLANATION OF PLATE 17.

\section{Orgyia postica.}

Fig. 1. Mass of eggs, natural size.

Fig. 2. Egg, magnified ( $\times 13)$.

Fig. 3. Newly-batehed larva, magnified.

Fig. 4. Full-grown larva, natural size.

Fig. 5. , , ,, magnified $\left(\times 2 \frac{1}{2}\right)$.

Fig. (i. Cocoon, natural size

Fig. 7. Pupa, magnified $\left(x_{2}^{1}\right)$.

Fig. 8. Female motl, natural size.

Fig. 9. , ,,$\quad$ magnified $(\times 1 \mathrm{f})$.

Fig. 10. Male moth, magnified $\left(\times 2 \frac{1}{2}\right)$. 

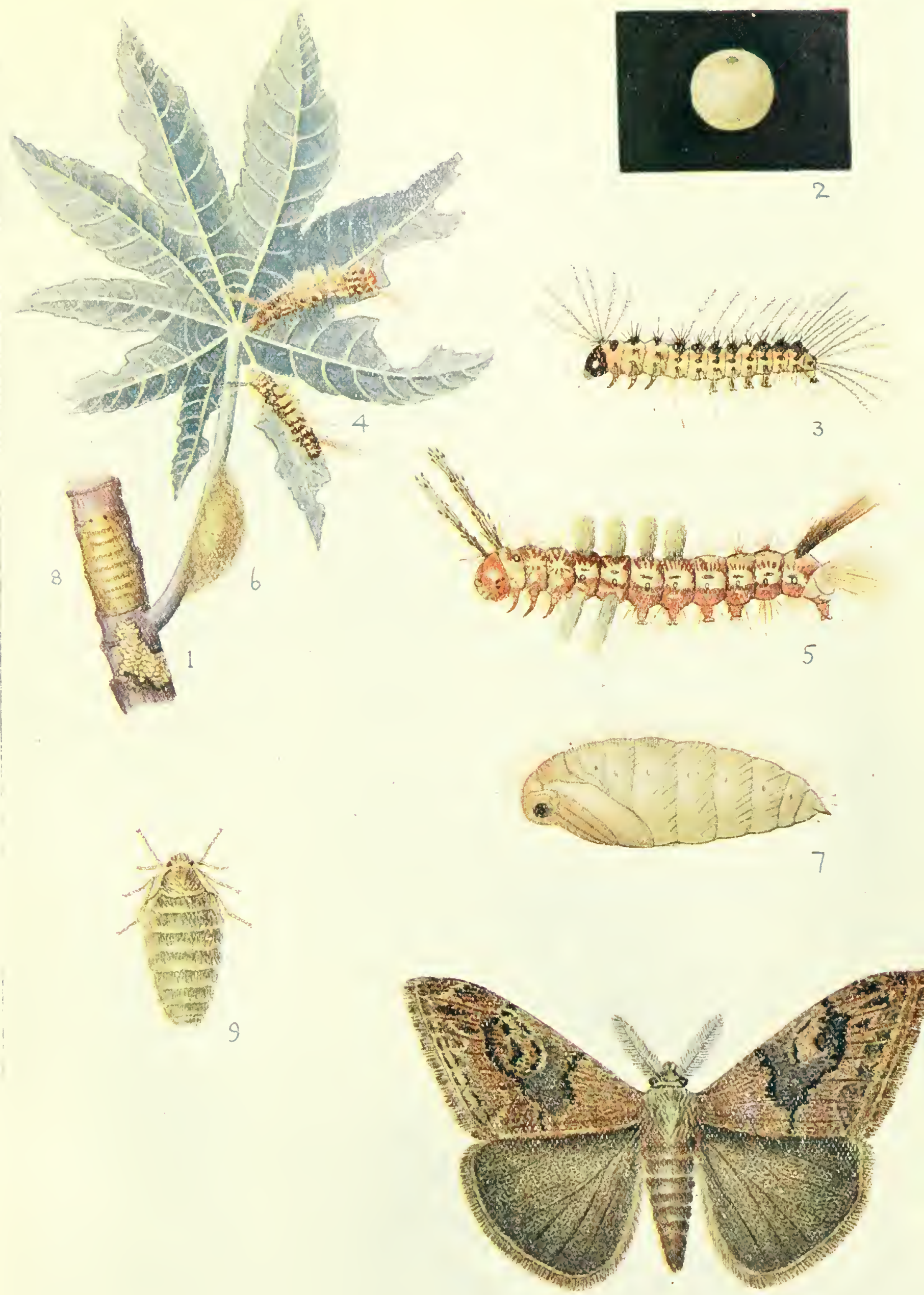



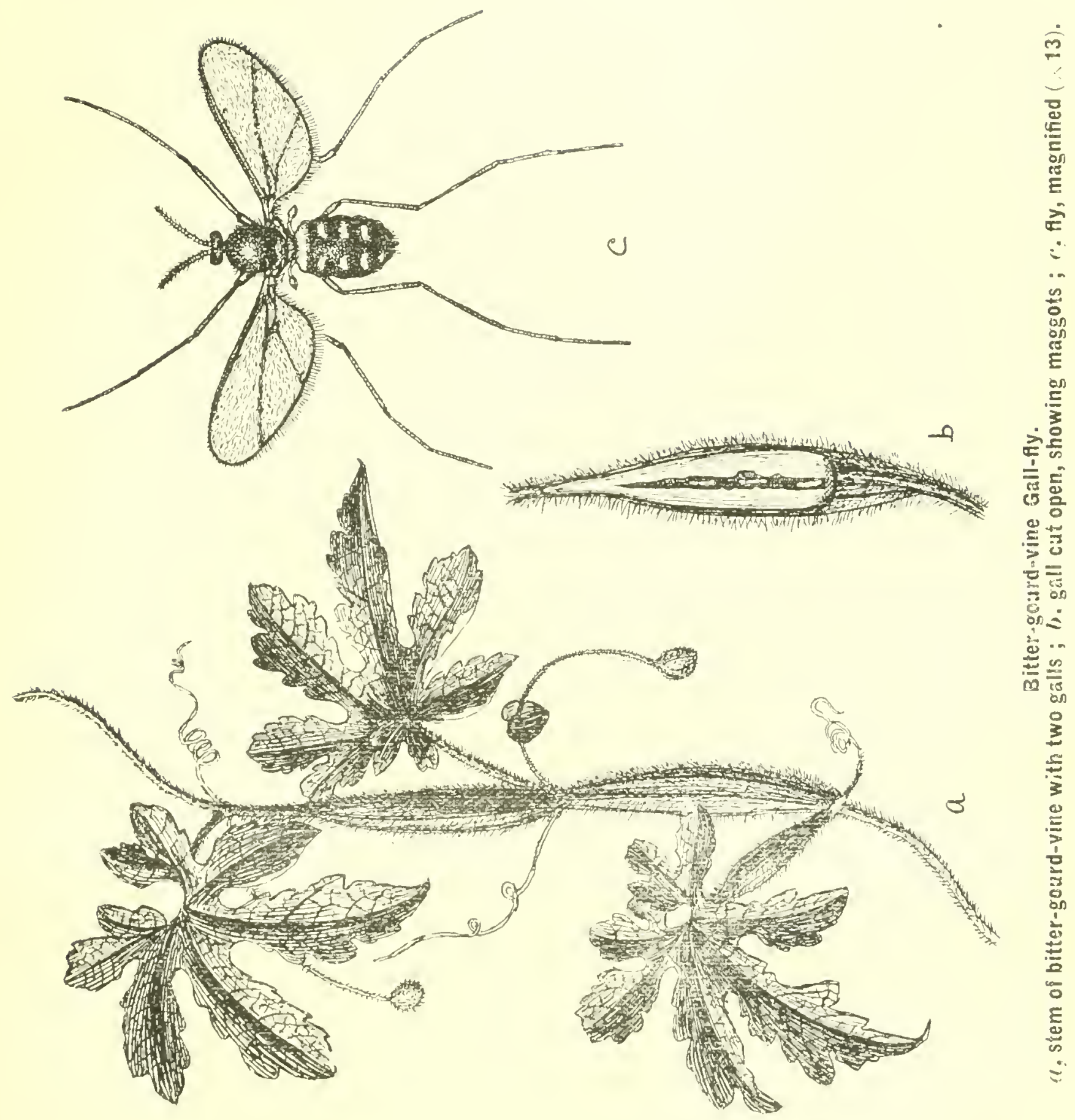






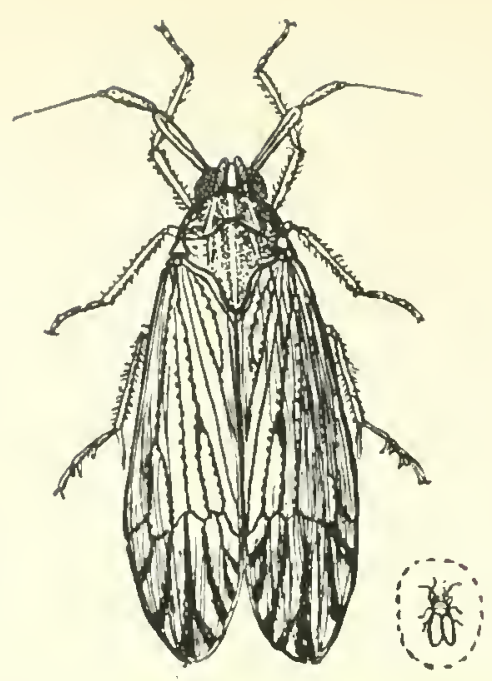

Fig. 1.-Prirolite sp. $\times 5$. (The smaller outline figure shows the natural size.)
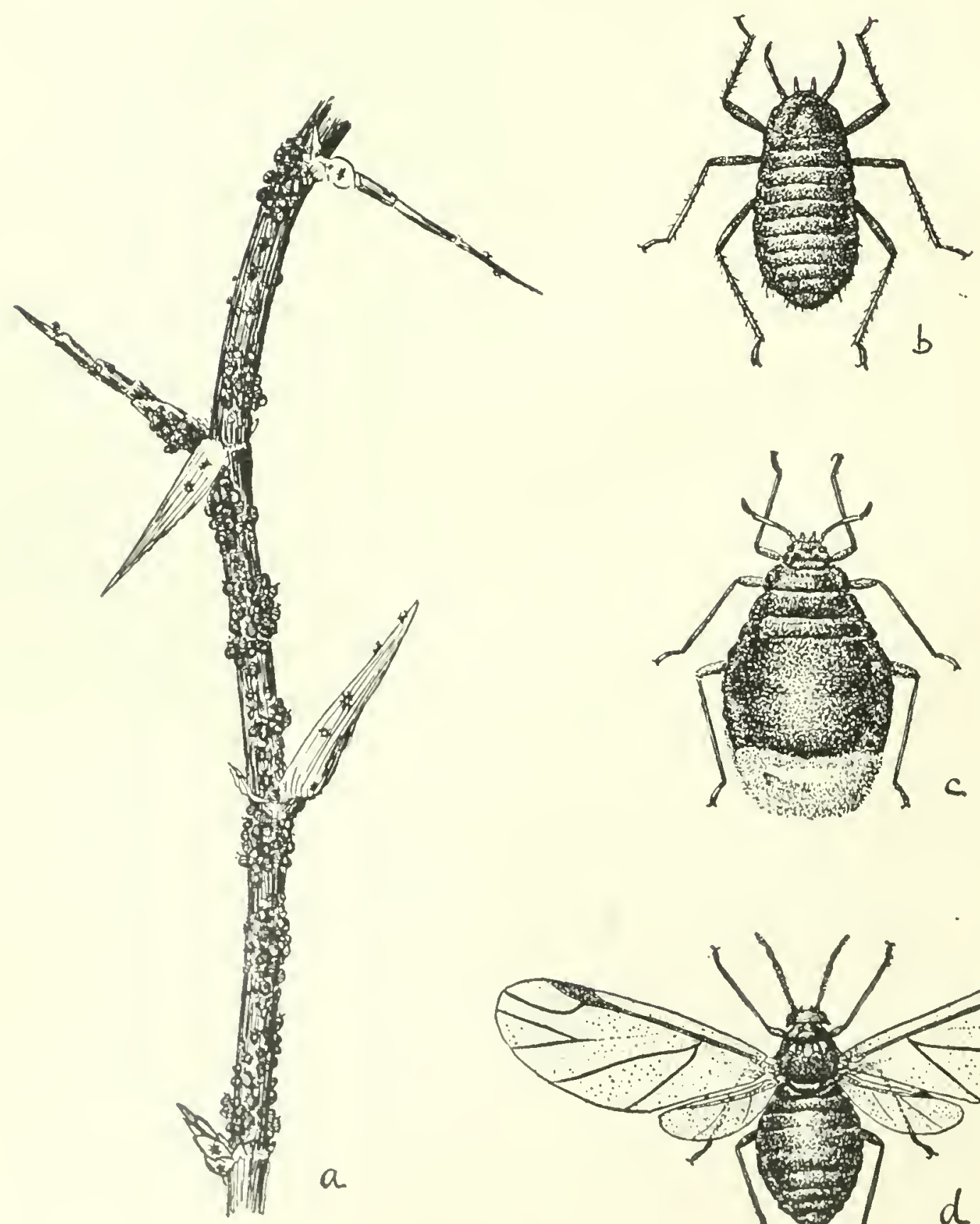

Fig. 2.-Woolly Aphid on bámboo; 1 . Aphids clustered on bamboo shoot; 1 , yourg Aphid $\times 40$; $c$, wingless adult $\times 13 ; 1$, winged adult $\times 11$. 
Teak leaf-gall. Throughout the West Coast. teak leaves are found covered with numerous gall-like formations with hairy out-growths on the lower surface. I believe the galls are caused most probably by a gall-fly; I even got bright pink-coloured maggots crawling out of these but have not succeeded in rearing out the adults. Mr. Stebbing in his book on Indian Forest Insects. p. 120, thinks that the gall is due to 8 Cueujid beetle, Sitramus adiena. This has to be verified.

\section{RhYаснота.}

Two or three species or Coptosoma have been noted as swarming on different plants in Sonth India. These are-

Coptosoma nuzice (Plate 10. figure 1). On most regetables such as cluster-beans, Hibiscus, etc., and mango shoots.

Coptosoma ostensum, Dist., a minute light-yellowish-green speeies found by the thousand on young shoots and leaves of Butea frondosa in the forest around Coimbatore in December.

The black oval shining Pentatomid, Biachyplatys vahlii, is often found in numbers in company with the common Coptosoma cribraria on agathi (Sesbamia).

Vitellus orientulis (Plate 10, figure i) is a large greenish Pentatomid with sharp prothoracic spines which has been noted as puncturing orange fruits in Kurmul. The effect of the puncturing appears to hasten rotting and also attraction for fungi. It has to be verified whether the real injury is done by these or fruit-sucking Noetuids of the genus Ophideres.

The Lygieid bug, Nysius inconspicuus. is often found bad on growing gingelly in South Kanara during the months of February-April.

Helopeltis (theirora*s) on tea in Pirmaad and Travaneore, and Hegacolum stramineum, found in company with Calocoris angustatus (see Year Book Madras Deparment. 1917, p. 83, for a paper by Mr. Ballard), are the Capsids of importance.

Puiohita sp. (Pl. 19, fig. 1). A pale-greyish bug found in some numbers at the stem of growing bamboo, especially betwcen the stem and the sheaths. The mealy mass of eggs is very commonly found in that place also; Coimbatore.

Curry Leaf-hopper. A minute active Fulgorid found in numbers doing appreciable damage to the curry-leaf plant, Murraya koenigi, in Combatore and Malabar.

Clovia lineaticollis (Plate 10, figure $m$ ). Common on jak sloots and tender leaves all over Malabar. Due to the attack the leaves curl up; often inside these curls nymphs enclosed in frothy matter are also found.

* Helopeltis antonii is perhaps intended. [Editor] 
Of mealy-wings we have chiefly the Dialeurodes engenice on Eugenia and Aleurodids on Bassia and Citrus.

Of plant-lice pests we have several, and of these the chief are those found on cotton, tobacco, Citres, lab lab, cow-pea and cholam.

Bamboo Troolly Aplis. On bamboo we occasionally find a species of wolly aphis coming in large colonies (Pl. 19, fig. 2). It is not the same as Fletcher's fig. 392.

The Coconnt Aphis (Cerataphis latanice), Fleteher's fig. 393, has not been noted since.

Coming to Scales and Nealy-bugs there are a good many species of importance. In a paper I prepared for the Session of the Indian Science Congress held at Lahore in 1918, I listed 32 species of Coccids having some economic importance. Though all these are not bad pests at present. some of them are really important. Of these mention might be made here of the following.

Pulvinavia maxima, Gr., a bad pest of nim trees (Melia azadirachta).

Ceroplastortes cajani, on lab lab stems and Ocimum; often bad.

Anomalococcus indica, Gr., on babul (Acacia arabica).

Psendococcus sacchari. Bad on paddy. The disease is called Scorai no: $u$ in Tamil and often reported from Tanjore, Trichinopoly and Madura districts. Fields badly attacked show the infestation patches here and there.

Phenacoccus insolitus. Bad on brinjal plants, Madras, C'oimbatore, etc.

Ripersia sacchari. On sugarcane stems. This is the commonest species of mealy-bug on cane, and is different from Pseudococcus sacchari.

Icerya agyptiaca. On jak, Malabar and Nilgiris. This is the species to which I referred at the last meeting (p. 152 of Report).

Hemichionaspis aspidistra. On pepper in Malabar. and also on Ficus leares elsewherc.

Aspidiolus lamarindi. On tamarind. Coimbatore etc.

Phenacoccus iccryoides. On mango; in Combatore, Northern Circars and Tanjore.

Pseudococcus corymbahs. On cotton, mango and jak. In different places.

Aspidiotus amantii. On rose, Nalabar.

Aspidiolus curcume or hartii. On turmeric rhizomes at Coimbatore.

Psendococcus longispims? Bad insicle leaf-sheaths of young coconut trees; Coimbatore, Malabar and South Kanara.

\section{ORTHOPTERA.}

Among grasshoppers no new pest of any importance has been noted. The wingless grasshopper, Crthacris sp., was however found pretty bad 



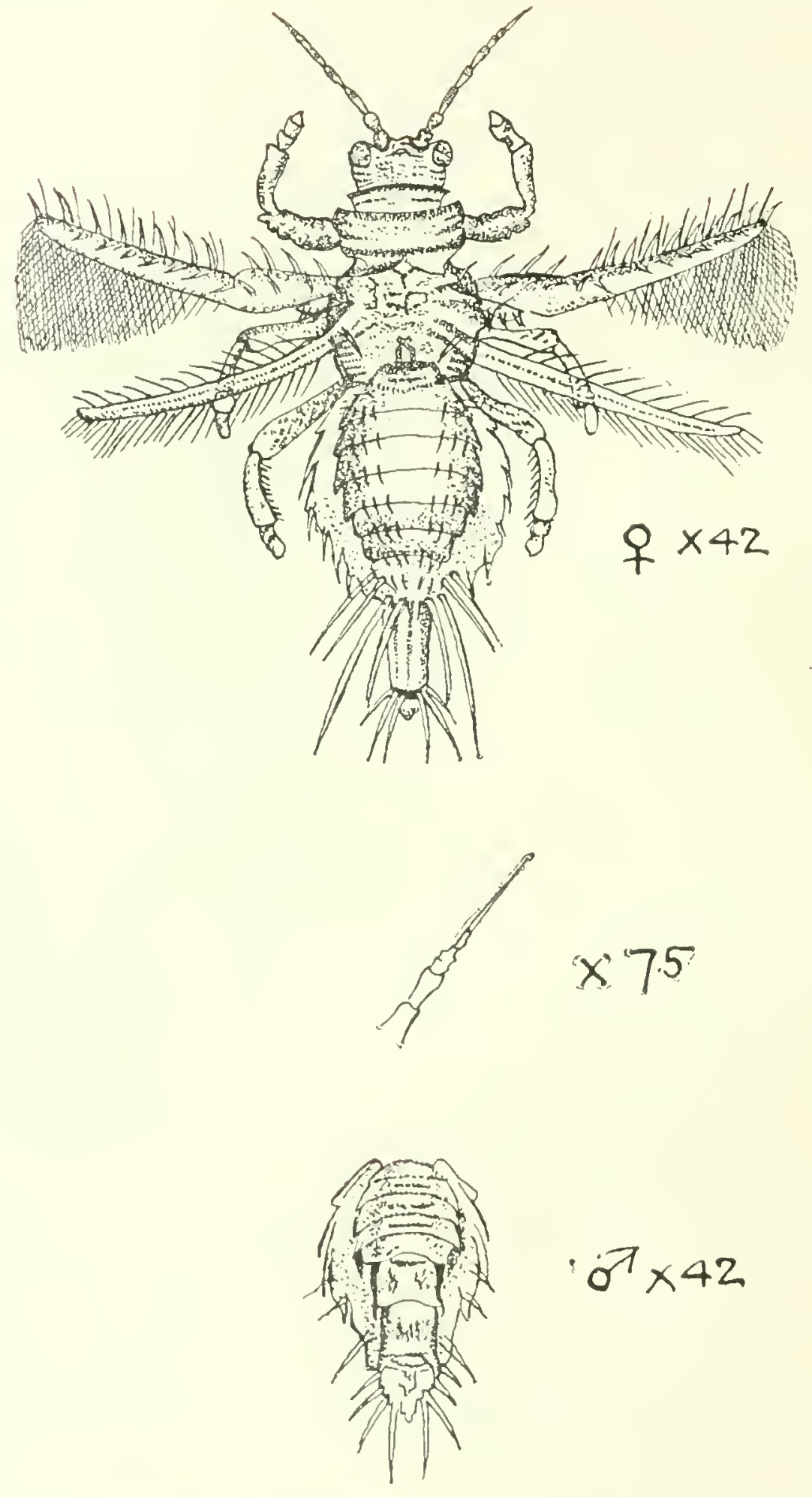

L'cuchcetothrips indica, Bgll., on arcw-root leavas. 
on mulberry plots in Kollegal more than once. And on one occasion. surface-grasshoppers of the genera Eolopus and Edaleus were noted very bad in paddy nurseries in one village in the Coimbatore district.

\section{Thysanoptera.}

Tery little attention has been paid till now to the insects of this group and there is little on record regarding their economic importance** In South India the following species have been noted so far, as having some economic importance:-

On paddy. Thrips (Baynallia) oryze on seedlings in many parts of the Province. Pretty bad sometimes. (Some p. 353, Bulletin of Entomological Research, 1915. for description of this species by Williams).

On turmeric and arrowroot. Panchetothips inticus, Bagn. (Plate 20). On turmeric in Coimbatore and on arrow-root in Malabar. Not serious. Circars.

On onion. Heliothrips indicus, Bgl. Bad sometimes in Northern

On grape-vine. Rhipiphorothrips cruentatum, Hood. On tender grape-vine leaves. Turns the leaves pale brown. Found in numbers on the foliage at certain seasons.

On Mimusops clengi. Arhenothrips ramakishna, Hood, (Plate 99). Very serious on this garden plant in Coimbatore. The leaves are very badly twisted and galled.

Thrips of sorts have also been noted doing some damage to chillies: indigo, etc., in different parts of the country.

On groundnut.-In the Palur farm a species of Thrips was once reported doing serious damage.

Just a few words regarding non-hexapod pests of some importance may not be out of place before I close. Small Mites of sorts have been noted occasionally bad on cotton, cholam, castor and coconut; those on cholam and cotton have often been found to do appreciable damage.

The others among non-hexapods are the eel-worms. I have seen young tea-seedlings and pepper-vines suffer from the attacks of eelworms. In one or two places eel-worms appeared bad on pepper in the Wynaad last November [1918]:

The question of crabs on paddy seedlings has become well-known and needs no further remarks from me.

As already stated in the beginning, my chief idea in getting this list prepared was to gather more information regarding all or any of these from observations made by my colleagues in other parts of India so that

\footnotetext{
* In another paper I have prepared for this Meeting, I have dealt at some length on our present knowledge of this group (See pp. 618-621).
} 
our information regarding these forms may be kept as up-to-date as possible.

Mr. Fletcher.

This paper forms quite a useful supplement to my book on South Intian Insects, which, as I noted at the time, was only to be taken as an incomplete and preliminary introduction to the study of the insect pests of Southern India. I hope that the Madras Department will give us a further interesting supplement at the next Meeting.

\section{4.-NOTE ON THE MORE IMPORTANT INSECT PESTS OF PLANTING DISTRICTS OF SOUTH INDIA AND THE IIETHODS OF CONTROL USED, 1917-18.}

\section{By Rudolph D. Axstead, M.A., Deputy Director of Agriculture, Planting Districts.}

The author of this Note is in no sense of the term an Entomologist and the Note is merely intended to be an indication of the methods adopted on estates in Sonthern India to control some of the more important inseet pests. From this point of view it is hoped that it may be of interest to the members of the Entomological Meeting, but the author is seeking for information rather than trying to impart it.

\section{COFFEE.}

Coccus viritis. A Bulletin on the subject has been published by Coleman and Kannan (Mysore Department of Agriculture, Entomological Series, No. 4, 1918). The form of this scale-insect which occurs in Mysore is considered to be a new species and has been named Coccus colemani.

Certain species of Ants-Cremastogaster sp. and Plagiolepis longipes -are found to play an important role in the distribution of the scale. Nests of Cremastogaster on coffee estates are found crowded with seales in September and it is found that if the ants' nests are removed the infection of the trees is considerably diminished. In fact, the destruetion of ants' nests has now become part of the regular control measures ądopted on estates.

The most important natural checks of the scale are two species of fungi, Cephalosporium lecanir, which frequently lills off more than 90 per cent. of the scales in coffee estates during wet weather, and Empusa lecunii. which is usually found attacking the seale during the early part of the cold weather.

The pest is most troublesome in years when the North-East nonsoon is seanty and a long period of dry weather succeeds it. Dispersion is largely effected by wind, the young scale insects being blown as far as 
450 feet. It is also carried about by game birds, and can be spread from field to field by passing coolies who carry young scales on their clothes.

The artificial methods of control adopted are the removal of ants' nests, and spraying and brushing with fish-oil-resin soap used at the rate of $1 \mathrm{lb}$. of soap to 2 gallons of watcr. Dispersal of the fungi mentioned abore is encouraged by tying branches containing them to trees free from them.

These methods when conscientiously carried ont are highly efficient and no fcar is now felt of the pest causing the damage to coffee in Mysore and Coorg which it did in the Nilgiris, where it was neglected, rendering the cultivation of coffee to be unprofitable and necessitating its replacement by tea.

Saissetia hemisphcerica, Pulvinaria psidii, and other scales are always to be found on coffice estates but these are easily controlled by periodical spraying.

Pseudococcus (Dactylopius) citri, a Mealy-bug scale which attacks the roots of young coffee.is still a bad pest, especially in South Coorg and some parts of Iysore. This scale is also found on the roots of certain shade trees, particularly Erythrina lithosperma, and on some weeds. So troublesome is it in infected land that unless some precautionary measures are taken it is impossible to raise young plants. At the beginning of the dry weather it is usual to see young plants, either in new clearings or supplies, suddenly wilt and die. On pulling them up they are found to have lost all their feeding roots except a small tuft set out at the collar which have kept the plant alive so long as the surface soil was wet, while the bark is also eaten into by the scales. As soon as the surface soil dries out with the advent of the dry weather the plant dies.

A similar effect is produced by the larvæ of a species of Cockchafer, Holotrichia conferta, which in some years is very troublesome and appears in very large quantities. These insects were very prevalent in 1912 and there are signs of their recurrence again on a wide scale now. In such years the soil is full of the larvæ and the pits round a dead coffee-plant may contain half-a-dozen of them.

Against both these pests Apterite has been found effectual. Apterite . was obtained before the war from Messrs. Cooper Nephews and appears to consist of a mixture of crude naphthaline and pink carbolic powder. It is a soil disinfectant and was recommended as a top dressing for new land put under the plough in England during the war in the Joumal of the Board of Agricullure (England) although the reason was not stated. If this disinfectant is applied at the rate of 2 cwt. per acre, or if a shallow trench about an inch deep is madc in a ring round the young plants about six inches to a foot away from the stem and an ounce of apterite is placed 
in the trench and corered with soil, complete protection is afforded to the plants, and young clearings have been successfully raised in this way in places where before it was found impossible to grow them. Care must be taken that the young feeding roots do not come in actual contact with the apterite or they will be damaged, hence the reason for making the trench some little distance aray from the plant to be protected, outside the root range.

During the war it has been impossible to obtain apterite from England and stocks in the country were soon exhausted. Messrs. Parry \& Co., Madras, however, came to the rescue and manufactured a substitute under the trade name "Ranicide" which appears to act quite as well. The price of naphthaline, however, caused the cost of this material to be very high.

Xylotrechus quadripes, the coffee borer, is still troublesome. The most efficient remedy so far discovered is to scrub the stems of the bushes in October-November with coconut husk to destroy and dislodge the eggs which are laid in the crevice and under loose pieces of bark. Dr. Coleman, the Director of Agriculture in Mysore, has published the results of some work done with methods of control of this insect.

TEA.

Of tea pests Helopellis contimues to be the worst insect pest and no new remedies have been found for it. A combination of spraying, pruning large areas at one time down wind, burning the prunings, and hand-catching are employed and these give a certain measure of control. but do not materially help to stamp out the pest. Its attacks are most severe in the monsoon which renders all work in connection with it difficult and spraying out of the question.

Of other pests there have been small sporadic outbreaks of the caterpillars of Thosea cevina which were easily controlled by hand-picking and collection of cocoons and cultivation of the soil round the affected bushes after the cocoons had been formed in it. Caterpillars and cocoons were sent me on 20th August 1917 and from these moths began to emerge in the laboratory at Bangalore on 3rd January 1918.

Some specimens of a bark-eating borer have been recently received which are said to do a certain amount of damage. This appears to be a species of Arbela but more specimens are required for identification purposes. This pest is still under investigation and I have no notes at present of any ralue about it.

Aspidiotus camellice, the yellow bark-louse, a seale which used to give a considerable amount of trouble in young tea, especially in replanted 
coffee land, has not of late done much damage and it is found to be controllable by means of fish-oil-resin sprays.

Caterpillars of Contheyla rotumla did a little local damage to tea in the Wynaad in 1917 and specimens of caterpillars of Terias sithetena in Mundakayam attacked Albizzias and the tea beneath them. Both attacks were easily controlled.

\section{RubBer.}

Rubber continues free from insect pests. All the diseases of importance are due to fungal attacks.

\section{Fruit.}

An interesting beetle attacking Citrus trees-Oranges and Limesat Bangalore has come under observation lately. This is Chelidonium cinctum the larvæ of which bore the young shoots and old stems and do a large amount of damage. The following observations and notes may prove of interest :-

The eggs are deposited in June in the axils of young living twigs (never on dead wood or on old branches). The eggs are covered with a sort of yellow transparent varnish. As soon as the eggs hatch the young larva bores into the twig and works upwards for about $\frac{1}{2}-1 \frac{1}{2}$ inches and then makes two tiny holes about the size of a pin's head. It then turns back and bores down the twig occasionally making small openings. Finally it gets into the main branches where it makes tunnels $\frac{1}{4}$ inch in diameter. The young twigs at once die, turning black so that they are easily seen and they can be cut off with the larva inside them. By doing this and by catching the adult insects with handnets the attack was to a large extent controlled. The time taken after deposition for the eggs to hatch appears to be about two weeks.

\section{Miscellaneous.}

The larva of a Tiger Beetle was found in the Shevaroys in December 1917 boring into the tops of young coffee stems. It enters the stems abont 9 inches from the top and makes a tumnel uprards some 2 inches long. An attempt to raise the perfect insect in captivity failed and the insect has not been seen since.

Stegodyphus sarasinorum, a spider which makes long bags in which to live, is sometimes found in tea bushes where it is untidy but of course does no harm. 
The following special notes on insects have been published in the pages of the Planters' Chronicle during 1917-18:-

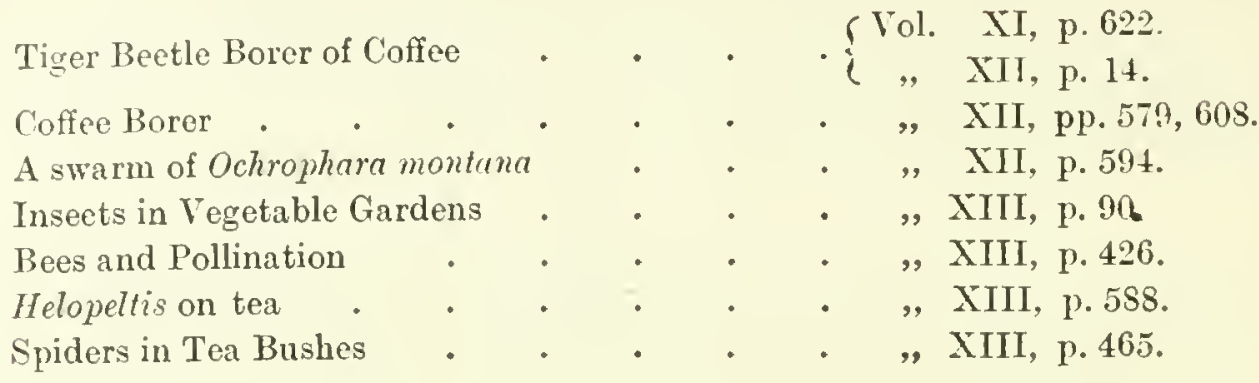

This paper is now open for discussion, and in the first place I should like to say that we are considerably indebted to Mr. Anstead for giving us this summary of the insect pests which he has come across in the Planting Districts of South India during the last two years.

In speaking of Pseudococeus citri he mentions a loss of feeding-roots of young coffee-plants as due to this scale which is also described as eating into the bark. As this scale is a sucking insect, it could not eat away the roots or eat into the bark, and this type of injury is presumably due to cockichafer grubs.

\section{5.-A LIST OF LEPIDOPTERA NOTED TO ATTACK CULTIVATED PLANTS IN CEYLON.}

By R. Senior-White, F.E.S.

Numphalid

Hypolimnas bolina.

Neptis eurynome. Canaralia gladiata, Vigna catjang.

Melanitis ismene. Sorghum, Panicum maximum. Parasitized by a Tachinid.

Danais plexippus. Stephanotis sp.

(U. R. 3.) Ficus parasitica, Carissa carandas.

Telchinia violce. Passiftora foetida.

Papilionidæ.

Papilio demoleus. Citrus spp., Feronia elephantum.

Papilio agamemnon. Anona muricata.

Papitio pammon. Citrus spp., Murraya kanigii.

Papilio parinda. Citrus sp.

Papilio aristolochice. Aristolochia sp.

Pieride.

Terias hecabe. Cassia fistula. 
LYCAXIDA.

Catochrysops cnejus. Tigna catjang.

Jamides bochus. Tigna catjang.

Chilades lains. Feronia elephantum.

Spalgis epius. Pseudococcus sp. on Solamm sp.

HESPERIADA.

Hesperia galba. Hibiscus sp. (hollyhock).

Eupterotidæ.

Eupterote geminata. Erythrina indica, Theobroma cacan, Cajanus indicus. Parasitized by Tachinid.

SPhingide.

Rhyincolaba actens. Callatium vars. Parasitized by Tachinid.

Charocampa theylia (vinacen).* Balsamifera impatiens; very bad in November only.

Charocampa theylia.† "Pach-arisi-pillu" (Tamil). This plant is a bad dry-weather weed in rubber.

Nephele hespera. Carissa carandas.

Deilephila nerii. Tinca sp., Oleander spp.

Acherontia lachesis. Erythrina indica, Solanum melongena, Capsicum spp. Parasitized by Tachinid.

Acherontia styx. Solanum melongena. Tery rare in Matale District.

Herse convolvuli. Vigna catjang.

Notodontide.

Stauropus altermus. Cajamus indicus.

Sratonide.

Syntomis passalis. Phaseolus vulgaris, Capsicum spp. Kohlrabi, Daisy vars, Trichosmthes anguina. Parasitized by two species of Tachinids.

Symtomis cyssea. I pomoa rubro-carulea.

ThYRIDID E.

Dysodia ignita. Croton aromaticus.

LASIOCAMPIDA.

Suana concolor. Psidium guyara, Cajamus indicus, Hibiscus rosasinensis. Attacked by a Phorid parasite.

* The species here referred to as $C$. theylia (vinacea) is presumably Hippotion rafflesi, Butl. (See Roths and Jordan, Revis Sphing., p. 755.)-Editor.

$\dagger$ The species hero referred to as $C$. theylin is presumably Hiprotion boerlinvice, Fab. (vidoloc-cit p. 756). The true Sphinx thyelia of Linnous is a South American Xylophanes.-Editor. 


\section{LIMACODIDE.}

Altha lacteola. Carissa carandas.

Thosea cana. Rose.

Naiosa conspersa. Feronia elephantum.

LYMANTRIADE.

Dasychira fasiformis. Pelargonium vars, Canna sp., Citrus sp., iose. Tigna catjang, C. carandas, Kohl-rabi, Solanum melongena, Phaseolus mungo, Cajams indicus, Antigonon sp., Moringa pterygosperma.

Dasychira divisa. Daisy vars, Amaryllid lily.

Dasychira mentosa. Vigna catjang.

Dasychira horsfieldi. Tigna catjang.

Dasychira sp. (? mendosa). Solanum melongena, Citius sp., Acalypha $\mathrm{sp}$.

Lymantria ampla. Pelargonium vars, Theobroma cacao, Begonia sp., Carissa carandas, rose, Quisqualis indica, Cajanus indicus.

Orgyia postica. Pelargonium vars, Erythina lithosperma, Vigna caljang, Cama sp., P. gratissima, Cajanus indicus, Solanum melongena, mangosteen.

Latia exclamationis. Canna sp.

Euproctis scintillans. Rose, Daisy vars, Capsicum sp., Cajamus indicus.

Euproctis fraterna. Citrus sp., Feronia clephantum, Pelargonium vars, Solanum melongena, rose, Hibiscus rosa-sinensis. Parasitized by a Tachinid.

Euproctis semisignata. Quisqualis indica.

\section{PSICHID五.}

Acanthopsyche cana. Hevea brasitiensis.

A. punctimarginalis. Bred on Algæ on bamboo.

(AO. 2.) Anona muricala. Failed to rear out. Bad pests.

(PO.) Antigonon sp. Failed to rear out. Bad pests.

Clania crameri. Cajanus indicus.

\section{ARCTIADE.}

Estigmene lactinea. Onion, kohl-rabi, beet.

Pericallia ricini. Solanum melongena, Phaseolus vulgaris, Colocasia sp., Oleander, liohl-rabi, rose, Cajamus indicus, mustard, Momordica charentia, Luffa aculangula. Parasitized by a Tachinid.

Pisara lucidalis. Carissa carandas.

Selea plagiola. Solamum melongena.

Nyctemora lacticinia. Vernonia emeria, a bad weed. Feeds mainly on seed heads. 
Noctutd e.

Glottula dominica. Amaryllis spp.

Polytela gloriosa. Amaryllis spp., Gloriosa superba.

Plusia. (Co. 6). Daisy vars. (? P. limbirena).

Plusia orichalcea. Kohl-rabi, carrot, Pimpinella anisum.

Plusia agramma. Trichosanthes anguina.

Plusia chalcytcs. Onion, Zimia, Solanum melongena, dahlia.

Plusia obtusisigna. Coleus sp.

Cosmophila indica. Hibiscus sp. (hollyhock), H. rosa-sinensis.

Achaca melicerte. Rose.

Oplives coronata. Quisqualis indica.

Plotheia nephelotis. Solamm melongena.

Chlorider obsoleta. Pelargonium vars, Dianotess sp., Canna sp.\% Hibiscus esculentus.

Chloridea assulta. Physalis peruviana.

Prodenia litura. Solamum lycopersicum, S. melongena, Capsicum spp., Petumia, onion, cabbage, carrot, beet, Balsam. impatiens, Zimnia, Canna sp., Gossypium sp. (Cambodia), P. gratissima, Dioscorea sp., C'olocasia sp., mustard, Pelargonium vars, $H$. esculentus, Momordica charantia, Begonia vars, Phaseolus vulgaris, Tigna catjang.

Eublemma divacea. Solamum melongena.

Eublemma scitula. Pseudococci on C. carandas.

Acontia tiansiersa. Hibiscus esculentus, H. sp. (hollyhock).

Euplexia opposita. Carrot, Daisy var.

Panilla alboprenctata. Polyporus zonatis (hymenium surface only).

Amyma selenampha. Croton aromaticus.

Hypena cognata. Lantana.

Lacera alope. C'cesalpinia sappan.

Earias chromataria. Hibiscus sp. (hollyhock).

Earias fabia. Hibiscus esculenters.

Remigia frugatis. Panicum maximum.

(Z. A.3.) Himeola lispidula.

Beara dichromella. Hibiscus rosa-sinensis.

Geometride.

Craspedia fibulata. Kohl-rabi, Pelunia, Dendrobium macarthice, Calanthe restita. Pimpinella anisum, spinach.

Craspedia remotata. Gnaphatium sp. "Ponmandey Kriey" (Tam) garden edging plant.

Hyposidia talaca. Salvia sp., Peltophorum ferrugineum, Canna sp. Zinnia sp., rose, Solanum melongena, Casalpinia sappan, Vigna catjang.

YOL. I 
Gymnoscclis albicandata. Hibiscus sp. (hollyhock).

Thalera caudularia. Antigonon sp.

Boarmia acaciaria. Cassia fistula.

Boamia bhumitra. Solanum melongena, Capsicum sp.

Pseudoterpna chlora. Cajanus indicus.

Cidaria cingala. Balsam. impatiens.

Nemoria integranota. Cajanus indicus.

Thalassodes veraria. Rose.

Pyralide.

Hymenia fascialis. Celosia sp., beet.

Hellula undalis. Kohl-rabi, turnip, cabbage, mustard.

Glyphodes bivitralis. Ficus religiosa, F. glomerata.

Glyphodes indica. Trichosanthes anguina, melon vars.

Terastia meticulosatis. Erythina lithosperma.

Sylepta derogata. Hibiscus esculentus, H. sp. (hollyhock), H. rosasinensis, Gossypium sp. (Cambodia).

Lepyrodes geometralis. Jasmine.

Nephopteryx mimutella. Solanum melongena.

Cracidolomia binotalis. Kohl-rabi, cabbage, mustard, Capsicum sp.

(Cut-worm). Parasitized by a Tachinid.

Myelois pectinicornella. Theobroma cacao.

Epicrocis lateritialis. Beleropone sp.

Pachyzancla agrotalis. S. melongena, S. indicum?

Nacolcia indicata. Anona muricata. A single occurrence between

two small leaves. Larva dark blue from ingested food.

Maruca testulalis. Phaseolus vulgaris rars.

Lencinodes orbonalis. Solamum melongena.

Dichocrocis punctiferalis. Sorghum (in heads).

Lygropia quaternatis. "Damum," Singhalese (? Malvaceous.)

Euzopliera perticella. Solanm melongena.

Tineina.

Plutella maculipennis. Turnip, cabbage, mustard.

Gelechia gossypiella. Gossypizm sp. (Cambodia).

Comocritis pieria. Hevea brasilicnsis. 11th December 1918. Young larva found in No. 12. Evidently hatehed within last few days. Webbing patch somewhat eircular, but beginning to extend into usual line in large ears, usually upwards. Size of patch up to $\frac{1}{4}$ " diameter. Cold weather a few days earlier.

TORTRICIDE.

Adorophyes privatana. Cajanus indicus.

(C. O.). Dahlia. 
Pterophoride.

Sphenarches caffer. Pelargonium vars, Theobroma cacao.

Steganodactyla conoursa. Lanlana, Passiflora fotida.

6.-A LIST OF PLANTS. WITH THEIR LEPIDOPTEROUS PESTS, IN CEYLON.

ACANTHACE

By R. SeNior-White, F.E.S.

Beleropone sp. Epicrocis lateritialis.

Amarantacee.

Celosia sp. Hymenia fascialis.

Amarillide.

Cultivated species. Glottula dominica, Polytela gloriosa, Dasychira divisa.

Anonacee.

A. muricata. Papilio agamemnon, Psychid, Nacoleia indicata.

Apocynaceæ.

Carissa carandas. Altha lacteola, Nephele hespera, Pisara lucidalis, Dasychire fusiformis, Lymantria ampla.

Vinca sp. Deilephila nerii.

Oleander spp. Deilephita nerii, Pericallia ricini.

AROIDE A.

Calladium vars. Theretra actea.

Colocasia sp. Pericallia ricini, Prodenia litura.

Aristolochiaceæ.

Aristolochia sp. Papitio aristolochice.

Asclepiadeæ.

Stephanotis sp. Adtoxophyes privatana, Danais plexippus.

Begoniace.e.

Cultivated vars. Lymantria ampla, Prodenia litura.

Bromeliacel.

Ananas sativus. (Pseudococcus sp.).

Chenopodiaceæ.

Spinach. Craspedia fibuluta.

Beet. Hymenia fascialis, Estigmene lactinea, Prodenia litura.

"Ponnandey-Kirey." Craspedia remotata.

Combretace

Quisqualis indica. Euproct is semisignala, Lymantria ampla, Ophiusa coronata. 
Composites.

Daisy vars. Dasychiva divisa, Plusia (CO. 6), Syntomis passalis. Adoxophyes privatana, Euplexia opposita.

Gnaphalium sp. Craspedia rematata.

Chrysanthemum vars. Homona sp.

Dallia vars. Plusia chalcytes, Euproctis scintillans.

Zimia vars. Hyposidra talaca, Plusia chalcytes, Prodenia litura.

\section{Convolyulace}

I pomoea nubro-coerulea. Syntomis cyssea.

\section{CruCiFERE.}

Kohl-rabi. Hellula undalis, Craspedia fibulata, Crocidolomia binotalis, Plusia orichalcea, Dasychira fusiformis, Syntomis passalis, Estigmene lactinea, Pericallia ricini.

Turnip. Hellula undalis, Platella maculipennis.

Cabbage. Hellula undalis, Crocidolomia binotalis, Plutella maculipennis, Prodenia litura.

Mustard. Hellula undalis, Plutella maculipennis, Pericallia ricini, Prodenia litura, $C$. binotalis.

\section{Cucurbitace as.}

Trichosanthes anguina. Plusia agramma, Glyphodes indica, Syntomis passalis.

Melon vars. Glyphodes indica.

M. charantia. Pericallia ricini, Prodenia litura.

Luffa acutangula. Prodenia litura.

DIOSCORACEA.

Dioscorea sp. ("angili-ala"). Prodenia litura.

Caryophyllacede.

Dianthus sp. (Indian fruits). Chlovidea obsoleta.

\section{Euphorbiace E.}

Hevea brasiliensis. Acanthopsyche cana, Comocritis pieria.

Acalyplea sp. Adoxophyes privatana, Dasychira (? mendosa).

Croton aromaticus. Amyna selenampha, Dysodia ignita.

\section{Geraniaceæ.}

Pelargonium vars. Homona sp., Dasychira fusiformis, Lymantria ampla, Sphenarches caffer, Prodenia litura, Orgyia postica, Euproctis fraterna, Adoxophyes privatana, Chloridea obsoleta.

Balsamifera impalichs vars. Chorocampa theylia (vinacea), Cidaria cingala, Prodenia litura. 


\section{Graminex.}

Sorghum. Mclanitis ismene, Dichocrocis punctiferatis.

P. maximum. Melanitis ismene, Remigia fragalis.

\section{Guttifere.}

Mangosteen. Orgyia postica.

\section{LABIAT死.}

Salvia sp. Hyposidia talaca.

Coleus sp. Plusia obtusisigna.

\section{LAURACE $\circledast$.}

P. gralisima (avocado). Orgyia postica, Prodenia litura.

\section{LEGUMINOS无.}

Canaralia gladiata. Homona sp., Neptis eurynome.

Vigna catjang. Dasychira fusifomis, Orgyia postica, Calochrysops cnejus, Dasychira mendosa, Jamides bochus, Adoxophyes privatana, Herse comolvuli, Dasychiva Torsfieldi, Neptis eurynome, Prodenia litura, Hyposidia talaca.

Phascolus mungo. Dasychira fusiformis.

Cajanus indicus. Dasychira fusiformis, Orgyia postica, Pseudoterpna chlora, Stauropus altermus, Nemoria integranota, Enproctis scintillans, Pericallia ricini, Suana concolor, Clania crameri, Adoxophyes privatana, Lymantria ampla, Eupterote geminata.

Enythrina spp. Orygia postica. Terastia meticulosalis, Eupterote geminata, Acherontia lachesis.

Pcltophorum ferrugincum. Hyposidya talaca.

Casalpinia sappan. Hyposidra talaca, Lacera alope.

Phaseolus vulgaris vars. Syntomis passalis, Maruca testulatis, Pericallia ricini, Prodenia litura.

Cassia fistula. Terias hecabe, Boarmia acaciaria.

\section{LILIACE丑.}

Gloriosa superba. Polytelagloriosce.

Onion. Estigmene lactinea, Plusia chalcyles, Prodenia litura.

\section{Malvace无.}

Hibiscus esculcntus. Sylepta derogata, Acontia transversa, Earias fabia, Chloridea obsoleta.

Hibiscus sp., (Hollyhock). Sylepta derogata, Cosmophila indica, Hesperia galba, Gymnoscelis albicaudata, Earias chionataria, Acontia transversa.

Hibiscus rosa-sinensis. Sylepta derogata, Cosmophila indica, Beara dichromella, Euproctis fraterna, Suana concolor.

Gossypiuin sp. (Cambodia). Sylepta derogata, Gelechia gossypiella, Prodenia litura. 


\section{MIORINGE.}

Moringa pterygosperma. Dasychira fusiformis.

Myrtacew.

Psidium guyava. Suana concolor.

Oleacem.

Jasmine. Lepyrodes geometralis.

ORCHIDE א.

Dendrobium macarthice. Craspedia fibulata.

Calanthe vestita. Craspedia fibulata.

Passifloracex.

P. fotida. Homona sp. (CO 3), VB 2, ? Telchivia viola.

Polygalacex.

Antigonon sp. Thalera caudularia, Psychid, Dasychira fusiformis:

ROSACEæ.

Roses. Dasychira fusiformis, Lymantria ampla, Achoea melicerta, Euproctis scintillans, Thosea cana, Euproctis fraterna, Pericallia ricini, Thalassodes veraria, Hyposidra talaca.

\section{Rutace}

Citrus spp. Dasychira fusiformis, Euproctis fraterna, Papilio demoleus, Homona longipalpus, Papilio polytes, P. parinda, Dasychira sp. (? mendosa).

Feronia elephantum. Papilio demoleus, Chilades laius, Narosa conspersa, Euproctis fraterna.

Murraya koenigii. Papilio polytes.

Scitamineæ.

Canna vars. Dasychira fusiformis, Orgyia postica, Hyposidra talaca, Latia exclamationis, Prodenia litura, Chloridea obsoleta.

\section{Solanace}

Solamm melongena. Dasychira fusiformis, Orgyia postica, Hyposidra talaca, Acherontia lachesis, Plusia chalcytes, Euproctis fraterna, Plotheia nephelotis? Pericallia ricini? Nephopteryx minutella, Pachyzancla agrotalis, Prodenia linura, Eublemma olivacea, Leucinodes orbonalis, Dasychira sp. (? mendosa), Selca plagiola, Acherontia styx, Boarmia bhurmitra, Euzophera perticella.

Petunia. Crasperia fibulata, Prodenia litura.

Capsicum spp. Crocidolomin binotalis, Syntomis passalis, Euproctis scintillans, Prodenia litura, Boarmia bhumitra. Acherontia lachesis.

S. Iycopersicum. Prodenia litura.

Physalis peruviana. Chloridea assulta.

S. indicum? Pericallia ricini, Pachyzancla cogrotalis. 


\section{Sterculiace E.}

Theobroma cacao. Lymantria ampla, Sphenarches caffer, Chloridea obsoleta, Myelois pectinicornella, Eupterote geminata.

\section{UMBELLIFFERÆ.}

Pimpinella anisum. Craspedia fibulata, Plusia orichalcea.

Carrot. Plusia orichalcea, Prodenia litura, Euplexia opposita.

\section{URTICACEÆ.}

Ficus parasitica. Adoxophyes privatana.

Ficus religiosa. Glyphodes bivitralis.

Ficus glomerata. Glyphodes bivitralis.

\section{VERBENACEE.}

Lantana. Hypena cognata, Steganodactyla concursa.

Fungi.

Polyporus zonalis. Panilla albopunctata.

Hrincola hispidula. (ZA. 3) (also eaten by Ceropia induta, fide Petch).

\section{7.-A LIST OF THE PESTS OF CEREALS IN BURMA.}

By K. D. Shroff, B.A., Entomological Assistant, Burma.

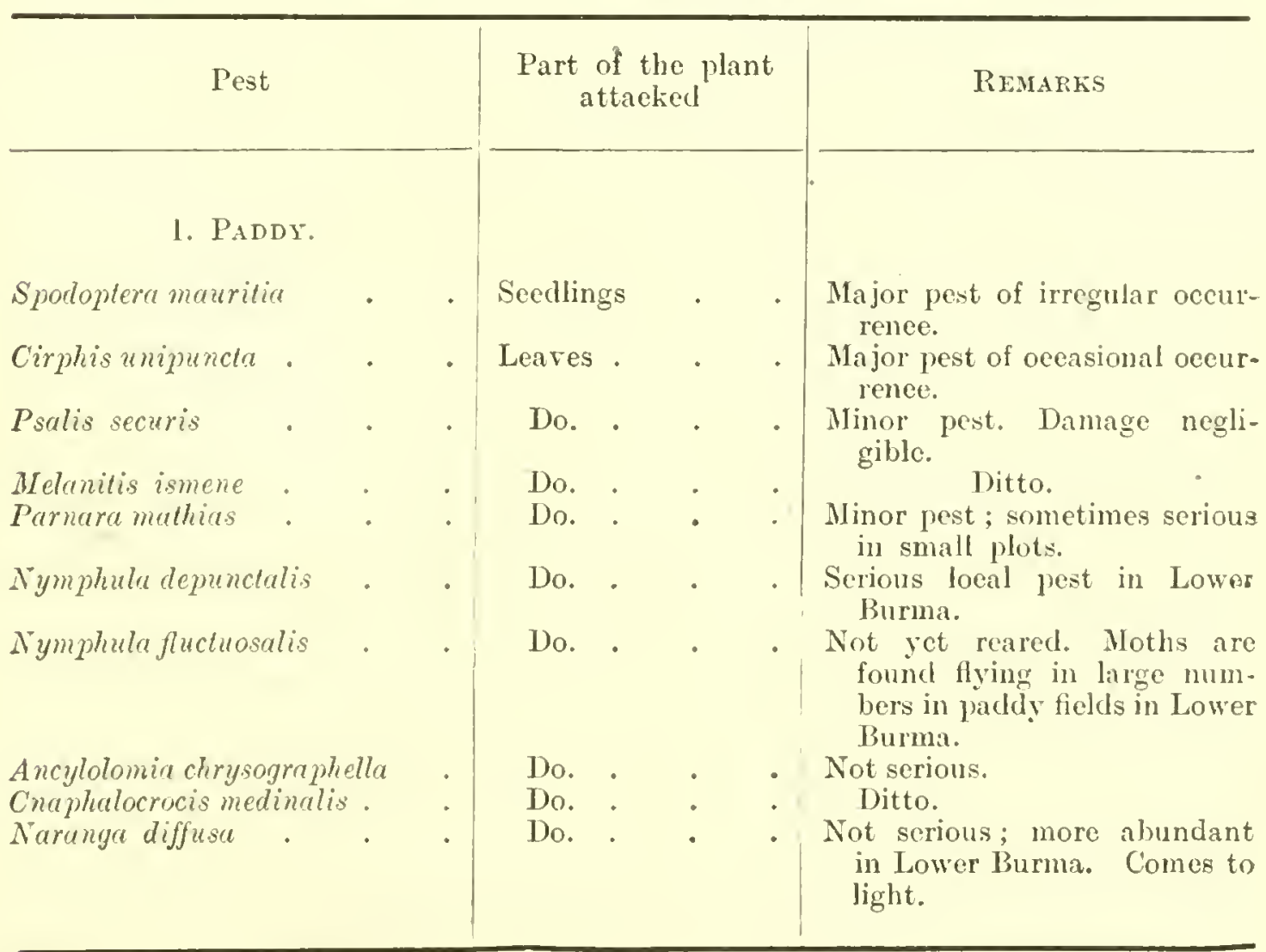


7.-A LIST OF THE PESTS OF CEREALS IN BURMA-contd.

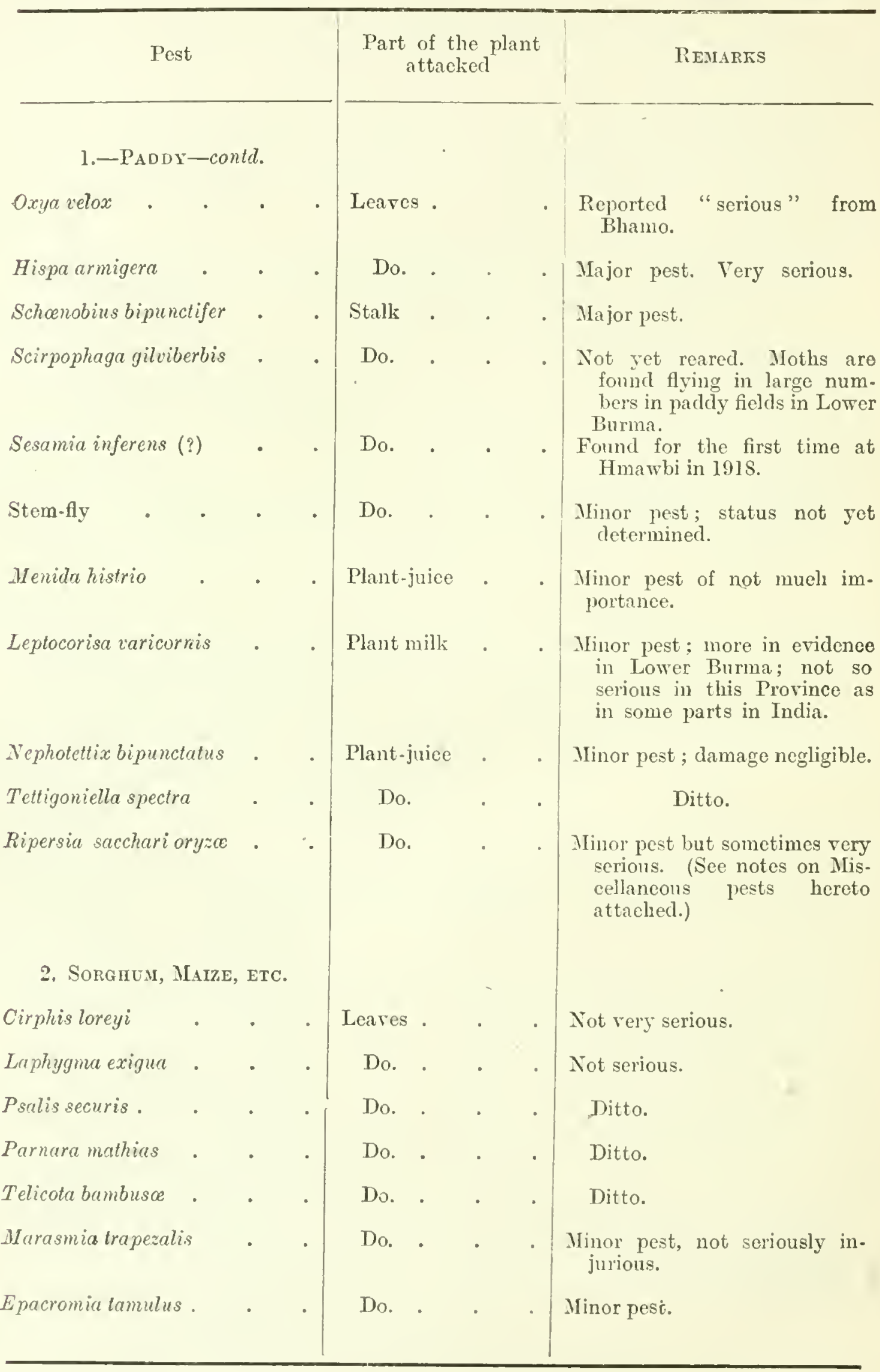




\section{7.-A LIST OF THE PESTS OF CEREALS IN BURMA-concld.}

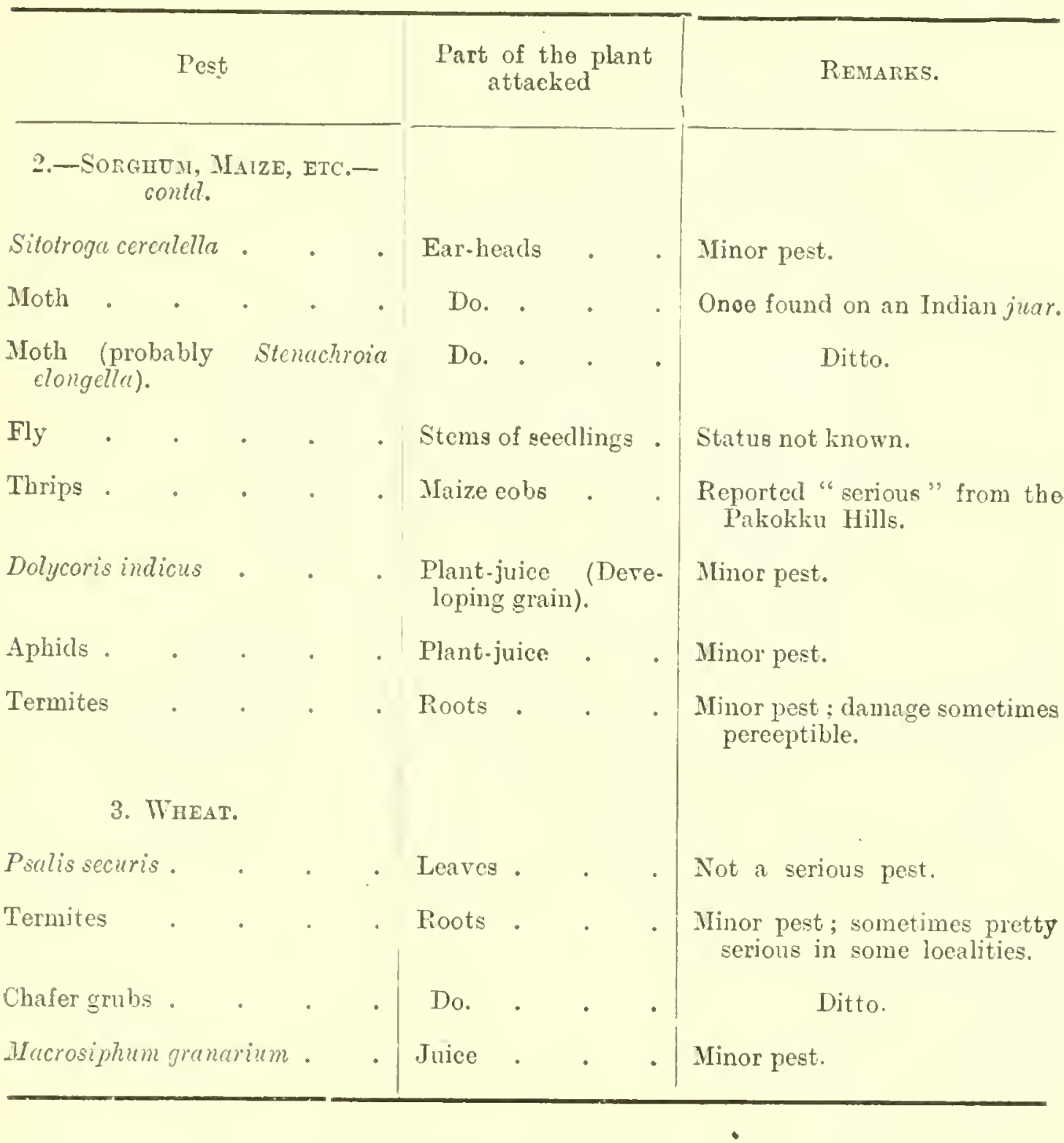

\section{8.-A LIST OF THE PESTS OF PULSES IN BURMA.}

By K. D. Shroff, B.A., Entomological Assistant, Buma.

\begin{tabular}{|c|c|c|c|}
\hline Pest & - & $\begin{array}{l}\text { Part of the plant } \\
\text { attacked }\end{array}$ & Remares \\
\hline \multicolumn{2}{|c|}{$\begin{array}{l}\text { 1. TUR (PE-SEIX-GOX) (CAJAYTS } \\
\text { INDICES). }\end{array}$} & & \\
\hline Solenopsis geminata & . & Leares of seedlings . & Minor pest. \\
\hline Flea beetles . & . & Do. & Ditto. \\
\hline
\end{tabular}


8-A LIST OF THE PESTS OF PLLSES IN BURMA-contd.

\begin{tabular}{|c|c|c|c|c|c|}
\hline \multicolumn{3}{|l|}{ Pest } & \multicolumn{2}{|c|}{$\begin{array}{l}\text { Part of the plant } \\
\text { attaeked }\end{array}$} & Remarks \\
\hline \multicolumn{6}{|c|}{$\begin{array}{l}\text { 1. TUR (PE-SeIN-GoN) (CAJANUS } \\
\text { INDIOUS)-contd. }\end{array}$} \\
\hline Euproctis fraterna. & . & . & Loaves. & . & $\begin{array}{l}\text { Minor pest of not much import } \\
\text { anee. }\end{array}$ \\
\hline Euproctis scintillans & . & . & Do. . & . & Ditto. \\
\hline Lanaguna breviuscula & . & . & Do. . & . & Ditto. \\
\hline Dasychira fasciformis & . & . & Do. & . & Ditto. \\
\hline Dasychira mendosa. & $\cdot$ & - & Do. . & . & Ditto. \\
\hline Celama internella . & - & - & Do. . & . & Ditto. \\
\hline Cacoecia micaceana. & $\cdot$ & . & Do. . & . & Ditto. \\
\hline Green Geometrid moth & $\cdot$ & . & Do. . & - & Ditto. \\
\hline Meranoplus bicolor & · & - & Do. . & . & Ditto. \\
\hline Zonabris pustulata. & . & . & Flowers & . & Minor pest ; searcely serious \\
\hline Thrips . · . & $\cdot$ & . & Do. & . & Ditto. \\
\hline Adisura atkinsoni. & $\cdot$ & . & Seeds in poc & . & \\
\hline Heliothis obsoleta . & $\cdot$ & - & Do. & - & \\
\hline Catochrysops cnejus & $\cdot$ & - & Do. & - & \\
\hline Sphenarches caffer . & . & . & & $\cdot$ & Minor pests; eause large \\
\hline Maruca testulalis . & . & . & Do. & $\cdot$ & aggregate damage. \\
\hline Etiella zinchenella . & . & . & Do. & - & \\
\hline Agromyza sp. . & 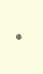 & - & Do. & . & \\
\hline Apion sp. & $\cdot$ & $\cdot$ & Do. & . & \\
\hline Coptosoma cribraria & $\cdot$ & - & Plant-juiee & . & Minor pest; not serious. \\
\hline Coptosoma sp. & . & . & Do. & . & Ditto. \\
\hline Cyclopelta obscura . & . & $\cdot$ & Do. & · & Ditto. \\
\hline Clavigralla gibbosa. & $\cdot$ & $\cdot$ & $\begin{array}{l}\text { Plant (unri } \\
\text { in pods). }\end{array}$ & e seeds & Ditto. \\
\hline Graptostethus servus & $\cdot$ & - & Do. & - & Ditto. \\
\hline Aphis (cardui?) & $\cdot$ & . & Shoots and & ods & Not very serious. \\
\hline
\end{tabular}


PROCEEDINGS OF TIIE THIRD ENTOMOLOGICAL MEETING

\section{8.-A LIST OF THE PESTS OF PULSES IN BURMA-contd.}

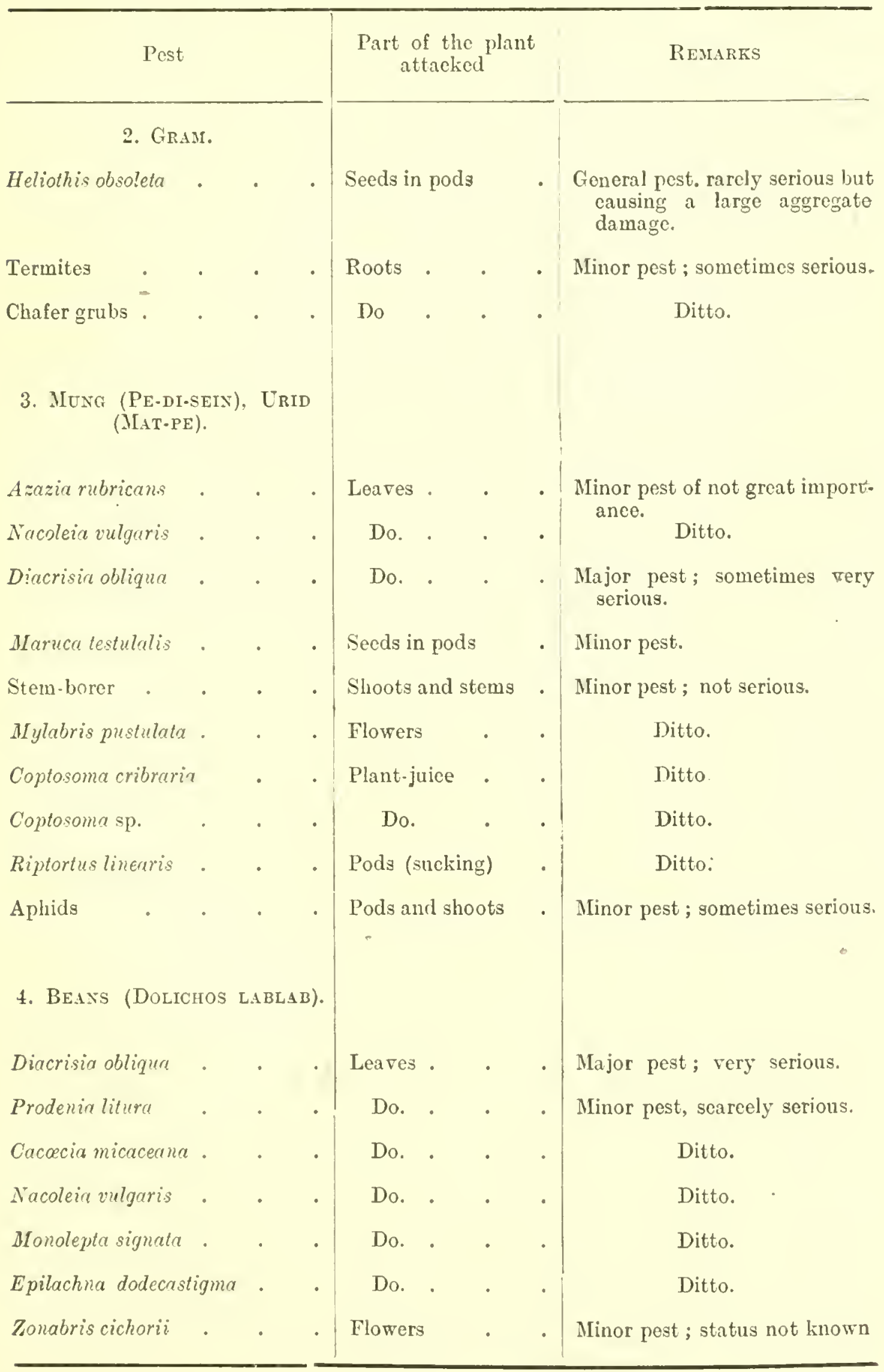


8.-A LIST OF THE PESTS OF PULSES IN BURMIA-concld.

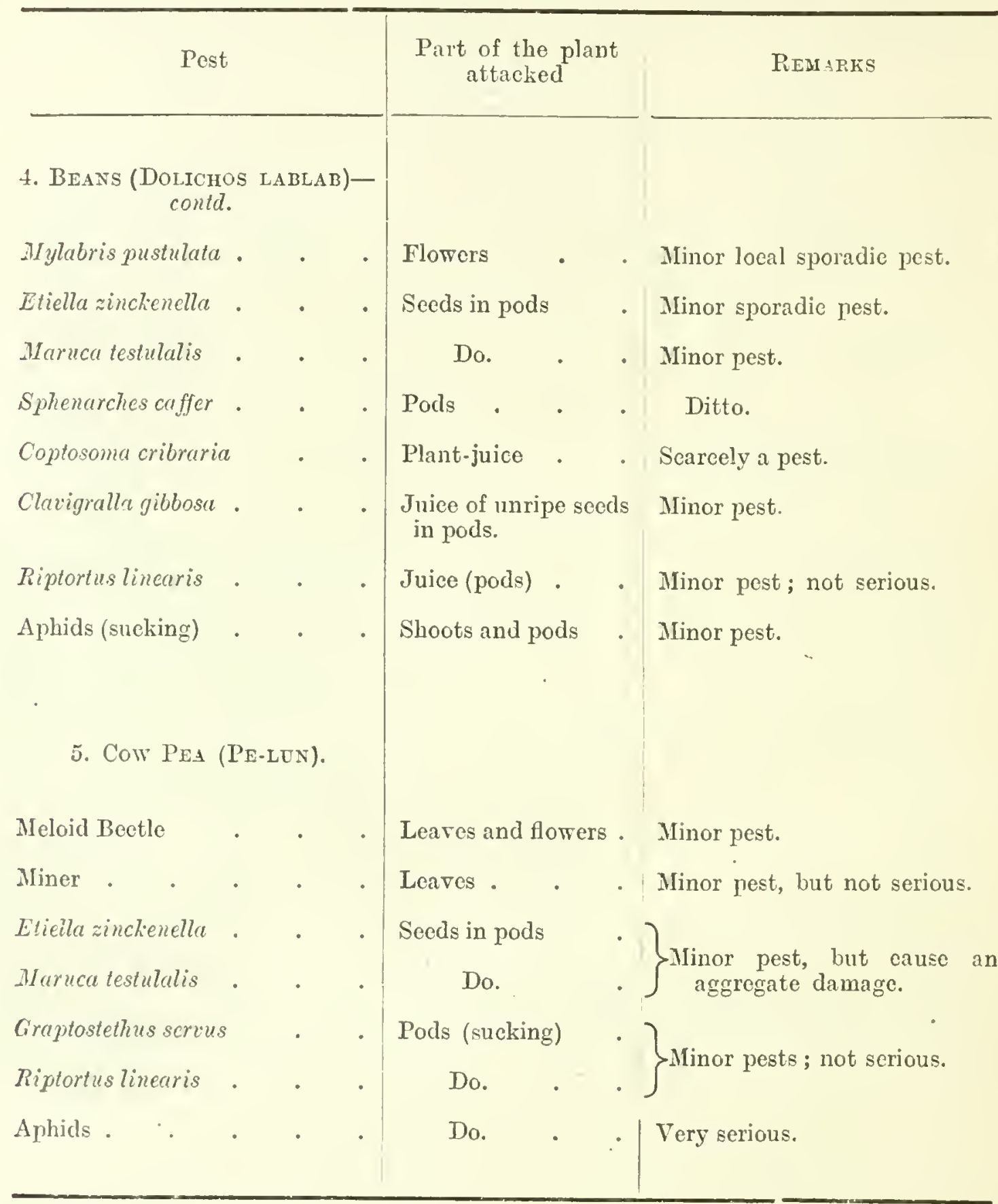

Mis. Fletcher.

This paper is open to discussion. It is unfortunate that Mr. Shroff has not been able to attend this Neeting, although we are indebted to him for sending us these lists of insect pests in Burma. The only remark I have to offer is that perhaps not too much reliance should be placed on the exact identification of some of the insects listed here. The name Dasychira fasciformis, for example, is based on an error in copying the name fusiformis, which is probably the same as $D$. mendosa. The names of the Meloid beetles also require check. 
PROCEEDIYGS OF THE TIIRD ENTOMOLOGICAI MEETING

\section{9.-A LIST OF THE PESTS OF OIL-SEED PLANTS IN BURMA.}

By K. D. Shroff, B.A., Entomological Assistant, Buma.

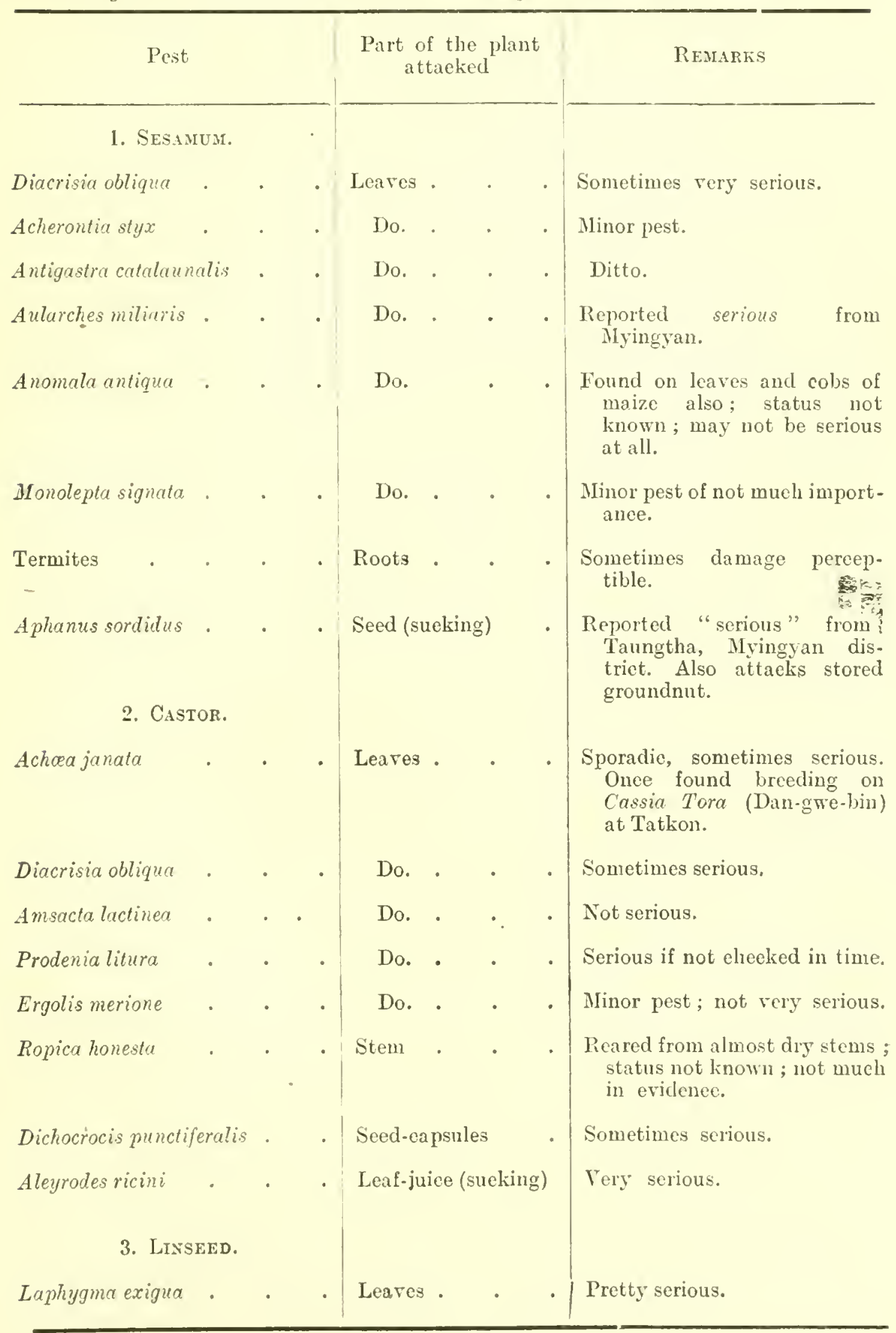




\section{9.-A LIST OF THE PESTS OF OIL-SEED PLANTS IN BURMA- contd.}

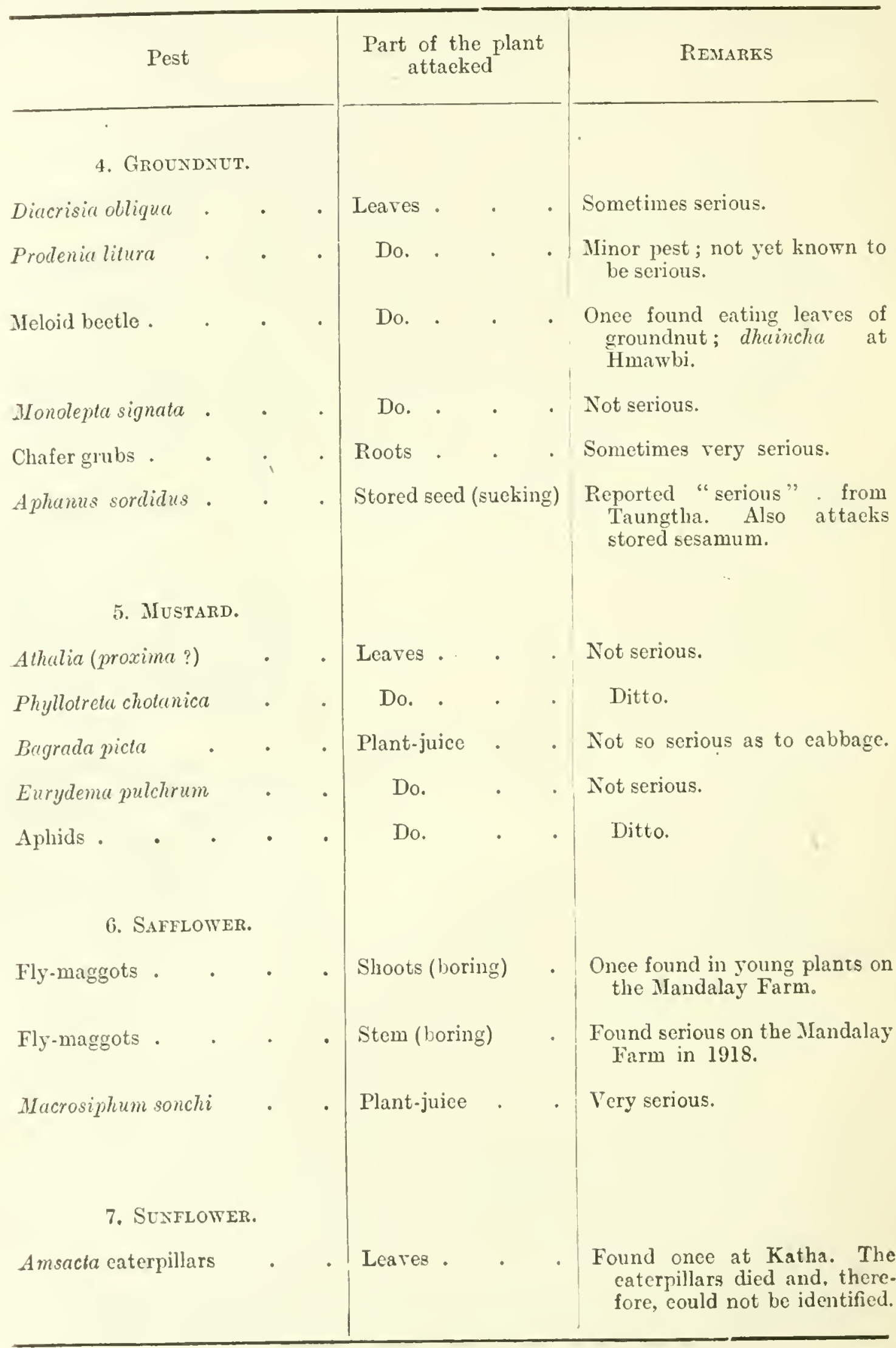


10.-A LIST OF THE PESTS OF TOBACCO IN BURMA.

By I. D. Shroff, B.A., Entomological Assistant, Burma.

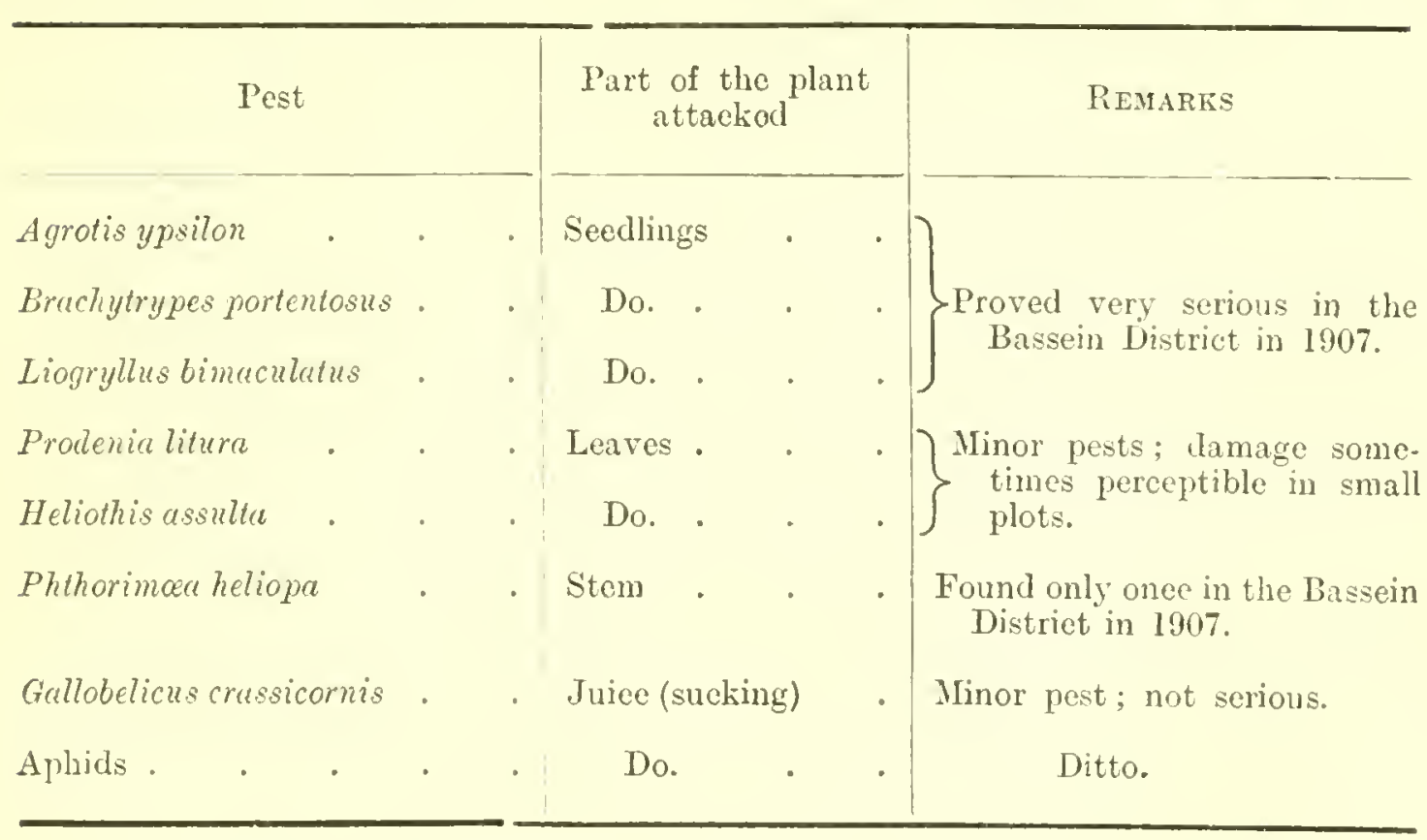

11.-LIST OF THE PESTS OF VEGETABLES IN BURMA.

By K. D. Shroff, B.A., Entomological Assistant, Burma.

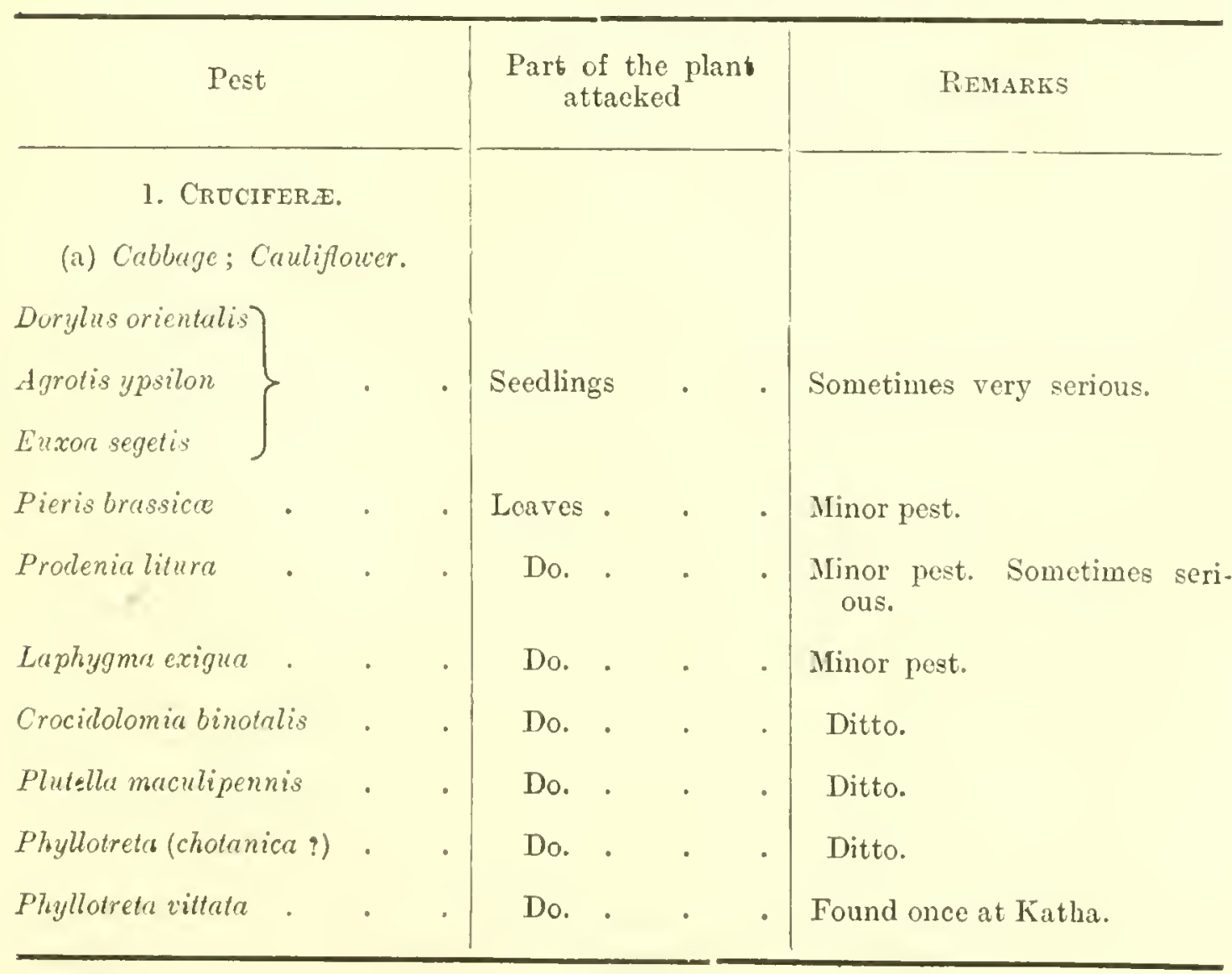


11.-LIST OF THE PESTS OF VEGETABLES IN BURMA-contd.

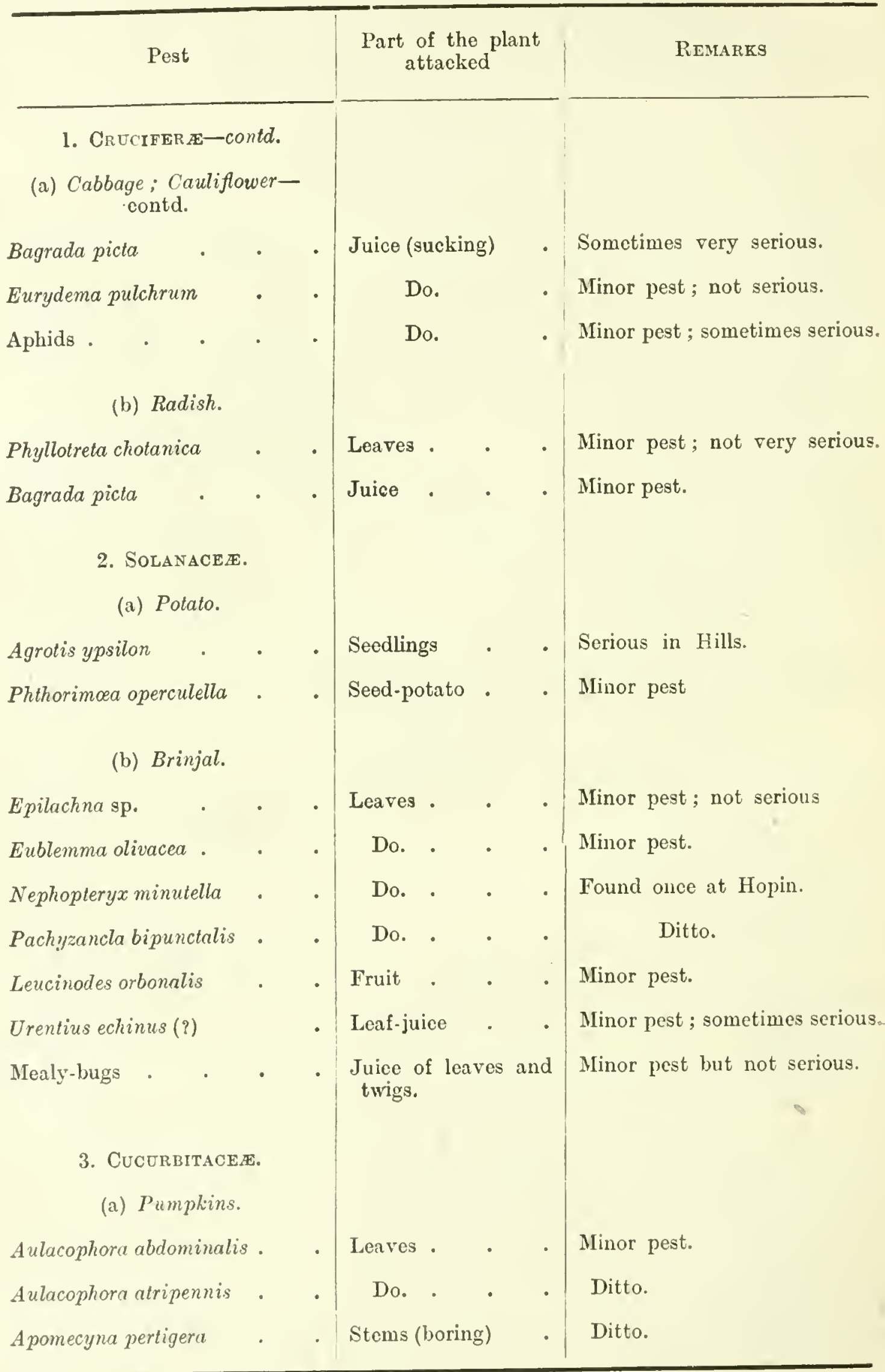


PROCEEDINGS OF THE THIRD ENTOMOLOGICAL MEETING

\section{1.-LIST OF THE PESTS OF VEGETABLES IN BURUA-contd.}

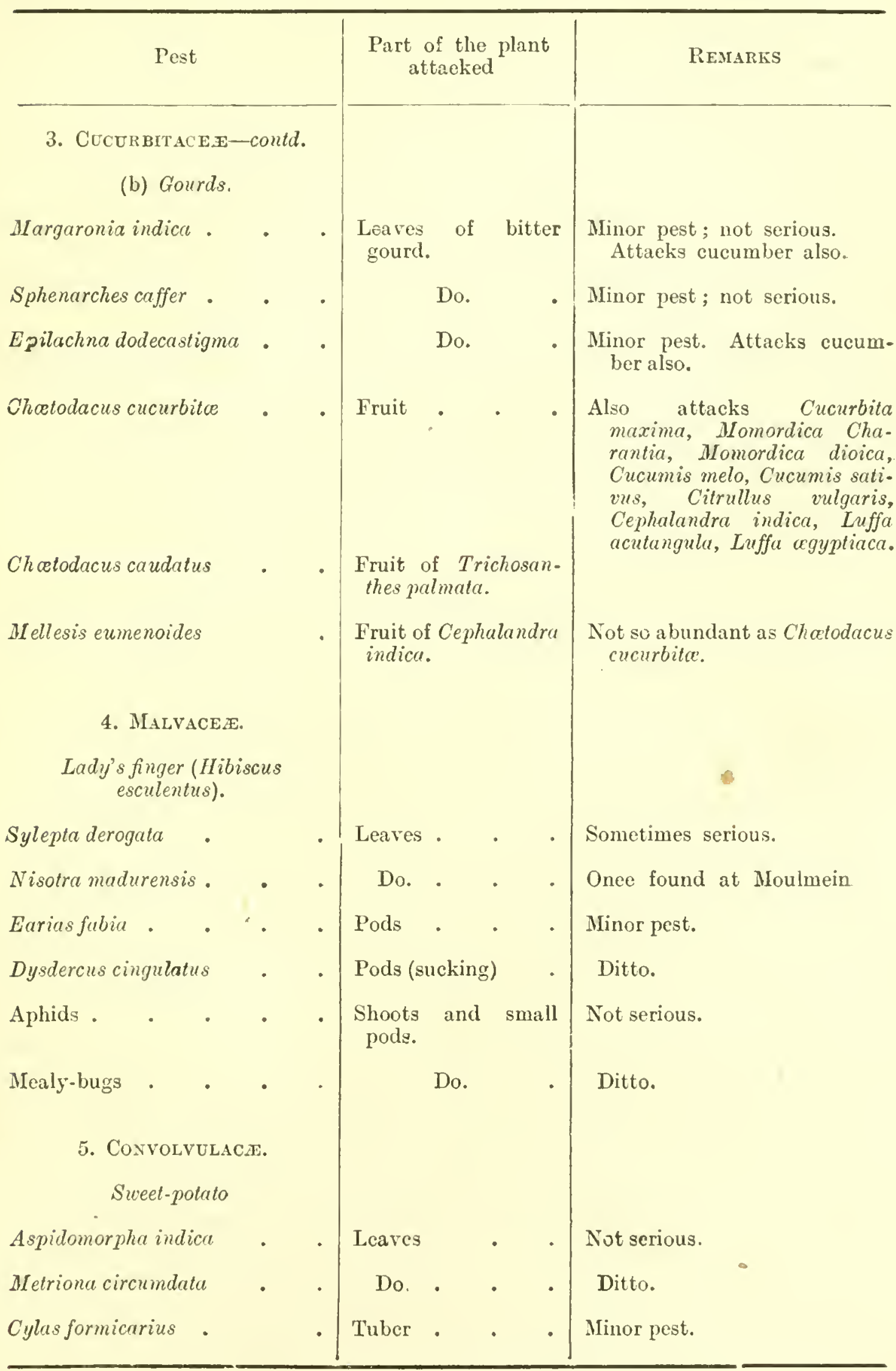




\begin{tabular}{|c|c|c|c|c|}
\hline \multicolumn{2}{|l|}{ Pest } & \multicolumn{2}{|c|}{$\begin{array}{c}\text { Part of the plant } \\
\text { attacked }\end{array}$} & \multirow[t]{2}{*}{ REMARKS } \\
\hline \multicolumn{2}{|c|}{ 6. AMARANTACEX. } & & & \\
\hline Deredus sparsus. & - & Leatas. & . & Not scrious. \\
\hline Lixus brachyrrhinus & . & Stem & . & Ditto. \\
\hline Cletus bipunctatus. & . & Plant-juice & . & Ditto. \\
\hline
\end{tabular}

Mr. Fletcher.

In this list of vegetables also I think that some of the names require check. It would, for example, be interesting to confirm the existence of Agrotis ypsilon in Burma. I also feel rather doubtful about Pieris brassicce as, when I looked over Mr. Shroff's collection at Mandalay in 1914, the Maymyo examples labelled as $P$. brassica. were all $P$. canidia.

\section{2.-NOTES ON MISCELLANEOUS PESTS IN RURMA.}

\section{By K. D. Shroff, B. A. Entomological Assistant, Rumma.}

The Paddy Case-worms (Nymphula). This pest is more prevalent in Lower Burma than in Upper Burma. The following notes on his observations and experiments were submitted by Mr. R. A. Beale, Assistant Botanist, Southern Circle, Burma :-

"Only tender leaves of young rice plants are attacked. Except in very rare cases (where the pest is present in large numbers) the attack is usually not fatal to the plants. When the plants reach a certain stage of development, their leaves become too tough for the pest which then seeks more tender food either among the crop of neighbouring fields or in the grasses on the bund.s."

"Keeping the bunds clean should be a fairly effective way of checking the spread of the pest, but it is hardly possible to do so on a large scale. Besides, the moths, which are numerous, may fly from field to field and deposit their eggs on healthy tender plants. The caterpillars in their cases may be carried by irrigation or drainage water ; so it is advisable, when draining an infested area, to place a net or trap across the opening in the bund through which the water passes. The ease-worms collect here in large numbers and may be removed and destroyed. Light traps may be used to eatch the moths at night." 



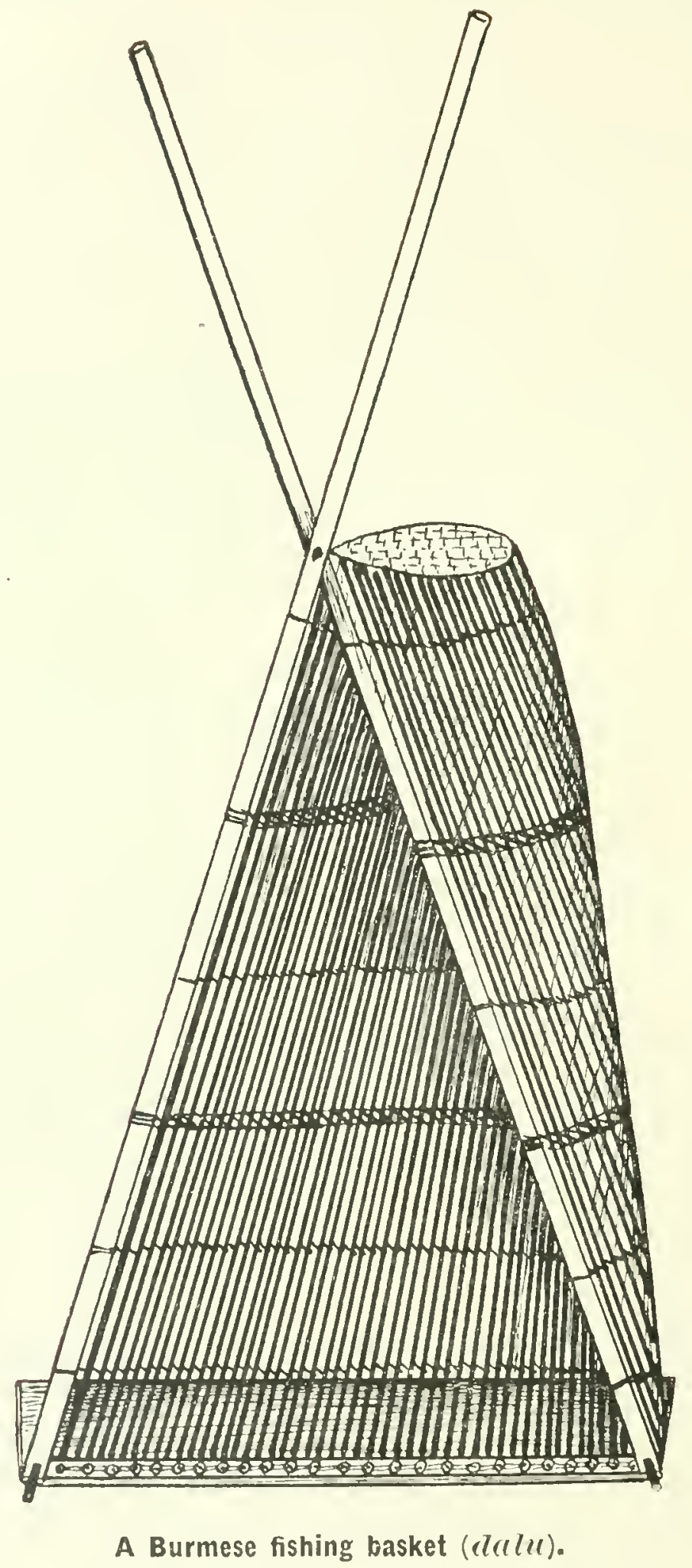


"Measures adopted on the Hmawbi Farm :-

1. Water was let out, where possible, from the fields attacked.

2. This was followed by two men walking along the bunds of the fields, holding a rope between them; with this the plants were shaken to dislodge the caterpillars. Generally it is safer to keep the field without water for three or four days, during which time the rope-dragging should be carried out a couple of times. This ensures the removal of all insects from the plants.

3. Where complete draining is not practicable, the insects may be collected after dragging with a rope either $(a)$ by hand in the corners of the fields and near the bunds, whither they are blown by wind, or (b) by means of a dalu (See Plate 21). This is a flat, triangular, open bamboo basket with handles, ordinarily used for catching mud-fish in drains, etc. By means of the handles it is pushed along, the open edge, which forms the base of the triangle, rumning along the ground. When used for collecting insects on water, the flat edge should run on the surface of the water. The insects floating anong the plants may thus be caught in large numbers. Very slight, if any, damage is done to the plants by the dalu passing over them."

2. Ripersia sacchari. This pest sometimes proves very serious to paddy plants in experimental plots and in patches in transplanted areas. If the plants are tender, they are completely killed; if they are tough, they are damaged but side-shoots sometimes come out. These new plants are evidently inferior to the healthy plants in the uninfested area. Mr. Lefroy, when he came to Burma, recommended to Mr. Warth, Agricultural Chemist, the destruetion of his infested experimental plots. This measure is not desirable. Is there any other remedy by means of which the attacked plants could be saved?

3. A Plantain Stem-boring Beetle. Please see the specimen No. 1, sent for identifieation.

This pest came to notice for the first time at Hmawbi. The grub first attacks the stalk of the leaf (probably the egg is laid on it) and gradually goes down to the stem. The slimy substance oozing out from the eracks and holes in the damaged parts, indicates the presence of the borer at work. It pupates inside the stem. All the stages are fornd inside the plant. It appears to be a serious pest.

4. A small Horned-bectle looking like a Rhinoceros beetle. See the specimen No. 2, sent for identification.

Two beetles were found along with Oryctes rhinoceros inside the rotten top of a dead coconut tree at Moulmein. 
13.-A LIST OF THE PESTS OF SUGARCANE IN BURMA.

By K. D. Shroff, B.A., Entomological Assistant, Burma.

\begin{tabular}{|c|c|c|c|c|c|c|}
\hline \multicolumn{4}{|l|}{ Pest } & \multicolumn{2}{|c|}{$\begin{array}{l}\text { Part of the plant } \\
\text { attacked }\end{array}$} & REMARKS \\
\hline Long-horned grass-1 & -hopt & & . & Leaves. & . & $\begin{array}{l}\text { Found eating leaves of young } \\
\text { cane in pots. }\end{array}$ \\
\hline Parnara mathias & . & . & . & Do. . & . & Not serious. \\
\hline Dasychira securis & . & . & . & Do. . & . & Ditto. \\
\hline Marasmia trapezali & & - & . & Do. . & . & Ditto. \\
\hline Chilo simplex (?) & . & . & . & Stem . & . & $\begin{array}{l}\text { Found pretty serious on the } \\
\text { Hmawbi Farm in } 1918 \text {. }\end{array}$ \\
\hline Scirpophaga & . & . & . & Do. & . & $\begin{array}{l}\text { A larva was once found in eane } \\
\text { at llandalay. As it died, } \\
\text { the species could not be } \\
\text { determined. }\end{array}$ \\
\hline Termites & . & . & . & Setts . & . & $\begin{array}{l}\text { Found serious on the Nagu } \\
\text { Farm, Shwebo Distriet, in }\end{array}$ \\
\hline Dorylus orientalis & . & $\cdot$ & . & Do. . & . & $\begin{array}{l}\text { 1918. Not yet reported } \\
\text { from any sugareane-grow- } \\
\text { ing locality. }\end{array}$ \\
\hline Cullitettix versicolor & & . & . & Plant-juice & . & $\begin{array}{l}\text { Is found in large numbers on } \\
\text { cane. Searcely a pest. }\end{array}$ \\
\hline Phenice mosta & . & . & - & & & $\begin{array}{l}\text { Found on eane but not in. } \\
\text { jurious. }\end{array}$ \\
\hline Abidama producta & $\cdot$ & . & & & & Ditto. \\
\hline Elasmocel is platypo & & - & & & & Ditto. \\
\hline Ricania speculum & . & - & & & & Ditto. \\
\hline Ripersia sacchari & . & . & • & Plant-juice & - & $\begin{array}{l}\text { Reported "serious" from } \\
\text { Hmawbi in September } 1918 .\end{array}$ \\
\hline
\end{tabular}

14.-BORERS IN SUGÁRCANE, RICE, Etc.

By T. Bainbrigge Fletcher, R. N. F.L.S., F.E.S., F.Z.S., Imperial Entomologist, and C. C. Ghosн, B.A., Assistant to the Imperial Entomologist.

\section{INTRODUCTORY.}

The borer pests of sugarcane, rice, etc., have a wide range of foodplants included under the Natural Order Graminex and some of them have been observed to extend this range into the Natural Order Cyperaceæ, the plants of which order have stems very well suited to serve as food 
for boring insects. Therefore in the investigation of these pests we have to include for observation not only the cultivated gramineous crops but also the wild grasses and sedges which can possibly serve as alternative food-plants. The endeavour to trace their occurrence in alternative food-plants, however, has so far been confined principally to the neighbourhood of Pusa. Some of the wild grasses have been observed to harbour borers which do not, or have not yet been found to, occur in the cultivated crops; while among the borer's of the wild plants there are others which, although principally confined to their wild food-plants, occur occasionally in the eultivated crops. The borers which are at present found only in the wild grasses may be considered as potential pests of allied cultivated plants and should very properly be included in any inquiry on borer pests of gramineous crops.

The inquiry has been in progress for the last two years and is far from being complete and the present note must only be regarded as a preliminary one. As will appear later on, we have recorded the borers of twenty-nine gramineous and two cyperaceous plants, but of all these the borers of only two of them, viz., sugareane and rice, have been under systematic observation. There are numerous other plants of these two Natural Orders which have yet to be examined and it is certain that at least many of the thick-stemmed ones among them will prove to be alternative food-plants of the borers of our gramineous crops.

\section{The Agents of Dailge.}

Among the insects which bore the stem of sugarcane, etc., there are some which live in the soil and ginaw into the stem from outside. They do not live inside the stem and therefore camnot, strictly speaking, be called borers. But the effect of their attack is in most cases similar to that of attack by the borers proper. Noreover, they appear along with and at the same time as the borers. Therefore, in order to be able to obtain an approximate idea of the share of damage cansed by the borers, not only all insects but also other agents affecting the plants with similar effect and simultaneously with the borers liave to be taken into consideration. We have to inelude :-

I. Fungal diseases.

II. External agents of damage, i.e., insects which do not live and feed inside the plants but attack or gnaw into them from outside.

III. Borers which live and feed inside the plants. 


\section{Fungal diseases.}

The fungal diseases observed in sugarcane are of the nature of Red Rot which canses a redness of the internal tissue. Their occurrence has only been noted in an attempt to allocate their share of the damage to the crop. Smut appeared extremely rarely. The first effect of the occurrence of these fungal diseases in new shoots of sugarcane is the "dead heart" characteristic of borer attack. On splitting open the stem the growing buds of the affected shoots are found to have become red. Ultimately the shoots dry up. When the diseases appear in plants which have developed their stem, e.g., cane, to some extent, the plants become stunted and gradually wither. Entire stools may be affected in this mamer. Sometimes the leaves of the affected young shoots. lose their green colour, becoming yellowish white. In all cases the affected plants wither.

Besides being the primary agents of damage themselves, these fungal diseases invariably follow in the wake of the borers, both external and interual, and in all stages of the cane. In fact at Pusa grown-up canes do not actually suffer much from the borers themselves but the real damage is caused by the fungal diseases which follow. Thus, when Scimpophaga caterpillars bore the top, the top withers and the cane may dry from the top downwards, the drying being due to fungal diseases. When borers or rats gnaw the base of the cane, fungal diseases working at the base cut short the supply of sap and the entire eane dries up. Similarly borer or jackal damage in the middle of the sten introduces fungal diseases which may redden the whole of the internal tissue of the stem, ultimately leading to the death of the entire plant.

\section{The External agents of damage.}

Among the external agents are included-

(1) Termites, commonly known as "white ants."

(2) Mole-crickets (Gryllotalpa africana).

(3) Beetle grubs (Melolonthid, Curculionid, Chrysomelid and Elaterid grubs); also the Red Ants (Dorylus).

\section{Termites.}

Termites or white ants are common pests and attack young. fruit and other trees, cuttings of plants, garden vegetables, and also 
field crops such as sugarcane. rice, whcat, barley, maize, etc. They gnaw the roots of plants but more often the base of the stem, causing entire young plants and shoots to wither. Usually they avoid wet and muddy places and are common in all moist soils. Thus, rice plants. standing in water or growing in muddy places are immune but are liable to attack when the water dries up. Host of the other important crops such as sugarcane, wheat, barley, etc., camnot be grown in water and the moist soils in which they can be grown are the most favourable situations. for termites' activities. Only in the case of sugarcane have attempts. been made to check their ravages. The setts are liable to be attacked as soon as they are placed in the ground and in the worst cases all the setts may be eaten. Trials in treating the setts with chemicals, etc., which can act as repellents, formed a subject-matter of discussion at the Second Entomological Meeting and the information regarding them will be found at pages 137-139 of the published Proceedings of that Meeting. It is a common belief that sugarcane setts are attacked only through the cut ends and recommendations have been made to protect the ends by dipping them in melted resin. Our experience has been that setts may be attacked at any point on their surface as well as at the ends and that it is the young shoots which require to be protected more than the setts. Our observations at Pusa as well as outside and the experiments which we have carried out to protect setts against termites go to show that the liability of cane to damage by termites depends largely on the nature of the soil in which it is grown. Generally speaking, the crop suffers much less or not at all when grown in clayey soils than in sandy soils. In soils which are liable to be infested by termites no single treatment of the setts can render them immune nor can any treatment of the setts save the shoots; whilst in other soils little or no damage is done by termites either to setts or to shoots even when no treatment is adopted. Later on, when we come to discuss damage to sugarcane by the borers, we shall see that sugarcane grown in Chaunia field at Pusa in 1917 suffered very little from termites without treatment, and in the Brickfield both treated and untreated plots suffered equally heavily. In order to find out what it is in the soils which makes this difference the first step we have taken is to submit the soils for analysis to the Imperial Agricultural Chemist to whom we have to acknowledge our thanks for undertaking this work. We quote below the results of his analyses of the surface nine inches of soils of the places where no or little damage was done as well as of the places where damage was severe. There are small differences in the constituents of the soils but without further experiments which we have in hand we camnot hazard any opinion. 


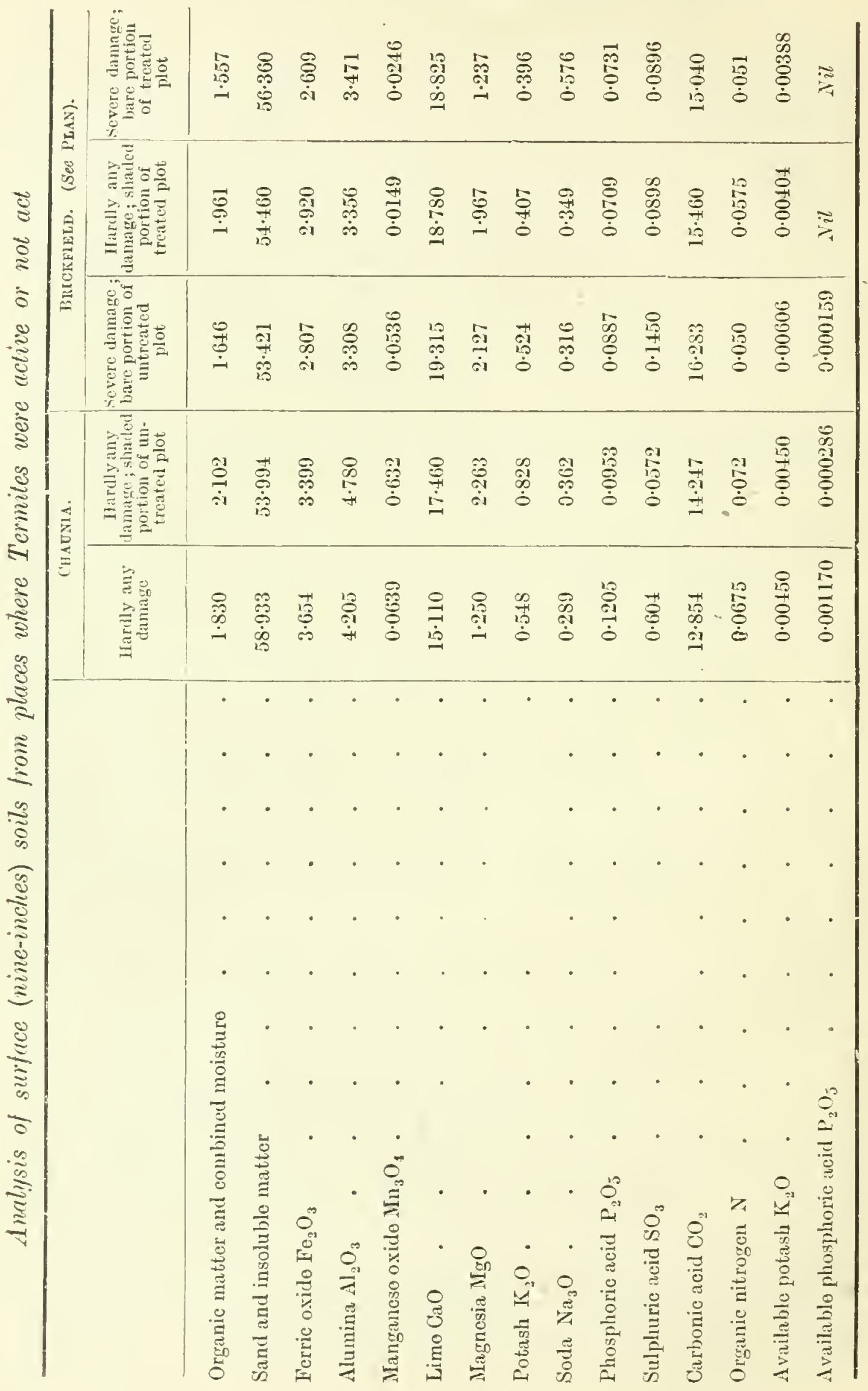





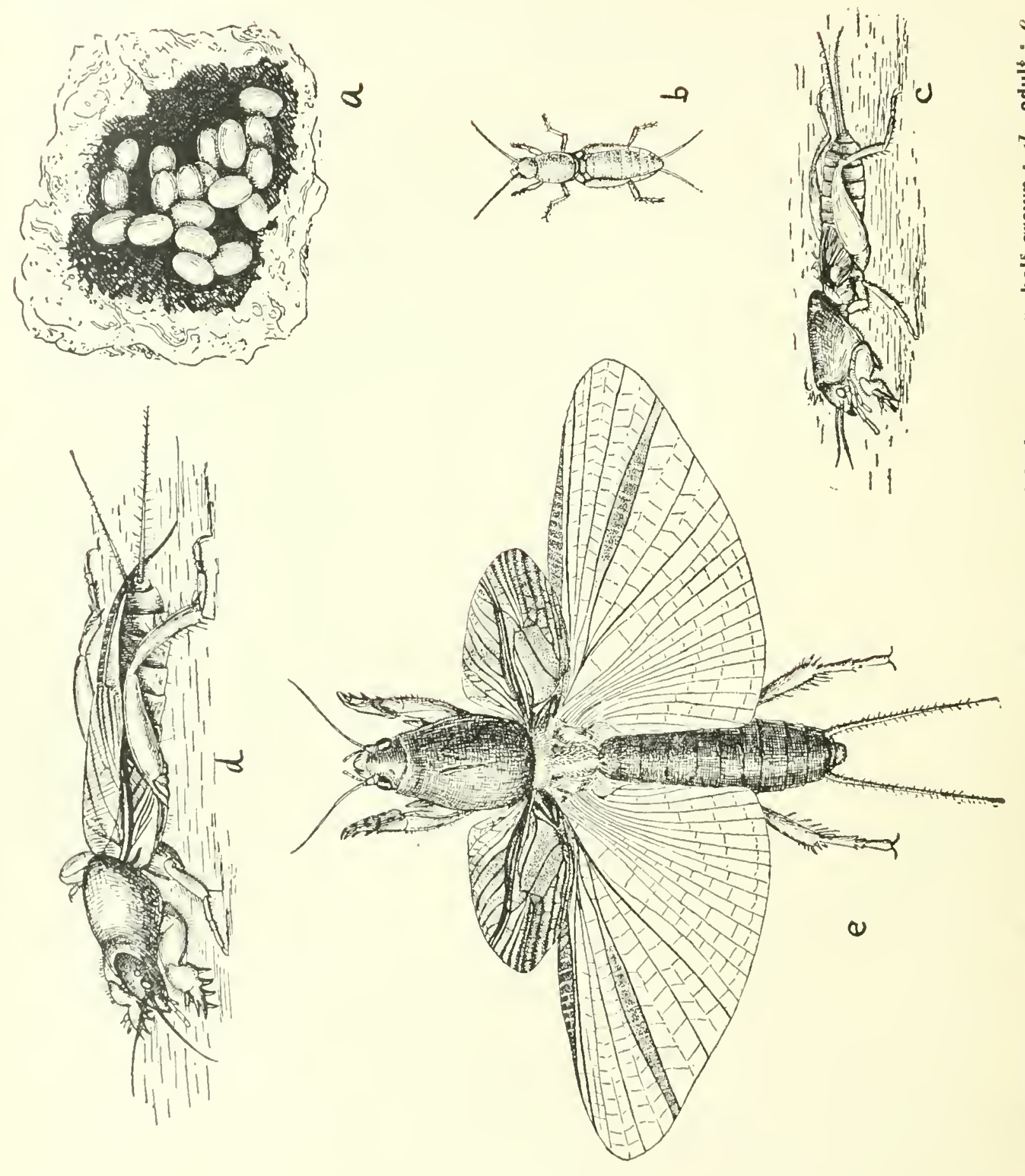





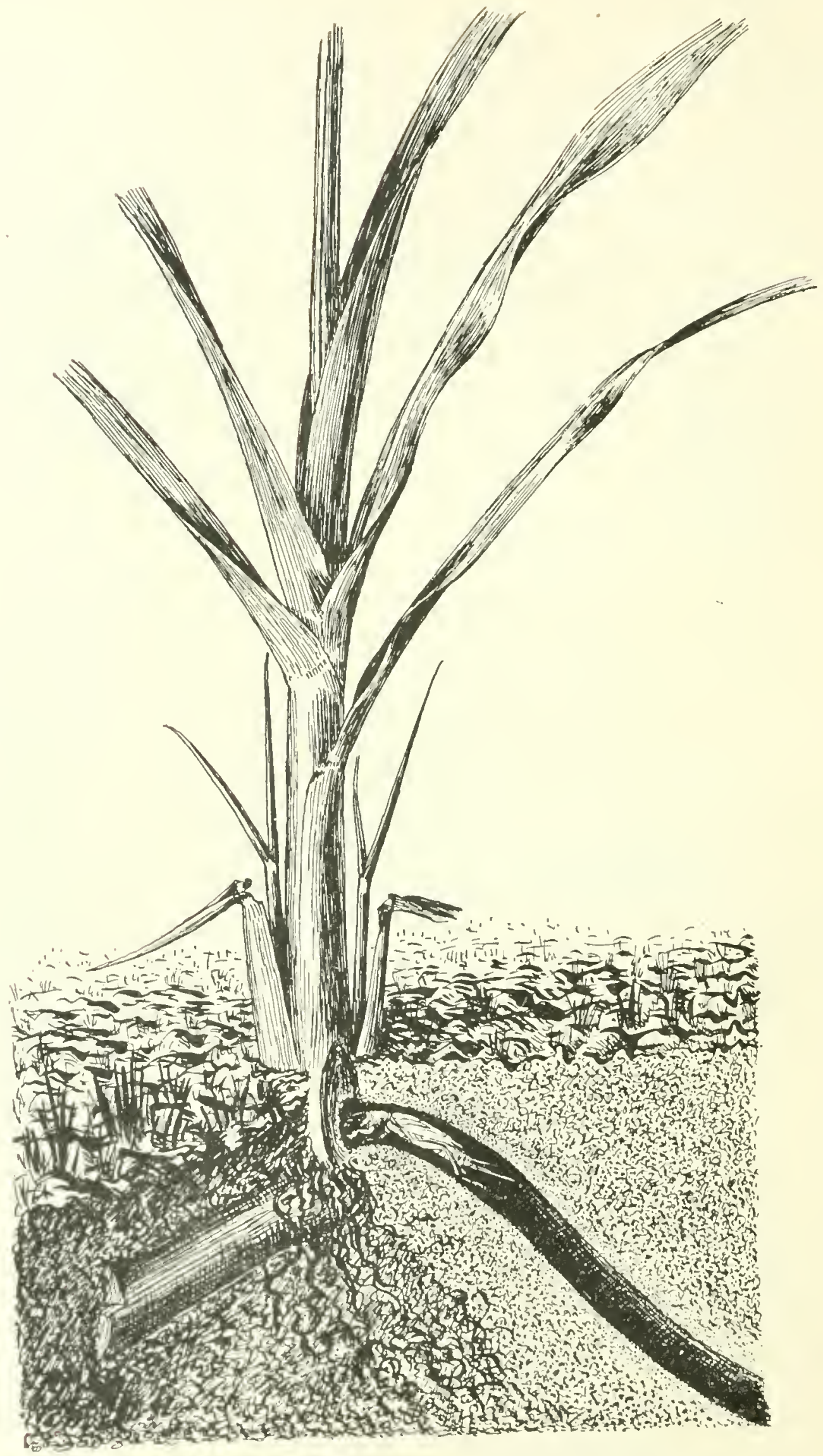

Diagrammatic figure to show how mole-crickets feea. 
When termites attack the new shoots of sugarcane the first visible external symptom is the "dead heart." The termites begin to gnaw in just at the base of the shoot and gradually eat into the centre, thus destroying the growing point. Therefore the heart leaf dries quickly. They may continue to eat and consume the entire base, detaching the shoot entirely from the sett. Then the entire shoot dries and comes ont of the ground at the slightest pull. Cases are frequent when only the shoots are attacked, leaving untouched the setts from which they arise; but more often the setts as well as the shoots are corroded. Older canes with well-developed stems or even ripe canes are not immune, as has been observed at Dacea and other places. Damage to grown or ripe canes has so far been slight at Pusa even in the Brickfield plots where damage to new shoots and setts has been severe. In this field the termites were active from about March to July and what led to the stoppage of their activity afterwards cannot be explained. We propose to continue our observations by growing sugareane in the same field.

\section{Mole-cricliets.}

The mole-crickets (Giyllotalpa aficana) are common underground insects which usually frequent moist soils. They are very common in the moist or rather wet sandy beds of the River Gandak where their eggs can easily be collected. Eggs collected from this place have been reared in the Insectary. The nymphs were fed wholly on live fly maggots and they took about five-and-a-half months to come to the adult stage. The life-history is illustrated in Plate 22. Up to about fifty eggs are deposited loosely in a chuster in a chamber.specially formed at the bottom of the hole. There does not seem to be any regularity of broods as all stages of the insect are observable throughout the year.

Giyllotalpa africanc has been observed to cause rather serious damage to new shoots of sugarcane at Pusa on two occasions. once about MarchApril in the Jhilli field in 1913 and again abont the same time of the year in the Brickfield in 1918. In cultivated fields, the insect lives in underground holes about two feet or more deep. It comes up and attacks the new shoots of sugarcane much in the way somewhat diagrammatically shown in Plate 2\%. The shoots are gnawed from the side at a point above their junction with the sett, the gnawing being like a scooped-out round hole with cliewed-up fibrous margins and extending up to the core of the stem. The tender base of the lieart leaf is eaten. Therefore the heart leaf dries and a "dead heart," characteristic of borers, is the result.

It is not easy to observe the mole-crickets in the act of gnawing the shoots. Therefore the following corroborative experiment was carried 
out in the Insectary. A zine cylinder with a solid bottom was filled to a depth of a little more than a foot with earth which was carefully examined before being put in. Six perfectly healthy sugarcane shoots with the setts from which they grew and of the age at which they were observed to be attacked by this insect in the field were transferred into this cylinder and eleren mole-crickets introduced into it between 13 th and 15 th March. The characteristic " dead heart" with the characteristic damage appeared as early as the 17th March in one shoot. Another shoot exhibited "dead heart" and damage on 3rd April. On the 12th April five pumpkin chips were buried in the earth and two of them were found on the next day to have been bored. The buried piees were remored on the 15th April and a few fresh pieces were placed on the surface of the earth. On the 17th April they were observed to have been bored from below. The pumpkin chips were removed on the 19th April. On the 5th May a third shoot was damaged. The remaining three shoots were not damaged and the insects were dead before the 30th May.

This experiment seems to prove that the mole-crickets cannot live on sugarcane alone. They attack sugarcane if it is planted in the land in which they are present. There was practically no damage to sugarcane by this insect in the Chaunia field which has been under cultivation for many years. The experimental plots of sugarcane in the Brickfield in 1918 were situated in a piece of land brought under cultivation about five or six years ago. It was previously a waste land overgroyn with Saccharum spontaneum and Imperata arundinacea and was bordered by similar waste lands. (See Plate 69.) Mole crickets have been observed to eat Saccharum spontaneum shoots in the same way as they do sugarcane shoots. As proved by rearing in the insectary, they can live on animal food and probably depend on such food principally. Many kinds of soft-bodied Melolonthid, Chrysomelid and Curculionid grubs are known to abound among Saccharum spontancum roots. Therefore mole-crickets obtain plenty of food in such waste lands and would naturally occur there in large numbers. This explains why so much damage was done to the experimental plots in the Brickfield. The occurrence of this insect in the sugarcane in Jhilli field in 1913 was under exactly similar conditions. Sugarcane was grown again in Jhilli in 1918 but so much damage was not done by this insect as on the former occasion. Repeated cultivations for a series of years naturally kill and drive away the molecrickets from the field.

\section{Beetle-rrubs.}

Among the third class of external agents of damage we have included the Melolonthid, Chrysomelid, Curculionid and Elaterid grubs and may 

PLATE 24.

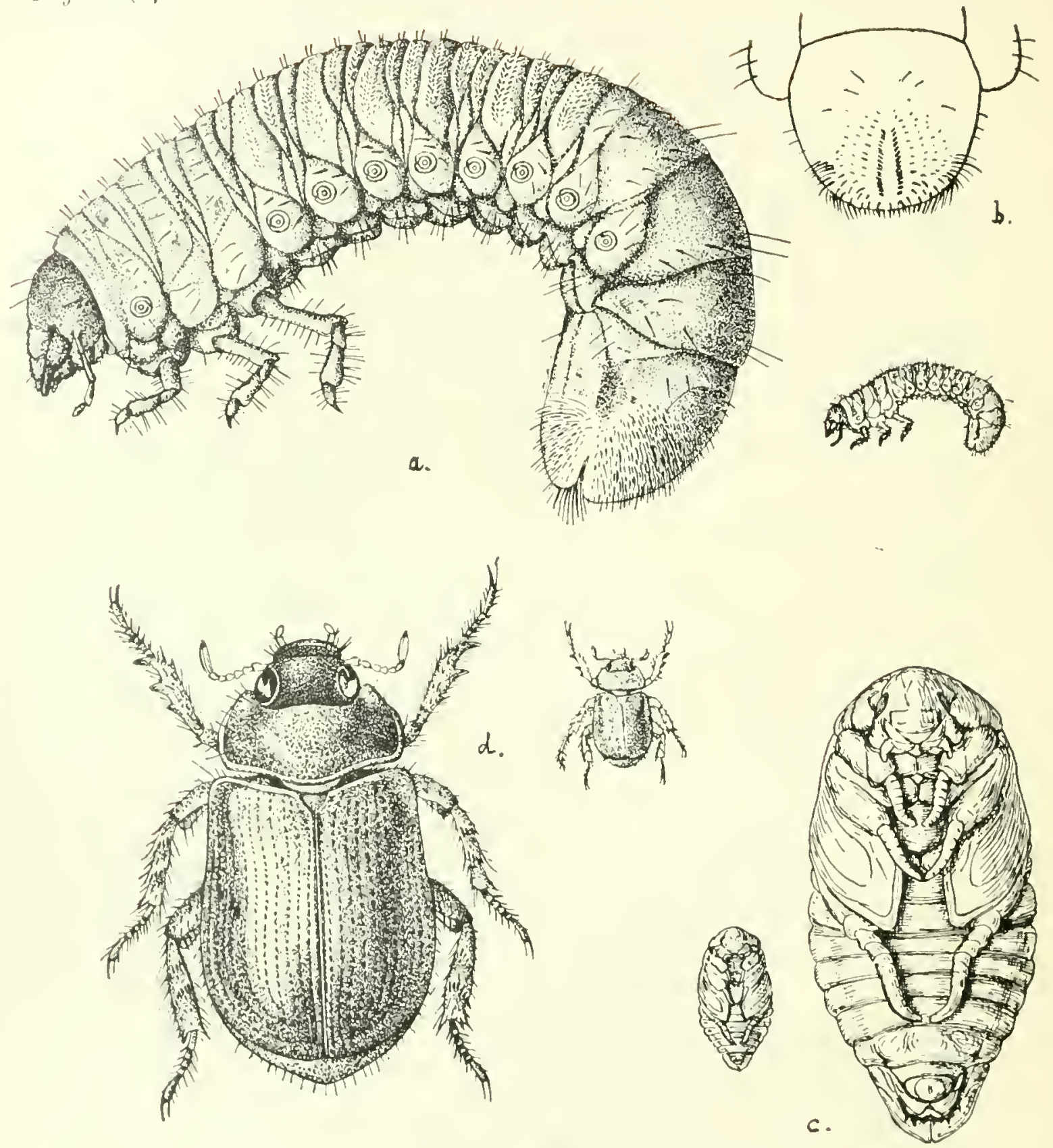

Anomula biluaremis (C. S. 1744).

1, Larva, natural size and magnified $\times 4$.

6. details of posterior extremity of larva.

i. Pupa, natural size and enlarged.

i, Imago, " " " " 



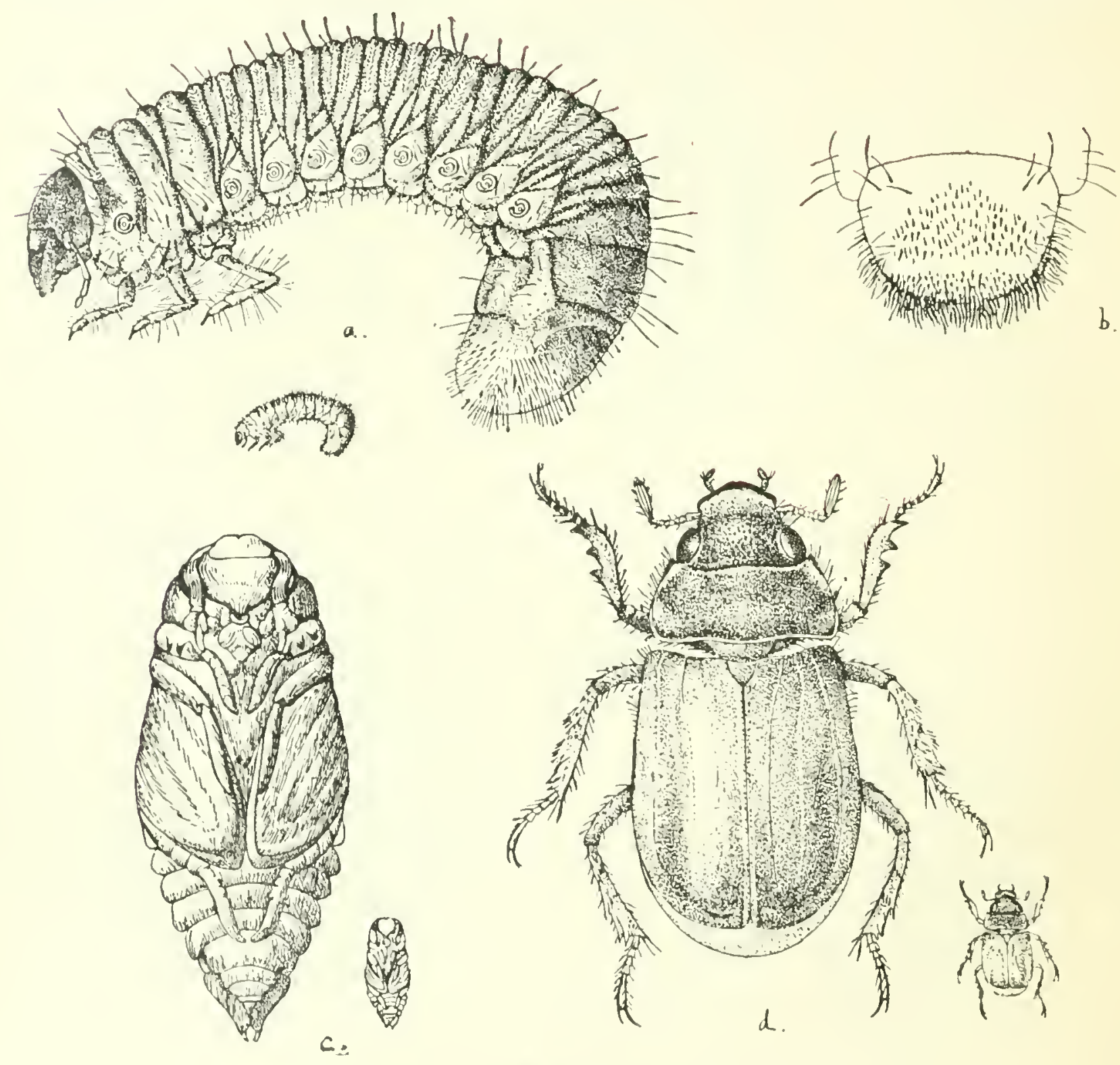

Arovetus rrligimosus (C. S. 1793).

$a$, Larva, natural size and magnified $\times 5$.

1), details of posterior portion of larva, magnified.

$\therefore$ Pupa, natural size and magnified.

1/. Imago. 



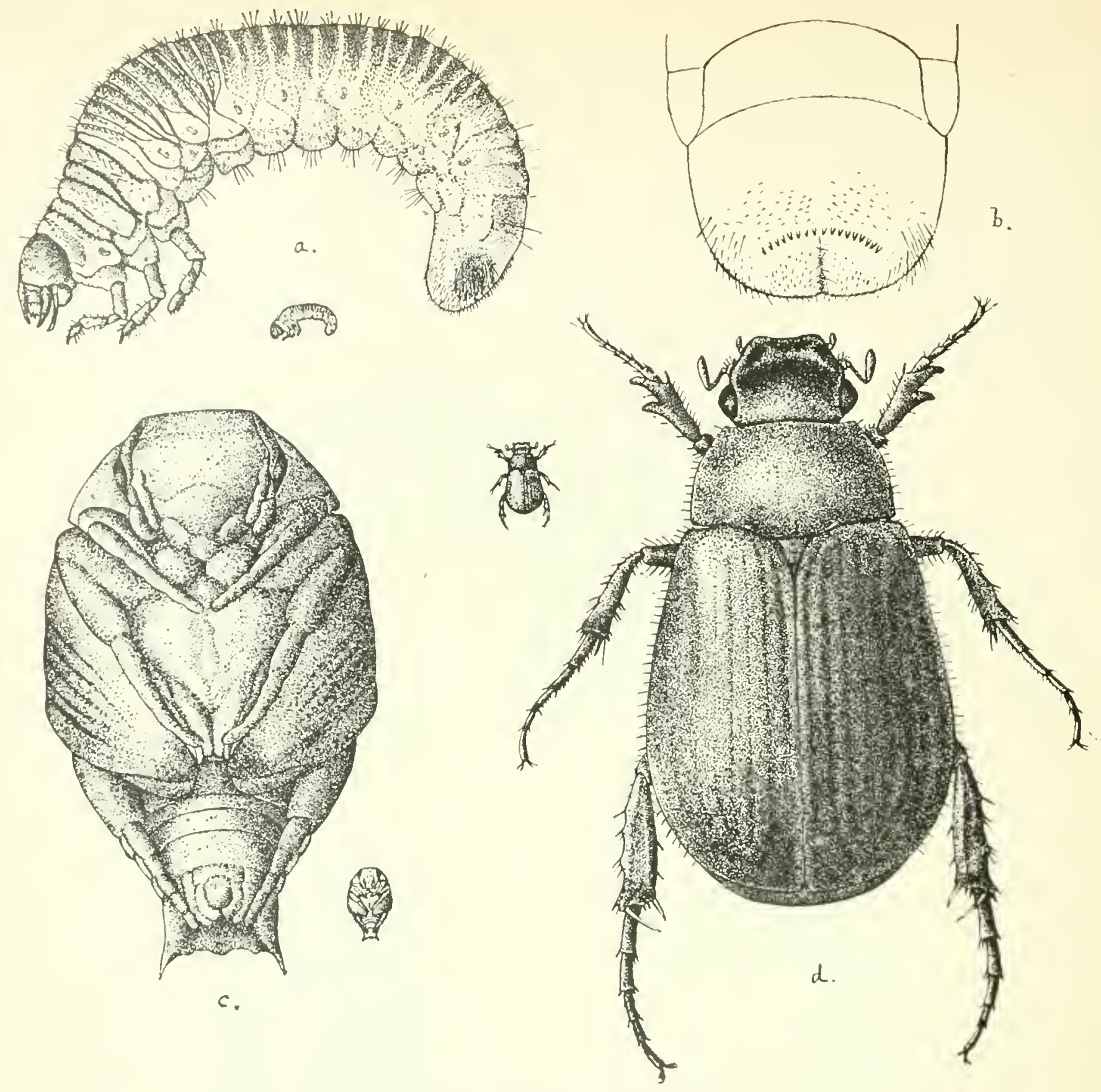

Fig. 1.- lutoserirn sp. (C. S. 1654). 11. Larva, natural size and magnified $(x 8)$.

11. details of posterior portion of larva, magnified. (. Pupa, natural size and magnified $(; 8)$. 1.'Imago,
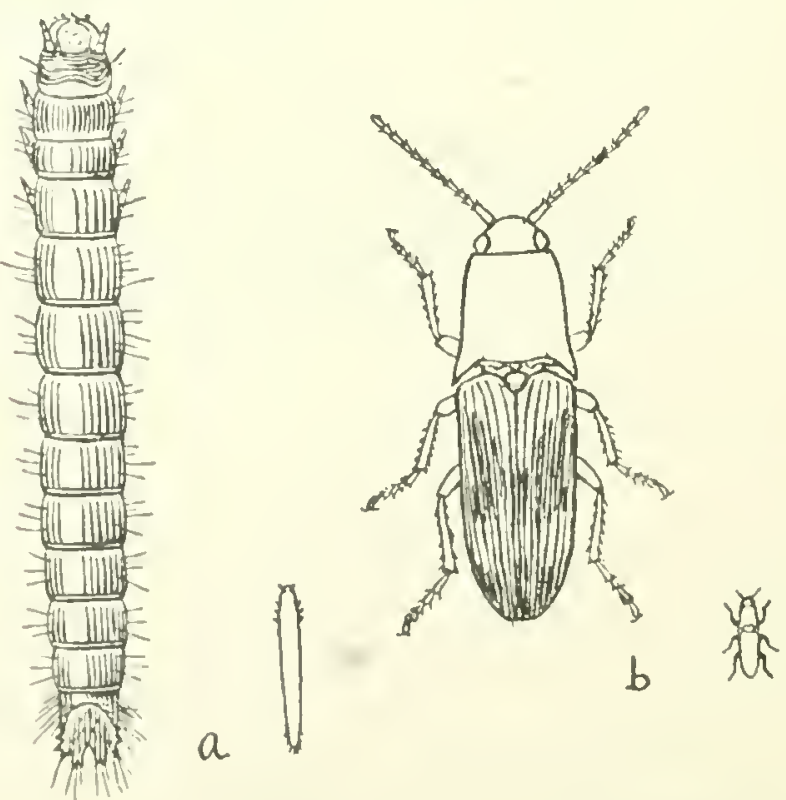

Fig. 2.-Dmestruils sp. ; ". Iarva, natural size 



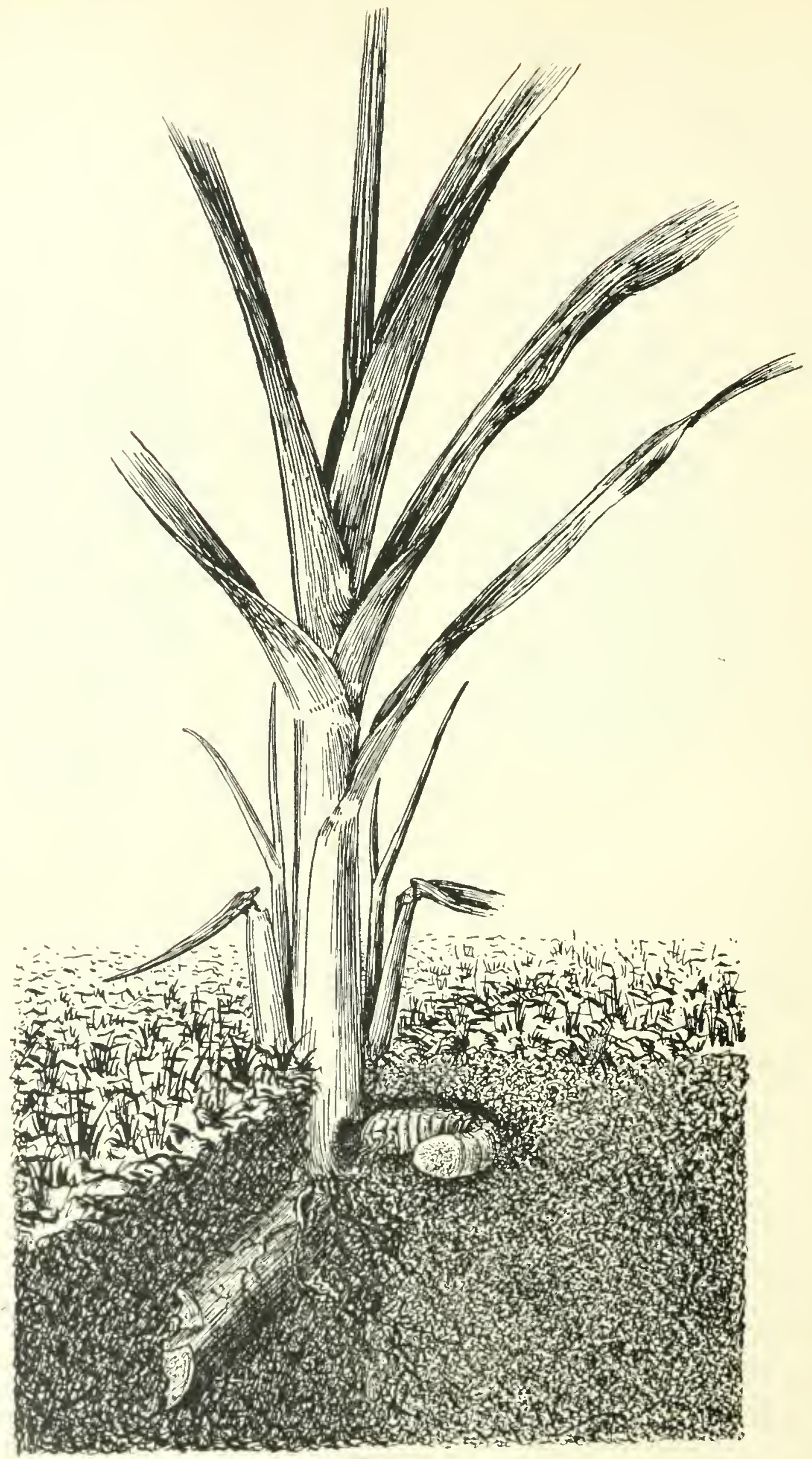

Diagrammatic figure to show how Melolonthid grubs feed. 
also mention in this connection Tipulid and Asilid magrots. Many kinds of these grubs abound among the roots of wild and semi-cultivated grasses as well as of sugarcane, maize, juar, wheat, barley, oats and similar crops grown in soils having a tolerable amount of moisture. When a crop is in the soil for the full year like sugareane, or more or less permanently like the semi-cultivated grasses mentioned later on, these grubs increase to an enormous extent. As mentioned in the Imperial Entomologist's Annual Report for 1917-18, among the roots of sugareane and semi-cultivated and wild Sacharum spp. we have so far found the larva of no less than sixteen different species of beetles including A nomala bengalensis, A. bitarensis (P1. 24), Adoretus caliginosus (P1. 25), Autoserica sp. (Pl. 26, fig. 1), Myllocerus discolor, M. blandus, Honolepta signata, Fornicomus sp.. Pachnephorus spp., Alissonotum piceum, A simile and Apogonia sp. To these we may add Anomala polita, Adoretus versutus, Myllocerus 11-pustulatus and Diasterius sp. (C. S. 1211, Elateridx; Pl. 26. fig. 2). Of all these the grubs of Anomala liengalensis have been definitely observed at Pusa as well as at Dacea to gnaw new shoots of sugarcane under the soil surface from the side much in the same manner as mole-crickets do and as somewhat diagrammatically shown in Plate 27. The result is the "dead heart" characteristic of borers. The other Melolonthid grubs are similar in habit and are capable of damaging the shoots in the same way although. they have not yet been observed to do so. The amount of damage howerer has so far been small. If the damaged shoots are examined after some days, the gnawing by these grubs is easily confused with that of mole-crickets.

The Red Ants (Dorylus) have also been observed to gnaw the base of sugarcane shoots in a few cases.

Chewing. One form of damage quite common in new sugarcane shoots and also in young as well as somewhat advanced wheat, barley and oat plants, is the chewing of the external layers of leafsheaths on one side at a point just below or at the soil surface. Such plants invariably show "dead heart" and in some eases may become dry. Although the chewing does not extend into the core of the shoots, the part of the heartleaf near about the level of the point of damage becomes discoloured and withers, causing "dead heart", and frequently the base of the heartleaf below the point of discoloration grows rather sideways. The shoot however is permanently injured and ultimately dies. Five sugarcane shoots showing "dead hearts" of this nature were submitted for examination to the Imperial Mycologist who reported Red Rot in two of them. In wheat, barley and oats the chewing is frequently carried further the entire base being converted into a fibrous mass and leading to the. 
drying of the entire plant. It has not yet been possible to determine the agents of this form of damage. Probably mole-crickets and most of the coleopterous grubs ordinarily found in the fields may be concerned.

\section{The Borers.}

The following is the list of the borers so far observed. They are grouped according to the Orders and Families. Most of them are not identified. In the case of those which are taken as identified there is a confusion in the names, especially of the species of Chilo and Diatrca. Therefore all the insects are referred to under the number in the Insectary Register of Cage Slips. When names are used they should be taken as those under which the insects have been known up to this time.

\section{Diptera-}

Anthomyiadx.-At present it is not known whether one or more species are concerned. The flies are apparently alike and are grouped together as "Muscid flies."

Cecidomyiadæ.-Packydiplosis oryzce.

Trypaneidæ.-Stictaspis ceratitina.

$$
\begin{aligned}
& \text { Coleoptera- } \\
& \text { Lamiadx.-C. S. } 1814 . \\
& \text { Curculionidæ- } \\
& \text { C. S. 1778. } \\
& \text { C. S. } 1397 .
\end{aligned}
$$

\section{LEPIDOPTERA- \\ Zeuzeridæ- \\ C. S. 1805 . \\ C. S. 1696.}

Noctnidx-

Sesamia inferens.

Sesamia uniformis.

C. S. 1666.

Hetiothis obsoleta.

Pyralidæ-

Emmalocera depressella.

Emmalocera sp. (C. S. 1771.

C. S. 1700 .

C. S. 1837.

Scirpophaga xanthogastrella.

Scirpophaga monostigma.

Schonobius bipunctifer.

Schoonobius sp. (C. S. 1780. 
LEPIDOPTERA-contd.

Pyralidæ-contd.

Raphimetopus (Anerastia) ablutella (C. S. 1801.)

Chilo simplex. (C. S. 1551.)

Diatraca auricitia. (C. S. 1574.)

Diatraa venosata. (C. S. 1607.)

? Diatrea sp. in sugarcane. (C. S. 1610.)

? Diatrcea sp. in sugarcane and rice. (C. S. 1674.)

? Chito sp. in rice. (C. S. 1677.)

? Chilo sp. in Kanra. (C. S. 1769.)

? Chilo sp. in Ikri. (C. S. 1795.)

? Chito sp. in Batri. (C. S. 1831.)

? Chilo sp. in Iliri. (C. S. 1835.)

? Pyralid Borer in Butri. (Not reared yet.)

Pyralid Borer in Ikri. (Not reared yet.)

Pyralid Borer in Batri. (Not reared yet.)

Ramila ruficostalis. (C. S. 1533.)

Eucosmidæ--

Argyroploce paragramma. (C. S. 1631.)

Bactia truculenta. (C.S. 1489.)

Ayloryctidæ.-Procometis trochala. (C. S. 1708.)

Tineidæ.-Dasyses rugosellus. (C. S. 1873.)

Foodplants. Below are mentioned the plants, cultivated as well as wild, which have been observed to harbour internai borers, noting at the same time which of the borers listed above occur in each. All the plants belong to the Natural Order Graminex, with the exception of two which, as noted against them, belong to Cyperaceæ.

\section{Cultivated Crops.}

Sugarcane-

Sesamia inferens.

Sesamia uniformis.

C. S. 1666.

Emmalocera depressella.

Scirpophaga xanthogastrellis.

S. monostigma.

Procometis trochala.

Raphimetopus ablutella.

Chito simplex.

Diatroca auricitia.

Diatraa renosata. 
Sugarcane-contd.

Diatrcea sp. (C. S. 1610.)

Diatrca sp. (C. S. 1674.)

Dasyses rugosclla. (C.S. 1873.)

Maize-

Muscid flies.

Sesamia inferens.

Sesamia unifomis.

C. S. 1700.

Chilo simplex.

Heliothis obsoleta.

Laphygma exigua.

Juar: (Andropogon sorghum)-

Muscid flies.

C.S. 1696.

Sesamia inferens.

Chilo simplex.

Diatraca auricitia.

Diatrea venosata.

Bajra: (Pennisetum typhoideum)-

Muscid flies.

Chilo simplex.

Diatrace renosata.

Heliothis obsoleta.

Rice-

Muscid flies.

Pachydiplosis oryza.

Sesamia inferens.

Schœnobius bipunctifer.

Chilo simplex.

Diatrae sp. (C. S. 1674.)

Chilo sp. (C. S. 1677.)

Marua (Eleusine coracana)-

Muscid flies?

Sesamia inferens.

C. S. 1837.

Chito simplex.

Kodon (Paspalum scrobiculatum, Linn.)-

Muscid flies.

Inani (Setaria italica)-

Muscid flies. 
Sama (Panicum frumentaceum)-

Muscid flies.

Sesamia inferens.

Chilo simplex.

China (Panicum miliaceum)-

Inscid flies.

Gandli (Panicum miliare)-

Hnseid flies.

Wheat-

Muscid flies.

Sesamia inferens.

Barley-

Museid flies.

Sesamia inferens.

Oats-

Muscid flies.

Sesamia inferens.

11. Fodder Grasses (cultivated).

Guinea grass.-

Sesamia inferens.

Sudan grass-

Museid Hies.

Sesamia inferens.

Chilo simplex.

Diatrae venosata.

\section{Semi-cultivated Plants.}

These are not cultivated like field crops but have a market-value and are of more or less economic importance. Some grow without attention, in a more or less wild state, when once introduced into uncultivated lands, such as Dabh (Eragrostis cymosuroides) and Dabhi or Ulu (Imperala arundinacea) extensively used as thatehing grass. Kanra (Saccharum arundinaceum) is grown in the same namner as bamboos and their top portions are used for making munj ropes and lower portions in thatches and walls of huts. Sar (Saccharum arundinaceum var. ciliaris) and Ikri (Saccharum fuscum) are also grown in the same way as bamboos and are used in thatches and walls of huts. Batri (Sacharum spontaneum batri) is also grown practically in the same manner but is of a more wild nature. It too is used in thatches and walls of huts. Rarki or the proper: hans grass (Saccharum spontaneum rarhi) is, as is well known, a wild grass and troublesome weed which has invaded and occupied large tracts 
of land. It is found to grow in a stray manner in cultivated fields but it cannot get a footing there. Its leaves are sometimes used along with other thatching grasses. The Botanical Survey Department, to whom we are indebted for the identification of these grasses, identified both Batri and Rarhi as Saccharum spontaneum. Batri has, however, a much thicher, taller and stouter stem than Rarhi, almost approaching that of Kanra and Ikri. For our purposes we have therefore named Batri as Saccharum spontaneum batri and Rarhi as Saccharum spontaneum rarhi. Kanra, Sar, Ikri and Batri have thick stems almost like thin sugarcane. For the borers hitherto found only in these semi-wild grasses, the step. into sugarcane seems to be a short one and there will be no cause for wonder if they are actually observed to occur in sugarcane in some parts of India. We note below the borers which have so far been found in them and we include bamboo in the list in order to complete the record. The borers of bamboo, however, are not expected to occur in sugarcane.

Fanra (Saccharumarundinaceum, Retz.)-

C. S. 1805.

Sesamia inferens.

Sesamia uniformis.

Emmalocera sp. (C. S. 1771.)

Scirpophaga xanthogastrella.

Chito sp. (C. S. 1769.)

Sar (Saccharum arundinaceum, Retz., var. ciliaris)-

Sesamia inferens.

C. S. 1666.

Ikri (Saccharum fuscum, Roxb.)-

Sesamia inferens.

Sesamia uniformis.

C. S. 1666.

Diatrcea auricilia.

Diatrcea venosata.

Diatrea sp. (C. S. 1795.)

Chilo sp. (C. S. 1835.)

Pyralid borer (not reared yet).

Batri (Saccharum spontaneum batri)-

Lamiad borer (C. S. 1814).

C. S. 1696.

Sesamia inferens.

Sesamia uniformis.

C. S. 1666 .

Scirpophaga xanthogastrella.

Diatrcea auricilia. 
Batri (Saccharum spontaneum batri) - contd.

Diatraa venosata.

Chito sp. (C. S. 1831.)

Pyralid borer (not reared yet).

Pyralid borer (not reared yet).

Rarhi (Saccharum spontaneum rarhi)-

Lamiad borer (C. S. 1814).

Cureulionid borer (C.S. 1778).

C. S. 1696.

Sesamia inferens.

C. S. 1666.

Chilo sp. (C. S. 1831.)

Bamboo-

Stictaspis ceratitina.

Ramila ruficostalis (C. S. 1533).

Argyroploce paragramma.

\section{Witd Grasses and Plants.}

Dabhi or Ulu. (Imperata arundinacea, Cyrill)-

Museid flies.

Dabh or Kush. (Eragrostis cynosuroides, Beauv.)-

Museid flies.

Dub. (Cynodon dactylon, Pers.)-

Museid flies.

Motha. (Cyperus rotundus, Linn.; Cyperacex)-

Museid flies.

Weevil borer (C. S. 1397).

Bactra truculenta (C. S. 1488).

Sami-ghas. (Panicum colonum, Linn.)-

Museid flies.

Jove-ghas. (Rotibollia compressa, Limn.)-

Sesamia inferens.

Diatraca auricitia.

Golmootha. (Scirpus affinis, Roth; Cyperacex)-

Sesamia inferens.

Baijanti or Job's Tears (Coix Lachryma-Jobi, Linn.)Chilo simplex.

Narkat. (Phragmites Karka, Trim.)-

Sesamia inferens.

Schœnobius sp. (C. S. 1780.)

VOL. I 


\section{Differentiation of the Borers.}

The larval forms of the Zeuzerid, Noctuid and Pyralid borers can be distinguished with the help of the following key :

1. Prothoracic shicld with short spines

Prothoracic shield without spines

2. Colour, deep purple

Colour, pale yellowish-white; body speckled with violet markings

3. Caterpillars with the body of a uniform colour, with. out stripes, warts, spots or markings . .

Caterpillars having stripes, warts, spots or markings on the body

4. Caterpillars grouped as below aecording to colour :-

A. Colour creamy yellow; skin almost transpa rent; boly very soft and pliable, slightly compressed dorsoventrally; thoracie region prominently tapering forwards ; dorsal vessel very prominent; spiracles like a slender brown streak

B. Colour greenish-yellow; body cylindrical, of a rather slender build; dorsal vessel visible; spiraeles much elongated, oval, with a black or brown rim

C. Colour pinkish, like that of raw flesh; spiraeles elongated oval, black

G. Colour white (or ereamy white) with or without the dorsal ressel being visible; spiracles oval or round .

H. Colour green or partly green and copperish; spiracles round

I. Colour light grey; skin soft; hairs long ; forming silken galleries in which pellets of excreta aro webbed ; spiraeles oral

5. Catcrpillars with six stripes .

Caterpillars with less than six stripes or with warts (species of Chilo and Diatrea whieh had hitherto been known as the Moth-borer-Chilo simplex) .

6. With middorsal stripe

Without middorsal stripe

7. Spiracles elosed, i.e., without any elear space inside; no other longitudinal stripe but segments having purplish markings on side

Spiracles open, i.e., with a elcar space inside; in addition to the middorsal stripe there are two stripes on each side of back

2

C. S. 1805 .

C. S. 1696 .

Scirpophaga xanthogas. trella; s. monos. tigma.

Schanobius bipunctifer; Schonobius sp. (C. S. 1780).

Sesnmia inferens; Sesamia uniformis. (C. S. 1666.)

Emmalocera depres. sella; Emmalocera sp. (C. S. 1771); C. S. 1837 ; C. S. 1700 .

Raphimetopus

ablu• tella.

Dasyses rugosellus (C. S. 1573).

Procometis trochala. (C. S. 1708.)

6

7

10

C. S. 1835

8 
8. Hooklets on prolegs forming a half eircle which is open externally ; hooklets on internal cdge of sole largest, diminishing in size externally

\section{Diatraca auricilia. (C. S. 1574).}

Hooklets on prolegs forming a complete or almost. complete eircle

9. Spiracles toucling, or situated in, the stripe above them; stripes grey-brown; looklets on internal edge of sole largest, diminishing in size externally

Spiracles situated well below the stripe above them; etripes reddish brown; hooklets on prolegs practically equal in size or those on external colge slightly smaller than those on internal edge

10. Spiracles open, i.e., with a clear space inside .

Spiracles closed, i.e., without a elcar space inside .

11. The posterior trapezoidal warts in a line with the anterior trapezoidal warts; looklets on prolegs in a complete circle, largest on intermal edge of sole, diminishing in size externally (Caterpillars usually with prominent warts and no stripes; sometimes warts absent and some markings present on side of the segments) . .

The posterior trapezoidal warts much further re. moved from the middorsal line than the anterior trapozoidal warts; hooklets on prolegs much as in C. S. 1610 .

12. Hooklets on prolegs forming a half circle open externally; those on internal edge of sole largest diminishing in size externally; spiracles with a rather closed slit along their longer axis; eaterpillars with two stripes on each side of back

Hooklets on prolegs forming a complete or almost complete circle

13. Hooklets in a complete circle and equal in size; spiracles with rather an open slit along their major axis

Hooklets in a more or less eomplete eircle and much shorter externally; spiracles with an oval-shaped conearity whose major axis eoincides with that of spiracles; eaterpillars usually with large shiny dark-brown warts situated on broad pinkish stripes, warts disappearing in hibernating larva
9

Rice Chilo (C. S. 1677).

C. S. 1674.

12

C. S. 1610 .

C. S. 1769.
Chilo simplex.

(C. S. I55I.)

Dintrene veirosule (C. S. 1607).

The pupal forms of the species of Raphimetopus (Anerastia), Diatrace and Chilo, which are likely to be and had hitherto been confused in the adult stage, can be distinguished with the help of the following key.

I. Pupa withont any clitinous protuberanees on anal segment which has a few cireinate hairs

\section{Raphimetopus (Aner- astia) ablutella \\ (C. S. 1S01). \\ 2}

C. S. 1677 .

3

Pupa with such 
3. Pupa with scattercd spines on 7 th abdominal seg. ment formed out of the larval tubercles .

Pupa with continuous ridges, hooks, spines or roughness in the form of a collar on 7 th abdominal scgment . . . . .

4. The collar makes a complete circlo round the segment

C. S. 1835 .

The eollar makes a circlo incomplete on the ventral side

5. The circle composed of distinct and separate double hooks

The circle composed of ridges, more or less joined .

6. Incomplete circle of distinct straight spines

Incomplete circle of roughness

7. Dorsal part of anal end with six spines in two groups of threc, triangularly arranged

orsal part of anal end with four spines

8. The spines situated on the tip and pointing posteriorly . . . . . .

The spines situated on the dorsal margin and pointing dorsally

9. The collar of roughness on 7 th abdominal segment extending much beyond the spiracles

The collar extending up to the spiracles

The collar nct extending up to the spiracles

\section{S. 1610 .}

Diatrea auricilio.

C. S. 1674.

7

\section{Chilo simplex. \\ (C. S. 1551).}

\section{Diatrae venosata}

(C. S. 1607).

\section{Life-histories of the Borers.}

The life-histories of the borers are given in the following pages. 'I he observations were carried on principally in the year 1918. In order to give some idea of the nature of the year regarding rainfall, temperature and humidity a chart is appended giving weekly rainfall, weekly mean temperature (dry bulb at 8 A.Mr.) and weekly mean humidity, calculated from the records at Pusa. (Plate 28.)

The Anthomyiad Flies.

Plate 29.

Foodplants-

Juar (Andropogon sorghum)-October, January, May, August,

September, July.

China (Panicum mitiaceum)-July, May.

Samighas (Panicum colonum)-July.

Kodon (Paspalum scrobiculatum)-July.

Sudan grass-August.

Rice-April, June.

Sama (Panicum frumentaceum)-September. 


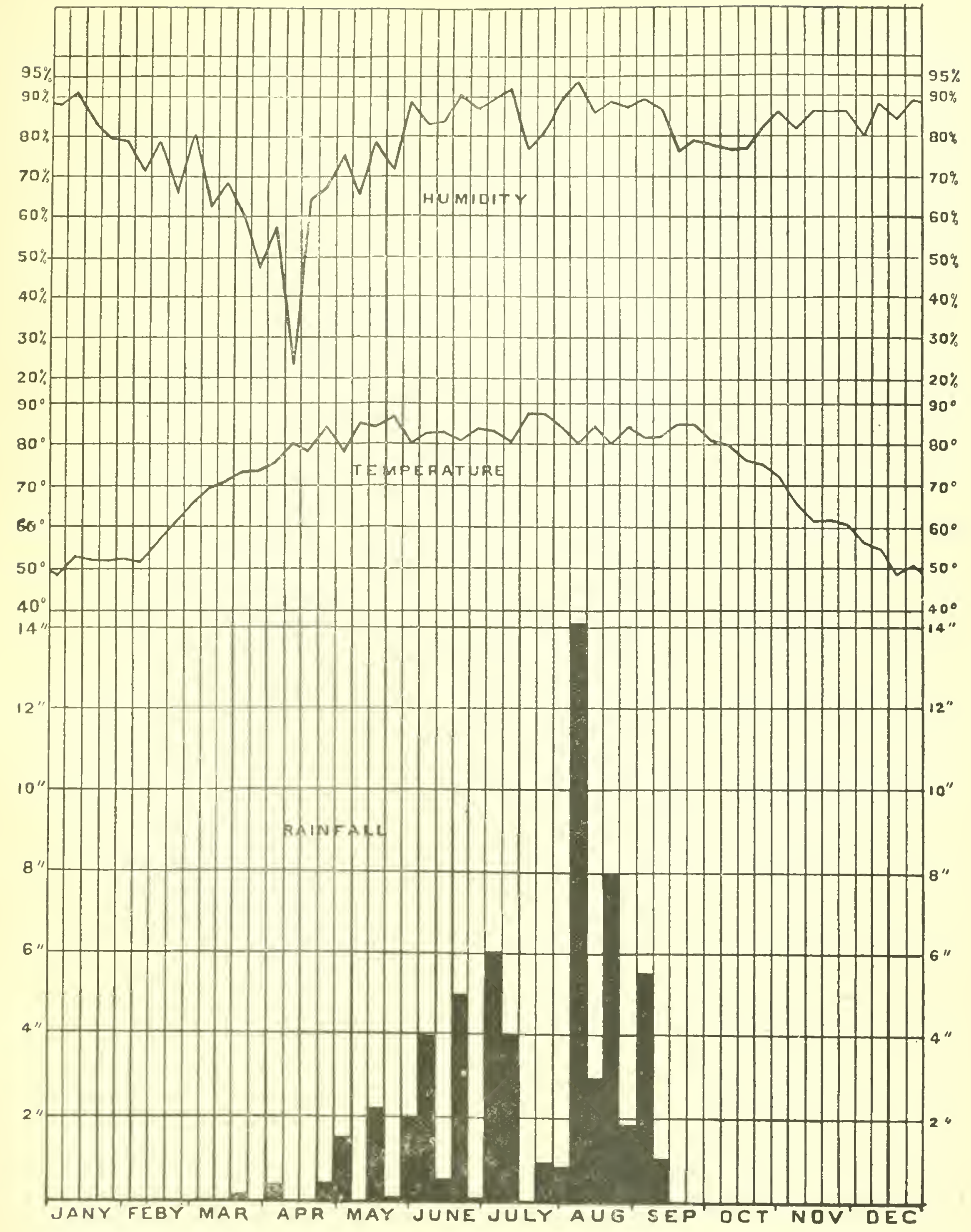

Weekly rainfall, mean temperature and mean humidity at Pusa during 1918. 

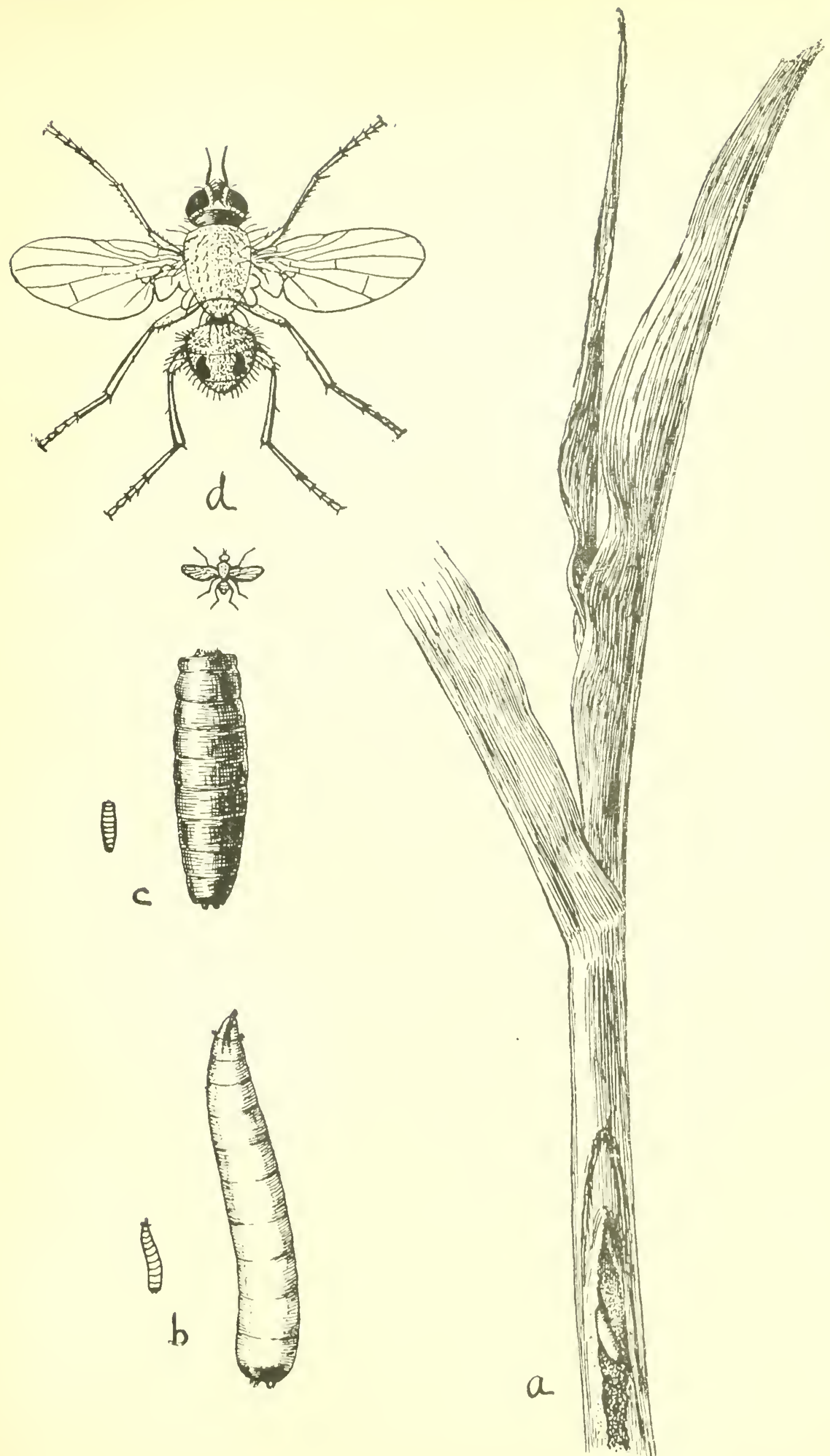

AnthomyiadIFly (C. S. 1867) in .jull' shoot; "l, attacked, ju(l) shoot, cut open to show * maggot ; $b$. larva $>8$; $c$, pupa $>8$;, . fly $\times 8$. (N.B.-The smaller outline figures * $b, c$, and $l l$ are $1 !$ tinies the natural sizes.) 




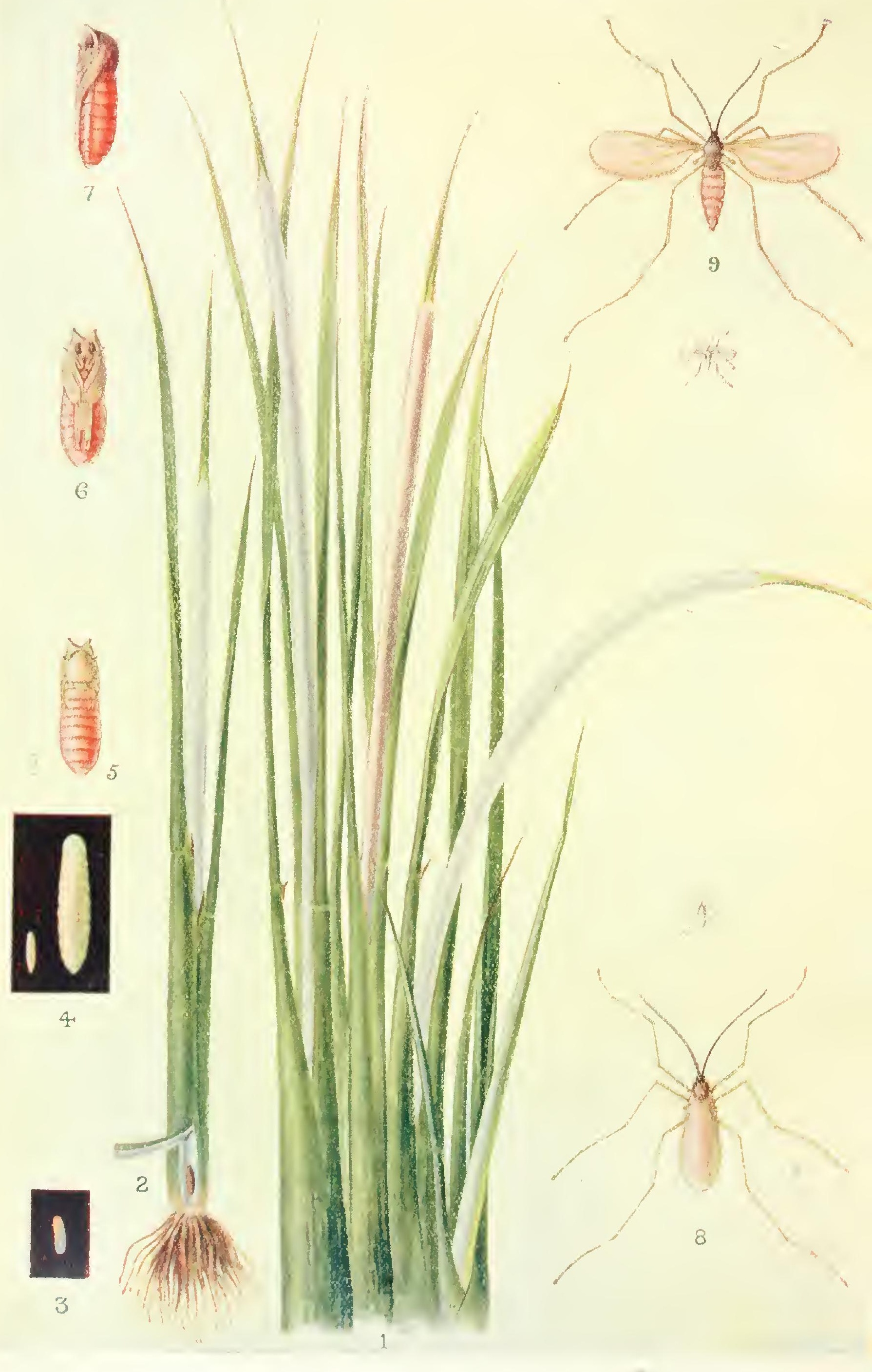


EXPLANATION OF PIATE 30.

Prochydiplosis oryzae. Wuod-Mason.

Fig. 1. A cluster of riee plants sereral of which are affected.

Fig. 2. An affected plant, with the pupa in its natural position exposel.

Fig. 3. Egg enlarged.

Fig. 4. Fullgrown maggot.

Figs. 5-7. Different views of pupa.

Firs. 9 \& 9. The adult fly in sitting and flying attiturles.

The small outline figures indicate natural sizes. 


\section{,}

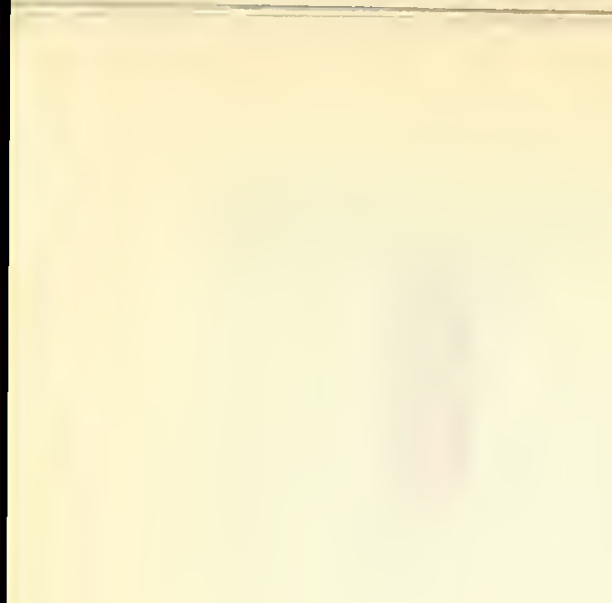

, 


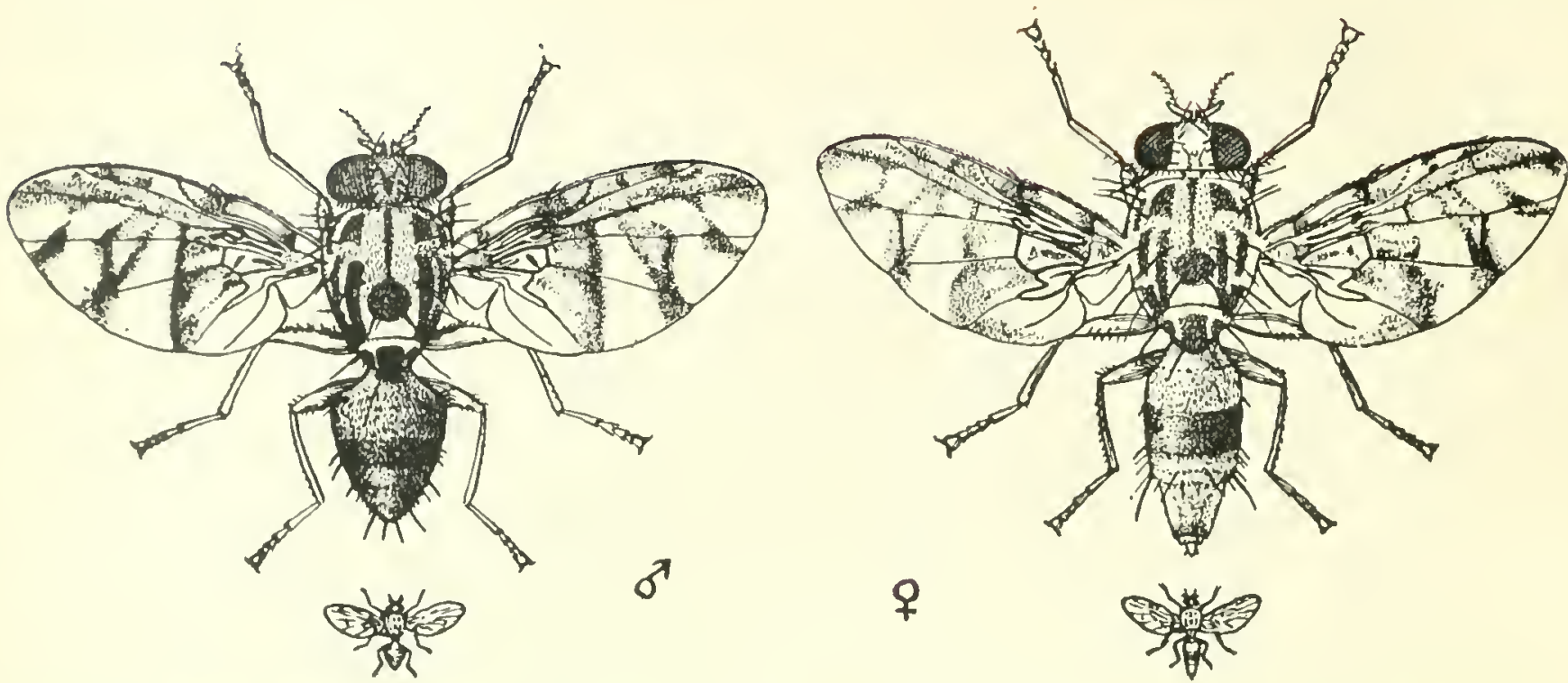

Fig. 1.-Stictuspis cerutitima, male (left) and female (right) $\times 5$. (The smaller figures show the natural sizes.)

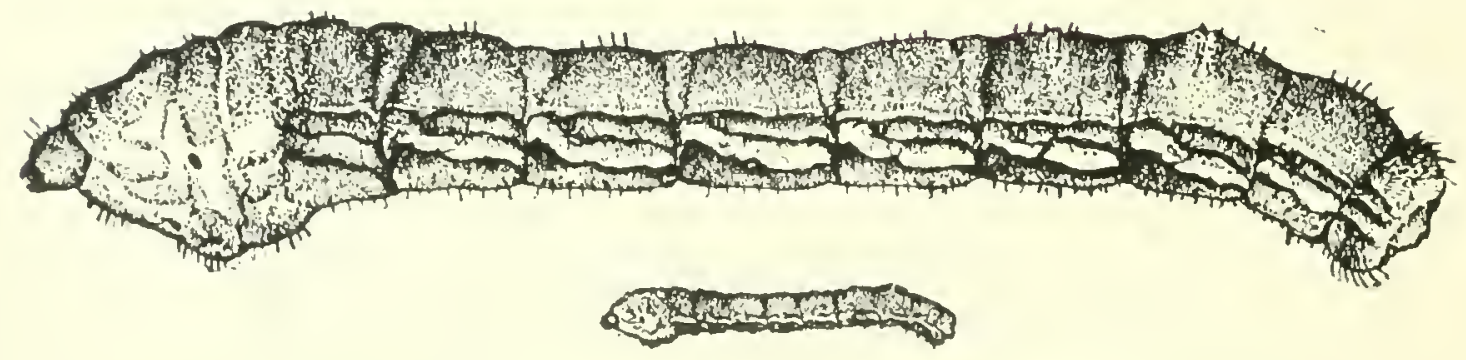

Fig. 2.-C. S. 1814. Larva. The smaller figure shows the natural size.

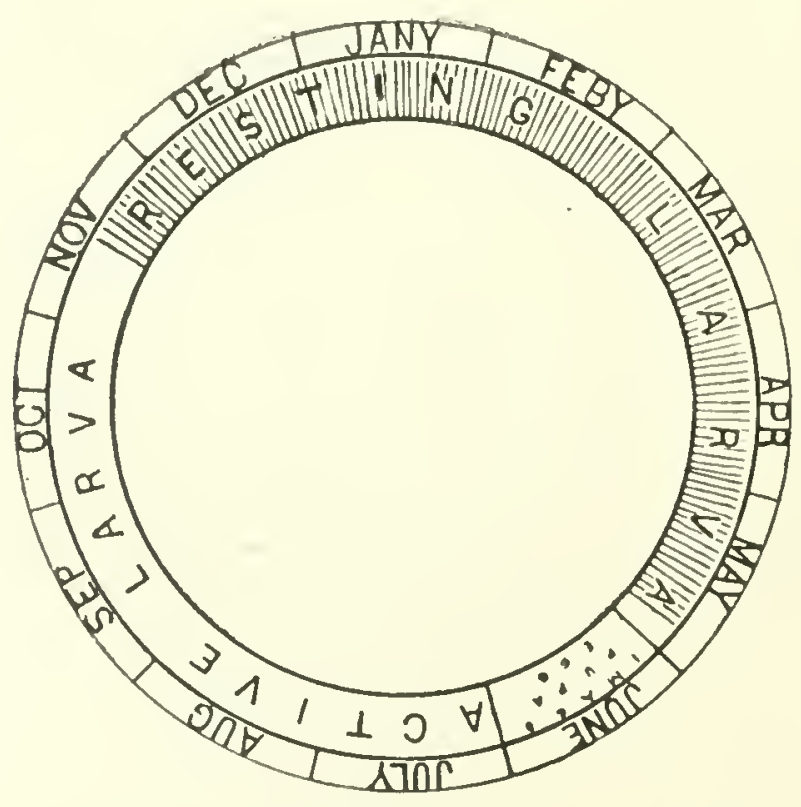

Fig. 3.-Annual life-cycle of Lamiad Borer (C. S. 1814! 
Foodplants-contd.

Dub (Cynodon dactylon)-March, June.

Gandli (Panicum miliare)-July.

The above are some of the foodplants from which these flies have been reared in the Insectary. Fly maggots are found in other grasses and even in the top shoots of bamboo branches. The maggots work at the base of the heart-leaf, lacerating and chewing the part entirely, producing the characteristic "dead heart." Usually the maggots are found in young plants. In China and Gandli, however, they occur in plants in ear, gnawing the bases of the ears which dry up. The effect is exactly similar to that caused by lepidopterous borers in ears of rice and wheat.

These muscid flies are a real pest and very little is known about them. As will appear from the dates of collection of maggots given along with the foodplants above, the flies are active throughout the year. The period of their life-cycle is short, being completed approximately within a fortnight.

\section{Pachydiplosis oryza.}

$$
\text { Plate } 30 .
$$

Foodplant-Rice.

This sinall Cecidomyiad fly causes serious damage to newly transplanted rice seedlings, especially when transplanting is done late in the season. The maggots feed in the middle of the shoot, producing a peculiar long tube-like gall in place of the main stem. Further growth of the shoot is thus stopped. Therefore the result is the same as that of attack by the ordinary borers which cause " dead heart."

This has not been observed to occur in the neighbourhood of Pusa, but it is a serious pest in parts of Bihar and Orissa, Bengal and Madras.

\section{Stictaspis ceratitina. \\ Plate 31, fig. 1 . \\ Foodplant-Bamboo.}

The maggots of this Fruitfly have been observed to occur in large numbers in the new bamboo shoots which grow in the Rains. The grubs bore the soft stem, killing the shoots entirely. These, together with termites and to a less extent caterpillars of Argyroploce paragramma, are responsible for the death of a large proportion of the new shoots, which do not become immune until their stem hardens. The stem and especially the apical portion of it, which is the part liable to attack, 
does not harden very quickly and not until the shoot has grown to a great height. On the 18th September 1918 the top of a new shoot abont fifteen feet high was observed to drop off. On examination, the top was found to be full of maggots of this fruit-fly, which riddled the soft stem, causing the internodes to break off. There were 178 maggots in it out of which 146 attained the adult stage between 29th September and 30th October, 82 being females and 64 males. The shoot itself somewhat shrivelled and dried at the top and did not grow any further. But it hardened and its branches, especially those towards the apical part, grew thick and long. Such damaged bamboos are frequently met with.

The Lamiad Borer (C. S. 1814).

Plate 31 , figs 2,3 ; Plate 32.

Foodplants-Batri and Rarhi (Saccharum spontaneum).

This longicorn borer has only one generation in the year. The adults emerge about June and deposit eggs. Young grubs have been collected on the 20th June. The grubs are available in very large numbers in Rarhi and Bati from June onwards. They are extensive borers and voracious eaters and convert the stems into hollow tubes. They remain active till about November and then rest inside the stems, pupating just before emergence abont June.

The full-grown grub measures about $24 \mathrm{~mm}$. in length, about $3 \mathrm{~mm}$. across the abdominal region and about $3.5 \mathrm{~mm}$. across the thorax. The lhead is small compared with the thorax which is swollen and protuberant ventrally. On the back of the sixth and seventh abdominal segments there are some small tubercles arranged across the segments in double rows. The hind end is truncated. The body has small brown hairs all over. There are no legs of any kind. The colour is yellow. The young grubs resemble the older ones in appearance and colour.

\section{The Weevil Borer (C. S. 1778). (Plate 33, fig. 1.) \\ Foodplant-Rarhi (Saccharum spontaneum rarhi).}

The external symptom of attack is the "dead heart." The grubs are found in large numbers in Mareh-April and although their size is small they are very vigorous borers and bore up and down the stem extensively.

The full-grown grub is about $5.5 \mathrm{~mm}$. long and about $1.5 \mathrm{~mm}$. across the middle of the body which tapers towards each extremity. The head is pale-yellow, glossy, and the body is also of the same colour 


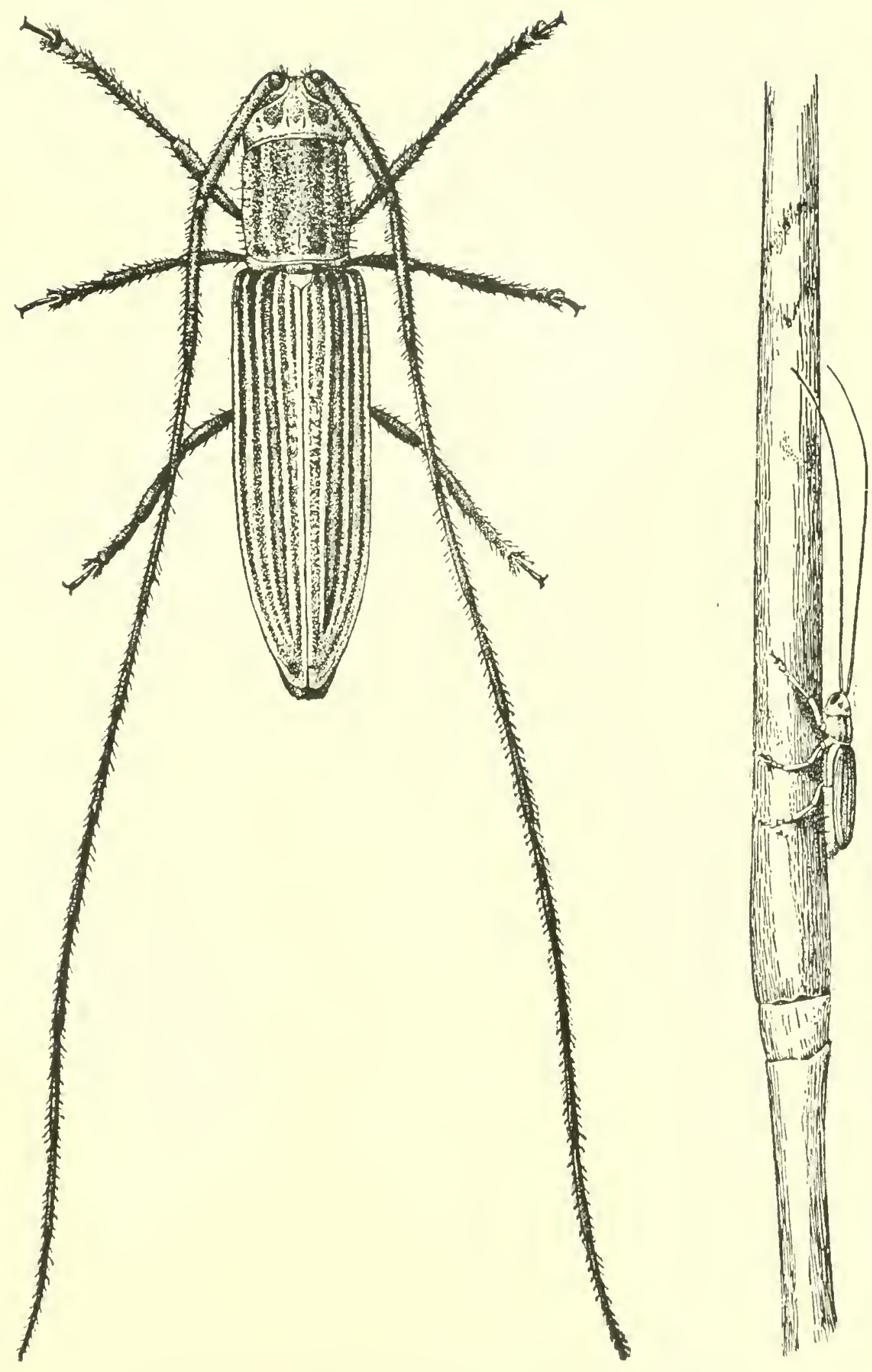

C. S. 1814. (The smaller figure shows the natural size.) 


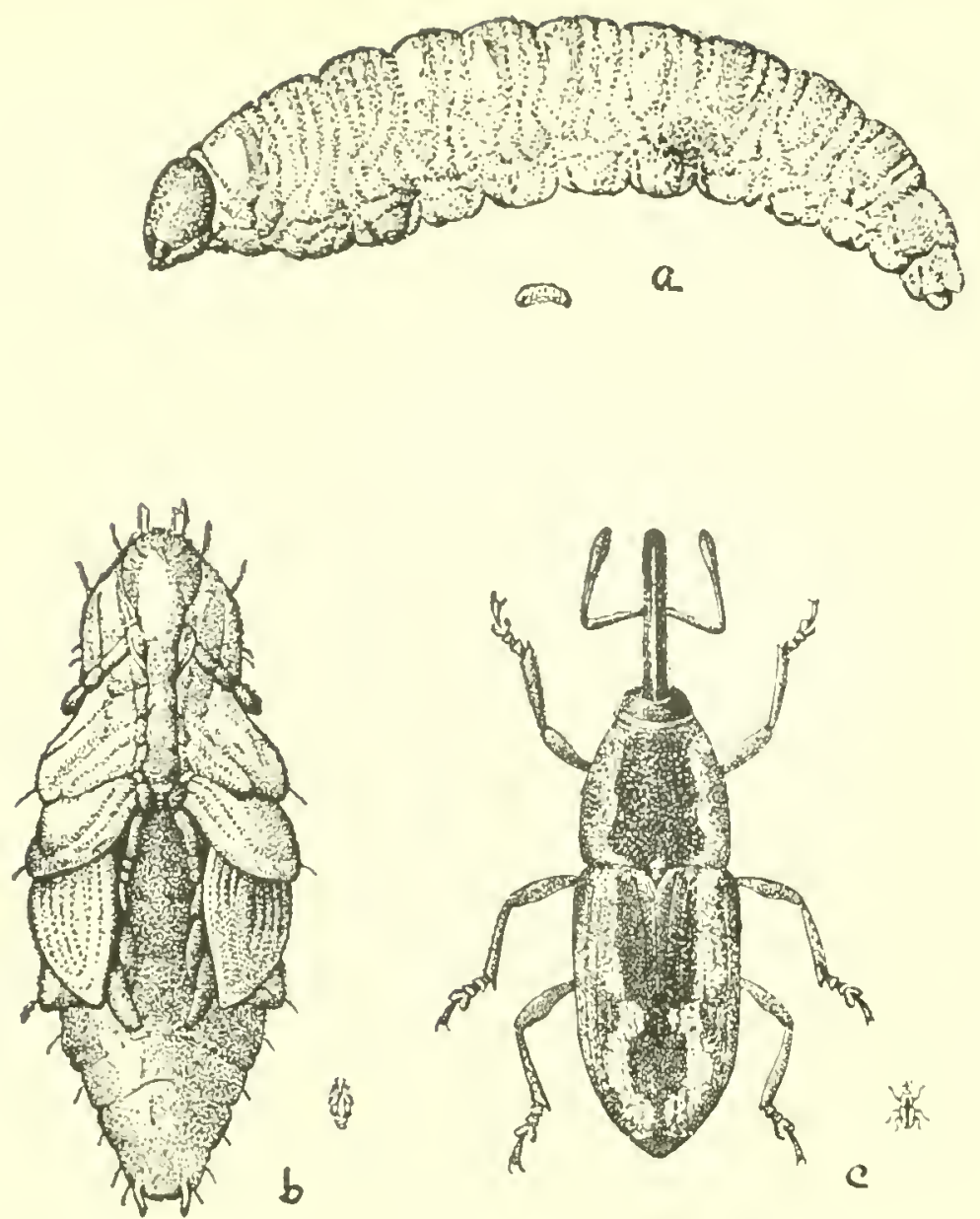

Fig. 1.-C. S. 1778. Weevil borer in $1 / 11 / 1$ i shoot. ", larva ; b. pupa; ", imago ; all magnified. The small figures show the natural sizes.

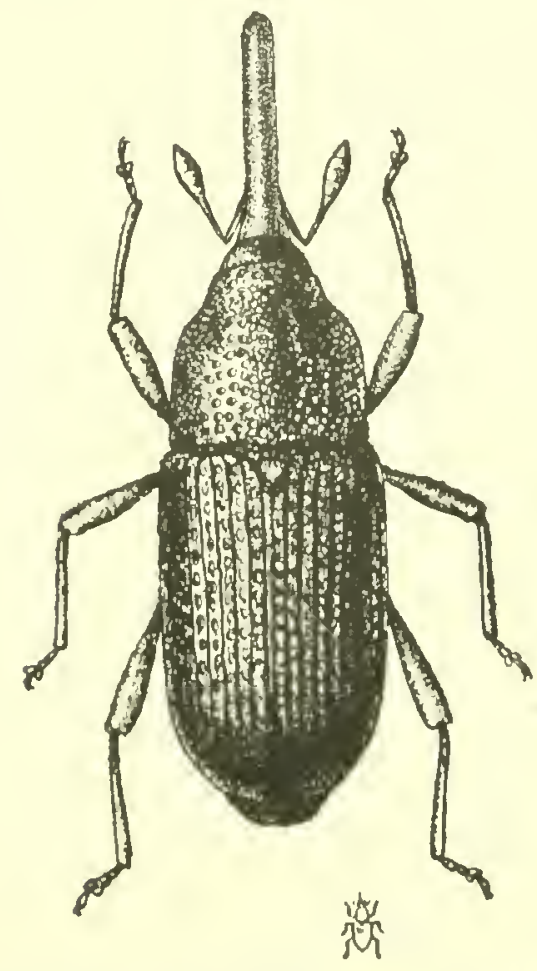

Fig. 2.-(C. S. 1397). Weevil Borer in montlin stem $\times 13$. The small outline figure shows the natural size. 




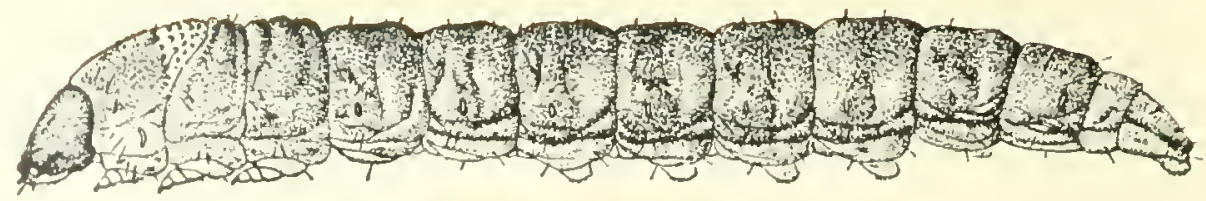

Q ish
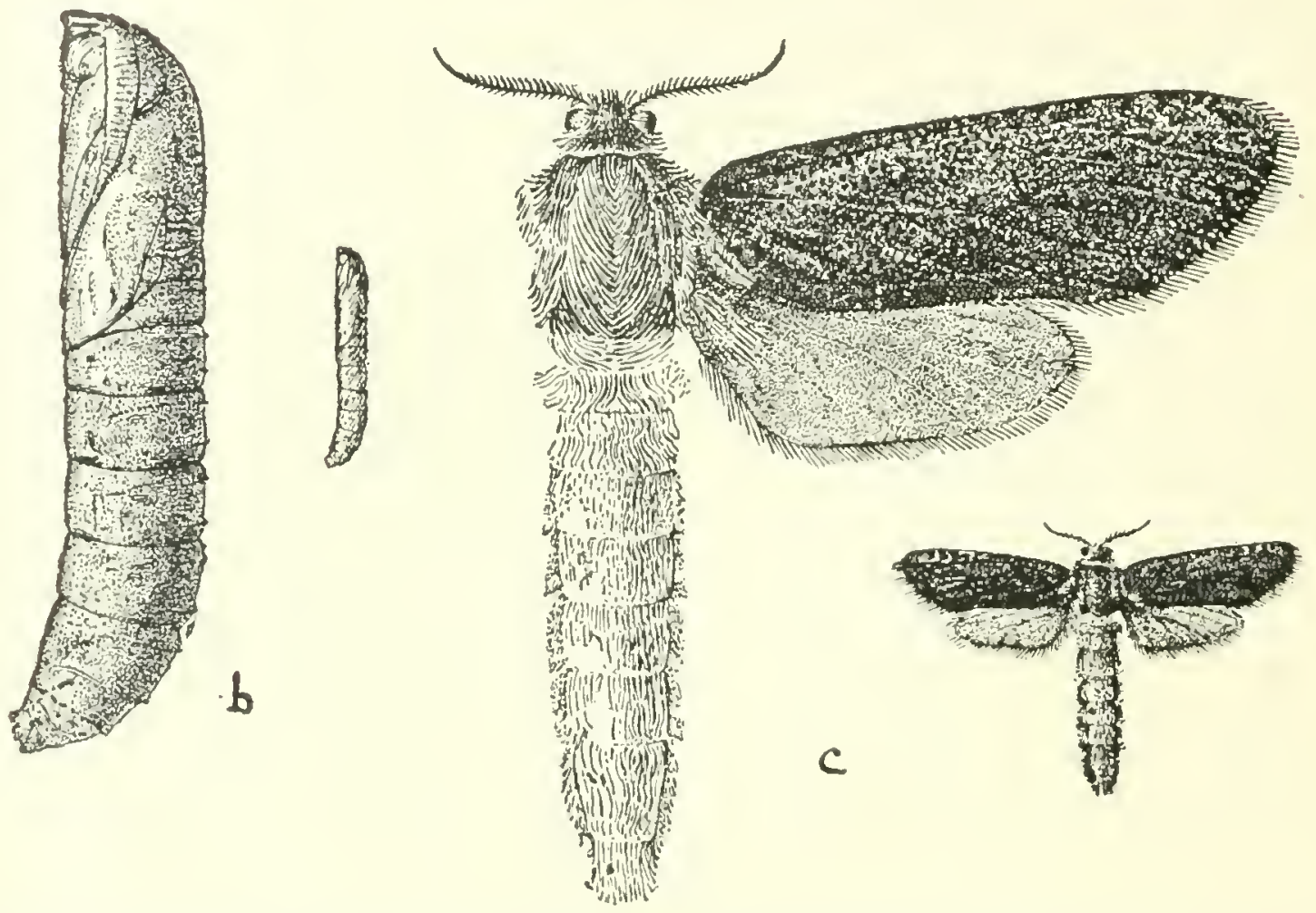

Fig. 1.-C. S. 1805. Purple zeuzerid larva boring in lirmoll ; a. larva ; 1, pupa ; c, moth ; all magnified ; the small figures show the natural sizes.

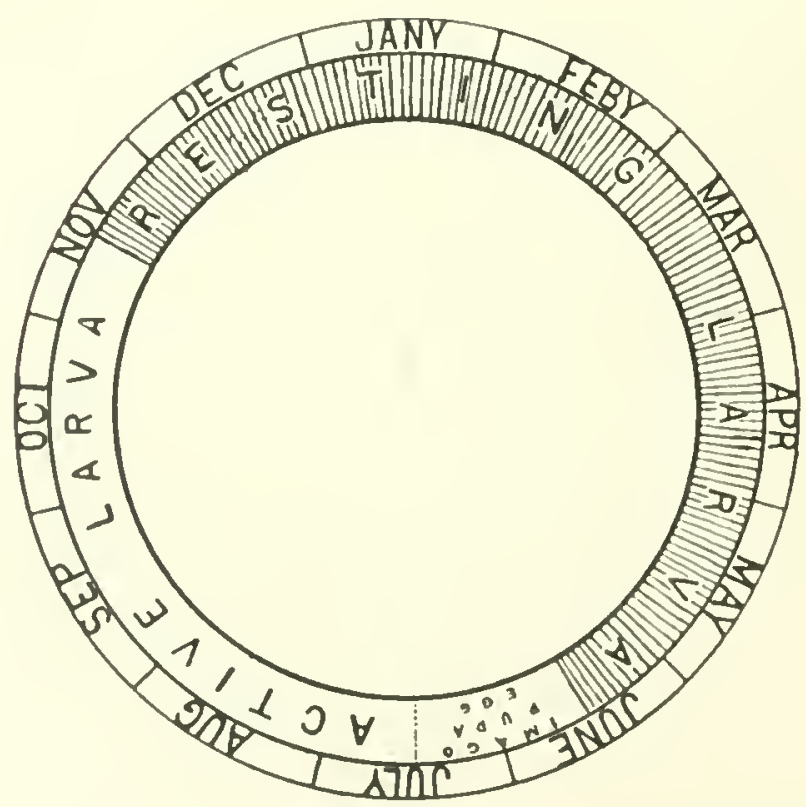

Fig. 2.-Annual life-cycle of Purple Zeuzerid Borer (C. S. 1805). 
As, however, the contents of the body show through the slin the abdominal region looks brownish. The grubs pupate inside the stems.

The full seasonal life-history is not lnown. From grubs collected in March and April weevils appeared by the end of May.

\section{The Weevil Borer (C. S. 1397). (Plate 33, fig. 2.)}

$$
\text { Foodplant-Motha (Cyperus rotundus). }
$$

Legless pale-yellowish-white grubs, boring the stem and causing dead heart were collected on 22nd May and weevils emerged from these in the Insectary between 13 th and 17 th June.

The purple-coloured Zenzerid Borer (C. S. 1805). (Plate 34.)

Foodplant-Kanra (Sacharum arundinaceum). In the Insectary the caterpillars fed on maize and also on juar (Andropogon Sorghum) to a small extent.

This borer has only one generation in the year. Young caterpillars have been collected from outside on the 8th July and gradually developing ones onward till about November when they become fullgrown. Fullgrown hibernating and restivating caterpillars have been collected in winter and up to about May. Moths emerged in the Insectary between 15th June and 10th July.

As usual with all internal borers, they cause "dead heart" in plants and bore in the centre of the stem, converting it into a hollow tube. The caterpillars go down right into the roots to hibernate and restivate.

A fullgrown caterpillar measures about $35 \mathrm{~mm}$. in length and about $4.5 \mathrm{~mm}$. across the abdomen. The shape is cylindrical and slightly tapering posteriorly. The head is red-brown and smaller than the prothorax which is the broadest segment, measuring a little more than $5 \mathrm{~mm}$. across. The prothoracic shield is large, yellow-brown in colour, having on its hinder part a number of posteriorly-directed flattened brown spines. The spiracles are elongated brownish slits and the five pairs of prolegs are rather short but equally developed. The colour of the body excepting that of prothorax is deep purple.

Pupation takes place inside the tunnel formed by the larva. Before the emergence of the moth the pupa wriggles out to some extent through an opening on the side of the stem previously made by the larva, the mouth of the opening being left closed by a thin epidermal layer of the bark. 
The violet-spotted Zeuzerid Borer (C. S. 1696 and C. S. 1857) (? Phrag matcecia sp.). (Plate 35.)

Foodplants.-Batri (Saccharum spontaneum batri); juar (Andropogon Sorghum). In the Insectary the caterpillars fed on Saccharum arundinaceum (Kanra) stem.

This borer has only one generation in the year. Moths appear about October and deposit eggs probably among the foodplants. The eggs hatch within a few days. The caterpillars feed throughout the winter, summer and the rains and are available in all these seasons. Their growth is very slow. They occur in profuse numbers in Butri and have been found in small numbers in juar. In the Insectary moths emerged between 1st October and 6th November. Young eaterpillars have been collected from outside on the 11th October and more and more advanced ones practically in all the later months up to August when full-grown ones are available. They pupated in September-October.

In the Insectary a moth laid 80 unfertilized eggs in an irregular heap. Each egg is about $1 \mathrm{~mm}$. long and about $0.6 \mathrm{~mm}$. thick, elongated, tubular'in shape with truncated ends. The shell is glossy and has very faint longitudinal furrows.

A fullgrown caterpillar measures about $30 \mathrm{~mm}$. in length and about $5 \mathrm{~mm}$. across the body. The head is yellow, glossy and smaller than the prothorax. The prothorax is pale yellow with a large shield similarly coloured as the head. The shield has a pair of brown spots one on each side and comnected by a brown bar. The posterior half of the shield is armed with a number of posteriorly-directed flattened brown spines. The meso and metathoracic segments are divided into three and the abdominal segments into two sub-segments, the posterior subsegments of all these and the anal segments have on the dorsum a number of minute tubercles surmounted with thin small hairs. There are similar tubercles clustered below the spiracles and also on the fold above the legs. The spiracles are elongated oval, yellow. The five pairs of prolegs are short but equally developed. The general colour of the body is yellowish-white. The metathorax and the first abdominal segment are violet coloured or rather purple with a violet tinge. The other abdominal segments have prominent violet markings which make up a thin middorsal stripe, a broad interrupted dorsolateral stripe and a similar spiracular stripe. The ventral surface is without any violet markings.

The young caterpillars resemble older ones to some extent in appearance but have long hairs on the body. 


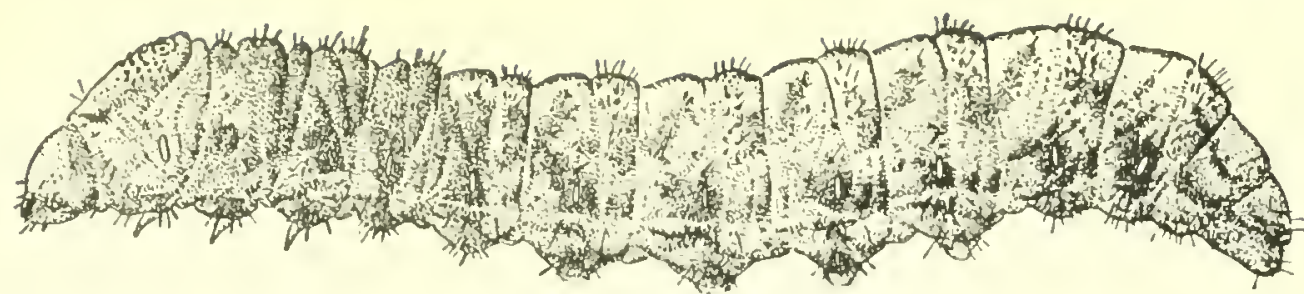

a.
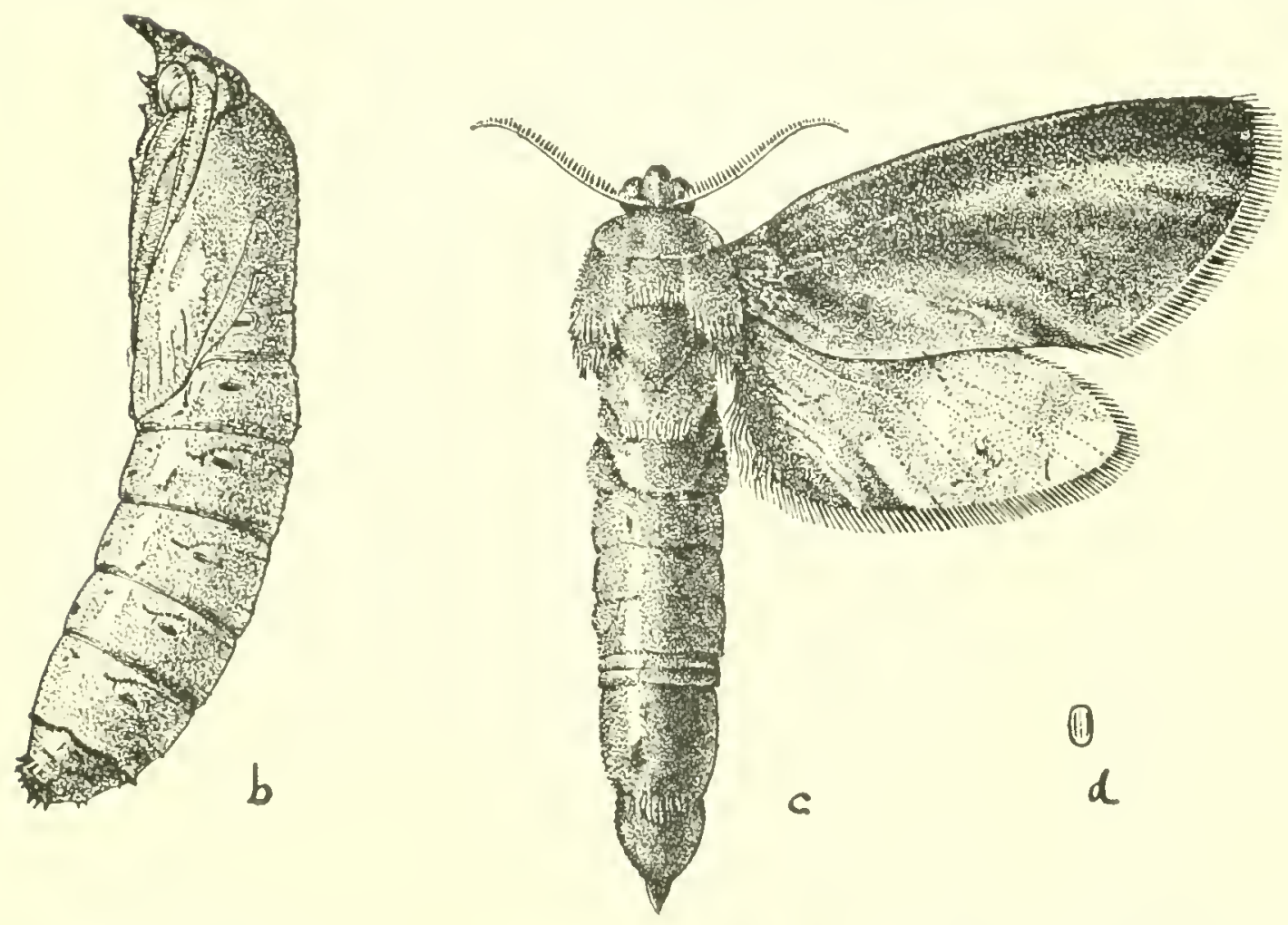

Fig. 1. C. S. 1696. Borer in surerlerrum spontoneum stem ; 1 , larva ( $\times 2:$; li, pupa $\left(\times 2 \frac{1}{2}\right) ; c$, moth $\left(2 \frac{\pi}{3}\right) ; 1$, egg $\left(\times 2 \frac{3}{3}\right)$.

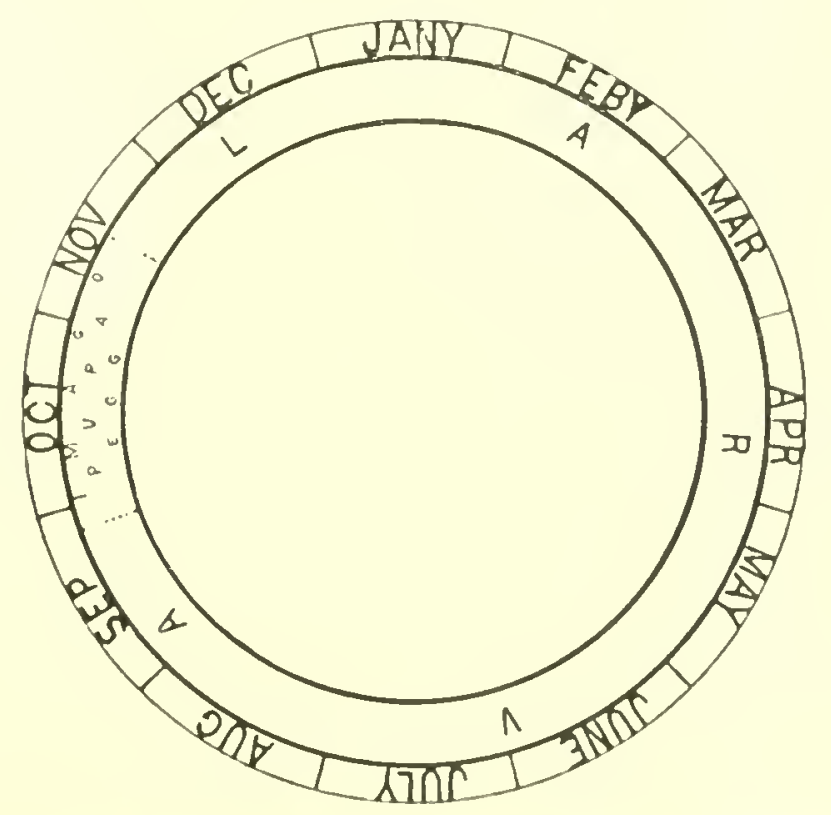

Fig. 2.-Annual life-cycle of Bores in Serrohrerum spontreneure (C. S. 1696). 

PLATE 3

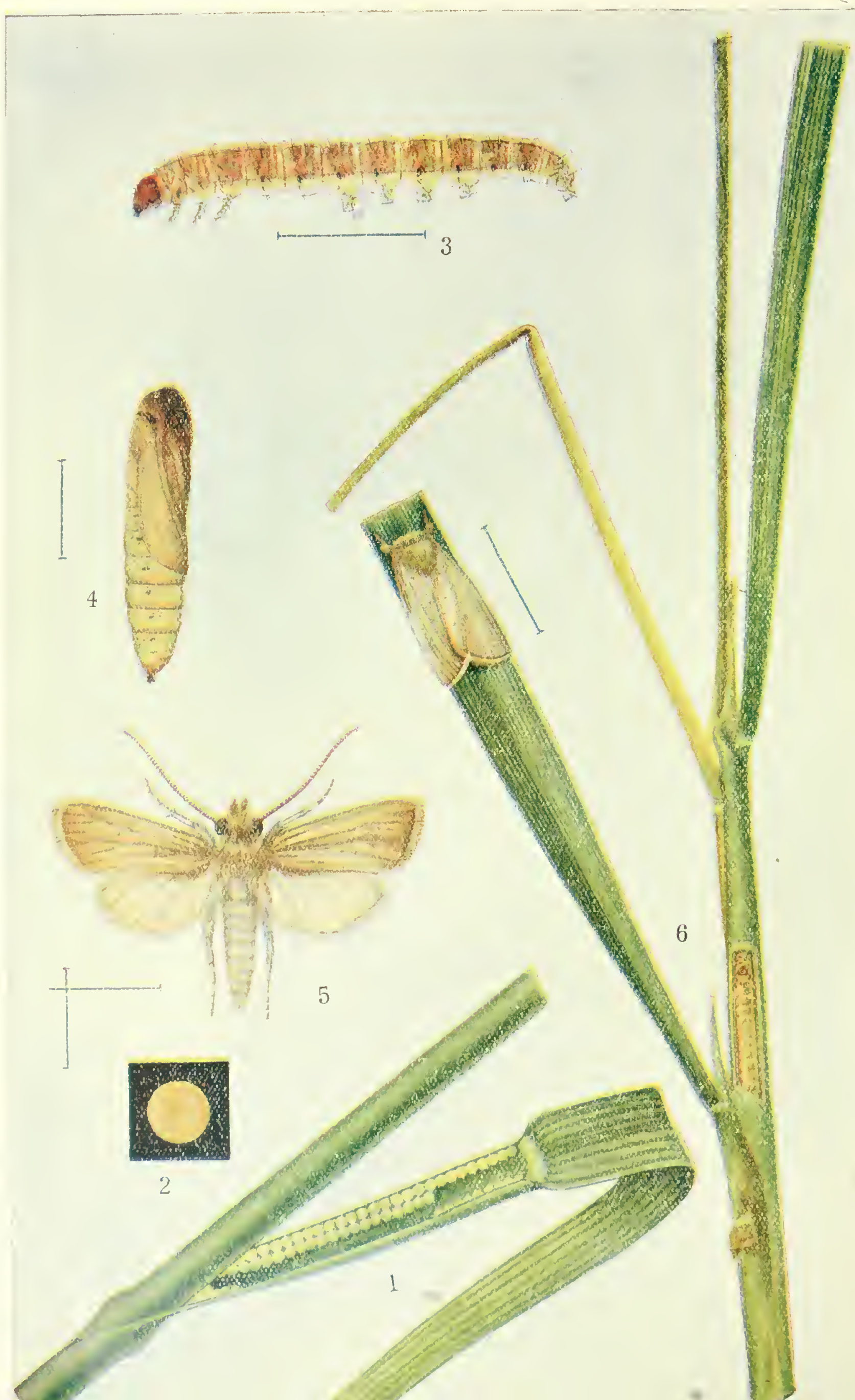




\section{EXPLANATION OF PLATE 36.}

Sestmia inferens.

Fig. 1. Egga laid inside leat slueath.

Fig. 2. A oingle egg magnified.

Fig 3. Lavra magnifiel.

Fin 4. Papa magnifiel.

Fige b. Moth with wings spreas.

Fig b. An affected plant showing larva in the stem and moth sitting on leaf. 
(1) 110 i 11 

Page 8\%.5 (9).

PLATE 3
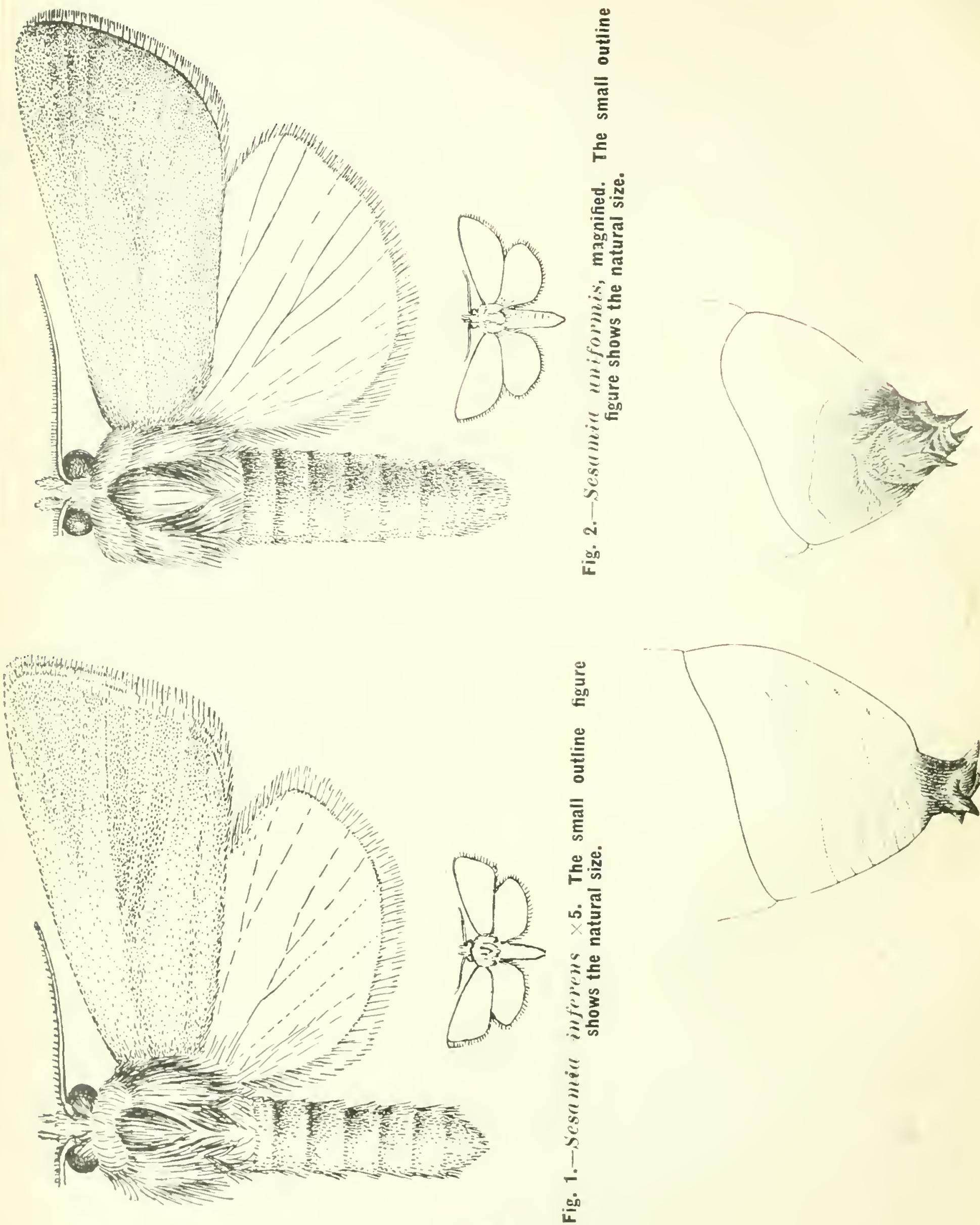
Pupation takes place inside the stem. Before pupating, the larva gnaws an opening on the side of the stem, the mouth of the opening being just covered by a thin epidermal layer of the bark. The pupa is provided with a snout having spines on its tip with which to pierce this epidermal covering. The pupa wriggles out to some extent before the moth bursts out of the pupal case.

\section{Sesamia inferens.}

Plate 36.

Foodplants-Rice; wheat; barley; oats; marua (Eleusine coracana); sama (Panicum frumentaceum); Guinea grass; Sudan grass; Jove grass (Rottbollia compressa); golmootha (Scirpus affinis); nartat (Phragmites karka); sugarcane ; maize; juar (Andropogon Sorghum); liama (Sacchamm arundinaceum); rarhi and batri (Sacharum spontaneum); ikri (Saccharum fuscum).

Caterpillars have been collected from the above plants. Besides these, they have fed in the Insectary on bajra (Pennisetum typhoideum) stems. In Madras they are known to occur in Setaria italica.

The caterpillars of Sesamia inferens, S. uniformis and the moth reared under C. S. 1666 are liable to be confused, as all of them are similar in appearance. Those of C. S. 1666 are more slender-looking than the larvo of the Sesamia spp. and have a faint purplish tinge. The larvæ of the two species of Sesamia cannot yet be distinguished. The pupa of C. S. 1666 (Plate 38, fig. 1) can be easily distinguished as it has no hair or spine on its hind end. The pupæ of Sesamia inferens and $S$. uniformis are liable to be confused but can be distingnished by the structure of, and the spines on, the hind end (Pl, 37, f. 3). The hind end of the pupa of $S$. inferens is rounded and has four spines on a distinct stalk. The hind end of S. uniformis pupa is protruded into a horuy process concave on the ventral side and having four spines arranged on its tip at some distance apart and two more spines behind the first four, i.e., six spines in all. The moths of $S$. inferens and $S$. uniformis are liable to be and have been confused in the past. They can be distinguished easily by the trained eye from the shape of the forewings (Plate 37, figs. 1, 2) and also from the structure of the male antennæ as indicated in Entomological Note No. 62 of Pusa Bulletin No. 59.

In the neighbourhood of Pusa $S$. inferens is active throughout the ycar, active caterpillars being available in all the months of the year. Also the larvæ are observed to pupate and adults to emerge throughout the cold weather. In the cold scason however the period of the lifecyclc is very much extended. In ordinary years, in March, April and 
May, the shortest period of life-cycle observed is 49 days, viz., egg 7 days, larra 30 days, and pupa 12 days, the longest period taken by some of the individuals out of the same lot being 71 days in which the larral life only was extended to 48 days. In the cold weather from Norember to January the larval stage has been observed to take about $2 \frac{1}{2}$ months and the pupal stage about a month.

As growth is very slow in the cold season the caterpillars are hardly found in numbers in winter. With the spell of warm weather about February their activity is observed in wheat and barley in which dry ears appear. In March-April they are common in all the foodplants mentioned above which happen to grow at the time and may cause serious damage to maize. They occur in new shoots of sugarcane at this time. But ordinarily they have not been observed to infest sugarcane in large numbers. From about June onwards they occur commonly on rice and in very large numbers when rice is in ear about OctoberNovember.

From observations so far made $S$. inferens can be considered a pest only of maize and rice. Normally it does not cause much damage to the other foodplants mentioned.

The female moth is capable of laying more than 400 eggs. One laid 419 eggs in the Insectary. The eggs are thrust between the leafsheaths and the stem in rows two to three deep. As many as 161 eggs have been comnted on a single plant. The egg is hemispherical in shape, being about $0.7 \mathrm{~mm}$. in diameter and having fine ridges on the surface, the ridges ruming in regular order down the sides from the top. The colour is creamy white, changing to brownish and ultimately to grey before hatching.

The newly-hatched larva is about $1.5 \mathrm{~mm}$. long, pale yellow in colour and has its head and cervical and anal plates dark brown. After the first moult it assumes the characteristic appearance and colour seen in older larræ.

On hatching from the eggs the young caterpillars issue out of the leaf-sheath and may disperse, going into neighbouring plants. They may gnaw into the stems of young seedling plants either from the top or from the side and bore in the central part causing "dead heart" invariably. When they hateh on tall plants such as rice and wheat in ear, most of them bore into the upper part of the stem and do not disperse until they are somewhat grown. Many young caterpillars are therefore found in individual plants with dry ears. The caterpillars migrate from plant to plant, thus injuring many plants in the course of their life. 



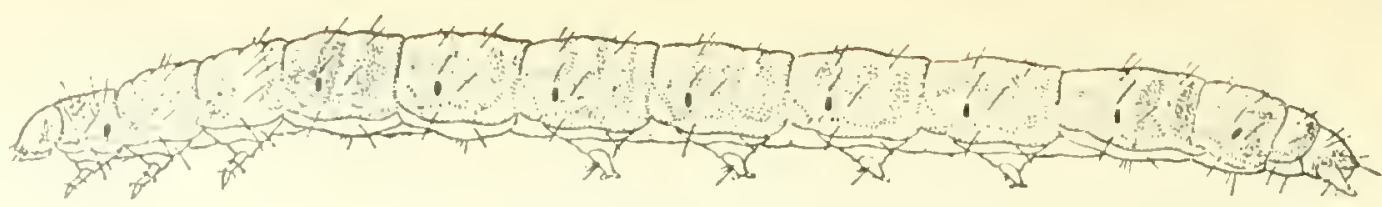

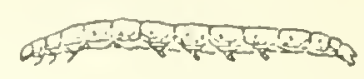

$a$
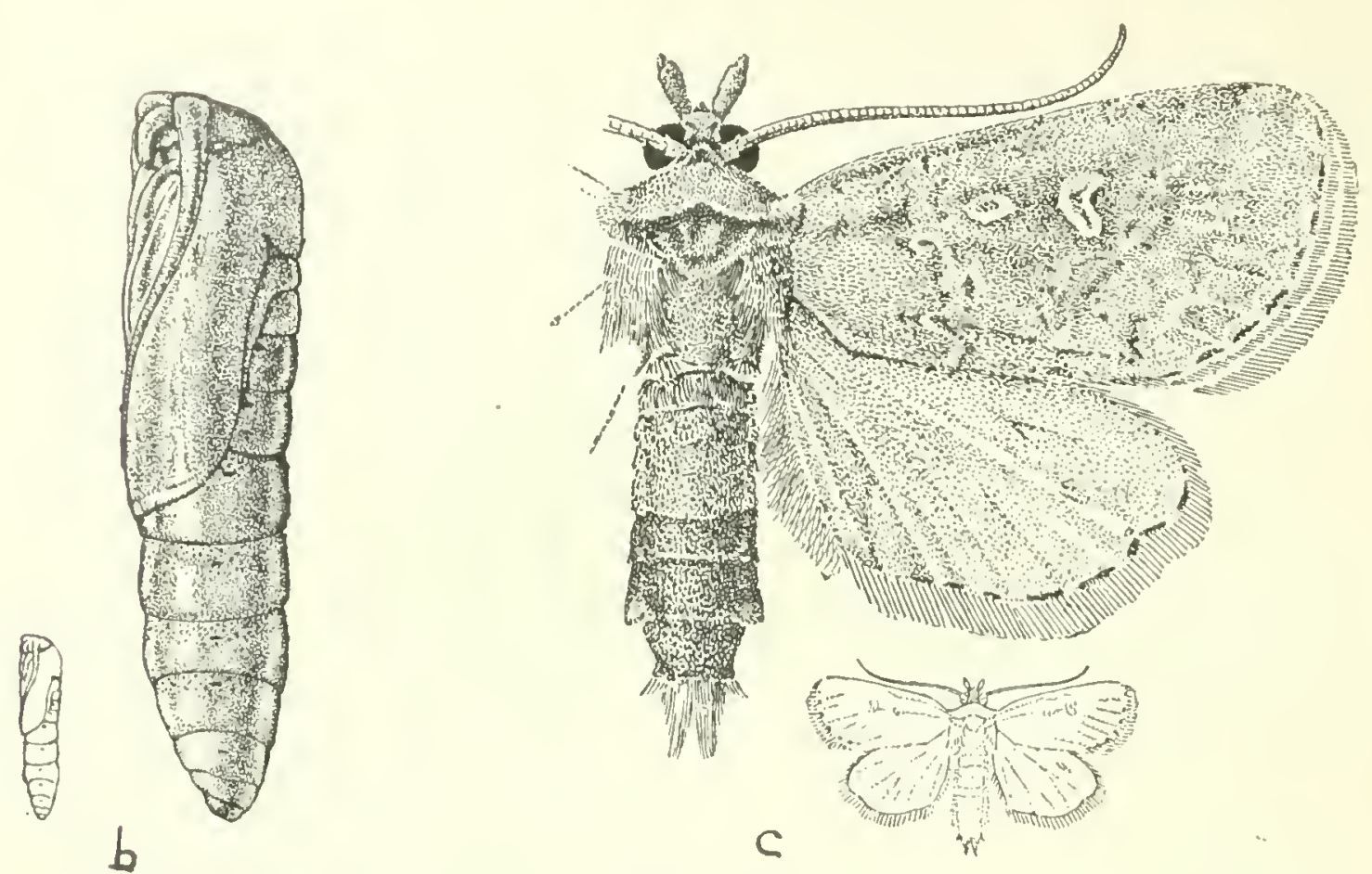

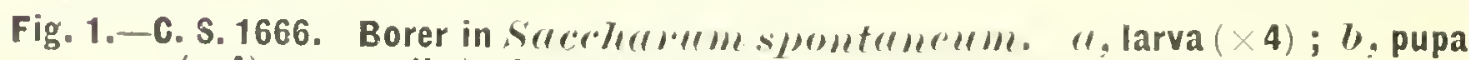
$(\times 4)$; 1 , moth $(\times 4)$; the smaller figures show the natural sizes.

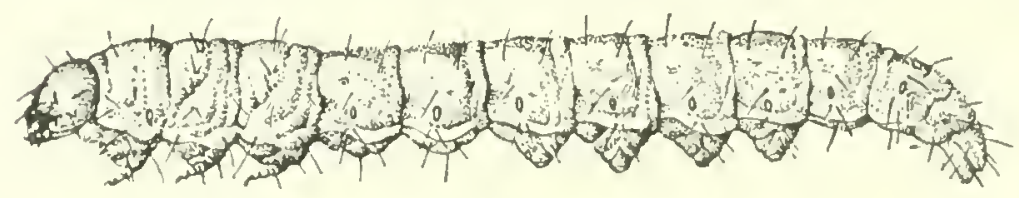

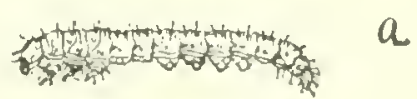
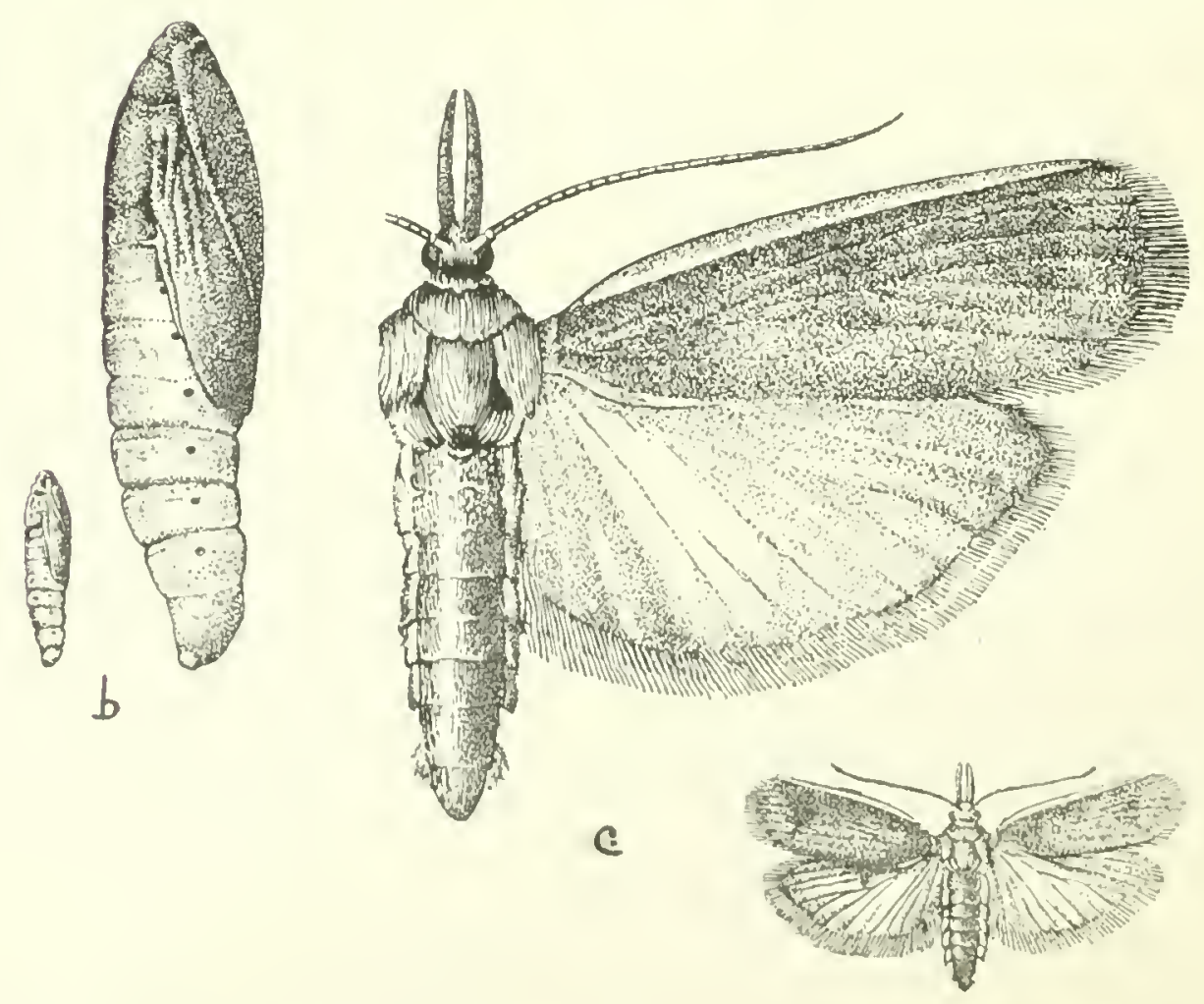

Fig. 2,-C.S. 1771, Borer in Kílul'r ront 
Pupation takes place inside the bored stem or under a leaf-sheatli on the stem in which the larva has fed. Before pupating the larva prepares an exit hole for the moth.

\section{Sesamia uniformis. (Plate 37. figs. 2,3.)}

Foodplants-Sugarcane; maize; rarhi and batri (Saccharum spontaneum); iliri (Saccharum fuscum); kama (Saccharum arundinaceum). Besides the above, the caterpillars have been fed on juar (Andropogon Sorghum) in the Insectary.

Like S. inferens, S. uniformis also remains active practically throughout the year, the growth in winter being however very slow. In March young larvæ are available in large numbers, especially in kanra, and active caterpillars have been collected practically throughout the year. To judge from its occurrence it prefers kama to the other foodplants. It is similar to $S$. inferens in babit.

\section{S. 1666 (Plate 38, fig. 1.)}

Foodplants-Rarhi and batri (Saccharum spontaneum); itri (Saccharum fuscum) ; sugarcane (Munni, Muzaffarpur, October).

The caterpillars of this species have been observed to be active throughout the year and occur in enormous numbers in rarki and batri. Only on one occasion were they found in itri at Pusa in small numbers. At Munni, a village in the Muzaffarpur District, they were observed in fair numbers in sugarcane in October, probably because there was no batri growing there within a radius of about three miles. In winter, active caterpillars have been collected from outside but the pupal stage has been observed in the Insectary to extend to more than two-and-ahalf months, although moths emerged in November and January.

As usual with all internal borers, the caterpillars cause "dead heart" and bore extensively up and down the stem, converting it into a hollow tube. They pupate inside the bored stem after gnawing an opening on the side for the emergence of the future moth, the mouth of the opening being stopped by a thin layer of the epidermis of the stem.

Emmalocera sp. (C. S. 1771).

$$
\text { Plate 38, fig. } 2 .
$$

\section{Foodplant-Lanra (Saccharum anundinacerm).}

These caterpillars exactly resemble those of Emmalocera depressella in appearance and like the latter bore the stem near the roots. Their 
seasonal history also is apparently similar. They remain active in the hot weather and the rains and hibernate right inside the thick roots. Hibernating larvæ collected in March developed into moths between 13th Mareh and 14th April.

Phycitid Borer (C. S. 1700).

Foodplant-Tender maize cob.

On the 18th September a single caterpillar was collected boring a tender maize cob. It was $10 \mathrm{~mm}$. long, cylindrical and tapering slightly hindwards. The head was yellow and body pale yellowish-white with faint and indistinct spiracular and dorsolateral stripes visible under lens. The spiracles were round, a brownish rim enclosing a clear space inside. The hooklets on abdominal prolegs were in complete circle.

The caterpillar pupated on 23rd September in a sillken cocoon formed lining the tumnel. The pupa was about $7.5 \mathrm{~mm}$. long, yellow-brown in colour and withont any marking or spine on any of the abdominal segments or on the hind end. The moth emerged on the 3rd October. It resembles the moth of C. S. 1837 to a very great extent.

Phycitid Borer (C. S. 1837).

Plate 39, fig. 1.

\section{Foodplant-Marua (Eleusine coracana).}

Caterpillars were collected in Marua stems which they were boring near the base, on 16th August. They were not however found in large numbers. Three of them developed into moths between 28th August and 6 th September and the rest have been hibernating.

The caterpillars resemble those of Emmalocera depressella in colour and appearance but are much smaller in size, being only about $12 \mathrm{~mm}$. long. The head is yellow-brown and the body creamy-white. The spiracles are round with a clear space inside. The five pairs of prolegs are equally developed.

Pupation takes place inside the stem. The pupa is yellow-brown and has on its hind end two conical tubercles, one on each side, and four to six much smaller tubercles between these two, all being surmounted with a thin hair. 


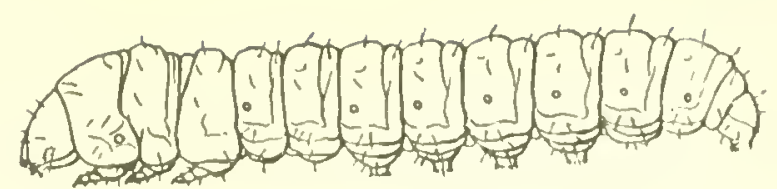

a
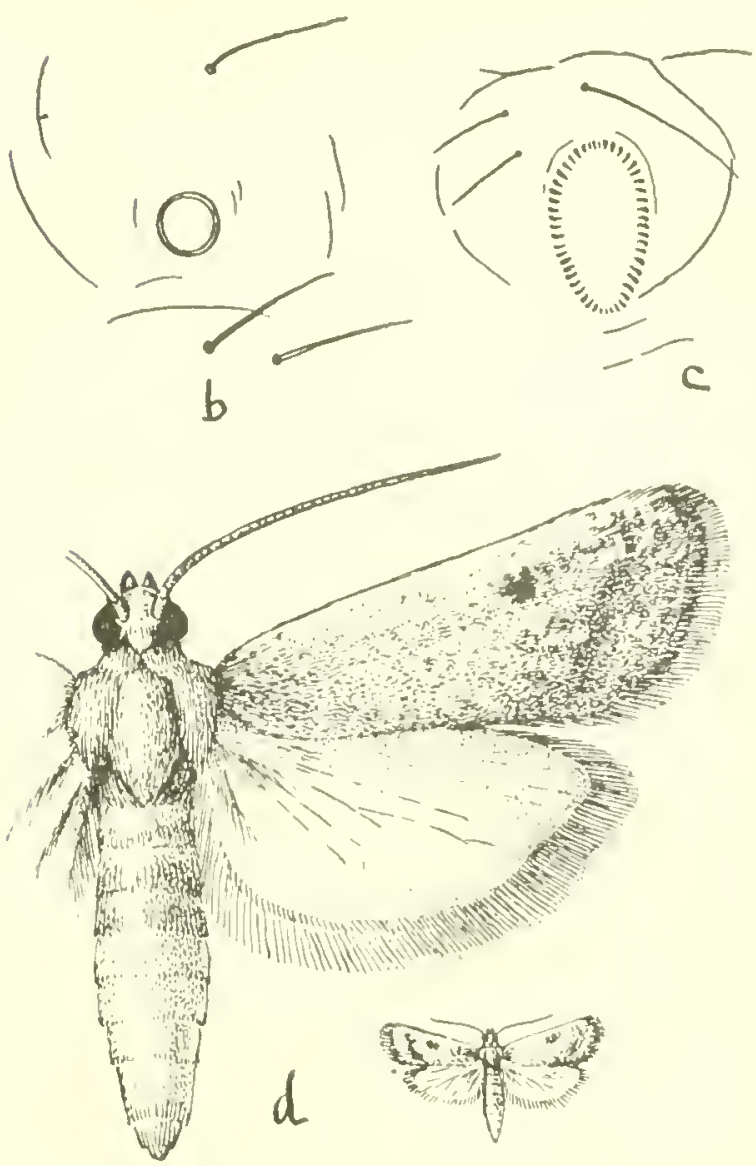

Fig. 1.-(C. S. 1837). Ecrer in Elputirr rofrerma: rl. larva $\times 5 ; \mathrm{l}$, details of larval spiracle; $r$ arrangement of crochets on proleg of larva; 17 moth $\times 5$ (the smaller figure shows the natural size).

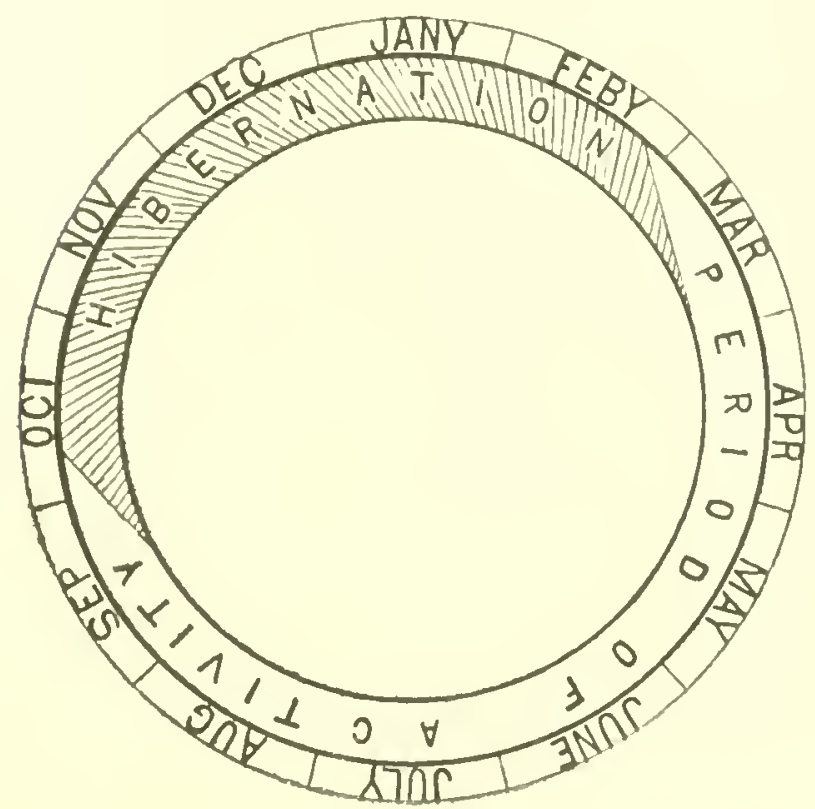

Fig. 2. Annual life-cycle of Emmaloceren 



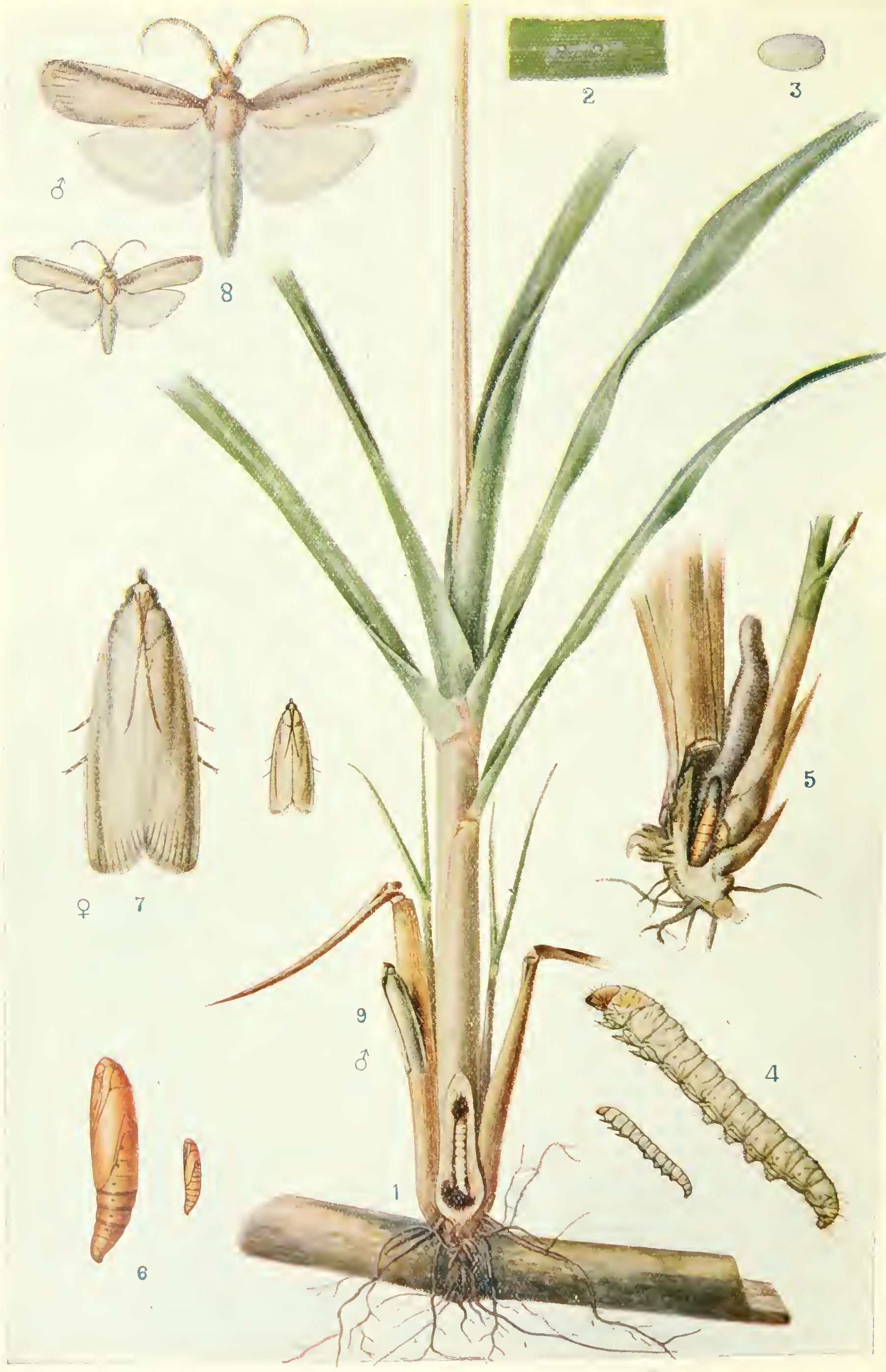




\section{EXPLANATION OF PLATE 40.}

\section{Emmalocera depressella.}

Fig. 1. Young eane shoot ent open to show attack by larva. Note "dead.heart." Fir. 2. Eggs as laid on a leaf, natural size.

Fig. 3. Egg, magnified $(\times 11)$.

lige. 4. Full-giown larva, magnitied ( $\left.\times 2 \frac{1}{2}\right)$ and liatural sizl.

Fig. J. Cane plant cut open to show pupa, natural size. Note cocoon witl gallery prepared for exit of moth.

Fig. 6. Pupa, natural sizo and magnitied ( $\times 20$ ).

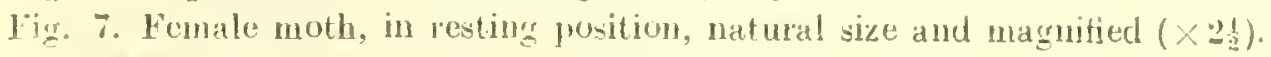

Fig. s. Male moth, natural size aud magnified. 


\section{Emmalocera depressella (Polyocha saccharella).}

Plate 39. fig. 2 and Plate 40.

Foodplant--Sugarcane.

Emmalocera depressella may be described as the specific pest of sugareane. It has not yet been found in any other plant and it causes the greatest damage of all the internal borers which occur in this crop. As its caterpillars always work near the roots of the plants and mostly oceur in the roots of old stools in the latter part of the season, it had hitherto been supposed to be simply a root-borer and hence of minor importance. Closer observation has revealed its real nature. In the neighbourhood of Pusa and probably everywhere the greatest damage to sugareane from borers occurs when the erop is young and the share of $E$. depressella is usually greater than the damage by all other borers taken together. It cannot most probably be said that this insect has changed its habit recently. The first external symptom of damage in young plants is the "dead heart" characteristic of all internal borers and superficial observation would place it to the credit of Diatrcea or Chito or Scirpophaga, whose larve are usually found in the stems of the shoots affected by these latter insects. It is not only at Pusa that $E$. depressella has been observed to damage young canes. About three years ago more than fifty young shoots were sent from Etawaln and they were all damaged by this insect. Last year (1918) out of 69 borers sent from Sipaya early in May, as many as 48 were E. depressella, 20 Diatian auricitia and I Sesamia. E. depressella has also been reported from Sind and observed at Chinsurah in Bengal. In the Agricultural Joumal of India, Vo. III, p. 104, Messrs. Lefroy and Mackenzie mention its occurrence in young sugareane at Hathwa, Saran.

The modes of feeding of the internal borers which have so far been observed in sugareane shoots are quite distinet. Scirpophaga caterpillars bore down from the top forming a single distinet tumnel ending in the characteristic exit hole for the future moth. The base of the heart leaf does not usually rot and therefore does not give out any offensive smell.

Diatrace auricilie and Chilo simplex caterpillar's also bore down from the top, and Sesamia larve may similarly bore down from the top but more often they enter from the side. In the ease of all these the tunnel is filled with a wet mass of frass, the " dead heart" comes off with a pull and there is a very offensive smell. Also there are always side-holes in the affected shoots but all of these holes may not extend up to the exterior and therefore may not be noticed unless some of the sheaths are removed. 
E. depressella caterpillars usually effeet entranee into the base of the shoot through the side near or below the soil surface. The caterpillars seldom work upwards through the shoot but confine themselves to the extreme base of the shoot or to the newly-formed stem (cane). The tunnel usually runs across the stem and may go round somewhat in a circular manner and it is closely filled with dry powdery frass. The base of the shoot is weakened and when pulled sideways the entire shoot is dislodged at the base. When no stem (cane) is formed the caterpillar in the majority of cases may either come off with the shoot or is more often left exposed to view. But, when the shoot has grown somewhat and has formed a stem (cane), the caterpillar is usually left behind in the stem and can be got at by splitting open the stem. The first external symptom of damage is the "dead heart" and the entire shoot gradually dries. Side shoots are given off by the affected one but the same caterpillar may attack and kill some of them too, if not all. This form of damage is common up to about May. Later in the season, when the stools have formed thick roots, the caterpillars are usually found among the roots where however they are in no want of new shoots which appear practically throughout the season.. Even if no new shoots be found the caterpillars may bore the thick root or rarely the base of the grown-up canes. In a few cases they have been observed to bore the setts.

E. depressella has been observed to be active from about Mareh to October and the winter is passed in hibernation in the larval state in the roots. The 14th of Oetober is the latest date before winter and 28th February is the earliest date after winter, when moths have emerged. Ordinarily the life-cycle is completed in about a month-and-a-half. In the Insectary one brood took 56 days, viz., egg 3 days, larva 41 days, and pupa 12 days.

The eggs are flattened, scalc-like, and creamy-white in colour and are deposited singly or a few at one place but separately, on the stem or even on the ground and less frequently on leaves. The young larva is about $2 \mathrm{~mm}$. long, pale yellow with a yellow-brown head and five pairs of equally developed prolegs. The fullgrown larva measures about $30 \mathrm{~mm}$. in length, has a yellow-brown head and creamy white body which is somewhat wrinkled transversely. The dorsal vessel is usually visible as a brown marking on the back. The larva are rather sluggish. They pupate in the tunnel they form in the stem or roots. Before pupation an opening for the emergence of the future moth is made in the form of a silken tube which comes up to the surface of the earth when pupation happens to take place at some depth. The pupa is yellow-brown in colour and can be easily distinguished from the pupæ 



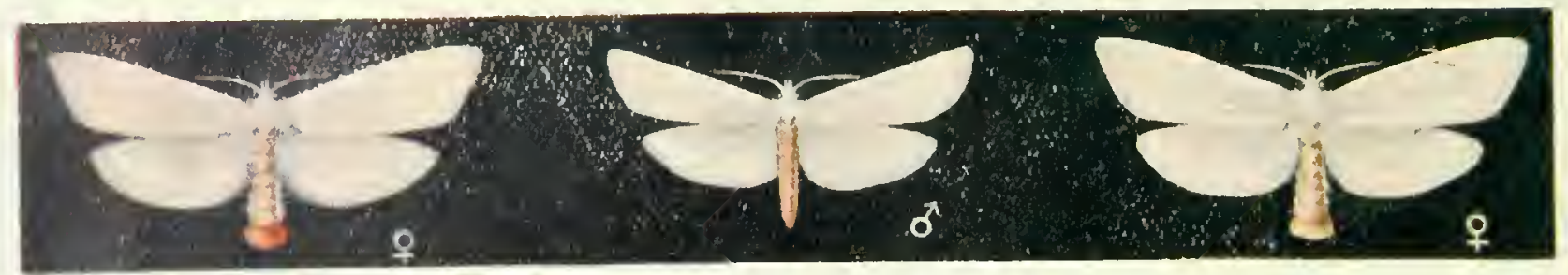

10

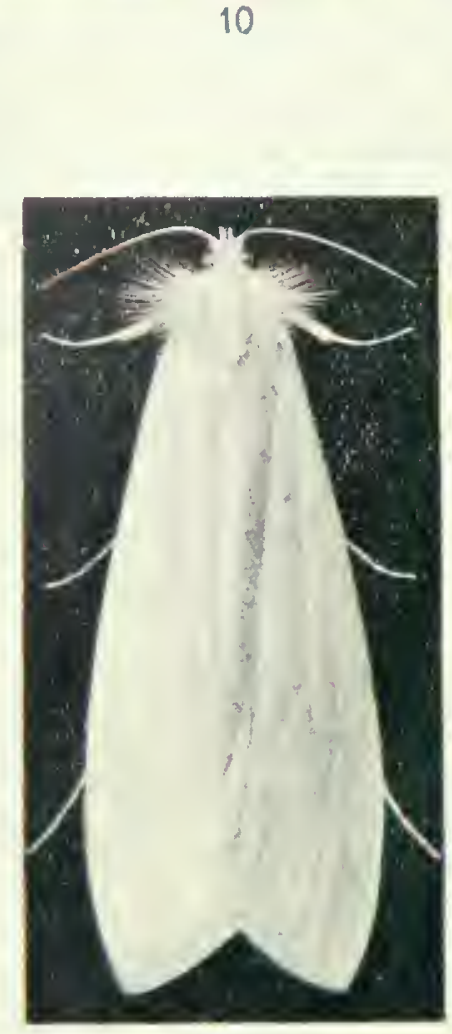

9

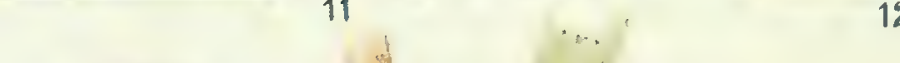

12

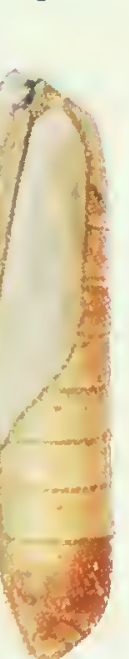

7

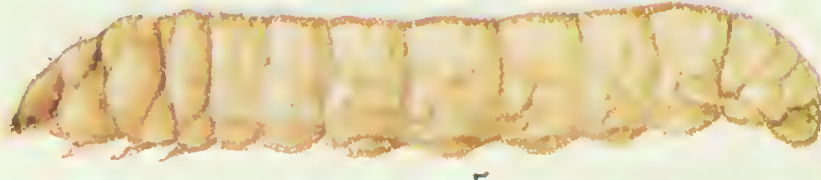

5

(3)

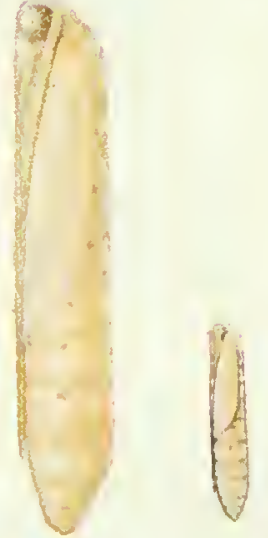

8
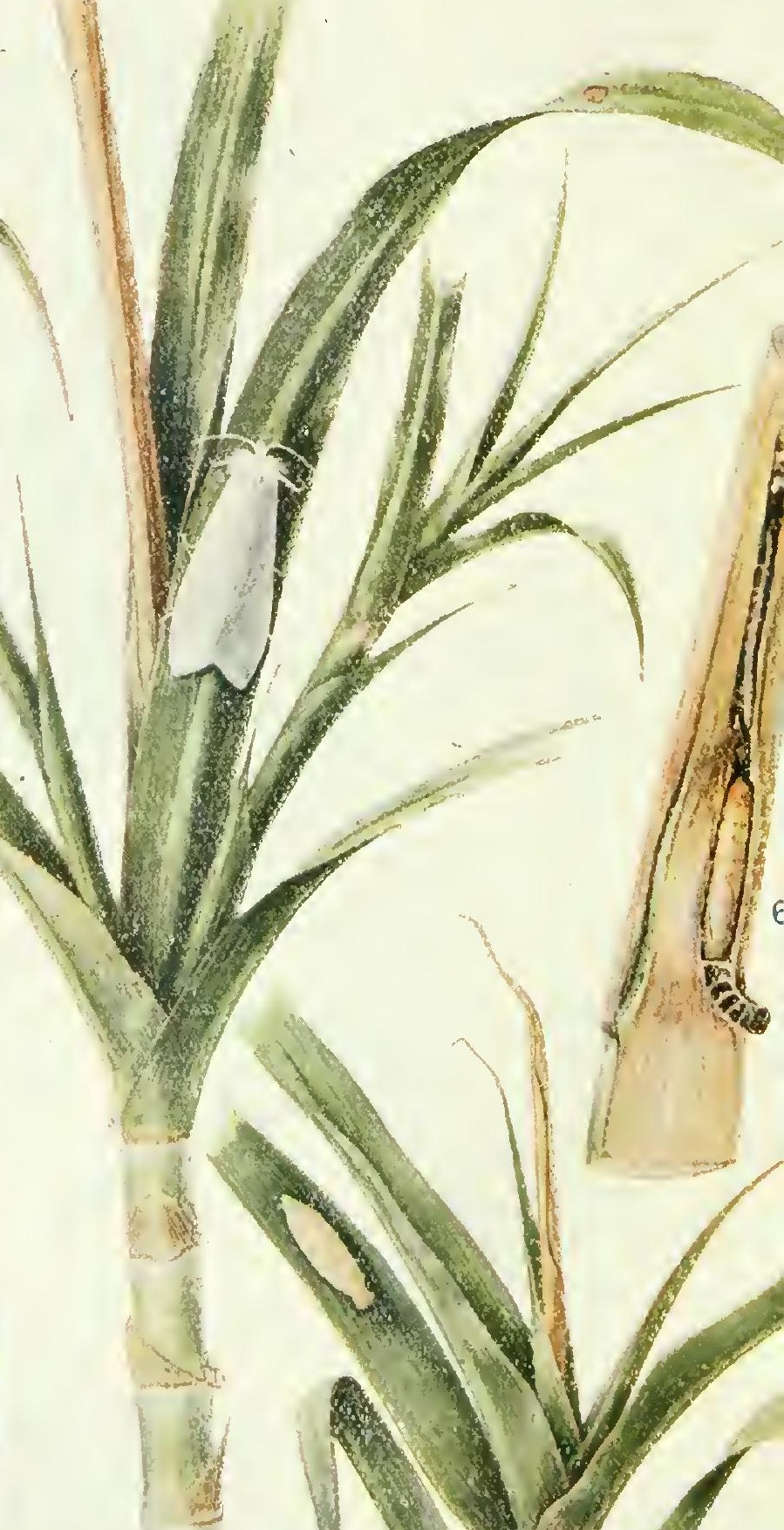


\section{EXPLANA'IION OF PLATE 41.}

\section{Scirpophaga xanthogastrella.}

Fig. 1. Attacked shoot of sugarcane cut opon, showing larva inside. Note "dead. heart" and egg-mass on leaf.

Fig. ". Attacked shoot of sugarcano with" dead-heart" and sido-shoots (typical of attack) thrown out. Cn leaf is a moth in resting position (natural size).

Fig. 3. Egg-mass with eovering hairs renoved, magnified $(\times 21)$.

Fig. 5. Full-grown larva, magnified $\left(\times 2 \frac{1}{2}\right)$.

Fig. 6. Pupa in stem (cut open), natural size. Note hole of exit clused by silkeu barriers, prepared for escape of the moth.

Fig. 7. Pupa of female, magnified $\left(\times 2 \frac{1}{2}\right)$.

Hig. S. Pupa of male, magnified $\left(\times 2 \frac{1}{2}\right)$. The smallen tigure shows the natural sizc.

Fig. 9. Moth in natural resting position, magnified $(x 21)$. Tlie natural siza is shown in the moth on the leaf in figute 2.

Fig. 10. Noth, female, form with reddish anal tuft, natura 1 sizc.

Fig 11. Moth, malo, natural size.

Fig. 12. Moth, fomale, form with ycllow anal tuft, natural sizc.

Fig. 13. Nowly-hatched larra, magnified. The natural sizo is indicated by the smaller figure to the right. 

of the other borers as it has no horny process or hairs at the hind end which has a hump-like protuberance on the dorsal side.

\section{Scirpophaga xanthogastrella (auriflua).}

Plate 41 and Plate 42, fig. 1.

\section{Foodplants-Sugarcane; kanra (Saccharum arundinaceum) ; batri (Sac- charum spontaneum batri).}

This insect is active from about March to October, the winter being passed in hibernation in the larval state on the foodplants. The hibernating larvæe emerge as moths in large numbers about March and the two sexes appear practically in equal numbers. Out of a lot of such larve collected in February, 114 moths consisting of 58 males and 56 females emerged between 3rd March and 5th April. During the active season the life-cycle takes about 6 to 7 weeks, viz., egg 1 week, larva 4 to 5 weeks and pupa about $1 \frac{1}{2}$ weeks. Unlike the moths of other borers, which are dry-grass colour and therefore inconspienous on plants or on the ground, the moths of this borer are perfectly white and conspicuous creatures which can be observed flying about in the fields and ovipositing.

Eggs are deposited nostly on leaves in a cluster which is covered with brown hairs from the anal tuft of the female moth. These brown clusters are prominently visible on green leaves. The eggs are flattened, scale-like, and overlap one another in the eluster. They are pale yellow in colour and become dark grey before hatching, when the embryo is visible coiled inside the shell.

The newly-hatched larva is about $2.5 \mathrm{~mm}$. long, slightly flattened in shape, with the head shiny black, the prothorax entirely covered by a black shiny shield, the next two thoracic segments dark smoky in colour, the first abdominal segment pale yellow and the rest of the body brownishgrey. The hairs on the body are longish and there are five pairs of short prolegs.

Unlike the grown-up caterpillars, which are extremely sluggish, and helpless when taken out of their tumnels in the foodplants, the young larve are very quick and active. They issue out of the hairy covering of the erg-cluster and walk about briskly on the leaves, some letting themselves down by means of silken threads, and are thus blown hither and thither on to neighbouring shoots. They disappear into the rolled base of the top leaves and form the characteristic tumnel downwards through the growing bud, thus killing the growing point and producing " dead heart." If the larva is now taken out of the tumel it cannot form a fresh one even when placed in a suitable situation at the top 
of a plant. The tunnel goes downwards and opens on the side a little way down from the top. The larva pupat es near the mouth of this opening through which the moth emerges. There is always a single larva in one plant.

The effect of attack by the larva is always disastrous to the plant. Further growth is stopped in every case. Only very vigorous plants, whether young or old, can and do give out sideshoots or branches. In the case of grown-up plants it has been assumed that they give out branches so that the top becomes bunchy. But actually this happens in the case of only a very small proportion of such plants, as will appear from the facts stated below. Between the 3rd and 4th August, fifty affected plants of Sathi No. 131 with stems (actual canes measured below the base of the whorl of leaves at the top) varying in height from $1^{\prime} 4^{\prime \prime}$ to $3^{\prime} 10^{\prime \prime}$ were marked. From half of them the "dead heart" leaf was pulled ont with the hand and these we may call Lot I, and the rest Lot II. The height of all was measured at intervals and none of them except one in Lot I was observed to grow. On the 23rd October, nine in Lot I and twelve in Lot II were observed to have given out branches and eight in Lot I and ter in Lot II were practically wholly dry and all the others in process of drying from the top downwards. The internal tissue of the dry and drying ones was practically wholly red. The tops of those which had given out branches were also drying. It was evident that hardly any of them would contribute to the harvest. The one in Lot I which was growing measured $3^{\prime} 2^{\prime \prime}$ when marked on 4th August and $7^{\prime} 4^{\prime \prime}$ on the 23rd October. It was afterwards chewed and damaged by a jackal. The same effect as recorded in these two lots is observable in mature canes but, as they are harrested soon, they have hardly time to dry.

Scirpophaga xanthogastrella occurs commonly in the three foodplants mentioned but more in kanra than in either of the other two. In the Purple Nauritius sugarcane plot in Chamia in 1917 the caterpillars appeared very early in April. But in about $S$ acres of different varieties of cane in Jhilli and Brickfield in 1918 even on the 6th May there were hardly any observable, a search through the whole fields revealing only one caterpillar, though at a distance of about half-a-mile they were occurring plentifully in kanra.

Scirpophaga monostigma. (Plate 42, fig. 2.)

Foodplant-Sugarcane.

This is similar to S. xanthogastrella in habit. The larval and pupal forms of these two species are indistinguishable. The moth of $S$. monostigma is however distinguishable as it has a black spot on the fore-wing. 


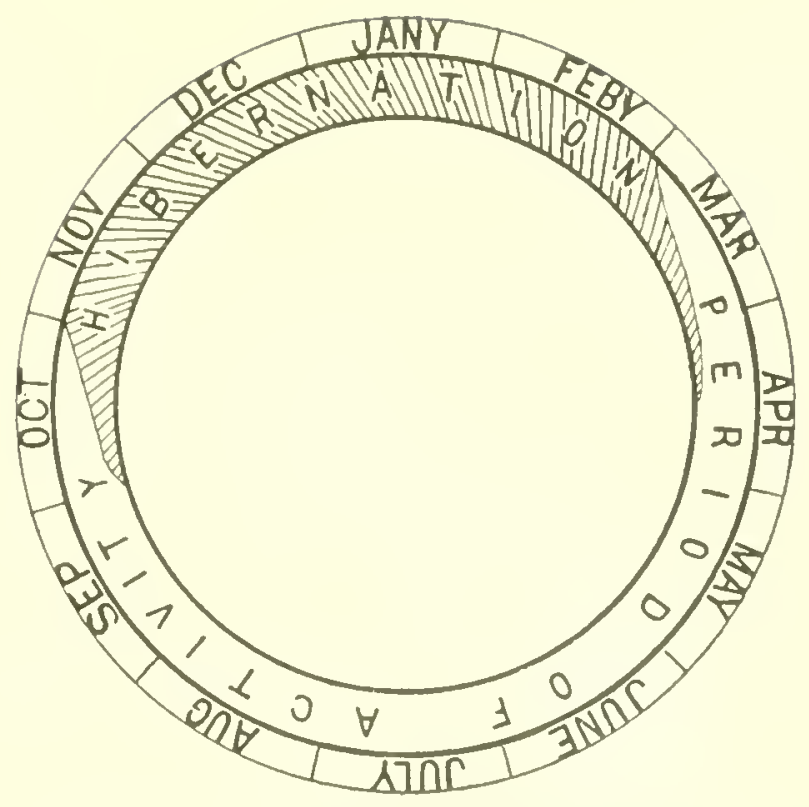

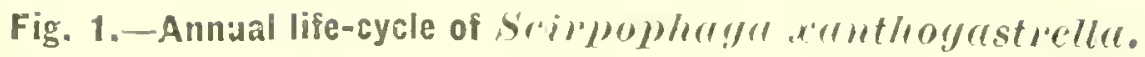

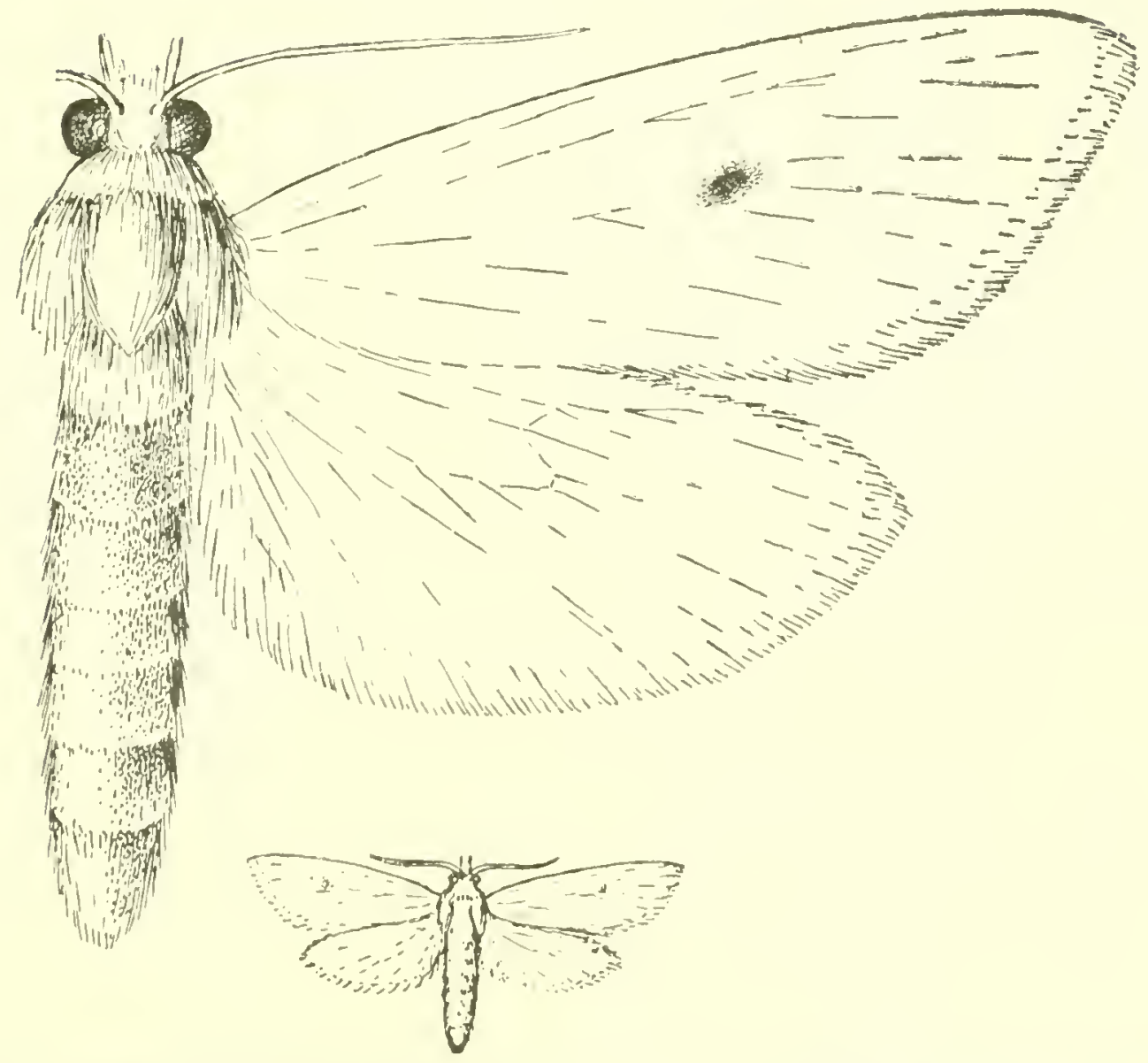

Fig. 2.- Scimpollleyge momosligme $\times 5$. Th: smallar figure shows the natural size. 


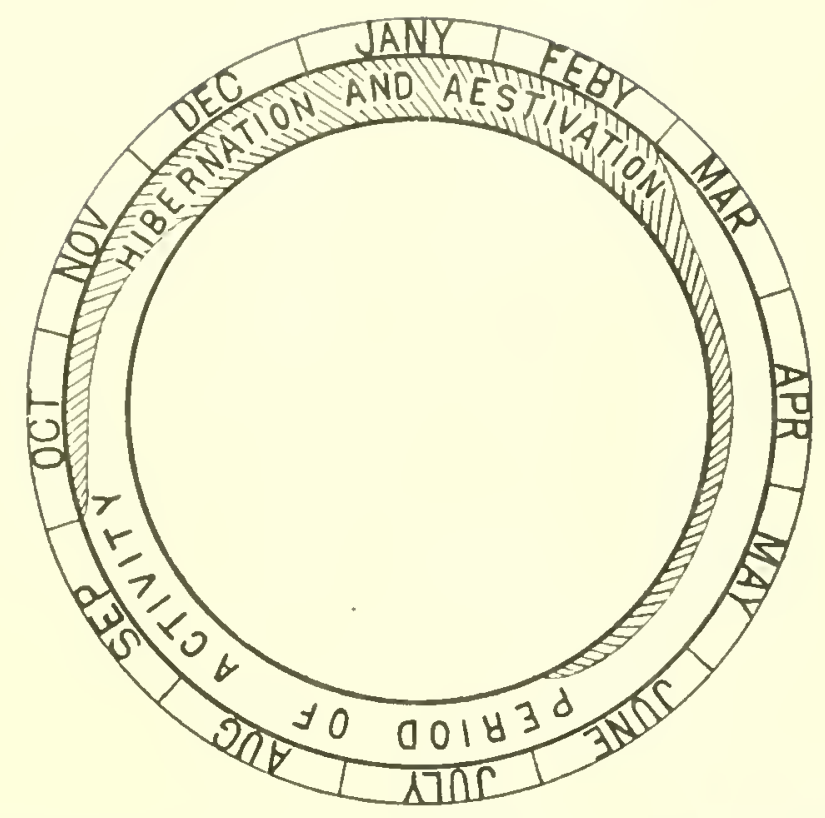

Fig. 3.-Annual life-cycle of schonobius bipunctifer. 


PLATE 43

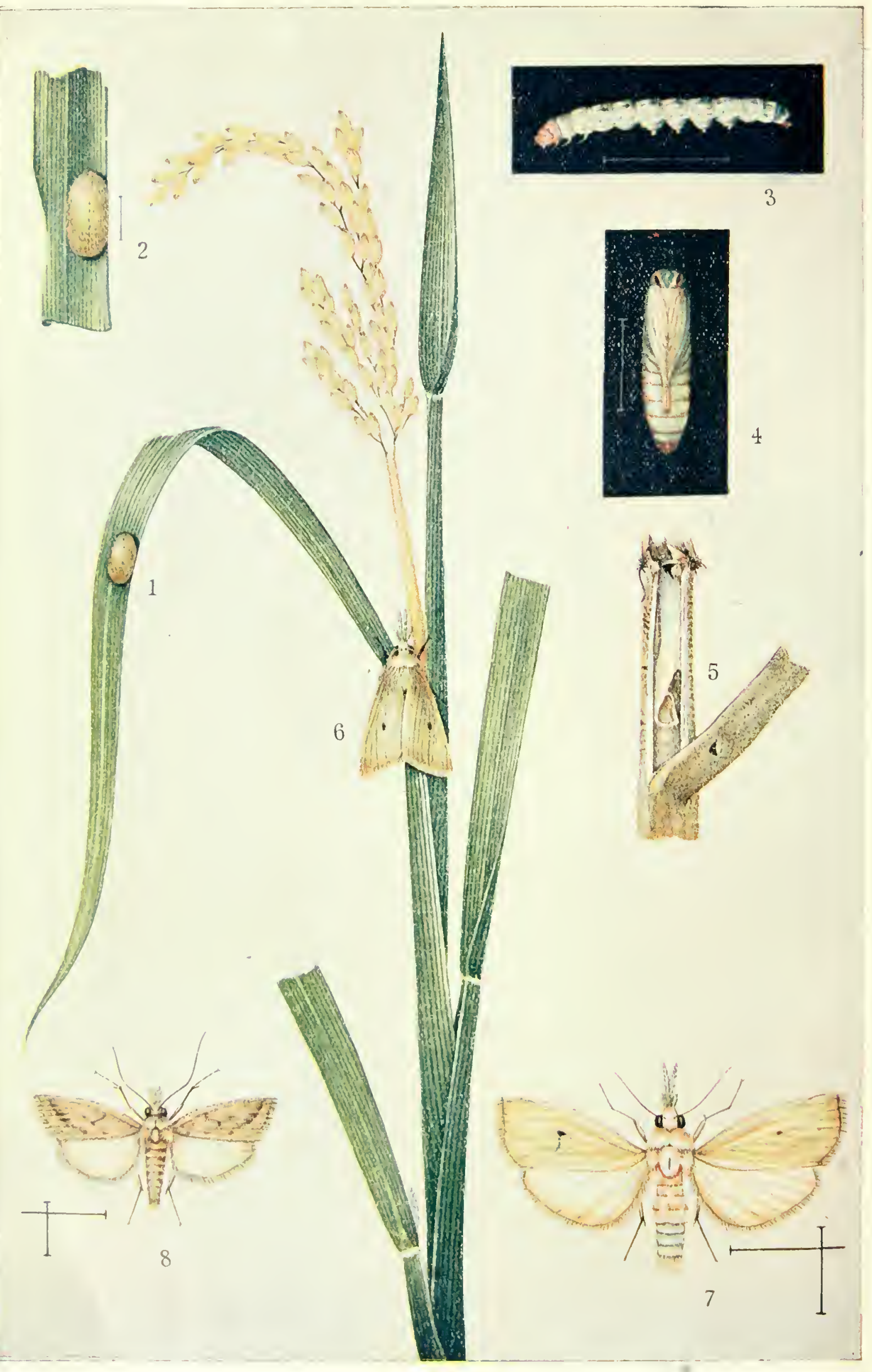




\section{EXPLANATION OE PLATE 43.}

\section{Schonobius bipunctifer.}

The caterpillar (fig. 3) bores into the stem and destroys the lieart: conseruently the ear dies. The female moth (figs. $6 \& 7$ ) deposits eggs in a eluster on the leaf (tigs. $1 \& 2)$ and eovers them with yollow hais. The eatupillars which hatch bore into the stem and eat the interior parts. When fullgrown they prepare a white cocoon lining the hollow stem; one end of the eoeoon is open and a romd hole is ent in the stem opposite the open end in order to enable the future moth to eome out casily (fig. 5). In these coeoons they turn into pupe (fig. 4) and ultimately cone out as mothe (fig-. $f, i \& 8)$. Normally the eaterpillars pass the winter in the stubbles after rice is harvent

Figs. I \& 2. Eggelusters.

Fig. 3. Caterpillar.

Fig. 4. Pupa.

Fig. 5. Coeoon in stem.

Fig., $6 \& 7$. Female moth.

Fig. 8. Male moth. 
The season of activity, as in S. xanthogastrella, lasts from about Narch to October, the winter being passed in hibernation. This speeies has so far been observed to occur in verr small numbers at Pusa. Out of a lot of hibernating caterpillars collected in February, 114 S. xanthogastrella moths and only three of this species were obtained, these latter emerging on 10th and 11th March. Similarly, ont of a lot of caterpillars collected in new sugarcane shoots in April, 22 S. xanthogastrella and only one of this species emerged.

\section{Schonobius bipunclifer, ITlk.*}

Plate 43.

\section{Foodplant-Rice.}

This is a specific pest of rice and oceurs in all rice-growing tracts. It has not yet been observed in any other plant. In Bombay Bulletin No. 69 of 1915 - The Rice Stem Borer in the Konkan - Messrs. Kasargode and Deshpande state that it has been observed to occur in the following plants :-

(1) Coix lachryma-jobi,

(2) Ischamum aristatum,

(3) Andropogon odoratus,

(4) Anthistiria citiata.

This statement, however, should be taken with caution as the hibernating larve found in them do not seem to have been definitely reared and identified. Similarly in Formosa, Dr. T. Shiraki, in spite of his very careful work on this insect, recorded in a large volume, $\uparrow$ did not succeed in tracing any other foodplant.

In the neighbourhood of Pusa the moths have been observed to oviposit in May on a large scale on a reed-like grass, locally known as chichori (Ilelcorharis plantaginea), growing in rice fields, especially in marshy situations. Search has been made in these grasses at different times in the year but no trace of any larva has been found in them.

Schunobius bipunctifer is active from about Mareh to October or November and the rest of the year is passed in hibernation in the stubbles. Moths emerged in March from hibernating larve collected between December and Harch. Some larva may continue to rest till about May or June. On the other hand, young larre hatched from eggs in

* The name bipunclifer, Wh., although ante-dated by incertellus, Whk., is retained for this spceics for the present.

† Paddy Borer (Schanobius incertellus, Wlk.); Taiholiu Agric. Expt. Station, Formosa, 1917.

VOL. 1

$2 \mathrm{C}$ 
November have been observed in January to feed on ratoon shoots growing from stubbles. During the active season the life-cycle is completed in about six weeks, viz., egg 5 to 6 days, larva 25 to 30 days and pupa 9 to 10 days. Eggs are deposited mostly on leaves in clusters covered over with brown hairs. The young larvæ hatch and bore into the stem in the middle of which they feed and pupate. As will appear from the record of its occurrence along with the other burers in rice (Table XII), it is found in small numbers up to about September, after which oviposition takes place on a very large scale on rice in ear in October and the earlier part of November. The larvæ which hatch from these eggs hibernate. (Plate 42, fig 3.)

Schœnobius sp. (C. S. 1780).

Foodplant-Narlat (Phragmites karka).

The larvæ and pupæ of this species are apparently indistinguishable from those of Schonobius bipunctifer, with which it seems to agree in seasonal history.

Procometis trochala (C. S. 1708).

Foodplant-Usually decaying sugarcane stem.

The larve of this moth were found in drying stems of sugarcane which they were boring. On only one occasion a larva was observed boring a fresh stem. The larvæ have the habit of webbing up pellets of excreta and forming galleries under which they live hidden. The fullgrown larva measures about $28 \mathrm{~mm}$. in length, has a dark brown glossy head, a large prothoracic plate of the same colour as the head and the body dirty light-brown with six yellowish longitudinal stripes on the back. The tubercles on the segments bear longish hairs and are small brown spots, the supraspiracular ones being larger than the others. The five pairs of prolegs are equally developed.

Pupation takes place in the stem in holes previously made by the larva and opening on the side of the stem. The pupa is brown and can be easily distinguished by a pair of pointed spines on the lind end joined at their bases and bent so much ventrally as to have their longer axis almost at right angles to the axis of the body of the pupa. 


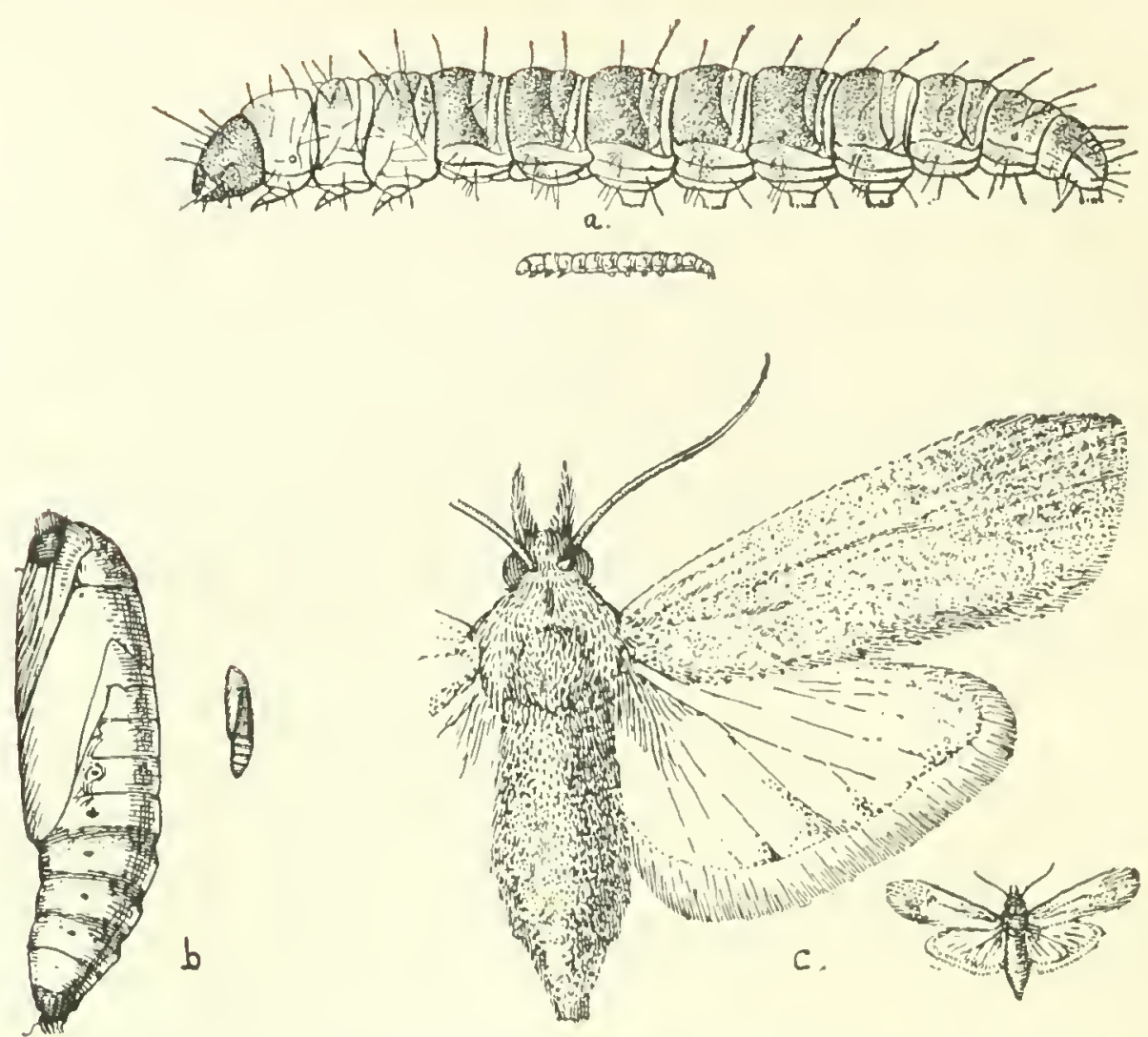

Fig. 1.-Lí(1) limetopus ablutella in sugarcane (C. S. 1801). ", Larva, $\times 5$. 1.. Pupa, $\times 5$.

c. Imago, 5 .

The smaller figures show the natural sizes.

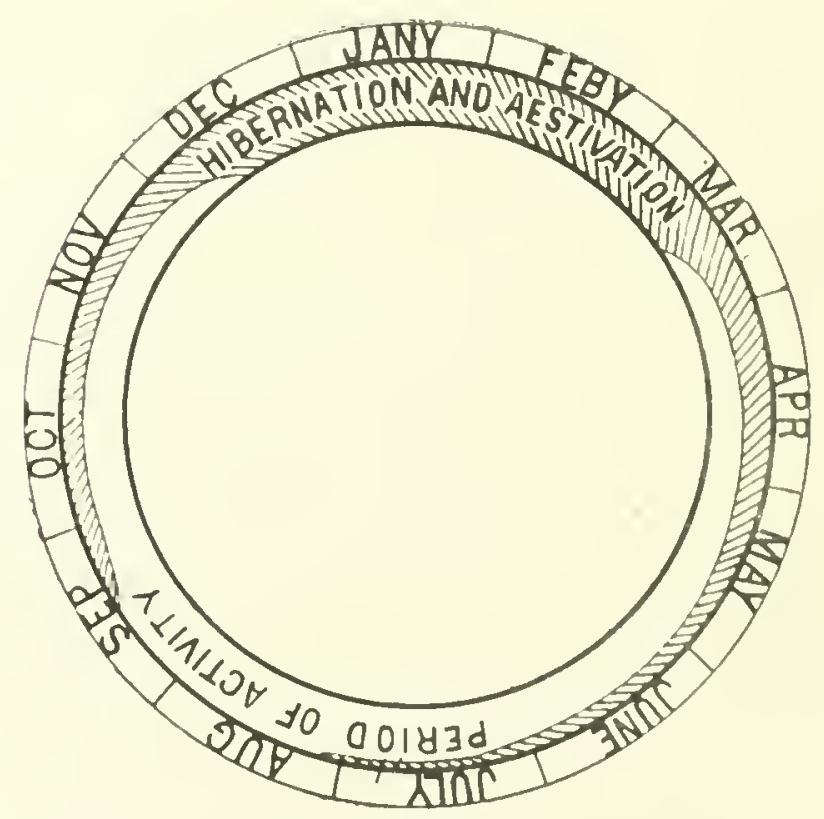

Fig. 2.-Annual life-cycle of Chilo simplex. 


$$
\begin{gathered}
\text { Raphimetopus (Anerastia) ablutella (C. S. 1801). } \\
\text { Plate 44, fig. } 1 . \\
\text { Foodplant-Sugareane. }
\end{gathered}
$$

In the course of the two seasons 1917 and 1918, the caterpillars of this species were observed to occur in very small numbers in young sugarcane in April 1918 and to cause " dead heart" like the other borers.

The full-grown larra is about $16 \mathrm{~mm}$. long and about $2 \mathrm{~mm}$. across the middle of the body which is eylindrical and slightly tapering at the ends. The head is yellow-brown, glossy. The prothorax green; the meso-and metathorax and the abdomen copper-coloured dorsally and greenish ventrally. The spiracles are round, yellow-brown. The hairs are brown, thin and longish. The hooklets on prolegs are in a complete circle.

One pupated on 3rd May and emerged as moth on the 11th May. The pupa is about $8 \mathrm{~mm}$. long and tapering hindwards, the hind end having a few long circinate hairs. The colour is greenish brown.

This.insect is stated by Messis. Mackenzie and Lefroy to have been found in great numbers at Siripur, Hathwa, Saran, in young sugareane when about three weekis to a month above the ground. (Agri. Journ. Ind. III, p. 104). The larra observed by them was completely green.

\section{Chilo simplex, Butl.}

Plates 4.5- -47 .

Foodplants-

Maize-Pusa; Mirpurkhas ; Sukkur ; Poona ; Jhalrapatan ; Lyallpur.

Juer (Andropogon Sorghum)-Pusa; Mirpurkhas; Landhi ; Larkana; Sukkur; Jalaun; Jhalrapatan ; Babugarh; Lyallpur.

Sugarcane-Pusa.

Rice-Pusa; Konkan.

Bajra (Pennisetum typhoideum)-Pusa; Sukkur; Mirpurkhas.

Suma (Panicum frumentaceum)-Pusa.

Marua (Eleusine coracana)-Pusa.

Sudan grass-Pusa.

Job's Tears (Coix lachryma-jobi)-Konkan.

In this list of foodplants the localities cited are those from wh:ch the larva have been collected in the course of the last two years and definitely identified as those of Chilo simplex. 
The seasonal history of Chilo simplex is most irregular. Many laiv $x$ begin to rest from September and may continne to do so till July or even Angust next year. On the other hand moths have emerged up to 12 th December and oviposition has been observed to continue in the fields up to the earlier part of November. Again, from the same batch of eggs laid in September some larre have been observed to develop into moths in the earlier part of the cold weather while the others rested till the following July. The earliest date after the cold weather on which moths have been observed to emerge from over-wintering larræ is the 13th of May. The time when over-wintering larva generally develop into moths is May to July. But active feeding caterpillars, apparently hatched from eggs laid after the winter, have been collected on the 10th April and the eggs from which these larra developed must have been laid towards the end of Harch. Therefore the shortest absolute resting period when no aetirity is observable extends from about December to about March and the longest resting period so far noticed lasts from about September to about July or August. Some larve have been observed to continue their rest beyond July but they died in August and it is not known whether they would have rested till the hot weather in the following year. While over-mintering larve rest in this manner, normal successive broods occur in the case of those which become active in spring. (Plate 44, fig. 2.)

The shortest and longest periods required for the completion of the life-cycle in the warm weather during the active season have been observed to be 36 and 6.3 days respectively, viz., egg 3 to 5 days, larva 28 to 50 days and pupa 5 to 8 days. In the case of resting larvæ the life-cycle may take up to about nine months.

The creamy-white flattened scale-like eggs are deposited on the stem or leaves, more usually on leaves in cluster's, and overlapping one another like the tiles on a roof. The clusters stick to the substratum like scale: When the eggs hatch, the young larva walk down into the heart of such plants as maize and juar. Some may be disturbed by the waring of the leares by wind and let themselves down with silk and are thus blown on to neighbouring plants. They are active creatures, capable of ralking over the ground to neighbouring plants and effecting their entrance into the stem through the side. In the worst cases the plants may be riddled by the larre and maize and juar which are somewhat grown may not show "dead heart" althongh their stems may be bored through and through. 'The larvo pupate inside the stem.

It is really a pest of maize, juar and rice. Maize is mainly attacked when young and practically wholly aroided when mature. Juar is however attacked in all stages. It oceurs in rice throughout the seasor 


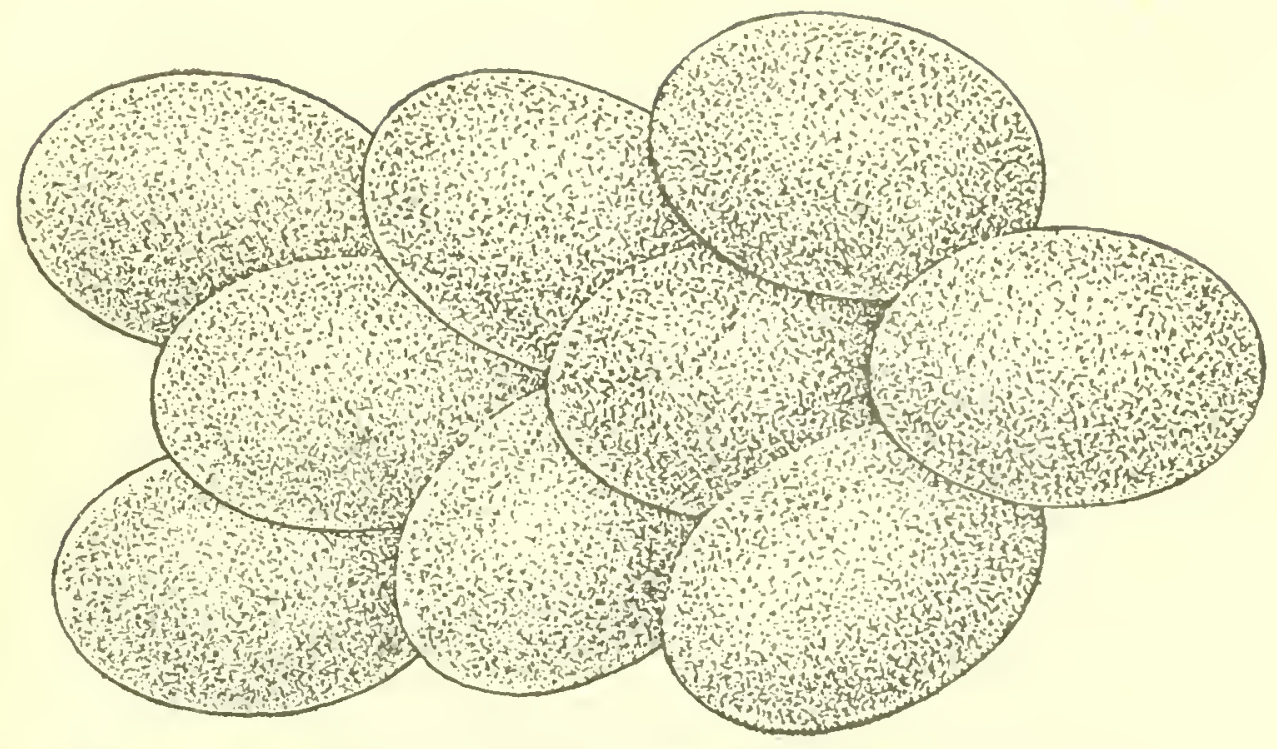

Fig. 1.-Egg-cluster of Chilo simplex (C. S. 1819) $\times 30$.
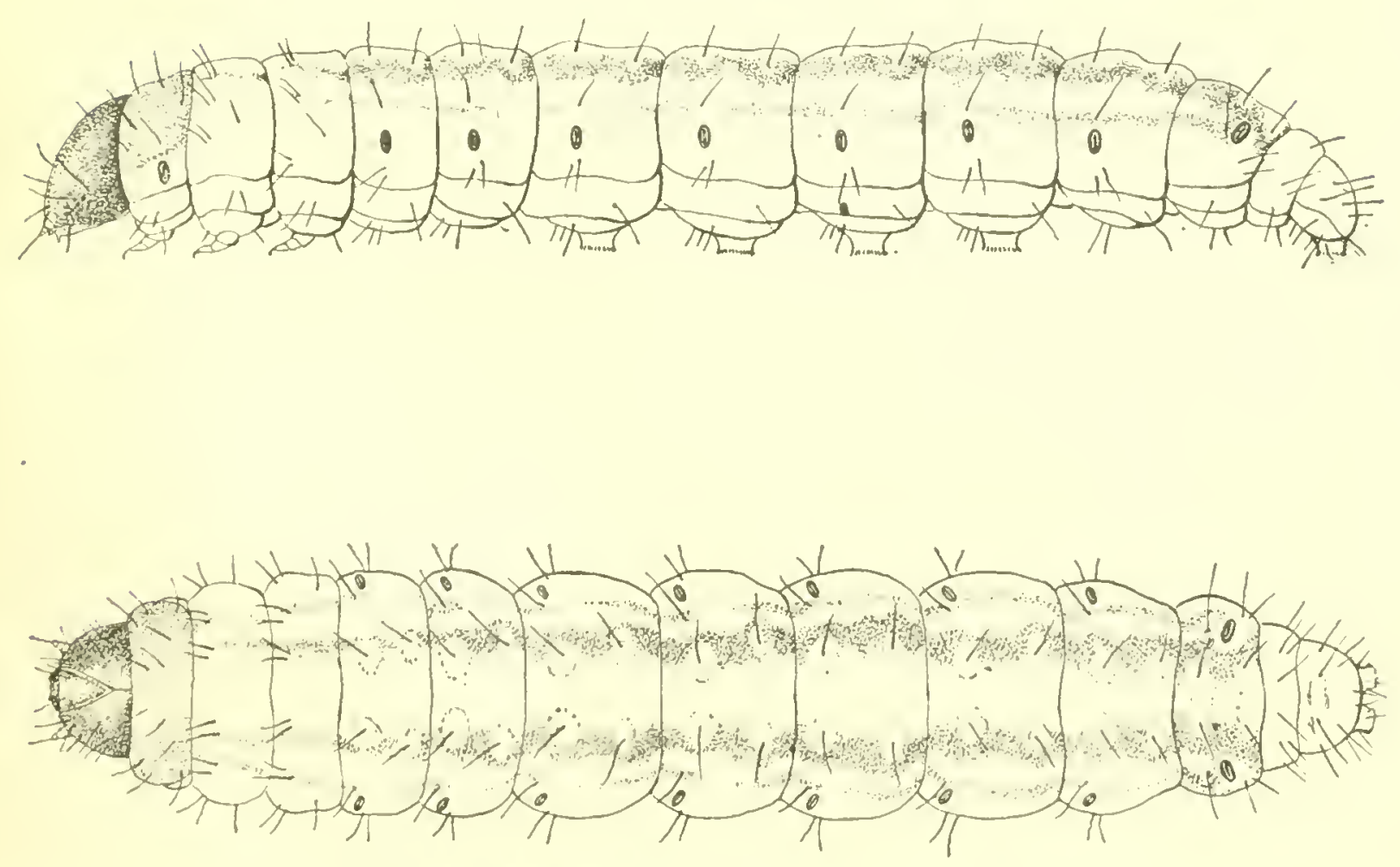

Fig. 2.-Chilo simplex, larva, lateral and dorsal views, $\times 5$. 



\section{EXPLANATION OF PLATE 46.}

Fig. 1. Chito simplex (C. S. 1580).

a. Lateral, and, $b$, dorsal riew of larva, $\times 5$.

c. Details of spiracle on fifth segment, more highly magnified.

d. Details of first proleg, scen lrom helow, more highly magnified.

(Note-Anterior hair on right side of anal plate was absent in this specimen )

Fig. 2. Chito simplex (C. S. 1561).

a. Pupa, $\times 5$.

b. Posterior segments of pupa, lateral view, more highly magnified.

c. Anal segment of pupa, ventral surface, more highly magnified, 


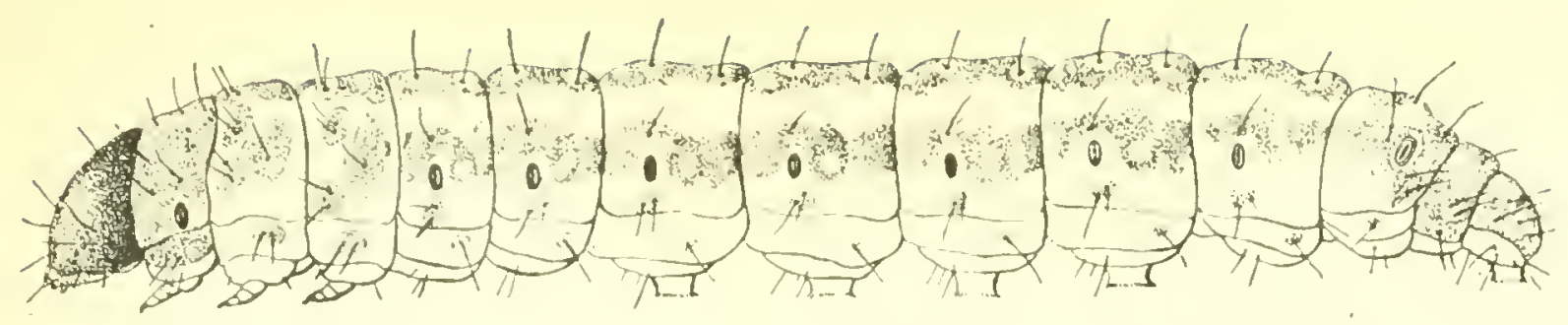

a.
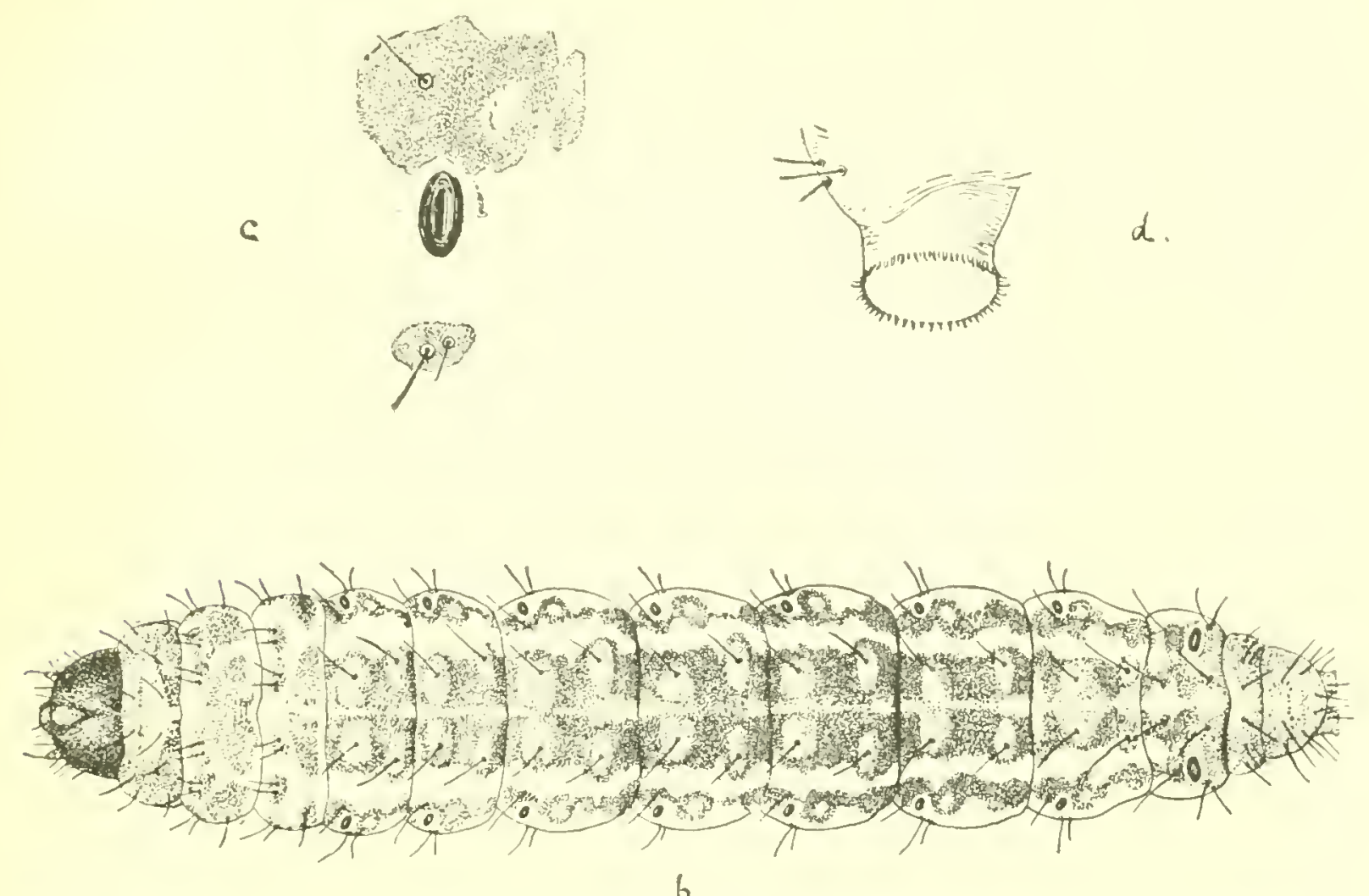

b.

Fig. 1.-Chilo simplex (C. S. 1580).
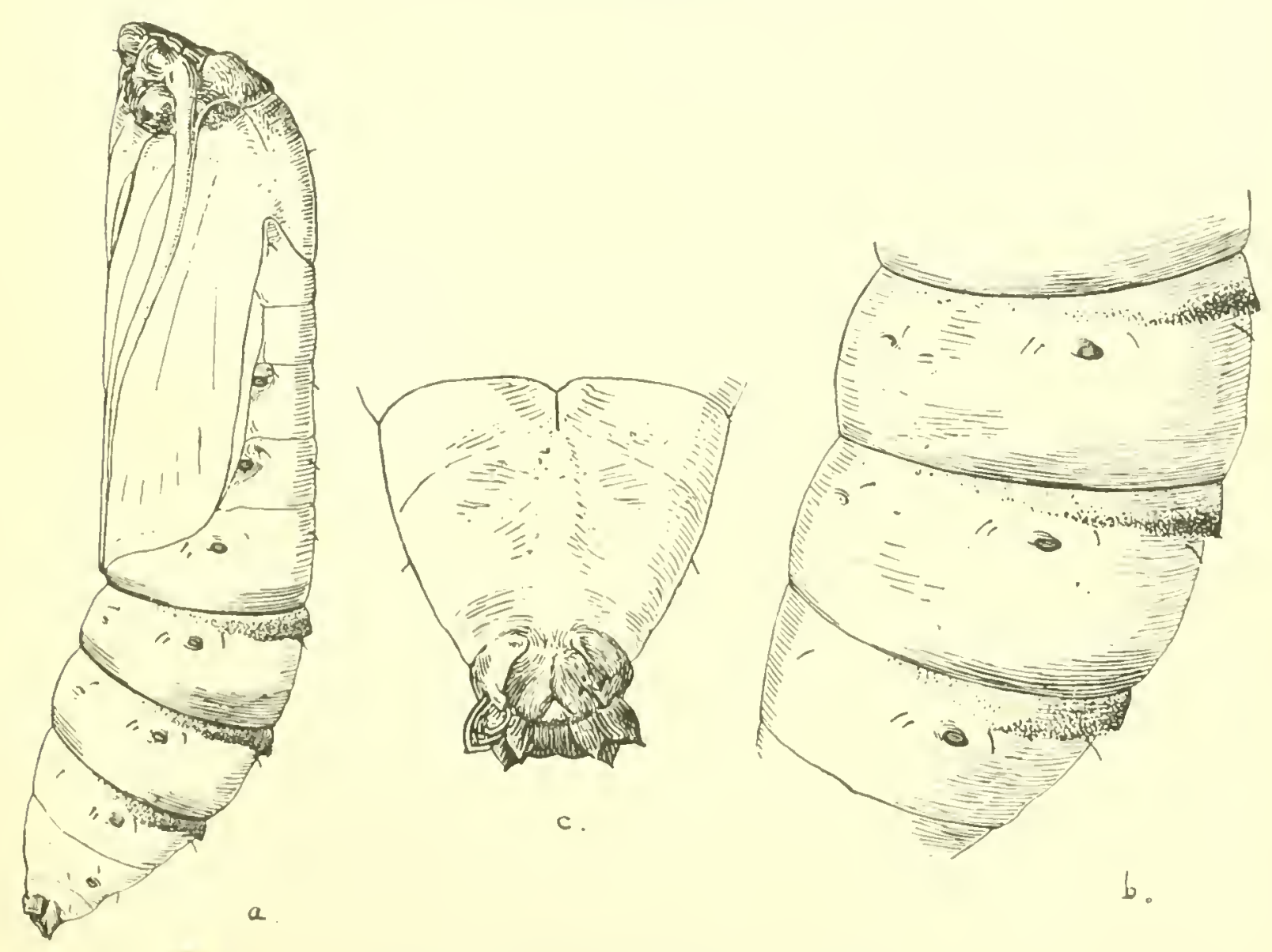

Fig. 2.-Chilo simplex (C. S. 1561). 



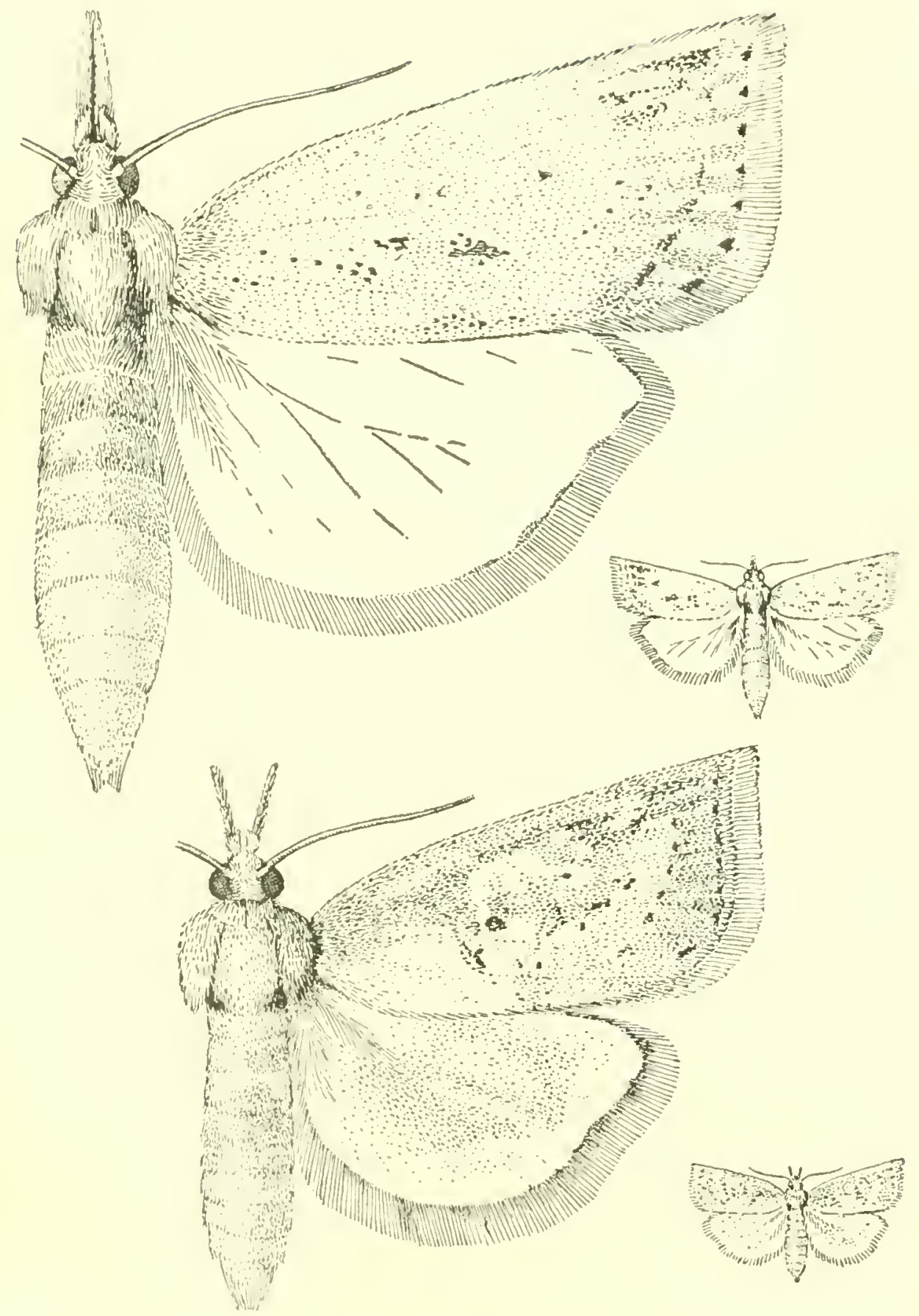

ililo simplex (C. S. 1551). Moths $\times 5$. The sinaller figures show the natural sizes. 


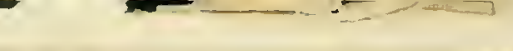





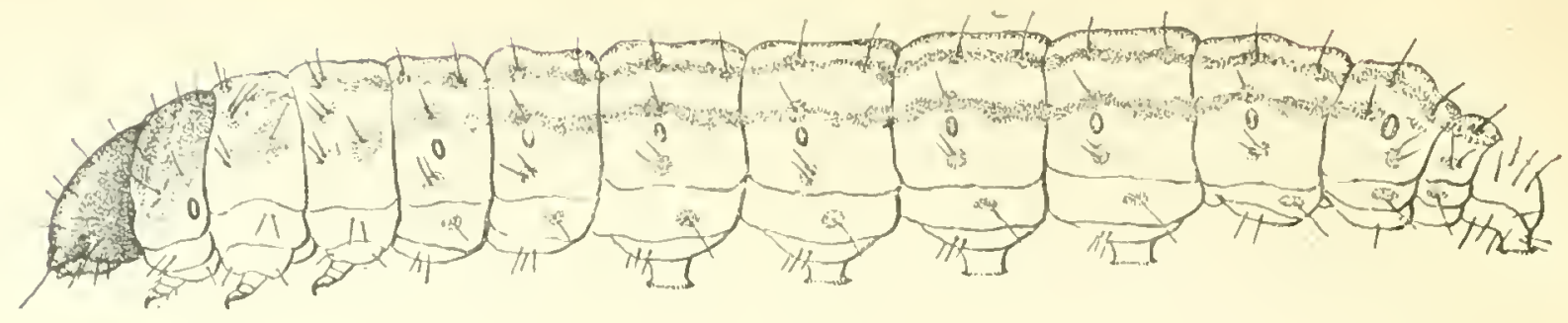

a.
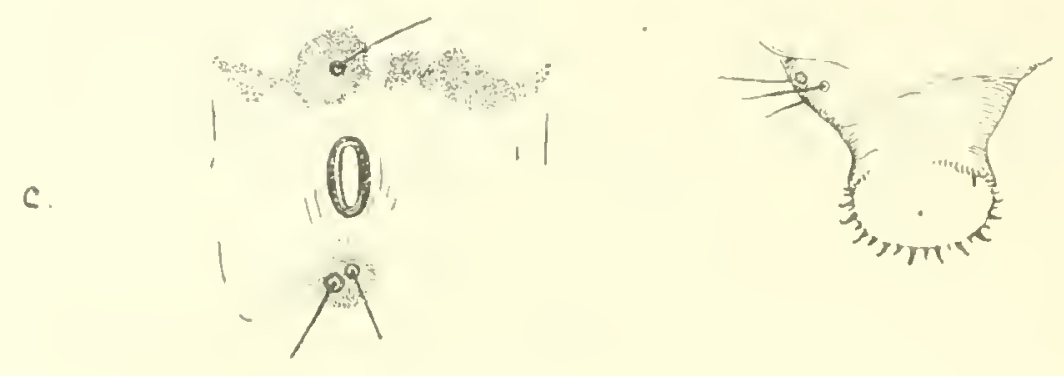

d.

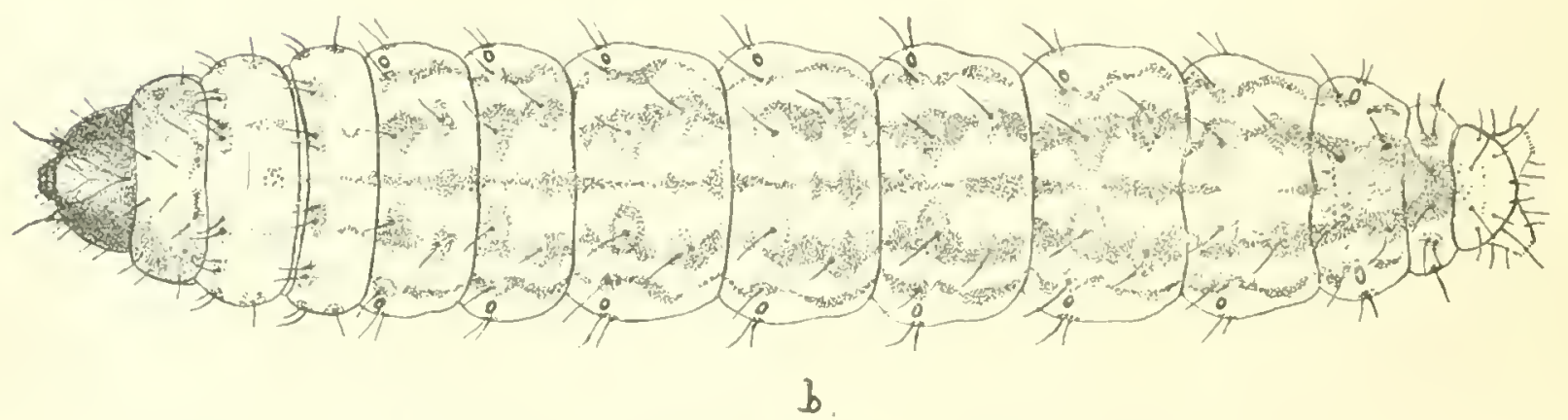

Fig. 1.-Dintrea unricilin (C. S. 1574).
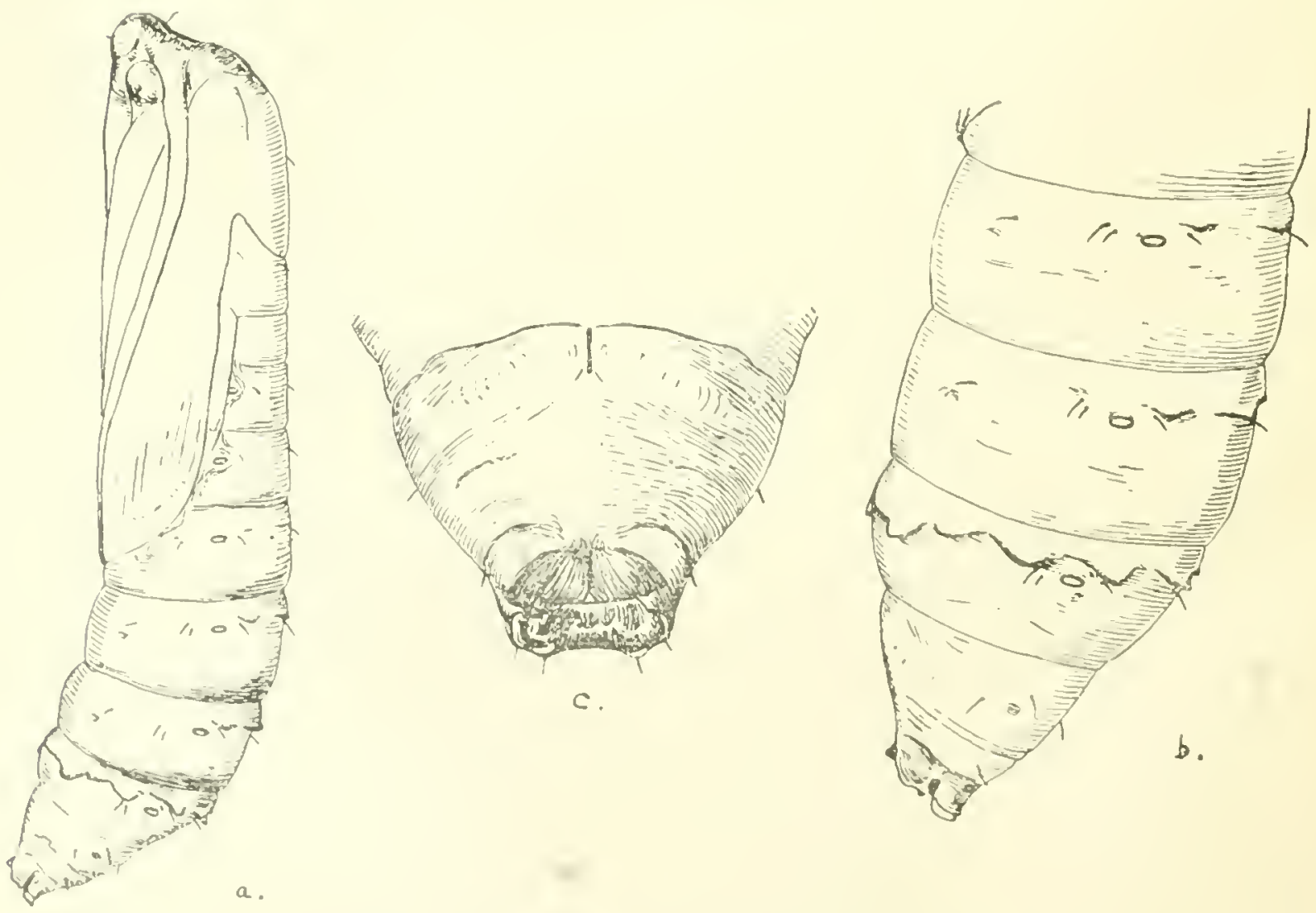

Fig. 2.-Dietreen U1ericilie (C. S. 155i). 


\section{EXPLANATION OF PLATE 48.}

Fig 1. Diatran auricilia (C.S. 1574).

x. Lateral, and, l, dorsal view of larva, $\times 5$.

c. Details of spiracle on fifth segurent, more highly magnified.

d. Details of prolegr, seen from helow, nore highly magnificel.

Fig 2. Diatrea arericila (C. S. 1560 ).

a. Pupa, $\times 5$.

b. Posterior segments of pupa, seen laterally, nore highly magnified

c. Anal segment of pupa, ventral surface, more highly magnifica. 


PLATE 49.

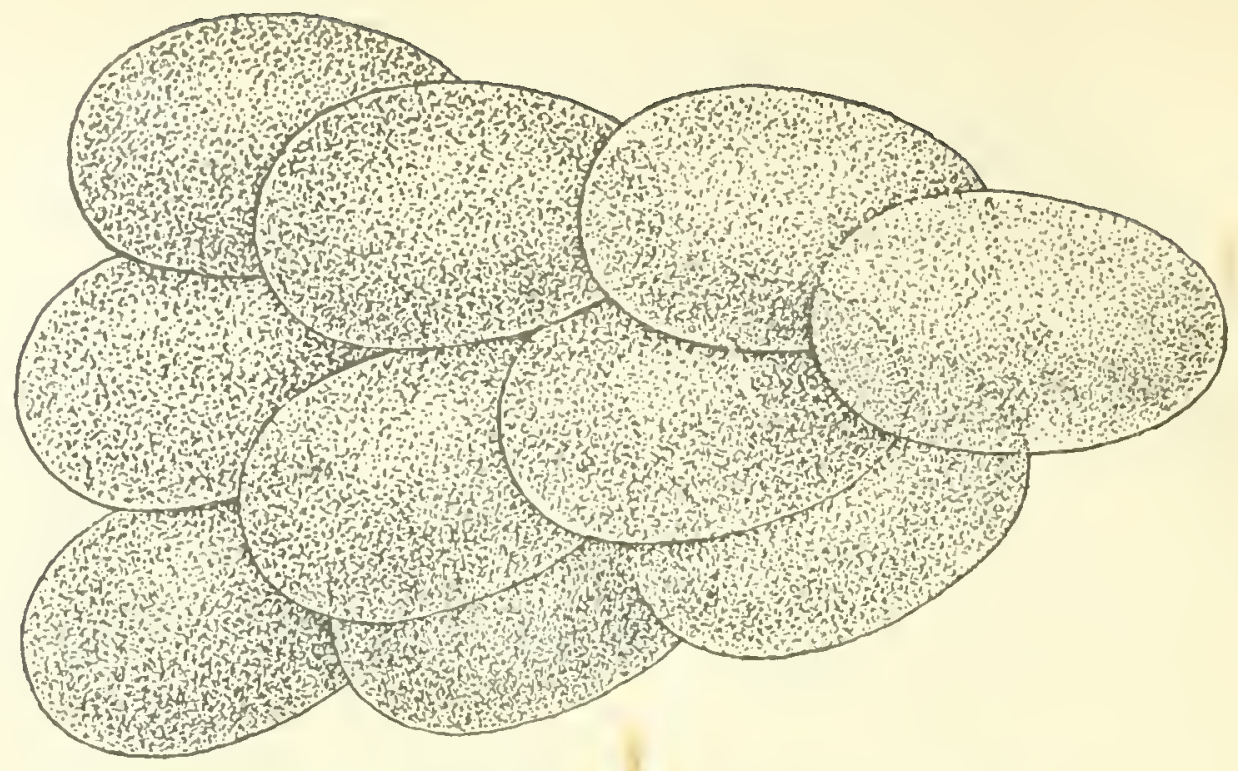

Fig. 1.-Egg-cluster of Ilictruen "nevicilin (C. S. 1787), 30.

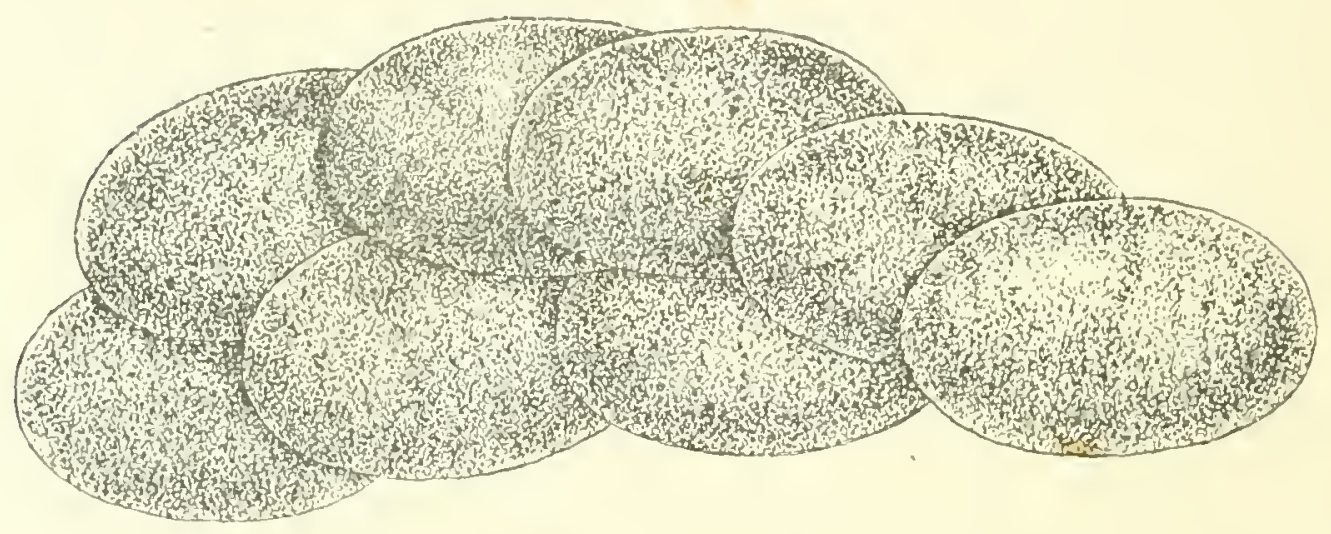

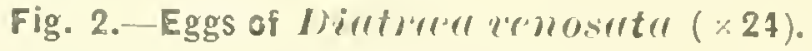
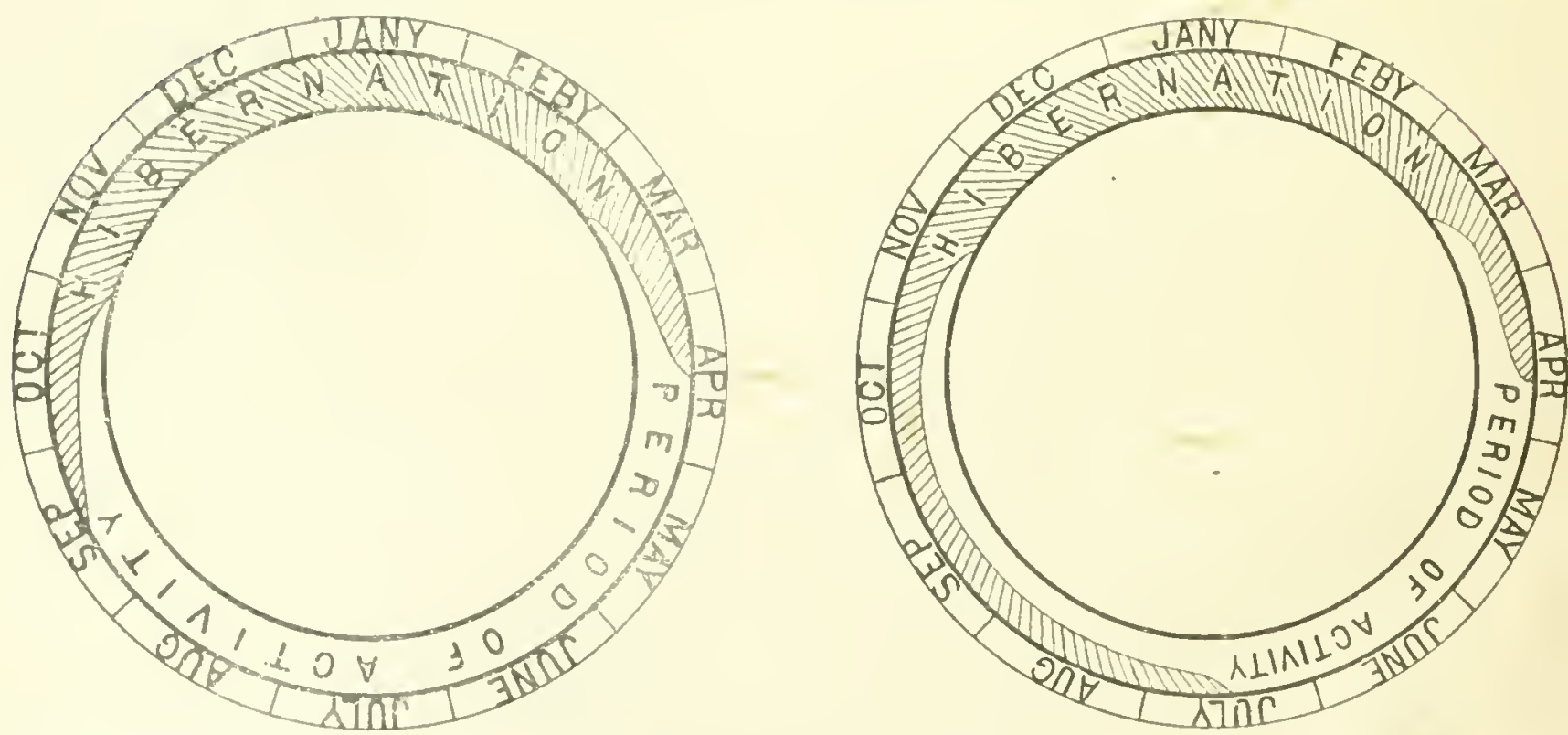

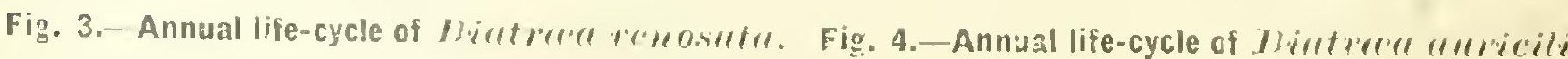


and in greatest numbers about October-Norember when the rice comes into ear. Hibernation and astiration take place mainly in rice stubbles and juar stallis.

Of all the borers in gramineons crops this is the most widespread and occurs in the largest numbers.

The appearance of the caterpillar's varies a little. The common form is shown in I'l. 45. f. 2 in which there are distinct sub-dorsal brown stripes with the warts indistinct. In a second form (Pl. 46, f. 1) the subdorsal stripes approach one another on the back and practically meet. In a third form the stripes are rather indistinct and the warts prominent. This third form is not common.

\section{Diatraea auricitia (C. S. 1574).}

Plate 48 ; Plate 49, figs. $1,4$.

Foodplants-

Sugarcane-Pusa; Sipaya ; Sabour: Munni, Muzaffarpur ; Chinsurah; Bankura; Cawnpore; Lyallpur; Sukkur; Landhi ; Manjri.

Juar (Andropogon Sorghum)-Pusa.

Raihi and Batri (Sacharum spontaneum)-Pusa.

Ikri (Sacchamu fuscum)-Pusa.

Jove grass (Rotthollia compressa)-Pusa.

The localities mentioned above are the places where caterpillars have been collected in the course of the last two yeass and definitely identified. Out of these foodplants it occurs in the largest numbers in batri and, next to that, in sugareane. In the other foodplants it has been found occasionally and in small numbers.

'The seasonal history of this species too is very irregular. Some larva begin to lest from about July and pupate and emerge as moths in the following March-April. Many caterpillars however, continue to be active up to about October when hibernation on a general scale commences. Hoths have been obtained up to 15 th November before winter and the earliest date after winter when moths have emerged from over-wintering larvæ is the 12 th March, on which date young larvæ also have been collected from batri. During the active season the life-cycle occupies about five to six weeks, viz., egg about 3 days, larva about 30 days and pupa 7 to 8 days. Eggs are deposited in the same manner as observed in the case of Chilo simplex. The eaterpillars bore in the middle of the stem. In sugareane they occur more commonly in young shoots than in grown canes. In batri they occur in all stages 
of the plants. They pupate in the affected stems and the moths emerge through holes previously made by the larvæ. (Plate 49, fig. 4.)

The caterpillars have five brown stripes on a pale yellow body and show no variation or change in appearance.

Diatrcea venosata (C. S. 1607).

Plate 49, figs. 2,3; Plates 50, 51.

Foodplants-

Sugarcane.

Sudan grass.

Rarhi and Batri-(Saccharum spontaneum).

Juar-(Andropogon, Sorghum).

Ihri (Saccharum fuscum).

Bajra (Pennisetum typhoideum).

All these foodplants have been recorded in the neighbourhood of Pusa. The caterpillars occur largely in batri, Sudan grass and juar and only occasionally in the other plants.

The seasonal history of this species is more regular than that of Chilo simplex and Diatrea auricilia. Hibernation in the larval state commences about September and continues up to March-April when the over-wintering larvæ pupate and emerge as adults. During the active season the life-cycle occupies about five to seven reeks, viz., egg about 6 days, larva about 21 to 30 days and pupa 9 to 11 days. Eggs are deposited in the same manner as Chito simplex. The caterpillars feed inside the stem and have been observed to occur more in grom plants than in young ones, many of them being found in individual stems. Pupation takes place inside the tumnels in the affected stems.

This insect is a real pest of juar among the cultivated crops.

The caterpillars have large shining dark brown warts, usually with broad pinkish stripes along the line of the trapezoictal and supra-spiracular warts. In some cases the stripes may be indistinct and in certain other cases again the warts may be indistinct. In hibernating larvæ both the stripes and warts may be indistinct.

$$
\begin{aligned}
& \text { Diatroe sp. (C. S. 1610).* } \\
& \text { Plates 52, 54, aud 53, fig. } 1 . \\
& \text { Foodplant-Sugarcane. }
\end{aligned}
$$

This borer has so far been observed to be confined to Eastern Bengal and Assam, the western-most places where it has been found being Goalundo and Pabna. There lias been no opportunity of investigating it properly. Therefore neither its seasonal history nor altemative

\footnotetext{
* Since named by Sir George Hampson as Argyria tumidicostalis, Hmpsn.
} 


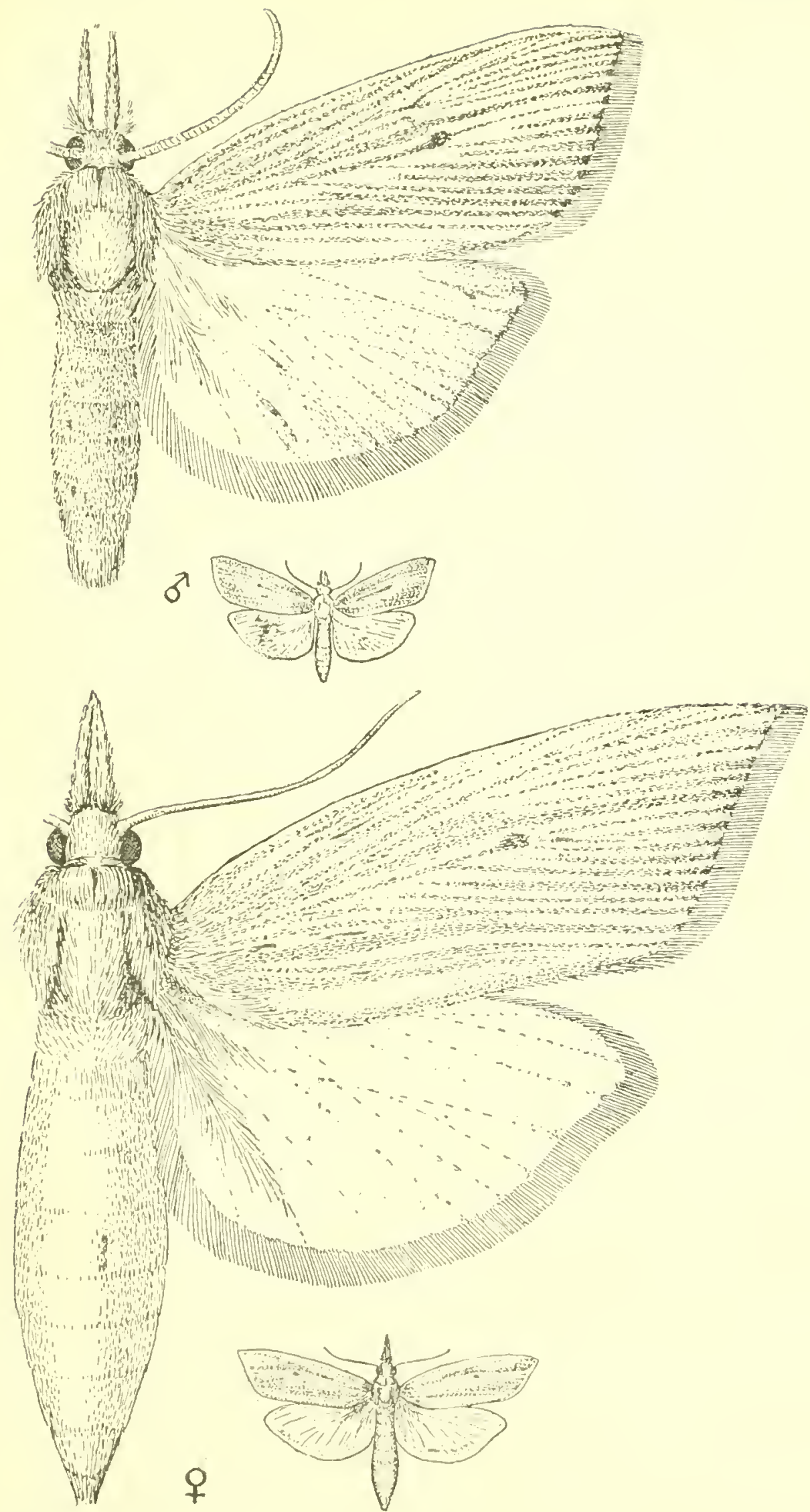

Jirller"l irmosertll, moths $\times 5$. The smaller figures show the natural sizes. 




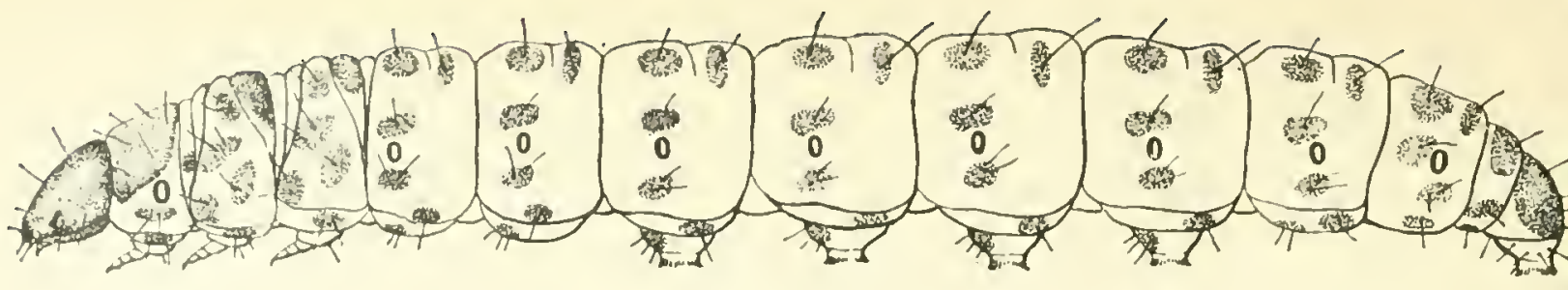

a.
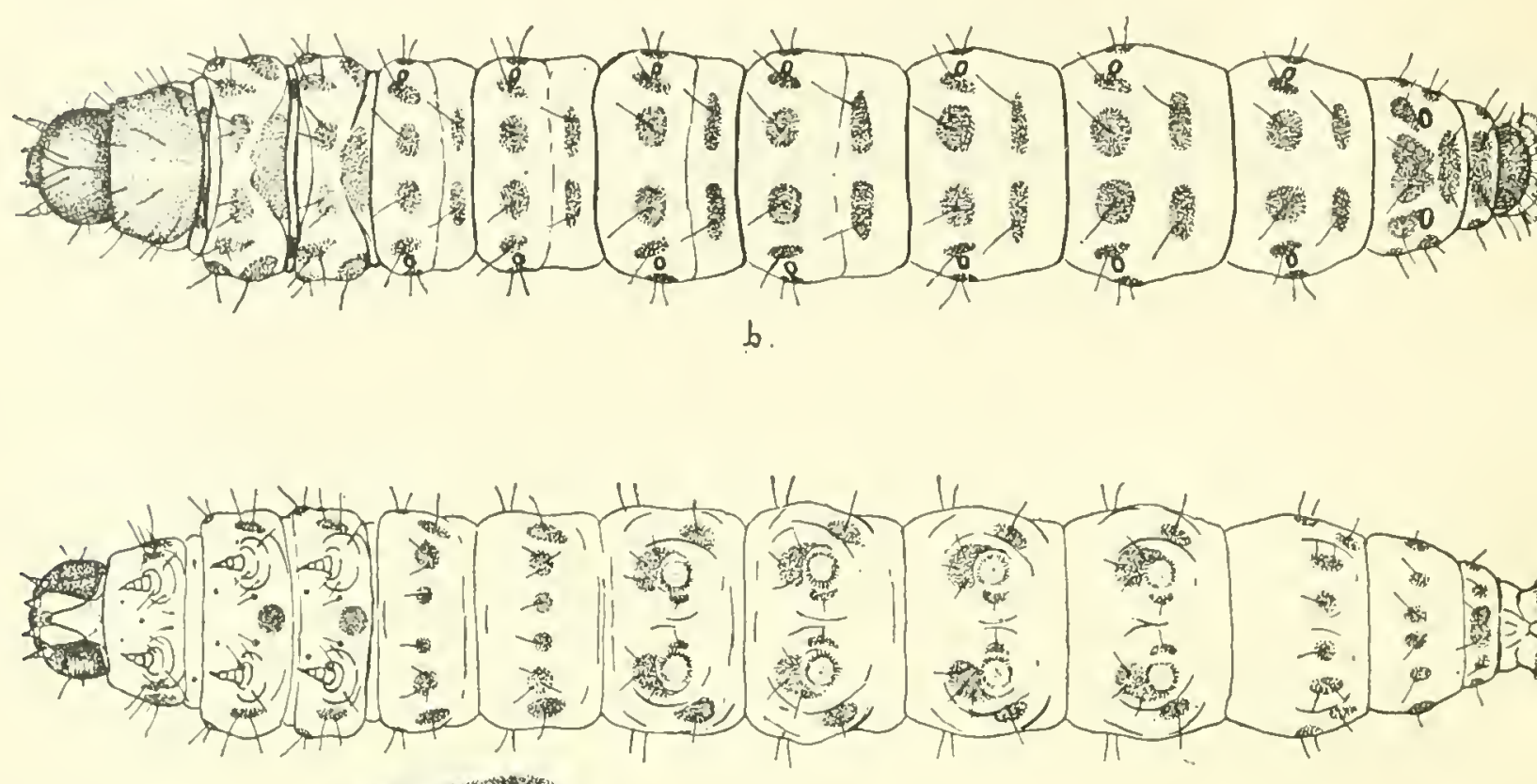

d.
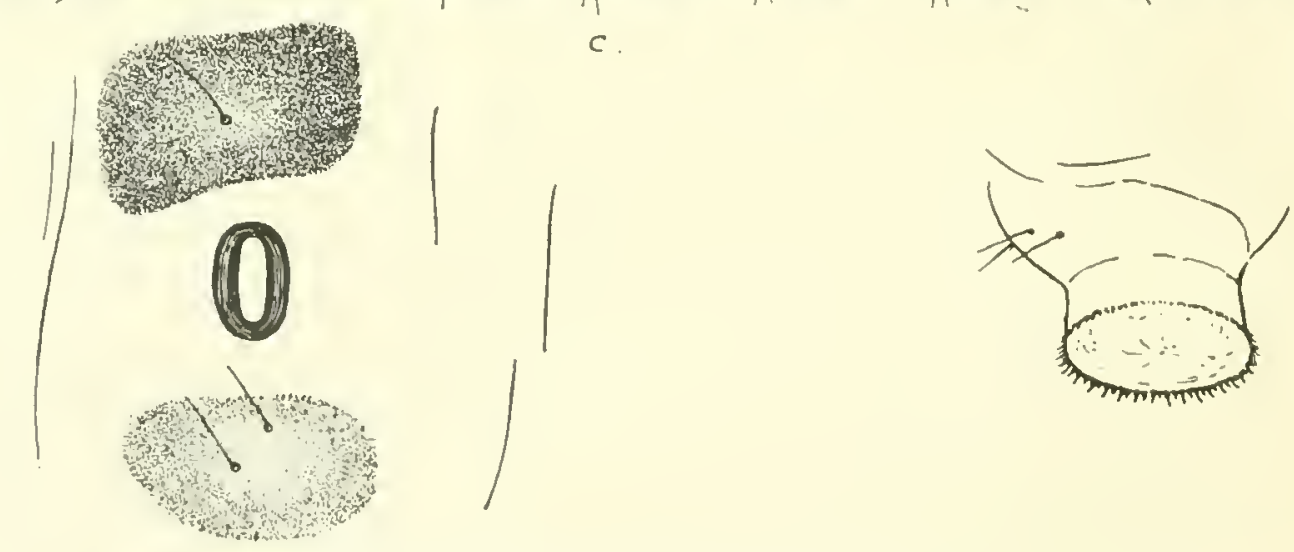

Fig. 1.-Argyria tumidicostalis (C. S. 1610).
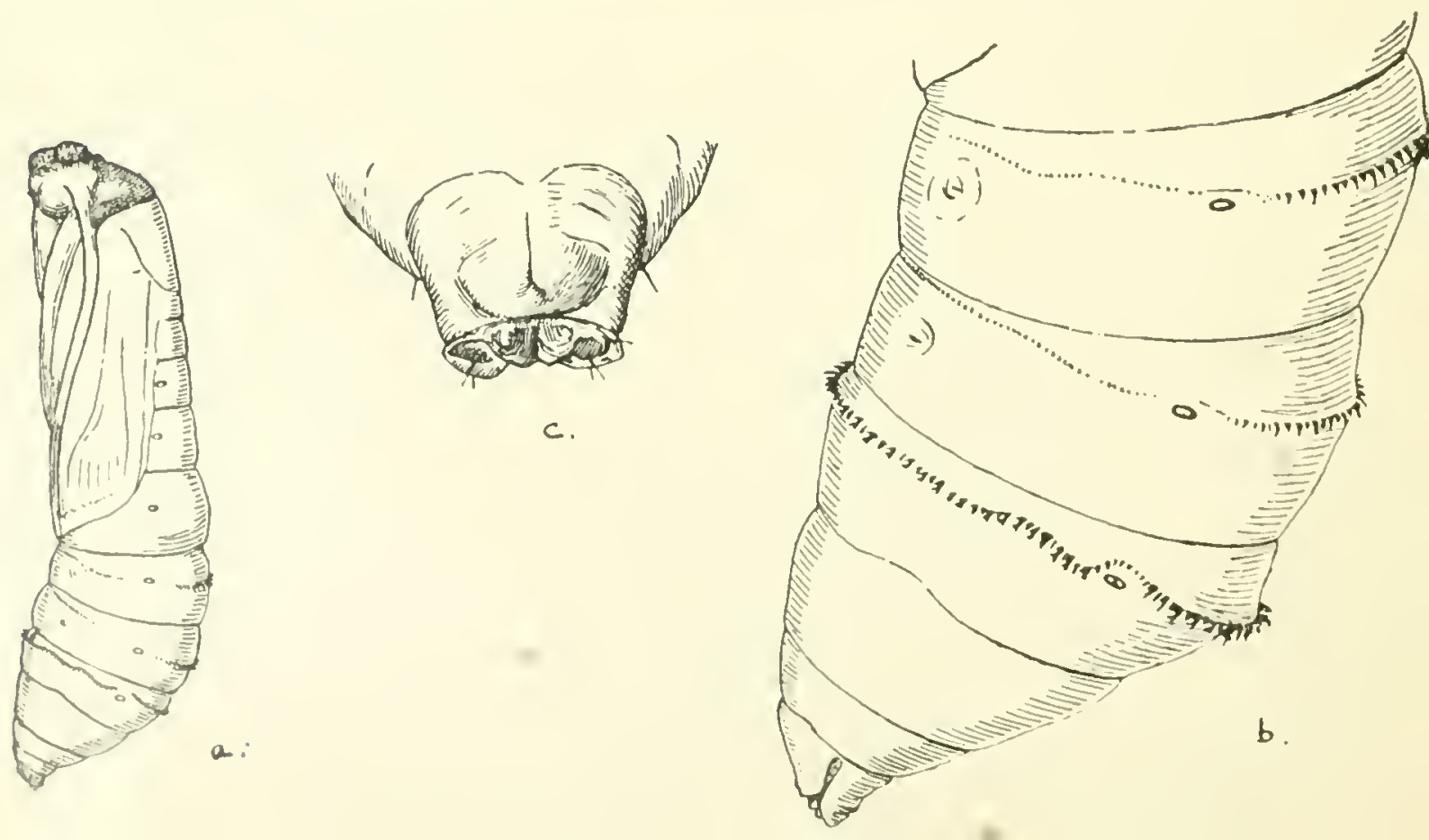


\section{LXPLANATION OF PLATE 52.}

\section{Fig. 1. Argyria tumidicostalis (C. S. 1610).}

a. Lateral, b, dorsal, and, $c$, ventral view of larva, $\times 1$

d. Details of spiracle on fifth segment, more highly magnified.

e. Details of roleg, soen from below, more highly magnified.

Fig. 2. Argyria tumidicostalis (C. S. 1610).

a. Pupa, $\times 4$.

b. Posterior segments of papa, scen laterally, more highly magnified.

c. Anal segment of pupa, ventral surface, more highly magnified. 



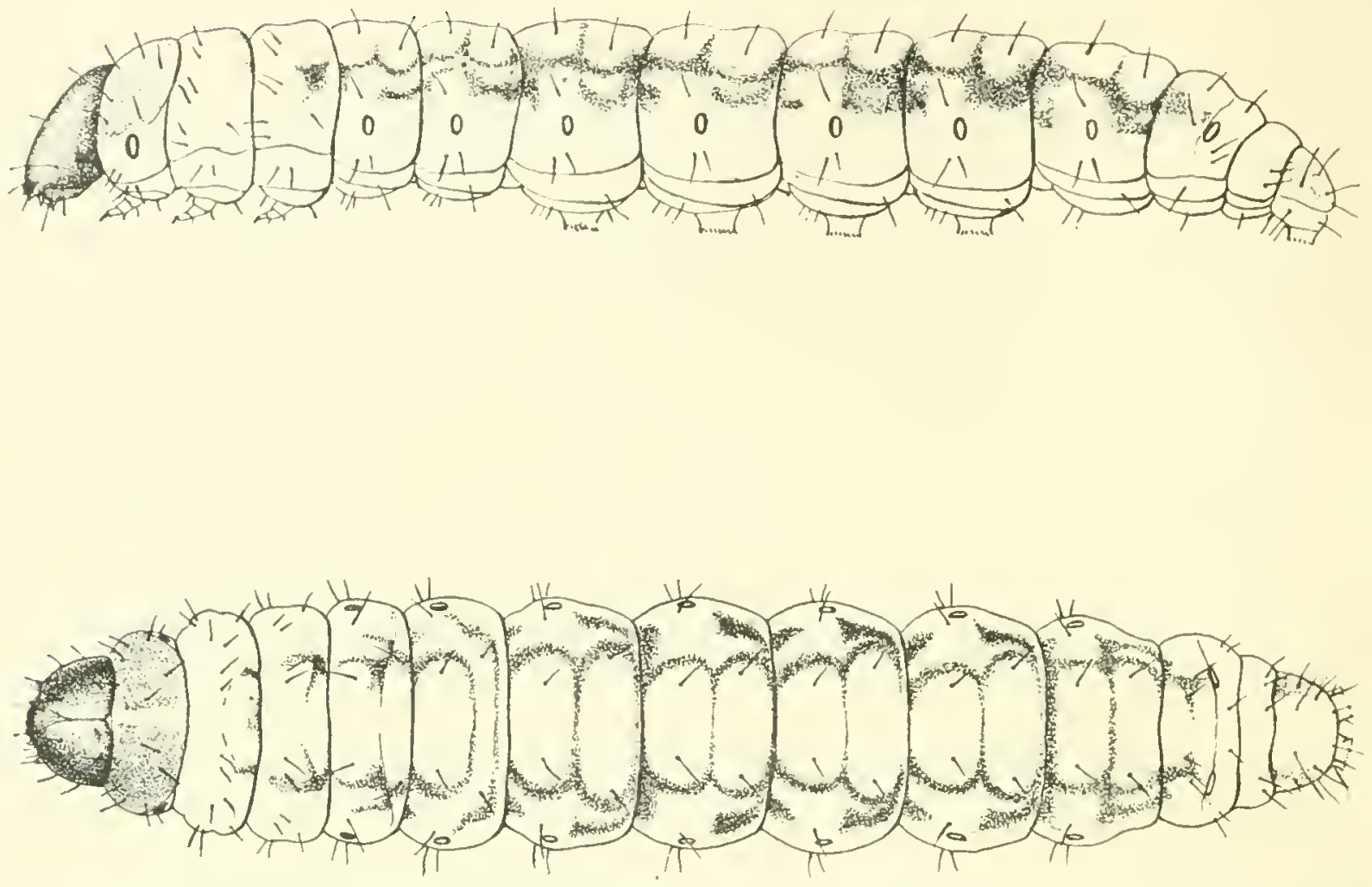

Fig. 1. - In!g!/mill tlm millirrustulis, Hmpsn. (C. S. 1610), third form of larva. (Nete.-The submedian hair on left side of penultimate segment was absent in this individual lârvà bu was present on the right side.)

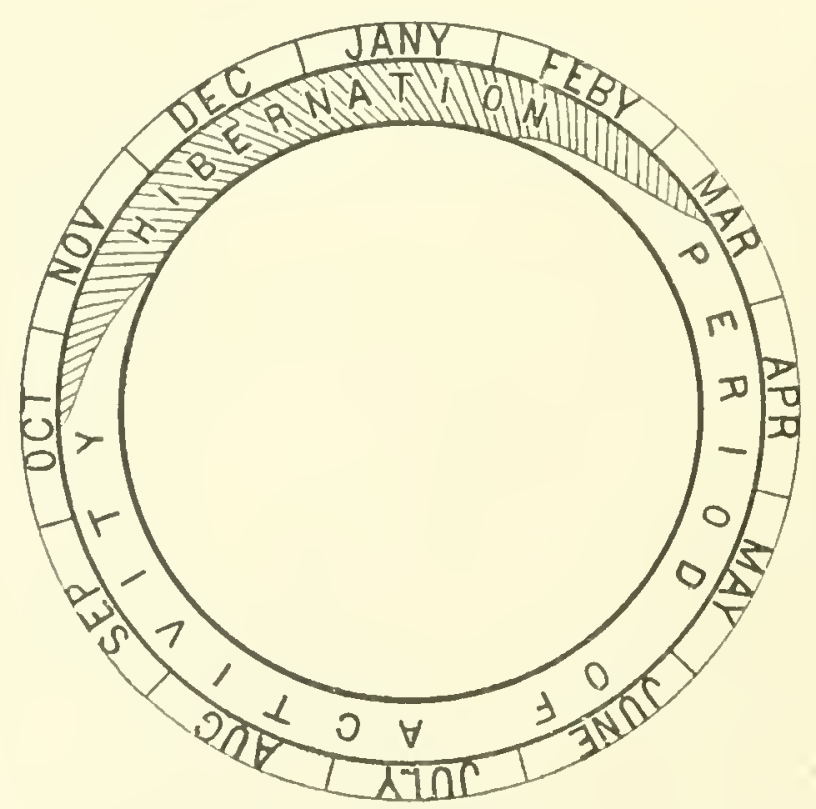

Fig. 2.-Annual life-cycle of II irll'r,r sp. (C. S. 1674). 



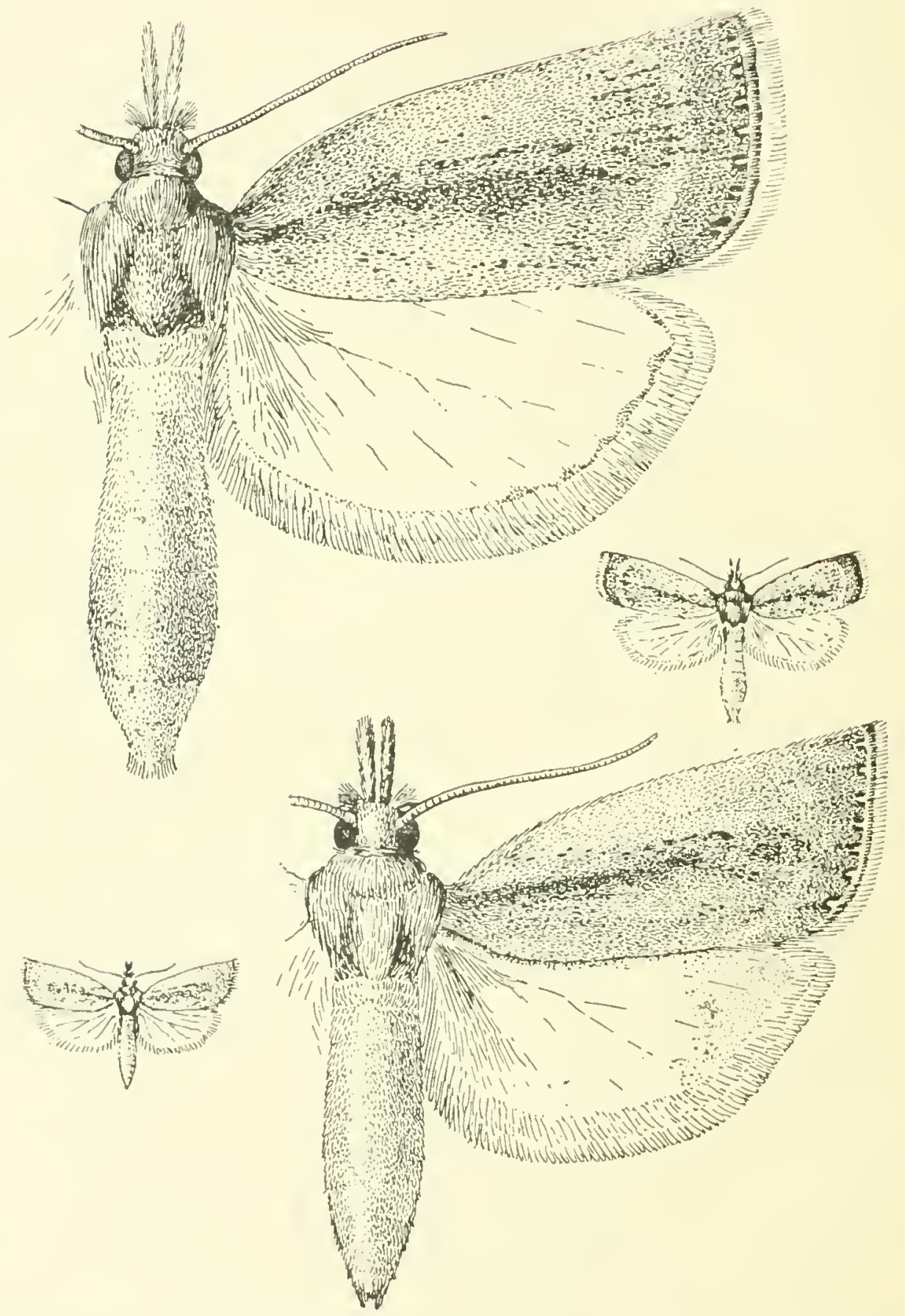

A'y!dritu tumidicostalis (C. S. 1610). Moths $\times 5$. The smaller figures indicate the natural sizes. 
foodplants are known. The larve have been collected at Pabna in the latter part of August, at Dacea in July and September and at Jorhat, Assam, in Angust, in all cases in sugarcane. All of them developed into moths in August, September and before 2nd October. Mr. S. R. Gupta sent 138 larræ and 12 pupæ from Jorhat in August 1918. Ninetytwo of them developed into moths, 59 females and 33 males, between 23rd August and 26th September. Almost all of them were tried for eggs in the Pusa Insectary withont success.

The full-grown larva is about $30 \mathrm{~mm}$. long and cylindrical in shape. The head is red-brown. shiny. The prothoracic shield is large, dirty brown in colour and divided longitudinally by a faint marking. The general colour of the body is pale yellowish-white. The marling and warts on the body show the following variations: (1) There may be two broad slightly pinkish-bromn stripes on each side of the body, one subdorsal and the other supraspiracular, the dark brown large shiny warts being situated on these stripes; such larve elosely resemble the active larra of Dialrea venosata. (2) The stripes may be indistinct, the warts only being very prominent on the skin. (Pl. 52, f. 1). These larve too are liable to be mistaken for those of Dialra venosata. (3) The warts may be altogether indistinet, the stripes only being present in an interrupted manner and the two stripes on each side approaching each other at intervals (P1. 53, f. 1). Such larvæ are liable to be confused with those of Chito simplex. (4) Both stripes and warts may be indistinet. Of these four types of larve the second is the commonest. The morphological character's given in the key of the larval forms, on which the differentiation is based, are always constant.

The caterpillars oceur in large numbers in individual plants which are literally riddled, some dust being thrown out from side-openings in the stem. They pupate inside the affected stems near previouslymade holes through which the mature pupa wriggles out before the moth emerges. The pupa is brown and the characters given in the key of the pupal forms distinguish it sufficiently. Of all the internal borers so far observed this is the most injurious to grown-upeanes.

Dialrae sp. (C. S. 1674).

Plates 5.j. 56.

Foodplants-

Sugareane-Dacea: Pusa.

Rice-Pusa ; Karimganj, Sylhet.

This species is active from about February-March to Ostober-November, the winter being passed in libemation in the larval state. (Plate 53 , fig. 2). 
The eaterpillars were found in some numbers in grown-up sugarcanes at Dacea in July and September, and have been observed at Pusa only in small numbers in rice from July to November and in grown canes in Oetober.

The larva elosely resembles those of Diatraca auricitia (C. S. 1571) and Rice Chilo (C. S. 1677), but can be distingnished with the help of the key.

The full-grown larva is about 20 to $25 \mathrm{~mm}$. long. The head is redbrown, shiny. The prothoraeie shield is almost similarly coloured as the head and divided longitudinally in the middle by a faint marking. The general colour of the body is pale yellow. There are five brown stripes on the back, one mid-dorsal and two on each side. In some larve there is a black band on the inner side of the abdominal prolegs.

The pupa is rather slender-looking compared with the pupæe of the other borer's and either brownish-grey or brown in colour. On the head end just above the eyes there is a transverse ridge the two ends of which protrude slightly in the form of a pair of short horns. The prothoracic spiraeles are rather large arching ridges and the abdominal ones are protuberant short tubes with elear holes. These eharacteristies distinguish it altogether from the pupæ of the other borers.

\section{The Rice Chito (C. S. 1677).}

\section{Plates 57,58.}

\section{Foodplant-Rice.}

'This species has not yet been observed to oecur in any other plant. In the Insectary the larva fed on maize and sugareane stems. But i was evident that they did not like these two plants and were compelled to bore them in the absence of rice.

As a general rule, the caterpillars hibernate in rice stubbles from about the end of November to about March, the over-wintering larva pupating and emerging as moths on a large seale in March to May. But moths liave been observed to emerge up to 12 th November before winter and on 5th, 13th and 20th January and 2nd, 18th, 20th, 25th and 28th February. The early-emerging moths breed in early-sown rice ; larvæ have been collected in desaria rice in April. Up to about September the larvæ are found in rice in small numbers. They occur in large numbers when rice comes in to ear in October and November. This why we observe such large numbers of the larvæ in rice stubbles in winter. 


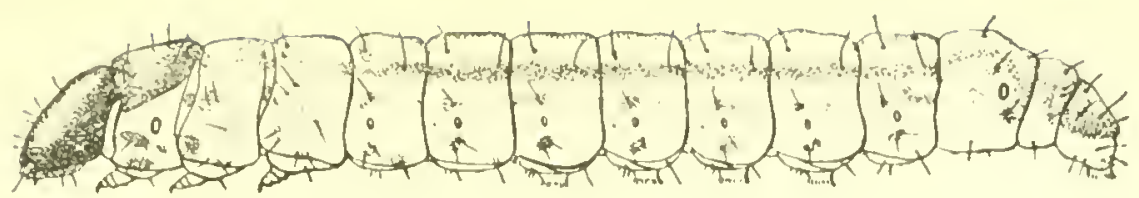

a.
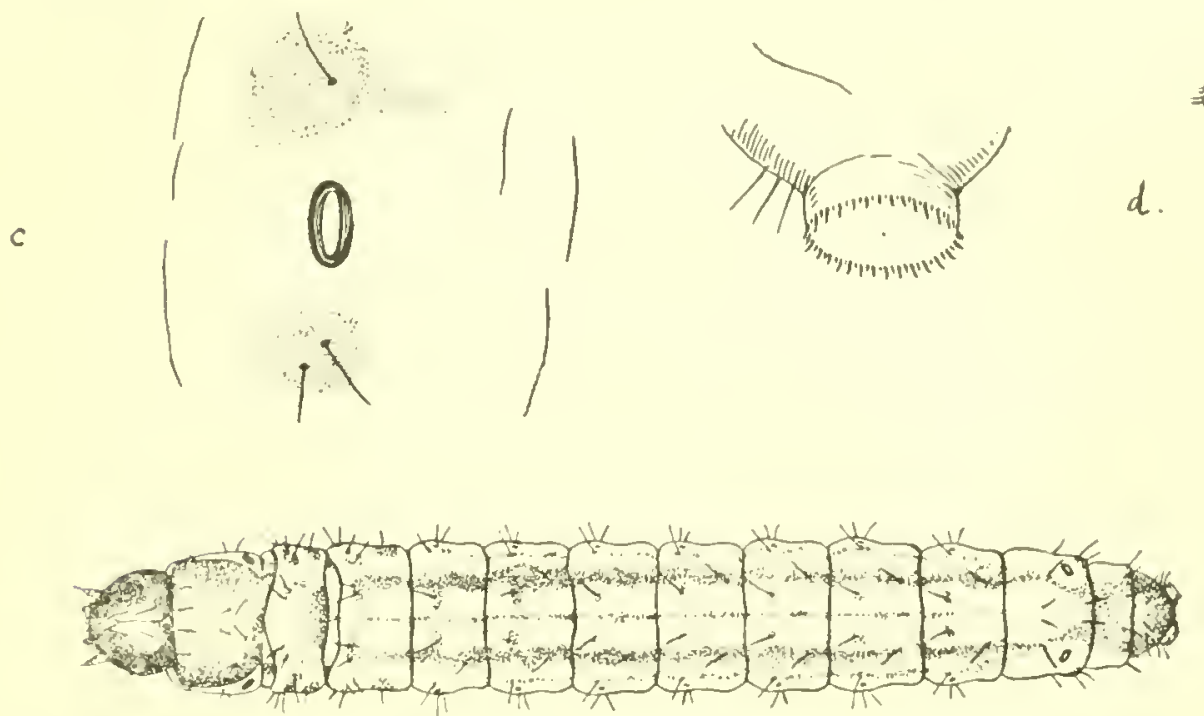

b.

Fig. 1.- Jirrtirrel sp. in Sugarcane at Dacca (C. S. 1674). "I. lateral, and $b$, dorsal view of larva, $4 ; c$. details of spiracle $\mathrm{c}$. fifth segment, more highly magnified;,$l$, details of first proleg, seen from below, more highly magnified.
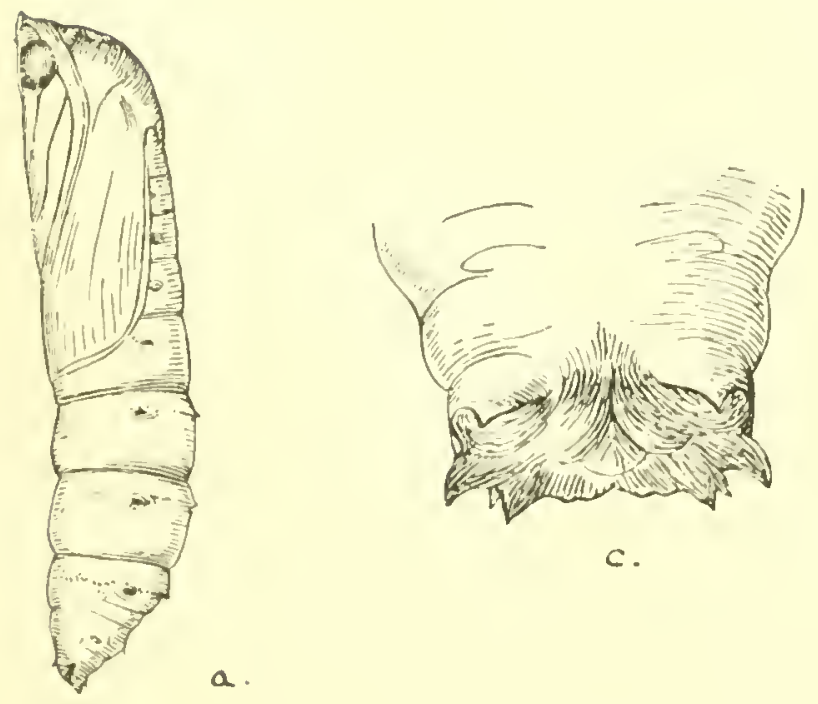

c.

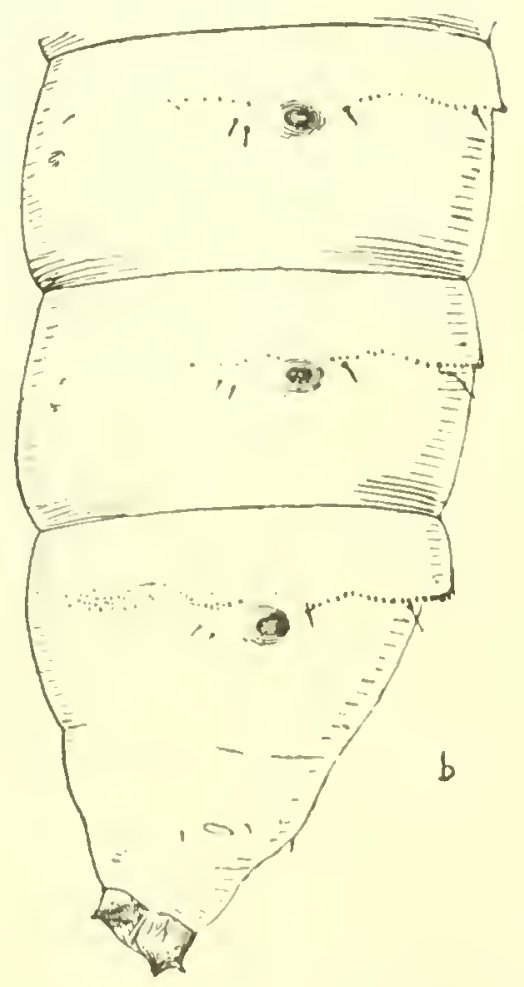

Fig. 2. - Jirllrerr sp. in sugarcane at Dacca (C. S. 1674). ", Pupa > 5. "l, Posterior segments of pupa, seen laterally more highly magnificd; $c$, anal segment of pupa, ventral surfacc, more highly magnified. 

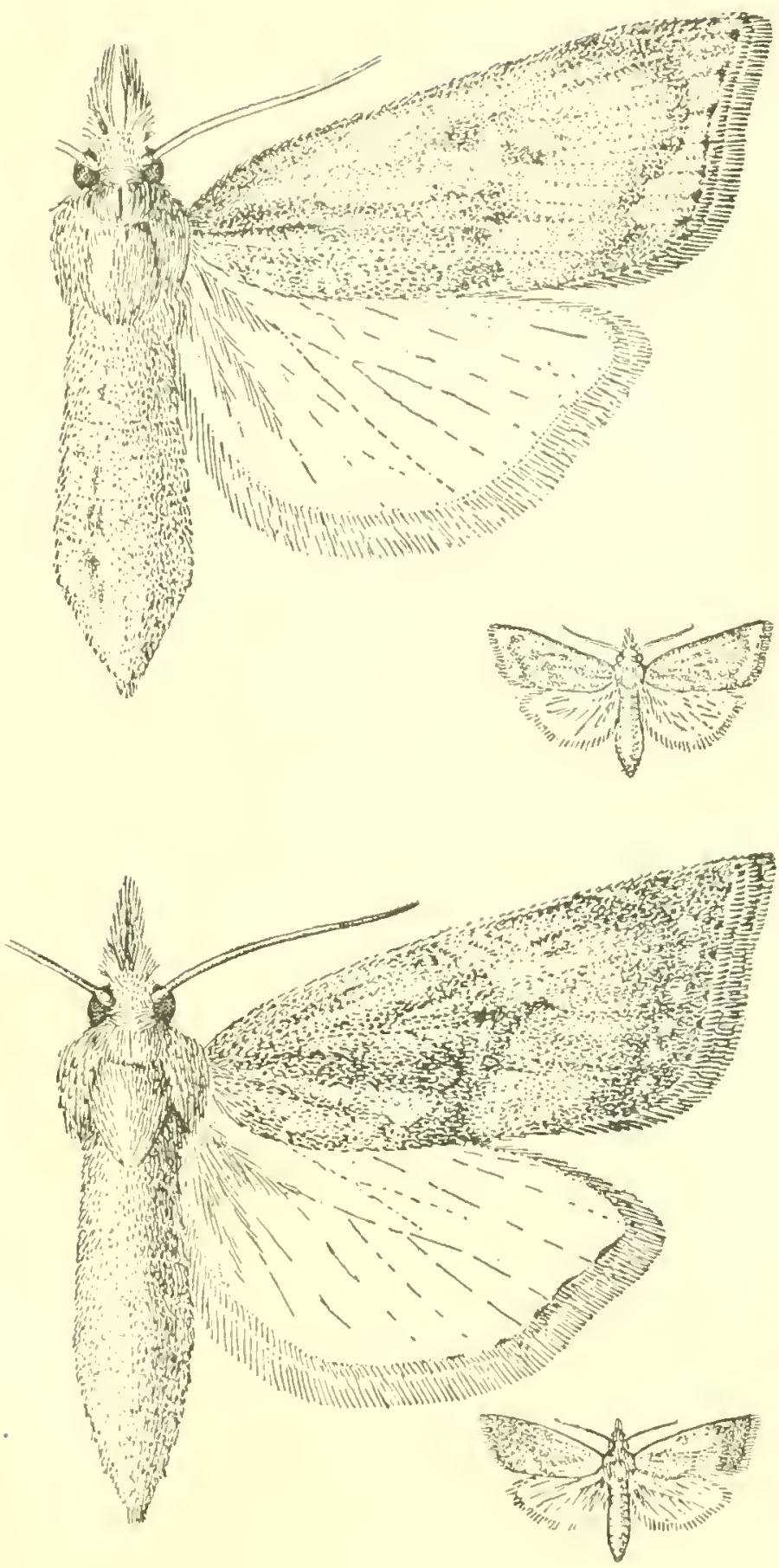

(C. S. 1674). Moths $\times 5$. The smaller figures show the natural sizes. 



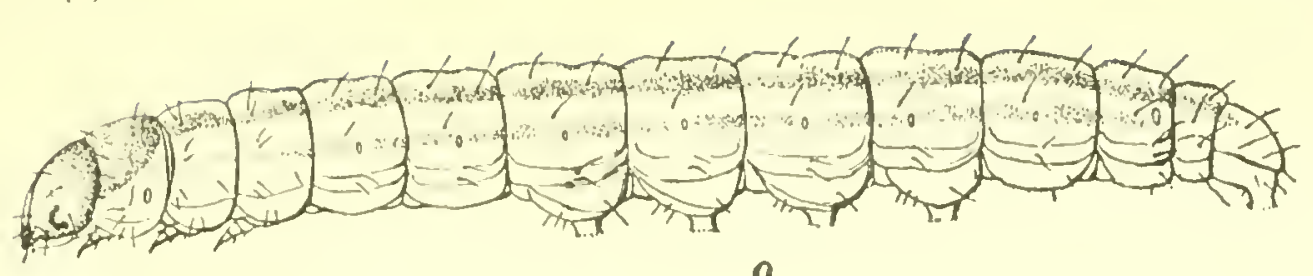

a
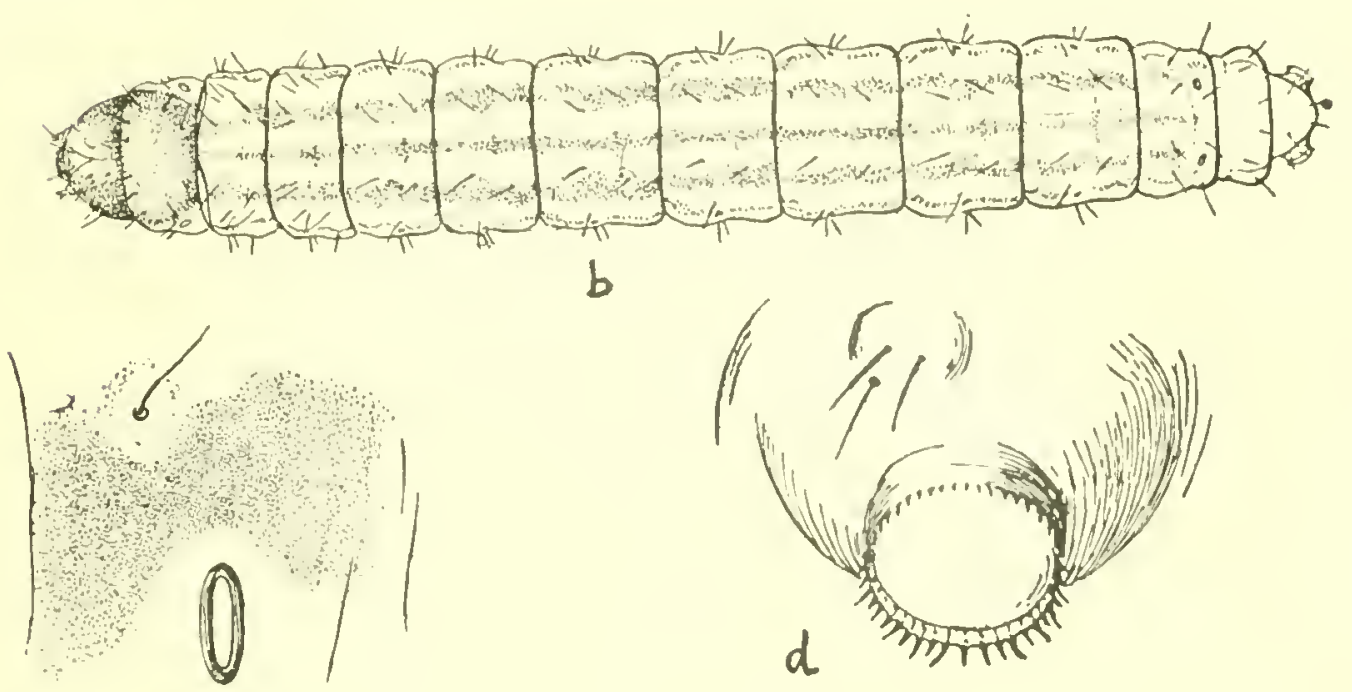

C

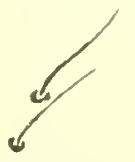

Fig. 1.-C. S. 1677 ; 11 , larva, side-view, 5 ; b, larva, dorsal view $\times 5$; $r$, details of spiracle ; 1 , arrangement of crochets on proleg of larva.
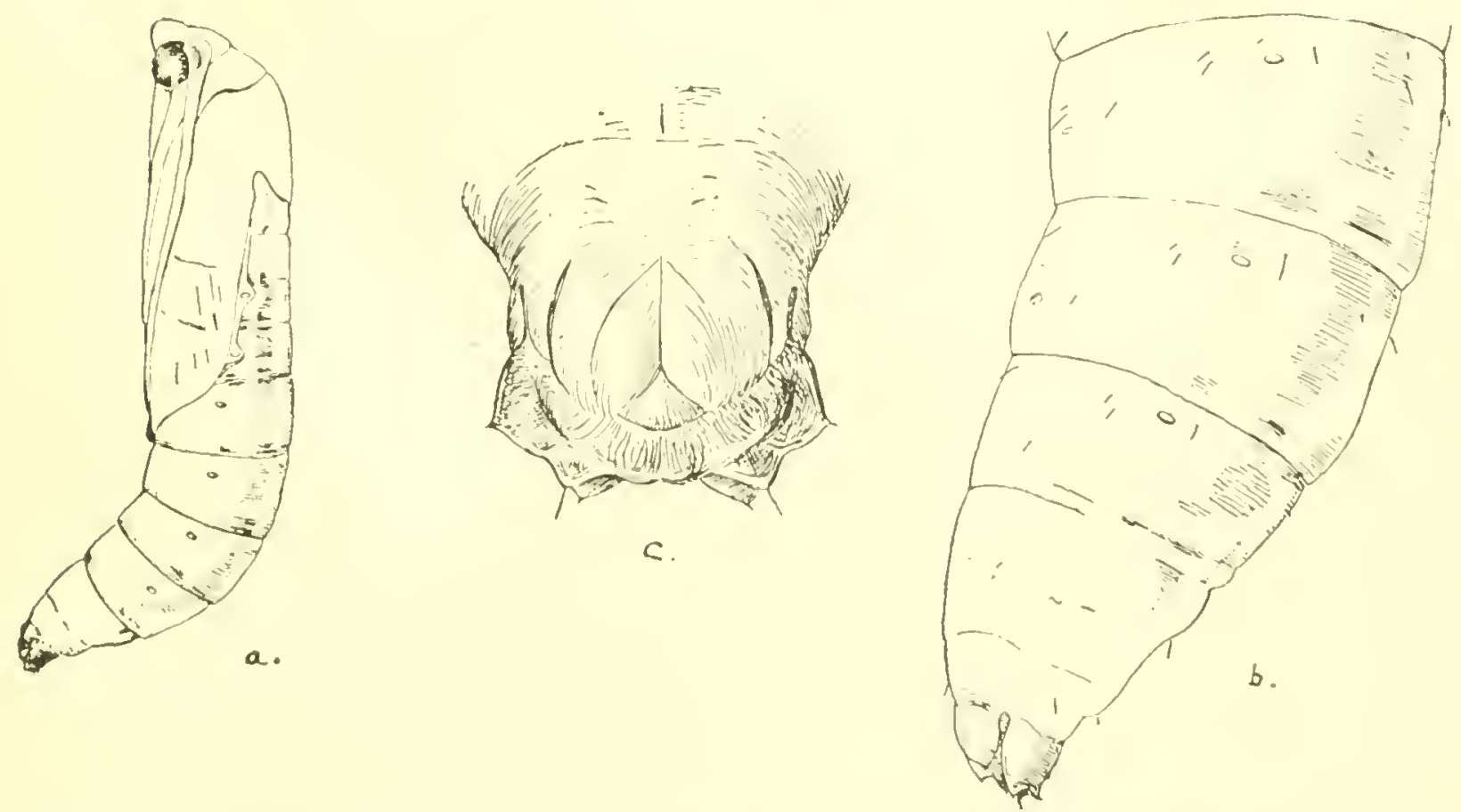

Fig. 2.-Rice Chilo in rice at Pusa (C. S. 1677). "1. pupa >5; 1, posterior segments of pupa, seen laterally, more highly magnified; 1 , anal segment of pupa, ventral surface, more highly magnified. 


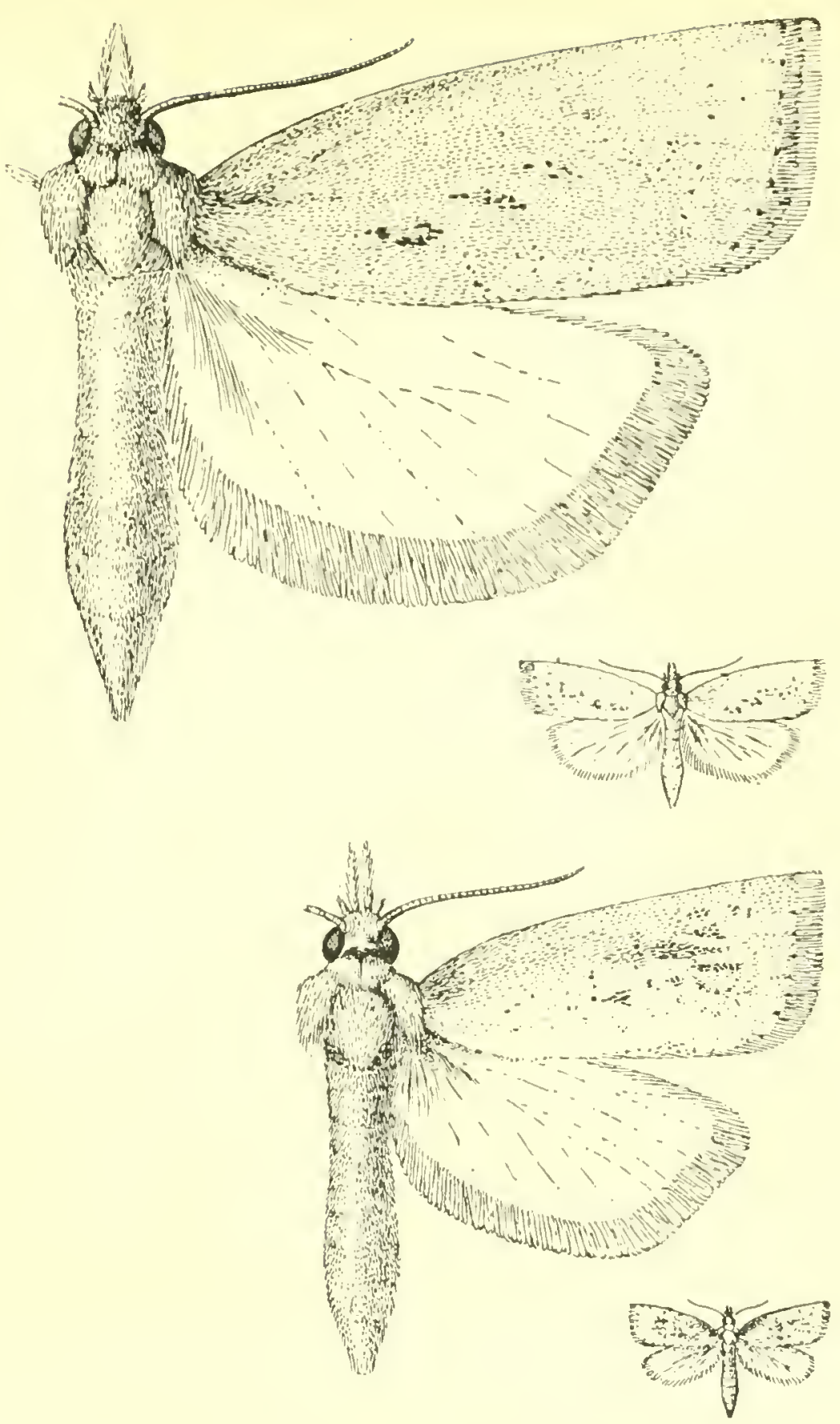

Fig. 1. C. S. 1677. Moths $\times 5$. The smaller figures indicate the natural sizes.

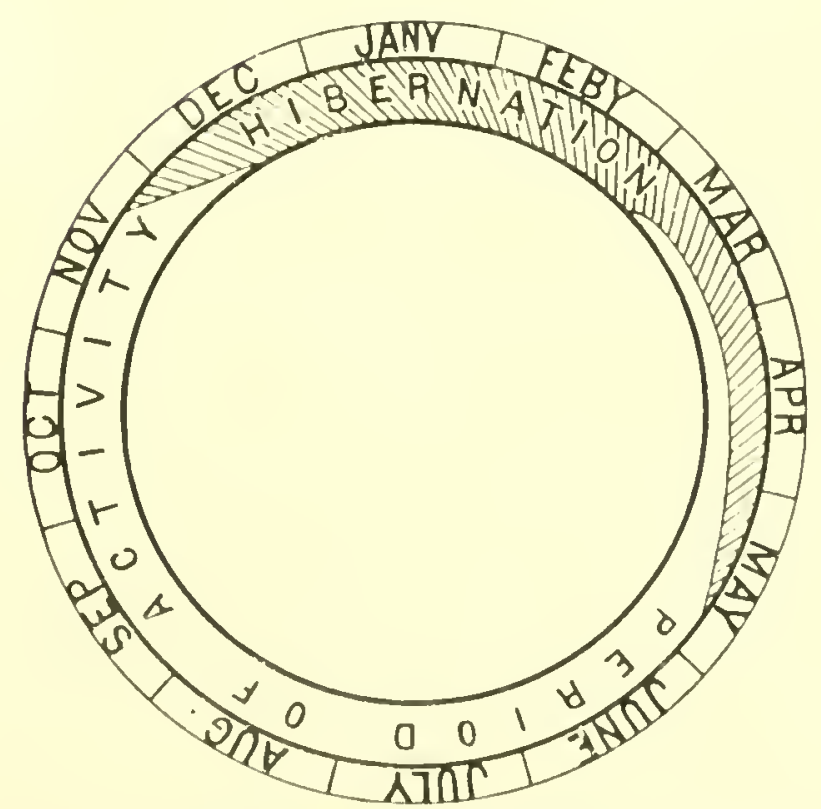

Fig. 2.-Annual life-cycle of Rice Chilo (C. S. 1677). 


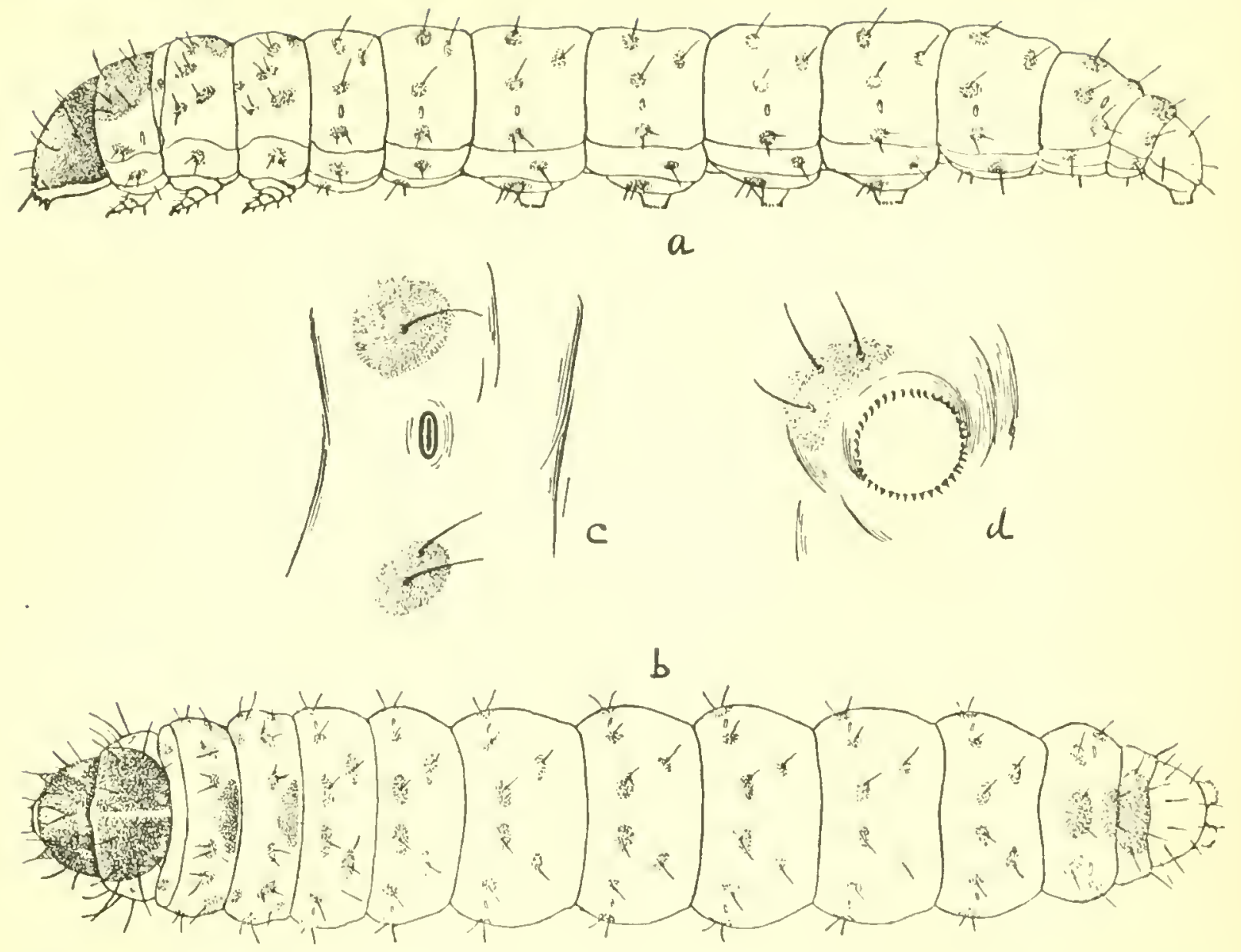

Fig. 1.--(C. S. 1769). " Iarva, lateral view $\times 5 ; 1$, larva, dorsal view $\times 5$; c, details of spiracle ; "l, arrangement of crochets on proleg.

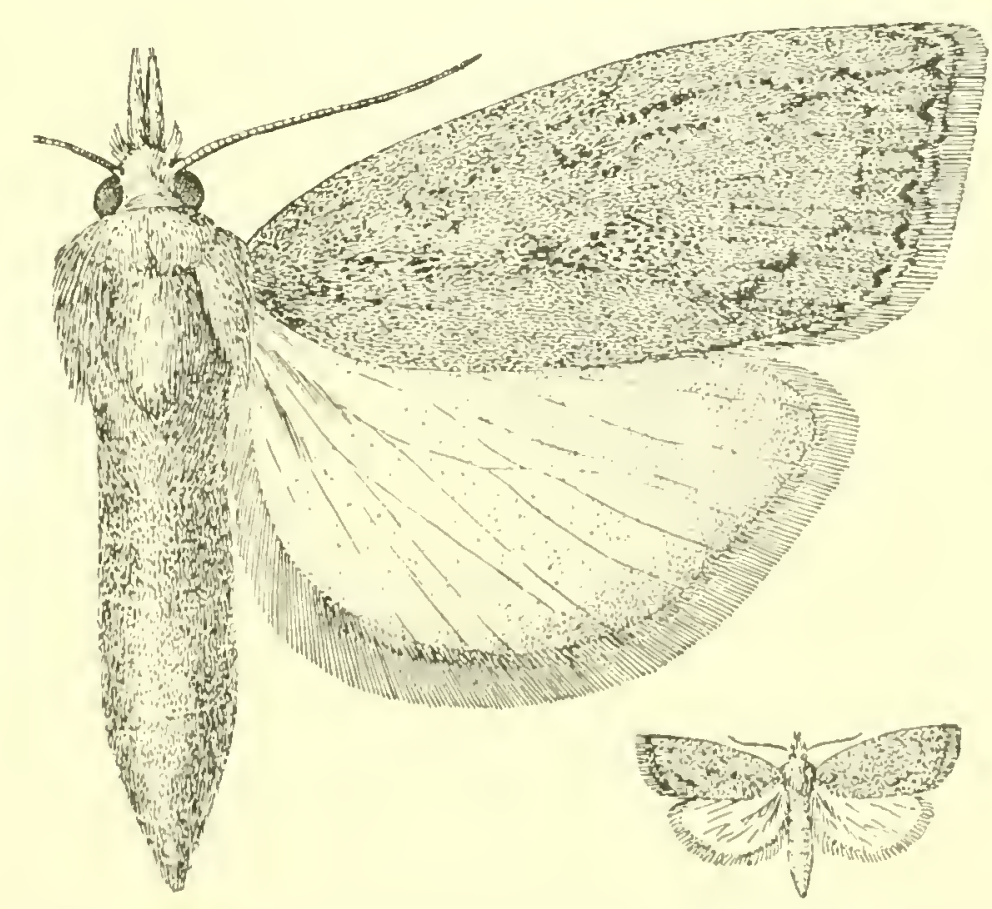

Fig. 2.-(C. S. i769). Borer in ke(m)' stem ; moth, nalural size and magnified. 



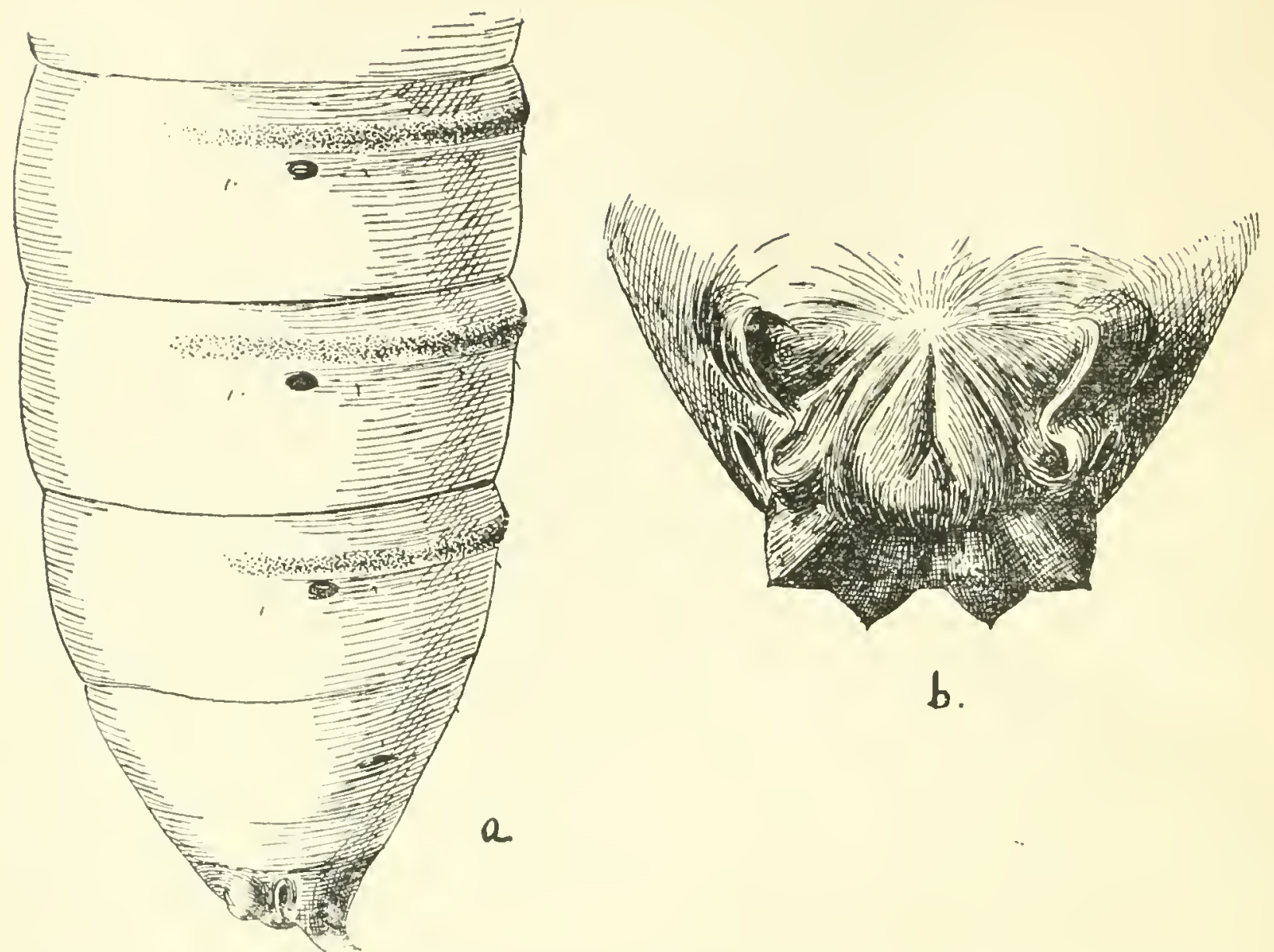

b.

Fig. 1.- (C. S. 1769). ", pupa, posterior pertion from side $(\times 13)$; ", anal segment of pupa, end view, more highly magnified.
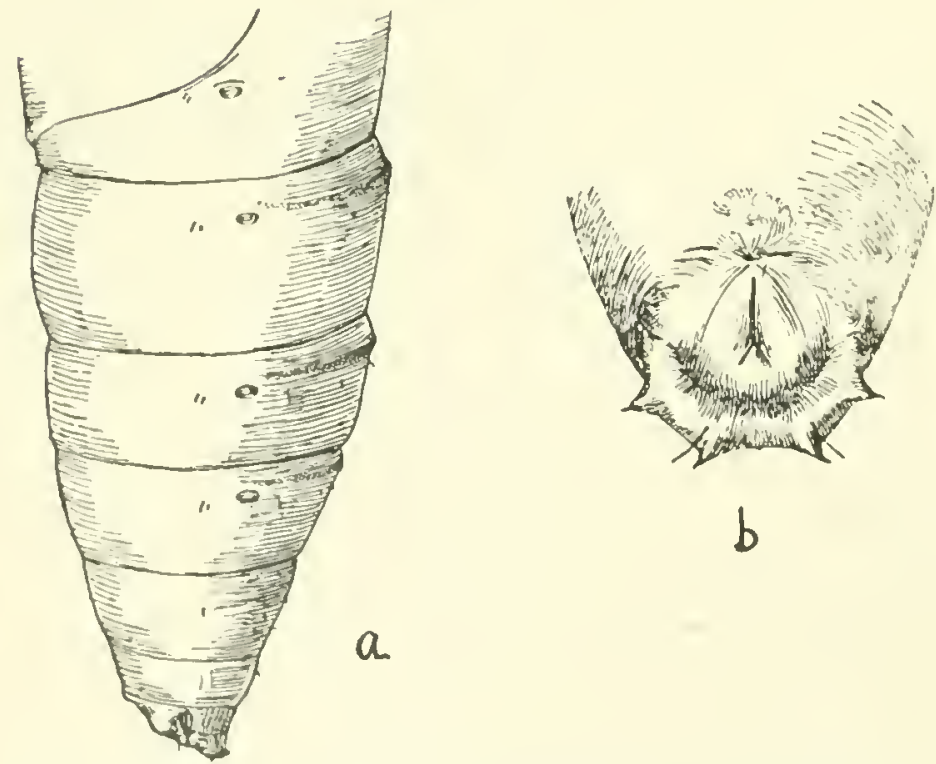

Fig. 2.-(C. S. 1795). (l, posterior portion of pupa, magnified ; 6 . anal segment of pupa, posterior view, magnified.

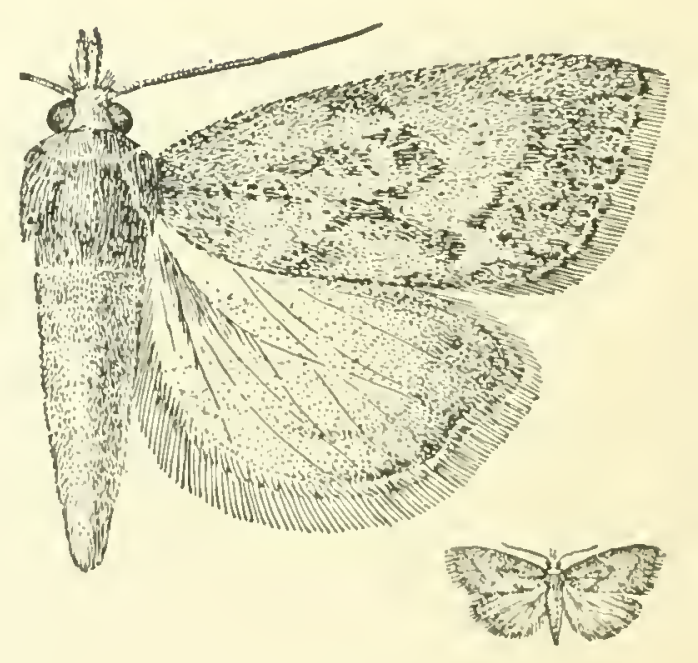

Fig. 3.-(C. S. 1795). Borer in ilili; stem ; moth, natural size and magnified. 
Eggs are deposited in the same mamner as those of Chilo simpler. The caterpillars bore inside the stems and also pupate there. The fulgrown larva measures about $20 \mathrm{~mm}$. in length, and tapers slightly at the extremities. The young larva have practically the same thickness throughout their length. The head is yellow and the prothoracic sliteld paler than the liead. The body is pale-yellow and, in the rase of hibernating larve, greyish. The five stripes on the back are greybrown. The pupa is about $12 \mathrm{~mm}$. long and yellow-brown in colour. The surfaces of the fifth, sixth and seventh abdominal segments are practically smooth, a very faint roughness being observable at the anterior part of their back under a high-power lens.

\section{Chilo sp. (C. S. 1769).}

Plate 59 ; Plate 60, fig. 1.

Foodplants-

Kanra (Saccharum arundinaceum).

Ihri (Saccharum fuscum).

The caterpillars were found in small numbers in these two plants in March-April. They were boring new shoots and causing "dead heart."

The fullgrown caterpillar is about $25 \mathrm{~mm}$. long. The head is dark red-brown, shiny; the prothoracic shield similarly coloured as the head and divided longitudinally in the middle. The general colour of the body is pale yellowish-white with prominent shiny warts. The dorsal ressel is visible and looks like a stripe.

The caterpillars pupate in the stem near previously-made holes through which the moths emerge. The pupa is dark-brown in colour.

Diatrat sp. (C. S. 1795).

Plate 60, figs. 2,3 .

Foodplant-Ihri (Saccharum fuscum).

The caterpillars were found in very small numbers in March. They have a red-brown shiny head, a large brown plate on the prothorax and prominent warts on a pale-yellow body. The pupa is brown. 
Chilo sp. (C. S. 1831).

Plate 61 ; Plate 62 , fig. 1.

Foodplant-Rarhi and Batri (Saccharum spontaneum).

The caterpillars were found in small numbers from July to September buring in the stems of grown-up plants.

The fullgrown larva is about 18 to $20 \mathrm{~mm}$. long, with a glossy yellowbrown head, a shiny yellow shield on the prothorax and a pair of broad brick-reddish stripes on each side of a pale-yellow body. The distinguishing characters are given in the key of the larval forms of borers. The larva pupates inside the stem. The pupa is brown.

\section{Chilo sp. (C. S. 1835).}

\section{Plate 62, fig. 2 ; Plate 63.}

\section{Foodplant-}

Ihri (Saccharum fuscum).

The larvæ fed on juar (Andropogon) stem in the Insectary.

The caterpillars were found in small numbers and boring near the top of the stems and causing "dead heart." A young caterpillar collected on 12th March died on 10th May without pupating. Caterpillars collected on 5th July pupated and emerged before the 3rd September, the pupal stage occupying 12 days.

The larva attains a length of about $21 \mathrm{~mm}$. and is rather thick in appearance, measuring about $3.25 \mathrm{~mm}$. across the mesothorax from which the body tapers slightly both ways. The head is brown-yellow and glossy. The prothorax is pale-yellow and rather glossy. The other two thoracie and the abdominal segments have on the dorsal side above the spiracles a purplish tinge on the pale-yellow skin, the purplish marking being deeper in the dorsolateral region and almost disappearing on the dorsal region. The dorsal ressel is visible like a faint and somewhat interrupted stripe.

The larva pupates inside the affected stem. The pupa is about $15 \mathrm{~mm}$. long and yellow-brown in colour. The head has a thick short protuberant ridge on the front. The primary tubereles on the body of the larva develop into strong prominent spines on the body of the pupa. The spines are pointed, have a broad base and a hair arising from the side below the tip. 


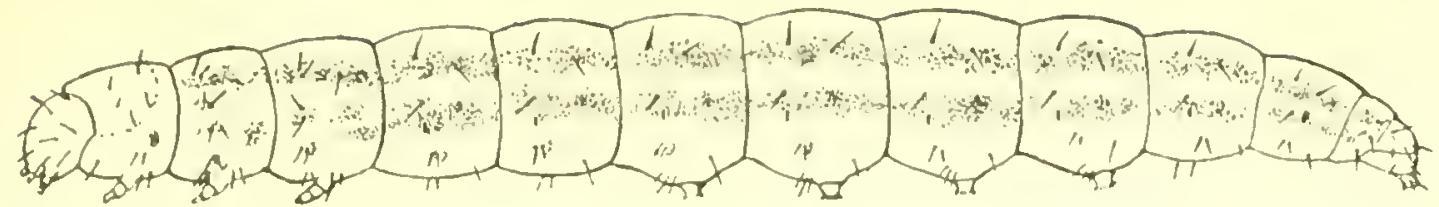

$a$
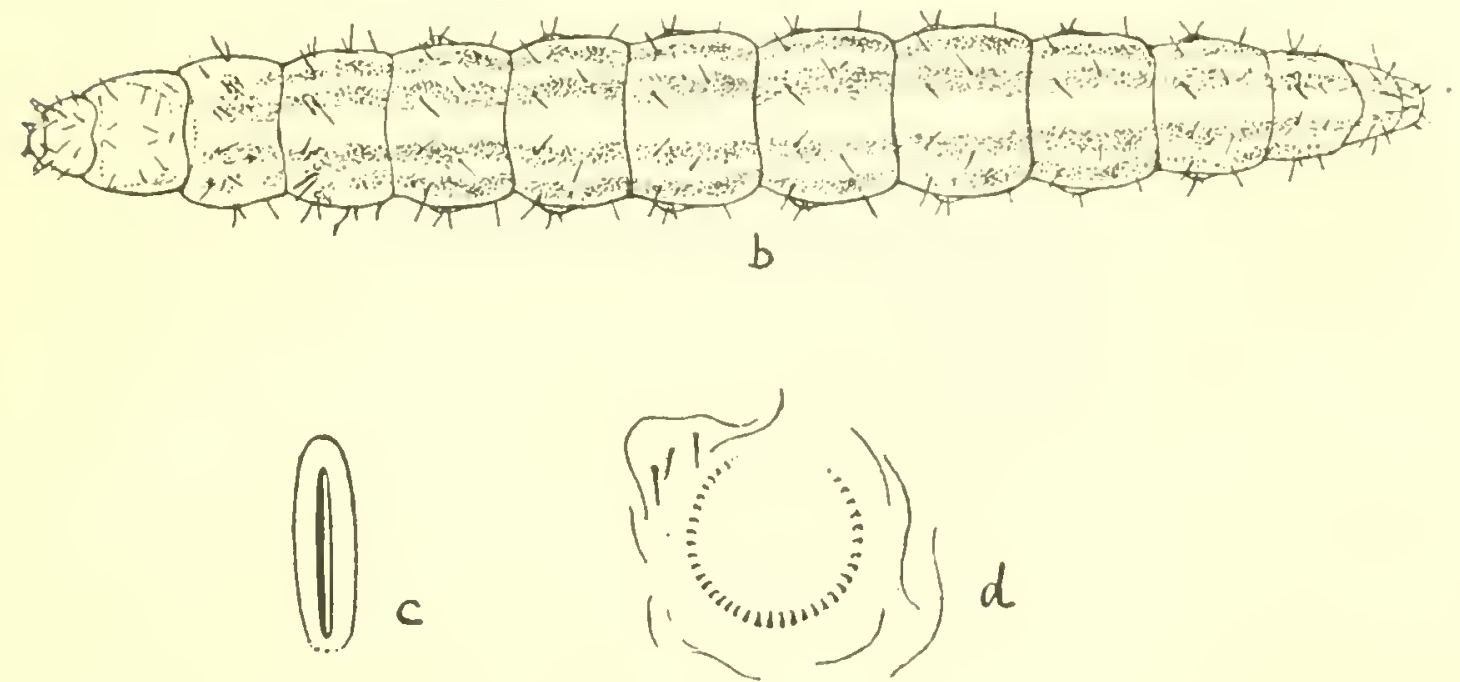

Fig. 1.-(C. S. 1831). "l. larva, side-view . 5 ; 6 . larva, dursal view $\times 5$; r, spiracle more highly magnifieo;, arrangement of crochets on proleg of larvá.
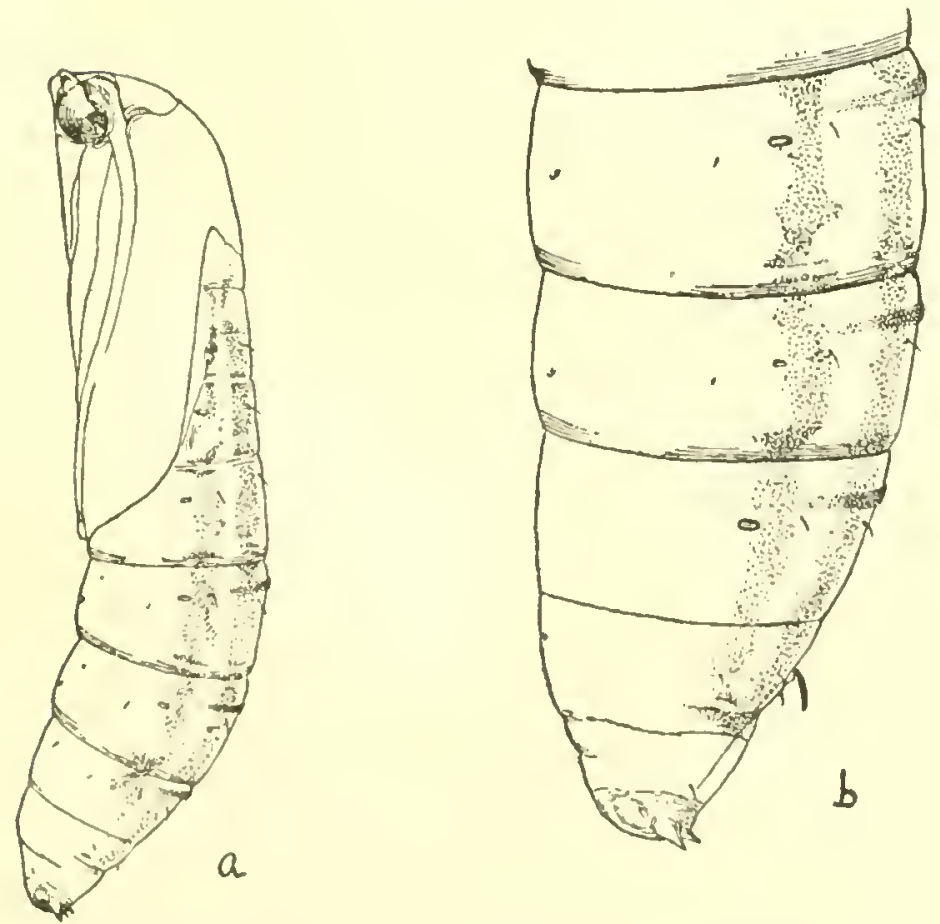

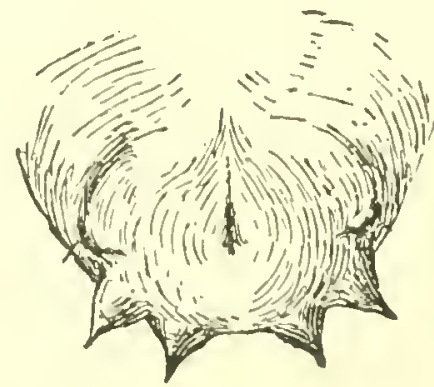

C.

Fig. 2.-Pupa of (C. S. 1831), Borer in $1.1 \%$; 11 , pupa $\times 5$; 1, posterior extremity of pupa, side-view, more highly magnified; ", posterior extremity of pupa, anal view, more highly magnified. 

Page 392(?).

PLATE 62.
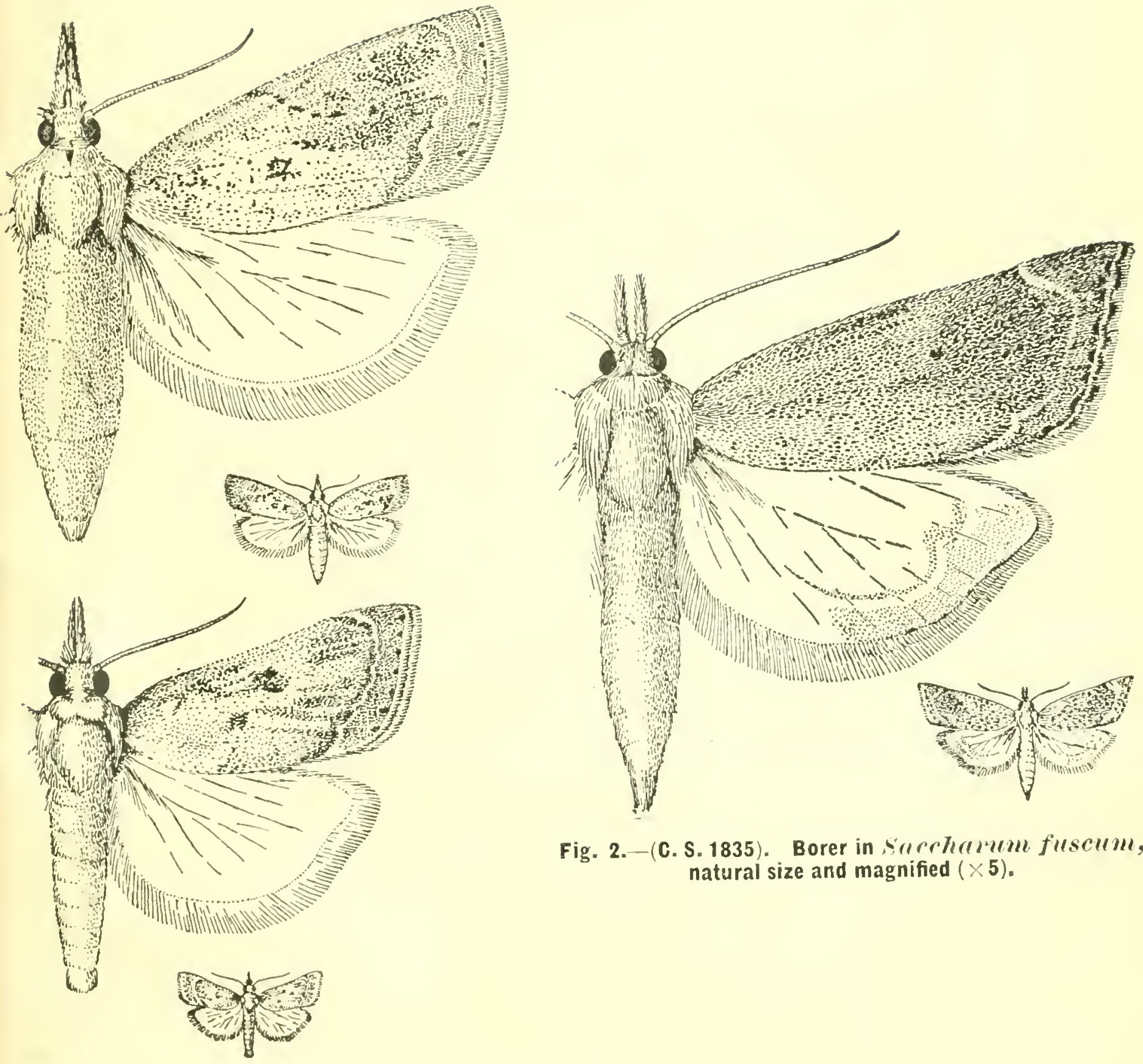

Fig. 2.-(C. S. 1835). Borer in surehermul fuscum, natural size and magnified $(\times 5)$.

Fig. 1.-Borer in rerrhi stem (C. S. 1831). Moths $\times 5$. Th: smaller figures indicate the natural sizes, ${ }^{\prime}$ 


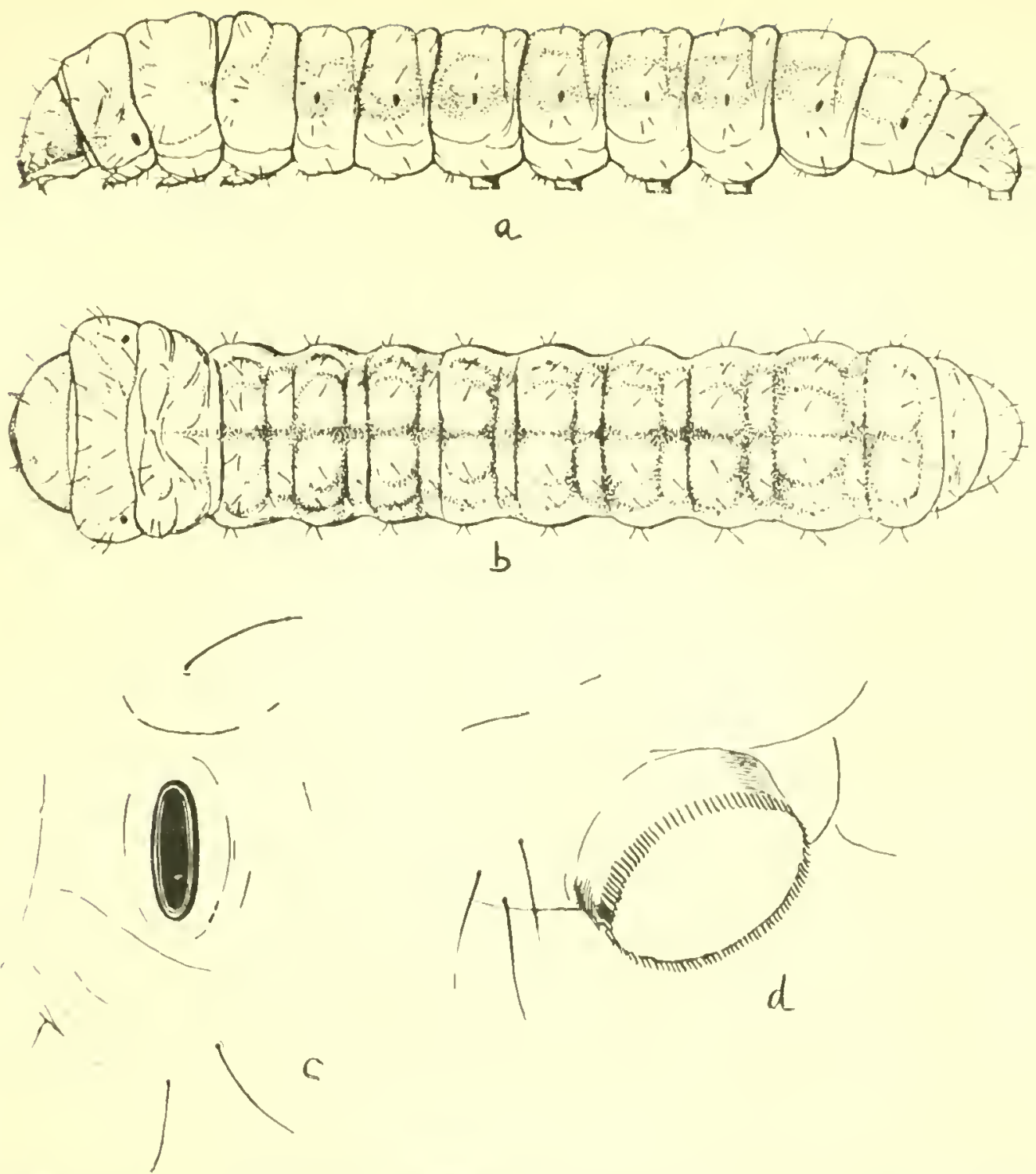

Fig. 1.-Borer in ilivi (6. S. 1835). "l, larva, "side-vicw 5 ; 11. acrsal

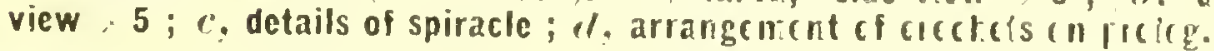
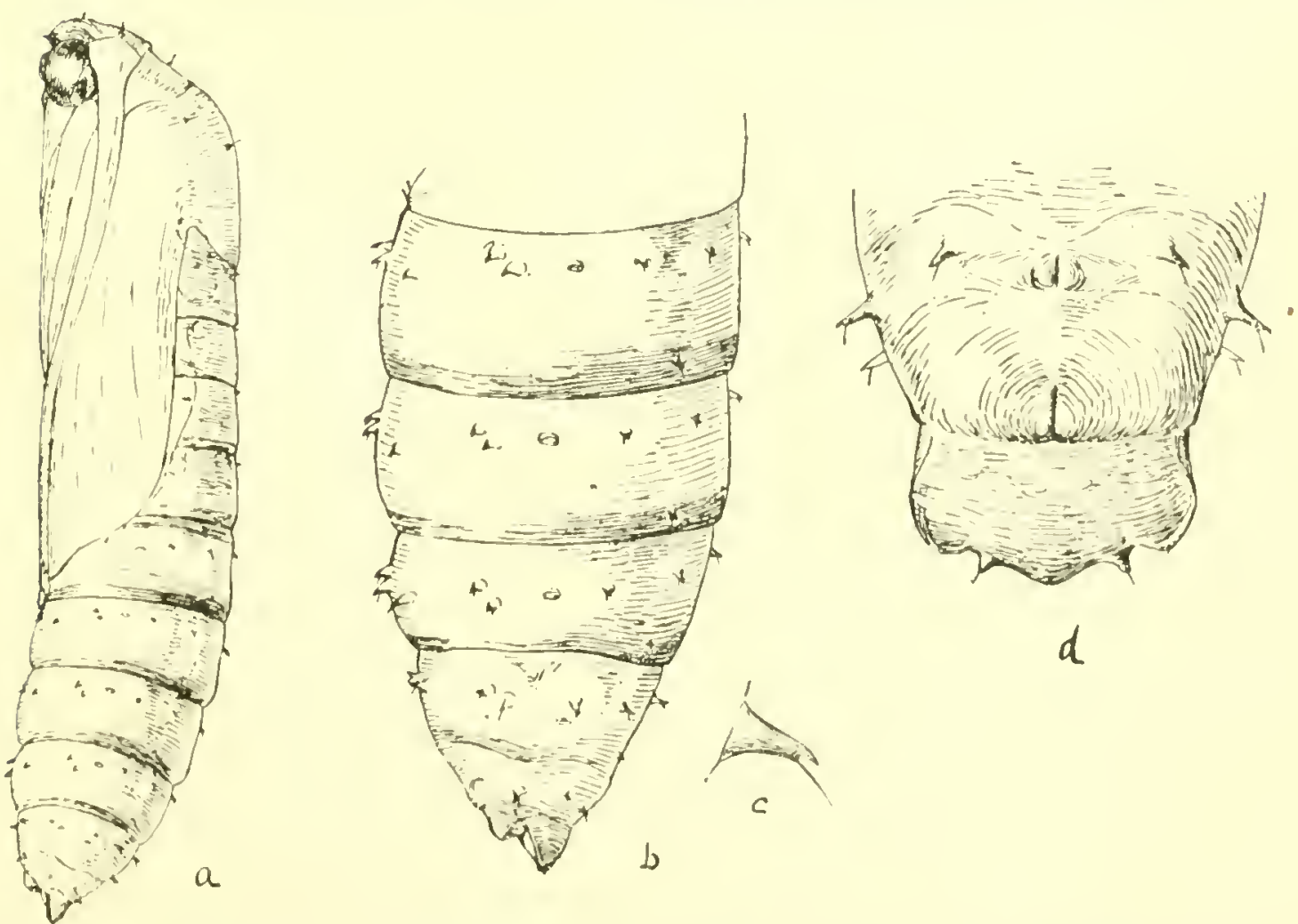

Fip: ". - C. S. 1835). Pupa of borer in ilil: : ", side-view, magnified $>5$; 1.. posterior extremity, sida-yicw, more highly magnified; $c$; a :ingle spine, inzre highly magnified; $/$ : anal segment, highly magnifizd. 



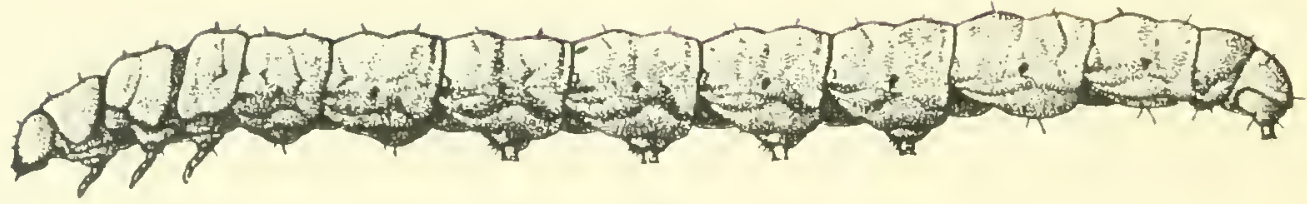

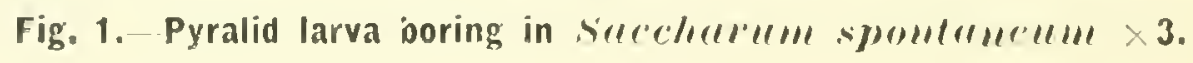

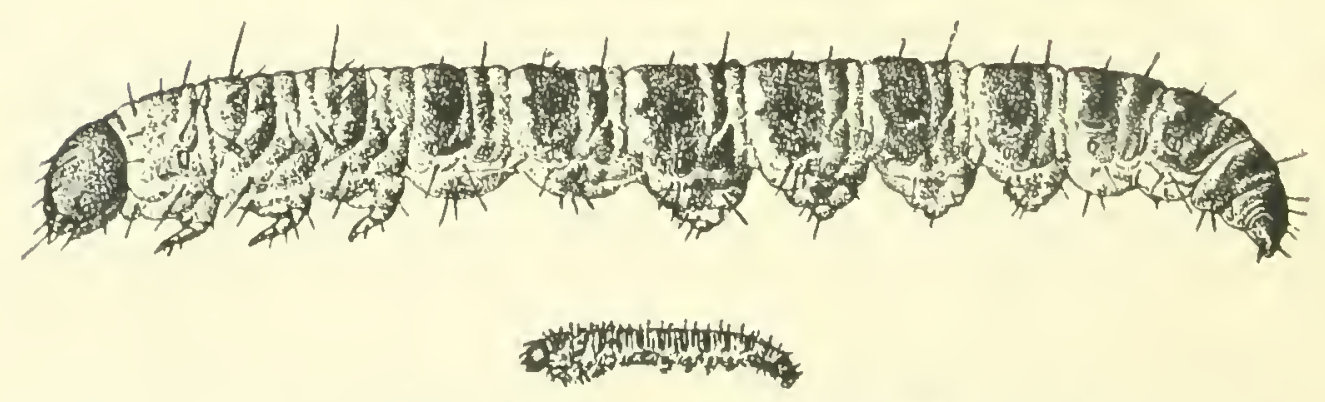

Fig. 2.-(F. 18). Borer in ilili stem. (The smaller figure shows the natural size.) 
? Pyralid borer.

Plate 61, fig. 1.

Foodplant-Rarhi and Batii (Saccharum spontreneum).

These caterpillars, which we have not yet been snceessful in rearing, occur in very large numbers. The hard stems of grown-up plants are converted into hollow tubes throughout their length, a single larra usually occurring in individual plants. The heart shoot dies and dries only when the larva bores near the top.

The insect has only one generation in the year. Young larve are found abont. July and they feed up to about the early part of November, by which time they become fullgrom. Then they rest through the winter and the hot weather, pupating and emerging as moths about June-July. The larva have been observed to rest in the Insectary up to the middle of Angust and then die.

The fullgrown larva is abont $35 \mathrm{~mm}$. long. The shape is crlindrical or rather semicylindrical being slightly compressed dorsoventrally. The head is glossy-yellow. The segments of the body have an elongated and slightly chitinized and glossy appearance. The hairs are small and black. The spiracles are elongated oval, brown with a dark narrow rim. The five pairs of prolegs are short, equally dereloned and have their hooklets in complete circles.

2. Pyralid borer. (Plate 64, fig. 2).

Foodplant-Ihri (Saccharum fuscum).

A caterpillar with a glossy yellow-brown head and the body having a green colour on the ventral surface and the sides and dorsally a brownish tinge on the prothorax, pink on the mesothorax and deep pink or rather red on the rest of the serments, was observed to occur in large numbers in March. They fed on sugareane stems in the Insectary but could not be reared.

$$
\begin{aligned}
& \text { ? Pyralid borer. } \\
& \text { Foodplant-Batri (Sacchamen spontaneum batri). }
\end{aligned}
$$

A rather slender-bodied, pale-yellow caterpillar," with a yellow head. reddish-brown patches in the subdor'sal region of the segments of the body arranged in longitudinal rows on the back and a vely prominent visible broad brown tracheal tube running from the thoracic to the last abdominal spiracle on each side, was collected in small numbers in Jume. It conld not be reared. 
Ramila ruficostalis (C. S. 1533).

Plate 65, fig. 1.

Foodplant-Bamboo.

A few caterpillars were collected from the top shoots of bambon branches showing "dead heart" on 10th January. They had bored the trigs and were apparently hibernating. They continued to rest and pupated in Mareh, emerging on 26th March.

\section{Argyroploce paragramma (C. S. 1631).}

Plate 65, fig. 2.

Foodplant-Tender bamboo shoots.

The caterpillars are very common in the rainy season, infesting and boring new bamboo shoots as they come out of the ground. Generally a great many caterpillars are found in the same shoot boring the stem, completely hidden under the leafsheaths. They are responsible for the death of a fair percentage of the new shoots.

\section{Bactra truculenta (C.S. 1489).}

Foodplant-Mootha (Cyperus rotundus).

The caterpillars of this Encosmid moth were found boring the stems in October.

\section{Heliothis obsoleta. \\ Plate 66.}

Foodplants-Gram ; tobaceo ; pigeon-pea (Cajamus indicus); mangelwurzel ; Incerne ; hemp (Cannabis sativa); Khesari (Lathyrus sativus); wheat; val (Dolichos lablab); flax; oats; castor; bajia (Pennisetum typhoideum); maize ; tomato; onion ; indigo ; rose ; Dhutra (Datura stramonium); pumplin ; sweet-potato; sunflower; cottonbud ; marua (Elasine coracana); ban-bhindi (Malachra capitata); Physalis perwiana.

In the neighbourhood of Pusa IIeliothis obselota occurs in large n:1mbers only on gram and arhar (Cajanus indicus) of which they bore the pods. Sometimes the caterpillars oceur in small numbers on maize of which the tender cob or the soft part of the top of the stem is bored. - Similarly they ocenr in small numbers on bajra heads which are bored. 


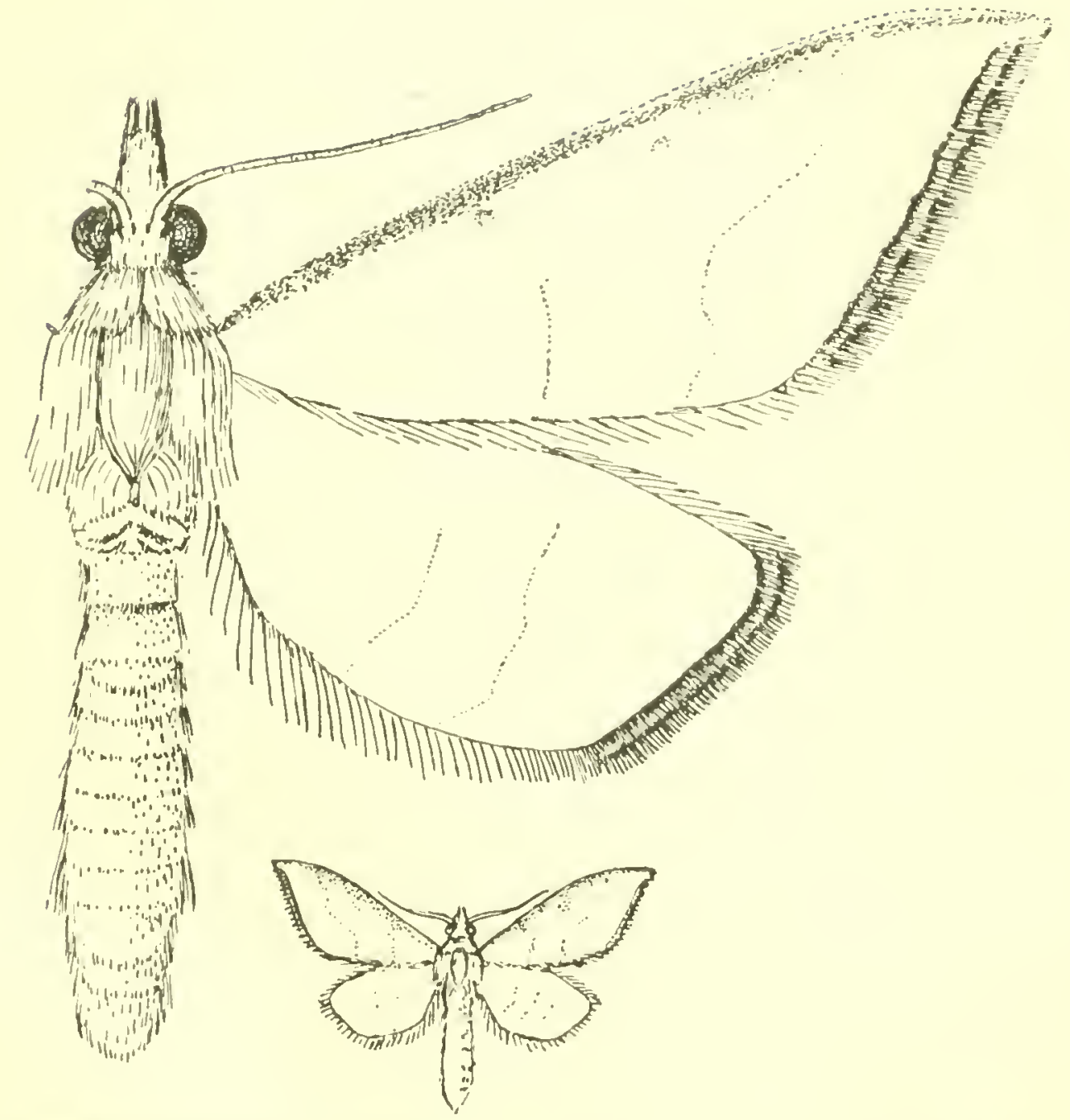

Fig. 1. - Rollmill mofirostrlis 5. The smaller figure shows the natural size. 


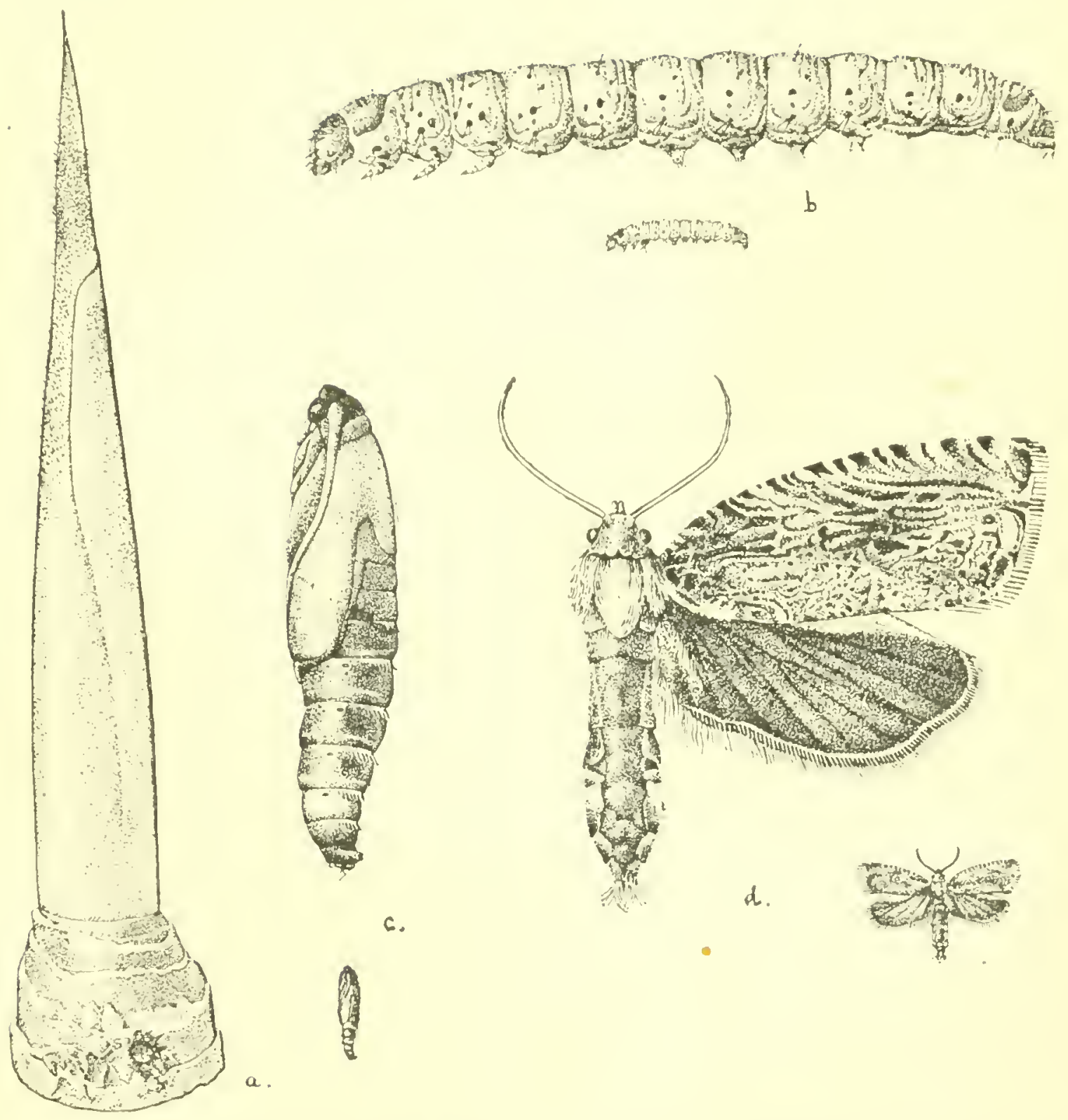

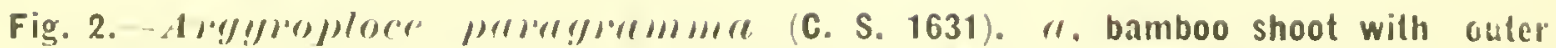
sheathing leaves removed, showing bore-hole of larva; I. larva, natural sice ird magnified $(\times 5) ; c$, pupa, natural size and magnified $(5) ; 1$, imago, natura! size and magnified $(; 5)$. 



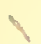




\section{EXPLANATION OF PLATE 66.}

Heliothis obsoleta, $\mathrm{Fb}$.

Fig. 1. An egg laid on a tur-pod (magnified).

Figs. 2-5. Caterpillars on a gram plant, two eating into the pods (life-size).

Fig. 6. Pupa in its underground cell (life-size).

Fig. 7. Moth in repose (life-size).

Fig. Moth with wings expanded (life-size). 


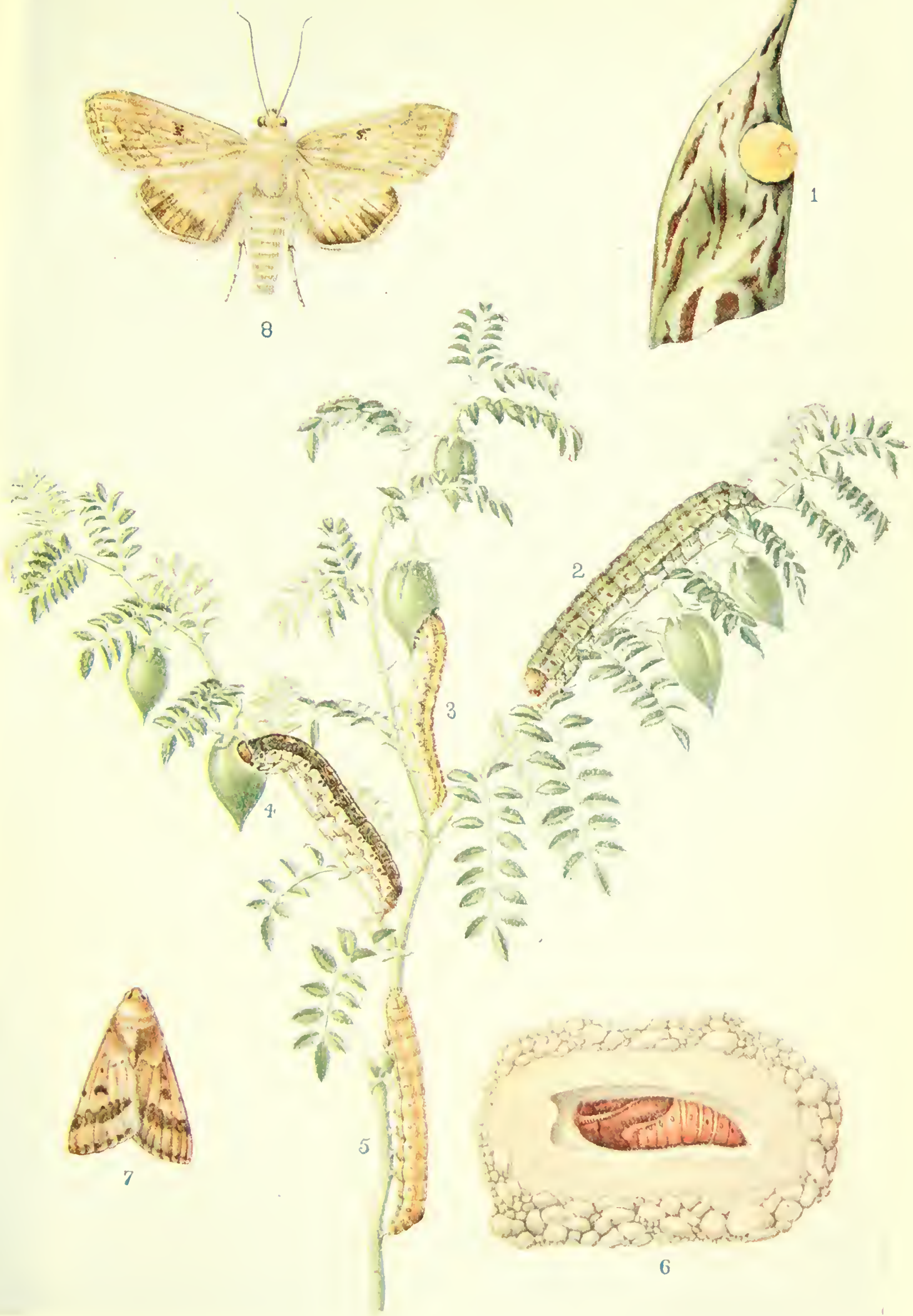






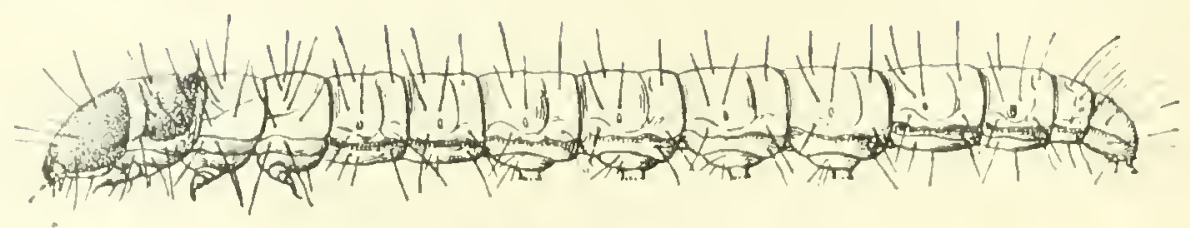

2)

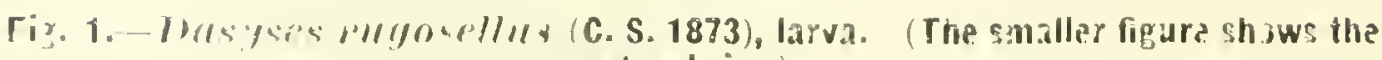
natioral size,

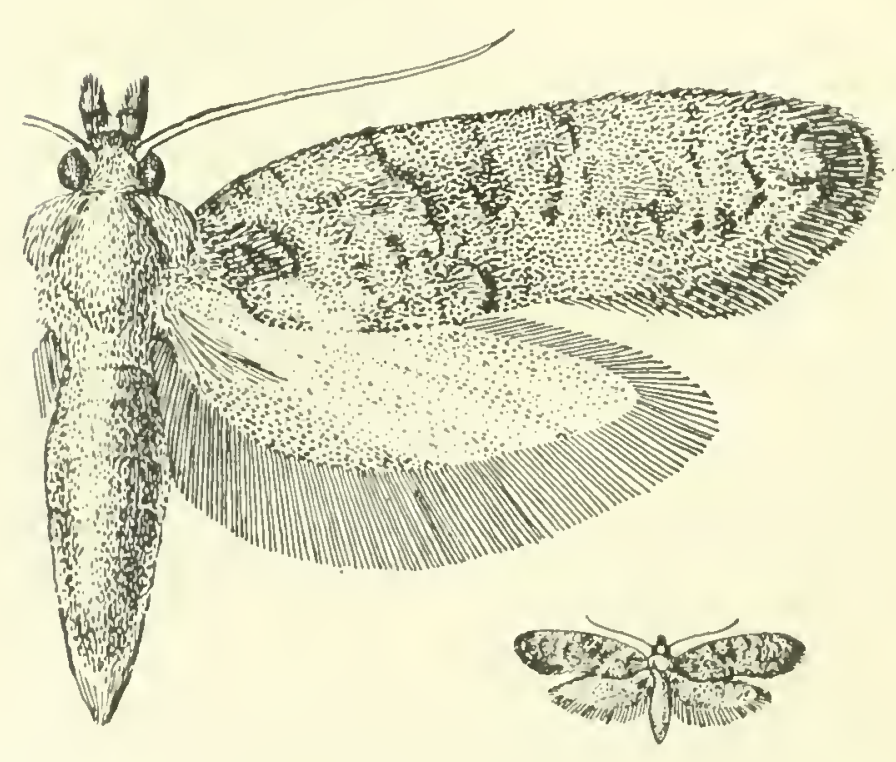

Fig. 2. - Hors!ses mu!josellus, natural size snd magnified $(\times 5)$. 
Dasyses rugosellus (C. S. 1873).

Plate 67.

Food-Lsually decaying vegetable matter.

Caterpillars of this moth were observed to feed gregariously by boring inside sugarcane stems which had been affected by fungal diseases following the attack of borers such as Scirpophuga and Diatrea. They did not infest healthy canes. They exuded a profuse amount of silk with which the pellets of excreta were webbed up into tube-like galleries.

The caterpillars were observed to hibernate from about October to February. Pupation took place in oval silken cocoons covered over with pellets of excreta. Noths emerged in March.

\section{The DAIAGE TO SUGARCANE CAUged BY BORERs.}

Let us commence with the planting of the setts in the ground. The setts are liable to be eaten by termites. A short account of what is being done to prevent this damage has been given when dealing with these insects. When the new shoots appear they are liable to be attacked by Termites, Mole-crickets, Melolonthid grubs and other external agents, as well as by all the interual borers mentioned under this crop. Of the internal borers, however. usually only Scirpophaga spp. and Diatroa auricitia are common at this stage at Pusa, the others occurring in small numbers. The fungal diseases also may appear at this time. The first external symptom of attack by all these destructive agents is " dead heart." The infested shoots are either killed and become entirely dry or continue to be green for some time with their heart-shoot dead and dry. The effect however, is the same in all cases, viz., their further growth is stopped. Except when affected by fungal diseases, all such shoots throw ont new shoots from the base, giving rise to the tillering effect so commonly observed. Many of the new shoots or tillers also are attacked in their turn. 'This struggle between the shoots and their' enemies goes on and only those of the shoots which escape being attacked continue to grow. Those which have grown somewhat and formed stems (canes) become immune against some of the enemies but their growth may be stopped at a later stage, as they lemain liable throughout their life to be bored at the top by Scirpophaga spp., in the stem by the species of Diatrac, Sesamia and Chilo, and at the roots by Termites and Emmalocera. E. depressella itself cannot kill a grown-up cane but the funga' diseases, to which its tumel aftords access, do the work for it. Termites may kill a grown-up plant and, even when they merely 
gnaw the surface and do not kill it themselves, fungal diseases follow. When fungal diseases affeet the base of the stem usually the entire eane dries up. The borers in the grown cane itself, observed at Pusa in the course of the last two seasons, did not prove to be serious. They are the same which infest the young shoots. They do not however ocenr in large numbers in individual plants and one or two eaterpillar's in the stem of a grown-iup plant are not able to kill it or retard its growth seriously, although a single larva is sufficient to kill a young shoot. Besicles, they seem to prefer young shoots to grown-np canes and, as there are plenty of young shoots always in the field, the majority of the grown canes eseape being attacked. The tunnel of the borers in the stem always opens externally and,affords aecess to fungal diseases, which in extreme cases may cause the upper part of the eane to dry up. The effect of fungal diseases in grown canes is observed to be slow. Sometimes the tumnel of the borers may run aeross the stem in such a manner as to eause it to break at that point or to stop further growth above it. When growth stops in this manner vigorous plants put forth side shoots (Pl. 68, f. $1 a, c, d$ ). The effect of attack at the top by Scripophaga caterpillars is always to stop further growth and the plants may either wither from the top downwards or put forth side-shoots (fig. 2 and fig. 1 b). No other borer attacks grown eanes at the top.

The planting of cane is usually done about February and the greatest injury to the erop is caused by the borers in the young stage and up to about July. By this time some plants are grown and become partly immune, the harvest being obtained principally from these plants. As will appear from records of actual observations given below of two varieties of thick eanes, viz., Purple Mauritius and Sathi No. 131, on the average, out of every four shoots which grow only one eomes to be harvested, the other three being killed at various stages of growth, mainly by the injurious aetivities of insects and fungal diseases. All thick varieties seem to be liable to a similar amount of damage. Thin varieties are however more resistant. A rongh idea of the comparative immunity of thick and thin varieties may be formed from column 6 in Table $V$ giving the number of harvestable canes out of every 100 setts planted.

\section{The experiments of $191 \%$.}

In November 1916 a plot $\frac{1}{4}$ acre in area in Chaunia field at Pusa was planted with Purple Mauritius. In Table I, the percentage of affected plants, inchding dry ones as well as those with "dead heart," and the proportion of the agents of damage are shown. 

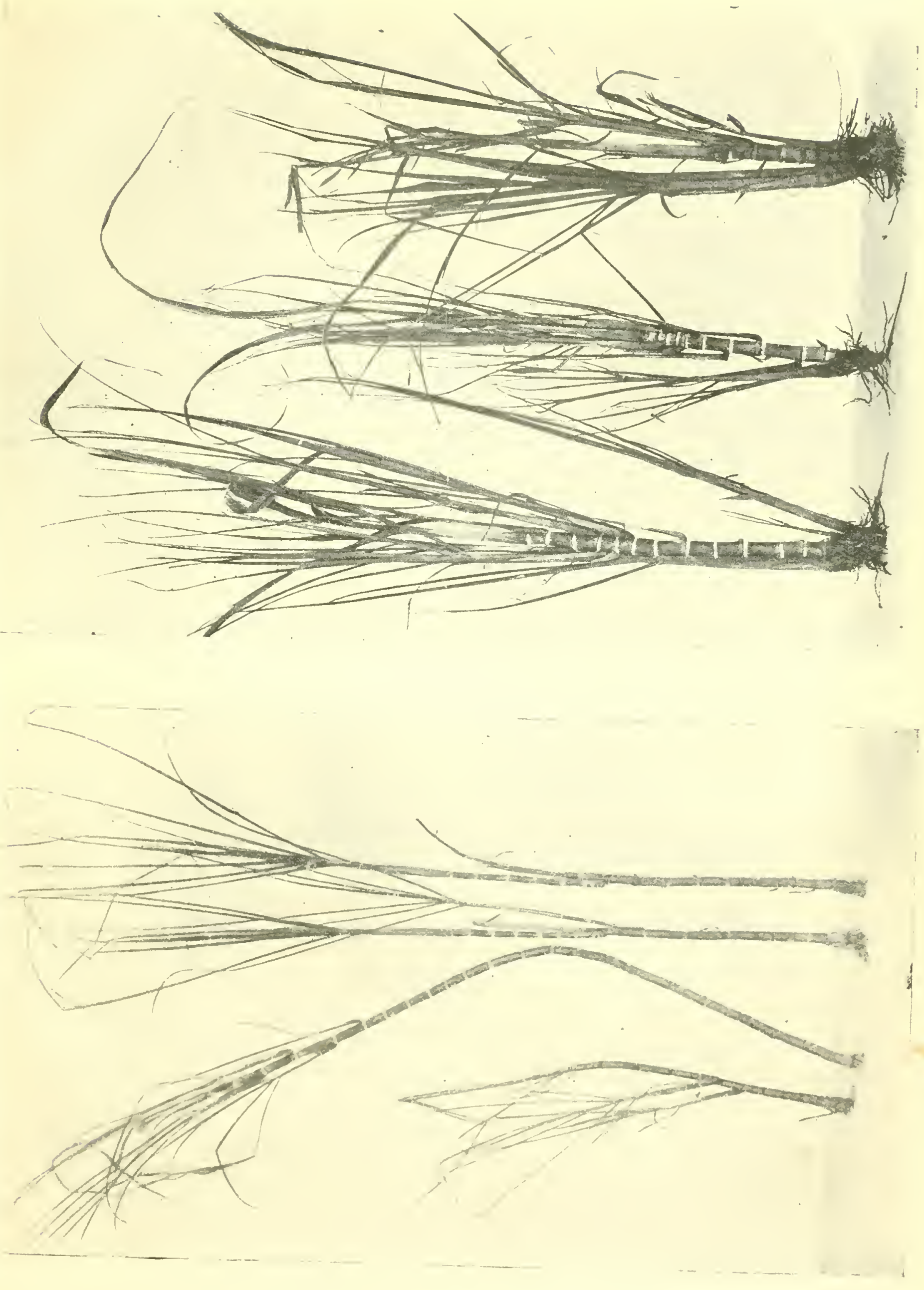

PROCEEDIYGS OF THE TIIRD ENTOMOLOGICAL MEETING

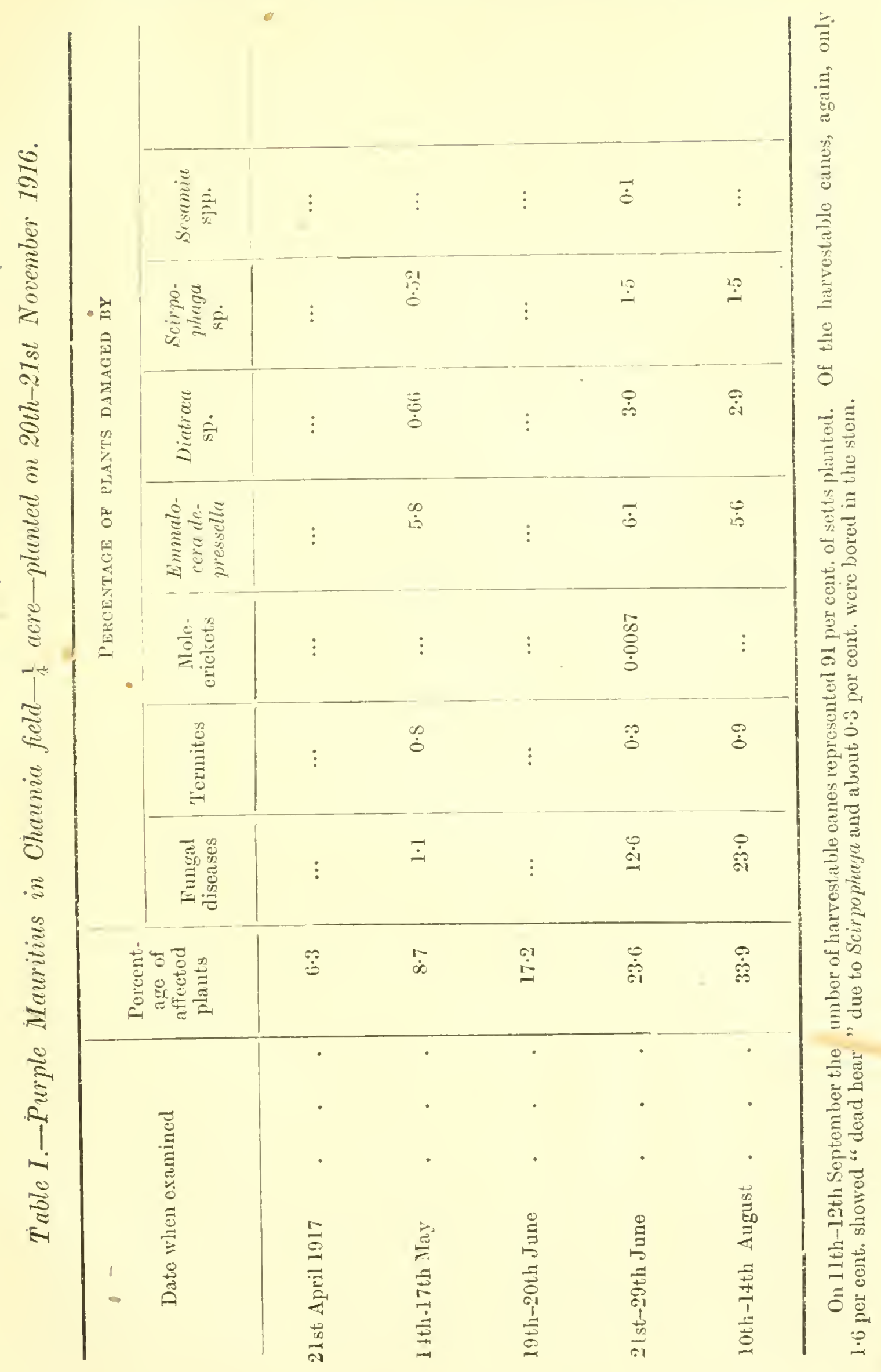


398 PROCEDNTGS OF THE THIRD ENTOMOLOGICAL MEETING

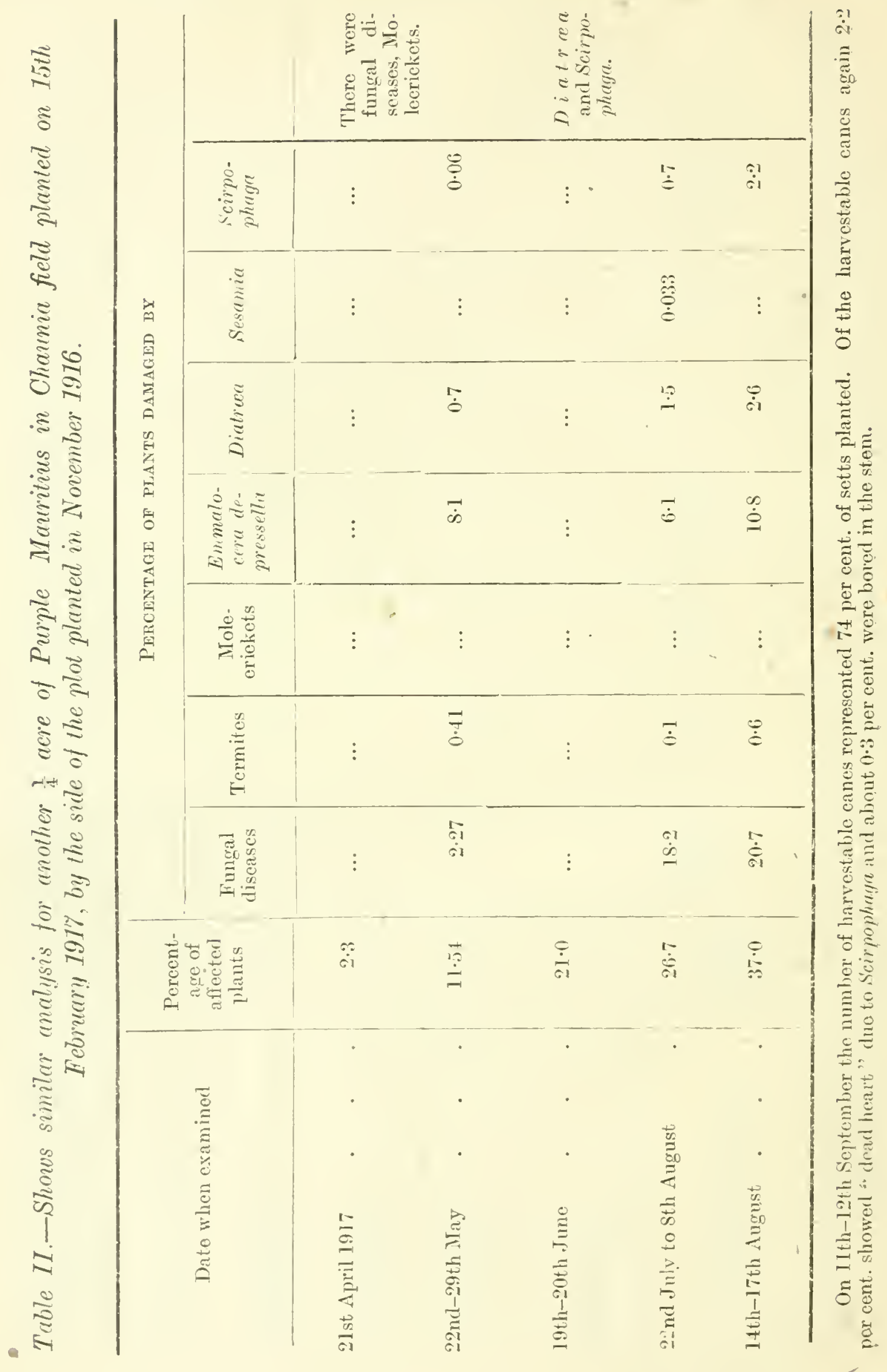


PROCHEDINGS OF THE THIRD ENTOMOLOGICAL NEETING 399

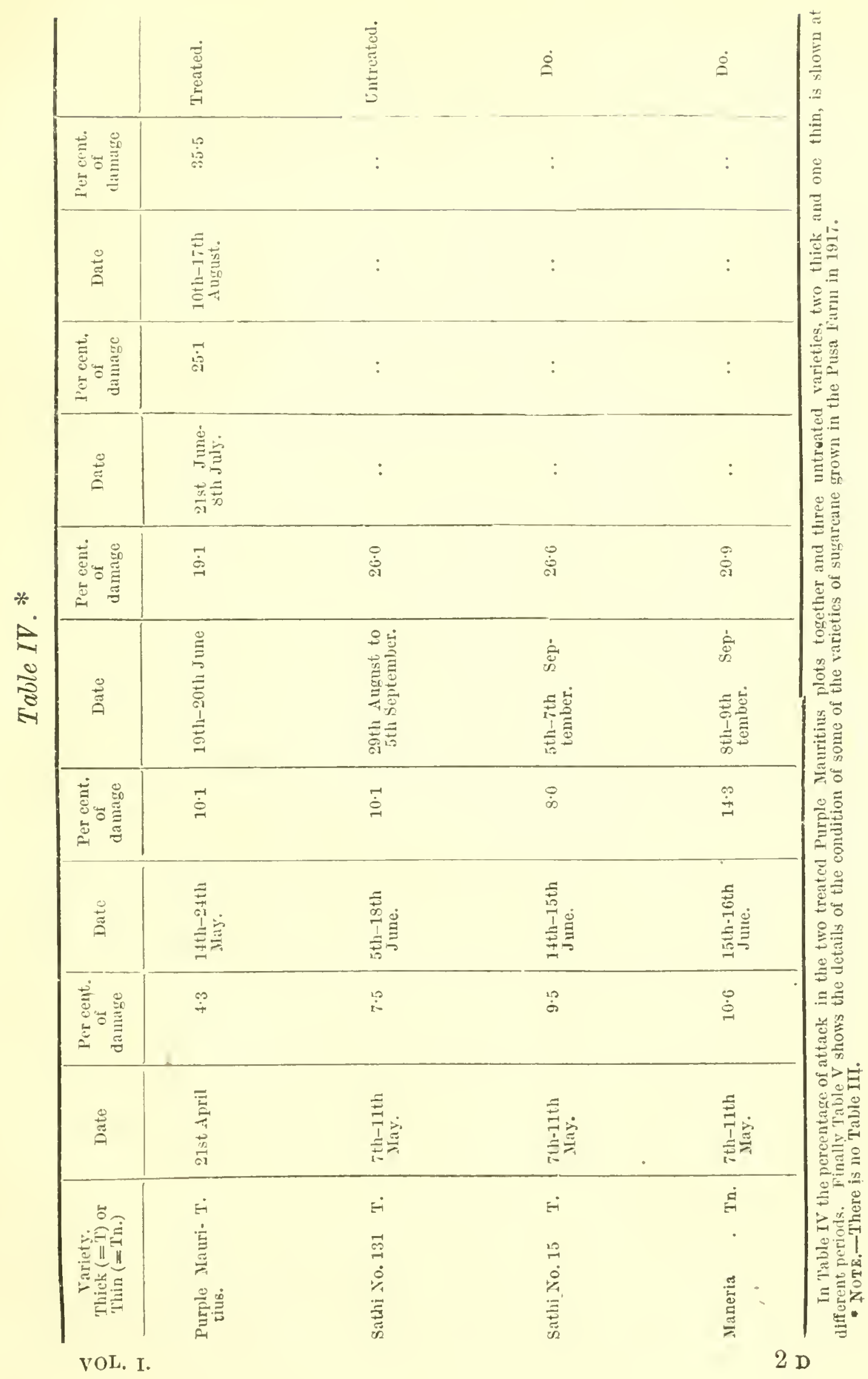




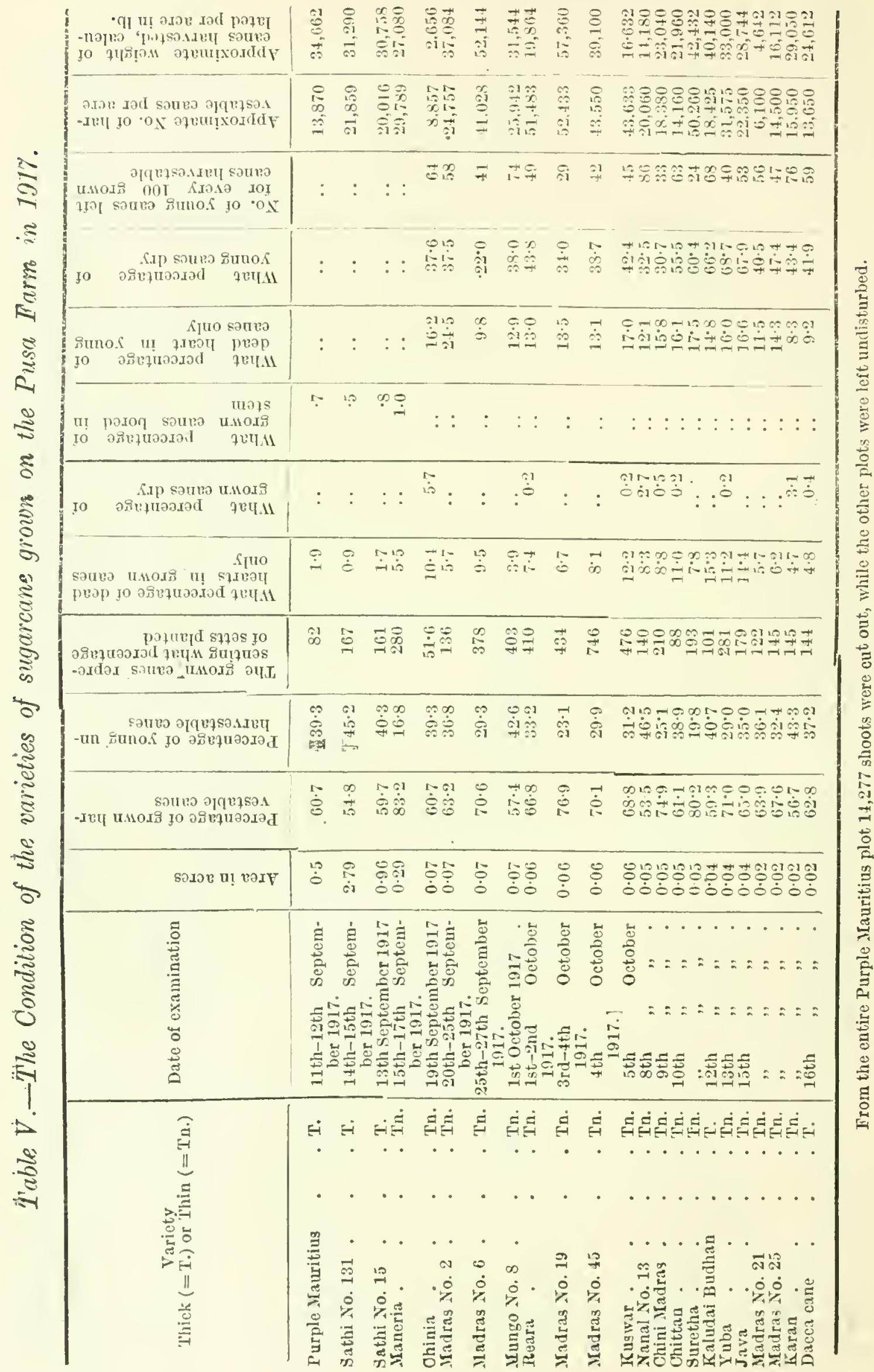


Proceedisg OF THE THIRD ENTOMOLOGICAL MeEtixg 401

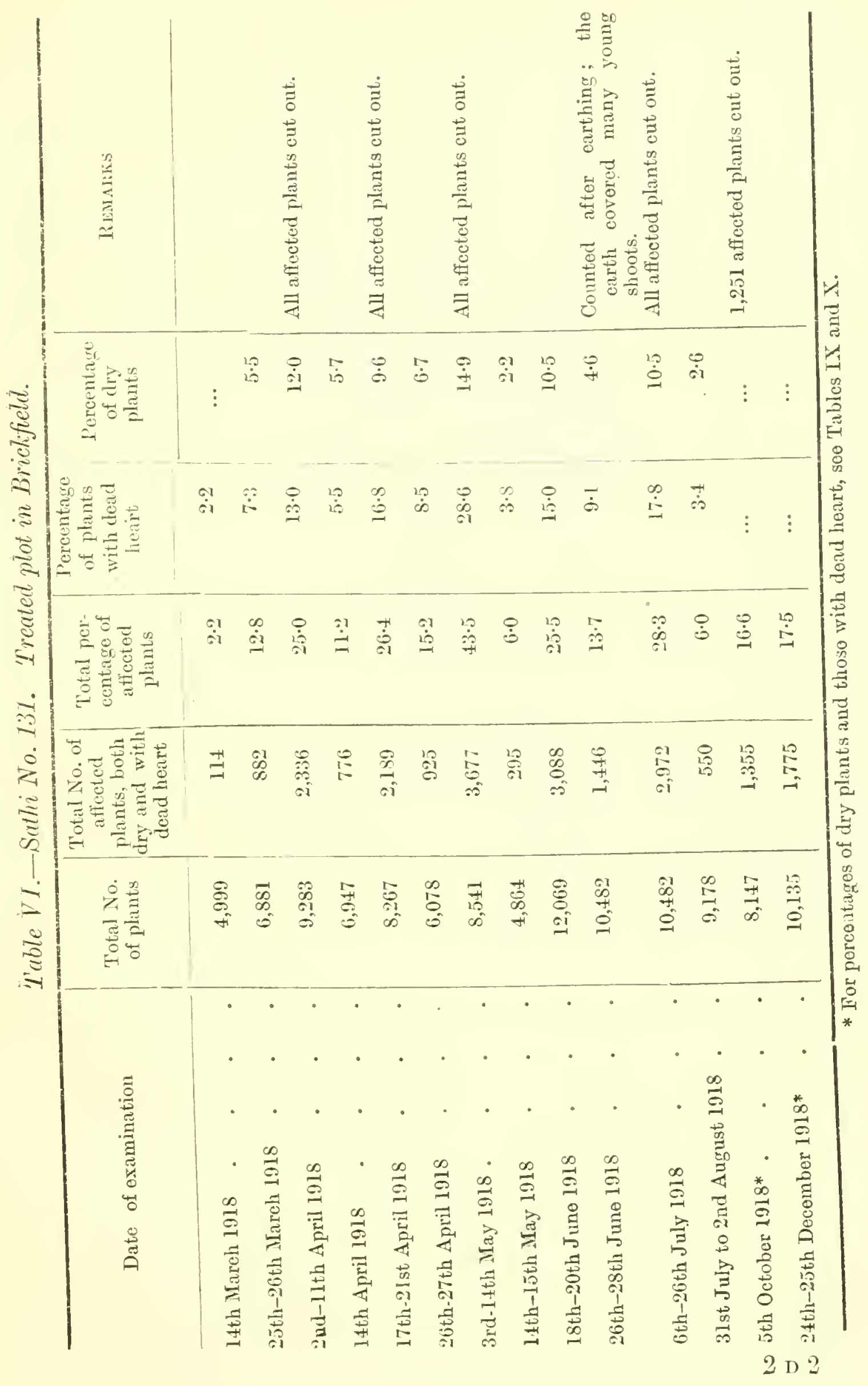


LOE PROCEEDIFGS OF THE THIRD ENTOMOLOGICAI MEETING

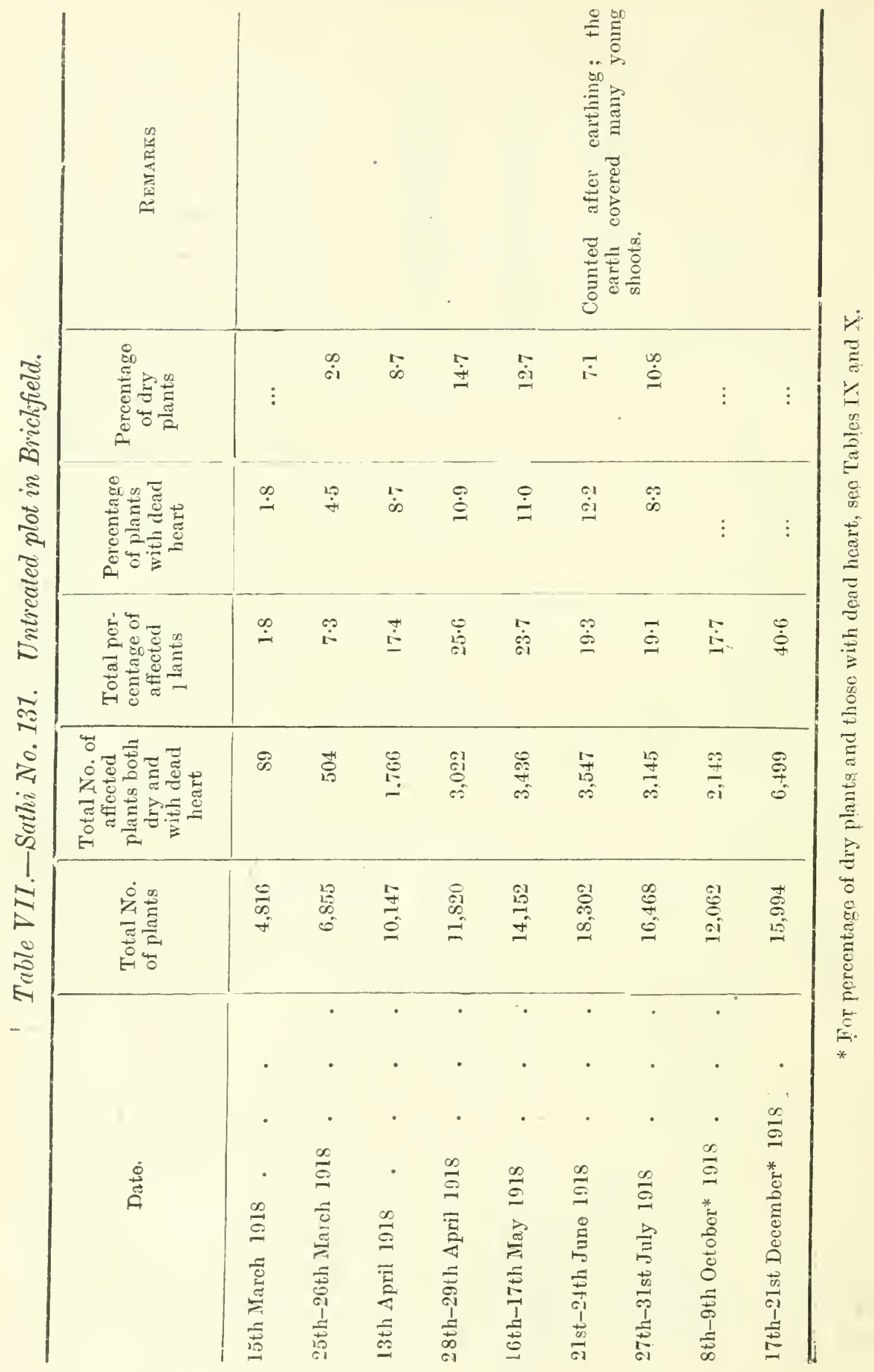


PliOCEEDIXGS OF TIE THIRD IXTOMOLOGICAL MEETING

403

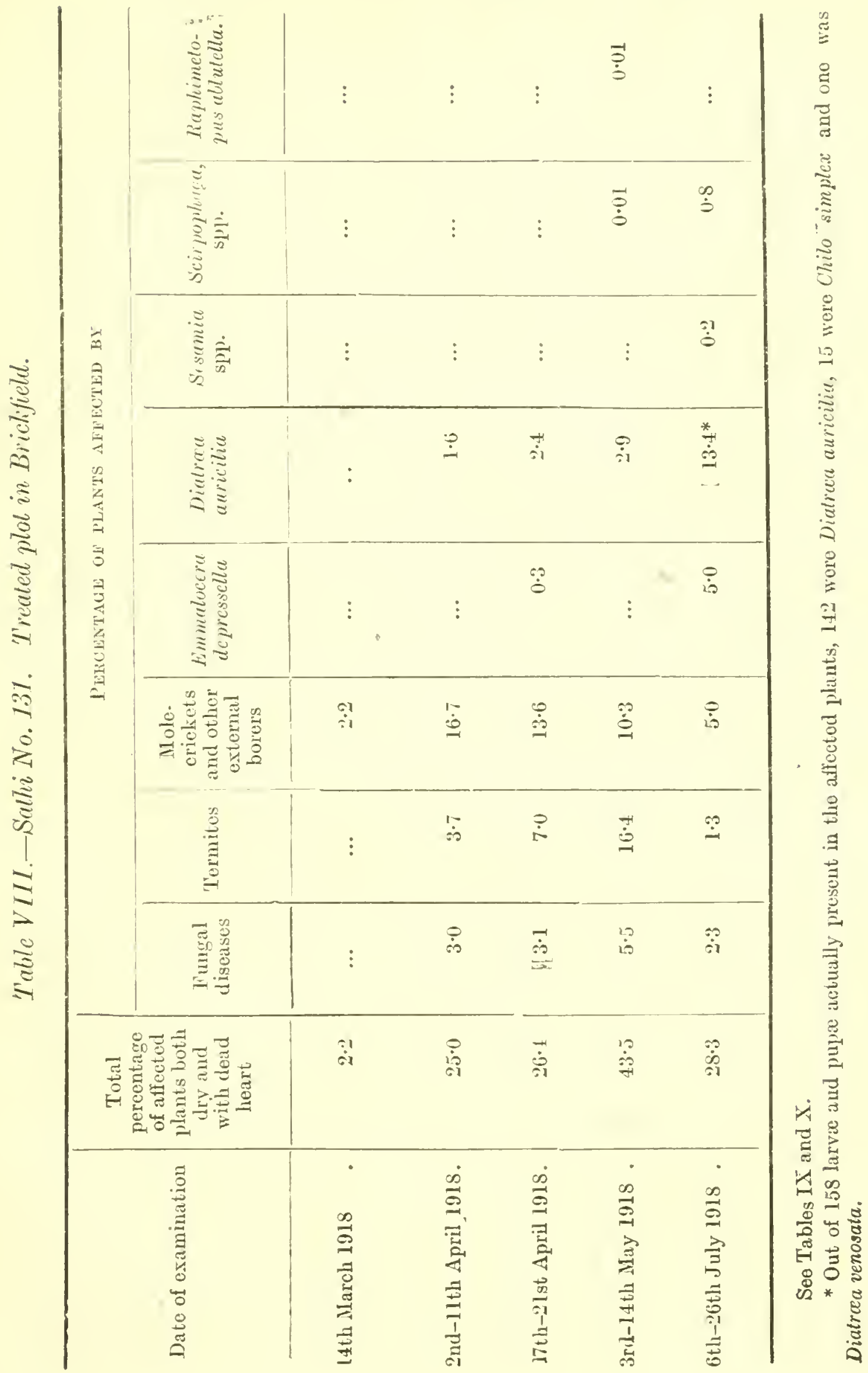




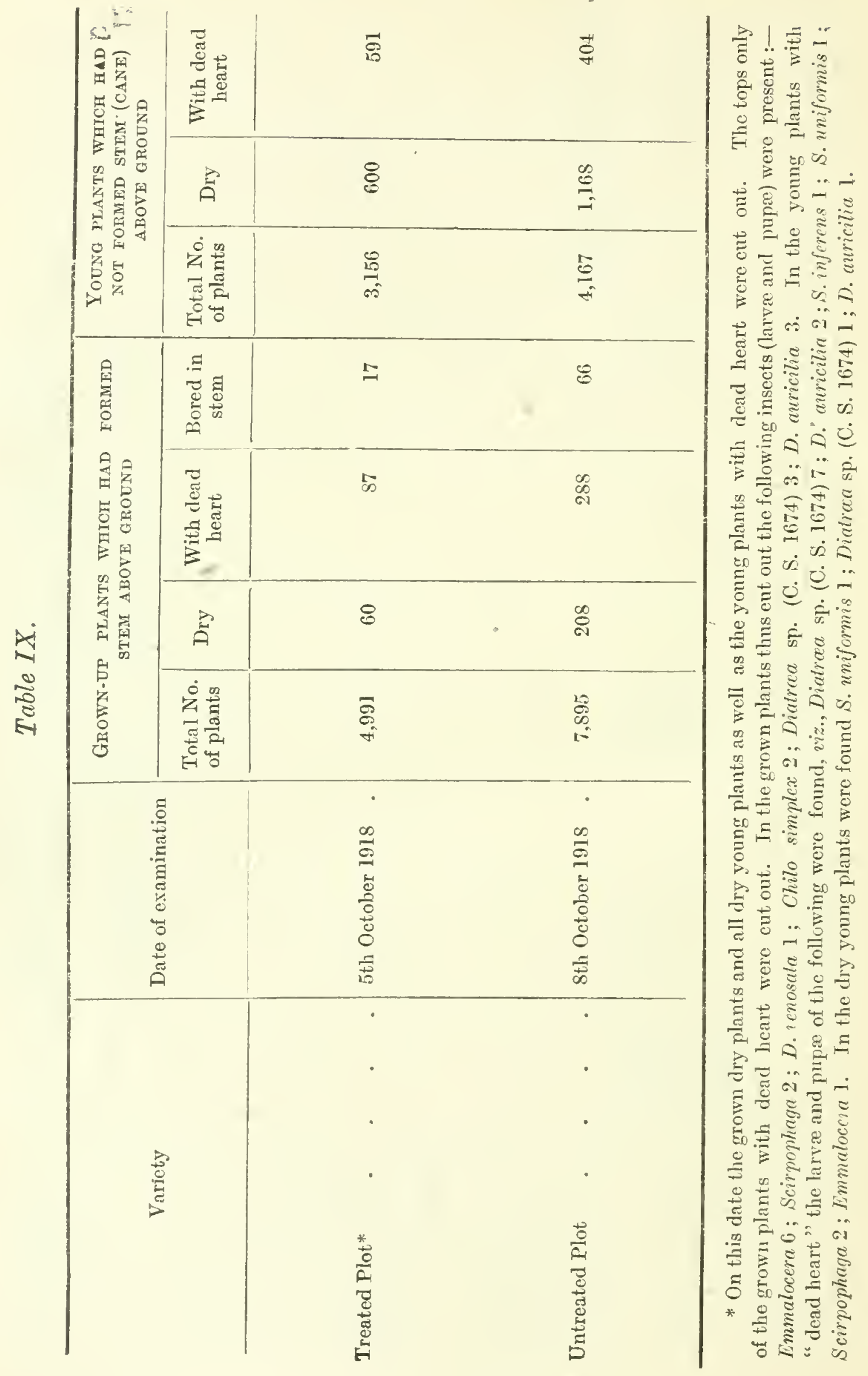


PROCEEDINGS OF THE THIRD FNTOMOLOGICAI, MEETING

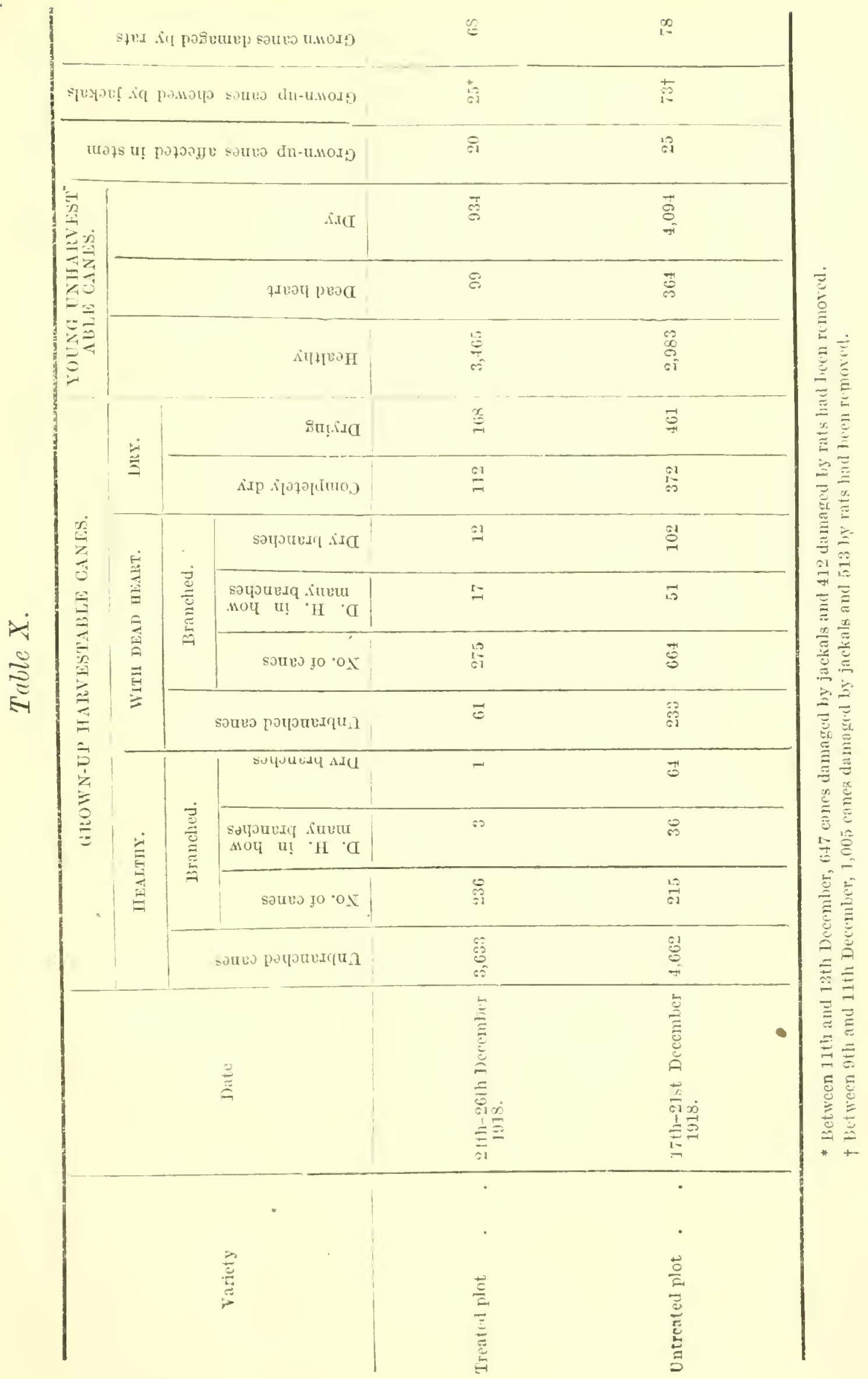




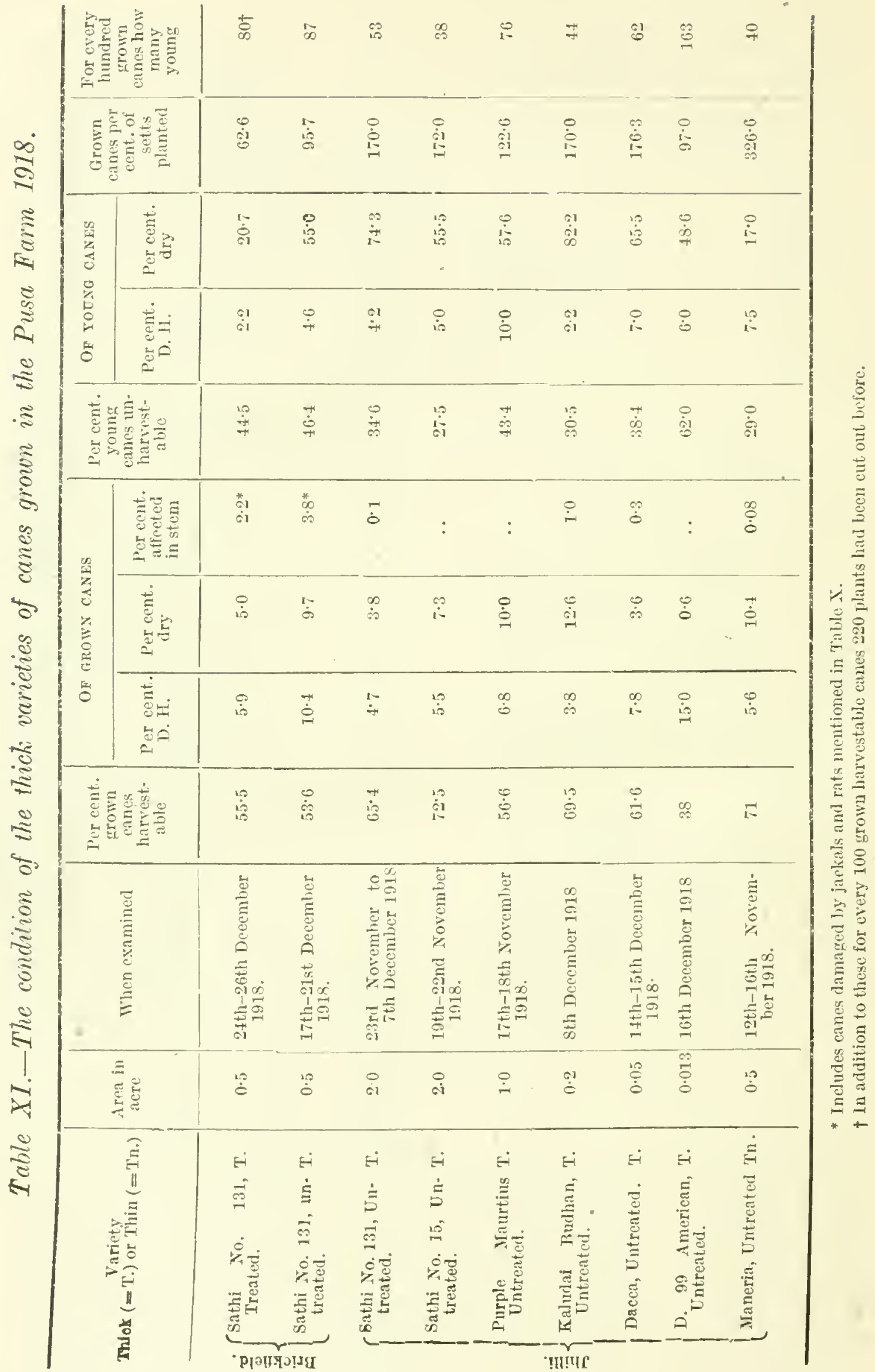


As regards growth. in the middle of April 1917. the plants in the plot planted in Norember 1.916 were slightly ahead of those of the plot planted in February. But the difference in arowth did not indicate a difference of four months in planting. The difference disappeared by May. As regards yield the plot planted in November was better than that planted in February. This result, however, cannot be depended upon as conclusive.

From the two plots of Purple Mannitins all the affected plants examined on the different dates given in Tables I and II were cut out with the insects. No other plot was similarly treated.

\section{The Experimen's of 1918 .}

In Febnary 1918 two half-acre plots of Sathi No. 131 were planted, one for treatment by cutting ont and removing plants and shoots which were dry or showed "dead heart" together with the insects found in them, and the other to be left untreated as a check. The two plots were in an area known as the Brickfield at some distance from the main sngarcane area of the Farm in Jhilli. They were practically similar as regards soil and were not contignous. having abont half-an-acre of indigo between them. This field was previonsly a piece of wasteland overgrown with Sacharum spontenem and Imperala amminacea and was even now bordered by similar wastelands on the west side, as will appear from the plan. The setts, abont a foot in length, were examined by the Entomological and Mycological Asistants against borers and Red Rot. For the treated plot the setts were dipped in lead arsenate solution (1lb. of Thompson Chemical Co.'s to per cent. lead arsenate in 2 gallons cold water) and dried in the shade before being planted, jlbs. lead arsenate being used for about 9.000 setts.

The setts were planted in furrows made with a plongh and, before the furrows were filled up with the harrow, powdered oilcake was sprinkled in them. Both the plots were weeded in the third week of June, pow lered oilcake was sprinkled near the base of the plants and their bases earthed up by driving a ridging plough between the rows of plants. No further cultivation was given to either of the plots. As usual with the cultivation of sugarcane at Pusa no irrigation was given. Between the 7th and 13th Angust both the plots were submerged in water, the water standing a few inches above the ground. The water was pumped ont by the 13th and 14th Angust but the furrows between the rows of sugarcanes remained fu!l and the soil did not dry or become fit to be walked on before the middle of September.

Both the plots were examined on various dates, the actual number of plants and those with "dead heart" or dry being noted, and the 
affected plants in the treated plot being cut out at intervals. The results of examination are given in Tables VI to $X$. The work of the different agents of damage is shown in Table VIII. In Table XI are shown the final results of the two plots and also the results of examination of the thick varieties of sugarcane grown by the Farm in Jhilli.

As has been indicated in the plan, portions of both the plots adjoining the wasteland became bare. This was practically due to termites which ate the setts as well as the new shoots. The figures in Table VIII relate only to the shoots which grew and were then attacked and not to the setts which were eaten underground by the termites. The crop was obtained only from the shaded portion of each plot as indicated in the plan, which in the case of the treated plot was about 13,544 sq. feet and in that of the untreated plot about 18,281 sq. feet. In calculating the harvested result given in Table XI the entire plots including the bare parts have been taken into consideration. (See Plate 69.)

If we exclude the bare portion of each plot and calculate on the approximate number of setts which covered only the shaded parts which yielded the harvest, the number of canes which came to harvestable stage represents 111 per cent. of setts in the treated and 116 per cent. of setts in the untreated plot. The weight of canes harvested was $6,550 \mathrm{lb}$. in the treated and $11,440 \mathrm{lb}$. in the untreated plot. Taking only the shaded portions of both the plots into consideration the yield worked out at $21,066 \mathrm{lb}$. per acre in the treated and $27,259 \mathrm{lb}$. per acre in the untreated plot.

Therefore, we see that the cutting out treatment, instead of helping the crop, actually does some harm to it. The same effect was observed in the 1917 experiment with Purple Mauritius. The yield of the treated plot of Purple Mauritius given in column 6 of Table V may be compared with the yield of the same cane in 1918 given in Table XI. The reason of the inefficacy of the treatment is obvions. "Dead heart" in young canes is caused by various agents which are not removed simply by the removal of the shoots with " dead heart." Scirpophaga is the only insect which is likely to be removed if the shoot is cut before the moth emerges. Dialraca and other internal borers usually live so far down the base of the new shoots that the majority of them are left behind unless the shoot is cut near its point of growth from the sett. In order to counteract the evil effects of borer attack the quicker and more the tillering the better. The cutting-ont treatment interferes with tillering, as invariably some of the new side shoots, which begin to grow from the affected ones, are either injured or remored in the operation. Therefore the treatment causes a set-back to the crop 


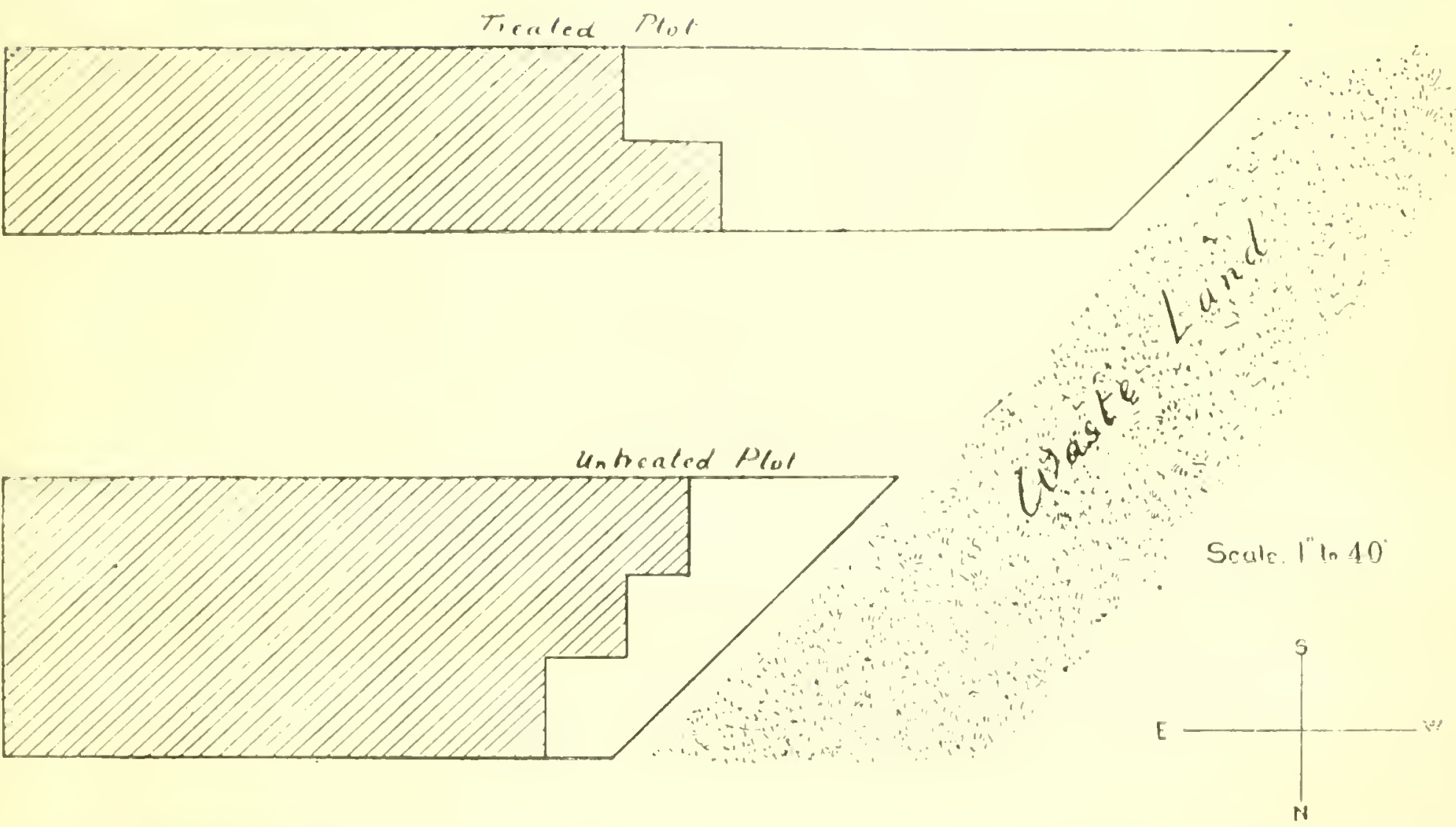

Plan of the two experimental plois of Sintlli No. 131 Sugarcane in Brickfield arca in Pusa Farm. The crop was obtaineul from the shaded portions. The unshaded portions became barc. Scale should read 1 " to $80^{\prime}$. 

It is better to let the crop grow undisturbed, especially in its earlier stage:

But the borers are there and they cause a serious loss. As has been pointed out already, out of every four shoots only one is allowed to come to the harvesting stage, the other three being killed prineipally by the borers. Even when the plants are allowed to grow, in many of them branching is brcught about by their injurious activities at the expense of glowth. Ihe idcal cor diticn would be to allow the first shoots to grow. Mr. M. L. Kulliani in his paper read at the Science Congress, 1918, and reprinted in Agrict. Jcurnal of India (Special Se. Congrcss No., 1£1ל) on experiments in planting sugarcane setts, gives a thotograph of a very thick unifomly grown crop, raised from setts with single eyekuds and planted with the bud upwards. The tillers were not allowed to grow. At Yusa and probably in most places the borers make such a crop impossible. On account of the borers and other agents of damage the return ficm the outlay in the cultivation of sugarcane, especially the thick varicties, is less than 50 per cent. of what it ought to be.

\section{Damage to Rice by Borers.}

In the neighbourhood of Pusa various kinds of rice are grown according to the nature of the lands.

The earliest rice to be somn is locally known as Desaria which is gromn in deep chaurs: i.c., kw marky laces which allow water to accumulate to a depth of about 10 or 12 feet or more. The seeds are sown in seedbcds abcut February and the secdlings transplanted into the chaw's as soon as water begins to collect in them. The harvesting is done along with winter paddy in November-December.

The sccond kind of rice may be broadly called Aus or, as locally named, Bhadai. It includes various rarieties, some being broadeasted and others transplanted. For the transplanted rarieties the seed is sown in sech-beds about March, the transplanting being done as early as possible in May or June. The broadcasted varicties arc usually sown about Nay-june and generally on slightly higher lands. The harvesting is done about September.

The third kind is Aman or winter paday, which also includes broadcasted and transplanted varieties and which is grown both in chaurs with shallow water and in higher places. For the transplanted varieties seeds are sown in seed-beds about April-May and transplanted about July. For the broadcasted varieties the sects are sown about MayJune. About four-fifths or more of the rice-growing tracts in the neighbourhood of Pusa grow Aman paddy. 
There has been no opportunity of examining Desaria paddy. Both Aus and Aman varieties were kept under observation in different fields a short description of which is given below.

Dhougamma chaur is about 400 acres in area. About 100 acres in the middle remains permanently under water. land.

Harpur chaur, about 250 acres in the area, is a somewhat marshy

Guzarmalla, a high land, is about 30 acres in area.

Deopar Gonhri, a high land, is about 40 acres in area.

Jhilli, a high land, is about 60 acres in area.

Sweeper's' plot, consisting of about one or two acres in area, is in the trenching ground within the Pusa Estate.

The method of examination was as follows: Plots 5 yards $\times 5$ yards were marked out at different places in the fields and the plants which showed "dead heart" or were dry within this area were comnted. In order to get an approximate number of the plants growing within 5 yards $\times 5$ yards, the plants within an area of 1 yard $\times 1$ yard anywhere within the $5 \times 5$ area were counted. Plants standing in water as well as in dry ground were selected for examination. The results of examination of the plants at various periods of their growth are given in Table XII. The amount of damage in the different plots and in the different fields varied, it being more in some and less in others. Table XII gives an idea of average damage over large tracts. The damage hardly exceeds about 4 per cent.*

The results of the examination of stubbles in five of the fields mentioned above, excepting Dhougamma and Harpur chaurs, are given in Table XIII.

From the stubbles which showed signs of borer attack the percentage of damage was calculated to vary from 14 to 55 in the various countings and to be about 29 on the average. This pereentage would indicate the proportion of chaff in the harvested grain. Actually, however, as will appear from Table XII, giving results of the examination of growing rice, the damage at no period of the growth of the plants exceeded about 4 per cent. and usually it was much less than 2 per cent. All the four principal borers, viz., S. inferens, Chilo simplex, Rice Chilo and Schonobius bipunctifer, appear on a large seale in October-November when the plants put forth ears. At this time a large number of young larva of all these borers is found in individual plants, the maximum number

\footnotetext{
* It must be pointed out that this figure represents the state of affairs only in a small distriet in North Bihar. In other parts of India the damage is ecrtainly much greater. In Madras, for example, the average loss may be taken as ten per cent., representing a money value of approximately one hundred millions of rupees every year in this Presidency alone.
} 
IROCEHDINGS OF THE THIRD ENTOMOLOGICAT, MEETIXG 41]

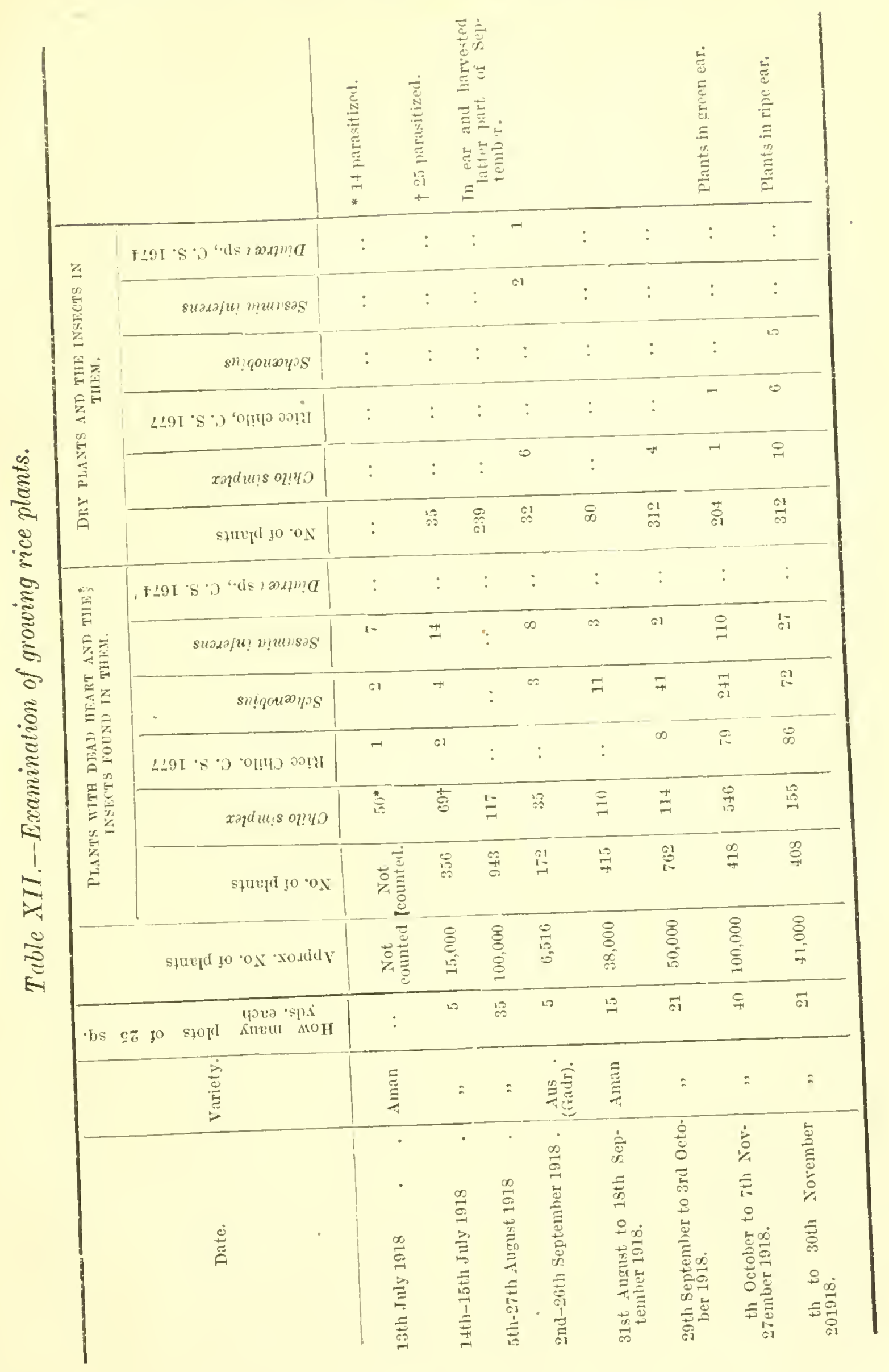




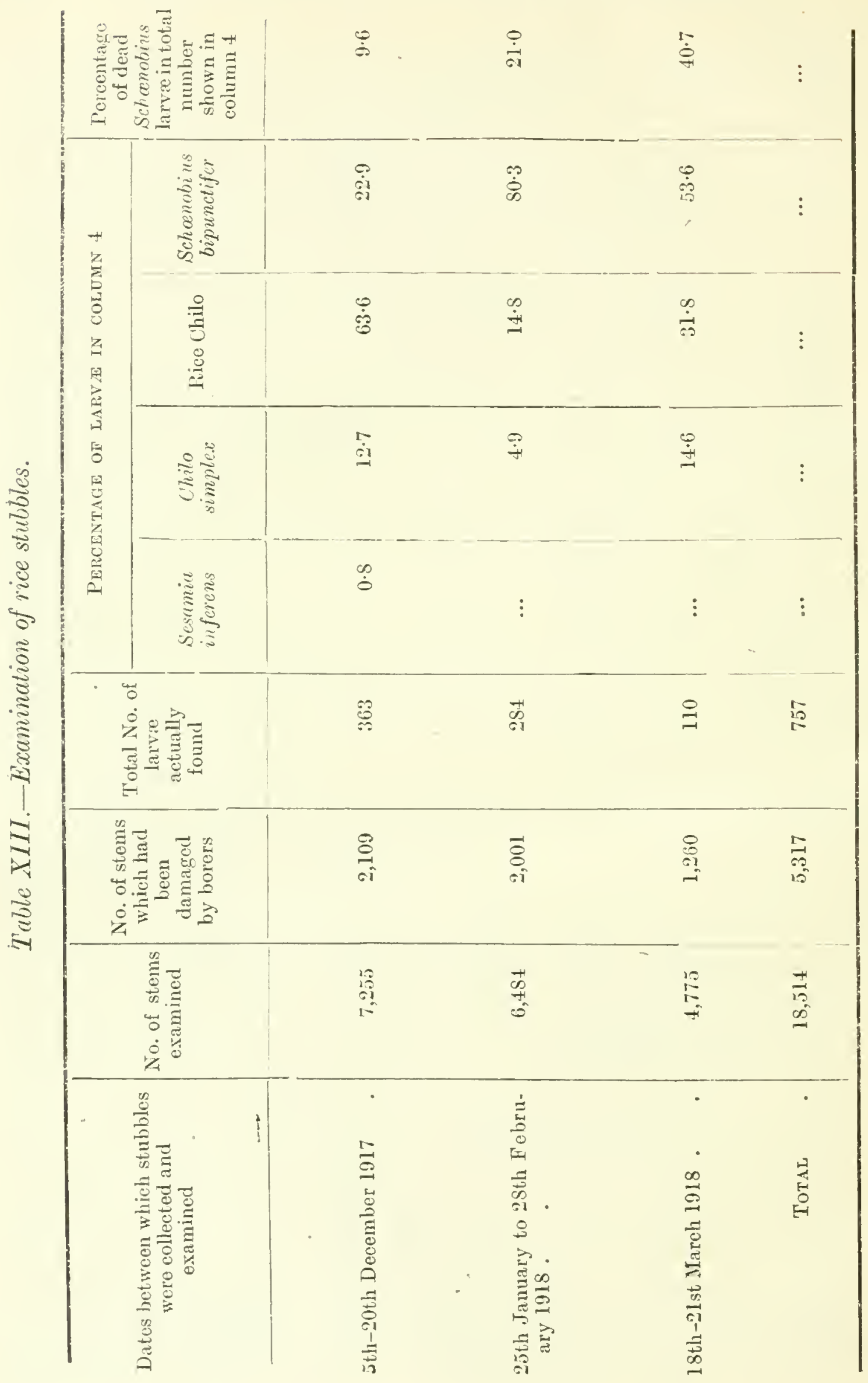


IROCkLDINGS OF TILE TIIRD ENTOMOLOGICAL MEETING

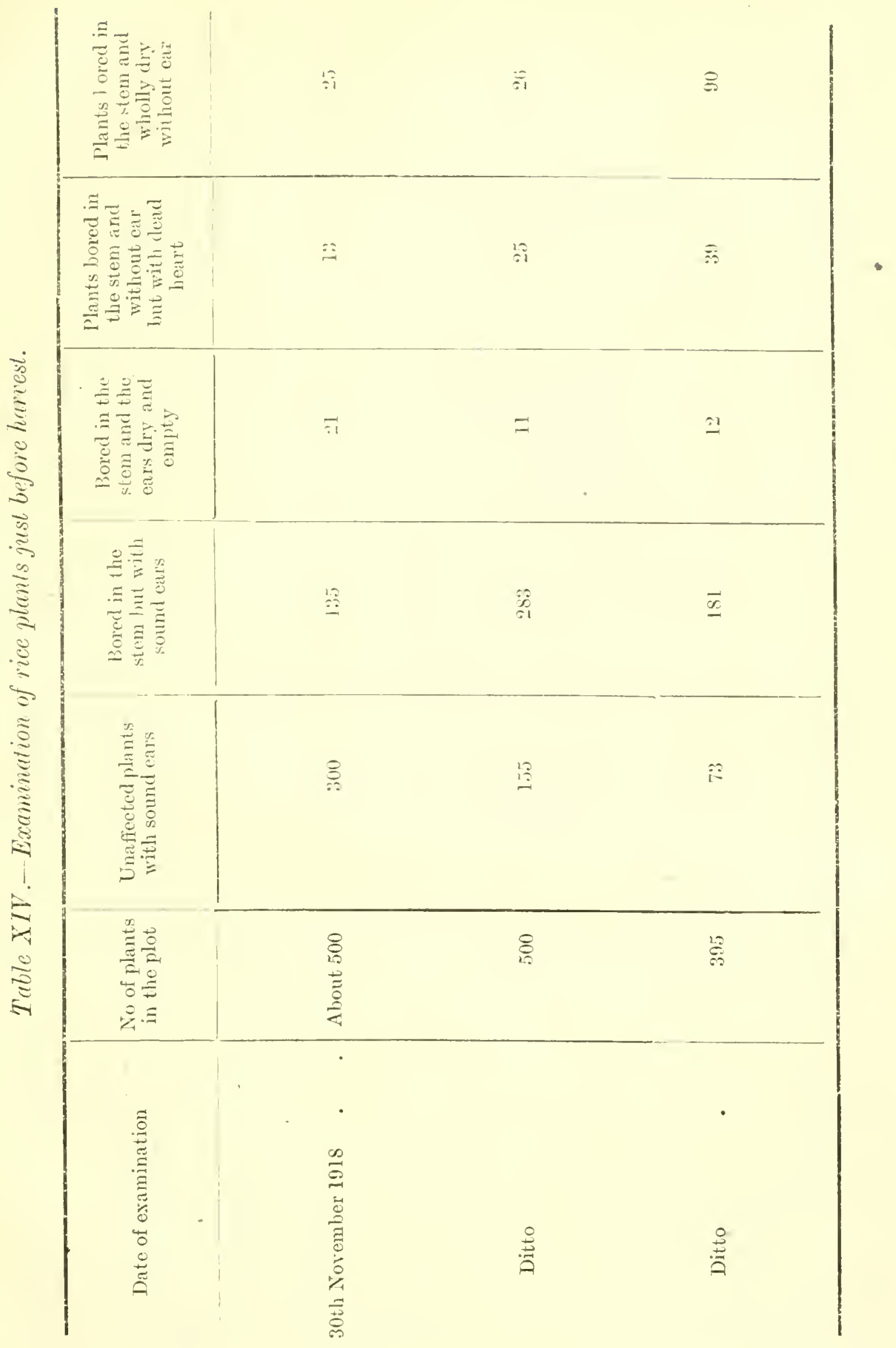


actually found being as many as 72. These young caterpillars spread after a short time and go into other plants; but by that time the grains are formed and developed so that although many plants are bored they are observed to have sound ears. Three $2 \frac{1}{2}$ yards $\times 2 \frac{1}{2}$ yards plots were selected at random at Bhoraha which showed a bad attack, just before harrest, and the results of the examination are given in Table XIV. The plants in columns 6 and 7 of this Table must have been attacked before the crop came into ear and many of them were young undeveloped shoots the tillers of which developed and bore ears. As will appear from this Table, no correct idea can be formed of the actual damage by the borers from an examination of the stubbles.

The presence of a large number of hibernating larva, at least of some species. in the stubbles of a field does not seem to affect the crop in the next year. In September 1917 large numbers of Rice Chilo caterpillars were obtained in the sweepers' plot within the Estate. In 1918 there was hardly any Rice Chilo in this plot.

\section{DAMAGE TO Juar (Andropogon sorghum) BY BoRERS.}

In the young state juar is very liable to be affected by Muscid fies and throughout its grown-up state by the other borers mentioned under it. Chilo simplex and Diatraca venosata are however, the most injurious. Both these borers hibernate in large numbers in juar stalks, individual stalks harbouring as many as twenty or even more hibermating larvæ.

Twenty-five varieties of juar were grown in small plots (one-fortieth of an acre) in the permanent experimental area of the Pusa Farm in 1918. The result of examination of them in the first week of November is given in Table $\mathrm{XV}$.

Table XV.-The varieties of Juar in small plots were side by side in the Punjab experimental area excepting No. 25, Dura, which was at some distance.

\begin{tabular}{|c|c|c|c|c|c|c|c|}
\hline \multirow[b]{2}{*}{$\begin{array}{l}\text { Serial } \\
\text { No. }\end{array}$} & \multirow[b]{2}{*}{$\begin{array}{l}\text { Farin } \\
\text { No. }\end{array}$} & \multirow{2}{*}{\multicolumn{2}{|c|}{ Variety }} & & \multicolumn{2}{|c|}{$\begin{array}{c}\text { COUNTEN 6TH NOT- } \\
\text { EMBER } 1918\end{array}$} & \multirow{2}{*}{$\begin{array}{l}\text { Insects found in two affected } \\
\text { plants brought for cxamination }\end{array}$} \\
\hline & & & & & $\begin{array}{l}\text { Total No. } \\
\text { of plants } \\
\text { in the } \\
\text { plot }\end{array}$ & $\begin{array}{l}\text { No. of } \\
\text { affected } \\
\text { plants }\end{array}$ & \\
\hline 1 & $1 \mathrm{IB}$ & Emphic juar & - & - & 777 & 11 & 3 J. venosatu larve. \\
\hline \multirow[t]{2}{*}{2} & $2 \mathrm{~A}$ & Nilva juar. & . & . & 911 & 10 & 1 Chilo simplex larva. \\
\hline & 213 & Utavali juar & . & . & 832 & 8 & $\begin{array}{l}\text { No living larva or grub or pura } \\
\text { ease. }\end{array}$ \\
\hline 4 & $3 A$ & Sundhia juar & - & - & 847 & 13 & 3 Chilo simplex larva \\
\hline
\end{tabular}


Tablo XV.-The varieties of Juar in small plots were side by side in the Punjab experimental area excepting No. 25, Dura, which was at some distance-contd.

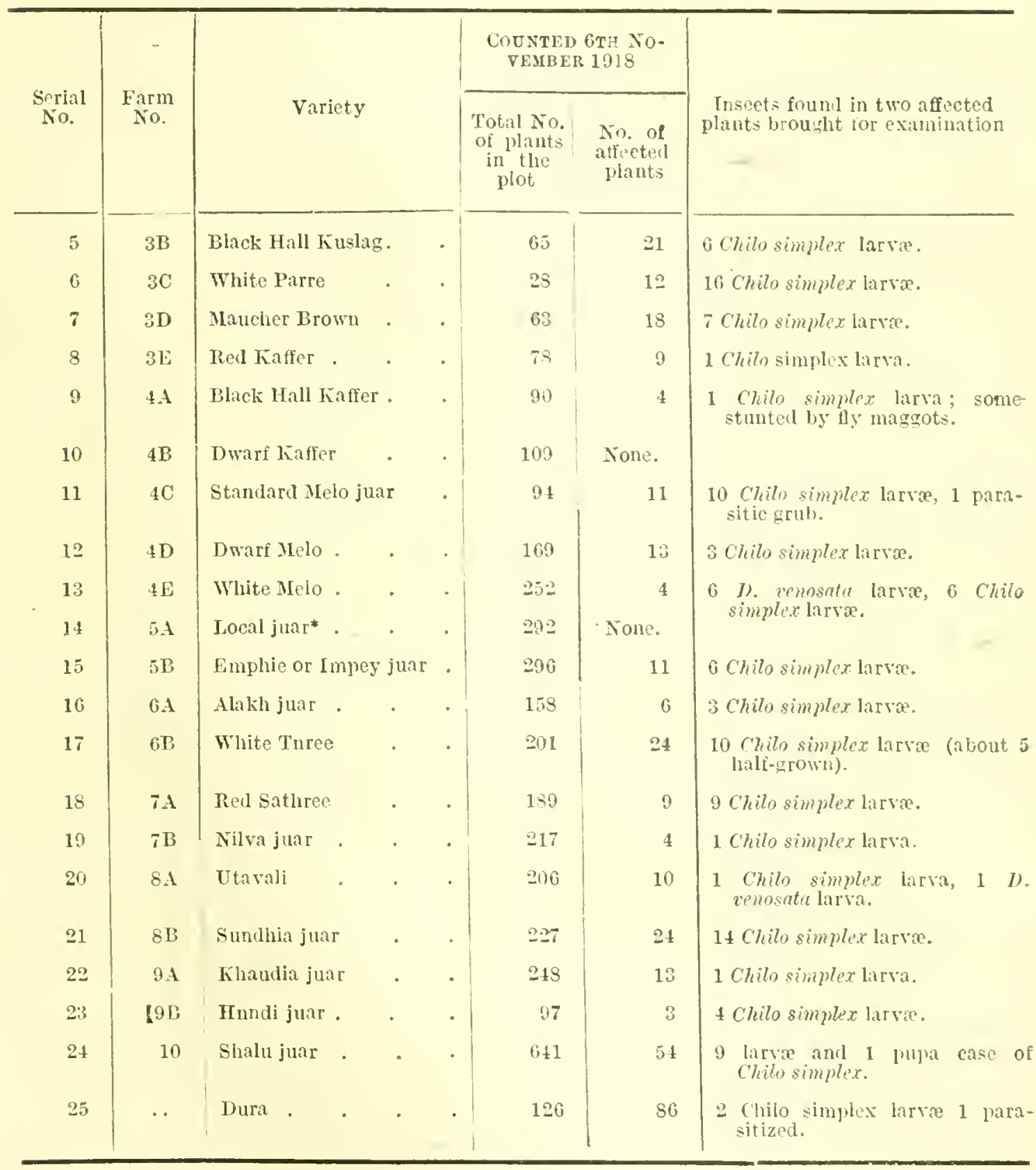

By "affected" plants are meant those only which showed signs of being bored by borers. Two affected plants from each plot were brought and examined to see what the borers were. The borer larve found were all grown-up.

With regard to local juar, in 1917 up to about May there was a large area grown as a rabi crop in Jhilli and it was entirely free from borers, although there were large numbers of Chilo simplex and Sesamia inferens in the contiguous maize crop.

VOL. I 
For entomological observation the following plants were grown in $\frac{1}{7}$ acre plots side by side :

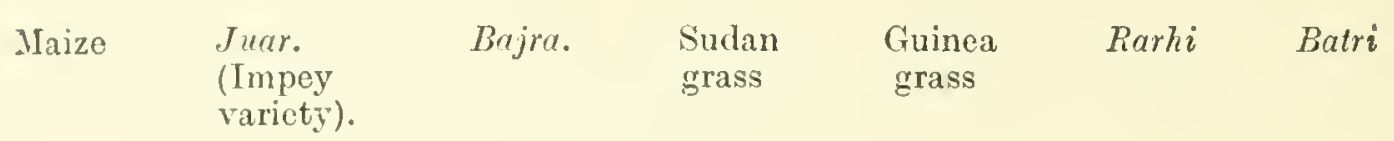

It a distance of about 200 yards from this variety plot there was in the trenching ground about 2 acres of winter paddy, there bcing no other rice within about half a mile. All of the above remained on the ground from about June to November. Rarhi and batri did not have good growth as they require well-developed roots which cannot grow unless they be at a place for a few years continuously.

In the juar, Chilo simplex occurred in large numbers, Diatrcea venosata in smaller mumbers and Sesamia inferens in still smaller numbers. Between 11th and 16th October, out of 3,174 plants in the entire plot, 501 were observed to have been bored in the stem and each stem to harbour from 3 to 8 larvæ and pupx of Chilo simplex. The affected plants were cut and kept under observation. The caterpillars hibernated in them.

In Sudan grass, Chilo simplex and Diatraca venosata occurred to the same extent as in juar.

In maize, Chito simplex and Sesamia inferens, the latter in smaller numbers. occurred up to about August. In the ripening plants there was hardly any borer.

In baja there was no borer. Only one Chilo simplex larva was abserved in the entire plot. This erop is usually observed to be practisually immunc.

In Guinea grass there was no borer.

In rarhi, Diatrea anricilia occurred in small numbers.

In batri, Diatraca auricilia and the Zenzerid borer (C. S. 1696) occurred in small numbers.

In the neighbouring rice plot hardly any Chilo simplex occurred although it was occurring in numbers on rice outside the Pusa Estate.

\section{Parasites and Predators.}

Special attention has not been paid to parasites of the borers but parasites necessarily came under observation in the course of examining thousands of caterpillars and pupe. At Pusa, Dacea and Cawnpore and probably in the whole of North India there arc hymcnopterous parasites including Chalcidids, Braconids and Ichneumons on practically 
all species of Diatroa, Chilo and Scirpophaga, and they are present throughout the period of activity of the borers. No Dipterous parasite has been observed in Northern India although some were obtained from Chilo simplex caterpillars sent from Gujarat and the Konkan. Occasionally Carabid grubs (speeies of Chlonius) are observed preying upon the larve in affected stems. But the combined influence of all these enemies does not seem to be great.

\section{Conclusion.}

The borer pests of gramineous crops of only one locality, viz., Pusa, have so far been investigated. Although most of them are wide-spread there are some which are apparently confined to particular localities. For instance, Diatrea sp. (C. S . 1610) is confined to Eastern Bengal and Assam. As of all the borers it is the most injurious to grown-up canes, its introduction to other localities should be guarded against. Further work may reveal the presence of other borers in particular localities whose indiscriminate spread may not be desirable. The presence of one such borer is suspected in Southern India.

In the present incomplete state of the investigation no practical effective measures can be suggested against the borers. The old recommendation of cutting out "dead hearts" in sugarcane is of hardly any use and is distinetly injurious under certain conditions especially when the erop is young. Similarly cutting out dry ear's of rice has hardly any effect on the crop. We are not yet in a position to suggest anything. The presence or absence of alternative foodplants has certainly some effect on the prevalence in any crop of the Pyralid and Noctuid borers. This, as already stated, has been definitely observed in the case of Scirpophaga and the Noctuid borer C. S. 1666. The presence of alternative foodplants has a great deal to do with the absence of Chilo simplex, Diatrce venosata and Sesamia spp. in injurious numbers at Pusa although each of them is capable of doing serious harm. A good deal of work is necessary in order to be able to study this question thoroughly under different conditions and to regulate alternative foodplants as an effective weapon to fight the borers, if it is proved that control can be effected in this way.

While we cannot suggest any treatment of the young erop of sugarcane, in the ease of those insects which attack grown-up canes such as Scirpophaga spp. and Diatraa sp. (C. S. 1610) removal of the affected stems is expected to reduce their number or at least prevent the inerease of their number and hence this practice can be followed in the absence of a better method of dealing with them. 
CALCUTTA

SUPERINTENDENT GOVERNMENT PRINTING, INDIA

8, HASTINGS STREET 


$\mid \begin{aligned} & \text { है } \\ & \text { है } \\ & \text { है } \\ & \text { है } \\ & \text { - }\end{aligned}$ 
